
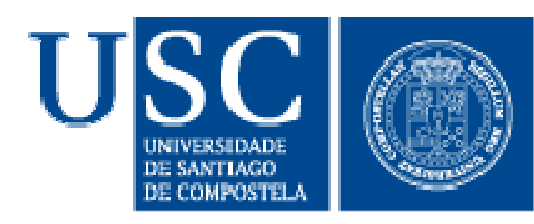

UNIVERSIDAD DE SANTIAGO DE COMPOSTELA DEPARTAMENTO DE DERECHO COMÚN ÁREA DERECHO INTERNACIONAL PRIVADO

TESIS DOCTORAL

\title{
LA LEY APLICABLE A LOS PACTOS SUCESORIOS
}

Isabel Rodríguez-Uría Suárez

Santiago de Compostela, octubre de 2013 

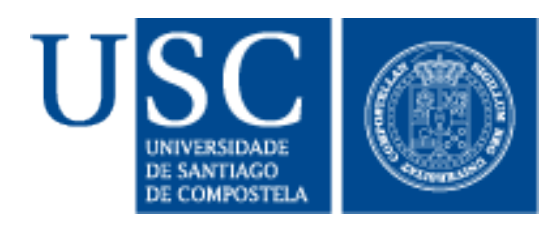

UNIVERSIDAD DE SANTIAGO DE COMPOSTELA

\section{LA LEY APLICABLE A LOS PACTOS SUCESORIOS}

Proyecto de tesis doctoral que presenta la licenciada Isabel Rodríguez-Uría Suárez para la obtención del título d Doctor en Derecho, bajo la dirección del Profesor Doctor Santiago Álvarez González

Santiago de Compostela, octubre de 2013

$\mathrm{V}^{\mathrm{o}} \mathrm{B}^{\mathrm{o}}$

Santiago Álvarez González

Isabel Rodríguez-Uría Suárez 


\section{TABLA DE CONTENIDOS}

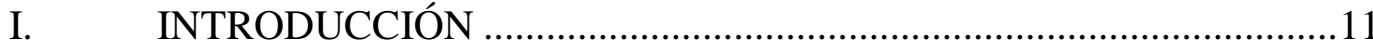

1. Delimitación del objeto de estudio.......................................................11

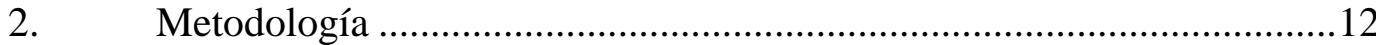

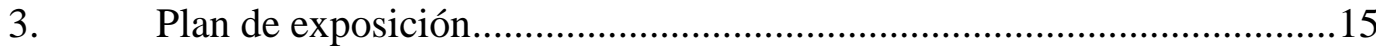

CAPÍTULO I: LOS PACTOS SUCESORIOS: INTERESES, TIPOLOGÍA Y CARACTERÍSTICAS

I. APROXIMACIÓN A LA FIGURA DE LOS PACTOS

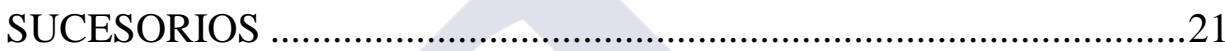

1. Concepto y caracteres de los pactos sucesorios ...................................21

2. Tipología de los pactos sucesorios. Criterios de clasificación. ................26

3. La presunta doble naturaleza jurídica de los pactos sucesorios ..............29

II. INTERESES SUSTANTIVOS PRESENTES EN LOS PACTOS SUCESORIOS …................................................................ 31

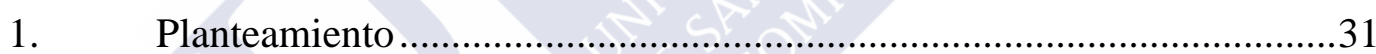

2. Intereses derivados del carácter sucesorio de los pactos.........................33

2.1. Intereses materiales vinculados al causante: la libertad de disposición (vinculación y libertad)

2.2. Intereses materiales vinculados a terceros al pacto sucesorio:

la protección de familiares próximos al causante

3. Intereses derivados del carácter contractual de los pactos ......................37

3.1. Autonomía de la voluntad de las partes ..................................................37

3.2. Vinculación de las partes al pacto sucesorio: pacta sunt servanda

3.3. Seguridad y previsibilidad jurídicas ..................................................... 40

4. La confluencia de intereses materiales contrapuestos en los pactos sucesorios: el principio de libre revocabilidad de las disposiciones mortis causa y la irrevocabilidad unilateral de las disposiciones realizadas a través de pacto sucesorio

III. LA DIVERSIDAD DE SISTEMAS DE PACTOS SUCESORIOS COMO PRESUPUESTO 


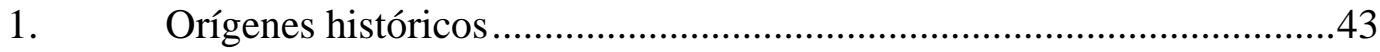

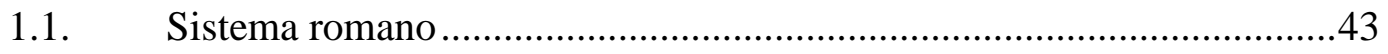

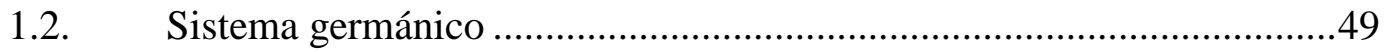

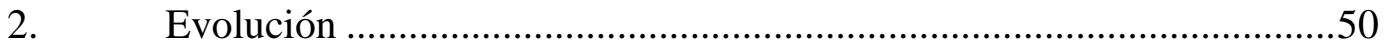

2.1. Sistemas favorables a los pactos sucesorios.......................................50

2.2. Sistemas contrarios a los pactos sucesorios ......................................52

2.3. Sistemas ajenos a la figura de los pactos sucesorios .............................56

2.3.1. Desconocimiento de los pactos sucesorios y admisión de

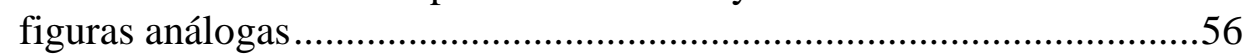

2.3.2. Contracts to make a will ....................................................................57

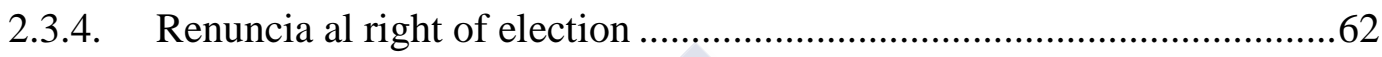

2.4. La situación en España .......................................................................64

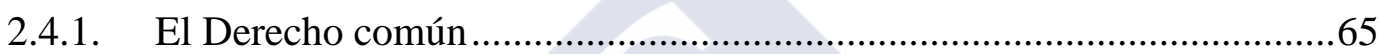

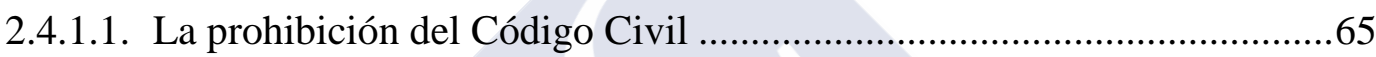

2.4.1.2. Las excepciones a la prohibición del Código Civil...............................67

2.4.1.3. El Estatuto de la explotación agraria y de los jóvenes

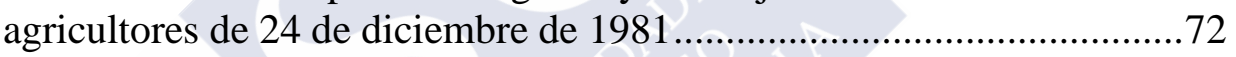

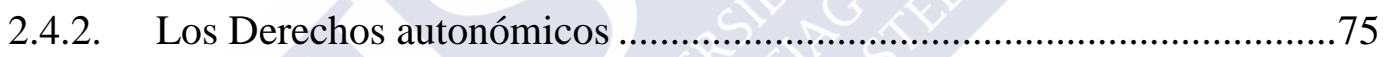

2.4.2.1. Derechos civiles autonómicos que prohíben los pactos

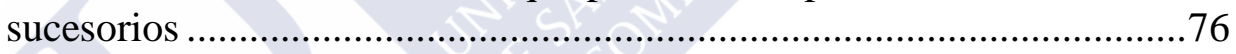

2.4.2.2. Derechos civiles autonómicos que admiten los pactos sucesorios de manera limitada

2.4.2.3. Derechos autonómicos que admiten los pactos sucesorios de manera amplia

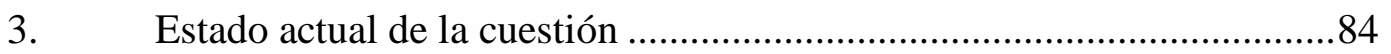

3.1. Flexibilización de la prohibición de los pactos sucesorios en Derecho comparado

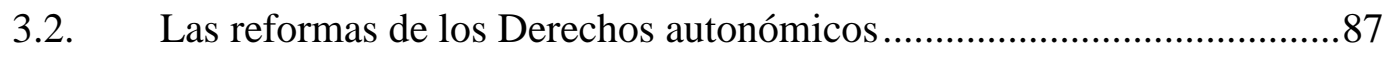

3.3. Hacia una pertinente reforma del Código Civil sobre los pactos sucesorios

3.4. Los pactos sucesorios en la Unión Europea .............................................90 


\section{CAPÍTULO II: LA LEY APLICABLE A LOS PACTOS SUCESORIOS EN DERECHO INTERNACIONAL PRIVADO COMPARADO: MODELOS POSITIVOS}

I.

II. CALIFICACIÓN CONTRACTUAL

1. La ignorancia de los pactos sucesorios: posibilidad de una calificación contractual .96

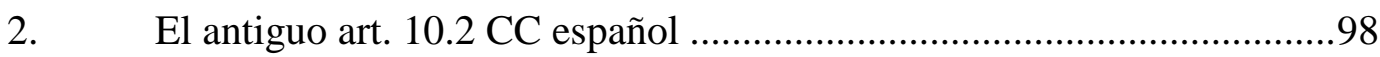

2.1. La defensa de una calificación contractual ..........................................98

2.2. La defensa de una calificación sucesoria ..............................................102

2.3. La superación del problema: el actual art. 9.8 CC .................................103

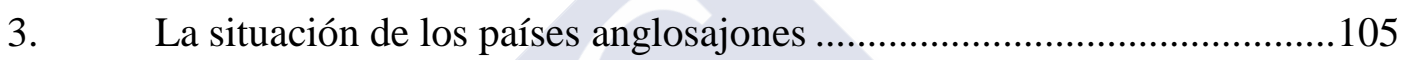

3.1. El desconocimiento de los pactos sucesorios .......................................105

3.2. Figuras análogas (próximas) a los pactos sucesorios ............................107

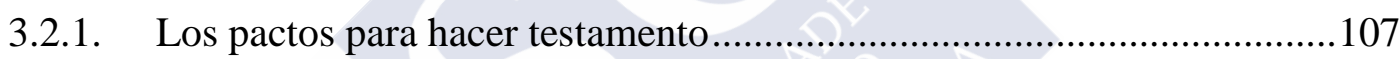

3.2.2. La renuncia de derechos del cónyuge ................................................. 114

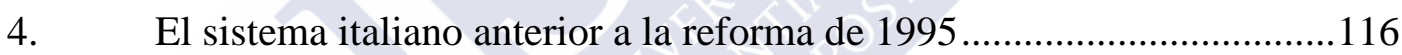

III. CALIFICACIÓN SUCESORIA: TRATAMIENTO INDIFERENCIADO DE LOS PACTOS SUCESORIOS .....................119

1. La ignorancia de los pactos sucesorios .................................................119

2. Influencia de las opciones de DIPr sobre la ley aplicable a la sucesión en los pactos sucesorios

2.1. Los sistemas que siguen la unidad de la sucesión ...................................120

2.1.1. Breve referencia a la unidad de la sucesión .............................................120

2.1.2. La unidad en los pactos sucesorios .....................................................123

2.2. Los sistemas que siguen el fraccionamiento de la sucesión......................126

2.2.1. El fraccionamiento de las sucesiones y su problemática .......................126

2.2.2. Calificación sucesoria de los pactos sucesorios y fraccionamiento de la sucesión internacional

2.2.3. Los problemas particulares del fraccionamiento en los pactos sucesorios 
3. Análisis de la solución de ley aplicable a los pactos sucesorios: especial referencia a los pactos sucesorios que afectan a más de una sucesión

IV. CALIFICACIÓN SUCESORIA: TRATAMIENTO INDIFERENCIADO DE LA CONEXIÓN Y ESPECIALIDAD EN EL MOMENTO TEMPORAL

1. La toma en consideración de los pactos sucesorios por el sistema de DIPr

1.1. La inclusión de los pactos sucesorios en la norma de conflicto de sucesiones

1.2. La especialidad temporal de la conexión sucesoria:

Errichtungsstatut

2. La solución de ley aplicable a los pactos sucesorios que afectan a más de una sucesión

2.1. La falta de solución expresa y las propuestas de interpretación

2.2. La situación del art. $9.8 \mathrm{CC}$

V. CALIFICACIÓN SUCESORIA: TRATAMIENTO INDIFERENCIADO

1. La existencia de una norma de conflicto ad hoc para pactos sucesorios

2. Diferenciación conflictual entre pactos sucesorios

VI. BALANCE DE LOS SISTEMAS DE REGULACIÓN DE LA LEY APLICABLE A LOS PACTOS SUCESORIOS EN TÉRMINOS DE INTERESES

1. Los modelos de regulación caracterizados por la ignorancia de los pactos sucesorios: la ausencia de intereses contractuales

2. Los sistemas que prevén una solución específica para los pactos sucesorios: la atención a los intereses contractuales

3. La permanente presencia de la ley sucesoria y los intereses sucesorios presentes en los pactos.... 


\section{CAPÍTULO III. LA LEY APLICABLE A LOS PACTOS SUCESORIOS: LA AUTONOMÍA DE LA VOLUNTAD}

I. UN MODELO REGULATIVO GLOBAL: LEY APLICABLE A LA SUCESIÓN Y LEY APLICABLE A LOS PACTOS SUCESORIOS 163

1. Interacción entre ley sucesoria y ley rectora de los pactos sucesorios

2. Significado y alcance de la ley aplicable a los pactos sucesorios

II. LA AUTONOMÍA CONFLICTUAL, JUSTIFICACIÓN Y EXTENSIÓN A LOS ÁMBITOS PERSONAL, FAMILIAR Y SUCESORIO

1. Introducción

2. Autonomía de la voluntad material y autonomía de la voluntad conflictual...

3. Origen y ámbito primario de la autonomía de la voluntad conflictual: justificaciones

4. La autonomía de la voluntad conflictual en los ámbitos personal y familiar.

III. AUTONOMÍA DE LA VOLUNTAD CONFLICTUAL EN MATERIA DE SUCESIONES: LA PROFESSIO IURIS 184

1. Autonomía de opción, pacto de lege utenda y professio iuris..................184

2. La professio iuris como solución de ley aplicable .................................188

2.1. La toma en consideración de la professio iuris sucesoria ......................188

2.2. La professio iuris como mecanismo de flexibilización y de materialización en la selección de la ley aplicable

2.3. La professio iuris sucesoria en el Reglamento .....................................197

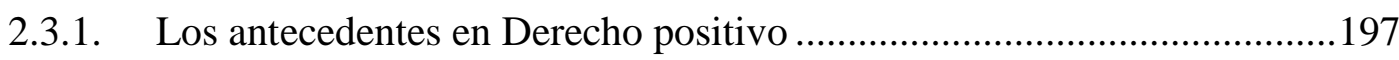

2.3.2. La nueva regulación europea ............................................................201

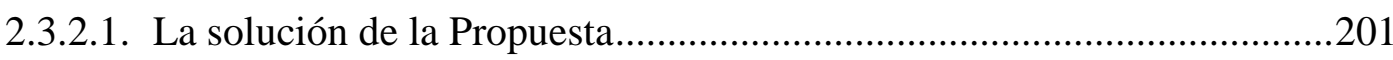

2.3.2.2. La solución prevista por el art. 22 del Reglamento................................204

2.3. La elección de la ley aplicable en los pactos sucesorios .........................206

IV. ESTRUCTURA DE LA AUTONOMÍA CONFLICTUAL EN LOS PACTOS SUCESORIOS 
1. Particularidades de los pactos sucesorios en torno a la estructura de la elección de la ley aplicable

2. Vías para la elección de la ley aplicable a los pactos sucesorios

2.1. La elección unilateral de la ley aplicable: professio iuris y pactos sucesorios

2.1.1. Características

2.1.2. Professio iuris en los pactos sucesorios: su articulación en el Reglamento de sucesiones.

2.2. La elección bilateral de la ley aplicable: pactos de lege utenda y pactos sucesorios

2.2.1. Características

2.2.2. Los pactos de lege utenda en los pactos sucesorios: el art. 25.3 del Reglamento de sucesiones

3. Alcance de la elección de la ley aplicable a los pactos sucesorios

3.1. Consecuencias de la elección en términos de admisibilidad, validez y régimen jurídico del pacto sucesorio

3.1.1. Elección de ley aplicable al pacto a través de professio iuris y su modificación por una professio iuris posterior....

3.1.1.1. La ulterior modificación unilateral de la ley aplicable a la sucesión no afecta a la admisibilidad y validez del pacto sucesorio.

3.1.1.2. La ulterior modificación unilateral de la ley aplicable a la sucesión no afecta a los aspectos dinámicos del pacto sucesorio: régimen jurídico

3.1.2. Elección de ley aplicable al pacto sucesorio a través de professio iuris o de pacto de lege utenda y realización de pacto de lege utenda posterior

3.2. Consecuencias para el pacto sucesorio del cambio de ley sucesoria por professio iuris: las relaciones entre la ley del pacto sucesorio y la ley sucesoria en términos de autonomía de la voluntad conflictual

3.2.1. Distinto alcance de la ley sucesoria: la tutela de todos los legitimarios versus La tutela de los legitimarios terceros al pacto

3.2.2. Consecuencias del ejercicio de la professio iuris tras la conclusión del pacto

3.2.2.1. Planteamiento.....

3.2.2.2. Professio iuris sin ánimo de afectación del pacto 
3.2.2.3. Professio iuris con ánimo de afectación del pacto

V. EXTENSIÓN DE LA AUTONOMÍA DE LA VOLUNTAD

CONFLICTUAL .256

1. Los límites de la autonomía de la voluntad conflictual en el ámbito de las sucesiones internacionales .256

2. La autonomía de la voluntad conflictual en los pactos sucesorios: autonomía libre versus autonomía vinculada .259

3. Autonomía de la voluntad y posibles leyes elegibles a los pactos sucesorios

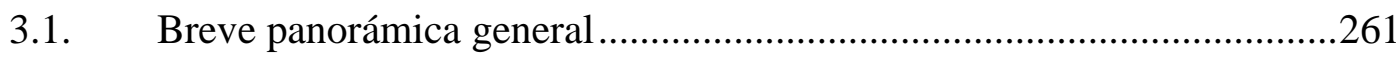

3.2. Las leyes elegibles en el marco del Reglamento..................................262

3.3. Otras alternativas de leyes elegibles a los pactos sucesorios .................267

3.3.1. La residencia habitual del causante .....................................................267

3.3.2. La ley del régimen económico matrimonial........................................2270

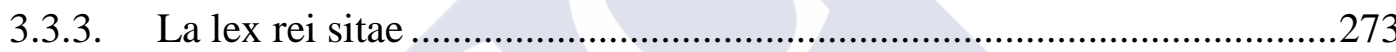

VI. LA FORMA DE ELECCIÓN DE LA LEY APLICABLE A LOS PACTOS SUCESORIOS .......................................................2 274

1. La elección de ley como acto jurídico ...............................................274

2. La forma de la elección de ley a los pactos sucesorios ..........................278

\section{CAPÍTULO IV: LA LEY APLICABLE A LOS PACTOS SUCESORIOS EN DEFECTO DE ELECCIÓN}

I. ALTERNATIVAS A LA AUTONOMÍA CONFLICTUAL. LA CONEXIONES SUCESORIAS ..................................................281

1. Las conexiones objetivas en el ámbito sucesorio ..................................281

2. La dialéctica entre la conexión de la nacionalidad del causante y la conexión del domicilio o de la residencia habitual del causante .283

2.1. La dialéctica en el ámbito general del estatuto personal ........................283

2.2. La dialéctica en las sucesiones internacionales....................................285 
II. LA DETERMINACIÓN DE LA LEY APLICABLE A LOS PACTOS SUCESORIOS QUE AFECTAN A UNA ÚNICA SUCESIÓN .288

1. Admisibilidad, validez material y régimen jurídico de los pactos sucesorios que afectan a una única sucesión: la estructura del art. 25.1 del Reglamento de sucesiones .288

2. Aplicación de la ley sucesoria anticipada: neutralidad en la solución de ley aplicable

2.1. Aplicación de la ley de la nacionalidad del causante

2.2. El Reglamento y la aplicación de la ley de la residencia habitual del causante.

2.3. El Reglamento y la aplicación de la ley más estrechamente vinculada como excepción a la ley de la residencia habitual

2. El juego de la ley sucesoria como regla de validación: solución materialmente orientada .306

2.1. La regla de validación y su funcionamiento ..........................................306

2.2. Contexto sustantivo de la regla de validación: pactos sucesorios que afectan a una única sucesión

2.2.1. Instrumentos normativos que prevén la regla de validación

2.2.2. Problemas de inadecuación de la regla de validación en los pactos sucesorios que afectan a más de una sucesión

2.3. Análisis valorativo de la regla de validación .318

2.3.1. Naturaleza de la regla de validación .318

2.3.2. La regla de validación desde el punto de vista de los otorgantes

2.3.3. La regla de validación desde el punto de vista de terceros 326

2.3.4. Balance 328

III. LA DETERMINACIÓN DE LA LEY APLICABLE A LOS PACTOS SUCESORIOS QUE AFECTAN A MÁS DE UNA SUCESIÓN

1. Especialidades de los pactos sucesorios que afectan a más de una sucesión: la estructura del Reglamento de sucesiones

2. La ley aplicable a la admisibilidad de los pactos sucesorios que afectan a varias sucesiones: el art. 25.2 párrafo primero del Reglamento de sucesiones

2.1. Solución neutral de ley aplicable: la aplicación aleatoria de la ley sucesoria anticipada 
2.2. Soluciones materialmente orientadas en la determinación de la admisibilidad de los pactos sucesorios que afectan a más de una sucesión

3. Ley aplicable a la validez material de los pactos sucesorios que afectan a más de una sucesión

3.1. Soluciones neutrales de ley aplicable a la validez material

3.1.1. Aplicación distributiva o aleatoria de las leyes en presencia

3.1.2. Aplicación de la ley más estrechamente vinculada: el art. 25.2 segundo párrafo del Reglamento.

3.2. Soluciones materialmente orientadas para la validez material de los pactos sucesorios que afectan a más de una sucesión

3.2.1. Solución alternativa: la solución de la Propuesta de Reglamento

3.2.2. Solución cumulativa: la solución del Reglamento

4. La ley aplicable al régimen jurídico de los pactos sucesorios que afectan a más de una sucesión

4.1. Consideraciones previas en torno al concepto de régimen jurídico del pacto sucesorio.

4.2. Soluciones neutrales de ley aplicable

4.2.1. Solución aleatoria o distributiva.

4.2.2. La aplicación de la ley más estrechamente vinculada: de nuevo sobre el art. 25.2 párrafo segundo del Reglamento de sucesiones

4.3. Soluciones materialmente orientadas .360

4.3.1. Aplicación alternativa de las leyes en presencia .360

4.3.2. Aplicación cumulativa de las leyes en presencia .362

5. Alternativas neutrales de ley aplicable a los pactos sucesorios que afectan a más de una sucesión

Conclusiones

Bibliografía citada .385

Práctica judicial citada 409 


\section{INTRODUCCIÓN}

\section{Delimitación del objeto de estudio.}

El presente estudio aborda la problemática relacionada con la determinación de la ley aplicable a los pactos sucesorios. Los pactos sucesorios son figuras dirigidas a la ordenación por anticipado de la sucesión mortis causa que, tradicionalmente, han estado rodeados de cierta polémica, sobre todo porque chocan con el principio fundamental en Derecho de sucesiones de la libre revocabilidad de las disposiciones mortis causa por parte del causante hasta el mismo momento de su fallecimiento. Nuestro punto de partida es la existencia de una gran diversidad y una marcada heterogeneidad en la regulación de los pactos sucesorios tanto a nivel de Derecho material, como a nivel de DIPr, hablando en términos de Derecho comparado. Además, la complejidad intrínseca que encierran los pactos sucesorios, así como la concurrencia en ellos de la doble naturaleza contractual y sucesoria hacen que el análisis de la ley aplicable presente importantes dificultades.

El estudio de estas figuras se limitará a la regulación de ley aplicable; es decir, no se analizarán otros problemas de DIPr tales como la competencia judicial internacional o el reconocimiento de decisiones que afecten a pactos sucesorios. Dentro de las cuestiones de ley aplicable el estudio se limitará además a los aspectos relativos a la admisión de los pactos sucesorios, ley aplicable a la validez material y ley aplicable al régimen jurídico de los pactos sucesorios, es decir, el trabajo de centra en lo que podría denominarse la determinación de la ley aplicable al fondo del asunto. Se excluyen, por tanto, de nuestro objeto de análisis otras cuestiones tales como la determinación de la ley rectora de capacidad para otorgar los pactos sucesorios o la ley rectora de validez formal de estas figuras. Tampoco hay una atención particular a asuntos estrechamente vinculados con la ley aplicable, tales como la posible presencia del orden público o de normas de policía que puedan condicionar o incluso que hagan inviables los pactos sucesorios que posibilite o prevea la ley aplicable. Se trata de un estudio de las soluciones básicas a la identificación de la ley aplicable a los pactos sucesorios 
La elección del tema viene avalada por un doble orden de cuestiones: en primer lugar, existe una razón académica, en cuanto que hasta el momento no existe un estudio monográfico ni en la literatura científica española, ni en la literatura científica europea, que aborde las particularidades de la ley aplicable a los pactos sucesorios y, por tanto, éste ya se hacía necesario. En segundo lugar, se trata de un tema especialmente oportuno y de gran actualidad. Y ello porque en los últimos tiempos los pactos sucesorios han cobrado creciente importancia, al haber un proceso revitalización de estas figuras que además tiene su colofón en la existencia de un artículo específico para la determinación de su ley aplicable en el Reglamento núm. 650/2012, del Parlamento Europeo y del Consejo de 4 de julio de 2012, relativo a la competencia, la ley aplicable, el reconocimiento y la ejecución de las resoluciones, a la aceptación y la ejecución de los documentos públicos en materia de sucesiones mortis causa y a la creación de un certificado sucesorio europeo (el Reglamento o el Reglamento de sucesiones). Por ello, este es un momento idóneo para profundizar en lo que hay y en lo que puede haber; en las soluciones existentes, sus ventajas, sus inconvenientes y sus posibles vías de mejora.

\section{Metodología}

Lo primero que hemos de poner de manifiesto en cuanto a la metodología empleada es que hemos tratado en todo momento de huir de un método exegético. No ha sido fácil no caer en la tentación, teniendo en cuenta la oferta que nos proporcionaba la regulación del Reglamento. Es verdad que a lo largo del trabajo se da un especial protagonismo y presencia al Reglamento europeo de sucesiones, en cuanto que sus soluciones serán las que se apliquen con carácter general en Europa en un futuro próximo. Pero no se trata de un simple comentario al Reglamento, sino de un estudio de las cuestiones relativas a la ley aplicable a los pactos sucesorios global, más general e independiente de una norma concreta. Ello no obsta que rara llevar a cabo este análisis se hagan numerosas y continuas referencias no sólo al Reglamento, sino también a la legislación positiva en Derecho comparado, al Convenio de La Haya de 1989 y a la Propuesta de Reglamento. La normativa positiva es, como no puede ser de otra forma, 
referencia básica; pero lo es más, si cabe, el problema en sí mismo considerado; las distintas hipótesis con las que trabajamos; los singulares pactos sucesorios impregnados de la nota de internacionalidad y los problemas inherentes a esta nota.

A lo largo de la Tesis Doctoral se parte de grandes opciones o tendencias de DIPr; así, tiene presencia tanto la especialización, la flexibilización, como la materialización en la determinación de la ley aplicable a los pactos sucesorios. Es necesario también un estudio de Derecho comparado, tanto a nivel de Derecho material, como a nivel de DIPr. Ambos ocupan un papel importante en el trabajo y tienen fundamentalmente efectos instrumentales para llevar a cabo el resto del estudio, aunque pensamos que también tienen efectos explicativos, especialmente el Capítulo II. Tampoco se ha tratado de proyectar una plantilla preconfigurada, analizando transversalmente las tendencias o grandes opciones descritas. Se ha querido hacer una tesis de DIPr de sucesiones y, dentro de éstas, de pactos sucesorios. Se estudian las grandes opciones pero dirigidas o aplicadas a las sucesiones internacionales, en concreto, a los pactos sucesorios. El análisis que se hace, por tanto, sólo se entiende y es válido para los pactos sucesorios; esta razón explica la importante presencia que tiene el Derecho material y también por qué se acude continuamente a ejemplos que llevan a distintos Derechos materiales y que, por tanto, conectan con el Derecho comparado.

Para la realización de la Tesis hemos acudido fundamentalmente a fuentes de Derecho positivo y a estudios doctrinales. En cuanto a las fuentes de Derecho positivo, de nuevo ocupa un lugar importante el Derecho comparado, tanto material como de DIPr. También hemos dado una gran importancia al Convenio de La Haya de 1989, y los debates que en el seno de la Conferencia de La Haya se dieron a raíz de este Convenio, que recogen una valiosa información, quizá la primera realmente especializada sobre pactos sucesorios, en las intervenciones de los delegados. Basta echar un vistazo al plantel de los mismos para percatarse de la calidad de sus intervenciones y la importancia de sus aportaciones. 
La otra gran referencia, como no podía ser de otro modo, ha sido el Reglamento con especial atención a todo el proceso que lo precedió. Ya la Propuesta de Reglamento recogió una regulación específica de los pactos sucesorios y cuya comparación con la versión definitiva del Reglamento creemos que resulta de gran interés, más allá de su mera consideración de precedente inmediato: los cambios que experimentó el Reglamento desde el texto de la Propuesta son importantes.

Qué duda cabe que los estudios de la doctrina tienen también una importante presencia, tanto los que abordan cuestiones generales sobre las sucesiones internacionales, como, en mucha menor medida por ser menos habituales, aquellos que analizan cuestiones particulares de la ley aplicable a los pactos sucesorios. La orientación que hemos dado al estudio también nos ha permitido y exigido profundizar en cuestiones de teoría general que, en todo caso, hemos tratado de reducir a lo justo en la exposición de una tesis que, como hemos señalado, pretender ser una tesis de DIPr sobre ley aplicable a los pactos sucesorios. En todo caso, a veces no nos ha sido posible huir de desarrollos que exceden del concreto objeto de estudio (pactos) puesto que sus relaciones con la general problemática sucesoria hacían necesario ampliar la perspectiva: por ejemplo, la imbricación entre ley aplicable a los pactos sucesorios y professio iuris, la relación entre la ley rectora de los pactos y la ley sucesoria y otros extremos.

En menor medida se ha acudido también a la jurisprudencia, si bien no son habituales los casos en los que hay un problema de ley aplicable a pactos sucesorios con elemento extranjero. En cuanto a la documentación, tienen una importante presencia los trabajos que se han llevado a cabo en el seno de la UE desde que la regulación de las sucesiones internacionales empezó a ser un objetivo comunitario. Por otro lado, es fundamental toda la documentación que se derivó de la negociación en el seno de la Conferencia de La Haya del Convenio de La Haya de 1989. 


\section{Plan de exposición}

Hemos dividido esta Tesis Doctoral en cuatro capítulos. El primero de ellos tiene un carácter introductorio a las figuras de los pactos sucesorios y, por ello, consta de un fuerte contenido de Derecho material. Empezar por este capítulo es fundamental para el estudio, pues supone un punto de partida necesario para conocer las vicisitudes de estas figuras y así adquirir las herramientas necesarias para enfrentarse al análisis de las soluciones de ley aplicable.

El primer paso, por tanto, debe ser una aproximación al concepto y características de los pactos sucesorios. De este análisis se derivan datos fundamentales que van a aparecer repetidamente a lo largo del trabajo: en primer lugar, es fundamental tener en cuenta y conocer la doble naturaleza jurídica contractual y sucesoria de los pactos sucesorios. Esta circunstancia va a condicionar siempre el análisis de las soluciones de ley aplicable. En segundo lugar, procede detenerse en los intereses sustantivos presentes en los pactos sucesorios; de esta forma podemos conocer cuáles son las exigencias que presentan estas figuras y que deben tenerse en cuenta en orden a su respeto a la hora de dar soluciones de ley aplicable. Estos intereses tienen una importancia vital y una también presencia continua a lo largo de la Tesis Doctoral. Por un lado, destacan los intereses contractuales, esto es, la vinculación de las partes al contenido del pacto sucesorio en cumplimiento del principio de pacta sunt servanda y la seguridad y previsibilidad jurídica; por otro lado, entre los intereses sucesorios destacan la libertad de disposición del causante y la protección de los derechos o expectativas de los familiares próximos al causante. En tercer lugar, es importante también conocer la diversidad que a nivel de Derecho material existe sobre estas figuras; por ello, es necesario un análisis de Derecho material comparado, del que además se deriva otra característica fundamental de los pactos sucesorios, que va a suponer otro importante condicionante en el resto del trabajo, cual es el del carácter generalmente reglado o típico de los pactos sucesorios.

El capítulo I se cierra con una referencia al estado actual de la cuestión; contextualizar esto tiene su importancia, en cuanto que en los últimos años se ha dado un movimiento a favor del renacer o revitalización de los pactos sucesorios, 
que ha supuesto en algunos vasos la flexibilización de clásicas prohibiciones que algunos sistemas prevén, así como la promoción de estas figuras en el seno de la UE. Este proceso de revitalización o renacer de los pactos sucesorios se debe tener en cuenta también a la hora de estudiar las soluciones de ley aplicable.

Este Capítulo I se caracteriza, o al menos eso hemos pretendido, por su sobriedad (no se trataba de hacer un estudio sustantivo exhaustivo sobre los pactos sucesorios) y por su precisión: los instrumentos tienen que ser sólidos para que su uso posterior no desvirtúe el resultado. En este sentido hemos contado con la inestimable ayuda de dos especialistas en la materia, como son la Profesora García Rubio y la Profesora Herrero Oviedo.

Tras esta aproximación sustantiva y la contextualización de los pactos sucesorios, el siguiente paso necesario es el de la aproximación al estado actual de la regulación de la ley aplicable a los pactos sucesorios tanto en nuestro sistema como en Derecho comparado. A ello se dedica el capítulo II, donde el análisis se hace además desde el punto de vista de una de las grandes tendencias del DIPr: la especialización. Como hemos señalado con anterioridad, nuestra pretensión no era un análisis exegético de las distintas normas; en este caso, un análisis de "Derecho extranjero" y de Derecho nacional, sino un verdadero análisis de Derecho comparado. El estudio de los distintos modelos de regulación que de los pactos sucesorios existen se hace desde el menos especializado hacia el más especializado; de esta forma se pueden ir analizando tanto las deficiencias de cada sistema, como la forma de abordarlas. Ni que decir tiene que la propuesta de estos modelos es totalmente personal y que la clasificación que hemos realizado no excluye otras que puedan llegar a hacerse. Este capítulo no sólo da una visión general de Derecho comparado, necesaria para ver cómo se ha abordado en Derecho positivo la regulación de la ley aplicable a los pactos sucesorios, sino que también permite aproximarse ya a problemas fundamentales para abordar una buena regulación de la determinación de la ley aplicable a los pactos sucesorios. Así, destaca por un lado, la necesidad de conocer desde el mismo momento del otorgamiento la validez y régimen jurídico del pacto sucesorio. En este capítulo se empieza a hablar ya de la ley sucesoria anticipada o ley sucesoria determinada en 
el momento del otorgamiento del pacto sucesorio como solución fundamental para los pactos sucesorios. Por otro lado, queda también patente que para la regulación de la ley aplicable a los pactos sucesorios es necesario distinguir entre los pactos sucesorios que afectan a una única sucesión y los pactos sucesorios que afectan a varias sucesiones. Asimismo, vemos cómo las soluciones más avanzadas conceden un papel protagonista a la autonomía de la voluntad.

Tras esta panorámica general, ya quedan contextualizados los pactos sucesorios tanto a nivel de Derecho material, como a nivel de DIPr y, por tanto, ya estamos en condiciones de abordar el estudio concreto y particular de las cuestiones que surgen a la hora de analizar las posibles soluciones de ley aplicable, tanto en el caso de que haya una elección de ley, como en el caso de que haya que acudir a soluciones objetivas. En este análisis cobra central protagonismo, aunque no exclusivo, el Reglamento de sucesiones.

El capítulo III se centra en el análisis de la ley aplicable a los pactos sucesorios a través de una elección de ley. Para ello nos pareció necesario primeramente realizar una introducción a la elección de ley aplicable a las sucesiones en general, en cuanto que la calificación sucesoria de los pactos sucesorios, visión casi exclusiva derivada del análisis efectuado en el Capítulo II, implica siempre esa dependencia de la ley sucesoria, de las conexiones sucesorias y, en definitiva, de las soluciones de ley aplicable a la global sucesión.

Para analizar la elección de ley aplicable a los pactos sucesorios se sigue una estructura que se corresponde con la doble naturaleza contractual y sucesoria de estas figuras. Todo el estudio de las posibilidades de elección de ley aplicable a los pactos sucesorios parte de la existencia de dos posibles vías de elección: la unilateral, a través de la professio iuris y la bilateral a través del pacto de lege utenda. Con base en esta distinción se analiza el alcance y régimen jurídico de cada tipo de elección. En concreto, en todo este Capítulo tiene una presencia fundamental el Reglamento de sucesiones, en cuanto que permite la elección de ley aplicable a los pactos sucesorios a través de las dos vías y, además de ser el nuestro, es el sistema más evolucionado hasta la fecha. 
Especial importancia tiene la cuestión de la relación de la ley sucesoria y la ley del pacto sucesorio. Ambas leyes conviven y tienen su propio ámbito de aplicación, condicionando, entre otros aspectos, la real determinación de la libertad de disposición del causante y la protección de los derechos de legitimarios, que son competencia de la ley sucesoria y que, por tanto, pueden suponer una importante corrección del contenido del pacto sucesorio; corrección que puede, incluso, dejar en papel mojado lo estipulado. En este contexto tiene especial importancia esta relación entre la ley sucesoria y la ley del pacto sucesorio en términos de autonomía de la voluntad conflictual. Por ello, en este Capítulo III se dedica una parte especial a la posibilidad de modificar la ley a través de la autonomía de la voluntad conflictual unilateral del disponente o futuro causante y con ello conseguir la posible frustración, en términos de eficacia, del pacto sucesorio.

La elección de ley en las sucesiones internacionales siempre se ha concebido de manera limitada; en consecuencia, también la elección de ley aplicable a los pactos sucesorios es limitada. Se analizarán las posibles leyes elegibles; en primer lugar, la ley de la nacionalidad del causante, por ser la posibilidad que permite el Reglamento; pero también se valorarán otras posibles leyes elegibles, fundamentalmente la ley de la residencia habitual del causante.

Por último, el análisis de la elección de la ley aplicable a los pactos sucesorios se cierra con el estudio de la forma a través de la cual debe llevarse a cabo tal elección: en este caso, también con especial referencia al régimen que prevé el Reglamento de sucesiones. En este apartado es de especial interés el tema de la posibilidad de elegir tácitamente la ley aplicable a los pactos sucesorios.

Una vez analizadas las cuestiones relacionadas con la elección de ley aplicable a los pactos sucesorios, el siguiente paso lógico es el de analizar la determinación de la ley aplicable en defecto de elección. A ello se dedica el capítulo IV de la Tesis Doctoral. Dada la calificación sucesoria de los pactos sucesorios, para analizar la ley aplicable en defecto de elección, vuelve a ser necesario empezar de nuevo por la ley sucesoria. Las conexiones sucesorias son las que van a determinar la ley aplicable a los pactos sucesorios, por lo que es 
oportuno comenzar por conocerlas y profundizar en su funcionamiento. En concreto, es necesario estudiar la clásica dicotomía entre la ley de la nacionalidad del causante y la ley del domicilio del causante, así como la progresiva adquisición de protagonismo de la ley de la residencia habitual, fundamentalmente en el contexto de la UE. Tras este análisis ya estaremos en condiciones de abordar la regulación de los pactos sucesorios. Para ello, tal y como ya se deriva de las lecciones aprendidas en los capítulos I y, sobre todo, II, se seguirá la clasificación fundamental, de los pactos sucesorios en función del número de sucesiones que están afectadas por el contenido de lo estipulado. El análisis de las concretas soluciones de ley aplicable a los pactos sucesorios en defecto de elección se hará además desde la perspectiva de otra de las grandes tendencias del DIPr, cual es la materialización.

En primer lugar, analizamos las soluciones de ley aplicable a los pactos sucesorios que afectan a una única sucesión. En concreto, se trata por un lado, de un análisis de las soluciones neutrales de ley aplicable basadas en la simple aplicación de la ley sucesoria anticipada de la persona cuya sucesión esté afectada por el contenido del pacto sucesorio; es decir, se trata de trasladar las conexiones sucesorias al momento temporal pertinente, que no es otro que el de la celebración del pacto sucesorio. Por otro lado, se analiza una solución con un carácter materialmente orientado, a favor de la válida celebración de los pactos sucesorios, que es la denominada norma de validación. Se valorará la norma de validación, que supone dar entrada a la ley sucesoria, determinada en el momento del fallecimiento del causante, para la regulación del pacto sucesorio.

En segundo lugar, se analizan las soluciones de ley aplicable a los pactos sucesorios que afectan a más de una sucesión. Este tipo de pactos sucesorios exigen una atención particular en cuanto que hay más de una ley sucesoria anticipada en juego y, por tanto, es necesario dar un paso más para concretar su solución de ley aplicable. En este punto se analizarán tanto las soluciones de ley aplicable de carácter neutral, esto es la denominada solución distributiva o aleatoria y el juego que puede tener la cláusula de los vínculos más estrechos; y también soluciones materialmente orientas, tanto en una dirección restrictiva de la 
válida celebración de los pactos sucesorios, a través de la solución cumulativa; como en una dirección favorable a la celebración de estas figuras, a través de la solución alternativa.

La Tesis concluirá con unas sucintas conclusiones, en las que recogemos y sintetizamos todo el análisis previo. 


\section{CAPÍTULO I: LOS PACTOS SUCESORIOS: INTERESES, TIPOLOGÍA Y CARACTERÍSTICAS}

\section{APROXIMACIÓN A LA FIGURA DE LOS PACTOS SUCESORIOS \\ 1. Concepto y caracteres de los pactos sucesorios}

La primera idea que debemos tener presente y que aparecerá a lo largo de este trabajo es la gran heterogeneidad que sobre los pactos sucesorios existe en el Derecho material. Esta heterogeneidad es un punto de partida y la explicación de muchas de las dificultades que presentan los pactos sucesorios en Derecho internacional privado, pero también implica problemas en el propio Derecho material. El primero de ellos es dar un concepto de pacto sucesorio. La diversidad de figuras a las que se califica como pactos sucesorios hace que el concepto que podamos manejar sea muy genérico. Como primera aproximación, y siguiendo a la doctrina más moderna, podemos señalar que los pactos sucesorios son acuerdos entre dos o más personas cuyo contenido tiene una trascendencia, más o menos directa, en la sucesión de una persona viva ${ }^{1}$. Se trata de una forma de ordenación del patrimonio mortis causa de carácter voluntario en la que la voluntad del causante queda vinculada a través del pacto sucesorio a la voluntad de otra u otras personas, de tal forma que el causante no puede revocar unilateralmente las disposiciones realizadas a través de dicho pacto sucesorio, salvo en determinados casos excepcionales. Los pactos sucesorios, por tanto, forman un tercer modo de vocación de la herencia, junto al testamento y a la ley. No obstante, debemos realizar una pequeña matización conceptual en el sentido de que, tal y como ha puesto de relieve la doctrina civilista, el concepto de pacto sucesorio es más

\footnotetext{
1 Vid., M.P. García Rubio/M. Herrero Oviedo (2011), p. 1260. Se han dado distintos conceptos, más o menos genéricos, de pactos sucesorios tanto en la doctrina española como en la doctrina extranjera; vid. entre otros, R.M. ROCA SASTRE (1948), p. 341; J.L. LACRUZ BERDEJO/F. SANCHO Rebullida (1981), p. 381; L. DíEZ-PiCAZO/ A. Gullón (1989), p. 507; F. Puig PeÑA (1976), p. 676; M. ESPEJO LERdo DE TEJADA (1999), pp. 27-33; R. SÁNCHEZ ARISTI (2003), pp. 7 y ss.; T. SPECKert (1951), p. 9; E. Roguin (1912), p. 230; G. VismarA (1986), p. 2. R. KANZLEITER (2006), p. 154, núm. 4. H. BROX/W-D. WALKER (2007), pp. 102 y ss.
} 
amplio que el concepto de sucesión contractual. Con carácter general, se distingue, sin perjuicio de otro tipo de clasificaciones, los pactos de institución, los pactos de renuncia y los pactos sobre herencia de tercero, constituyendo sucesión contractual propiamente dicha únicamente los pactos de institución ${ }^{2}$.

Si bien el concepto de pacto sucesorio que manejamos es ciertamente genérico, detenernos en los caracteres propios de estas figuras nos permitirá hacernos una idea más concreta de lo que son en realidad. La heterogeneidad también influye a la hora de mencionar los caracteres de los pactos sucesorios, puesto que cada figura concreta tiene sus propias especialidades. Por ello, nos vamos a referir aquí a los caracteres comunes a todo pacto sucesorio.

El pacto sucesorio es un negocio jurídico bilateral o multilateral. Son actos creados por la concurrencia de dos o más voluntades, que constan de un objeto y producen unos determinados efectos jurídicos. Frente al carácter estrictamente unilateral del testamento, los pactos sucesorios exigen al menos la concurrencia de dos voluntades, por lo que para su otorgamiento son necesarias como mínimo dos personas, una de las cuales tiene que ser el disponente o futuro causante, esto es, la persona cuya sucesión queda afectada por el contenido del pacto sucesorio. Con este rasgo ya estamos adelantando que se excluye la modalidad que más arriba se ha denominado pactos sobre herencia de tercero.

Los pactos sucesorios son negocios jurídicos con una naturaleza mixta; por un lado, se trata de un acto inter vivos generalmente irrevocable; pero por otro lado, el objeto del pacto sucesorio es la ordenación de la sucesión del futuro causante, esto es, a través de un pacto sucesorio se ordena por anticipado la sucesión no abierta de uno o más de los otorgantes ${ }^{3}$. Por ello, los genuinos efectos de los pactos sucesorios, que no todos, se producen una vez que fallece el causante, lo que le otorga una naturaleza mortis causa. Puesto que se trata de la ordenación de una sucesión, a través de pacto sucesorio, con carácter general, se puede instituir heredero al beneficiario (que puede ser otorgante del pacto o puede

\footnotetext{
${ }^{2}$ Vid., R.M. RoCA SASTRE (1948) p. 341.

${ }^{3}$ Dicho de otro modo, el pacto sucesorio debe afectar a la sucesión del causante, F. PUIG PEÑA (1976), p. 680.
} 
ser un tercero) o se pueden realizar atribuciones a título particular, lo que equivale a la realización de un legado a través de testamento ${ }^{4}$; también es posible a través de pacto sucesorio renunciar por anticipado a determinados derechos que se pudiera tener sobre la herencia del causante, donde el ejemplo más claro es la renuncia a la legítima.

Al tratarse de acuerdos, los pactos sucesorios tienen un carácter contractual del cual se deriva uno de sus efectos, a nuestro juicio, más significativos: la vinculación de las partes al contenido del pacto sucesorio. Este efecto se produce desde el mismo momento en que el pacto sucesorio es otorgado, esto es, en vida del causante ${ }^{5}$. De la vinculación se desprenden a su vez otros dos efectos importantes que también son característicos de los pactos sucesorios y que en cierta medida son las dos caras de una misma moneda. Por un lado, la vinculación de las partes al pacto sucesorio implica que con carácter general, esto es, a salvo determinados casos previstos y otros excepcionales, las partes no pueden revocar el pacto unilateralmente. Así, como norma general, los pactos sucesorios son irrevocables; no obstante, debemos matizar que, por un lado, las partes pueden consignar en el pacto motivos por los que éste pueda ser revocado por cualquiera de las partes de manera unilateral y que, por otro lado, las legislaciones que admiten los pactos sucesorios también prevén generalmente la posibilidad de revocarlos en determinadas situaciones excepcionales, ligadas fundamentalmente a las causas de desheredación o indignidad ${ }^{6}$. Por otro lado, tratándose de pactos sucesorios de institución, el futuro causante, al estar vinculado por las disposiciones realizadas a través del pacto sucesorio, pierde de manera correlativa sus facultades de disposición mortis causa, pues al no poder revocar unilateralmente lo dispuesto en el pacto sucesorio, posteriores ordenaciones mortis causa que realice el causante y que contraríen el contenido del pacto sucesorio, serán ineficaces. Dicho de otro modo, una vez vinculado por

\footnotetext{
${ }^{4}$ X. M. ReQUeIXo SOUTO (2012), pp. 1746 y ss.

${ }^{5}$ H-L. MusielaK (1997), p. 1675, núm. 3, quien dice que los pactos sucesorios no son una clase especial de testamentos, sino que se trata de verdaderos contratos, que como otros contratos generan una vinculación para las partes desde el mismo momento de su otorgamiento.

${ }^{6}$ M.P. GARcía Rubio/M. HerRero OVIEDO (2009), p. 477 y ss.
} 
un pacto sucesorio, el testamento posterior que otorgue el causante no producirá efectos en todo aquello que contraríe lo dispuesto en dicho pacto sucesorio.

El carácter naturalmente irrevocable de los pactos sucesorios ha sido la nota característica más destacada de estas figuras, como diferencia fundamental respecto de la otra forma de disponer del patrimonio de forma voluntaria, el testamento $^{7}$. Sin embargo, pese a que la irrevocabilidad haya sido la nota que tradicionalmente ha caracterizado y diferenciado a los pactos sucesorios, lo cierto es que no se trata de un aspecto esencial de los pactos sucesorios no sólo porque siempre existen causas excepcionales de revocación unilateral previstas por la ley, sino porque las propias partes pueden pactar todas aquellas causas de revocación que estimen por conveniente. En el caso de los pactos sucesorios de institución sí es una nota esencial la pérdida de disposición mortis causa del causante. No ocurre, sin embargo, cuando se trata de los pactos de renuncia. En efecto, en los pactos de renuncia alguien renuncia por anticipado a un derecho sobre la herencia del causante y con dicha renuncia se consigue que ampliar la libertad de disposición de éste, por lo que no hay en realidad una pérdida de libertad de disposición mortis causa, sino lo contrario ${ }^{8}$. Ahora bien, cuando alguien es instituido heredero o legatario a través de pacto sucesorio, el causante no puede posteriormente realizar una disposición mortis causa que contraríe el contenido del pacto, de ahí la limitación de su capacidad de disponer para después de la muerte.

Por último, cabe señalar que los pactos sucesorios son, con carácter general, un negocio jurídico ad solemnitatem, pues habitualmente, las legislaciones que prevén este tipo de sucesión exigen para su válida celebración la

\footnotetext{
${ }^{7}$ De hecho, no es extraño que la nota de irrevocabilidad natural de los pactos sucesorios aparezca dentro de la propia definición de estas figuras; vid. en este sentido la definición de J.L LACRUZ BERDEJO/F. SANCHO REBULLIDA (1981), p. 381, para quienes un contrato sucesorio es "aquella ordenación mortis causa en la que la voluntad del ordenante queda vinculada a otra voluntad, no pudiendo revocarse dicha ordenación, por tanto, por el causante de modo unilateral".

${ }^{8}$ Un ejemplo de esta ampliación de la libertad dispositiva del causante lo podemos encontrar en el art. 239 de la Ley de Derecho Civil de Galicia (Ley 2/2006, de 14 de junio, de Derecho civil de Galicia; BOE de 11 de agosto de 2006, núm. 191, p. 30073), donde se dispone que el apartado sí hace número para el cálculo de las legítimas; en concreto, el art. 239 dispone que "a pesar de no tener la condición de legitimarios, los apartados, los que repudiaran el llamamiento legitimario así como sus descendientes hacen número para el cálculo de las legítimas".
} 
intervención de una autoridad pública, generalmente un notario, y su otorgamiento en una escritura pública.

Para terminar con esta aproximación al concepto y caracteres de los pactos sucesorios debemos detenernos en sus elementos personales, que pueden ser de distinto tipo. En cada pacto sucesorio debe haber al menos un otorgante disponente $^{9}$, esto es, la persona cuya sucesión queda afectada por el contenido del pacto sucesorio, o dicho de otro modo, la persona cuya sucesión constituye el objeto del pacto. Es necesario, a nuestro juicio, que al menos uno de los otorgantes sea disponente, que quede vinculado por lo dispuesto en el pacto, lo que implica excluir como pacto sucesorio (y, por tanto, excluir de nuestro objeto de estudio) a los pactos sobre herencia de tercero ${ }^{10}$. El otro, o los otros otorgantes, pueden ser de distinto tipo. Puede tratarse de otro otorgante disponente, de tal forma que el pacto sucesorio afecte a dos (o más, dependiendo del número de otorgantes disponentes concurrentes en el pacto sucesorio) sucesiones; un ejemplo sería el pacto de institución recíproca de dos cónyuges, en el que cada uno instituye, de manera recíproca, al otro heredero, quedando ambas disposiciones vinculadas. Puede tratarse también de un otorgante no disponente, esto es, una persona que celebra un acuerdo con el causante sobre la sucesión de éste y que, por tanto, su sucesión no queda afectada ni tampoco su capacidad de disposición mortis causa. Sí puede adquirir otro tipo de obligaciones estipuladas en el pacto; un ejemplo es la adquisición del compromiso de otorgar los cuidados necesarios al causante hasta el momento de su muerte. El pacto sucesorio puede tener un beneficiario, por ejemplo el caso del instituido heredero o legatario. Tal beneficiario puede ser el otorgante no disponente o un tercero ajeno al pacto. La doctrina no se pone de acuerdo en la calificación de la situación jurídica en la que se encuentra el tercero ajeno al pacto y beneficiario del mismo. Así, parte de la doctrina entiende que dicho beneficiario no goza de ningún futuro derecho ni

\footnotetext{
${ }^{9}$ Seguimos la denominación de otorgante disponente para referirnos al otorgante del pacto que es el futuro causante; no obstante, somos conscientes de que en el caso de los pactos de renuncia no se trata de un acto de disposición sobre la herencia propiamente dicho.

${ }^{10}$ Con carácter general, la doctrina ha mantenido que los pactos sobre herencia de tercero no son pactos sucesorios en sentido estricto. Vid. E. RoguIN (1912), p. 230; J. CASTÁN ToBEÑAs (1944), p. 685; J.L LACRUZ BERDEJO/F. SANCHO REBULLIDA (1981), p. 382; F. PUIG PEÑA (1976), p. 677; M. HeRrero OVIEDO (2009-1), p. 203. En contra, P.A. RoMERo CANDAU (1998), passim.
} 
expectativa jurídica garantizada alguna hasta el fallecimiento del causante ${ }^{11}$; por el contrario, otros entienden que al ser el pacto irrevocable, nace para el instituido un derecho de crédito y no una mera expectativa jurídica ${ }^{12}$. A nuestro juicio, dicho beneficiario tendrá una expectativa jurídica (y no un verdadero derecho adquirido) tal si fuera un legitimario ${ }^{13}$. Ahora bien, no tiene la misma posición el beneficiario que también es otorgante del pacto que el beneficiario tercero al pacto. El primero tiene una posición más sólida puesto que, salvo circunstancias excepcionales, el causante sólo podrá revocar la disposición realizada a su favor con la concurrencia de su voluntad. El beneficiario que no fue otorgante en el pacto tendrá una expectativa cuya consolidación o no dependerá de otras personas.

\section{Tipología de los pactos sucesorios. Criterios de clasificación.}

Los pactos sucesorios pueden ser objeto de distintas clasificaciones en función de aquel aspecto que queramos destacar. La realización de las siguientes clasificaciones nos permitirá conocer con más exactitud la variedad de pactos sucesorios que puede existir.

En primer lugar, los pactos sucesorios se pueden clasificar en función del objeto, siendo ésta la taxonomía que con carácter general maneja la doctrina. Según este criterio los pactos sucesorios pueden ser:

A) Pactos positivos, de institución o de succedendo: son aquellos en los que se constituye un derecho sucesorio en la herencia del otorgante disponente a favor de una persona, otorgante o no, que se denomina beneficiario o instituido. Es el tradicional contrato de herencia o Erbvertrag. El derecho sucesorio atribuido puede ser una institución de heredero o una atribución particular (lo que equivaldría al legado en el testamento).

\footnotetext{
${ }^{11}$ R. KANZLEITER (2006), p. 156, párrafo 10.

12 J.I. CANO MARTínez de Velasco (2002), p. 27; también, R.M. RocA SASTRE (1984), p. 347, quien al hablar del pacto de institución, señala que su fundamento más importante es la garantía inmediata que supone para el heredero.

${ }^{13}$ M.P. García Rubio/M. Herrero Oviedo (2011), p. 1260.
} 
B) Pactos negativos, de renuncia o de non succedendo: son aquellos en los que uno de los otorgantes renuncia de manera anticipada a algún o todo derecho sucesorio que sobre la herencia del otro otorgante pudiera tener. Es el pacto conocido en Derecho alemán como Erbverzicht. Como ya hemos señalado, no se trata de un acto de disposición propiamente dicho ni tampoco se limita la capacidad de disposición mortis causa del futuro causante, sino que al contrario ésta se amplía. Por ello la doctrina entiende que el pacto sucesorio de renuncia no es sucesión contractual propiamente dicha.

C) Pactos sobre herencia de tercero o pacto de hereditate tertii: son aquellos pactos en los que lo otorgantes realizan estipulaciones sobre la herencia futura de un tercero que no participa en el otorgamiento. Este tipo de pactos no vinculan al futuro causante que, por lo tanto, no ve modificada su capacidad de disposición mortis causa. Como ya hemos señalado, este tipo de negocios no son, a nuestro juicio, pactos sucesorios al faltar que el elemento de la vinculación del futuro causante al pacto. En realidad son actos bilaterales inter vivos que se refieren a la sucesión de otra persona ${ }^{14}$.

En segundo lugar, los pactos sucesorios se pueden clasificar en función del número de sucesiones que queden afectadas por el contenido del pacto. Esta clasificación nos interesa especialmente porque, como vamos a ver a lo largo del trabajo, el número de sucesiones implicadas va a tener relevancia a la hora de dar una solución a la ley aplicable a los pactos sucesorios. Se distinguen desde este punto de vista:

A) Pactos sucesorios que afectan a una sucesión: son aquellos en los que sólo hay un otorgante disponente o futuro causante, puesto que sólo hay una sucesión que es objeto del pacto y que, por tanto, está afectada por éste.

B) Pactos que afectan a más de una sucesión: son aquellos en los que hay dos o más otorgantes disponentes y, por tanto, dos o más sucesiones afectadas.

\footnotetext{
${ }^{14}$ M.P. García Rubio/M. HerRero OVIEdo (2011), p. 1261; C. CACCAVAle (1994), p. 30.
} 
En tercer lugar, cabe clasificar los pactos sucesorios desde el punto de vista de la legitimación para otorgarlos; es decir, en función de la condición de parentesco que, en su caso, respecto del futuro causante la ley exige para otorgar un pacto sucesorio válido. Desde esta perspectiva podemos distinguir:

A) Pactos sucesorios matrimoniales: son pactos sucesorios cuya validez exige que sean otorgados entre cónyuges. Ejemplo de legislación que sólo legitima a los cónyuges para otorgar pactos sucesorios es el Derecho austriaco $(\S$ 364 c) AGBG); en Cataluña se exigió también la calidad de cónyuge para el otorgamiento de pacto sucesorio hasta la reforma operada en el año $2008^{15}$.

B) Pactos sucesorios familiares: son aquellos pactos en los que para su válida celebración se impone un determinado grado de parentesco más o menos amplio; el círculo de personas que están legitimadas para otorgar pacto sucesorio es más amplio que en los pactos sucesorios matrimoniales, pero está limitado. El Derecho catalán es un ejemplo de este tipo de pactos sucesorios; en la reforma del año 2008 se amplió el círculo de legitimados para otorgar pactos sucesorios de cónyuges a parejas de hecho y parientes en línea recta de forma ilimitada y parientes en línea colateral hasta el cuarto grado (art. 431. 2 CCCat.)

C) Pactos sucesorios libres: son aquellos en los que para su válida celebración no se pone límite alguno a la condición de los otorgantes. El Derecho aragonés, tras la reforma operada por la Ley 1/1999 de sucesiones por causa de muerte, es un ejemplo de legislación donde no se pide parentesco alguno entre los otorgantes para la celebración de un pacto sucesorio; también el Derecho foral navarro permite los pactos sucesorios libres. En Derecho comparado Alemania o Suiza son ejemplos también de legislaciones que permiten este tipo de pactos.

En cuarto lugar, los pactos sucesorios se suelen clasificar en función de su carácter oneroso o gratuito:

A) Pactos sucesorios onerosos: son aquellos en los que se pacta una contraprestación; es habitual, por ejemplo, que en los pactos de institución de

${ }^{15}$ Vid. J. EgEA (2009), p. 17; M.P. GARCÍA RUBiO/M. HERRERO (2009), p. 465. 
heredero se prevea que el instituido deba prestar al instituyente los cuidados y atenciones que en vida le sean necesarios.

B) Pactos sucesorios gratuitos: son aquellos en los que la institución o disposición realizada se hace sin contraprestación o condición alguna a cambio.

Por último, cabe clasificar los pactos sucesorios en función del carácter de las disposiciones contenidas en el pacto. A este respecto se distinguen:

C) Pactos sucesorios con disposiciones no correspectivas: son aquellos en los que las disposiciones que se otorgan se establecen con carácter independiente una de las otras.

D) Pactos sucesorios con disposiciones correspectivas: aquellos pactos en los que los otorgantes condicionan las disposiciones de uno a las del otro, existiendo una interdependencia entre ellas. Dicho de otro modo, el otorgamiento de unas disposiciones trae causa en la existencia de las otras y viceversa.

\section{La presunta doble naturaleza jurídica de los pactos sucesorios}

Una de las cuestiones más controvertidas acerca de los pactos sucesorios es la del esclarecimiento de su naturaleza jurídica. Se suele decir que la especialidad de estas figuras radica en su doble naturaleza contractual y sucesoria $^{16}$. Por un lado, los pactos sucesorios son una forma de disponer mortis causa; pero por otro lado, se trata de verdaderos contratos que vinculan a las partes desde su otorgamiento y que, por tanto, producen efectos desde ese mismo momento. Esta doble cara de los pactos sucesorios explica la polémica en torno a su naturaleza jurídica, pues la doctrina no se pone de acuerdo en considerarlos negocios mortis causa o inter vivos, bien es cierto que, en parte, porque tampoco está claro cuál es el criterio determinante de uno y otro tipo de negocio ${ }^{17}$. A

\footnotetext{
${ }^{16}$ BROX/WALKER (2007), p. 102, núm. 145.

17 S. PElayo Hore (1967), p. 827; GiampiCCOlO, consciente de la falta de claridad en la distinción entre acto inter vivos y acto mortis causa, propone una dualidad distinta basada en acto inter vivos-negocio de última voluntad, no siendo excluyente que un negocio tenga a la vez carácter inter vivos y mortis causa. Vid. G. GIAMPICCOLO (1954), pp. 53 y ss.
} 
nuestro juicio, se trata de negocios jurídicos con una naturaleza mixta ${ }^{18}$, puesto que por un lado son negocios bilaterales realizados entre vivos y con el efecto inmediato de la vinculación de las partes otorgantes al mismo; y, por otro lado, está destinado a producir sus efectos fundamentales en el momento del fallecimiento del disponente o futuro causante.

En nuestra opinión, el objeto fundamental de los pactos sucesorios es la ordenación de manera anticipada de la sucesión del causante y, por tanto, sus genuinos efectos tienen lugar después de la muerte del causante. Ahora bien, como ha puesto de relieve la doctrina, este carácter no se riñe con el hecho de que se trate de un acto inter vivos, al crearse un vínculo jurídico desde el momento de su otorgamiento entre dos personas que están vivas ${ }^{19}$.

La cuestión se complica con respecto a determinados pactos sucesorios en los que además del establecimiento de las disposiciones oportunas para la regulación por anticipado de la sucesión futura, hay una entrega de bienes o de una cantidad de dinero que se produce en el mismo momento de la celebración del pacto. En estos casos se producen efectos sustanciales de los negocios mortis causa antes del fallecimiento del causante, circunstancia ésta que afecta directamente al carácter mortis causa del pacto sucesorio. Algunos han querido ver que en estos casos el pacto sucesorio viene acompañado de una donación ${ }^{20}$; mientras que otros entienden que no es suficiente para calificar dos negocios de manera independiente, sino que se trata de una característica de este tipo de pactos que adelantan la transmisión de parte o toda la propiedad; que no se trata de negocios independientes, razón por la cual no se puede fraccionar esa unidad del

\footnotetext{
${ }^{18}$ Según Díez Picazo se trata de negocios jurídicos con una naturaleza sui generis, L. DíEz PiCAZO/A. GULLÓN (1989), p. 507.

${ }^{19}$ Con respecto a los pactos de institución, vid. M. HERRERo OVIEDO (2009-1), p. 201; M.P. GARCÍA RUBIO/M. HERRERO OVIEDO (2011), p. 1260; también sobre el doble carácter inter vivos y mortis causa de los pactos sucesorios, G. GIAMPICCOLO (1954), p. 53.

${ }^{20}$ Vid. J. EGEA (2009), p. 29, quien entiende que en el caso de un heredamiento simple con la entrega de presente de algún bien se trata en realidad de dos negocios que otorgan al favorecido dos títulos adquisitivos distintos; si bien, en el caso del heredamiento cumulativo, que por definición prevé ya la entrega de bienes de presente, entiende el autor que se trata de un mismo título adquisitivo para todo, el del pacto sucesorio.
} 
pacto sucesorio $^{21}$. A nuestro juicio, el hecho a tener en cuenta es el del fallecimiento del causante, que es el hecho que fundamentalmente se toma en consideración a la hora de celebrar cualquier pacto sucesorio, y por ello el pacto sucesorio, pese a los efectos que eventualmente en vida del causante pueda producir, sigue manteniendo también su carácter de negocio jurídico mortis causa $^{22}$.

La cuestión sobre la naturaleza jurídica no es controvertida, sin embargo, cuando se trata de los pactos sobre sucesión de tercero. En este caso, se trata claramente de un acto inter vivos, pues como hemos visto no tienen por objeto la regulación de la sucesión del causante, quien no se ve vinculado por tal acuerdo. Se trata de negocio bilateral inter vivos y, como hemos señalado, tal y como entiende la mayor parte de la doctrina, no se trata de verdaderos pactos sucesorios.

\section{INTERESES SUSTANTIVOS PRESENTES EN LOS PACTOS SUCESORIOS 1. Planteamiento}

A mediados del siglo pasado surgió en la doctrina americana un movimiento contra el tradicional método del Derecho internacional privado, representado por la norma de conflicto. Este movimiento se dirigía fundamentalmente a criticar la norma de conflicto por ser un instrumento rígido e independiente de cualquier valor social, lo cual desembocaba en ocasiones en resultados insatisfactorios dentro del nuevo contexto del Estado social y la dimensión social del Derecho. Todos estos movimientos influenciaron en la doctrina europea, que pronto mostró su interés por las críticas que la norma de conflicto recibía entre la doctrina americana. De esta forma, las doctrinas americanas hacen eco en los autores europeos, que empiezan a mostrar una creciente preocupación por la toma en consideración de factores valorativos a la hora de dar soluciones de Derecho internacional privado. Así surge la llamada crisis del Derecho internacional privado o crisis de la norma de conflicto. Se trata

\footnotetext{
${ }^{21}$ LL. Puig Ferriol (1990), p. 285; S. PELAyo Hore (1967), p. 827.

${ }^{22}$ En este sentido, M. HerRero OVIEDO (2009-1), p. 201.
} 
de una crisis estructural, que afecta directamente a la teoría y al método del DIPr y que va a marcar un cambio en las tendencias de la disciplina.

A lo largo, fundamentalmente, de los años setenta se produce un proceso de reflexión sobre el clásico método construido por Savigny y el nuevo enfoque de la doctrina americana ${ }^{23}$. Este proceso de reflexión dio rápidamente importantes resultados; en este sentido, se sistematizan una serie de principios generales del $\operatorname{DIPr}^{24} \mathrm{y}$ se comienza a hablar del método de la jurisprudencia de intereses, como alternativa al método de la jurisprudencia de conceptos en $\operatorname{DIPr}^{25}$. En definitiva, con independencia de las críticas formuladas a las teorías americanas, basadas fundamentalmente en la idea de que dan al juez una libertad que va más allá de los límites de la discrecionalidad judicial y rompen con la seguridad jurídica, las nuevas tendencias americanas influyeron en la doctrina europea, de tal forma que alrededor de los años setenta se puede decir que el DIPr se somete al método de la jurisprudencia de intereses, cuyo punto central es el análisis de intereses en presencia y su recíproca ponderación ${ }^{26}$. Así es cómo nace la idea de que el DIPr debe atender a los intereses sustantivos presentes en la relación jurídica de que se trate; es decir, es necesario averiguar los intereses materiales en la relación jurídica concreta, en nuestro caso los pactos sucesorios, para así poder analizar cómo se debe articular la regulación de DIPr de tal forma que se respeten aquellos. Se tiene presente, por tanto, que al fin y al cabo de lo que se trata es de dar respuesta a un problema jurídico en el que confluyen los intereses de personas individuales respecto de un asunto concreto y particular. Y la determinación de la ley aplicable ha de tener en cuenta la particularidad del asunto (discriminar, por ejemplo, entre una sucesión testada y una paccionada) con lo que la materialización de la respuesta comienza a acompañarse de una especialización de la misma.

\footnotetext{
${ }^{23}$ W. WENGLER (1952), pp. 595-622 y (1953), pp. 37-60; G. KEGEL (1953); K. ZWEIGERT (1973).

${ }^{24}$ W. WENGLER (1952), pp. 600 y ss.

${ }^{25}$ G. KEGEL (1953), quien además de repasar los seis principios generales del DIPr sistematizados por Wengler, habla de otros factores tales como los intereses de las partes, del tráfico y de regulación.

${ }^{26}$ En España, vid. la monografía de E. PÉREZ VeRA (1973), passim.
} 
En este apartado vamos a analizar cuáles son los intereses sustantivos de los pactos sucesorios. En teoría, deberían guiar la solución conflictual o, al menos, estar presentes en su diseño y/o aplicación. Dicha tarea no es fácil por varias razones. En primer lugar, vamos a ver cómo los pactos sucesorios, con su naturaleza híbrida, son figuras en las que pueden concurrir intereses contrapuestos. En segundo término, los intereses sustantivos presentes en los pactos sucesorios no tienen la misma intensidad en un ordenamiento jurídico o en otro. Incluso a la hora de analizar cuál es la mejor forma de regular los pactos sucesorios dentro de un ámbito regional delimitado como pueda ser la UE, se genera el problema de tratar con una gran heterogeneidad de intereses en la regulación de los pactos sucesorios en cada ordenamiento jurídico, lo que dificulta en gran medida esta tarea.

\section{Intereses derivados del carácter sucesorio de los pactos}

\subsection{Intereses materiales vinculados al causante: la libertad de disposición (vinculación y libertad)}

En aquellos casos en los que, como en España, se reconoce la propiedad privada como un valor, incluso con consagración constitucional, ésta se garantiza a través de la herencia ${ }^{27}$; el propietario está provisto de la facultad de disponer para después de su muerte, de tal forma que la propiedad no se extingue en el momento en que fallece el propietario, sino que se garantiza su perpetuidad a través de su transmisión mortis causa ${ }^{28}$. En el marco de la UE esta facultad del propietario se desprende del art. 17 de la Carta de los Derechos Fundamentales de la Unión Europea de $2000^{29}$. El mencionado artículo reconoce el derecho a la propiedad y dispone que "toda persona tiene derecho a disfrutar de la propiedad de sus bienes adquiridos legalmente, a usarlos y a disponer de ellos y a legarlos”. Es precisamente de la regulación del destino del patrimonio de una persona a su fallecimiento de lo que se encarga principalmente el Derecho de sucesiones ${ }^{30}$.

\footnotetext{
${ }^{27} \mathrm{El}$ art. 33.1 CE dispone que "se reconoce el derecho a la propiedad privada y a la herencia".

${ }^{28}$ J. DELGADO ECHEVERRÍA (2011), p. 1.

${ }^{29}$ DOCE C364/1 de 18 de diciembre de 2000.

${ }^{30}$ J.L. LACRUZ BERDEJO/F. SÁNCHEZ REBULlidA (1981), p. 10.
} 
Como propietario de sus bienes el causante tiene el interés fundamental de disponer sobre ellos con la mayor libertad posible para organizar su patrimonio y ordenar su destino para el momento de su fallecimiento. Esta libertad de disposición tiene dos vertientes: por un lado, qué vías posee el causante para disponer de su patrimonio mortis causa; por otro lado, con qué grado de libertad puede decidir sobre el destino de sus bienes.

Como forma de disponer mortis causa, el pacto sucesorio es una manifestación de esa libertad. La elección por el causante del pacto sucesorio como vía para ordenar su patrimonio para después de su muerte, desechando otras alternativas generalmente más flexibles, como el testamento, constituye en sí misma una manifestación de su libertad de disposición. El causante hace uso de la libertad que la ley le da y escoge otorgar un pacto sucesorio, y un tipo de pacto sucesorio en concreto, entre las distintas opciones que se le ofrecen, de ordinario, típicas. La propia elección del pacto sucesorio por el causante tiene, por tanto, un significado o valor que debe tomarse en consideración.

Es la ley la que establece el marco de libertad de disposición que el de cuius posee a la hora de organizar su patrimonio para después de la muerte. La heterogeneidad existente en Derecho material supone que esta libertad tiene un margen más o menos amplio en función del ordenamiento jurídico que sea aplicable. Así, existen sistemas, como el recogido en el CC español, en los que los pactos sucesorios no tienen prácticamente cabida alguna ${ }^{31}$; otros en los que se admiten los pactos sucesorios pero de una manera muy rígida dadas las clases y condiciones exigidas por la ley para su otorgamiento, como es el caso del sistema austriaco donde sólo se admiten entre cónyuges; y, por último, existen otros sistemas en los que el causante goza de una gran libertad de disposición, puesto que los pactos sucesorios son reconocidos con carácter general y de manera flexible; ejemplos de este tipo de sistemas son el ordenamiento jurídico alemán, el Derecho navarro o el aragonés.

\footnotetext{
31 En el sistema español del CC la regla general es la prohibición de estas figuras, a salvo determinadas excepciones que la doctrina considera auténticos pactos sucesorios.
} 
La otra vertiente de la libertad de disposición del causante, también presente a la hora de otorgar un pacto sucesorio (como a la hora de testar), tiene que ver con el margen del que el causante disponga para decidir sobre el destino de sus bienes. Esta vertiente está directamente relacionada con otro de los intereses sustantivos presentes en pactos sucesorios: la protección de determinados familiares próximos al causante.

\subsection{Intereses materiales vinculados a terceros al pacto sucesorio: la protección de familiares próximos al causante}

Tradicionalmente se han puesto límites a la libertad de disposición mortis causa del causante basados fundamentalmente en razones de índole familiar, con el fin de mantener y garantizar la subsistencia de determinados parientes más o menos cercanos al causante. Tales limitaciones se han configurado de distinta forma; para nosotros el más conocido es el sistema legitimario, esto es, aquel en el que la ley reserva forzosamente derechos sucesorios a determinadas personas ${ }^{32}$. Pero no es la única forma de limitación a la capacidad de disposición mortis causa. En el mundo anglosajón, donde se dice que impera la libertad de testar, también hay limitaciones a esta libertad de disposición a través del sistema conocido como family provisions ${ }^{33}$, el cual no se basa en la existencia a priori de derechos legitimarios de determinadas personas fijados por la ley, sino que prevé la legitimación de algunas personas para acudir al juez en ciertas situaciones y solicitar una family provision. Existen también en otros sistemas europeos algunas soluciones intermedias, en los que los legitimarios tienen derecho a una cuota fija de los bienes de la herencia o de su valor sólo en el caso de que se encuentren en una situación de necesidad ${ }^{34}$.

Desde este punto de vista existe un interés sustantivo de esas personas próximas al causante en ver cumplidas sus expectativas jurídicas al fallecimiento de este, recibiendo aquello a lo que, según lo que establezca el sistema de

\footnotetext{
32 Aunque en adelante nos refiramos a la legítima como un derecho a la herencia, somos conscientes de que no siempre se trata de un derecho a una parte de los bienes de la herencia, sino que se puede tratar de un derecho a un valor del patrimonio del causante.

${ }^{33}$ Vid. una aproximación de este sistema, M. ANDERSON (2006), pp. 1275 y ss.

${ }^{34}$ A. VAQUer Aloy (2007), p. 6.
} 
protección de que se trate, tengan derecho. Este interés concurre con el del de cuius de tener la máxima libertad de disposición posible, de tal forma que cada ordenamiento jurídico conjuga ambos intereses resultando una mayor o menor libertad de disposición mortis causa del causante y una correlativa menor o mayor expectativa de los parientes próximos a éste.

Creemos oportuno en este punto hacer una breve referencia a las últimas tendencias que en materia de protección de familiares próximos al causante en los modernos Derechos de sucesiones. En general, se puede decir que los sistemas que, como el legitimario, la ley reserva un derecho o cuota de bienes forzosamente a determinados parientes del causante, se han producido algunas reformas que tiene como característica fundamental el flexibilizar ese sistema rígido de legítimas, aunque sin renunciar a ellas ${ }^{35}$; mientras que donde se conoce una mayor libertad de testar, esto es en el mundo jurídico anglosajón, existen voces que piden una intervención de la ley que excluya la discrecionalidad judicial con la que ahora se protege a esos familiares próximos al causante. En definitiva, se desprende un acercamiento entre las dos grandes opciones de los derechos sucesorios, continental y anglosajón ${ }^{36}$. En términos de intereses, que la heterogeneidad disminuya es un factor favorable a la configuración de normas de ley aplicable más satisfactorias.

Por último, además de los derechos de los legitimarios existen otras posibles limitaciones a la libertad de disposición mortis causa, basadas también en la protección de intereses familiares y otros. Un ejemplo de este tipo de restricciones podría constituirlo las normas sobre troncalidad del Derecho vizcaíno (regulado en los arts. 17 y siguientes de la Ley de Derecho civil del País Vasco). Esta limitación consiste en que un causante con vecindad civil vizcaína y titular de un bien troncal sólo puede disponer del mismo a favor de los llamados parientes tronqueros (señalados en los arts. 20 y 21 de la Ley de Derecho civil del

\footnotetext{
${ }^{35}$ En España existe un movimiento doctrina a favor de la reforma del sistema legitimario del CC; vid. una panorámica general, T. F. TORRES GARCÍA (2006), pp. 215 y ss. A favor de la reforma y flexibilización del tradicional sistema de las legítimas, vid. entre otros, A. CALATAYUD SIERRA (1995), p. 251; E. VALLADARES RASCÓN (2004), p. 4902; A. VAQUER AlOY (2007), pp. 14 y ss.;

${ }^{36}$ Vid. M.A. PARRA LUCÁN (2009), pp. 14 y ss.
} 
País Vasco), que son los descendientes, ascendientes y parientes colaterales de consanguinidad hasta el cuarto grado de parentesco; es decir, la limitación en este caso, viene dada por las personas a favor de las cuales el causante puede realizar disposiciones mortis causa de los bienes troncales ${ }^{37}$.

\subsection{Intereses vinculados al co-pactante}

Los dos centros de intereses personales o subjetivos son típicos del Derecho de sucesiones y afectan por igual a la sucesión testamentaria y a la paccionada. Es el carácter contractual de esta última el que introduce un elemento diferenciador que recae, fundamentalmente, en el interés de sujeción bilateral al pacto. Algo que atañe al causante (o los causantes en caso de pacto sucesorio que afecta a dos sucesiones) y al co-pactante, cuando su sucesión no está comprometida. El interés vinculado al pacta sunt servanda, lo analizamos en los siguientes epígrafes.

\section{Intereses derivados del carácter contractual de los pactos}

\subsection{Autonomía de la voluntad de las partes}

La autonomía de la voluntad, como presupuesto que es de la autorregulación de los individuos y de sus intereses a través de la creación, modificación o extinción de relaciones jurídicas ${ }^{38}$, es un bien jurídico ampliamente reconocido en los ordenamientos de nuestro entorno. El negocio jurídico encierra, según la conocida definición dada por el jurista italiano BETTI, el concreto significado de la autonomía de la persona, como poder para regular sus propios intereses y relaciones ${ }^{39}$.

\footnotetext{
${ }^{37}$ La troncalidad es una forma de organización de la propiedad, vinculada a la familia, cuya estructura consta de tres elementos: un elemento real, que consiste en la existencia de un bien inmueble, denominado bien raíz, sito en el territorio del Infanzonado o Tierra Llana. Un elemento personal, que consiste en una relación de parentesco entre el titular del bien troncal y los llamados a recibir con preferencia el bien troncal en caso de transmisión del mismo. Un elemento causal, a través del cual se explica la conexión de un determinado bien con unos determinados parientes; vid. por todos, A. Celaya IbarRa (1965), pp. 240 y ss.

${ }^{38}$ Vid. J.L. LACRUZ BERDEJO (2005), p. 126.

${ }^{39}$ Vid. E. BetTi (1959), p. 40 y ss.
} 
El pacto sucesorio es un negocio jurídico que crea una relación jurídica entre las partes con determinados derechos u obligaciones para cada una de ellas. Como negocio jurídico, el pacto sucesorio constituye una manifestación de la autonomía de la voluntad de las partes. Los otorgantes expresan su voluntad de celebrar el pacto sucesorio, de tal forma que éste constituye un medio para que las partes alcancen los efectos jurídicos que se proponen. Dicho de otro modo, a través del pacto sucesorio las partes realizan su ejercicio de autonomía de la voluntad y ponen los medios para alcanzar los efectos jurídicos buscados.

Los otorgantes expresan su voluntad de celebrar un pacto sucesorio y además la expresan para otorgar uno en concreto, con también concretos efectos, concretas obligaciones asumidas. Así, por ejemplo, en el caso de que se quiera hacer una institución de heredero o una atribución a título particular, las partes celebrarán un pacto positivo o de succedendo; mientras que si lo que se quiere es extinguir determinados derechos que sobre una herencia tenga una persona, generalmente porque al causante le interesa tener un mayor margen de maniobra en el reparto de su patrimonio, las partes otorgarán un pacto de non succedendo. El significado concreto de esa autonomía de la voluntad de las partes no sólo se deriva de la propia celebración del pacto sucesorio, sino también del contenido de éste, que nos remite directamente a los efectos concretos del negocio jurídico que se está celebrando. En este sentido, es habitual, por ejemplo, celebrar un pacto sucesorio a través del cual se instituye heredero al otro otorgante bajo la condición de que éste preste la atención y cuidados necesarios al futuro causante hasta el momento de su fallecimiento.

\subsection{Vinculación de las partes al pacto sucesorio: pacta sunt servanda}

El interés sustantivo más visible y característico de los pactos sucesorios es la vinculación que las partes otorgantes tienen a su contenido desde el mismo momento en que éste es celebrado y ello sin perjuicio de la trascendencia sucesoria del pacto. A través de los pactos sucesorios las partes adquieren determinados compromisos, pues se trata de verdaderos acuerdos o contratos sujetos al principio de pacta sunt servanda. Esa vinculación es, a nuestro juicio, la característica más importante que presentan estas figuras con vistas a la 
articulación de una respuesta en cuanto a la ley aplicable. Ya hemos señalado que de la vinculación de las partes al contenido del pacto sucesorio se derivan dos efectos fundamentales: por un lado, la natural irrevocabilidad unilateral, salvo determinadas excepciones, de las disposiciones contenidas en los pactos; y por otro lado, en el caso de los pactos sucesorios de institución, la correlativa pérdida de la libertad de disposición mortis causa por parte del causante.

La vinculación que el causante tiene al contenido del pacto supone la diferencia más importante entre las disposiciones realizadas a través de pacto sucesorio y las disposiciones otorgadas a través de un testamento unilateral, las cuales pueden ser libremente revocadas por el causante hasta el mismo momento de su fallecimiento. Generalmente es este efecto vinculante el que da soporte a la razón económica del pacto sucesorio; dicho de otro modo, es habitual que el causante decida ordenar su sucesión a través de un pacto sucesorio, y no a través de un testamento, por el efecto vinculante de estas figuras, que, en función de las circunstancias, puede garantizar una mayor satisfacción de los objetivos del disponente a la hora de ordenar su sucesión. Un ejemplo sobre la relación entre la vinculación y la razón económica del pacto sucesorio, puede darse en los casos en los que el futuro causante realiza un pacto sucesorio con uno de sus descendientes para transmitirle íntegramente la empresa familiar. Los estudios sobre la transmisión de la empresa familiar muestran que muchas de ellas cierran su actividad cuando su titularidad es compartida por varios herederos $\mathrm{y}$, por tanto, aconsejan para su continuidad la transmisión íntegra de la misma a una sola persona $^{40}$. El causante que quiere garantizar la continuidad de su empresa puede otorgar un pacto sucesorio instituyendo heredera a la persona a la que quiera confiar la dirección de la empresa (generalmente es uno de los hijos que trabaja en ella); la vinculación de las partes al pacto sucesorio da una garantía al causante de que a su fallecimiento la empresa estará dirigida por la persona que estime conveniente y habrá más posibilidades de éxito en la continuidad de la actividad empresarial; pero además, se consigue una mayor implicación de esta persona en la empresa, al tener la seguridad el instituido de que ésta será de su propiedad en

${ }^{40}$ Vid. S. NAVAS NAVARRO (2011), p. 43. 
un futuro. Este grado de seguridad no la tiene el instituido a través de un testamento, puesto que el causante no está vinculado a las disposiciones del mismo y puede modificarlas en cualquier momento.

En definitiva, la vinculación de las partes al contenido del pacto sucesorio es un interés sustantivo fundamental de estas figuras, que debe ser garantizado desde el mismo momento del otorgamiento En la solución de ley aplicable, este interés se ha de transformar en una conexión previsible desde el primer momento y no susceptible de alteración o fácil manipulación.

\subsection{Seguridad y previsibilidad jurídicas}

En efecto, relacionado con la vinculación de las partes al pacto sucesorio, está el interés universal de la seguridad jurídica. Decimos que se trata de un interés universal porque toda relación jurídica precisa de cierta seguridad; ahora bien, en el caso de los pactos sucesorios, tal y como vamos a ver, el valor de la seguridad jurídica se erige en algo fundamental o incluso en ocasiones esencial para que exista la propia razón de la figura. El interés de la seguridad jurídica se manifiesta en los pactos sucesorios en la necesidad de las partes de conocer el régimen jurídico al que está sometido el pacto sucesorio desde el mismo momento en el que éste es celebrado. Los otorgantes deben saber con seguridad a qué y en qué términos se han vinculado, de tal forma que las partes puedan ser conscientes con exactitud cuál es la situación jurídica en la que se encuentran respecto del pacto sucesorio. Con carácter general, conocer con seguridad el régimen jurídico al que el pacto sucesorio está sometido permite a las partes saber cuáles son sus derechos y obligaciones; en particular, tiene especial relevancia el tener conocimiento de cuáles son las causas por las que las partes pueden revocar unilateralmente el pacto sucesorio, de tal forma que puedan anticipar el alcance de sus actuaciones y adecuar su comportamiento. No nos estamos refiriendo a las causas de revocación que las partes puedan acordar libremente al celebrar el pacto, pues tales son de sobra conocidas por los otorgantes, sino a esas causas excepcionales de revocación unilateral de los pactos sucesorios que la ley generalmente prevé. Es habitual, por ejemplo, que el causante tenga la facultad de 
revocar la institución de heredero realizada a favor del cootorgante cuando éste concurra en alguna de las causas de desheredación recogidas en la ley ${ }^{41}$.

Puesto que la seguridad jurídica está relacionada con la vinculación de las partes al pacto sucesorio, también se postula este interés como determinante para salvaguardar la razón económica del mismo. Sólo conociendo el régimen jurídico del pacto de institución, tendrá el cootorgante instituido heredero la seguridad de que va realmente a heredar; o de la misma forma, sólo conociendo tal régimen tendrá el causante que realizó un pacto de renuncia con uno de sus legitimarios la seguridad de poder disponer eficazmente con mayor libertad de su patrimonio.

\section{La confluencia de intereses materiales contrapuestos en los pactos sucesorios: el principio de libre revocabilidad de las disposiciones mortis causa y la irrevocabilidad unilateral de las disposiciones realizadas a través de pacto sucesorio}

Desde el punto de vista de los intereses materiales, los pactos sucesorios presentan una importante particularidad, cual es que se trata de figuras en las que confluyen intereses directamente contrapuestos. Como hemos dicho, los pactos sucesorios tienen una doble naturaleza, contractual y sucesoria. Y es precisamente de esta doble naturaleza de donde se derivan ciertas fricciones. Tal circunstancia tiene que ver, por un lado, con una máxima reinante en el Derecho de sucesiones: la libre revocabilidad por parte del causante de las disposiciones de última voluntad hasta el mismo momento de su fallecimiento; y, por otro lado, con una característica propia de los contratos, cual es la vinculación al contenido del pacto sucesorio que se crea para las partes otorgantes desde el momento de su celebración, que implica la imposibilidad de revocar, con carácter general, libremente las disposiciones realizadas a través del pacto sucesorio del causante. $\mathrm{Su}$ traducción en DIPr ha implicado tradicionales soluciones personales en materia sucesoria (nacionalidad, domicilio...) y conexiones subjetivas (autonomía conflictual) o de proximidad estricta, para la salvaguarda de los intereses contractuales.

\footnotetext{
${ }^{41}$ Vid. por ejemplo el art. 431. 14 CCCat.
} 
Como hemos dicho, una de las máximas del Derecho de sucesiones es el principio de libre revocabilidad de las disposiciones por causa de muerte; se trata de un interés material que pretende proteger la última voluntad del causante, según la cual éste puede realizar las modificaciones oportunas en la organización mortis causa que haya podido hacer de su patrimonio hasta el mismo momento de su fallecimiento. Tal posibilidad significa que el causante no está vinculado por aquellas disposiciones mortis causa de su patrimonio que hubiera podido realizar con anterioridad. Así, por ejemplo, un causante podrá revocar o modificar las disposiciones realizadas a través de un testamento en cualquier momento ${ }^{42}$.

Si sólo este interés prevaleciera, desde el punto de vista sucesorio, los pactos sucesorios, como instrumentos para organizar la sucesión de una persona deberían contener disposiciones que fueran libremente revocables por el causante. Sin embargo, los pactos sucesorios tienen también un carácter contractual del que se deriva el efecto de la vinculación a su contenido y, consiguientemente, la imposibilidad del causante de poder revocar unilateralmente las disposiciones realizadas. La libre revocabilidad en manos del causante quiebra cuando éste ha dispuesto de su patrimonio mediante un pacto sucesorio.

El resultado de este doble carácter sucesorio y contractual es el de la irrevocabilidad general de las disposiciones contenidas en los pactos sucesorios, a salvo determinadas excepciones; es decir, la irrevocabilidad en los pactos sucesorios es algo natural, pero no esencial ${ }^{43}$. Esto es, como ya hemos visto, con carácter general y a salvo de determinadas excepciones pactadas o previstas en la ley, el causante no puede revocar unilateralmente las disposiciones realizadas en el pacto sucesorio. Por ello ha puntualizado la doctrina que los pactos sucesorios no contienen disposiciones de última voluntad, pues al quebrar el principio sucesorio de libre revocabilidad, es posible que el pacto sucesorio no refleje la que

\footnotetext{
${ }^{42}$ El art. 737 del CC recoge tal revocabilidad cuando señala que "todas las disposiciones testamentarias son esencialmente revocables, aunque el testador exprese en el testamento su voluntad o resolución de no revocarlas".

${ }^{43}$ F.J. GAS (1953), p. 315; M.P. GARCÍA RUBIO (2000), p. 1474, donde dice que "aunque no sabe duda que como ocurre en todo tipo de contratos la regla general es la irrevocabilidad, derivada de la esencia bilateral del acuerdo, existen supuestos en los que, por una u otra vía, uno solo de los intervinientes pueden desvincularse de lo pactado".
} 
fuera la última voluntad del causante ${ }^{44}$. Por otro lado, es precisamente la contraposición de estos dos intereses, el de la libre revocabilidad de las disposiciones de última voluntad y la irrevocabilidad natural de los pactos sucesorios, la que explica en mayor medida, tal y como vamos a ver, el carácter polémico de los pactos sucesorios y la actitud reacia a este tipo de figuras propia de los sistemas sucesorios de origen romano ${ }^{45}$. En el DIPr las soluciones no han sido capaces, hasta la fecha de decantarse claramente por una de las dos caras de los pactos, su carácter híbrido (el de las soluciones de DIPr) plantea no pocos problemas: sin salirnos de nuestro $\mathrm{CC}$ : el art. 9.8 concilia la dimensión predominantemente sucesoria (ley nacional en el momento del fallecimiento), con la dimensión esencialmente contractual (ley nacional en el momento del pacto). Pero no hay jerarquía. Hay colaboración. Y la colaboración entre dos potenciales leyes para regular un mismo asunto no suele ser un punto de partida fácil.

\section{LA DIVERSIDAD DE SISTEMAS DE PACTOS SUCESORIOS COMO PRESUPUESTO}

\section{Orígenes históricos}

\subsection{Sistema romano}

La estructura social en el Derecho romano giraba en torno a la persona (en concreto, al cives romano sui iuris) y al ensalzamiento de su personalidad individual. Como consecuencia de esa personalidad individual la persona podía disponer de sus bienes libremente para después de su muerte, facultad ésta que se plasmaba a través del testamento. En consecuencia, la sucesión hereditaria en el Derecho romano giraba en torno al testamento, un acto mortis causa unilateral y revocable, que respetaba la máxima según la cual una persona puede mudar su voluntad siempre que lo desease y hasta el mismo momento de su fallecimiento ${ }^{46}$. La forma de suceder en el Derecho romano era la sucesión universal, que consistía

\footnotetext{
44 ; G. GiAMPICCOLO (1954), p. 52; M.P. GARCÍA Rubio/M. HerRERO OVIEDO (2011), p. 1260.

${ }^{45}$ Sin perjuicio del mayor desarrollo que más adelante se hará sobre la actitud contraria a los pactos sucesorios en Derecho romano, tal y como dispuso BIONDI, vinculación contractual y libertad testamentaria son principios contrapuestos, razón por la que estas figuras desataron tanta polémica en este Derecho; vid. B. BIONDI (1954), p. 170.

${ }^{46}$ B. BIONDI (1943), pp. 3 y ss. y pp. 30 y 31.
} 
en que los herederos subentraban en la posición del causante y continuaban con sus titularidades; es decir, el heredero sustituye al causante, se coloca en su lugar, de tal forma que una personalidad individual se coloca en la posición de otra personalidad individual $^{47}$.

Con carácter general, se mantiene la opinión de que el Derecho romano fue extremadamente reacio a los pactos sucesorios. Son varias las causas sobre las que se fundamenta esta posición contraria a los pactos sucesorios. Por un lado, se decía que tales pactos eran contrarios a la moral de la época; en primer lugar, no estaba bien visto desde el punto de vista sociológico realizar un contrato en el que el centro del negocio jurídico se situaba en el fallecimiento de una de las partes ${ }^{48}$; en segundo lugar, de la celebración de estos pactos se desprendía un temor a despertar el denominado votum mortis, esto es, la posibilidad de que el favorecido por el pacto deseara el fallecimiento del disponente. Por otro lado, se alegaron también razones de orden público, al ser tales acuerdos contrarios a las leyes en vigor; en concreto, y esta parece ser la razón de más peso para mantener una postura contraria a los pactos sucesorios, el carácter irrevocable de estos acuerdos chocaba frontalmente con la libertad de testar, principio fundamental del Derecho de sucesiones romano ${ }^{49}$.

En realidad, en el Derecho Romano no se llegó a reconocer una figura genérica de pacto sucesorio ni tampoco se realizó una sistematización de estas figuras. La práctica sobre pactos sucesorios en el Derecho romano se limita a figuras particulares y aisladas. Por ello, tampoco se recogió en este Derecho una prohibición genérica o general de los pactos sucesorios ${ }^{50}$. Sí se establecieron, no obstante, prohibiciones particulares de algunas de esas concretas figuras. Como

${ }^{47}$ P. BONFANTE (1930), pp. 3 y ss.; R. SOHM (1951), pp. 310 y ss.; B. BIONDI (1954), pp. 51 y ss.; P.VOCI (1960), pp. 135 y ss.

${ }^{48}$ M. HerRero OVIEDO (2009-1), p. 204; M.P. García Rubio/M. HERRERo OVIEDO (2011), p. 1262.

${ }^{49}$ G. Vismara (1986), p. 83; M. HeRrero OVIEDO (2009-1), p. 205.

${ }^{50}$ G. Vismara (1986), p. 110; M.L. Marín Padilla (1992), p. 59; S. Pelayo Hore (1967), p. 822. No obstante, hay quien ha sostenido (información que no hemos podido contrastar) que en la época de Justiniano se enunció por primera vez una prohibición general de los pactos sucesorios, tratándose más bien de una simplificación de las numerosas normas existentes y no de una teoría general de los pactos sucesorios, vid., 72E CONGRÈs DES NOTAIRES DE FRANCE (1975), p. 543. 
ejemplos de este tipo de prohibiciones concretas podemos señalar la prohibición de la promesa de gratificación testamentaria bajo sanción de una cláusula penal (esto es, un acuerdo a través del cual se promete pagar una suma de dinero si no instituye a la otra parte heredero ${ }^{51}$ ); la venta de la sucesión de un hombre vivo ${ }^{52}$ o la donación de la parte de heredero antes de la apertura de la sucesión ${ }^{53}$; en el ámbito de los acuerdos familiares también se recogieron prohibiciones de figuras concretas, tales como, por ejemplo, la prohibición de la promesa de partes iguales en la sucesión del padre de la cónyuge, contenida en un contrato matrimonial ${ }^{54}$, o la renuncia a la cuarta falcidia (un auténtico pacto de renuncia tal y como nosotros lo conocemos actualmente ${ }^{55}$ ). Son varias las razones que se dieron para justificar la posición contraria a los pactos sucesorios en el Derecho romano, muchas de las cuales, tal y como hemos visto con anterioridad, siguen hoy en día invocándose respecto de aquellos sistemas que tienen una actitud reacia frente a estas figuras. En primer lugar, se entendió que los pactos sucesorios eran contrarios a la moral, en cuanto que el fallecimiento de una persona era un elemento integrante del propio contrato $^{56}$. Incluso se llegaron a considerar contrarios al orden público ${ }^{57}$.

En segundo lugar, se entendía que los pactos sucesorios creaban el peligro del llamado votum captandae mortis o peligro de que los favorecidos por el pacto sucesorio desearan el fallecimiento de la persona de cuya sucesión se tratase. Si bien, este argumento parece de poca consistencia, no sólo porque tal deseo se puede predicar en cualquier tipo de sucesión mortis causa al ser el fallecimiento del causante el elemento relevante ${ }^{58}$, sino también porque con

\footnotetext{
${ }^{51}$ Juliano, Dig. XLV, I, 61.

${ }^{52}$ Pomponio, Dig. XVIII, IV, 1.

${ }^{53}$ Papiniano, Dig. XXXIX, V, 29-II.

${ }^{54}$ Valeriano y Galieno, C., II, III, 15.

55 Papiniano, Dig. XXXV, II, 15.

${ }^{56}$ M. HERRERO OVIEDO (2009-1), p. 204.

${ }^{57}$ J. Castán Tobeñas (1944), p. 689; M. Herrero Oviedo (2009-1), p. 204.

${ }^{58}$ B. BIONDI (1954), pp. 172 y ss.
} 
mayor razón se podría desear tal fallecimiento en el caso de instituido por testamento, ante la posibilidad que siempre tiene el testador de revocarlo ${ }^{59}$.

En tercer lugar, también se han dado razones específicas para tipos de pactos sucesorios concretos. En este sentido se ha predicado que determinados pactos sucesorios son nulos por falta de objeto; en concreto, fue Pomponio quien respecto de la venta de la herencia del que vive dispuso que no existe tal pacto, en cuanto que no existe el objeto de la venta ${ }^{60}$. Por su parte, y en relación con los pactos de renuncia, cuando se trataba de renuncia a la sucesión legítima, Papiniano defendió su nulidad con base en la consideración del orden de la sucesión legítima como una cuestión de derecho público y, por tanto, no modificable por la voluntad de los sujetos privados ${ }^{61}$.

Por último, la razón de mayor peso jurídico que se ha dado para justificar una posición contraria a los pactos sucesorios es la de su contraposición con la libertad de testar, principio básico del Derecho romano ${ }^{62}$. El carácter naturalmente irrevocable de los pactos sucesorios choca frontalmente con este principio según el cual el causante puede modificar y revocar las disposiciones mortis causa hasta el mismo momento de su fallecimiento. No obstante, incluso esta razón no es categórica, dado que sólo sería aplicable a los pactos sucesorios de institución, en los que el causante al realizar disposiciones mortis causa pierde correlativamente su libertad de disposición mortis causa; pero no ocurre lo mismo con los pactos sucesorios de renuncia, en los que el causante adquiere una mayor libertad de disposición mortis causa sobre su patrimonio y nada impediría que posteriormente hiciera disposiciones testamentarias incluso a favor del renunciante.

Con carácter general, por tanto, los pactos sucesorios no fueron bien vistos en el Derecho romano. Sin embargo, un estudio más detallado de la situación en el Derecho romano revela que la situación reacia respecto de los

\footnotetext{
${ }^{59}$ J.L. LACRUZ BERDEJO/F. SANCHO REBULLIDA (1981), p. 382.

${ }^{60}$ Pomponio, Dig. XVIII, IV, 1.

${ }^{61}$ Papiniano, Dig. XXXVIII, XVI, 16. En contra de este argumento se muestra C. FADDA (1900), p. 310.

${ }^{62}$ M. HeRrero OVIEDO (2009-1), p. 205.
} 
pactos sucesorios no era tan drástica. Pese a esta actitud $a$ priori hostil a los pactos sobre sucesión futura, también se permitieron en Derecho romano algunos acuerdos, parece ser que por influencia de costumbres provinciales ${ }^{63}$. En este sentido, a la vez que se prohibieron determinadas figuras concretas, también se reconoció validez a otras que constituían verdaderos pactos sucesorios, puesto que en Roma también existieron actos mortis causa bilaterales e irrevocables. En concreto, en las distintas épocas del Derecho romano se conocieron concretas excepciones de pactos sucesorios que fueron admitidos de forma aislada. A título de ejemplo podemos destacar la existencia de diversos pactos sucesorios de atribución particular relacionados con el matrimonio de una hija; una de estas excepciones es el pacto de restitución de la dote, contenido en un acuerdo dotal, a través del cual se admite la restitución de la propia dote a favor del hermano, para el caso de que la mujer, una vez casada, premuera a su marido. El pacto es celebrado entre los hermanos y en el acto interviene también el esposo ${ }^{64}$. De igual forma se suele destacar también la existencia de pactos sucesorios vinculados con militares en campaña de guerra; en este contexto, se conoció de un caso que afectaba a un pacto recíproco de sucesión otorgado por dos hermanos militares, en el que se estipulaba que el hermano sobreviviente se haría dueño de los bienes del otro. El pacto se planteó en la época de los emperadores Diocleciano y Maximiano y se reconoció en la $L$. Licet inter privatos ${ }^{65}$. Bien es cierto que esta ley, en el reconocimiento de este acto, lo configuró formalmente como si de un testamento se tratara; pero ello no obsta para que la doctrina lo haya identificado como un verdadero pacto sucesorio ${ }^{66}$; hay quien no sólo entiende que se trata de un pacto sucesorio, pese a la forma en que se le reconoce validez al acto, sino también que el reconocimiento de este pacto sucesorio por la ley tiene un alcance

\footnotetext{
${ }^{63}$ Al final de la época clásica, especialmente en las provincias, el uso de pactos sucesorios fue bastante frecuente, pese a que la legislación imperial negara su validez; vid. B. BIONDI (1954), p. 171.

${ }^{64}$ Dig. XXIII, IV, 29-II; G. ViSMARA (1986), pp. 88 y 121; M.L. MARÍN PADILLA (1992), pp. 59 y Ss.

65 C. II.III.19

${ }^{66}$ G. Vismara (1986), p. 123; M.L. Marín PAdilla (1992), p. 38; sin embargo, también ha habido autores que con base a esta configuración formal que la ley realiza como un testamento, entienden que se trata de un testamento y no de un pacto sucesorio, vid. B. BIONDI (1954), p. 171.
} 
general, de tal forma que los militares tenían el privilegio de poder disponer de sus bienes para después de su muerte de la forma que estimaran conveniente ${ }^{67}$.

Existen más ejemplos particulares de pactos sucesorios admitidos en el Derecho romano; entre los actos bilaterales por causa de muerte que tuvieron lugar en este Derecho también se encuentran las donaciones mortis causa, que en ocasiones, en función de sus características y, fundamentalmente, en el caso de que fueran irrevocables, se han identificado como ejemplos de pactos sucesorios $^{68}$. Se mencionan también otros, tales como la posibilidad de pactar el destino de la dote, la promesa de igualdad o la denominada "divisio parentis inter liberos", a través de la cual se permitía la repartición contractual del patrimonio familiar con efecto desde el fallecimiento del padre (si bien, algunos autores descartaron el carácter contractual de esta técnica, al entender que se trataba de una disposición obra de la voluntad unilateral del causante) ${ }^{69}$. También determinados pactos de renuncia puesto que tales tipos de pactos no chocaban tanto con los principios del Derecho sucesorio de Roma, como lo hacían los pactos de institución ${ }^{70}$.

En definitiva, y a modo de síntesis, podemos concluir que en el Derecho romano no se conoció la figura del pacto sucesorio de forma sistemática; por ello, no existió prohibición o admisión de los pactos sucesorios con carácter general, sino más bien tratamientos específicos de figuras concretas. Pese a que con carácter general se identifica el Derecho romano con un comportamiento hostil respecto de los pactos sucesorio, lo cual es verdad a grandes rasgos, lo cierto es que, en gran medida por la influencia de las costumbres provinciales, también debemos reconocer la existencia de aisladas excepciones en las que se reconoció validez a determinados pactos sucesorios.

\footnotetext{
${ }^{67}$ M.L. MARÍN PADILLA (1992), p. 33 y p. 38.

${ }^{68}$ G. VisMARA (1986), p. 117.

${ }^{69}$ 72E CONGRÈS DES NOTAIRES DE FRANCE (1975), p. 545.

${ }^{70}$ M.P. GARCÍA RUBio/M. HeRRERo OVIEDO (2011), p. 1262.
} 


\subsection{Sistema germánico}

A diferencia de lo que ocurre en el sistema romano, donde el centro de la estructura social se situaba en la persona individualmente considerada, en el sistema germánico la estructura social giraba en torno a la familia. La comunidad familiar gozaba de un fuerte vínculo, esto es, los miembros de cada familia tenían un fuerte sentimiento de pertinencia a la misma; existía un jefe de familia y otra serie de miembros equiparados jurídicamente en cuanto a derechos en la comunidad familiar ${ }^{71}$. En realidad se trataba de una comunidad patrimonial, ligada a una economía agraria, que incluye tanto bienes inmuebles como bienes muebles. La propiedad de este patrimonio era en su mayor parte colectiva, de la comunidad familiar. El jefe de familia sólo tenía derecho a un disfrute vitalicio del patrimonio familiar y, como consecuencia, no se le reconocía al individuo la posibilidad de disponer libremente de sus bienes; paralelamente, los hijos tenían derecho a la sucesión por el mero hecho de nacer en la familia. Sólo en un momento posterior se posibilitó en pequeña medida disponer libremente de los bienes; así, por ejemplo, en el pueblo visigodo, el padre debía distribuir el patrimonio familiar en partes iguales entre sus hijos varones, quedando únicamente una cuota de un quinto a su libre disposición, si bien parece ser que la documentación de la época muestra que incluso en la ordenación de este quinto de libre disposición intervenían junto al padre su mujer e hijos ${ }^{72}$.

Con esta estructura social en la que todo giraba en torno a la familia se puede entender que el testamento, como máxima expresión de la personalidad individual, no tuviera acogida en los sistemas germánicos ${ }^{73}$. Tampoco se puede decir que en estos pueblos germánicos sólo se conociera la sucesión intestada, sino que los estudios revelan que el reparto equitativo entre los hijos que debía realizar el jefe de familia se solía realizar en vida de éste. Es decir, los sucesores recibían en vida del jefe de familia la parte que les correspondía en el patrimonio

\footnotetext{
${ }^{71}$ La familia germánica, desde el punto de vista jurídico y de los derechos que genera para sus miembros, era una comunidad en la que, al menos en un principio, participaban el padre y los hijos varones; la madre y las hijas no tenían derechos sobre la comunidad familiar y así, por ejemplo, no podían heredar los bienes familiares. Vid. M.L. MARÍN PADILLA (1992), p. 93.

${ }^{72}$ M.L. MARÍn PADILla (1992), pp. 91 y 95.

${ }^{73}$ Vid. S. PELAYO HORE (1967), p. 825.
} 
familiar, por ejemplo con ocasión del matrimonio o de la emancipación de un hijo. En estas circunstancias los pactos sucesorios se erigieron en un instrumento adecuado para organizar la sucesión en vida del causante. De esta forma, distintas figuras de naturaleza contractual y con eficacia sucesoria fueron apareciendo y desarrollándose a través de las costumbres, fuente del Derecho prevalente en el sistema germánico ${ }^{74}$.

\section{Evolución}

\subsection{Sistemas favorables a los pactos sucesorios}

Los ordenamientos jurídicos que han recogido en sus Códigos las influencias jurídicas de los pueblos germanos, dan cabida a los pactos sucesorios. Los ejemplos más visibles los constituyen el ordenamiento jurídico alemán y el suizo.

Los pactos sucesorios han sido admitidos ampliamente en el ordenamiento jurídico alemán. Es cierto que a la hora de redactar el BGB se alzaron voces en contra de la admisión de los pactos sucesorios; estas corrientes fundamentaron su postura, por un lado, en el peligro que supone la vinculación contractual del causante y la consiguiente imposibilidad de adaptar al cambio de circunstancias las disposiciones realizadas sobre su patrimonio; por otro lado, argumentaban también la falsa seguridad que crea el pacto sucesorio, puesto que el causante mantiene su libertad de disposición inter vivos ${ }^{75}$. Pese a la existencia de estas corrientes contrarias a los pactos sucesorios, el BGB admitió desde el principio los pactos sucesorios ${ }^{76}$. En esta decisión tuvo gran peso la tradición jurídica, concretamente las costumbres jurídicas de la Edad Media donde los pactos sucesorios eran frecuentes e incluso necesarios. Se realizaban tanto pactos de institución, por ejemplo en el seno de familias con una economía agraria o pactos sucesorios en los que el causante se comprometía a dejar su herencia a una institución pública o privada, a cambio de recibir los cuidados y asistencia

\footnotetext{
${ }^{74}$ Se conocen en aquella época pactos sucesorios de institución de heredero, pactos de ordenación de legados y pactos de renuncia a la herencia; vid. J. CASTÁN TOBEÑAS (1944), p. 689.

${ }^{75}$ R. KANZLEITER (2006), p. 153, núm. 2.

${ }^{76}$ R. KANZLEITER (2006), p. 153, núm. 2; T. KIPP (1976), p. 369.
} 
necesaria; como pactos de renuncia, frecuentes fundamentalmente entre la nobleza con el fin de mantener el patrimonio indiviso en manos de una sola persona. En casos como estos, era necesaria una figura vinculante, como los pactos sucesorios $^{77}$.

Como ya hemos adelantado los pactos sucesorios fueron admitidos ampliamente en el Derecho alemán. Se permitieron los pactos de institución (Erbvertrag) y los pactos de renuncia (Erbverzicht), mientras que se prohibieron los pactos sobre herencia de tercero ( $§ 311$ b párrafo $\left.4^{\circ} \mathrm{BGB}\right)$. Además se decidió que su celebración no se restringiera al ámbito del matrimonio, sino que se optó por no limitar el círculo de legitimados para su otorgamiento.

Actualmente el $\S 1941$ BGB posibilita al causante realizar instituciones de heredero o legatario a través de un pacto sucesorio; esta posibilidad se configura ampliamente tanto por el posible contenido del pacto sucesorio, como por la ausencia de limitación en cuanto a los legitimados para otorgarlo. En efecto, en cuanto a los elementos personales, el BGB sólo se refiere a determinados requisitos de capacidad que tienen que tener los otorgantes disponentes y la posibilidad de que la institución realizada a través de pacto sucesorio sea a favor de uno de los contratantes o a favor de un tercero ajeno al pacto ( $§ 1941.2$ BGB). Por otro lado, el BGB se ocupa de forma particular de los pactos de renuncia, que tienen una regulación más detallada en los § 2346 y siguientes del BGB. El contenido del pacto de renuncia puede ser también muy variado; en este sentido, es posible renunciar tanto a la legítima ( $\$ 2346$ BGB), como a los derechos derivados de una institución de heredero o legatario que se hubiera realizado a través de testamento ( $\$ 2352$ BGB), y puede ser al conjunto del derecho a la sucesión o a una parte del mismo. Es frecuente que la renuncia se realice a cambio de una contraprestación del causante, con la que el renunciante es compensado $^{78}$ y se puede configurar bien la renuncia sin más, bien a favor de una persona determinada, caso en el que la renuncia sólo tendrá eficacia si el beneficiario de la misma llega finalmente a heredar ( $\$ 2350$ BGB).

\footnotetext{
${ }^{77}$ T. KIPP (1976), pp. 369 y 729; T. HOEREN (2012), p. 2333, núm. 19.

${ }^{78}$ H.BROX/D.WALKER (2008), p. 202.
} 
El Derecho suizo es otro de los ejemplos de ordenamientos jurídicos en los que tradicionalmente se han permitido ampliamente los pactos sucesorios. El art. 494 CC suizo habilita de forma genérica la posibilidad de realizar pactos sucesorios positivos o de institución; al igual que en el caso alemán, no hay restricción alguna en relación a las personas legitimadas para el otorgamiento de tales pactos, limitándose la ley únicamente a señalar que la institución de heredero o a título particular podrá hacerse tanto a favor del otro contratante, como a favor de un tercero. La doctrina señala que el pacto puede tener carácter gratuito o bien acordarse una contraprestación que podrá ser inter vivos o mortis causa, tratándose finalmente en este último caso de un pacto sucesorio recíproco ${ }^{79}$. También en el caso suizo la regulación de los pactos de renuncia es más detallada que la regulación de los pactos sucesorios de institución. El artículo 495 CC suizo dispone que el disponente puede concluir, a título gratuito u oneroso, un pacto de renuncia a la sucesión con uno de sus herederos, perdiendo el renunciante su cualidad de heredero. Se entiende, para estos pactos, que el renunciante debe ser una persona que ostentaría la cualidad de heredero legitimario del causante de la sucesión en el momento del otorgamiento del pacto y puede renunciar a la totalidad o a parte de su cuota ${ }^{80}$.

\subsection{Sistemas contrarios a los pactos sucesorios}

La diversidad que sobre el reconocimiento de los pactos sucesorios existe actualmente entre los distintos ordenamientos jurídicos es el resultado de la mayor o menor influencia del Derecho romano sobre los mismos ${ }^{81}$. Los países de influencia latina recogieron en sus respectivos códigos la prohibición de los pactos sucesorios; ejemplos paradigmáticos de este fenómeno los encontramos en el sistema francés y en el sistema italiano.

En Francia, tras un corto periodo de influencia germánica en el que se permitieron algunos pactos sucesorios, a partir del siglo XIII y con la vuelta al Derecho romano, se construyó una teoría jurídica dirigida a la determinación de la

\footnotetext{
${ }^{79}$ G. SCYBOZ/P. SCYBOZ/P.R. GILlIÉRON, A. BRACONI, (2008), art. 494

${ }^{80}$ H.P. SCHÖMMER/U. BÜRGI, (2006), p. 125.

${ }^{81}$ R. SÁNCHEZ ARISTI (2003), p. 42.
} 
nulidad de los pactos sucesorios. Fue en este momento en el que se realizó una cierta sistematización de estas figuras, estableciéndose un concepto de pacto sucesorio o pacto sobre sucesión futura o no abierta y clasificándolos en pactos de succedendo, de non succedendo y de hereditate tertii ${ }^{82}$.

Ya en el Código Civil de Napoleón se estableció una postura contraria a los pactos sucesorios. Varios artículos del Code (art. 791 en sede sucesoria, art. 1130 en sede contractual, y arts. 1389 y 1600) recogían particulares prohibiciones de manera asistemática y repetitiva, pero no se puede hablar de la existencia de un principio de prohibición de los pactos sobre sucesión futura, puesto que esta categoría no fue considerada como tal por los redactores del $\operatorname{Code}^{83}$. De todos estos preceptos, es el art. 1130 el que se suele citar para situar la prohibición de los pactos sucesorios en Francia; dicho artículo establece de una manera más general que no se puede renunciar a una sucesión no abierta, ni hacer estipulación alguna sobre tal sucesión. Como justificación a la prohibición del Code se acude a las razones clásicas que se dieron en el Derecho romano, pero parece que mayor peso tiene la necesidad de preservar la libertad de disposición del causante para organizar su sucesión como estime conveniente hasta el mismo momento de su fallecimiento $^{84}$, así como la de evitar la concentración de la propiedad privada en unos pocos ${ }^{85}$. Por otro lado, debemos tener en cuenta también que la jurisprudencia francesa realizó una interpretación extensiva de las prohibiciones recogidas por estos artículos ${ }^{86}$.

Ahora bien, no obstante estos artículos que prohibían determinados pactos sucesorios y la jurisprudencia francesa que los interpretaba de forma extensiva, existieron desde el principio determinados pactos autorizados por la legislación francesa y que constituyen verdaderas excepciones a esa prohibición de los pactos sucesorios. La primera de esas excepciones la conforma la donación

\footnotetext{
82 72E CONGRÈS DES NOTAIRES DE FRANCE (1975), pp. 549 y 550.

83 72E CONGRÈS DES NOTAIRES DE FRANCE (1975), p. 570.

${ }^{84}$ M. HeRrero OVIEDO (2009-2), p. 449; L. LEVENEUR/S. LEVENEUR (1999), p. 29.

${ }^{85}$ M.P. García Rubio/M. Herrero OVIEdo (2011), p. 1264.

86 72E CONGRÈS DES NOTAIRES DE FRANCE (1975), p. 569; M. HERRERO OVIEDO (2009-2), pp. 452 y ss; L. LEVENEUR/S. LEVENEUR (1999), p. 44.
} 
de bienes futuros, o también denominada institución contractual. Se trata de un contrato por el cual un cónyuge, o un tercero (normalmente los padres de los futuros cónyuges), denominado el instituyente, se compromete a transferir al otro cónyuge, o a los cónyuges, los instituidos que aceptan, todo o parte de la sucesión o un bien determinado ${ }^{87}$. La donación de bienes a venir supone una derogación de la exigencia según la cual el objeto de una donación deben ser bienes presentes (art. 943 CC francés). Ahora bien, esta excepción es limitada, pues sólo se puede realizar entre cónyuges o en beneficio de los cónyuges (siendo habitual que los padres de los futuros cónyuges realicen una donación de bienes a venir, en razón del futuro matrimonio y a favor de los futuros contrayentes) $)^{88}$. La donación de bienes a venir es irrevocable, a salvo las causas excepcionales de revocación de las donaciones entre vivos recogidas en los artículos 953 y siguientes del CC francés, que se aplican también a esta figura ${ }^{89}$.

La segunda gran excepción a la prohibición de los pactos sucesorios es la denominada donation-partage (arts. 1075 y siguientes CC francés). Se trata de un contrato por el cual un ascendiente realiza la partición de manera anticipada a favor de sus descendientes, a los que se les transfiere, desde el momento mismo de la conclusión del contrato, la propiedad de los bienes presentes ${ }^{90}$.

Italia es otro de los ejemplos de ordenamiento jurídico que recogió las ideas contrarias a los pactos sobre la sucesión futura. El caso de Italia es más extremo que el que hemos visto en Francia, pues en el ordenamiento jurídico italiano existió una prohibición absoluta de los pactos sucesorios, sin excepción alguna. La prohibición de los pactos sucesorios se recogió ya en el art. 1118 del CCit de 1865, profundamente inspirado en el Código de Napoleón; a este artículo hay que añadir otros que también establecen determinadas prohibiciones sobre

\footnotetext{
${ }^{87}$ Vid. A.M. LEROYER, (2009), p. 217.

${ }^{88}$ Vid., A. M. Leroyer (2009), p. 217; también, C. JUBAUlT, (2010), p. 582.

${ }^{89}$ Se ha dicho que la donación de bienes a venir se aproxima al testamento en cuanto a los efectos, pero ofrece la seguridad de una donación: vid., C. JUBAULt (2010), p. 583; M. HERRERO OvIEDO (2009-2), p. 451.

${ }^{90}$ Se ha cuestionado el carácter de pacto sucesorio de la donation-partage con base en que su objeto sean bienes presentes y no futuros, vid., A.M. LEROYER, (2009), p. 219.
} 
estas figuras (art. 954 que prohibía la renuncia a la herencia de una persona viva, art. 1380 que prohibía el pacto realizado con ocasión del matrimonio y dirigido a modificar el orden legal de la sucesión y art. 1460 que establecía la nulidad de la venta de la herencia de una persona aún viva) ${ }^{91}$. La prohibición de los pactos sucesorios pasó al CCit de 1942 y se recoge ahora de manera unitaria en el art. 468 del mencionado Código en sede sucesoria (pese a la existencia de críticas doctrinales que solicitaban una flexibilización de la tradicional prohibición ${ }^{92}$ ), donde se declara la nulidad de todo negocio que atribuya o elimine derechos sobre una sucesión aún no abierta. La prohibición abarca tanto a los pactos sucesorios de institución, como a los de renuncia y a los dispositivos ${ }^{93}$. La razón fundamental que se arguyó en Italia para adoptar esta prohibición fue, una vez más, la necesidad de preservar la libertad de disposición mortis causa del causante, hasta el momento de su fallecimiento, en el caso de los pactos de institución ${ }^{94}$, y el miedo al votum mortis en los pactos de renuncia y dispositivos ${ }^{95}$. Además del art. 468 CCit., se destaca también el art. 557.2 CCit que prohíbe la renuncia al derecho a reducir donaciones en vida del donante ${ }^{96}$.

Pese a esta actitud claramente contraria a los pactos sucesorios, más incluso que en el caso de Francia, donde al menos existió alguna excepción, la mayor parte de la doctrina italiana no consideró los pactos sucesorios contrarios al orden público italiano. Además, esta postura contraria se ha suavizado recientemente con la introducción, como veremos de forma más detallada, del denominado pacto de familia, que supone al menos una derogación de palabra de la tradicional prohibición de los pactos sucesorios recogida en el $\mathrm{CCit}^{97}$.

\footnotetext{
${ }^{91}$ D. ACHILLE (2012), p. 42.

92 M.P. GArcía Rubio/M. Herrero Oviedo (2011), p. 1265.

${ }^{93}$ A. TAmburini (2008), p. 31; C. Caccavale (2010), p. 26; D. Achille (2012), p. 35.

${ }^{94}$ Por todos, A. TAMBURINI (2008), pp. 33 y 34; en la jurisprudencia, vid. la sentencia de la Corte di Cassazione de 18 de diciembre de 1995, núm. 12906, Il Foro Italiano. Razzolta generale di Giurisprudenza, 1997, vol. CXX, pp. 558-562, esp. p. 562.

95 A. TAMBURINI (2008), p. 42

${ }^{96}$ M.P. GARCía Rubio/M. HeRrero Oviedo (2011), p. 1265.

${ }^{97}$ D. ACHILLE (2012), p. 221. El pacto de familia será tratado más adelante.
} 


\subsection{Sistemas ajenos a la figura de los pactos sucesorios}

\subsubsection{Desconocimiento de los pactos sucesorios y admisión de figuras análogas}

Además de los ordenamientos jurídicos que admiten o prohíben los pactos sucesorios, hay otro tipo de sistemas que simplemente desconocen estas figuras; su postura no es favorable ni contraria a los pactos sucesorios, sino completamente ajena a este tipo de negocio jurídico. Este es el caso de los sistemas anglosajones, especialmente de EEUU e Inglaterra ${ }^{98}$. Ahora bien, estos ordenamientos jurídicos sí reconocen otro tipo de contratos que presentan ciertas similitudes con los pactos sucesorios, puesto que en cierto modo son contratos que pueden tener una repercusión más o menos directa en la sucesión de uno de los otorgantes. Estas figuras se pueden reducir a dos grandes categorías, con independencia de las variedades que dentro de cada una de ellas puedan darse; tales categorías son los llamados contratos para hacer testamento o contracts to make a will y la renuncia del cónyuge a los posibles derechos que pueda tener sobre la herencia del otro, como la renuncia al right of election o elective share.

Al igual que los países anglosajones no conocen lo que nosotros entendemos por pactos sucesorios, tampoco nosotros estamos familiarizados con negocios jurídicos como el contrato para hacer testamento. En todo caso, es interesante realizar un breve análisis de estas figuras, pues en el caso de que un juez español se encuentre con un supuesto de hecho en el que haya un contract to make a will, deberá calificar este negocio jurídico para así poder dar una solución de ley aplicable. El hecho de que sean contratos que afectan a la herencia de

\footnotetext{
98 Son gráficas la contestación del parlamento escocés al Libro Verde de Sucesiones y Testamentos, cuando ante la locución "agreements as to succession", se preguntan qué significa tal término;

http://ec.europa.eu/justice/news/consulting_public/successions/contributions/contribution_scottish _parliament_en.pdf. (última consulta el 6 de junio de 2013), p. 7. De igual forma, en el Memoramdum of Comments by the Succession Law Sub-Committee of the Law Society of Scotland se responde ante la pregunta concreta sobre los "agreements as to succession" que no está claro a qué se refiere tal término, vid. http://ec.europa.eu/justice/news/consulting public/successions/contributions/contribution_lss_en.pdf (última consulta realizada el 6 de junio de 2013), p. 7. También es ilustrativo el inicio de los debates en el seno de la Conferencia de La Haya sobre los pactos sucesorios, donde se percibe la preocupación en la delimitación de lo que son pactos sucesorios, así como la dificultad para algunos Estados contratantes para entender el concepto de pacto sucesorio. Vid. CónFERENCE DE LA HAYE DE DROIT INTERNATIONAL PRIVÉ (1990), pp. 409 y ss.
} 
alguno de los otorgantes nos lleva a plantearnos la posibilidad de incluir estas figuras dentro del concepto de pacto sucesorio que manejamos. Para poder dar una respuesta a este planteamiento es necesario en un primer lugar conocer la naturaleza jurídica de estas figuras bajo el propio Derecho anglosajón.

\subsubsection{Contracts to make a will}

La primera de las figuras con cierta proximidad a los pactos sucesorios que vamos a analizar son los denominados contracts to make a will; se pueden definir como los contratos en los que una de las partes, el promitente y futuro causante, se compromete frente a la otra a otorgar un testamento con determinadas disposiciones o a abstenerse de modificar una disposición ya realizada, bien a favor del otro contratante, bien a favor de un tercero. En este sentido, en el Derecho inglés se permite, por ejemplo, que una persona, el futuro causante, se comprometa frente a otra a través de un contrato a dejarle a través de testamento una propiedad específica o el conjunto o una parte de su propiedad residual; o, de forma similar, también se reconoce validez al contrato a través del cual una persona promete a otra no revocar o alterar un testamento o una disposición particular del mismo ${ }^{99}$. En EEUU, por su parte, este tipo de contratos también son válidos, admitiéndose igualmente un variado contenido en los mismos, pues tienen cabida tanto los contratos en los que el futuro causante se compromete a realizar una determinada disposición de última voluntad, como a abstenerse de modificar o revocar una ya realizada, como por ejemplo el contrato a través del cual las partes se comprometen a renunciar a la revocación de un testamento conjunto $^{100}$; además, el compromiso adquirido a través del contrato para realizar testamento puede también ser igualmente a favor del otro contratante o a favor de un tercero ${ }^{101}$.

El contrato para hacer testamento no es un instrumento suficiente por sí mismo para que el beneficiario de tal promesa reciba lo prometido, pues para ello es necesario que el futuro causante realice un testamento que contenga el sentido

\footnotetext{
${ }^{99}$ R. KERRIDGE (2011), p. 142.

${ }^{100}$ B.M. SPARKS (1956), pp. 1 y ss.

${ }^{101}$ E.M. HEPP (1991), pp. 15 y ss.
} 
de lo dispuesto en el contrato; testamento que, por otro lado, será naturalmente revocable, pese a recoger el contenido de la promesa a la que el causante se ha comprometido, como cualquier testamento unilateral ${ }^{102}$. Dicho de otro modo, si el contenido de la promesa se encuentra en el testamento del causante en el momento en que éste fallece, se habrán cumplido los términos del contrato y el beneficiario recibirá lo prometido; sin embargo, en el caso de que no exista tal testamento que recoja el contenido de la promesa, el acuerdo se habrá incumplido, el beneficiario no recibirá nada de lo prometido y cabe preguntarse qué mecanismos de defensa tendrá éste en su caso.

En cuanto a su naturaleza jurídica, en el mundo anglosajón este tipo de negocios jurídicos están configurados como verdaderos contratos ${ }^{103}$; en este sentido, es necesaria la existencia de determinados presupuestos para que se pueda hablar de un contrato para hacer testamento válido. Como todo contrato, precisa, en primer lugar, una oferta y una aceptación; en segundo lugar, es necesario que medie una contraprestación frente a la promesa realizada por el futuro causante. El elemento de la contraprestación (consideration) es necesario para que haya un contrato bajo el Derecho anglosajón ${ }^{104}$; puede tratarse tanto de una acción como de una omisión y debe ser una obligación legal y ejecutable ${ }^{105}$. En este sentido,

\footnotetext{
${ }^{102}$ M. RHEINSTEIN (1955), p. 1226, quien dice que no hay categoría alguna de "will made in conformity with a contract", que pudiera distinguirse de otros testamentos por el régimen de revocación. El testamento es revocable en todo caso, contenga o no el contenido de lo prometido en el contrato o incluso en el caso de que a través de un contrato se haya comprometido el causante a no revocarlo, E.M. HEPP (1991), p. 17.

${ }^{103} \mathrm{Vid}$., como ejemplo, el caso Johson v. Girtman donde expresamente se dice que la validez de un contrato para hacer testamento se mide bajo los requisitos generales de los contratos, SOUTHERN REPORTER, 2d Series, núm. 542, 1989.

${ }^{104}$ T.E. ATKINSON (1953), p. 212.

${ }^{105}$ En el asunto L.G. v. F.G.H. la demandante, hija del causante, demandó a la herencia y a sus hermanos para pedir la ejecución de un contrato para hacer testamento que había realizado con su padre. En el contrato para hacer testamento el padre se comprometía a modificar el testamento en beneficio de su hija, en el caso de que ésta abortara. La demandante abortó y una vez fallecido su padre y confirmado el incumplimiento de su parte del contrato, solicitó ante los tribunales de Missouri la parte que le correspondía en virtud de lo dispuesto en el contrato. Los demandados entendieron que el aborto era una contraprestación ilegal para el contrato para hacer testamento y que, por tanto éste no sería ejecutable. El tribunal entendió que pese a que el aborto se había realizado en cumplimiento de todas las garantías que la ley exige en estos casos, el contrato no debía ser ejecutado puesto que la demandante no debería recibir una recompensa por la realización de un aborto, vid., L.G. v. F.G.H., SOUTH WeSTERN REPORTER, 2d Series, núm. 729, 1987 , pp. 634 y ss.
} 
podemos señalar como ejemplos de posibles contraprestaciones en contratos para hacer testamentos aquellas que consisten en el compromiso por parte del otro otorgante del contrato de prestar los cuidados necesarios al futuro causante o promitente durante lo que le reste de vida ${ }^{106}$ o aquellas promesas que se realizan en consideración de un matrimonio ${ }^{107}$; cuando se trata de la renuncia a la revocación de un testamento conjunto en el que hay disposiciones de heredero recíprocas, la renuncia a través de contrato de uno de los otorgantes, vale como contraprestación a la renuncia del otro y viceversa. No obstante, el requisito de la contraprestación puede ser obviado en el caso de que el contrato se otorgue a través de una escritura pública ${ }^{108}$. Por último, se exige para que haya contrato, que los términos del mismo sean lo suficientemente claros ${ }^{109}$.

Al igual que lo que ocurrió y en gran medida sigue ocurriendo respecto de los pactos sucesorios, los contratos para hacer testamento han sido vistos con recelo. La desconfianza se debe al hecho de que las promesas realizadas por el causante deben ser ejecutadas cuando éste ya ha desaparecido. Por ello, las reclamaciones que por incumplimiento de estos contratos se llevan a cabo, tienen lugar cuando una de las partes contratantes ya ha fallecido. En ellos se ve un posible medio para cometer un fraude contra las herencias a las que afectan, por ello actualmente se exige con carácter general su constancia por escrito ${ }^{110}$.

\footnotetext{
106 En el caso Schaefer v. Schuhmann, sustanciado ante los tribunales británicos, el causante promete dejar a su ama de llaves la casa en la que vive, si continúa prestándole los cuidados necesarios hasta el momento de su fallecimiento; vid., Schaefer v. Schuhmann, [1972] A.C. 572.

${ }^{107}$ El antiguo caso Synge v. Synge sustanciado ante los tribunales británicos trataba de un contrato para hacer testamento en el que el promitente se comprometía a dejar una propiedad a la otra otorgante, para el caso de que ésta accediera a ser su cónyuge, Synge v. Synge [1894] 1. Q.B. 466; otro ejemplo lo podemos encontrar en el caso Hammersley v. De Biel, en el que un padre promete a su hija dejarle a través de testamento una cuantía dineraria determinada para el caso de que contrajera matrimonio; Hammersley v. DE BIEL (1845) 12 Cl. \& Fin. 45.

${ }^{108}$ Por ejemplo, Johnson v. Girtman.

${ }^{109}$ Sobre los requisitos en general del contrato para realizar testamento, E.M. HEPP (1991), pp. 6 y ss.

${ }^{110}$ En Derecho inglés, K. J. WALSH, (1981), pp. 241 y ss. En EEUU, donde estos contratos se admiten de forma generalizada, es habitual que las legislaciones exijan no sólo que sean otorgados por escrito, sino también, en ocasiones, que sean celebrados ante la presencia de algún testigo. En el Estado de Florida, por ejemplo, se recogen este tipo de acuerdos en el art. 732.701 del Probate Code, exigiéndose otorgamiento por escrito y la presencia de dos testigos; información que se puede encontrar en http://www.flsenate.gov/Laws/Statutes/2011/732.702 (última consulta realizada el 28 de septiembre de 2011); en Maine, 18-A §2-70, Maine Revised Statute Title 18-A,
} 
Una vez vistos los requisitos materiales y formales para el otorgamiento de los contratos para hacer testamento, y con el propósito de seguir analizando su configuración bajo el Derecho anglosajón, es pertinente detenerse ahora en las consecuencias de su incumplimiento. Como ya hemos adelantado, el hándicap de este tipo de contratos reside en que su posible cumplimiento o incumplimiento no se conoce hasta que fallece el promitente o futuro causante; esta circunstancia conlleva lógicamente que en el caso de incumplimiento contractual ya no se puede instar al promitente para que cumpla. Por ello, cabe preguntarse cuál es la posición del beneficiario de la promesa, ya sea el otro otorgante del contrato, ya sea un tercero; es decir, cuáles son sus mecanismos de defensa o a qué tienen derecho ante la ruptura del contrato para hacer testamento por parte del promitente ya fallecido. A priori, la posición de la persona afectada por el incumplimiento del promitente será la de un acreedor de la herencia de éste y podrá, con carácter general, reclamar ante los tribunales una indemnización por daños y perjuicios (damages $)^{111}$. Esta primera aproximación ya es suficiente para concluir que los contratos para hacer testamento no afectan a la libertad de disposición mortis causa del causante ${ }^{112}$; es decir, el testamento es válido con independencia de que se cumpla o no lo dispuesto en el contrato o, dicho de otro modo, el incumplimiento del contrato no es título suficiente para declarar la invalidez de un testamento. En definitiva, el contrato para hacer testamento no sirve por sí sólo como título hereditario.

El beneficiario de un contract to make a will incumplido por el promitente ya fallecido, se erige en un acreedor de la herencia de éste. Decíamos que generalmente se puede realizar una reclamación por daños y perjuicios, aunque en ocasiones también se ha concedido un cumplimiento in natura (specific

\footnotetext{
que exige forma escrita pero no la presencia de testigos; consultado en http://www.mainelegislature.org/legis/statutes/18-a/title18-Ach2.pdf (última consulta realizada el 28 de septiembre de 2011).

${ }^{111}$ R. KERRIDGE (2011), p. 142; también, J. WoOD (2010), p. 233.

${ }^{112}$ E.M. HEPP (1991), p. 18.
} 
performance $)^{113}$. En el asunto Synge v. Synge la demandante exige una indemnización por daños y perjuicios por incumplimiento por parte de su marido fallecido de un contrato en el que le prometía, para el caso de que se casaran, dejarle a través de testamento la casa y una parcela de tierra a disfrutar a lo largo de su vida. El tribunal sopesa la posibilidad de exigir un cumplimiento específico, pues señala que si bien no puede compeler al promitente a realizar un testamento o a ejecutar una escritura, sí puede ordenar al heredero o legatario que transfiera la propiedad de lo prometido en el contrato a la viuda, para que la disfrute a lo largo de su vida. Finalmente, el tribunal decide atender a lo estrictamente solicitado por la parte, esto es, una compensación por daños y perjuicios, y se centra en cómo hacer la valoración de tal compensación. En el asunto Hammersley v. De Biel el promitente no en su testamento la cantidad prometida a favor de su hija y los tribunales entendieron la reclamación como un crédito contra la herencia, dándole derecho a la hija a la percepción de la cantidad prometida más la suma de los intereses a contar desde el final del primer año desde el fallecimiento del promitente $^{114}$.

Ya hemos adelantado que en ocasiones también se prevé la posibilidad de remediar el incumplimiento de un contract to make a will a través de un cumplimiento específico o in natura; ejemplo de este modo de proceder de los tribunales lo encontramos en el asunto americano Johnson v. Girtman. En este caso la causante y sus hermanos habían firmado un contrato con sus padres por el que se comprometían a destinar determinadas propiedades de la familia a los nietos de aquellos; sin embargo, la causante, a su fallecimiento sin hijos, dejó un testamento en el que disponía que se lo dejaba todo a su marido. Los hermanos de la causante solicitaron ante los tribunales la ejecución del contrato a través del cual ésta se comprometía a destinar las propiedades a los nietos de sus padres y el tribunal concluye que el contrato realizado por la causante da lugar a una válida

\footnotetext{
${ }^{113}$ En un principio el cumplimiento in natura era una opción que jugaba con carácter subsidiario; sin embargo, en los últimos tiempos se ve una cierta tendencia a favor de este tipo de remedio, E.M. HEPP (1991), p. 22.

${ }^{114}$ Hammersley v. De Biel, XII CLARK \& FinNELLY, 44, 1845, pp. 312 y ss.
} 
reclamación por parte de sus hermanos que debe ser satisfecha antes de la determinación del elective share del cónyuge viudo ${ }^{115}$.

En determinados casos, los tribunales no han dado una posición al beneficiario del contract to make a will mejor que la que tiene un legatario o un heredero ${ }^{116}$. Es decir, hemos visto cómo, con carácter general, el beneficiario recibe lo prometido en el contrato o el equivalente en una compensación de daños y perjuicios en un momento anterior al que reciben los herederos, esto es, en el momento de la liquidación de las deudas de la herencia. Sin embargo, en función de lo que se haya prometido en el contrato para hacer testamento, en ocasiones el beneficiario no es tratado como un acreedor más, sino que para recibir su parte tiene que esperar a que la herencia sea repartida. Esto es lo que ocurre en aquellos casos en los que el futuro causante promete a través de contrato dejarle al beneficiario a través de testamento el residuo de su patrimonio ${ }^{117}$.

\subsubsection{Renuncia al right of election}

Junto a los contracts to make wills, existen en el mundo anglosajón otro tipo de acuerdos que presentan también importantes similitudes con los pactos sucesorios; es el caso, por ejemplo, de la posibilidad de renunciar por contrato a determinados derechos con contenido hereditario. Las legislaciones anglosajonas reconocen generalmente al cónyuge supérstite ciertos derechos en la herencia del causante. Así, por ejemplo, en EEUU se conoce la figura de right of election o elective share cuya finalidad es evitar que el cónyuge sea desheredado. Esta figura se puede definir como la prerrogativa del cónyuge supérstite para aceptar la provisión que el otro cónyuge hizo a su favor en testamento o hacer caso omiso del testamento y reclamar una cuota especificada en la ley ${ }^{118}$. En Inglaterra, por su

\footnotetext{
${ }^{115}$ Johnson v. Girtman, SOUTHERn REPORTER , 2d Series, núm. 542, 1989, pp. 1032 y ss.

${ }^{116}$ W.E. LEE (1971), p. 360.

${ }^{117}$ A. BORBOWSKI (2002), p. 45.

${ }^{118}$ Definición tomada en www.legal-dictionary.thefreedictionary.com (última consulta realizada el 27 de septiembre de 2011). Las cuotas a las que tiene derecho el cónyuge supérstite varían de una legislación a otra; el Estado de Indiana, por ejemplo, recoge la posibilidad bien de recibir lo dejado en testamento, bien una cantidad de hasta la mitad del neto de los activos personales y reales que dejó el causante (IC 29-1-3-1), consultado en http://www.in.gov/legislative/ic/2010/ title29/ar1/ch3.html (última consulta realizada el 25 de noviembre de 2011); la ley de Nueva York
} 
parte, pese a que no hay normas imperativas sobre legítimas que restrinjan la libertad de disposición del causante, existen ciertos mecanismos de protección para las personas que dependen del causante en el momento en que éste fallece, entre las que se puede encontrar el cónyuge supérstite. Al amparo de la Inheritance (Provision for Family and Dependants) Act de 1975, determinadas personas dependientes económicamente del causante pueden solicitar ante el juez que les sea concedida una cuantía razonable de la herencia, en concepto de aprovisionamiento o suministro, para paliar las situaciones de desamparo en los casos en los que estas personas quedan desprotegidas, ya sea por las disposiciones hechas por testamento, ya sea por las reglas de la sucesión intestada ${ }^{119}$.

En estos países anglosajones se reconoce también la posibilidad de que una persona renuncie a los derechos que sobre la herencia de su cónyuge la ley pueda otorgarle. En EEUU es habitual que las legislaciones de los distintos Estados prevean la posibilidad de que el cónyuge renuncie a este elective share o right of election a través de un contrato realizado con el futuro causante ${ }^{120}$. De igual modo, en Inglaterra e Irlanda también se dan contratos, generalmente prenupciales, en los que el futuro cónyuge renuncia a los derechos que le pudieran corresponder en la herencia del causante ${ }^{121}$. Al ser contratos deben estar provistos de una contraprestación para ser válidos, como ya hemos visto con los contracts to make wills. En el asunto Zamet v. Hyman sustanciado ante los tribunales británicos, la demandante, tres días antes de contraer matrimonio con el causante, firmó un contrato por el que renunciaba a todos los derechos que pudiera tener sobre la herencia de su futuro marido de acuerdo con la legislación inglesa. Como contraprestación, la demandante recibió una escasa cuantía de dinero. Una vez

prevé un derecho del cónyuge supérstite de 50.000 \$ o la mitad del neto de la herencia, http://www.nycprobate.com/411.html, (última consulta realizada el 25 de noviembre de 2011); en el Estado de Minnesota se establece el derecho a distintos porcentajes de la herencia en función del número de años que los cónyuges estuvieron casados, https://www.revisor.mn.gov/statutes/ ?id=524.2-202, (última consulta realizada el 25 de noviembre de 2011). Para una consulta general de las legislaciones de EEUU sobre los derechos del cónyuge supérstite, R.B. JOSLYN (2004), en internet, http://www.actec.org/resources/publications/studies/study10.pdf, (última consulta realizada el 25 de noviembre de 2011).

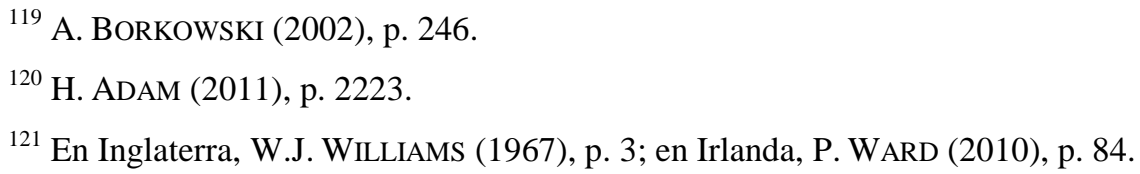


casados, el causante falleció intestado dejando una herencia caudalosa. El tribunal británico entendió que el contrato por el que la viuda renunció a sus derechos no debía tener efecto, basándose en que la renuncia era claramente desfavorable para la viuda y concluyendo que ésta había firmado sin un completo conocimiento de los derechos a los que renunciaba, no habiendo sido informada debidamente de lo que le podría corresponder en la herencia de su marido ${ }^{122}$.

En definitiva, aunque no se trate de contratos en los que se renuncia a derechos directos, automáticos, sobre la herencia del causante, como las legítimas, sí es cierto que todos ellos son contratos cuyo objeto es la renuncia a uno u otro tipo de derecho sobre la herencia de otra persona y por ello, tienen una importante analogía con lo que nosotros conocemos como contratos de renuncia.

\subsection{La situación en España}

A la hora de clasificar los sistemas jurídicos en función de su posición favorable, contraria o ajena a los pactos sucesorios no hemos hecho referencia a la posición del sistema español; y es que en el ordenamiento jurídico español confluyen a la vez sistemas favorables y contrarios a los pactos sucesorios. En efecto, la plurilegislación española refleja perfectamente la heterogeneidad propia de los pactos sucesorios en el plano del Derecho material. En los distintos Derechos civiles españoles encontramos todo tipo de variedad en torno a los pactos sucesorios; en este sentido, en esta pluralidad jurídica tenemos ejemplos de Derechos que prohíben pactos sucesorios, Derechos que los admiten de manera limitada o excepcional y Derechos que los reconocen ampliamente. Todo ello es resultado de las distintas influencias que se dieron en el medievo en el Derecho de los distintos territorios peninsulares; mientras que el Derecho de Castilla recogió una prohibición de los pactos sucesorios como consecuencia de la fuerte influencia del Derecho romano ${ }^{123}$, en los territorios donde no regía el Derecho de

\footnotetext{
${ }^{122}$ Zamet v. Hyman, [1961] 3 All. E.R. 933.

${ }^{123}$ E incluso en este Derecho se señalan algunas excepciones, al admitirse ciertos pactos de succedendo, como la promesa de igualdad o la institución contractual a título singular; VID. MP. GARCÍA RUBIO/M. HERRERO OVIEDO (2011), p. 1263.
} 
Castilla los pactos sucesorios formaban parte de la tradición jurídica, razón por la que se plasmaron en sus legislaciones hasta llegar a nuestros días.

\subsubsection{EI Derecho común}

\subsubsection{La prohibición del Código Civil}

La complicada evolución de los pactos sucesorios y su hostilidad por el Derecho romano dio lugar a que las Partidas recogieran ya una prohibición de la sucesión contractual $^{124}$. El Derecho de Castilla fue el principal precedente del CC de 1889, por ello es razonable que la prohibición pasara de dicho Derecho a nuestro Código ${ }^{125}$. De esta forma, en los trabajos de preparación del CC ya estaba presente la idea de una prohibición general de los pactos sucesorios. El espíritu liberal que reinaba durante el proceso codificador, que pretendía favorecer la subdivisión de las propiedades, supuso un importante factor en contra de los pactos sucesorios, tanto de institución como de renuncia, en tanto que son instrumentos idóneos para lo contrario, esto es, para la concentración e indivisibilidad de la propiedad ${ }^{126}$. En este contexto, el Proyecto de Código de 1836 ya recogió en su art. 936 la prohibición de los pactos sucesorios; esta tendencia se reitera en trabajos posteriores, entre los que cabe destacar el art. 994 del Proyecto de Código de 1851, donde la prohibición se recoge ya en sede contractual, bajo una sección rubricada "de la naturaleza y objeto de los contratos"; dicho precepto, admitía los contratos sobre cosas futuras e inmediatamente después exceptuaba los contratos que recayeran sobre herencia futura $^{127}$. También es de destacar el Anteproyecto de Código Civil de 1882-1888, donde se hace referencia a la prohibición de pactos sucesorios en tres preceptos (art. 1284 en sede contractual y con una redacción similar a la del art. 994 del

\footnotetext{
${ }^{124}$ En opinión de la mayor parte de los historiadores, vid. M. HERRERo OVIEDO (2009-1), p. 208.

${ }^{125}$ Para un análisis detallado de los trabajos de preparación del Código Civil en lo que respecta a la inclusión de la prohibición de los pactos sucesorios, M.P. GARCÍA RUBIO/M. HERRERO OVIEDO (2011), pp. 1266 y ss.

${ }^{126}$ M.P. García Rubio/M. Herrero OVIEdo (2011), p. 1264.

${ }^{127}$ El art. 994 del Proyecto de 1851 decía textualmente que "Pueden ser objeto de los contratos todas las cosas que no están fuera del comercio de los hombres aunque sean futuras. Se esceptúa la herencia futura acerca de la cual sería nulo cualquier pacto aunque se celebre con el consentimiento de la persona de cuya sucesión se trate" Consultado en F. GARCía GOYENA (1852), p. 27.
} 
Proyecto de 1851, art. 1331 respecto de los contratos matrimoniales y art. 801 en relación con la renuncia a la herencia futura) ${ }^{128}$.

De esta forma llega la prohibición de los pactos sucesorios al Código Civil de 1889; la prohibición se recoge en el art.1271.2 CC, en sede contractual. Según dicho artículo no se pueden celebrar contratos sobre la herencia futura, a excepción de lo dispuesto en el art. 1056 del propio Código, que recoge la división del caudal hereditario o partición de la herencia en vida del causante. Junto a este artículo, que contiene la regla general prohibitiva, la doctrina suele mencionar otra serie de preceptos que de forma particular reiteran o confirman la prohibición de los pactos sucesorios. En este sentido, se suele mencionar el art. $658 \mathrm{CC}$ como precepto que, ya en sede de sucesiones, viene a corroborar la inadmisión de los pactos sucesorios en general. Dicho precepto se encarga de recoger las dos formas de ordenación de la sucesión permitidas en el CC refiriéndose únicamente a la sucesión testamentaria y legal al disponer que "la sucesión se defiere por la voluntad del hombre manifestada en testamento y, a falta de éste, por disposición de la ley”. El art. 658 CC permite, por tanto, la sucesión voluntaria, si bien únicamente manifestada a través de testamento. En consonancia con este precepto está el art. $667 \mathrm{CC}$, que define el testamento como el acto a través del cual una persona dispone de sus bienes para después de su muerte. Por otro lado, el art. $816 \mathrm{CC}$ sanciona la nulidad de la renuncia anticipada a la legítima futura, pudiendo los herederos forzosos reclamarla una vez fallecido el causante, mientras que el art. 655.2 CC prohíbe la renuncia a la acción de reducción de las donaciones en vida del causante. Por último, podemos destacar también el art. 991 CC que, en la misma línea que los artículos anteriores, dispone que nadie puede aceptar ni repudiar la herencia sin estar cierto de la muerte de la persona a quien se va a heredar.

La prohibición general del art. 1271.2 CC plantea dudas en torno a su ámbito de aplicación; en efecto, tal precepto no establece con claridad cuáles son las figuras que entran dentro de la prohibición, como bien prueba la existencia de una jurisprudencia irregular sobre el tema y las dudas que entre la doctrina

${ }^{128}$ Consultado en M. PEÑA BERNALdo DE QuiRós (2006), pp. 389, 406 y 252. 
civilista de nuestro país hay al respecto. En lo que se refiere a la práctica de los tribunales, existe una jurisprudencia constante y ya clásica que afecta a la interpretación de la prohibición recogida en el art. 1271.2 CC. En concreto, se trata de una jurisprudencia que incide en una interpretación restrictiva de la prohibición de los pactos sucesorios, al considerar que la misma se refiere únicamente a los pactos sobre la universalidad de la herencia y no a los pactos sucesorios cuyo objeto sean bienes determinados del haber hereditario ${ }^{129}$. De esta forma, hay sentencias que han admitido pactos sucesorios en los que el objeto es un bien particular y también se han dado sentencias en las que se han admitido determinados acuerdos de carácter renunciativo ${ }^{130}$.

\subsubsection{Las excepciones a la prohibición del Código Civil}

Hemos visto cómo el punto de partida en el ámbito del CC es la prohibición general de los pactos sucesorios, con las dudas en torno a su ámbito de aplicación, unido a otra serie de prohibiciones particulares que también recoge el propio Código. Ahora bien, no obstante estas prohibiciones general y particulares, lo cierto es que, tal y como reconoce la doctrina, el propio CC siempre ha recogido determinadas excepciones a la prohibición general de los

\footnotetext{
${ }^{129}$ Vid. por ejemplo y entre otras, la STS de 22 de julio de 1997, núm. 718/1997, RJ/1997/5807, FJ $1^{\circ}$, que refiriéndose a la prohibición del art, $1271.2 \mathrm{CC}$ establece que "se refiere única y exclusivamente a los pactos sobre la universalidad de una herencia (...), pero no cuando el pacto se refiere a bienes conocidos y determinados existentes al tiempo del otorgamiento del compromiso en el dominio del causante". Esta doctrina es ya clásica y se reitera en la jurisprudencia de forma casi idéntica, vid. también STS de 4 de mayo de 1910 (Jurisprudencia civil mayo de 2010), donde se señala que no cabe atribuir a una convención el concepto jurídico de pacto sobre sucesión futura, en tanto que para llegar a tal calificación sería preciso que se tratara "no de un grupo o conjunto parcial de bienes propios, sino de herencia no deferida, de una universalidad patrimonial"; también la STS de 8 de octubre de 1915 (Jurisprudencia civil octubre 1915); STS de 6 de mayo de 1940 (RJ $\backslash 1940 \backslash 416$ bis) que dice expresamente que la prohibición establecida en el CC se refiere única y exclusivamente a los pactos sobre la universalidad de una herencia; SAP Cuenta de 30 de octubre de 2009, núm. 250/2009, JUR 2009/497002, FJ 3; SAP Zaragoza de 5 de diciembre de 2002, núm. 713/2002, AC 2003/222, FJ 3º; SAP de León de 8 de noviembre de 1995, núm. 428/1995, AC 1995/2254, FJ $4^{\circ}$. La distinción entre los pactos con objeto universal y los pactos con objeto particular para la delimitación de la prohibición contenida en el art. 1271.2 CC ha sido criticada por la doctrina, vid. M.P. GARCíA RUBIO/M. HERRERO OvIEDO (2011), p. 1269. Critican también esta jurisprudencia, en cuanto que sostienen que tanto en los casos de un pacto con objeto singular, como con objeto universal existen un pacto sobre sucesión futura prohibido por el CC, J.L. LACRUZ BERDEJO/F. SANCHO REBULLIDA (1976), p. 467; M. ESPEJO LERDO DE TEJADA (1999), pp. 40 y ss. Para un análisis detallado de esta jurisprudencia vid., X.M. REQUEIXO SOUTO (2012), pp. 1745 y ss.

${ }^{130}$ Vid. M.P. GARCÍA RUBIO/M. HERRERO OVIEDO (2011), p. 1268 y jurisprudencia ahí citada.
} 
pactos sucesorios; sobre esta cuestión la doctrina civilista no es unánime, en el sentido de que no siempre se ponen de acuerdo en entender qué es un pacto sucesorio o qué tipo de pactos sucesorios están prohibidos y permitidos. Vamos a mencionar ahora algunas de las figuras que con carácter general se han considerado excepciones a la prohibición general de pactos sucesorios que en el CC se recoge ${ }^{131}$.

En primer lugar, vamos a hacer referencia a la denominada promesa de mejorar o no mejorar, recogida en el art. 826 CC. Según este artículo será válida la promesa de mejorar o no mejorar hecha por escritura pública en capitulaciones matrimoniales. El propio precepto continúa diciendo que la disposición del testador contraria a tal promesa no surtirá efecto alguno; con base a este segundo inciso, la doctrina ha entendido que la promesa se transforma en realidad en una mejora o no mejora efectiva, ya que cualquier disposición que contraríe lo prometido no tiene cabida $^{132}$; dicho de otro modo, la promesa de mejorar o no mejorar se convierte en irrevocable ${ }^{133}$. Este segundo inciso viene además a confirmar que la promesa de mejorar o no mejorar tiene la característica esencial de los pactos sucesorios, cual es la vinculación del causante al contenido de lo acordado y la imposibilidad de realizar disposiciones mortis causa que lo contraríen.

El supuesto clásico de esta figura era el de las promesas de mejorar o no mejorar por razón de matrimonio de un hijo. Así, en las capitulaciones matrimoniales, el padre u otro ascendiente de cualquiera de los cónyuges se comprometía bien a mejorar al hijo que contraía matrimonio, bien a no mejorar al

\footnotetext{
${ }^{131}$ Además de los supuestos que vamos a nombrar a continuación, existieron otra serie de excepciones en el CC que hoy ya no están en vigor, tales como la denominada delegación de la facultad de mejorar hecha en capitulaciones matrimoniales o los acuerdos a través de los que se otorgaba derechos sucesorios al adoptado; vid. con mayor extensión sobre estas figuras, J.M. CASTÁN VÁZQUEZ (1964), pp. 370 y ss.; R. M. ROCA-SASTRE (1984), pp. 353 y ss.; M.P. GarCíA RUBIO/M. HERRERO OVIEDO (2011), pp. 1270 y ss.;

${ }^{132}$ Vid. R. SÁNCHEZ ARISTI (2003), p. 77, quien dispone que se trata de pactos que implican auténticos llamamientos sucesorios contractuales.

${ }^{133}$ R. SÁnChez Artisti (2003), p. 78; A. Domínguez LUelmo (2010), p. 945; M.P. GarCíA RUBIO/M. HERRERO OVIEDO (2011), pp. 1272 y ss.
} 
resto de descendientes que pudiera tener ${ }^{134}$. No está clara, sin embargo, entre la doctrina la posibilidad de que la promesa de mejorar o no mejorar se realice por uno o ambos cónyuges, bien sea a favor del otro o de alguno de sus descendientes ${ }^{135}$.

En segundo lugar, se suele mencionar también la llamada mejora irrevocable, recogida en el art. $827 \mathrm{CC}^{136}$. De este precepto se deriva la irrevocabilidad de la mejora en los casos en que se haya realizado a través de capitulaciones matrimoniales o a través de un contrato oneroso con un tercero ${ }^{137}$. Tal y como ha puesto de relieve la doctrina, la mención a la mejora en este artículo puede referirse, no obstante, a dos realidades bien distintas: se puede tratar de una donación de ciertos bienes a la que se da el tratamiento de mejora o de una verdadera mejora sucesoria contractual que se hará efectiva una vez fallecido el causante ${ }^{138}$.

En tercer lugar, vamos a hacer referencia a la donación de bienes futuros por razón de matrimonio, figura que para la mayor parte de la doctrina civilista también constituye una excepción a la prohibición de los pactos sucesorios ${ }^{139}$. Tal

134 J.B. VAllet de Goytisolo (1993), p. 2047; R. SÁnChez Artisti (2003), p. 78; A. Domínguez Luelmo (2010), p. 945; M.P. GARcíA Rubio/M. HERRERo Oviedo (2011), pp. 1272 y ss.

135 A favor, R. SÁNCHEZ ARISTI (2003), pp. 78 y ss.; en contra, y con base en el carácter excepcional de la admisión de estos pactos sucesorios, J.B. VALLET DE GOYTISOLO (1993), p. 2048.

${ }^{136}$ A favor de la consideración de la mejora irrevocable como un pacto sucesorio, vid. R.M. ROCA SAStre (1948), p. 354; J.M. CASTÁN VÁzQueZ (1964), p. 370 y ss.; M.P. GARcía Rubio/M. HERRERO OVIEDO (2011), p. 1274; sin embargo, entiende que es una donación mortis causa, R.R. GENSOLÍN (1962), p. 143.

${ }^{137}$ Dice el art. 827 CC que la mejora, aunque se haya verificado con entrega de bienes, será revocable, a menos que se haya hecho por capitulaciones matrimoniales o por contrato oneroso celebrado con un tercero. J.L. LACRUZ BERDEJO/ F. SANCHO REBULLIDA (1981), p. 449, donde se señala que, a diferencia de su antecedente, el art. 827 CC separa la irrevocabilidad del hecho de que haya una entrega de bienes al favorecido; le siguen, R. SÁNCHEZ ARISTI (2003), p. 88 y doctrina allí citada.

${ }^{138}$ M.P. GARCía RUBio/M. HeRrero OVIEDO (2011), p. 1274.

139 R.M. RoCa SAStre (1948), p. 353; F. Puig Peña (1976), p. 686; J.L. LACRUZ Berdejo/F. SANCHO REBULLIDA (1981), p. 385 donde señala que el hecho de que la donación se haga a través de capitulaciones matrimoniales confirma su carácter de acto bilateral equivalente al de una institución o legado contractuales; R. SÁNCHEZ ARISTI (2003), p. 98; J. SIRVENT GARCÍA (2003), p. 53, quien entiende que a través de esta vía no sólo se puede instituir heredero universal al cónyuge, sino que también es posible realizar instituciones de atribución particular o cosa determinada. 
posibilidad se recoge actualmente en el art. $1341 \mathrm{CC}$, cuyo segundo inciso señala la posibilidad de que los futuros cónyuges se donen antes del matrimonio y a través de capitulaciones matrimoniales bienes futuros sólo para el caso de muerte y en la medida marcada por las disposiciones referentes a la sucesión testada. La donación de bienes futuros por razón de matrimonio plantea diversas cuestiones problemáticas, de las cuales sólo vamos a hacer brevemente referencia a las más importantes ${ }^{140}$. Según el profesor Lacruz, bienes futuros no son aquí los bienes del art. $635 \mathrm{CC}$ (esto es aquellos que el donante no tiene en el momento de la realización de la donación), sino que se refiere a los bienes que el donante deje a su muerte ${ }^{141}$. Una de las cuestiones más importantes que se plantea es la de la revocabilidad o irrevocabilidad de la donación realizada. La mayor parte de la doctrina está de acuerdo en entender que tales disposiciones son naturalmente irrevocables, al contenerse en capitulaciones matrimoniales ${ }^{142}$; en este sentido también, se suele entender que la mención a las disposiciones referentes a la sucesión testada, se refiere no al carácter revocable de tales disposiciones, sino al hecho de que deben ajustarse a los derechos legitimarios que, en su caso, se establezcan $^{143}$.

En cuarto lugar, la doctrina se ha planteado también la posibilidad de que determinados acuerdos realizados en el seno de organizaciones societarias puedan implicar excepciones a la prohibición de los pactos sucesorios ${ }^{144}$; tales figuras son los denominados pactos sociales, recogidos fundamentalmente en el art. 1704.1 CC. Dicho precepto permite realizar pactos entre los socios con el objeto de que al fallecimiento de uno de ellos, la sociedad continúe para el resto, si bien los derechos del heredero están salvaguardados, pues previamente habrá que separar

\footnotetext{
${ }^{140}$ Para un análisis detallado de la figura, vid., J. SIRVENT GarCía (2003), esp. pp. 44 y ss.

${ }^{141}$ J.L. LACRUZ BERDEJO/F. SÁNCHO REBULLIDA (1981), p. 385.

${ }^{142}$ Decimos que serán naturalmente irrevocables (y no esencialmente irrevocables) porque, como en cualquier pacto sucesorio, siempre queda la posibilidad de la modificación de la voluntad de las partes, así como las causas de revocación recogidas en el art. $1343 \mathrm{CC}$, que se aplican a cualquier tipo de donación por razón de matrimonio y, por tanto, también a las donaciones del segundo inciso del art. 1341; en este sentido, M.P. GARCÍA RUBIO/M. HERRERO OVIEDO (2011), p. 1278.

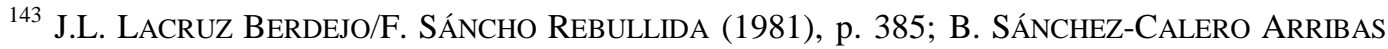
(2010), p. 1476; J. SIRVENT GARCÍA (2003), p. 50.

${ }^{144}$ M.P.GARCÍA RUbio/M. HerRero Oviedo (2011), pp. 1278 y ss.
} 
la participación económica del causante. Esta salvaguarda es precisamente la que ha llevado a parte de la doctrina a negar el carácter de pacto sucesorio de los pactos sociales que permite el art. 1704.1 CC, si bien se reconoce que la situación es muy próxima a la prevista en la prohibición del art. $1271.2 \mathrm{CC}^{145}$.

Existen además otras normas estatales en el ámbito societario que permiten la realización de este tipo de pactos sociales y que se encuentran también muy cercanas a la prohibición de los pactos sucesorios que recoge el CC. En este sentido, es muy gráfico el art. 15 de la Ley de sociedades profesionales ${ }^{146}$, que permite la posibilidad de que los socios acuerden que en caso de fallecimiento de un socio profesional las participaciones de éste no se transmitan a sus herederos ${ }^{147}$.

Por último, el art. 1271.2 CC hace expresa mención a una excepción a la prohibición que recoge, remitiéndose al art. 1056 CC. Dicho precepto se encarga de la denominada partición hereditaria entre vivos; se trata de la posibilidad de que el testador realice la partición de su herencia a través de un acto inter vivos ${ }^{148}$. En concreto, la partición se realiza en un contrato en el que intervienen tanto el testador como sus futuros herederos; ahora bien, al lado de esta partición hereditaria es necesario que haya una organización de la herencia a través de un testamento, ya sea anterior o posterior a la propia partición ${ }^{149}$. La doctrina no se pone de acuerdo en considerar la partición entre vivos como una excepción a la

\footnotetext{
${ }^{145}$ Cosa distinta sería la realización de un pacto a través del cual se acuerda que las participaciones sociales del socio fallecido se transmitan al resto de socios, sobre todo si se trata de una atribución simple y sin correspectivo, caso en el que claramente se trataría de un pacto sucesorio, prohibido por el art. 1271.2 CC; vid. en este sentido, J.L. LACRUZ BERDEJO/F. SANCHO REBULLIDA (1981), p. 384.

${ }^{146}$ Ley 2/2007 de 15 de marzo, de sociedades profesionales, BOE de 16 de marzo de 2007, núm. 65, pp. 11246-11251.

${ }^{147}$ Textualmente dice el artículo 15 de la ley de sociedades profesionales que "En el contrato social, y fuera de él siempre que medie el consentimiento expreso de todos los socios profesionales, podrá pactarse que la mayoría de éstos, en caso de muerte de un socio profesional, puedan acordar que las participaciones del mismo no se transmitan a sus sucesores. $\mathrm{Si}$ no procediere la transmisión, se abonará la cuota de liquidación que corresponda".

${ }^{148}$ El párrafo segundo del precepto fue modificado por la Ley 7/2003, de la Sociedad Limitada de la Nueva Empresa de 1 de abril de 2003, según la Exposición de Motivos de dicha ley para permitir al empresario diseñar una sucesión más adecuada.

${ }^{149}$ M. Royo Martínez (1951), p. 338; A. DomíngueZ Luelmo (2010.b), p. 1150.
} 
prohibición de los pactos sucesorios, aunque es de reconocer que la mayor parte se ha manifestado en contra de la consideración de la partición hereditaria en vida como un pacto sucesorio ${ }^{150}$; existe además cierta jurisprudencia en este sentido. Así, por ejemplo, es ilustrativa la sentencia del TS de 13 de junio de 1963, donde queda patente que al lado de una partición hereditaria hecha en un acto inter vivos es necesario un testamento; esta sentencia admite que el testamento pueda ser posterior a la partición acordada, pero proclama su necesaria existencia, pues la partición no es suficiente por sí sola para tener efectos hereditarios.

\subsubsection{El Estatuto de la explotación agraria y de los jóvenes agricultores de 24 de diciembre de 1981}

Además de las excepciones que a la prohibición de los pactos sucesorios recoge el propio $\mathrm{CC}$, existió durante unos años una norma de ámbito estatal que permitía expresamente la posibilidad de celebrar determinados pactos sucesorios; se trata del Estatuto de la explotación agraria y de los jóvenes agricultores de 24 de diciembre de $1981^{151}$. Esta ley se promulgó con el fin de proteger las explotaciones agrarias de carácter familiar y facilitar la incorporación de jóvenes agricultores a la actividad agraria. La ley estuvo vigente sólo unos años, puesto que fue derogada el año 1995 por la Ley de Modernización de las explotaciones $\operatorname{agrarias}^{152}$, parece ser porque, tal y como dice la Exposición de Motivos de esta última ley, el Estatuto de explotación agraria no tuvo apenas aplicabilidad. Pese a que se trata de una ley derogada, entendemos que es interesante detenernos brevemente en ella, por el interés que para nuestro estudio puede tener, en cuanto que se trataba de una ley estatal que permitía excepcionalmente la celebración de determinados pactos sucesorios.

El art. 1 de la Ley recogía los objetivos de la misma, entre los que cabe destacar, para lo que ahora nos interesa, el mantenimiento de la integridad de las

\footnotetext{
${ }^{150}$ R. M. RoCA SASTRE (1948), p. 355 para quien no se trata de un contrato, sino de un acto unilateral del testador y además se limita a una simple distribución o partición, no habiendo nada de disposición, característica propia de los pactos sucesorios; M. ROYO MARTíNEZ (1951), p. 339; J.L. LACRUZ BERDEJO/F. SANCHO REBULLIDA (1981), p. 385;

${ }^{151}$ Ley 49/1981, de 24 de diciembre, BOE 11 enero 1982, núm. 9, p. 539.

${ }^{152}$ Ley 19/1995, de 4 de julio, de Modernización de las explotaciones agrarias, (BOE 5 julio 1995, núm. 159, p. 20394); en concreto en la Disposición derogatoria única de esta ley.
} 
explotaciones agrarias y su continuidad como unidades empresariales (art. 1 a) y la estimulación de la incorporación progresiva a la cabeza de dichas explotaciones de los colaboradores que hayan de suceder profesionalmente en la titularidad de las mismas (art. 1 b). En el ámbito del Derecho agrario existe una preocupación por mantener la integridad de las explotaciones agrícolas, con el fin de evitar una excesiva subdivisión que haga inviable la producción rentable del cultivo. En esta cuestión tiene especial importancia el Derecho de sucesiones, pues en muchas ocasiones es precisamente como consecuencia de una transmisión mortis causa por lo que la explotación agraria se divide excesivamente. Por ello, esta ley recogía un régimen sucesorio especial para las explotaciones agrarias familiares que, como vamos a ver, incluía la posibilidad de realizar determinados pactos sucesorios.

El capítulo III de esta ley se rubricaba bajo el título de "protección de la integridad de la explotación" y se dividía en varias secciones, la segunda de ellas dedicada a los pactos sucesorios, concretamente en los arts. 16 y siguientes. En tales preceptos se permitía la posibilidad de transmitir mortis causa la titularidad de la explotación agrícola a través de determinados pactos sucesorios. Se trata de pactos sucesorios positivos o de institución y la ley establecía determinadas limitaciones y requisitos ${ }^{153}$.

La primera limitación que debemos mencionar hacía referencia a los sujetos legitimados para otorgar el pacto sucesorio. En este sentido, en primer lugar se preveía que el titular de la explotación agrícola acordara la transmisión de la titularidad de la explotación a través de un pacto sucesorio con uno de sus legitimarios que además reúna la cualidad de colaborador de la explotación (art. $16)^{154}$. Para el caso de que no hubiera ningún legitimario colaborador, se abría la

\footnotetext{
${ }^{153}$ Se ha planteado la posibilidad de que también se permitiera también un pacto sucesorio de renuncia; sobre esta cuestión, vid. R. SÁNCHEZ ARISTI (2003), p. 189. En el proyecto de esta ley, sin embargo, se preveía la amplia admisibilidad tanto de los pactos sucesorios positivos, como los de renuncia y también incluso los pactos sobre herencia de tercero; vid. C. VALTIER FUENZALIDA (1983), p. 896.

${ }^{154}$ La figura del colaborador de la explotación estaba también prevista en la ley, en concreto en el art. 5. En principio está prevista para algún familiar, cónyuge, descendiente u otro pariente del titular de la explotación, que siendo mayor de edad o menor emancipado tuviera una experiencia mínima de dos años en actividades agrarias y cuya principal ocupación fuera su trabajo en la
} 
posibilidad de otorgarse el pacto sucesorio a otra persona que ostentara la cualidad de colaboradora, si bien se exigía el consentimiento de los legitimarios ${ }^{155}$. Y sólo en el caso de que no existieran legitimarios del titular de la explotación cabría realizar tal pacto sucesorio libremente. Además, en el caso de que se tratara de una explotación familiar agraria, vigente un matrimonio, se exigía el consentimiento de ambos cónyuges para celebrar el pacto sucesorio.

La norma se encargaba también de prever un mínimo régimen jurídico aplicable a tales pactos sucesorios. En este sentido, se prohibía al titular de la explotación estando vigente el pacto sucesorio disponer de la explotación a título gratuito, salvo que tal disposición fuera a favor del instituido a través del pacto sucesorio. Establecía además ciertas cautelas a favor del instituido para el caso de que el titular de la explotación dispusiera de la misma a título oneroso, tales como el derecho a una adquisición preferente o el derecho a una compensación económica por el trabajo dedicado a la explotación. Por último, la ley preveía también una serie de causas excepcionales de revocación, que recogían los habituales supuestos en los que el pacto sucesorio puede ser revocado unilateralmente por alguna de las partes (art. 20 y también art. 18 en cuanto a la obligación por parte del instituido de mantener la cualidad de colaborador de la explotación).

Pese a no ser una particularidad de la transmisión de la explotación familiar agraria a través de pacto sucesorio, es interesante realizar también una breve referencia a las normas que en lo que respecta al cumplimiento de la legítima establecía el Estatuto, pues constituyen otra cara de la moneda para mantener la propiedad agraria indivisa. En los casos en los que la explotación agrícola familiar suponga la mayor parte del caudal relicto del causante, de tal forma que con el resto de bienes hereditarios no se pueda completar la cuota legitimaria a la que puedan tener derecho otros posibles parientes del causante no

explotación; se exigía además un acuerdo por escrito con el titular de colaboración. Sólo en defecto de pariente colaborador, se abría esta figura a cualquier otra persona que cumpliera el resto de requisitos exigidos.

${ }^{155}$ Esta exigencia de consentimiento de los legitimarios en la realización del pacto sucesorio a favor del colaborador no legitimario se explica por la potencial afectación de la legítima a tales legitimarios por parte del pacto sucesorio, vid. L .MARTínEZ VÁZQUEZ DE CASTRO (1982), p. 4. 
sucesores de la explotación, se prevé el pago de la legítima en metálico a cargo del sucesor en la titularidad de la explotación agraria (art. 29) ${ }^{156}$. Además se establece que, para el caso de que no haya otros bienes hereditarios o no sean suficientes para completar el pago del resto de las legítimas, se afecta la explotación agraria al pago de éstas (art. 32), y dice el artículo "hasta un límite máximo equivalente al tercio de su valor", lo que la doctrina ha interpretado con una reducción de la legítima a su medida estricta ${ }^{157}$.

De esta forma, en definitiva, durante casi quince años, existió una norma estatal, con eficacia para todo el territorio nacional, que preveía la posibilidad de realizar pactos sucesorios, lo que suponía una derogación de la regla general prohibitiva del art. 1271.2 CC, si bien limitada al ámbito de las explotaciones familiares agrarias ${ }^{158}$.

\subsubsection{Los Derechos autonómicos}

Ya hemos tenido ocasión de señalar que la plurilegislación propia de nuestro país constituye el escenario perfecto para observar la heterogeneidad que en materia de pactos sucesorios existe en el plano del Derecho material. Así, mientras que en el denominado Derecho común la regla general es la de la prohibición de los pactos sucesorios, con las excepciones que hemos visto, en los Derechos civiles autonómicos se admiten, con carácter general y con mayor o menor intensidad, los pactos sucesorios. En este apartado veremos una panorámica general de las distintas posturas que respecto de los pactos sucesorios adoptan los Derechos civiles autonómicos, distinguiendo entre los que prohíben los pactos sucesorios, los que admiten los pactos sucesorios de manera limitada y los que los admiten ampliamente.

\footnotetext{
${ }^{156}$ Situación ésta que no sería extraña, sobre todo, tal y como pone de relieve SÁNCHEZ ARISTI, si atendemos a la definición que la propia ley recogía de la explotación familiar agraria, en la que se incluyen requisitos tales como que constituya el medio de vida principal de la familia, y en la que se incluyen elementos como la propia vivienda familiar (arts. 2 y 3 del Estatuto). Vid. R. SÁNCHEZ ARISTI (2003), p. 188, npp. núm. 507.

${ }^{157}$ R. SÁNCHEZ ARISTI (2003), p. 191.

${ }^{158}$ L. MARTíneZ VÁZQUEZ de CASTRO (1982), p. 5.
} 


\subsubsection{Derechos civiles autonómicos que prohíben los pactos sucesorios}

Con carácter general los pactos sucesorios se han admitido y se han dado en los territorios forales, hasta recogerse en las legislaciones actuales. No obstante, existe una excepción de Derecho autonómico que prohíbe los pactos sucesorios. Se trata del Derecho de Menorca. En concreto, el art. 65 de la Compilación de Derecho Civil de las Islas Baleares ${ }^{159}$, dispone que en la Isla de Menorca regirá lo dispuesto en el Libro I de la Compilación (dedicado al Derecho mallorquín) a excepción de los arts. 6 y 7 en lo referente a la donación universal de bienes presentes y futuros y de los arts. 50 y 51, referidos a la definición o pacto sucesorio de renuncia a la legítima o demás derechos sucesorios. De estas exclusiones se deriva la no admisión en el Derecho menorquín de los pactos sucesorios $^{160}$.

Por otro lado, debemos mencionar aquí el Fuero de Ayala, puesto que genera dudas en torno a la admisión o no de los pactos sucesorios. En concreto, el art. 134 Ley de Derecho Civil del País Vasco" dispone que "los que ostenten vecindad civil foral podrán disponer libremente por testamento, manda o donación, a título universal o particular, apartando a sus herederos forzosos con poco o mucho, como quisieren o por bien tuvieren". El precepto no se refiere expresamente a los pactos sucesorios, lo que en principio podía interpretarse como una solución contraria a la admisión de los pactos sucesorios; sin embargo, la doctrina entiende que los pactos sucesorios se incluyen dentro del término donación y que, por tanto, sí se admiten también en el Fuero de Ayala ${ }^{162}$.

En definitiva, podemos concluir que el único Derecho civil autonómico que prohíbe los pactos sucesorios es el Derecho de las Islas Baleares en lo que respecta a su aplicación en Menorca.

\footnotetext{
159 Texto Refundido de Compilación de Derecho Civil de las Illes Balears, Decreto Legislativo 79/1990, de 6 de septiembre, BO Illes Balears de 2 de octubre de 1990, núm. 120, p. 6097.

${ }^{160}$ P. DE BARRÁn ARNiches (1999), p. 7; M.P. FERRER VANRELl (2009), p. 15.

${ }^{161}$ Ley 3/1992, de 1 de julio, BO País Vasco de 7 de agosto de 1992, núm. 153, p. 6989.

162 A. Celaya Ibarra (1997), p. 570; V. Angoitia Gorostiaga (1999), p. 134; Vid. L. ImaZ ZUBIAUR (2006), p. 201, quien entiende que el término donación hace una clara referencia a la tradicional identidad entre ésta y los pactos sucesorios.
} 


\subsubsection{Derechos civiles autonómicos que admiten los pactos sucesorios de manera limitada}

La mayor parte de los Derechos civiles autonómicos admiten los pactos sucesorios si bien de manera tasada o reglada; esto es, las propias legislaciones establecen qué determinados pactos sucesorios son los que están admitidos. En este grupo de sistemas se encuentran el Derecho gallego, el Derecho catalán, el Derecho mallorquín y los Fueros de Vizcaya y Guipúzcoa.

En Derecho catalán la sucesión contractual siempre ha tenido una presencia relevante, articulada fundamentalmente a través de la figura del denominado heredamiento, que no es más que un pacto sucesorio positivo o de succedendo que fue introducido en este Derecho a través de la vía consuetudinaria y cuya utilización se ha vinculado tradicionalmente a una economía familiar agraria, en la que era un objetivo primordial la conservación de la unidad del patrimonio familiar ${ }^{163}$. En la actual regulación catalana del Derecho de sucesiones, recogida en el Libro IV del CCCat, el punto de partida en lo que respecta a la regulación de los pactos sucesorios es el de la nulidad de los pactos o contratos realizados sobre sucesión no abierta, admitiéndose únicamente los previstos por el propio Código (art. 411.7); es decir, hay una prohibición general y determinadas excepciones que admiten pactos sucesorios en concreto.

Por un lado, existe una limitación común a todos ellos en lo que respecta a la legitimación para celebrar los pactos sucesorios; es decir, no se trata de pactos sucesorios libres, sino de pactos sucesorios familiares, en cuanto que podrán ser otorgados con el cónyuge o futuro cónyuge, con el conviviente y con determinados parientes, por consanguinidad y por afinidad hasta cierto grado (art. 431.2) ${ }^{164}$. Por otro lado, el Libro IV del CCCat determina concretamente qué pactos sucesorios de institución y de renuncia están permitidos. En concreto,

\footnotetext{
${ }^{163}$ L. PUIG FERriol/E. RoCA TríAs (2009), p. 475.

${ }^{164}$ En concreto, el art. 431.2 limita al cónyuge o futuro cónyuge, a la persona con quien convive el otorgante en unión estable de pareja, a los parientes en línea directa sin limitación de grado o en línea colateral dentro del cuarto grado, en ambos casos tanto por consanguinidad como por afinidad y a los parientes por consanguinidad en línea directa o colateral, dentro del segundo grado, del otro cónyuge o conviviente.
} 
recoge cuatro tipos de heredamientos ${ }^{165}$ : el heredamiento simple, aquel en el que únicamente se confiere la cualidad de heredero al beneficiario; el heredamiento cumulativo, en el que además de conferirse la cualidad de heredero se le atribuyen al instituido todos los bienes de presente salvo aquellos que se excluyan expresamente (art. 431.19.2); el heredamiento mutual, que recoge una institución recíproca de herederos (art. 431.20) y el heredamiento preventivo (art. 431.21.1), que tiene la particularidad de que puede ser revocable por un testamento posterior, debiéndose notificar notarialmente dicha revocación al resto de los otorgantes. Por último, se establece otro tipo de pacto sucesorio de institución, el denominado pacto de atribución particular (art. 431.29), a través del cual el futuro causante puede hacer atribuciones singulares sin necesidad de instituir heredero al favorecido $^{166}$.

Por último, el CCCat recoge una admisión limitada de los pactos sucesorios de renuncia; como punto de partida se establece la nulidad de las estipulaciones realizadas en pactos sucesorios y los contratos de transacción o de cualquier otra índole celebrados con anterioridad al fallecimiento del causante y que tengan por objeto la renuncia o un perjuicio del derecho a la legítima (art. 451.26.1); pero seguidamente establecen las siguientes excepciones: en primer lugar, se permiten los pactos celebrados entre cónyuges o convivientes en unión estable de pareja cuyo objeto sea la renuncia a la legítima a la que tuvieran derecho en la sucesión de hijos comunes (art. 451.26 .2 a). En segundo lugar, se permiten aquellos pactos sucesorios realizados entre progenitores e hijos a través de los cuales los progenitores renuncian a la legítima que les correspondería en la herencia del hijo premuerto (art. 451.26 .2 b). Por último, se permiten aquellos pactos otorgados entre ascendientes y descendientes, a través de los cuales el descendiente renuncia al posible suplemento a la legítima, recibiendo a cambio bienes o dinero en pago de la legítima futura (art. 451.26.2 c).

\footnotetext{
${ }^{165}$ Para un análisis más profundo de la nueva regulación catalana de los pactos sucesorios vid., entre otros, L.PUIG FerRIOL/E.ROCA TRÍAS (2009), pp. 441 y ss.; J. EgEA (2009), pp. 9 y ss.; M.P. GARCÍA RUBio/M. HERRERO OVIEDO (2009), pp. 465 y ss.; R. BRANCÓs NÚÑEZ (2009), pp. 9 y ss.; N. Ginés Castellet (2011), pp. 508 y ss.; R. Pratdesaba Ricart (2009), pp. 151 y ss.; S. NAVAS NAVARRO (2009), pp. 1 y ss.

${ }^{166}$ Según el Preámbulo de la ley, este tipo de pactos equivalen a los legados en la sucesión testamentaria.
} 
En Galicia también se establece una admisión limitada de los pactos sucesorios; la Ley de Derecho civil de Galicia establece como punto de partida que, "sin perjuicio de los que fueran admisibles conforme a derecho, de acuerdo con la presente ley son pactos sucesorios: $1^{o}$ ) los de mejora $2^{a}$ ) los de apartación” (art. 209). Antes de señalar cuáles son esos pactos sucesorios que recoge la propia ley gallega, es oportuno realizar un breve inciso para discernir qué quiere decir el precepto cuando se refiere a los pactos que "fueran admisibles conforme a derecho". En efecto, hay parte de la doctrina que ha interpretado que se trata de un sistema de numerus apertus y, por tanto, un principio de libertad de pactos, permitiéndose todos aquellos pactos sucesorios que no estén expresamente prohibidos por la ley gallega ${ }^{167}$. Otros, sin embargo, entienden que se trata de una confirmación de lo dispuesto en el art. 9.8 CC, para los casos en los que haya un cambio de nacionalidad (o vecindad civil) del futuro causante ${ }^{168}$. Por último, también se ha interpretado por pactos admisibles conforme a derecho aquellas modalidades de delación paccionada admitidas por el CC cuanto éste se aplica a título supletorio $^{169}$; esta es la interpretación que nos parece más adecuada, a la que hay que añadir también aquellos otros pactos sucesorios reconocidos por la propia ley gallega como puede ser el caso del usufructo voluntario del cónyuge viudo ${ }^{170}$.

Es posible que el Derecho gallego sea el que contiene una regulación más reglada de los pactos sucesorios; la ley establece de manera concreta quiénes ostentan legitimación activa para la celebración de cada pacto sucesorio que se recoge en la misma. Por un lado, se reconocen dos pactos sucesorios de institución o positivos: el pacto de mejora y la mejora de labrar o poseer. El pacto de mejora (regulado en los arts. 214 y ss. de la ley) se celebra entre un ascendiente y un descendiente, a través del cual se acuerda la sucesión de bienes concretos a favor de los descendientes ${ }^{171}$. La doctrina se ha planteado, ante la parquedad del

\footnotetext{
${ }^{167}$ F.M. ORDÓNEZ ARMÁN, et alt, (2007), pp. 342 y ss.

168 A.L. REBOLLEDO VARELA (2008), pp. 907 y ss.

169 J.M. BUSTO LAGO (2008), pp. 519 y ss.

${ }^{170}$ M.P. GARCÍA RuBio/M. HERRERo OVIEDO (2011), p. 1289.

${ }^{171}$ La denominación de pacto de mejora no es del todo afortunada en cuanto que tras la reforma del Derecho gallego operada por la ley de 2006 se suprimió la mejora del sistema legitimario; por
} 
art. 214, la posibilidad de que los otorgantes acuerden las disposiciones del pacto de mejora a favor de un tercero, descendiente, así como también la posibilidad de nombrar a varios descendientes mejorados ${ }^{172}$. El objeto del pacto de mejora, por su parte, deben ser bienes concretos y determinados, lo que excluye la posibilidad de pactar sobre una cantidad o cuota de la herencia.

El otro pacto sucesorio de institución expresamente recogido por la ley gallega es la denominada mejora de labrar o poseer (arts. 219 y ss.). Es un pacto de succedendo a través del cual, en principio y salvo que se disponga lo contrario, supone la institución de heredero del mejorado. Su función social consiste en el mantenimiento de la unidad del lugar acasarado o una explotación agrícola, industrial, comercial o fabril, de tal forma que el ascendiente que quiere mantener indiviso este lugar puede pactar con cualquiera de sus descendientes la adjudicación íntegra del mismo, conllevando en principio tal nombramiento el de la institución de heredero. Se prevén además determinados mecanismos para compensar en metálico a los demás interesados en la partición, dándosele al heredero determinadas facilidades, como por ejemplo el establecimiento de plazos largos para el cumplimiento de la compensación en metálico.

La apartación es el único pacto sucesorio negativo o de renuncia que se permite en el Derecho gallego, Es un pacto otorgado por el apartante y un legitimario, a través del cual el apartado queda excluido de modo irrevocable de la condición de heredero forzoso en la herencia del apartante, a cambio de unos bienes concretos que le son adjudicados (art. 224). Es necesario que el apartado tenga la condición de legitimario en el momento de la formalización del pacto sucesorio y el efecto paradigmático de este pacto sucesorio es el de la pérdida de la condición de legitimario del sujeto apartado ${ }^{173}$.

tanto, pese a la denominación, este pacto sucesorio no implica que contenga una mejora a favor de uno de los legitimarios en el sentido tradicional de la institución.

${ }^{172}$ A.L. REBOLLEDO VARELA (2008), p. 929.

${ }^{173}$ Sobre el apartamiento vid. con mayor profundidad, M.P. GARCÍA RUBIO (2000), pp. 1397 y ss.; A.L. REBOLLEDO VARELA (2008), pp. 970 y ss.; J.M. BuSTO LAGO (2008), pp. 540 y ss. 
Por último, como decíamos, la propia ley gallega admite la celebración de otros pactos sucesorios, tal y como ocurre con al constitución del usufructo voluntario del cónyuge viudo. Su ubicación sistemática en la ley, en un capítulo aparte justo a continuación de la regulación de los pactos sucesorios, se debe a la doble posibilidad de su constitución, que puede ser a través de testamento o a través de pactos sucesorio. Dice la ley que los cónyuges podrán pactar, a través de escritura pública, la creación de un usufructo sobre toda o parte de la herencia, pudiendo constituirse éste bien de forma unilateral bien de forma recíproca (art. 228).

El punto de partida del Derecho mallorquín respecto de los pactos sucesorios es también el de una admisión limitada, como bien prueba el hecho de que el art. 6 de la Compilación de Derecho civil de las Islas Baleares, dedicado a la delación hereditaria, establece que la herencia se defiere por testamento, por ley o por los contratos regulados por la ley. Seguidamente se regula la donación universal, que constituye un verdadero pacto de succedendo, en cuanto que a través del mismo se instituye al donatario, según lo dispuesto por la ley, en un heredero contractual del donante (art. 8). Por otro lado, se regula un pacto sucesorio de renuncia, denominado definición o diffinitio (art. 50), que es un pacto a través del cual los descendientes, legitimarios y emancipados, pueden renunciar a todos los derechos sucesorios o a la legítima que les pudiera corresponder, en contemplación de alguna donación, atribución o compensación a su favor.

El Fuero de Vizcaya recoge una admisión amplia de los pactos sucesorios de institución, pero nada dice expresamente sobre los pactos de renuncia. El art. 27 de la Ley de Derecho civil del País Vasco se refiere a la delación de la herencia y dispone que la designación de sucesor en bienes tiene lugar por testamento, por ley, por pacto sucesorio capitulaciones matrimoniales o donación. En sentido estricto el art. 27 se está refiriendo a la sucesión contractual, esto es, a los pactos sucesorios positivos o de institución. Seguidamente se establece una regulación concreta de los pactos sucesorios de institución en los arts. 74 y siguientes de la ley, pero nada se dice de los pactos de renuncia. No obstante, hay doctrina que 
interpreta que la fórmula amplia recogida en el art. $74^{174}$ incluye también a los pactos sucesorios de renuncia ${ }^{175}$.

Por último, el Fuero de Guipuzcoa, cuya regulación gira en torno al llamado caserío (que es una propiedad familiar agrícola de cuya explotación vive la familia) y al patrimonio familiar. En el título de la Ley dedicado al ámbito de aplicación del Fuero se establece un criterio funcional según el cual los guipuzcoanos que sean titulares de un caserío sito en el territorio histórico de Guipúzcoa podrán servirse de los instrumentos que, en orden a la transmisión del mismo, el Fuero disciplina. Uno de tales instrumentos es el pacto sucesorio, pudiendo ser con transmisión de presente del caserío y sus pertenecidos o con eficacia post-mortem. Por tanto, en el Fuero de Guipúzcoa los pactos sucesorios que se prevén son de institución y además su limitación viene dada por el objeto, que debe ser la transmisión del caserío.

\subsubsection{Derechos autonómicos que admiten los pactos sucesorios de manera amplia}

De todos los Derechos civiles autonómicos españoles el Derecho navarro admiten con la mayor amplitud los pactos sucesorios ${ }^{176}$. El Derecho navarro reconoce la posibilidad de hacer disposiciones a título lucrativo a través de pactos sucesorios (Ley 149 Fuero Nuevo de Navarra) ${ }^{177}$. Ofrece además una definición de pacto sucesorio (Ley 172) de la que se deriva la admisión tanto de los pactos sucesorios de institución, como los de renuncia e incluso también los pactos sobre sucesión de tercero ${ }^{178}$. No se establecen además limitaciones a la legitimación

\footnotetext{
${ }^{174} \mathrm{El}$ art. 74 de la Ley regula los medios formales para el establecimiento de pactos sucesorios y dispone que "mediante capitulaciones matrimoniales, donación o pacto otorgado en escritura pública, se puede disponer la sucesión en bienes de los otorgantes, bien a título universal o particular, con las modalidades, reservas, sustituciones, cláusulas de reversión, cargas y obligaciones que se acuerden. Los otorgantes podrán, asimismo, ordenar la transmisión actual de todos los bienes presentes, o parte de ellos, o bien diferirla al momento de la muerte".

${ }^{175}$ I. MONASTEIO ASPIRI (1994), pp. 337 y ss.

176 J.L. MEZQUITA DEL CACHO (2002), p. 525.

${ }^{177}$ Ley 1/1973, BOE 7 marzo 1973, núm. 57.

178 La Ley 172 del Fuero Nuevo de Navarra establece que "por pacto sucesorio se puede establecer, modificar, extinguir o renunciar derechos de sucesión mortis causa de una herencia o de parte de ella, en vida del causante de la misma. Cuando estos actos impliquen cesión de tales derechos a un tercero será necesario el consentimiento del causante".
} 
para otorgar pactos sucesorios, de tal forma que se trata de pactos sucesorios libres.

El Derecho aragonés sigue la misma línea de admisión amplia de los pactos sucesorios que el Derecho navarro; el art. 377 del Código del Derecho Foral de Aragón ${ }^{179}$ recoge el principio general de admisión de los pactos sucesorios al disponer que "son válidos los pactos que sobre la propia sucesión se convengan en escritura pública, así como los que en relación con dicha sucesión otorguen otras personas en el mismo acto”. De nuevo, al igual que ocurre en el Derecho navarro, no hay restricción alguna en cuanto a la legitimación para el otorgamiento de pactos sucesorios, al no exigirse vínculo de parentesco alguno entre los otorgantes para su celebración ${ }^{180}$.

El punto de partida de admisión general de los pactos sucesorios es también el que se sigue en el Derecho de Ibiza y Formentera. El art. 69 de la Compilación de Derecho civil de las Islas Baleares, dedicado a las formas de delación de la herencia, dispone que la sucesión se defiere por testamento, por pacto o por disposición de la ley, sin más limitaciones. No existe por tanto un punto de partida restrictivo de los pactos sucesorios; no obstante, sí es posible derivar una mayor restricción de la regulación particular de cada pacto sucesorio, sobre todo en lo que respecta al pacto de renuncia o finiquito. Los pactos de institución se prevén con una gran amplitud, tanto en el objeto y contenido de los pactos, como en las personas que pueden otorgarlos, respecto de las cuales no se establece limitación alguna de parentesco. Sin embargo, a la hora de regular el pacto de finiquito se limita al ámbito de los derechos de legitimarios; así, el art. 77 dispone que a través del finiquito el descendiente legitimario mayor de edad puede renunciar a la legítima o a cuantos derechos le pudieran corresponder en la herencia del ascendiente a cambio de una donación, atribución o compensación.

\footnotetext{
${ }^{179}$ Decreto Legislativo 1/2011, de 22 de marzo, BO Aragón de 29 de marzo de 2011, núm. 63, p. 6490.

${ }^{180}$ Con más detalle sobre los pactos sucesorios en Aragón, vid. J. SAPENA TOMÁs (1954), pp. 734 y ss.; C. BAYOD LÓPEZ (2003), pp. 5123 y ss.
} 


\section{Estado actual de la cuestión}

\subsection{Flexibilización de la prohibición de los pactos sucesorios en Derecho comparado}

En los últimos años se ha producido un giro favorable a los pactos sucesorios que se ha denominado renacer o revitalización de los pactos sucesorios ${ }^{181}$. Uno de los factores que han contribuido a esta nueva tendencia es la existencia de determinadas reformas de Derecho sustantivo que han supuesto una flexibilización de las tradicionales prohibiciones que sobre los pactos sucesorios re recogían tradicionalmente en algunos ordenamientos jurídicos. En este sentido, tenemos dos ejemplos cercanos y recientes de sistemas contrarios a los pactos sucesorios que han operado reformas en los últimos años, que han supuesto una flexibilización de la prohibición general que de los pactos sucesorios contienen sus legislaciones. Se trata del sistema jurídico francés y del italiano.

Hemos visto cómo el ordenamiento jurídico francés se caracteriza por ser contrario a los pactos sucesorios, si bien se han permitido desde la promulgación del Code determinadas figuras que constituyen excepciones a la prohibición de los pactos sucesorios. Ahora bien, en el año 2006 se produjo una reforma que amplía los casos en los que los pactos sucesorios están admitidos ${ }^{182}$.

En primer lugar, la reforma afecta a la figura de la donation-partage, aumentándose el círculo de personas con las que se puede realizar. En concreto, si bien en un principio esta figura estaba reservada para los ascendientes y descendientes en línea recta, desde la reforma del 2006, pueden hacerse a favor de cualquier heredero presunto, es decir, aquellos que serían herederos ab intestato del disponente en el momento del otorgamiento del acto ${ }^{183}$.

En segundo lugar, la ley del 2006 introduce una nueva figura, denominada donation-partage transgénérationnelle. Se trata de una donaciónpartición que puede realizarse en beneficio de los nietos, viviendo aún los padres,

\footnotetext{
${ }^{181}$ M. Herrero OVIEDO (2009-1), p. 199 y ss.

${ }^{182}$ Ley núm. 2006-728 de 23 de junio.

${ }^{183}$ C. Jubault, (2010), p. 592.
} 
lo cual implica un salto generacional que afecta al principio de proximidad de grado. Esta figura sólo se puede realizar entre parientes en línea recta y concretamente de abuelo a nietos. Los nietos reciben la parte de herencia que le correspondería a su padre en la herencia de su abuelo; por ello, la donationpartage transgénérationnelle participa de la naturaleza de la donación-partición pero añadiéndole un matiz, al desprenderse de ella también una renuncia, por parte del padre, a la herencia futura ${ }^{184}$.

En tercer lugar, se permite la posibilidad de renunciar anticipadamente a la acción de reducción recogida en los arts. 929 y siguientes del CC francés, constituyendo una excepción a la prohibición a la renuncia de la herencia futura tradicionalmente recogida en el CC francés. Todo presunto heredero reservatario puede realizar una renuncia a la acción de reducción de una sucesión no abierta, con el consentimiento del futuro causante y en beneficio de una o varias personas determinadas.

Estas tres innovaciones introducidas por la reforma del año 2006 afectan y flexibilizan la tradicional prohibición. Hoy día no falta doctrina francesa que ha manifestado el carácter erosionado o simplemente formal de la prohibición de los pactos sucesorios $^{185}$.

En Italia se puede decir que el carácter contrario a los pactos sucesorios ha sido históricamente más drástico, pues no se conoce excepción alguna a la rígida prohibición que de los pactos se recoge en el art. $468 \mathrm{CCit}$. En este contexto se proclamó en 2006 una ley que introduce una nueva figura, el pacto de familia, como una derogación parcial de la, hasta el momento, intocable prohibición de los pactos sucesorios ${ }^{186}$. Desde tal modificación, la prohibición de los pactos sucesorios se recoge haciendo salvedad a lo dispuesto en el art. 768 bis, donde se recoge la definición de pacto de familia. El pacto de familia se define como el

\footnotetext{
${ }^{184}$ M. PEREÑA ViCENTE (2008), p. 2489.

${ }^{185}$ N. BAILlON-WirTZ, (2006), p. 13; en opinión de P. MALAURIE (2008), p. 297 la vigencia de esta prohibición es más teórica que práctica.

${ }^{186}$ Legge 14 febbraio 2006, n. 55, Modifiche al codice civile in materia di patto di famiglia, $G U$, Serie Generale, n. 50, del 1-3-2006, www.guritel.it (consultado a fecha 24 de agosto de 2010).
} 
contrato por el cual un empresario transmite su empresa, en todo o en parte, o por el cual un titular de participaciones sociales transmite todo o parte de sus acciones o cuotas-parte, a uno o varios descendientes. El beneficiario o los beneficiarios de tal transmisión deben corresponderse con aquellos que serían legitimarios del disponente en el caso de que se abriera su sucesión en el momento del otorgamiento del pacto de familia (art. 768 quater $1^{\circ}$ y $2^{\circ}$ CCit.). En la celebración del pacto de familia se prevén tres partes participantes: el disponente, el descendiente beneficiario de la transmisión y se exige también la participación de todo aquel legitimario del disponente en el momento del otorgamiento (art. 768 quater $1^{\circ} \mathrm{CCit}$.). El beneficiario del pacto de familia debe compensar en metálico al resto de legitimarios y lo recibido por el pacto no es objeto de colación o reducción, de tal forma que esos bienes o participaciones no podrán ser tenidos en cuenta para el cálculo de las cuotas parte de las legítimas (art. 768 quater $2^{\circ}$ y $4^{\circ}$ CCit).

En Italia se ha producido un debate doctrinal en torno a la naturaleza jurídica del pacto de familia, pues su configuración como una derogación parcial del pacto sucesorio llevó a pensar a priori que se trata de un pacto sucesorio excepcionalmente válido; sin embargo, la mayor parte de la doctrina italiana no considera al pacto de familia como un verdadero pacto sucesorio ${ }^{187}$. Sea como fuere, también en el entorno del ordenamiento jurídico italiano se empiezan a oír las primeras voces que hablan de la erosión de la prohibición de los pactos sucesorios, así como de la oportunidad de una reforma del art. $469 \mathrm{CCit}^{188}$.

\footnotetext{
${ }^{187}$ El debate se ha centrado fundamentalmente en la determinación de si el pacto de familia tiene una naturaleza de acto inter vivos o mortis causa, considerándose pacto sucesorio únicamente en este último caso, B. InZITARi/P. Dagna/M. Ferrari/V. PiccininI, (2006), P. 63; F.TASSINARI (2006), p. 811; L. CAROTA (2008), p. 47 y ss.; D. DAMASCELLI (2008), pp. 90 y ss.; M.C. ANDRINI (2006), punto 6 in fine, para quien el pacto de familia es un negocio mixto comprensivo de una atribución no enteramente a título gratuito, en cuanto la obligación para el descendiente beneficiario de liquidación y además es un contrato a favor de tercero para los otros legitimarios. Sin embargo, aunque tímidamente, parece estar de acuerdo en considerar al pacto de familia como un pacto sucesorio, D. ACHILlE (2012), pp. 224 y ss; también se inclina en esta dirección G. PERONI (2007), p. 626, quien habla de que a través del pacto de familia se da legitimidad a los pactos dispositivos y a los de renuncia, pero no a los de institución.

${ }^{188}$ Sobre la erosión de la prohibición, vid. I. ANTONINI (1996), p. 606, donde hace un análisis jurisprudencial del que ya concluye la existencia de una erosión de la prohibición de pactos sucesorios. Por su parte, habla de una conveniente reforma del art. 468 CCit, F. TASSINARI, (2008), pp. 78 y ss.; también, D. ACHILLE (2012), p. 227.
} 


\subsection{Las reformas de los Derechos autonómicos}

El fenómeno del renacer o revitalización de los pactos sucesorios también ha tenido sus manifestaciones en el ordenamiento jurídico español. Varios Derechos civiles autonómicos han sido objeto de importantes reformas en los últimos años que han implicado ciertas modificaciones en lo que respecta a la regulación de estas figuras. El objetivo de todas estas reformas era el de modernizar tales regulaciones, adaptándolas a los cambios sociales y la característica común es la apertura de la regulación de los pactos sucesorios. En la mayor parte de los casos estas reformas han estado ligadas al mantenimiento de la unidad de la empresa familiar; es decir, si bien los pactos sucesorios estuvieron tradicionalmente ligados a la transmisión de la explotación agrícola familiar, hoy día se produce una adaptación a los cambios sociales y a la nueva economía y se piensa en la facilitación de la transmisión mortis causa de la empresa familiar.

El ejemplo paradigmático de estas modificaciones lo constituye el caso del Derecho catalán, con la reforma operada por la Ley $10 / 2008^{189}$; es ilustrativo el Preámbulo de la ley, donde se declara expresamente que la innovación más importante que se recoge en la nueva norma se refiere a los pactos sucesorios, cuya regulación pasa a tener ahora un carácter más abierto y flexible. Con esta reforma se pretende, fundamentalmente, adaptar la figura del tradicional heredamiento a la nueva sociedad, donde predominan los intereses industriales y mercantiles, focalizados muchas veces en la empresa familiar ${ }^{190}$. Destaca entre estas novedades, la eliminación del carácter matrimonial de los pactos sucesorios; se amplía el círculo de personas que tienen legitimación para celebrar pactos sucesorios, convirtiendo el régimen de estas figuras en pactos sucesorios de carácter familiar y no estrictamente matrimonial.

El Derecho de Aragón también sufrió una importante reforma con la Ley de sucesiones por causa de muerte de Aragón, del año $1999^{191}$. El tratamiento de

\footnotetext{
${ }^{189}$ Ley 10/2008, de 10 de julio, Libro Cuarto del Código Civil de Cataluña, DO Generalitat de Catalunya de 17 de julio de 2008, núm. 5175, p. 55923.

${ }^{190}$ Vid. p. IV del Preámbulo.

${ }^{191}$ Ley 1/1999, de 24 de febrero, BOE de 25 de marzo 1999, núm. 72, p. 11723.
} 
la sucesión paccionada por esta ley devenía necesario, puesto que la escasa regulación que de esta figura se hacía en la normativa anterior, unido a la interpretación restrictiva que la doctrina realizó de la misma, supusieron una importante reducción en la utilización de los pactos sucesorios ${ }^{192}$. En la nueva regulación se recogen novedades importantes y un desarrollo pormenorizado y sistematizado de los pactos sucesorios, de cara a su adaptación a los nuevos tiempos. Entre estas novedades destaca la eliminación de carácter familiar del pacto sucesorio, en cuanto que se suprime cualquier exigencia de parentesco para su otorgamiento.

El Derecho gallego ha sufrido también una importante reforma en los últimos tiempos que también ha afectado a la regulación de los pactos sucesorios. Destacan las novedades sobre el paco de mejora de labrar o poseer; con anterioridad a la ley de 2006, la mejora de labrar y poseer estaba vinculada al sistema legitimario, al constituir una mejora en el sentido tradicional del término, pero hoy día tiene un significado distinto, dada su adecuación a las nuevas necesidades sociales y su separación del sistema legitimario. Su función actual es la de conservar indiviso un lugar acasarado o una explotación agrícola, industrial, comercial o fabril.

Por último, debemos tener en cuenta también que el proceso de revitalización o renacer de los pactos sucesorios puede venir de la mano de reformas en otros campos del Derecho, como por ejemplo el Derecho fiscal. En el territorio balear, por ejemplo, se ha relacionado el resurgimiento de los pactos sucesorios por su relación con los protocolos familiares, de los que constituyen un complemento perfecto para la transmisión de la empresa familiar, y el favorable régimen fiscal del que gozan las transmisiones sucesorias y gratuitas desde 2006 en Baleares ${ }^{193}$.

\footnotetext{
${ }^{192}$ C. BAYOD LÓPEZ (2003), pp. 5125 y ss.

${ }^{193}$ M.P. FERRER VANRELL (2009),
} 


\subsection{Hacia una pertinente reforma del Código Civil sobre los pactos sucesorios}

El fenómeno de la revitalización o del renacer de los pactos sucesorios, así como la flexible interpretación de la que ha sido objeto el art. 1271.2 CC, ha conducido a que parte de la doctrina civilista se plantee la oportunidad de una reforma del Código Civil en el sentido de modificar la tradicional regla prohibitiva $^{194}$.

Una de las razones que se esgrimen para defender esta postura es la pérdida de sentido de las tradicionales razones que se esbozaban en contra de los pactos sucesorios. En este sentido, ya hemos tenido ocasión, en primer lugar, de rebatir los argumentos a favor del votum mortis como razón para no permitir los pactos sucesorios. No sólo hay otras figuras que también deberían ser prohibidas por este miedo, como ocurre con los seguros de vida o el contrato de renta vitalicia $^{195}$, sino que con mayor razón habría un miedo al votum mortis en el caso de instituidos a través de testamento, cuya institución puede ser modificada en cualquier momento por un posible cambio de voluntad del causante ${ }^{196}$.

En segundo lugar, ya hemos tenido ocasión también de señalar que de todas las razones que se esgrimen en contra de los pactos sucesorios goza de mayor relevancia aquella que se refiere a la pérdida de la libertad de disposición mortis causa y, por tanto, a la oposición de los pactos sucesorios al principio sucesorio de la libre revocabilidad de las disposiciones realizadas hasta el momento del fallecimiento del causante. Ahora bien, este argumento es únicamente válido para los pactos sucesorios positivos o de institución, y no para los pactos sucesorios de renuncia; sin embargo, el art. 1271.2 CC no hace distinción alguna en este sentido. En lo que concierne a los pactos sucesorios de institución la doctrina se ha planteado la posibilidad más o menos amplia de permitir una revocación unilateral ${ }^{197}$. Este argumento está relacionado también

\footnotetext{
${ }^{194}$ M.P. GARCÍA RUbio/M. HeRrero OVIEdo (2011), p. 1283.

${ }^{195}$ R. SÁNCHEZ ARISTI (2006), p. 482.

${ }^{196}$ J.L. LACRUZ BERDEJO/F. SANCHO REBULLIDA (1981), p. 382.

${ }^{197}$ M.P. García Rubio/M. Herrero Oviedo (2011), p. 1285; R. SÁNCHEZ Aristi (2006), p. 500 y pp. 517 y ss.
} 
con la autonomía de la voluntad; se apela al respeto de la autonomía privada como argumento contrario a la prohibición. En concreto, se entiende que un pacto sucesorio, como todo pacto, es el resultado del ejercicio de la libertad y autonomía de los otorgantes, y que si por otorgar tal contrato se pierde esa libertad pro futuro es precisamente porque se ha hecho uso de esa misma libertad ${ }^{198}$.

En tercer lugar, hay quienes han resaltado en el hecho de que la prohibición de los pactos sucesorios conlleva un obstáculo para la consecución de algunos fines protegibles, tales como el mantenimiento de la unidad de los patrimonios familiares, ya sean rurales o industriales; este valor es de difícil consecución en el marco de la regulación del $\mathrm{CC}^{199}$. Por ello, se rechaza la prohibición de los pactos sucesorios, en cuanto que han constituido y constituyen un mecanismo idóneo para el mantenimiento de la unidad de estos patrimonios en los procesos de transmisión transgeneracional de los mismos ${ }^{200}$.

Estas son las razones sobre las que con carácter general se apoya la doctrina para reivindicar la pertinente reforma del $\mathrm{CC}$ en lo que se refiere al tratamiento de los pactos sucesorios; bien sea a través de la eliminación absoluta del art. 1271.2 CC, bien a través de una mayor o menor flexibilización de la tradicional prohibición ${ }^{201}$.

\subsection{Los pactos sucesorios en la Unión Europea}

Otro factor de innegable importancia en el renacer de los pactos sucesorios es el interés que sobre estas figuras ha surgido en el seno de la Unión Europea. El inicio de este interés se puede datar a principios de la década de los noventa, momento en el que la UE empezó a mostrar su preocupación por la

\footnotetext{
${ }^{198}$ L. DíEZ PiCAZO/A. GULLÓN (2006), p. 467.

${ }^{199}$ M.P. GARCÍA RUBio/M. HERRERO OVIEDO (2011), p. 1284.

200 De hecho, los pactos sucesorios siempre han estado ligados a la conservación indivisa del patrimonio familiar, tal y como se desprende de la práctica en los Derechos forales españoles; vid. J.L. LACRUZ BERDEJO/F. SANCHO REBULLIDA (1981), p. 382; L. IMAZ ZUBIAUR (2006), p. 237; R. SÁNCHEZ ARISTI (2006), p. 483.

${ }^{201}$ A favor de la revisión de la prohibición de los pactos sucesorios, J. RAMS ALBESA (1993), p. 467; K.J. Albiez Dohrmann (2005), p. 589; R. SÁNCHEZ Aristi (2006), pp. 490 y ss.; L. DíEZ PiCAZO/A. GULlÓN (2006), p. 467; M.P. GARCÍA Rubio/M. HERRERo OVIEDO (2011), p. 1285.
} 
transmisión de las pequeñas y medianas empresas; un estudio puso de relieve que alrededor de un $30 \%$ de las empresas europeas cierran su actividad por problemas en su transmisión y por ello se hicieron una serie de estudios y trabajos encaminados a promover la realización de los cambios necesarios en las legislaciones de los Estados Miembros para facilitar y garantizar la transmisión exitosa de este tipo de empresas.

El primer documento a destacar es una Recomendación de la Comisión del año 1994 en la que se invitaba a los Estados Miembros a tomar las medidas oportunas para facilitar la transmisión de las pequeñas y medianas empresas ${ }^{202}$. En los Considerandos de esta Recomendación se declara la importancia de que el empresario planifique en vida su sucesión de una manera eficaz; por ello uno de los objetivos que se señalan en esta Recomendación es que los Estados Miembros ofrezcan al empresario los medios instrumentos necesarios para la preparación de la transmisión de su empresa, así como proporcionarle la necesaria formación e información para planificar adecuadamente su sucesión.

Cuatro años más tarde se publica una Comunicación de la Comisión en la que se recogen los resultados del Foro europeo sobre transmisión de empresas, celebrado en Lille en febrero de 1997, donde, por un lado, se presentaron las primeras reformas resultantes de la puesta en práctica de la Recomendación de $1994 \mathrm{y}$, por otro lado, se lanzaron ideas para futuras mejoras ${ }^{203}$. En dicha Comunicación se hace especial referencia a los denominados pactos de empresa o protocolos familiares como una de las posibles vías que se pueden poner en manos de los empresarios; al hilo de la atención a estos pactos o protocolos familiares, se hacen dos interesantes aseveraciones respecto de los pactos sucesorios. Por un lado, la Comisión, consciente de la fuerte oposición que sobre los pactos sucesorios mantienen algunos ordenamientos jurídicos, presenta la opción de los protocolos familiares como un medio para paliar los efectos derivados de la prohibición de los pactos sucesorios. No obstante, seguidamente

\footnotetext{
${ }^{202}$ Recomendación de la Comisión, de 7 de diciembre de 1994, sobre la transmisión de pequeñas y medianas empresas, DOUE L 385 de 31 de diciembre de 1994, pp. 0014-0017.

${ }^{203}$ Comunicación de la Comisión sobre transmisión de las pequeñas y medianas empresas DOUE C 93/2 de 28 de marzo de 1998.
} 
se proclama claramente que la medida de los protocolos familiares es claramente insatisfactoria en relación con los beneficios que podría reportar el poner en manos de los empresarios la posibilidad de realizar pactos sucesorios.

Sin duda la apuesta más fuerte de la Unión Europea por los pactos sucesorios se encuentra en la inclusión de estas figuras dentro del ámbito de aplicación del Reglamento de sucesiones ${ }^{204}$. Los pactos sucesorios han estado presentes desde los inicios de los trabajos en el nuevo Reglamento. El primer trabajo que hay que destacar en este proceso es el llamado comúnmente Informe Dörner-Lagarde ${ }^{205}$; se trata de un importante trabajo de Derecho comparado en el que se pone de relieve la situación de las sucesiones internacionales en los Derechos europeos. Además se hace hincapié en las cuestiones más problemáticas que plantean las sucesiones internacionales, momento en el que ya se hace referencia a los particulares problemas que presentan los pactos sucesorios, debido fundamentalmente a su inadmisibilidad en los Derechos materiales de un gran número de Estados Miembros ${ }^{206}$.

En segundo lugar, cabe destacar ya el Libro Verde sobre Sucesiones y Testamentos $^{207}$; el Libro Verde asume la inclusión de los pactos sucesorios dentro del ámbito regulativo del nuevo instrumento y recoge directamente en sus consultas dos preguntas en torno a la ley aplicable a estas figuras ${ }^{208}$. La primera de las preguntas se refiere a la determinación de la ley aplicable a los pactos sucesorios con base en una conexión objetiva, esto es, a falta de elección de ley aplicable; mientras que la segunda cuestión se plantea la posibilidad de admitir una elección de ley a los pactos sucesorios.

\footnotetext{
${ }^{204}$ Reglamento (UE) no 650/2012 del Parlamento Europeo y del Consejo relativo a la competencia, la ley aplicable, el reconocimiento y la ejecución de las resoluciones, a la aceptación y la ejecución de los documentos públicos en materia de sucesiones mortis causa y a la creación de un certificado sucesorio europeo, Reglamento (UE) no 650/2012 del Parlamento Europeo y del Consejo, de 4 de julio de 2012. DOUE de 27 de julio de 2012, L 201/107.

${ }^{205}$ DEUTSCHES NOTARINSTITUT (2002).

${ }^{206}$ DEUTSCHES NOTARINSTITUT (2002), p. 13, donde se pone de manifiesto el posible problema de reconocimiento de un pacto sucesorio en un sistema en el que no están permitidas estas figuras.

${ }^{207}$ COM (2005), 65 final, de 1 de marzo de 2005.

${ }^{208}$ Sobre el Libro Verde de Sucesiones y Testamentos, vid. R. MiQuel SALA (2007), pp. 695-718; A. RODRÍGUEZ BENOT (2008), pp. 142-150.
} 
El tercer gran documento a destacar en este proceso es la Propuesta de Reglamento $^{209}$, que incluye, tal y como veremos con más detalle, un precepto con cuatro apartados para regular la ley aplicable a los pactos sucesorios. Finalmente, el proceso culmina con el Reglamento de sucesiones, que mantiene el precepto de la Propuesta de Reglamento, aunque con considerables modificaciones.

\footnotetext{
${ }^{209}$ Propuesta de Reglamento del Parlamento Europeo y del Consejo, relativo a la competencia, la ley aplicable, el reconocimiento y la ejecución de las resoluciones y los actos auténticos en materia de sucesiones y a la creación de un certificado sucesorio europeo, de 14 de octubre de 2009, COM (2009) 145 final, DOUE C26/11 de 28 de enero de 2011.
} 


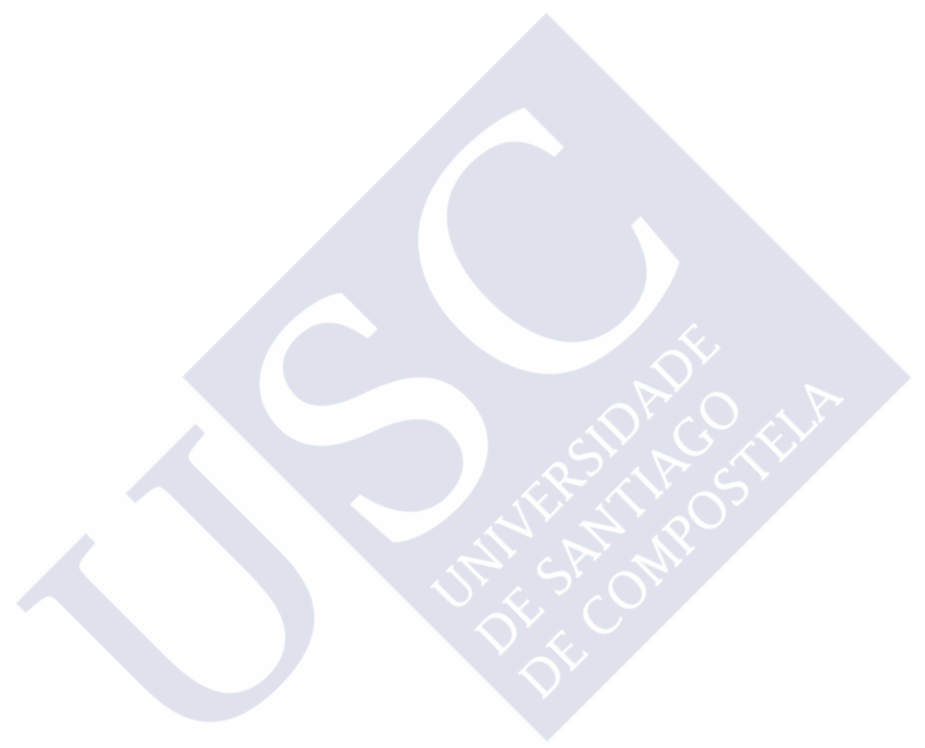




\section{CAPÍTULO II: LA LEY APLICABLE A LOS PACTOS SUCESORIOS EN DERECHO INTERNACIONAL PRIVADO COMPARADO: MODELOS POSITIVOS}

\section{INTRODUCCIÓN}

Tras habernos introducido en la realidad sustantiva del objeto de la presente tesis, resulta obligada una primera aproximación a la realidad del DIPr comparado. Analizaremos en el presente capítulo las grandes opciones regulativas sobre la ley aplicable a los pactos sucesorios que los distintos ordenamientos jurídicos han ido articulando a lo largo del tiempo. También reparemos en soluciones más especializadas, como las del Convenio sobre ley aplicable a las sucesiones por causa de muerte, concluido en La Haya, el 1 de agosto de 1989; instrumento de gran importancia, a pesar de no haber entrado en vigor (tan sólo Países Bajos lo incorporaron unilateralmente a su sistema estatal), no solo por la novedad de las soluciones que incorpora, sino por la innegable influencia que tuvo en el proceso que concluyó con el Reglamento sobre sucesiones.

Nuestro propósito en este Capítulo no es meramente hacer un estudio de Derecho extranjero de forma exegética, sino tratar de comprender las grandes opciones regulativas. Grandes opciones que exigen una primera distinción entre la calificación contractual y la calificación sucesoria de los pactos. Como hemos dicho y tendremos ocasión de ver en este y los capítulos que siguen, la naturaleza híbrida de los pactos sucesorios no desaparece, incluso aunque se opte nítidamente por uno de los dos polos. Y aunque generalmente se ha optado por incluir la regulación de la ley aplicable dentro de la órbita de las sucesiones, veremos cómo esa naturaleza contractual plantea exigencias que hace que las soluciones tradicionales para las sucesiones no sean totalmente extrapolables a los pactos sucesorios. 
Por otro lado, el Derecho comparado muestra que no ha sido ni es infrecuente que no se prevea ningún tipo de solución específica para la ley aplicable a los pactos sucesorios, lo que no sólo alimenta el problema de la calificación, sino que incluso dentro de cada una de las dos calificaciones, se precisa dar un paso adelante y ver la adecuación de las soluciones genéricas a los problemas específicos de los pactos sucesorios. Y allí donde existe tal toma en consideración de la peculiaridad de la sucesión paccionada, las diferencias en cuanto al grado de especialización de las soluciones positivas son grandes.

\section{CALIFICACIÓN CONTRACTUAL}

\section{La ignorancia de los pactos sucesorios: posibilidad de una calificación contractual}

El punto de partida del modelo que vamos a analizar en este apartado es la ausencia de referencia alguna a los pactos sucesorios en las normas de DIPr. Esta ausencia es bastante habitual, sobre todo en aquellos sistemas en los que el Derecho material prohíbe estas figuras. Es este, la ausencia de la regulación material o sustantiva, un elemento que no tendría por qué condicionar la solución de ley aplicable, pero justo es reconocer que en el actual estado de la evolución de las normas de conflicto en materia de sucesiones, sería una exigencia inusual que el legislador de DIPr fuese capaz de hacer el esfuerzo de prever una solución de ley aplicable para una institución que desconoce o incluso prohíbe. Es el caso, por ejemplo, del ordenamiento jurídico francés o del ordenamiento jurídico italiano. Ante la ausencia de referencia expresa a los pactos sucesorios, el operador jurídico debe buscar la norma de conflicto aplicable a estas figuras cuando se topa con una de ellas en una situación privada internacional. Debe indagar en su sistema de DIPr y es en este punto dónde se pueden dar distintas propuestas, si bien con carácter general se reducen o a la calificación contractual o a la calificación sucesoria $^{210}$.

\footnotetext{
${ }^{210}$ También se ha abogado en alguna ocasión, aunque más aislada, por la consideración de los pactos sucesorios como una cuestión de Derecho de familia, fundamentalmente en aquellos casos en los que los pactos sucesorios estaban vinculados al matrimonio y se realizaban por capitulaciones matrimoniales bien entre los padres de los contrayentes, bien entre los propios cónyuges o futuros cónyuges. En este contexto se ha defendido la aplicación de la ley del matrimonio o la ley del régimen económico matrimonial; vid. J. VALLET DE GOYTISOLO/R. Fraguas MASSIP/J.L. MARTíneZ GIL/V.L. SimÓ SANTOJA (1967), p. 12 y p. 18.
} 
En este contexto, aunque la falta de previsión no supone una falta de necesidad de solución, lo cierto es que las reacciones ante el silencio del sistema de DIPr suelen ser más nítidas cuando es el propio sistema sustantivo el que cambia. Aparece un problema de calificación que ha de resolverse, afortunadamente, dentro de la propia lex fori. Un ejemplo gráfico de estos problemas de calificación de los pactos sucesorios o figuras afines que se dan en los ordenamientos jurídicos en los que no se prevé una solución expresa de ley aplicable para los mismos es el que se dio en Italia al hilo del pacto de familia. El debate surgido en torno al pacto de familia entre la doctrina italiana es doble; por un lado, en el estadio del Derecho material, se discute sobre su naturaleza jurídica, centrándose la duda, principalmente, en si se trata o no de un verdadero pacto sucesorio $^{211}$; por otro lado, y en parte por extensión, en el estadio del DIPr, donde el debate se centró fundamentalmente en torno a dos posibilidades, la aplicación de la norma de conflicto de sucesiones o la aplicación de la norma de conflicto prevista para las donaciones $^{212}$.

Como decíamos, en los casos en los que el sistema de DIPr no menciona solución alguna para los pactos sucesorios la duda sobre qué norma de conflicto debe aplicarse se suele circunscribir, dada la doble naturaleza contractual y sucesoria que ostentan estas figuras, a una calificación sucesoria o un negocio (contractual). El operador jurídico se debate entonces entre la aplicación de la norma de conflicto de sucesiones y la aplicación de la norma de conflicto de contratos o, en su caso, donaciones, como hemos señalado en relación con el tema del pacto de familia italiano. Se trata de típicas figuras híbridas y con un alto grado de variedad sobre las que la calificación es una tarea que puede ser compleja en ausencia de previsión específica ${ }^{213}$.

\footnotetext{
${ }^{211}$ Como ya hemos tenido ocasión de ver en el capítulo I, el pacto de familia se introdujo en el Derecho italiano como una derogación de la prohibición de los pactos sucesorios recogida en el art. $458 \mathrm{CCit}$, lo que llevó a pensar en un principio que se trataba de un pacto sucesorio; sin embargo, la mayor parte de la doctrina italiana entiende hoy día que el pacto de familia no es un verdadero pacto sucesorio.

${ }^{212}$ Vid. D. DAMASCELLi (2008), p. 90 y ss.

${ }^{213}$ Hemos de recordar aquí que hemos excluido de nuestro objeto de estudio, por no considerarlos pactos sucesorios, los pactos sobre herencia de tercero Por la calificación contractual de los pactos sobre herencia de tercero, vid., A. MARín LóPEZ (1957), p. 126 y p. 130.
} 
Ante la falta de previsión de solución para los pactos sucesorios en las normas de DIPr el siguiente paso es examinar qué dicen los tribunales al respecto y si existe una jurisprudencia consolidada sobre la calificación de los pactos sucesorios, así como estudiar las posiciones doctrinales.

\section{El antiguo art. 10.2 CC español}

\subsection{La defensa de una calificación contractual}

El actual sistema de DIPr español hace referencia expresa a los pactos sucesorios en la norma de conflicto de sucesiones, el art. 9.8 CC. Pero esto no siempre ha sido así; durante largo tiempo el ordenamiento jurídico español no contenía mención alguna a los pactos sucesorios entre sus normas de DIPr. A diferencia del actual art. 9.8 CC, su antecedente, el antiguo art. 10.2 CC, nada disponía sobre los pactos sucesorios, omisión que, por otro lado, no deja de ser llamativa no sólo porque se trate de una forma de vocación de la herencia conocida en países próximos de nuestro entorno, sino, muy fundamentalmente, porque los propios Derechos civiles forales ya admitían y regulaban estas figuras $^{214}$. El antiguo art. 10.2 CC señalaba que

"las sucesiones legítimas y testamentarias, asi respecto al orden de suceder como a la cuantía de los derechos sucesorios y a la validez intrínseca de sus disposiciones, se regularán por la ley nacional de la persona de cuya sucesión se trate, cualesquiera que sean la naturaleza de los bienes y el país donde se encuentren".

La referencia expresa, y única, a la sucesión legítima y testamentaria en el art. 10.2 CC suscitó la duda entre la doctrina española en torno al tratamiento que debía darse a los pactos sucesorios. No obstante, debemos ya adelantar desde este momento, que la duda y el tratamiento no fueron ni monográficos ni profundos; que los pactos sucesorios no fueron objeto de especial atención por la doctrina de la época que, como norma general, se limitaba a realizar una breve referencia a la sucesión contractual al hilo de un análisis más profundo y general de las sucesiones internacionales en España.

${ }^{214}$ Vid., A.L. Calvo CaravaCA, (1991), p. 547. 
La reacción de la doctrina española ante la ausencia de referencia alguna a los pactos sucesorios en el sistema de DIPr dio lugar a dos debates. En primer lugar, entre las escuetas referencias a la sucesión contractual se solía encontrar una consideración sobre los pactos sucesorios y el orden público. En segundo lugar, al no haber una norma de conflicto en la que se incluyeran los pactos sucesorios, la doctrina se planteó cuál debía ser la calificación de estas figuras.

La tradicional prohibición general de los pactos sucesorios recogida en el art. 1271.2 CC, junto con la ausencia de referencia alguna a los mismos en el sistema de DIPr español, condujo a algún autor a plantearse la posible contrariedad de los pactos sucesorios con el orden público español. A favor de la contrariedad de los pactos sucesorios con el orden público español se mostró LASALA LLANAS; según este autor, la prohibición de tales figuras recogida en el ordenamiento jurídico español, léase CC en una tópica visión reduccionista de la pluralidad jurídica existente en España, no podía quedar sin efecto por la celebración de pactos sucesorios en el extranjero. Para ello, se basó en dos sentencias del TS de principios de siglo, en las que se trataba de casos que afectaban a pactos sucesorios pero en el tráfico interno. La primera de ellas en el tiempo es la STS de 3 de julio de 1902, en la que se invalidaba la renuncia anticipada a una sucesión. A lo largo de la sentencia, el TS se refiere a las leyes que regulan la sucesión como de orden público y sanciona la imposibilidad de su derogación a través de un convenio entre particulares. Respecto de los pactos sucesorios en concreto, se recuerda que su prohibición se debe a razones de moralidad; esta última razón también es reiterada en la segunda de las sentencias en las que se basa LASALA LLANAS para fundamentar la contrariedad de los pactos sucesorios con el orden público español, la STS de 20 de noviembre de 1915. Esta centra las críticas a los pactos sucesorios en el hecho de que supongan una derogación del principio de libre revocabilidad de las disposiciones de última voluntad $^{215}$. Por su parte, VERPLAETSE era partidario de entender que la prohibición de los pactos sucesorios era una cuestión de orden público, por razones morales y sociales concretadas en el principio de la libre revocabilidad de

${ }^{215}$ Vid. M. De LASALA LlanAs, (1933), pp. 250 y ss. 
las disposiciones testamentarias. Entendía este autor que se trata de una cuestión de orden público interno que debía prevalecer en aquellos casos en los que la relación internacional implicara un conflicto entre la ley nacional española, aplicable a los españoles, y la ley del lugar de situación o del domicilio; sin embargo, entendía que el orden público debía ser atenuado y, por tanto, no debía entrar en juego cuando se tratara de sucesiones de extranjeros ${ }^{216}$.

Hay que decir, no obstante, que la mayor parte de la doctrina, si bien se planteaba esa posible contrariedad, no entendía que los pactos sucesorios fueran contrarios al orden público. Para sostener esta postura se alegaba, con carácter general, que el propio CC contenía verdaderas excepciones a tal prohibición y, con una visión de conjunto mucho más atenta con la situación jurídica en España, que los Derechos forales españoles preveían en sus legislaciones la posibilidad de otorgar pactos sucesorios ${ }^{217}$. Obviamente, este sector estaba más certero en la apreciación de la no contrariedad en sí misma considerada de los pactos sucesorios con el orden público español. Con un concepto de orden público no centralista ni reduccionista montado alrededor del CC, puesto que, en materia de sucesiones, la enorme variedad regulatoria que se desprendía de los entonces derechos forales y se sigue desprendiendo de los hoy Derechos civiles españoles impedía e impide un orden público español amplio y exigente, no sólo en relación con los pactos sucesorios, sino también en relación con otros temas delicados, como puedan ser las legítimas, el orden de la sucesión intestada u otros.

El segundo de los debates que tuvo lugar en la doctrina se refería a qué calificación debía mantenerse de los pactos sucesorios ${ }^{218}$. Una interpretación literal del artículo 10.2 CC conducía a excluir a los pactos sucesorios del ámbito de aplicación de la norma de conflicto sobre ley aplicable a las sucesiones. En tal caso, el art. 10.2 sólo designaría la ley aplicable a los testamentos y a la sucesión $a b$ intestato, lo que, por otro lado, se adecuaba a las formas de vocación recogidas

\footnotetext{
${ }^{216}$ Vid. J. G. VERPLAETSE, (1954), p. 515.

${ }^{217}$ Vid., W. GoldSCHMidt (1954), pp. 350 y ss.; A. MARÍn LÓPEZ (1957), pp. 129 y ss.; A. MiajA DE LA MuElA (1967), p. 312. J.A. TOMÁS ORTIZ DE LA TORRE (1975), p. 755.

218 Obviamente LASALA LLANAS no llegó a cuestionarse la calificación de los pactos sucesorios, pues se limitó a señalar la contrariedad de los mismos con el orden público.
} 
en el art. $658 \mathrm{CC}^{219}$. Así se abría paso a la duda en torno a la calificación sucesoria o contractual de los pactos sucesorios.

Con independencia de que la mayor parte de la doctrina no siguió esta opción, la calificación contractual de los pactos sucesorios tuvo su hueco entre la doctrina española más reputada. Fue MiAJA DE LA MuEla quien, si bien de una forma tímida, pareció inclinarse por una calificación contractual de los pactos sucesorios; dicho autor se ciñe a la letra del art. 10.2 CC para hacer una interpretación simple del mismo y concluir que los pactos sucesorios son figuras extrañas, si no al concepto de sucesión, al menos a su extensión en la norma de conflicto de sucesiones. Según este autor, la delación contractual quedaba fuera del la norma de conflicto del art. 10.2 CC, donde sólo tenían cabida las sucesiones legítimas y las testamentarias. Opta, en definitiva, por darle una calificación contractual a los pactos sucesorios, de tal forma que era la autonomía de la voluntad, expresa o tácita, la que podía llevar a una ley extranjera que admitiera la sucesión contractual ${ }^{220}$.

La calificación contractual de los pactos sucesorios tuvo, por tanto, en España una acogida prácticamente marginal en número pero relevante en la persona de su sustento, el Profesor MIAJA DE LA MUELA. En todo caso, la mayor parte de la doctrina entendía que, pese a que el art. 10.2 CC se refiriera únicamente a la sucesión legítima y a la sucesión testamentaria, los pactos sucesorios debían calificarse dentro de la norma de conflicto de sucesiones ${ }^{221}$. El problema fue superado, como vamos a ver, con la reforma del Título Preliminar del CC y la adopción del actual art. 9.8 CC.

\footnotetext{
${ }^{219} \mathrm{El}$ art. $658 \mathrm{CC}$ recoge las formas de vocación admitidas en Derecho común español y dispone, para lo que aquí nos interesa que "la sucesión se defiere por la voluntad del hombre manifestada en testamento y, a falta de éste, por disposición de la Ley. La primera se llama testamentaria, y la segunda legítima". Dicho artículo es uno a los que se refiere la doctrina civilista para defender la prohibición de los pactos sucesorios en el CC.

${ }^{220}$ Vid. en varias ediciones, A. MiAJA DE LA Muela, (1967), p. 312; A. Miaja DE la Muela (1955), p. 297.

${ }^{221}$ Vid. infra 2.2
} 


\subsection{La defensa de una calificación sucesoria}

Como acabamos de señalar, casi la totalidad de la doctrina española defendió la inclusión de los pactos sucesorios dentro del ámbito de aplicación de la norma de conflicto de sucesiones. Pese a que el art. 10.2 CC se refería únicamente a la sucesión testamentaria y legítima, la doctrina defendió una calificación sucesoria de los pactos sucesorios, señalando que sería la ley nacional del decuius la que determinaría si se admiten estas figuras y en qué términos ${ }^{222}$.

De manera explícita el profesor VERPLAETSE distingue entre las disposiciones otorgadas a través de pactos sucesorios y las obligaciones contractuales. De hecho, según VERPLAETSE el pacto de institución (de heredero) es más un acto de última voluntad que un contrato; no obstante, la calificación del pacto de institución como acto de última voluntad tampoco es la más acertada, en cuanto que el carácter unilateralmente irrevocable de tales disposiciones no garantiza que se trate de las últimas voluntades del causante ${ }^{223}$. En todo caso, tal calificación lleva a este autor a aplicar el estatuto sucesorio a los pactos sucesorios $^{224}$.

Por su parte, el profesor GoLDSCHMIDT distinguió entre la capacidad para celebrar los pactos sucesorios y la licitud y requisitos de validez del contrato. Así, mientras la capacidad se determinaba por la ley nacional del causante en el momento del otorgamiento del pacto sucesorio, su licitud, validez y efectos se regían por la ley de la nacionalidad del causante en el momento del fallecimiento $^{225}$.

Debemos destacar la postura de GonZÁLEZ CAMPOS, quien no sólo abogó por una calificación sucesoria de los pactos sucesorios, sino que dio un paso más $\mathrm{y}$, teniendo en cuenta las particularidades y necesidades conflictuales de este tipo

\footnotetext{
${ }^{222}$ Vid., A. MARÍN LÓPEZ, (1957), p. 129 y ss.; J.D. GONZÁLEZ CAMPOS (1971), p. 240 citado por TOMÁs ORTIZ DE LA TORRE (1975), p. 756; J.A. TOMÁs ORTIZ DE LA TORRE (1973), p. 557. J.G. VERPLAETSE, (1954), p. 500 y p. 514; W. GOLDSCHMIDT (1954), p. 531.

${ }^{223}$ Se evita la calificación de los pactos sucesorios como disposiciones de última voluntad.

${ }^{224}$ J.G. VERPLAETSE (1954), p. 500.

${ }^{225}$ W. GOLDSCHMIDT (1954), p. 531.
} 
de pactos sucesorios, determinó que la ley aplicable debía ser la de la nacionalidad del causante determinada en el momento del otorgamiento del pacto sucesorio y no en el momento del fallecimiento ${ }^{226}$.

\subsection{La superación del problema: el actual art. $9.8 \mathrm{CC}$}

La situación cambió radicalmente, al menos desde el punto de vista de la regla positiva, con la reforma del Título Preliminar del CC que tuvo lugar en el año $1974^{227} \mathrm{y}$, en lo que a la regulación de las sucesiones internacionales se refiere, supuso un gran avance con respecto de la normativa anterior y dio solución al problema general de la calificación de los pactos sucesorios al establecer una regla específica que tan sólo exigía y exige la propia calificación de la institución como pacto sucesorio o no.

Como se sabe, la Ley de Bases estuvo precedida de varios trabajos que dieron lugar a propuestas de modificación del Título Preliminar que también se ocuparon de las normas de DIPr en general y de la norma de conflicto de sucesiones en particular. El primero de ellos fue el conocido como Proyecto Yanguas del año 1944, que no aportó novedad alguna respecto de los pactos sucesorios $^{228}$; dicho Proyecto reservaba el art. 8.4 para la determinación de la ley aplicable a las sucesiones y se limitaba a reproducir el supuesto de hecho del en aquel entonces vigente art. 10.2 CC, al referirse a las "sucesiones legítimas y testamentarias". La segunda propuesta articulada fue la contenida en el Proyecto Trías del año $1962^{229}$, que recogía la norma de conflicto de sucesiones en el art. 9. Fue en este Proyecto donde por primera vez apareció el supuesto de hecho que tiene el actual art. 9.8 CC. En efecto, en ese momento se cambia la dicción “sucesiones legítimas y testamentarias" por la más amplia de "sucesión por causa de muerte".

\footnotetext{
${ }^{226}$ Le sigue, J.A. TOMÁs ORTIZ DE LA TORRE (1975), p. 756.

${ }^{227}$ La reforma se recogió en la Ley 3/1973, de 17 de marzo, de Bases para la Modificación del Título Preliminar del Código Civil, Aranzadi-Westlaw, RCL\1973\498.

${ }^{228}$ Vid., Anteproyecto de reforma del Código Civil aprobado por el pleno de la Comisión general de Codificación en 25 de enero de 1944, que se puede consultar en M. Aguilar NAVARRO ET ALT. (1970), pp. 45 y ss.

${ }^{229}$ Vid., Proyecto de ley de reforma del título preliminar del Código Civil de 14 de noviembre de 1962, que se puede consultar en M. Aguilar NAVARRO ET ALT. (1970), pp. 47 y ss.
} 
El cambio de la enumeración recogida en el art. 10.2 CC por la expresión genérica de "sucesión por causa de muerte" es una de las diferencias más importantes entre el actual art. 9.8 CC y su precedente y conlleva una formal ampliación del ámbito de aplicación de la norma de conflicto de sucesiones ${ }^{230}$. Este supuesto de hecho amplio permite acoger ya sin lugar a dudas todo tipo de sucesión más allá de la legítima y la testamentaria. Esta ampliación del supuesto de hecho ya habría sido una razón suficiente para defender o, mejor, reafirmar una calificación sucesoria, puesto que el argumento positivo que motivaba la calificación contractual del profesor Miaja de la Muela habría perdido su soporte. No obstante, y para que la cuestión quede fuera de toda duda, el propio art. 9.8 CC, a diferencia de los proyectos de modificación del Título Preliminar, hace referencia expresa a los pactos sucesorios, quedando el problema de la calificación de los pactos definitivamente superado ${ }^{231} \mathrm{o}$, en todo caso, derivado a la interpretación del concepto propio de "pacto sucesorio". Obviamente no es descartable que sigan surgiendo problemas sobre la ley aplicable a un determinado tipo de pacto sucesorio, pero ya en un contexto distinto: en el de decidir si es o no pacto sucesorio a los efectos de lo prescrito por el art. 9.8 CC.

Parte de la doctrina entendió que la inclusión de una referencia expresa a los pactos sucesorios en el art. 9.8 CC se debía, al menos en un principio, a la necesidad de prever una solución a los conflictos interregionales que afectaran a estas figuras $^{232}$. Para ello se basaban en lo que disponía el art. $16.3^{\circ}$ b) del Anteproyecto de Reforma de 1962; dicho artículo recogía las especialidades que se debían tener en cuenta a la hora de resolver los conflictos derivados de de la plurilegislación española y en su apartado $3^{\circ}$ b) se preveía la posibilidad de que las disposiciones testamentarias vigentes otorgadas bajo el imperio de una ley personal anterior conserven su eficacia en todo lo que no afecte a los derechos de

\footnotetext{
${ }^{230}$ Sobre la ampliación del ámbito de aplicación de la ley nacional del causante en el art. 9.8, vid., M. Aguilar Benítez de Lugo, (1978), p. 190; también, E. Castellanos Ruiz, (2001), p. 144.

231 Vid. A. Miaja de la muela (1967), p. 326; M. DE Angulo, (1977), p. 488; M. Aguilar BENÍTEZ DE LUGO, (1978);

${ }^{232}$ A. Miaja De la Muela (1975), p. 184; E. PÉrez Vera (1980), p. 258.
} 
legitimarios $^{233}$. Esta idea es la que se recoge en el actual art. 9.8 CC para los testamentos y las disposiciones contenidas en pactos sucesorios. No es posible negar, sino todo lo contrario, la importante influencia de los problemas de Derecho intrregional en la nueva configuración del art. 9.8 CC surgido de la reforma del Título Preliminar en 1974. No obstante, una vez que los pactos sucesorios se incluían en una norma cuya función primera era dar solución a los conflictos de leyes externos (con independencia de su aplicación analógica para la resolución de los conflictos interregionales como opción ordenada por el legislador interno), no cabía duda de que, aunque en un principio sólo se procurara la solución de una especialidad de Derecho interregional, tal artículo se aplicaría a conflictos de leyes que afectaran a pactos sucesorios con elemento extranjero $^{234}$. Postura ésta que quedaría confirmada con la STS de 4 de octubre de 1982 en la que nuestro Alto Tribunal aplica el art. 9.8 para resolver un caso de un pacto sucesorio celebrado en el extranjero ${ }^{235}$.

\section{La situación de los países anglosajones}

\subsection{El desconocimiento de los pactos sucesorios}

La inclusión de los pactos sucesorios dentro del ámbito de aplicación del art. 9.8 CC no soluciona definitivamente el problema de calificación, puesto que como hemos adelantado aún queda interpretar qué se entiende por pactos sucesorios. A este respecto resulta indispensable que nos detengamos en la situación de los sistemas anglosajones, que, como ya hemos visto, desconocen los pactos sucesorios tal y como nosotros los conocemos, pero que, a la vez, conocen de otras figuras próximas a los pactos sucesorios, que podrían considerarse como tales a los efectos de la aplicación de las normas de conflicto que prevén

\footnotetext{
${ }^{233}$ El art, 16.3 b) disponía: En todo cambio de vecindad civil se observarán estas reglas: b) Las disposiciones testamentarias vigentes ordenadas con arreglo a la ley de la vecindad civil anterior conservarán su eficacia en la parte que no afecta a los derechos legitimarios establecidos por la ley que regula la sucesión en el momento del fallecimiento del causante. La preterición sobrevenida no anulará la anterior institución de heredero o el testamento, según sea el ordenamiento jurídico de que se trate, sin perjuicio de las reducciones que proceden.

${ }^{234}$ De nuevo, A. Miaja De la Muela (1975), p. 184; E. Pérez Vera (1980), p. 258.

${ }^{235}$ STS de 4 de octubre de 1982, RJ\198215537
} 
especificas soluciones para los pactos. Los sistemas anglosajones plantean dos problemas de calificación que pueden relacionarse con los pactos sucesorios.

El primero es aquel que se le puede presentar a un juez anglosajón que conoce de un caso que afecta a un pacto sucesorio típico de un sistema extranjero que los conoce ${ }^{236}$. Dicho problema se plantea en los términos de adoptar una calificación contractual o sucesoria de estas figuras: ellos no tienen norma específica para los pactos sucesorios. Respecto a la situación en Inglaterra la doctrina señala que los pactos sucesorios no son disposiciones de última voluntad y que en dicho sistema las únicas disposiciones de última voluntad conocidas son los testamentos ${ }^{237}$; la propia doctrina se cuestiona la posibilidad de que la eficacia de un pacto sucesorio, en lo que concierne a bienes inmuebles, se pueda regir por la lex rei sitae, esto es, por la norma de conflicto para las sucesiones inmobiliarias $^{238}$. Junto a las tímidas posiciones doctrinales al respecto, debemos traer aquí a colación la drástica respuesta al Libro Verde sobre sucesiones y testamentos que en su día elaboró el gobierno británico; a la pregunta de cuál debe ser la ley aplicable a la validez de los pactos sucesorios, el gobierno británico contesta que debe ser la lex contractus la aplicable a tales figuras que, por tanto, deben quedar fuera del ámbito de aplicación del Reglamento de sucesiones ${ }^{239}$.

Esta opción no se ve comprometida por el hecho de que la ley aplicable a las obligaciones contractuales esté unificada en un nivel europeo y por la circunstancia de que el Reglamento Roma I no incluya -muy probablementedentro de su ámbito de aplicación a figuras próximas a los pactos sucesorios. Ni

${ }^{236}$ G. MILLER (2000), p. 13, donde el autor pone de manifiesto las dificultades que puede plantear una calificación ex lege fori cuando se trata de casos que surgen de figuras desconocidas para el foro, como lo que ocurre en Inglaterra con los pactos sucesorios.

${ }^{237}$ F. ODERSKY (2008), p. 747; D. HEINRICH (1984), p. 55, núm. 160.

238 D. HEINRICH (1984), p. 10, núm. 30. De igual forma, la doctrina se plantea la aplicación de la Wills Act de 1963 a los pactos sucesorios; a favor, F. ODERSKY (2008), p. 723, núm. 11; en duda, D. HEINRICH (1984), p. 10, núm. 30. Vid. también la nota de la Oficina Permanente "Contracts of successión", de 11 de agosto de 1987, donde se dice que en common law no se aplica a los pactos sucesorios la ley sucesoria, sino la ley del contrato, la ley del régimen económico matrimonial o la ley del trust, CONFÉRENCE DE LA HAYE DE DROIT INTERNATIONAL PRIVÉ (1990), pp. 223-331, esp. p. 230 .

239 Las contestaciones al Libro Verde del gobierno de Reino Unido se pueden consultar en http://ec.europa.eu/justice/news/consulting_public/successions/contributions/contribution_uk_app b_en.pdf (última consulta realizada el 26 de septiembre de 2011). 
tampoco que en términos de sistema no quepa entender que existe solapamiento entre el ámbito de aplicación del Reglamento Roma I y el Reglamento de sucesiones. En primer lugar porque ninguno de ellos evita la posibilidad de problemas de calificación $y$, en segundo término, porque incluso si considerásemos que una concreta figura no entra en el ámbito de aplicación de ninguno de ellos, ahí está o bien la normativa autónoma o, incluso, la aplicación analógica de cualquiera de los dos.

El segundo problema de calificación se plantea respecto de esas otras figuras próximas a los pactos sucesorios: los pactos para hacer testamento y la renuncia de derechos del cónyuge. Vamos a ver a continuación cómo tratan los jueces anglosajones estas figuras, así como el tratamiento que, a nuestro juicio, se les debería dar desde el punto de vista del Reglamento de sucesiones.

\subsection{Figuras análogas (próximas) a los pactos sucesorios}

\subsubsection{Los pactos para hacer testamento}

Tal y como hemos visto en el capítulo I, en el mundo anglosajón existen otro tipo de contratos que tienen aspectos sucesorios pero que no son propiamente pactos sucesorios tal y como nosotros los entendemos. Se trata de unos acuerdos en los que el testador promete realizar una disposición testamentaria o abstenerse de hacerla, así como modificar o no alterar un testamento. Parece ser que, al menos en principio, estos sistemas conciben este tipo de acuerdos desde un punto de vista estrictamente contractual.

En EEUU los tribunales han conocido de casos que conciernen a este tipo de contratos con aspectos sucesorios y que implican un conflicto de leyes. No obstante, ya podemos adelantar aquí que la jurisprudencia al respecto no es ni representativa en términos cuantitativos, ni uniforme. Por un lado, sin llegar a defender una calificación sucesoria de este tipo de pactos, existe una jurisprudencia tendente a tomar en consideración de uno u otro modo los aspectos sucesorios de los contratos que nos ocupan. Pero, por otro lado, también existe otra tendencia centrada completamente en el aspecto contractual de estos acuerdos. 
Como ejemplos de la primera visión, ya en el año 1895, un tribunal de Massachusetts conoció del caso Emery v. Burbank que concernía a un conflicto de leyes que afectaba a un contrato para hacer testamento ${ }^{240}$. En este caso se trataba de una promesa oral hecha por la testadora al demandante en Maine, en la que le prometía dejar por testamento todas sus propiedades si le prestaba las atenciones y cuidados necesarios hasta el momento de su fallecimiento. El tribunal rehúsa la aplicación de la ley del contrato y entiende que el Statute of Frauds del foro contenía una política fundamental que debía extenderse, al menos a los contratos realizados por testadores de Massachusetts ${ }^{241}$. En efecto, el mismo resultado, la aplicación de la ley de Massachusetts, se podría haber conseguido de un modo mucho más fácil: a través de una calificación sucesoria del contrato para hacer testamento $^{242}$. De hecho el propio tribunal valora esta posibilidad, pues señala que la ley del domicilio del testador es la ley del testamento y que un contrato para hacer testamento significa un testamento efectivo y, por eso, válido conforme a la ley del domicilio. Sin embargo, seguidamente rechaza el considerar que la validez de los contratos para hacer testamento deba determinarse por la ley del domicilio del testador, por el hecho de que una postura tal implicaría dejar muchos de estos contratos en una situación de incertidumbre en cuanto a su validez hasta el momento del fallecimiento del testador, puesto que éste puede cambiar de domicilio cuantas veces quiera. Dicho de otro modo, razones de seguridad jurídica llevaron al tribunal a rechazar una calificación sucesoria de los contratos para hacer testamento. Reténgase que el razonamiento, más que conceptual, fue funcional. No es tanto la naturaleza jurídica de este pacto lo que cuenta, como los resultados de aplicar una ley u otra respecto de la garantía de seguridad y previsibilidad jurídica para las partes. Este tipo de preocupaciones reales son extensibles sin ambages a todas las soluciones en las que la ley sucesoria se localice en el momento de la muerte y se vincule a la persona del causante, como es una constante en el DIPr comparado. La tensión entre una visión contractual,

\footnotetext{
${ }^{240}$ North Eastern Reporter, vol. 39, 1895, pp. 1026 y ss.

${ }^{241}$ Lo que hace el Tribunal es proteger la herencia al declarar que el contrato realizado en Maine no era ejecutable en Massachusetts en aplicación de una policy que exige que ese tipo de contratos sean otorgados por escrito, con el fundamental de evitar el fraude y el perjurio.

${ }^{242}$ E.F. SCOLES/P.HAY/P.J. BORCHERS/S.C. SYMEONIDES (2004), p. 991, npp. 4.
} 
en la que pesa la seguridad jurídica y la previsibilidad, y una visión sucesoria, en la que predomina la localización más idónea en torno a la persona del causante, es una nota característica de las soluciones de ley aplicable de difícil solución.

Otro de los asuntos en los que también se hace hincapié en el aspecto sucesorio de los contratos para hacer testamento es el caso Rubin v. Irving Trust Co., sustanciado ante la Corte de Apelaciones de Nueva York ${ }^{243}$. En este caso se planteaba un conflicto de leyes en torno a un contrato oral para no alterar testamento, realizado en Florida y válido conforme a la ley de este Estado, aunque inválido conforme a la ley de Nueva York, ley del foro y ley del último domicilio del testador. A lo largo de la sentencia son varias las consideraciones que la Corte realiza en torno al aspecto sucesorio de estos contratos. Cabe destacar que, en opinión de la Corte, el contrato para hacer o abstenerse de hacer una alteración de un testamento no es un contrato ordinario, poniendo de manifiesto que, por la naturaleza, del mismo las pretensiones en él basadas se dan tras el fallecimiento del testador, lo que supone una gran dificultad en el litigio. Pero más significativa aún es la declaración de que para dictar la sentencia en torno a este caso, el tribunal no debe estar guiado por las mismas consideraciones que le llevan a la aplicación del Statute of Frauds a los contratos ordinarios o comerciales. Finalmente, el tribunal de Nueva York acude a la "center of gravity theory", que le lleva a considerar la aplicación de la ley del Estado con el que el contrato tenga los vínculos más estrechos; en el caso, se trataba de una promesa realizada por un testador domiciliado en Nueva York para no alterar un testamento y la pretensión jurídica se había realizado contra una herencia que estaba siendo administrada en Nueva York; mientras que Florida sólo aparecía como la ley del lugar donde se había contratado. Esto lleva al tribunal a aplicar la ley de Nueva York y, por tanto, declarar inválido el pacto objeto del litigio por no constar por escrito.

Sin embargo, como ya hemos adelantado, existe también jurisprudencia sobre los pactos para hacer testamento en la que los tribunales obvian la toma en consideración de cualquier aspecto sucesorio. Un ejemplo de esta tendencia lo encontramos en el caso Frey v. Estate of Sargent que tuvo lugar ante la Corte de

\footnotetext{
${ }^{243}$ North Eastern Reporter, 2d Series, vol. 113, 1953, pp. 424 y ss.
} 
Apelación Civil de Texas ${ }^{244}$. En este caso se trataba de determinar el alcance de un pacto prenupcial en contemplación del matrimonio celebrado en Oklahoma a través del cual el marido acepta legar una cantidad de dinero a su esposa si ésta le presta la atención y cuidados necesarios en su casa de Texas; el marido efectuó efectivamente un testamento legando tal cantidad a su esposa, pero ésta fallece un año después del matrimonio y el marido, bajo el amparo de la ley de Texas, que dispone que en tal caso la obligación de legar expira, otorga nuevo testamento revocando el anterior y obviando cualquier legado a su esposa ya fallecida. Los herederos de la esposa fallecida, descendientes fruto de un matrimonio anterior al celebrado con el causante, demandan a la herencia de éste para pedir la ejecución del contrato. El tribunal se limita a señalar que el contrato debe regirse por la ley del Estado en el que sus términos deben ser cumplidos y, por tanto, aplica sencillamente la ley de Texas como ley del lugar de ejecución.

Otro ejemplo de esta tendencia lo constituye el caso Bernkrant v. Fowler, ante la Corte Suprema de California ${ }^{245}$. El tribunal conoce de una acción contra la herencia de un causante domiciliado en California basada en un pacto oral, realizado en Nevada y válido conforme a la ley de dicho Estado, en el que el causante acuerda perdonar una deuda a través de testamento para el momento de su fallecimiento. El tribunal se plantea la aplicación o bien de la ley de Nevada o bien de la ley californiana, ésta última con el fin de proteger la herencia de un causante domiciliado en este Estado. Finalmente, el tribunal se centra en la protección de las expectativas de las partes, lo que le lleva a la aplicación de la ley de Nevada y a la ejecución del contrato que no había sido cumplido por el testador $^{246}$.

\footnotetext{
${ }^{244}$ South Western Reporter, 2d Series, vol. 533, pp. 142 y ss.

${ }^{245}$ West's California Reporter, vol. 12, 1961, pp. 266 y ss.

${ }^{246}$ Esta sentencia adopta así un criterio distinto al seguido en apelación, donde la District Court of Appeal de California aplicó el Statute of Frauds de California, en protección de una herencia californiana, West's California Reporter, vol. 8, 1961, pp. 326 y ss. Algunos autores han señalado que la sentencia Bernkrant v. Fowler no se riñe con otras sentencias en las que se acaba aplicando de uno u otro modo la ley del último domicilio del causante, como el caso de Emery v. Burbank o Rubin v. Irving Trust Co., porque en aquella el objetivo del contrato no era realizar una disposición testamentaria, sino que el contrato contenía un objetivo meramente comercial, vid., E.F. SCOLES/P.HAY/P.J. BORCHERS/S.C. SYMEONIDES (2004), p. 996 y ss.
} 
En definitiva, de la jurisprudencia de los tribunales de EEUU, pese a no ser uniforme, podemos deducir un dato: no se abandona la calificación contractual de estas figuras, aunque bien es cierto que es de notar, con carácter general, una atención con una repercusión más o menos importante, a los aspectos sucesorios de los contratos para hacer testamento, fundamentalmente en observación de una política de protección de las herencias de causantes domiciliados en el foro ${ }^{247}$.

Resulta sumamente significativo que las propias autoridades, enfrentadas a la calificación de una figura híbrida, opten por razonamientos también híbridos, sin perjuicio de la solución final. Solución que, en virtud de la importante dosis de flexibilidad de los sistemas de DIPr implicados, no necesita definir, calificar o clasificar. Basta con elegir la ley que en mayor medida sea capaz de responder a todos los intereses presentes o, al menos, a los intereses que en cada momento aparecen al juzgador como los más dignos de tutela. Y estos intereses son comunes a los que rodean a los pactos sucesorios tal cual los conocemos en gran parte de los países europeos.

Ahora bien, la pregunta en torno a la calificación de estas figuras también la debemos formular desde la perspectiva de un juez español o, en vistas a la puesta en aplicación del Reglamento de sucesiones, de un juez europeo. ¿Qué norma de conflicto aplicaría un juez español que conoce de un caso con elemento extranjero que afecta a un pacto en el que se promete realizar una disposición testamentaria? ¿Sería aplicable el Reglamento de sucesiones? Y, en concreto, ¿se aplicaría la norma específica prevista para los pactos sucesorios? En caso contrario, ¿la calificación será sucesoria y se reconducirá al 9.8 CC? O será distinta y habrá que buscar en otro lugar. Como hemos adelantado a propósito de temas próximos, la entrada en escena de un Reglamento comunitario hace que las alternativas clásicas de calificación, sucesoria o contractual, o sucesoria o no sucesoria, hayan de ser matizadas. Cabe una calificación sucesoria y considerar el supuesto excluido de un Reglamento que regule la ley aplicable a las sucesiones (del Reglamento en nuestro caso); y habría que buscar la ley aplicable en otra

\footnotetext{
${ }^{247}$ A favor de una calificación contractual de estas figuras, vid. P. MCCABE/S.K. JoHnSON (2010), p. 746.
} 
normativa sucesoria (por ejemplo, en el art. 9.8 CC si consideramos, como es plausible, que su supuesto de hecho pueda ser más amplio que el ámbito de aplicación material del Reglamento). Puede caber también una calificación sucesoria perfectamente enmarcada en el ámbito de aplicación del Reglamento y la necesidad de subcalificar dentro de las distintas figuras que éste regula. La calificación, como puso de manifiesto el Prof. Álvarez González, no se realiza en el vacío, en abstracto, sino a la luz de las concretas soluciones regulatorias que se tienen como alternativas ${ }^{248}$. Obviamente, tampoco la calificación que ahora nos ocupa parte de infinitas posibilidades: se trata claramente de pactos o contratos, y lo que se exige es saber si son pactos sucesorios o no.

La cuestión es pues, en primer lugar, determinar si los contratos para hacer testamento, tal cual están concebidos en el derecho anglosajón, pueden ser considerados pactos sucesorios a los efectos del Reglamento de sucesiones. Para ello se ha de acudir, en primer lugar, a la definición que de pacto sucesorio recoge el propio Reglamento. El art. 3.1 b) dispone que se entiende por pacto sucesorio

"todo acuerdo, incluido el resultante de testamentos recíprocos, por el que se confieran, modifiquen o revoquen, con o sin contraprestación, derechos relativos a la sucesión o las sucesiones futuras de una o más personas que sean partes en dicho acuerdo".

De esta definición se deriva que los pactos sucesorios tienen que tener un efecto directo sobre la sucesión del causante, esto es, que tienen que crear, modificar o suprimir por sí solos un derecho sobre la herencia del futuro causante. Este requisito no lo cumplen los contratos para hacer testamento, pues tal y como hemos visto, un contrato en el que el futuro causante se compromete a instituir heredero al otro otorgante en un futuro testamento no crea por sí mismo un derecho sucesorio a favor de éste. Es necesario en todo caso que el causante otorgue un testamento en ese sentido. En segundo lugar, es relevante también tener en cuenta cuáles son las consecuencias del incumplimiento por parte del causante de un contrato para hacer testamento; esta cuestión nos va a corroborar

${ }^{248}$ S. ÁlVAREZ GONZÁLEZ (1995), pp. 869. 
que los contratos para hacer testamento no son asimilables a los pactos sucesorios, puesto que tal y como hemos visto, el incumplimiento por parte del causante no da derecho a una ejecución forzosa, sino a una indemnización por daños y perjuicios o incluso en alguna ocasión ha dado lugar a un cumplimiento in natura, pero siempre configurado como un derecho de crédito contra la herencia, y no como un derecho sucesorio. Dicho de otro modo, un contrato para hacer testamento en el que el futuro causante se compromete a realizar una institución de heredero a favor del otro otorgante de contrato no limita la libertad de disposición mortis causa, elemento esencial, tal y como hemos defendido, de los pactos sucesorios de institución.

Una vez descartada la aplicación de la norma específica prevista para los pactos sucesorios, debemos preguntarnos si existe alguna otra norma en el Reglamento de sucesiones aplicable a los contratos para hacer testamento; o dicho de otro modo, si los contratos para hacer testamento entran dentro del ámbito de aplicación del Reglamento, puesto que aún queda la norma específica para las disposiciones mortis causa distintas de los pactos sucesorios y la norma general de sucesiones. El art. 24 del Reglamento prevé una norma específica para las disposiciones mortis causa distintas de los pactos sucesorios, esto es, para los testamentos, pues tal y como recoge el art. $3.1 \mathrm{~d}$ ) se entiende por disposición mortis causa los testamentos, los testamentos mancomunados y los pactos sucesorios. Descartado que los contratos para hacer testamento sean testamentos sólo queda la norma general. Ahora bien, el Reglamento entiende por sucesión (art. 3.1 a), la sucesión por causa de muerte que abarque cualquier forma de transmisión mortis causa de bienes, derechos y obligaciones; los contratos para hacer testamento no generan por sí solos ninguna forma de transmisión mortis causa de bienes, derechos u obligaciones, con lo que tampoco cabría incluirlos dentro de la norma general de ley aplicable a las sucesiones del Reglamento.

Descartada la aplicación del Reglamento de sucesiones, debemos determinar si estas figuras podrían tener cabida dentro del ámbito de aplicación del art. 9.8 CC; el supuesto de hecho del art. 9.8 $\mathrm{CC}$ incluye a los pactos sucesorios, pero no establece definición alguna de lo que se entiende por estas 
figuras. No obstante, si acudimos a la doctrina española podemos concluir que tampoco entran los pactos para hacer testamento dentro del ámbito de aplicación del art. $9.8 \mathrm{CC}$, puesto que cuando éste habla de pactos sucesorios se refiere, tal y como hemos mantenido desde el principio de este trabajo, a aquellos contratos a través de los cuales se crea, modifica o suprime algún derecho sobre la sucesión de uno de los otorgantes.

Rechazado el carácter sucesorio de los contratos para hacer testamento, habría que comprobar si este tipo de figuras entran dentro del ámbito de aplicación del Reglamento Roma I; en concreto, habría que determinar si los contratos para hacer testamento entran dentro de la exclusión recogida en el art. 1.2. c) del Reglamento, que se refiere, entre otras, a las obligaciones que se deriven de testamentos y sucesiones. En puridad, tal y como hemos visto en el capítulo I, de estos negocios sólo se derivan obligaciones de carácter patrimonial, y no obligaciones de carácter sucesorio, con lo que en una primera aproximación parece que nada impediría incluirlos dentro del ámbito de aplicación del Reglamento Roma I. No obstante, la cuestión es harto dudosa y, en caso contrario, esto es en caso de que estas figuras no tuvieran cabida dentro del ámbito de aplicación del Reglamento Roma I quedaría acudir al art. 10.5 CC.

\subsubsection{La renuncia de derechos del cónyuge}

El otro tipo de pactos conocidos en el mundo anglosajón y que presentan cierta analogía con los pactos sucesorios son aquellos contratos realizados entre cónyuges en los que uno de ellos renuncia a su derecho de elección o right of election. Es habitual que sistemas anglosajones recojan en sus legislaciones esta posibilidad, exigiendo generalmente que la renuncia conste por escrito ${ }^{249}$. Existe un caso en la jurisprudencia estadounidense sobre un acuerdo de renuncia que implica un conflicto de leyes en el que se hace hincapié en los aspectos sucesorios

\footnotetext{
249 Por ejemplo en Florida se recoge esta posibilidad en el art. 732.702 del Probate Code http://www.flsenate.gov/Laws/Statutes/2011/732.702 (última consulta realizada el 28 de septiembre de 2011); en Maine, Revised Statute 18-A \$2-204, http://www.mainelegislature.org/legis/statutes/18-a/title18-Ach2.pdf; o en Dacota Sur de una manera mucho más desarrollada, http://legis.state.sd.us/statutes/DisplayStatute.aspx?Type=Statute $\&$ Statute=29A-2, $\quad$ 29A-2-213 (última consulta realizada el 28 de septiembre de 2011).
} 
de este tipo de pactos. Se trata del caso In re Bulova's Will ${ }^{250}$, en el que el tribunal conoce de un acuerdo a través del cual un cónyuge renunciaba al denominado right of election sobre la herencia del otro. El pacto fue celebrado entre domiciliados en Nueva York, considerando la competencia de la ley neoyorkina aplicable a las herencias de domiciliados en dicho Estado y ante el Vice-cónsul de EEUU en Suiza. Lo cierto es que en primera instancia la Surrogate's Court de Nueva York se centra únicamente en la dimensión contractual del pacto y se limita a señalar que claramente las partes tenían la intención de que se aplicara al contrato la ley de Nueva York, entendiendo que la aplicación de la ley suiza sería un absurdo. Sin embargo, el tribunal que conoce de la apelación, se muestra mucho más sensible a los aspectos sucesorios del pacto en cuestión. Es de destacar la consideración de que el hecho de que se trate de un contrato no implica la aplicación de las normas de conflicto asociadas a las obligaciones contractuales, sino que el tribunal entiende que se debe prestar atención a las relaciones jurídicas afectadas por las disposiciones del acuerdo, en este caso la sucesión del fallecido. Finalmente, el tribunal se sirve de la teoría de agrupación de contactos y aplica la ley de Nueva York para determinar la validez del pacto en cuestión, a excepción de aquello que concierna a propiedades inmobiliarias sitas en Suiza, a las que se le debe aplicar la ley de dicho país ${ }^{251}$.

Como más atrás señalamos en relación con los supuestos estadounidenses analizados en torno a contrato para hacer testamento, la flexibilidad del sistema nos hurta una solución de calificación conceptual (sucesoria, no sucesoria): la técnica de agrupación de contactos es igualmente idónea para ambas. En todo caso, lo que bajo el presente epígrafe nos interesa es qué calificación daría un juez español si tuviera que decidir sobre un conflicto de leyes que afectase a un contrato de renuncia del derecho de elección o de renuncia a otro tipo de derechos que tenga el cónyuge supérstite. La figura nos recuerda a

\footnotetext{
${ }^{250}$ En primera instancia, New York Supplement, 2d Series, vol. 216, 1961, pp. 26 y ss; en apelación, New York Supplement, 2d Series, vol. 220, 1962, pp. 540 y ss.

${ }^{251}$ Para llegar a la conclusión de que la ley suiza también debería ser aplicable a la determinación de la validez del pacto en lo que concierne a propiedades inmobiliarias sitas en dicho país, el tribunal hace referencia al dominio de la lex rei sitae en materia sucesoria y en materia de disposición sobre los inmuebles en general (vid. especialmente, New York Supplement, 2d Series, vol. 220, 1962, p. 545).
} 
los pactos sucesorios de renuncia, tal y como los conocemos nosotros. ¿Cabe considerar este tipo de contratos del derecho anglosajón como pactos sucesorios de renuncia?

La clave de esta cuestión está en la naturaleza jurídica de los derechos a los que se renuncia; en los pactos de renuncia se renuncia se renuncia a un derecho sobre la herencia de otra persona. Así, por ejemplo, tal y como hemos visto en el capítulo I, la finalidad del right of election es evitar que el cónyuge del causante sea desheredado; con carácter general, al igual que en el caso de las legítimas, se trata de mecanismos que pretenden proteger a las personas próximas al causante, en concreto a las personas que dependen del causante en el momento en que éste fallece. Estos mecanismos suponen, en definitiva, que una parte de la herencia se destine a esas personas próximas al causante que merecen la protección; en unas ocasiones son cantidades fijas previstas en la ley, y en otras son cantidades establecidas por el juez en función de las circunstancias.

Es importante tener en cuenta lo dispuesto en el Reglamento de sucesiones sobre esta materia. $\mathrm{El}$ art. $23.2 \mathrm{~h}$ ) dispone que entra dentro del ámbito de aplicación de la ley sucesoria la parte de libre disposición, las legítimas y las demás restricciones a la libertad de disposición mortis causa, así como las reclamaciones que personas próximas al causante puedan tener contra la herencia o los herederos. El Reglamento no limita, por tanto, estos mecanismos a las legítimas, sino que está previendo de manera amplia cualquier reclamación que se pueda hacer contra la herencia del causante. En este contexto, por tanto, nos parece que estos contratos de renuncia anglosajones podrían perfectamente tener cabida dentro del ámbito de aplicación del Reglamento de sucesiones y, por tanto, pueden asimilarse a los pactos sucesorios de renuncia que nosotros manejamos.

\section{4. $\quad$ El sistema italiano anterior a la reforma de $\mathbf{1 9 9 5}$}

Tanto el vigente sistema de DIPr italiano, como su precedente constituyen ejemplos de modelos en los que no se prevé solución expresa para la determinación de la ley aplicable a los pactos sucesorios. Antes de la reforma 
operada por la ley núm. 218 de 31 de mayo de $1995^{252}$, las normas de DIPr se contenían en los arts. 17 y siguientes de las disposiciones preliminares del CCit. El art. 23 recogía la norma de conflicto de sucesiones, en donde se decía que la sucesión por causa de muerte se regula, donde quiera que estén los bienes, por la ley del Estado al cual pertenece en el momento del fallecimiento la persona de cuya sucesión se trata. Se seguía, por tanto, el principio de unidad de la sucesión bajo la aplicación al conjunto de la herencia de la conexión personal de la ley nacional del causante; y se hablaba de sucesión por causa de muerte, sin más especificación. La ley de reforma de 1995 no ha implicado novedad alguna al respecto, por más que la introducción de una solución especial para los pactos sucesorios hubiera sido una opción ${ }^{253}$. La nueva regulación dedica a las sucesiones internacionales los arts. 46 a 50, sin hacer mención alguna a los pactos sucesorios. El art. 46 recoge como supuesto de hecho, al igual que su precedente, la sucesión por causa de muerte.

Ante estas circunstancias la doctrina italiana ya se plantea desde hace años cuál es la calificación pertinente para los pactos sucesorios. Ya podemos adelantar aquí que la mayor parte de los autores italianos abogan por una calificación sucesoria; sin embargo, pese a ser residual, no podemos dejar de señalar la existencia de una posición favorable a la calificación contractual de estas figuras. Estando vigente el régimen anterior, BALLADORE PALLIERI se refirió a estas figuras afirmando que se les aplica la norma prevista para las obligaciones contractuales. Dicho autor distingue entre aquellos acuerdos por los que el heredero llamado dispone de su herencia, cuota o legado, de aquellos otros acuerdos que son verdaderos pactos sucesorios. En esta distinción el mencionado autor señala que es competencia de la ley sucesoria el determinar la posibilidad y

\footnotetext{
${ }^{252}$ Legge 31 maggio 1995 núm. 218 di reforma del sistema italiano di diritto internazionale privato; vid. traducción con nota de N. MARCHAL ESCALONA (1996), pp. 474-500. Sobre esta reforma en general, COMITATO REgIONALE NotARILE LOMBARDO (1996); B. Boschiero (1996); S. Annibale (1997); P. Picone (1998); G. Conetti/S.Tonolo/F. Vismara (2000); F. Pocar (2002); P. MENGOZZI (2002); T. BALlarino (2006); R. Clerici/F. MosCONi/F. POCAR (2009).

${ }^{253}$ Hay quien lamentó la oportunidad perdida por el legislador italiano en la reforma de 1995 de haber incluido una solución expresa de ley aplicable para los pactos sucesorios, teniendo estas figuras una cada vez mayor importancia práctica, vid., P. PICONE (1998), p. 92; también, P. DE CESARI (2001), p. 111.
} 
los requisitos de validez de las disposiciones sobre la herencia que el llamado a la misma realice y concreta que tales acuerdos se realizan en un momento posterior al de la apertura de la sucesión. Por otro lado, se refiere a aquellos otros acuerdos, los pactos sucesorios, realizados antes de la apertura de la sucesión, en los que se contempla el fallecimiento de una persona y la transmisión de los bienes hereditarios como un evento futuro, a los que les otorga una calificación contractual al señalar la aplicación de la ley prevista para las obligaciones contractuales $^{254}$. En concreto, esta calificación llevaría a aplicar el art. 25 de las disposiciones preliminares del CCit, de tal forma que se aplicaría a los pactos sucesorios, sin perjuicio del posible ejercicio de la autonomía de la voluntad de las partes, la ley de la nacionalidad común de los otorgantes o, en su defecto, la ley del lugar de celebración del pacto ${ }^{255}$.

Determinados autores han querido ver también una defensa de la calificación contractual en ciertas consideraciones que la doctrina ha realizado en torno a la ley aplicable a los pactos sucesorios. En concreto, se han citado como defensores de la calificación contractual a P. PiCONE y A. DAví ${ }^{256}$. Sin embargo, tras verificar sus concretas posturas, no estimamos que se pueda derivar una defensa por su parte de la calificación contractual de los pactos sucesorios. Tanto PICONE como DAVí se limitan a poner de relieve la inadaptación de la conexión sucesoria, fijada temporalmente en el momento del fallecimiento del causante, para determinar la ley aplicable a los pactos sucesorios. Crítica, dicho sea de paso, muy razonable y con la que coincidimos. Según dichos autores el interés de estas figuras exige que las partes otorgantes conozcan el régimen y efectos de los pactos sucesorios desde el mismo momento en que son otorgados. En definitiva, las consideraciones de estos autores en torno a la ley aplicable a estas figuras se centran en la inadaptación de una aplicación simple de la ley sucesoria y la

\footnotetext{
${ }^{254}$ G. BALLADORE PALLIERI (1974), p. 268.

${ }^{255}$ E. ViTTA (1992), p. 278. Resulta, cuando menos, llamativa la defensa de soluciones similares por parte de autores coetáneos, como Adolfo Miaja de la Muela y Giorgio Balladore Pallieri. No solo por la calificación contractual del pacto, sino también por la proximidad en la concreta solución a la ley aplicable al contrato.

${ }^{256}$ Se atribuye una defensa de la calificación contractual de los pactos sucesorios a P. PICONE en S. TONOlO (2002), p. 1239 y en G. PERONI (2007), p. 619; y a A. DAVÍ en G. PERONi (2007), p. 619.
} 
necesidad de una solución específica, orientada a la consideración de una ley determinada en el momento en que el pacto es otorgado; pero no creemos que de tal análisis se pueda derivar una defensa de calificación contractual de los pactos sucesorios con su correlativo sometimiento a la norma de conflicto prevista para las obligaciones contractuales ${ }^{257}$.

Descartada, a nuestro juicio, la posición de estos dos autores a favor de una calificación contractual de los pactos sucesorios, sólo nos queda reconocer el marginal mantenimiento de esta postura por el mencionado autor BALLADORE PALLIERI, que solo pudo mantener esta tesis bajo el régimen de DIPr italiano anterior al vigente ${ }^{258}$.

\section{CALIFICACIÓN SUCESORIA: TRATAMIENTO INDIFERENCIADO DE LOS PACTOS SUCESORIOS}

\section{La ignorancia de los pactos sucesorios}

El punto de partida de este tipo de modelos de regulación de pactos sucesorios es común al que hemos visto en el apartado anterior. El sistema de DIPr nada dice sobre los pactos sucesorios, de tal forma que el operador jurídico tiene todo un sistema para buscar la solución de ley aplicable a estas figuras, de donde surge la posibilidad de distintas calificaciones. Vamos a ver cómo a veces la respuesta se encuentra en la jurisprudencia y otras, simplemente, en posiciones doctrinales generalizadas. Ya hemos visto también cómo la gran pregunta en torno a la calificación de estas figuras se reduce a dos grandes opciones: la calificación sucesoria y la calificación contractual. Una vez que ya hemos visto la posible, aunque marginal, calificación contractual de los pactos sucesorios, vamos a detenernos ahora en la más generalizada calificación sucesoria de los pactos

\footnotetext{
${ }^{257}$ P. PICONE señala la necesidad de aplicar una ley determinada en el momento de la conclusión del pacto, pero no se refiere a la ley de las obligaciones contractuales, son que propone la aplicación de una ley específica, autónoma de la del resto de contratos, que tengan en cuenta las particularidades del fenómeno sucesorio, vid. P. PICONE (2008), p. 96, esp. npp. núm. 93; por otra parte, la inexactitud de la consideración de una calificación contractual de los pactos sucesorios por parte de A. DAVí nos parece aún más clara, pues dicho autor no sólo propone la aplicación de la llamada ley sucesoria hipotética o anticipada, sino que además asume sin duda alguna la inclusión de los pactos sucesorios en el futuro Reglamento de sucesiones europeo, vid., A. DAVí, (2005), p. 330.

${ }^{258}$ El autor italiano falleció en 1980.
} 
sucesorios. Todo ello sin olvidar que las enseñanzas de la calificación contractual, al menos en los casos vistos de la práctica judicial norteamericana: una calificación basada en sólidos intereses; una calificación funcional.

Lo primero que hay que tener en cuenta es que la calificación sucesoria de los pactos sucesorios tiene distintas implicaciones en función de la concepción que de la sucesión siga el DIPr del foro. Como bien es sabido, en el ámbito internacional hay dos grandes opciones para tratar las sucesiones: el sistema de la unidad de la sucesión y el sistema del fraccionamiento de la sucesión. Trasladado esto a los pactos sucesorios significa que la calificación sucesoria puede suponer una unidad de régimen de la validez del pacto sucesorio, de tal forma que una única ley es la que va a regular el pacto; o, por el contrario, puede suponer un fraccionamiento del régimen aplicable al pacto sucesorio en función de la naturaleza de los bienes que se vean afectados por el mismo y del lugar en que se encuentren. Tener en cuenta este aspecto es crucial a la hora de valorar el alcance de la calificación. Como dijimos más atrás, una calificación, la que sea, no puede hacer abstracción de sus consecuencias en función de las concretas soluciones de las también concretas normas de conflicto a las que conduzca.

\section{Influencia de las opciones de DIPr sobre la ley aplicable a la sucesión en los pactos sucesorios}

\subsection{Los sistemas que siguen la unidad de la sucesión}

\subsubsection{Breve referencia a la unidad de la sucesión}

En aplicación del principio de unidad y universalidad de la sucesión sólo una ley debe regular el conjunto de la sucesión, sin tener en cuenta ni la naturaleza ni la localización de los bienes que la componen. Este sistema es la traducción al ámbito internacional de la concepción romana de la herencia como un patrimonio universal $^{259}$. Según esta concepción la herencia del causante es un todo que se transmite como tal, y sin necesidad de formalidades concretas para cada uno de los bienes que conforman la herencia, al sucesor, que es quien subentra en la posición del causante respecto del conjunto de las relaciones patrimoniales. La

\footnotetext{
${ }^{259}$ F.K. VON SAVIGNY (1849), p. 304; H. LI (1990), p. 25; F. BOULANGER (2004), p. 32; A.L. CAlvo CaravaCa (1995), p. 354.
} 
traducción al ámbito internacional de esta concepción lleva a la aplicación del estatuto personal, esto es, la ley personal del difunto. La aplicación del estatuto personal conlleva, a su vez, la diferenciación de dos subsistemas de entre los que siguen la unidad de la sucesión: aquellos que fijan la conexión personal en el último domicilio del causante y aquellos que la fijan en la última nacionalidad del causante $^{260}$.

El seguimiento del principio de unidad evita los problemas que ocasiona el fraccionamiento de la sucesión al haber una única masa sucesoria regulada por una única ley ${ }^{261}$. No obstante, no debemos obviar que, como ya se ha puesto de relieve, en muchas ocasiones el principio de unidad de la sucesión no puede llevarse a cabo en la práctica de manera eficaz cuando se trata de aplicar a bienes inmuebles sitos en el extranjero, donde se aplica el sistema del fraccionamiento y, por tanto, la lex rei sitae para la sucesión de los inmuebles ${ }^{262}$. Por otro lado, la propia complejidad del fenómeno sucesorio hace difícil que, incluso partiendo del principio de unidad y universalidad de la sucesión y de sus ventajas, no se produzcan excepciones típicas: en los casos en los que medie negocio sucesorio de cualquier tipo, la forma del mismo, la capacidad para otorgarlo, incluso algunas cuestiones atinentes a su validez, pueden $-\mathrm{y}$ frecuentemente son- ser objeto de conexión autónoma. Y otro tanto puede decirse de algo tan importante como los aspectos reales de la trasmisión de la propiedad: la tensión entre estatuto real (que tiende a prevalecer) y estatuto sucesorio vuelve a plantear excepciones al principio general $^{263}$.

\footnotetext{
${ }^{260}$ Sobre el principio de unidad de la sucesión en general, vid. H. LEWALD (1925), pp. 13 y ss; A.E. VON OVERBECK (1961), pp. 561 y ss.; W. LAUTERBACH (1969), pp. 35 y ss.; M. FeRID (1974), pp. 95 y ss.; F. BOUlANGeR (1981), pp. 38 y ss.; H. LI (1990), pp. 25 y ss. y 55 y ss.; T. BRANDI (1996), pp. 206 y ss.; S. BILlarant (2004), pp. 104 y ss.; E. CAlo (2007), p.32; A. BONOMI (2011), pp. 99 y ss.; E. JAYME (2011), pp. 27 y ss.; L. PERREAU-SAUSSINE (2011), pp. 36 y ss. En España, E. CASTellanos Ruiz (2001), pp. 143 y ss.; C. AzCÁrRaga Monzonís (2008), pp. 124 y ss.

${ }^{261}$ Sobre los problemas del fraccionamiento de la sucesión nos detendremos más adelante.

${ }^{262}$ A. von OVERBECK (1961), p. 564; S. ÁLVAREZ GonZÁLEZ (2009), pp. 20 y ss.

${ }^{263}$ La doctrina española no se pone de acuerdo sobre la ley que debe regir los aspectos reales de la sucesión; A.L. CALVO CARAVACA (1995-2), pp. 414 y ss. defiende que es la ley sucesoria derivada del art. 9.8 CC la que debe regular también los aspectos reales; mientras que el profesor Virgós Soriano, en la misma obra, entiende que tales aspectos deben regirse por la lex rei sitae; vid. M. VIRGÓS SORIANO (1995), pp. 257 y ss. En el ámbito del Reglamento de sucesiones, vid. I. HEREDIA CERVANTES (2011), pp. 425 y ss.
} 
La extensión del principio de la unidad de la sucesión se puede datar a finales del siglo XIX y es claramente visible en los albores del XX. Por un lado, SAVIGNY ya había puesto de relieve que lo natural para los países que conciben la sucesión universal, puesto que se trata de una extensión de la personalidad del causante, es la aplicación de la ley del domicilio del fallecido a todo el conjunto de la sucesión ${ }^{264}$. Por otro lado, el principio de la unidad de la sucesión imperó en las primeras Conferencias de La Haya. En la sexta Conferencia de La Haya, que tuvo lugar en 1928, existía entre los delegados una fuerte contraposición entre el fraccionamiento y la unidad de las sucesiones, si bien la mayor parte de ellos estaban a favor de este último sistema. Así, en el proyecto de Convenio de La Haya de ese mismo año, el art. 1 recogía el principio de unidad de la sucesión al señalar como aplicable a la misma la ley de la nacionalidad del causante en el momento de su fallecimiento, cualquiera que fuera la naturaleza de los bienes y el país donde se encuentren ${ }^{265}$. Este principio parece estar consolidado en nuestros días, al menos en el círculo romano-germánico, una vez que el Convenio de La Haya de 1989 y, sobre todo, el Reglamento de sucesiones también lo han $\operatorname{adoptado}^{266}$.

Las ventajas que del principio de unidad se suelen señalar tienen que ver fundamentalmente con la mayor facilidad para gestionar la herencia, tanto para el futuro causante que quiere planificar el reparto de su patrimonio, como para el órgano judicial que tiene que conocer de una sucesión con elemento extranjero. Con carácter general, la unidad de régimen permite indicar de manera unitaria

\footnotetext{
${ }^{264}$ F.K. VON SAVIGNY (1849), p. 305.

${ }^{265}$ Project de Convention sur les conflits de lois et de jurisdictions en matière de successions et de testaments, que se puede consultar en CONFERÉNCE DE LA HAYE DE DROIT INTERNATIONAL PRIVÉ (1928), pp. 100-103. El principio de unidad podía ser excepcionado, en virtud de lo dispuesto por el art. 3, cuando la aplicación de la ley nacional del fallecido fuera manifiestamente incompatible con los principios de orden público reconocidos en alguno de los Estados contratantes, permitiéndose en tal caso la aplicación de la ley territorial.

${ }^{266}$ Dice el art. 21 del Reglamento que, salvo disposición contraria del presente Reglamento, la ley aplicable a la totalidad de la sucesión será la del Estado en que el causante tuviera su residencia habitual en el momento del fallecimiento". La Propuesta de Reglamento de sucesiones y testamentos ya había recogido también el principio de unidad en el art. 16 con el fin de evitar los problemas de sistema escisionista y permitir al testador que planifique "la distribución equitativa de sus bienes entre sus herederos con independencia de su ubicación". Vid. comentario al art. 16 en la Exposición de Motivos de la Propuesta.
} 
quiénes son los herederos y, en su caso, qué cuotas les corresponde sobre la herencia y evita los inconvenientes de tener que ajustarse a más de una legislación; pensemos, por ejemplo, en la posibilidad de que un mismo testamento pueda ser válido según una ley aplicable e inválido según otra o las dificultades a las que se enfrentaría el testador para planificar el destino de su patrimonio si tiene que atender a varios sistemas legitimarios.

\subsubsection{La unidad en los pactos sucesorios}

El modelo de regulación de la ley aplicable a los pactos sucesorios que ahora nos ocupa es aquel en el que concurre una ausencia de referencia expresa en el sistema de DIPr a los pactos sucesorios, junto con una defensa de una calificación sucesoria de los mismos y un sistema de sucesión internacional basado en el principio de unidad. Este sería el modelo correspondiente al sistema del antiguo art. 10.2 CC según aquella parte de la doctrina que ya entonces abogaba por una calificación sucesoria de los pactos sucesorios. Pero el ejemplo paradigmático de este modelo lo encontramos en el vigente sistema italiano, donde confluyen todos los caracteres referidos.

El actual sistema de DIPr italiano es fruto de una modificación que tuvo lugar con la promulgación de la ley núm. 218 de 31 de mayo de 1995. En dicha modificación, como hemos señalado, se perdió la oportunidad de recoger un régimen expreso de determinación de ley aplicable a los pactos sucesorios. La ausencia de referencia a los pactos sucesorios en el sistema de DIPr italiano no sólo se ha vinculado con la tradicional prohibición que de los mismos recoge el art. 458 CCit., sino también con la posible contrariedad de los pactos sucesorios con el orden público italiano ${ }^{267}$. Hoy en día podemos afirmar que tal posible contrariedad está superada, no sólo por la jurisprudencia y la doctrina, sino también por la ley, dada la clara configuración de la figura del pacto de familia

\footnotetext{
${ }^{267}$ P. DE CESARI pone de relieve que la razón por la que la ley de reforma no incluyó referencia alguna a los pactos sucesorios es la posible contrariedad de estas figuras con el orden público italiano, (2001), p. 110.
} 
como una derogación parcial de la tradicional prohibición de los pactos sucesorios $^{268}$.

En estas circunstancias, y a salvo la ya referida excepción aislada a favor de la calificación contractual, la mayor parte de la doctrina italiana otorga una calificación sucesoria a los pactos sucesorios, tanto bajo el régimen anterior a la reforma del año 1995, como bajo el régimen vigente ${ }^{269}$. Tal posición tiene como consecuencia la aplicación del art. 46 de la ley italiana de DIPr a los pactos sucesorios. Ya hemos señalado que en dicho artículo se da cumplimiento al principio de unidad de la sucesión bajo la aplicación de una ley personal. Según los que abogan por esta calificación y de acuerdo con el sistema italiano, se aplica a los pactos sucesorios la ley nacional del causante determinada en el momento de su fallecimiento.

El principio de unidad aplicado a los pactos sucesorios no añade mayor especialidad a la configuración, ventajas e inconvenientes del mismo, e implica que sólo una ley, en este caso la ley de la última nacionalidad del causante, es la que va a regir el régimen jurídico de estos actos. Sí es cierto que el principio de unidad puede tener una mayor relevancia cuando se trata de los pactos sucesorios, desde el punto de vista del carácter reglado de estas figuras, de su tipicidad y el

\footnotetext{
${ }^{268}$ En cuanto a la jurisprudencia italiana, una temprana sentencia de la Corte de Casación de Florencia entendió contrario al orden público italiano un pacto de renuncia, Corte di Cassazione di Firenze, 12 diciembre de 1895, consultada en Foro italiano, 1896, vol. I, pp. 142 y ss.; sin embargo, en el caso más moderno Kolarcsyk c. Gertrud el tribunal de Bolzano declara que un pacto sucesorio nulo conforme al ordenamiento italiano, pero válido conforme al sistema alemán, no es contrario al orden público y a las buenas costumbres de Italia, vid., Tribunal de Bolzano, sentencia de 8 de marzo de 1968, Repertorio Generale Annuale del Foro Italiano, vol. XCII, 1969, p. 2703, núm. 34. Entre la doctrina que entiende superada esta posible contrariedad, Vid., T. BALlarino (1999), p. 524; D. DAMASCELli, (2003), p. 86; P. MENGOZZI, (2002), p. 216; E. CALO, (2007), p. 77; B.BAREL/S. ARMELLINI (2008), p. 199; incluso hay doctrina que habla de la erosión de la prohibición de los pactos sucesorios, I. ANTONINI (1996), p. 602. El art. 458, recoge la prohibición del pacto sucesorio haciendo la salvedad de lo dispuesto en el art. 768 bis, artículo en el que se recoge la definición de pacto de familia.

${ }^{269}$ A favor de una calificación sucesoria de los pactos sucesorios bajo el régimen anterior de DIPr, E. VITTA (1975), p. 145, quien sin negar la existencia también de un elemento contractual, da preferencia al elemento sucesorio de estas figuras; bajo el régimen vigente las declaraciones sobre pactos sucesorios son más numerosas y se muestran favorables a la calificación sucesoria, B. BAREL/S. AMELLINI (2008), p. 199; P. PICONE (1998), p. 95, si bien hay autores que han entendido que este autor defiende una calificación contractual; también, P. DE CESARI (2001), p. 111; P. MENGOZZI (2002), p. 217; parece que abogan por una calificación sucesoria, aunque no queda del todo claro, G. CONETTI/S.TONOLO/F. VISMARA (2009), p. 206.
} 
hecho de que en muchas ocasiones tienen una admisión limitada o simplemente no son admitidos. La aplicación de varias leyes a un mismo pacto sucesorio, desde este punto de vista, puede plantear muchos problemas en torno a su admisibilidad y régimen jurídico. Pensemos en el ejemplo de un pacto sucesorio a través del cual un padre de nacionalidad alemana realiza dos instituciones a título particular a favor de su hijo, una que afecta a un inmueble sito en Berlín y otra que afecta a un inmueble sito en Mallorca. Según la norma de conflicto italiana, tal pacto se regulará por la ley de la nacionalidad que el causante ostente en el momento del fallecimiento. De esta forma, las partes sólo tienen que atenerse a un régimen y supongamos que, en confianza de que esa será la nacionalidad que siga ostentando el padre en el momento de su fallecimiento, realizan el pacto observando la ley alemana $^{270}$. El principio de unidad, que implica en este caso que el pacto sucesorio se pueda regular en su totalidad por lo dispuesto en el BGB, evita que las partes tengan que acudir a la legislación mallorquina y observar sus exigencias, distintas de las previstas en la legislación alemana, para transmitir por pacto sucesorio la propiedad del inmueble sito en Mallorca. En concreto, mientras que bajo la legislación alemana nada impide realizar un pacto sucesorio con una atribución particular de ambos inmuebles (§ 1941 BGB), bajo la legislación mallorquina la realización de tal acto implica necesariamente una institución contractual de heredero, bajo la forma de una donación universal de bienes presentes y futuros (art. 8.1. Texto Refundido de la Compilación de Derecho Civil de las Islas Baleares ${ }^{271}$ ). En el ejemplo, de tener que observarse la legislación mallorquina, sólo se podría realizar una institución a título particular, respecto del inmueble sito en Berlín, mientras que sería necesario seguir una opción distinta y un régimen diferente para la transmisión por pacto sucesorio del inmueble sito en Mallorca. En suma, el principio de unidad facilita considerablemente el otorgamiento de pactos sucesorios en el sentido de que evita multiplicar las complicaciones que el carácter reglado de estas figuras conlleva.

\footnotetext{
${ }^{270}$ Ciertamente, las partes en el momento del otorgamiento de pacto no conocen cuál va a ser la ley aplicable a éste, pues dicha ley se determina en el momento del fallecimiento del causante, pero este es otro problema que trataremos más adelante.

${ }^{271}$ Decreto Legislativo 79/1990, de 6 de septiembre, BO Illes Balears de 2 de octubre de 1990, núm. 120, p. 6097.
} 
Por otro lado, el principio de unidad aplicado a los pactos sucesorios mantiene el común problema de eficacia en la práctica de este principio respecto de pactos sucesorios que afecten a bienes inmuebles sitos en el extranjero en sistemas que sigan la concepción del fraccionamiento de la sucesión y, por tanto, aboguen por la aplicación de la lex rei sitae a la sucesión inmobiliaria.

\subsection{Los sistemas que siguen el fraccionamiento de la sucesión}

\subsubsection{El fraccionamiento de las sucesiones y su problemática}

La otra gran concepción de las sucesiones internacionales es el sistema del fraccionamiento de la sucesión; los ordenamientos jurídicos que siguen este sistema dividen la herencia en distintas masas sucesorias en función de la naturaleza de los bienes y del lugar donde se encuentren. De este modo, se prevé una ley personal para regular la sucesión mobiliaria, generalmente la ley del último domicilio del causante en cumplimiento de la máxima mobilia sequuntur personam, mientras que para la sucesión inmobiliaria se aplica la lex rei sitae ${ }^{272}$. Esto significa que la herencia de una persona se divide en distintas masas sucesorias, no sólo en función de la naturaleza mobiliaria o inmobiliaria del patrimonio de que se trate, sino también en función del lugar donde se encuentren los bienes inmuebles de la misma. Cada masa sucesoria va a tener una propia ley aplicable $\mathrm{y}$, por tanto, distinto régimen jurídico, lo que provoca determinados inconvenientes que la doctrina ha señalado de manera profusa. Nos estamos refiriendo aquí al fraccionamiento territorial, distinto del otro tipo de fraccionamiento denominado funcional. Este último se refiere a la aplicación de distintas leyes a diferentes momentos de la sucesión internacional, distinguiéndose fundamentalmente las cuestiones de la transmisión sucesoria, a las que se les reserva la aplicación de la llamada ley sucesoria, y las cuestiones de

272 Nos estamos refiriendo, en realidad, a un fraccionamiento mixto. El sistema del fraccionamiento puede ser puro o mixto. La diferencia entre uno y otro es que en el sistema del fraccionamiento puro no se agrupa el patrimonio mobiliario en torno a una sola ley determinada por una conexión personal, sino que la regla de la lex rei sitae se aplica indistintamente a la sucesión mobiliaria e inmobiliaria; sin embargo, en el sistema del fraccionamiento mixto, la aplicación de la lex rei sitae sólo se reserva para la sucesión inmobiliaria, vid., J. HERON (1986), p. 1 y ss.; C. AzCÁrRaga Monzonís (2008), pp. 72 y ss. Hoy día la mayor parte de los ordenamientos jurídicos que mantienen el fraccionamiento de la sucesión, siguen un sistema de fraccionamiento mixto; sobre el origen de éste, H. Li (1990), p. 22; E. CASTELlANOS RuIZ (2001), pp. 45 y ss. 
administración de la herencia, a las que se les aplica la ley del foro, dándose también determinada participación a la lex rei sitae ${ }^{273}$.

La justificación más habitual del sistema del fraccionamiento de la sucesión es la fuerte vinculación entre los bienes inmuebles y el lugar donde están sitos. Mas, junto a esta ventaja, aparejada no sólo a cuestiones estrictamente sucesorias, sino también a una deseable correlación entre estatuto sucesorio y estatuto real, la doctrina ha puesto de relieve cómo el fraccionamiento de la sucesión puede plantear problemas y resultados injustos. Con carácter general, se alerta, en primer lugar, de la dificultad que el fraccionamiento de la sucesión plantea al causante que quiere organizar su patrimonio para después de su muerte. Dicho causante tendrá que observar distintas legislaciones y atender a sus exigencias a la vez que busca el equilibrio concreto para repartir su patrimonio como desea; tal dificultad es aún mayor cuanto más repartido tenga su patrimonio inmobiliario, lo que a su vez implica además mayores costes en la planificación de su sucesión ${ }^{274}$.

En segundo lugar, se encuentran las complicaciones que se pueden derivar a la hora de liquidar una herencia por la existencia de distintas masas sucesorias. Así por ejemplo, es posible que como consecuencia del fraccionamiento un mismo testamento sea válido conforme a una ley e inválido conforme a otra. A ello se le suman los desajustes que se pueden provocar como consecuencia de la concurrencia, en su caso, de distintos tipos de sucesión legítima; nos referimos a la existencia de diversos sistemas legitimarios en función de la legislación aplicable a cada masa sucesoria, pues cada ordenamiento jurídico establece libremente, según su propio criterio, quiénes son legitimarios y a qué cuota de la herencia tienen derecho ${ }^{275}$. Como ejemplo de este tipo de

\footnotetext{
${ }^{273}$ Sobre la diferencia entre el fraccionamiento territorial y el fraccionamiento funcional, vid., M. FERID (1974), p. 110; también, H. LI (1990), p. 22.

${ }^{274}$ Vid. con carácter general sobre el fraccionamiento de la sucesión, H. LEWALD (1925), pp. 16 y ss.; A.E. VON OVERBECK (1961), pp. 565 y ss.; M. FERID (1974), p. 96; F. BOULANGER (1980), p. 40; H. Li (1990), p. 56; F. Boulanger (2004), pp. 33 y ss.; C. AZCÁRrAgA MonZONís (2008), pp. 71 y ss.; A. BONOMI (2011), pp. 117 y ss.

${ }^{275} \mathrm{El}$ antiguo asunto de la jurisprudencia francesa Stewart c. Marteau es un ejemplo paradigmático de cómo cada lex rei sitae determina, independientemente de otras legislaciones extranjeras, el
} 
desajustes resulta paradigmático el del ciudadano inglés que tiene dos hijas y prevé la transmisión de un inmueble de igual valor para cada una, uno sito en Francia y otro sito en Inglaterra. El desajuste vendría de la posibilidad de la hija que ha heredado el inmueble sito en Inglaterra de dirigirse a un tribunal francés y exigir la cuota a la que, en virtud de la ley francesa como lex rei sitae, tendría derecho; mientras que la hija que heredó el bien inmueble sito en Francia no podría reclamar derecho alguno sobre el inmueble de Inglaterra, por existir en ese sistema la libertad de testar. Lo mismo ocurriría, dicho sea de paso, si el causante fuese francés ${ }^{276}$.

Por último, otro de los inconvenientes fundamentales que suele presentar el fraccionamiento de las sucesiones tiene que ver con el reparto de las deudas de la herencia. El problema se plantea cuando la herencia tiene deudas y existen distintas masas sucesorias, cada una de las cuáles tiene su propia ley aplicable. Además la contribución a las deudas de la herencia exige considerar todas las masas sucesorias. El juez que conoce de tal deuda se encuentra con la duda de cuál o cuáles de entre esas leyes que se aplican a la sucesión de un causante se debe aplicar para determinar el reparto de la deuda sucesoria ${ }^{277}$.

Bien es cierto que, a pesar de estos inconvenientes, no han faltado voces que mantienen la defensa del sistema del fraccionamiento ${ }^{278}$. Pero ello no obstante, lo cierto es que con carácter general la valoración de las ventajas e inconvenientes que plantea el fraccionamiento de la sucesión ha supuesto el abandono o la no consideración de esta concepción a favor del sistema de la unidad de la sucesión en los últimos grandes hitos codificadores sobre la materia: el Convenio de La Haya de 1989 y el Reglamento sobre sucesiones.

sistema legitimario para la masa sucesoria correspondiente, Cour de cassation (Ch. civ.), 14 mars 1837, consultado en B. ANCEL/Y. LEQUETTE (1987), pp. 10 y ss.

${ }^{276}$ B. ANCEL/Y. LEQUETTE (1987), p. 16. P. LAGARDE (2005), p. 1702.

${ }^{277}$ Para un estudio amplio sobre el tema, J. HÉRON (1986), pp. 281 y ss.

${ }^{278}$ Vid. A. E. VON OVERBECK (1961), pp. 565 y ss; con carácter general, J. HÉRON (1986), pp. 119 y ss. 


\subsubsection{Calificación sucesoria de los pactos sucesorios y fraccionamiento de la sucesión internacional}

El ejemplo paradigmático de sistema de DIPr en el que no se hace referencia alguna a los pactos sucesorios en sus normas, sigue una calificación sucesoria de los mismos y adopta la concepción del fraccionamiento de la sucesión lo encontramos en el ordenamiento jurídico francés. Como constante que hemos observado en los sistemas en los que se prohíbe en su Derecho material los pactos sucesorios, la ausencia de referencia a los mismos en el plano del DIPr francés se ha relacionado también con la posible contrariedad con el orden público de estas figuras. A finales del siglo XIX una sentencia dictada por el Tribunal civil de la Seine declaró la contrariedad de los pactos sucesorios con el orden público francés y se negó a ordenar la liquidación de un pacto sucesorio extranjero $^{279}$. No obstante, al igual que hemos visto en el caso italiano, en Francia se ha producido también una evolución favorable a la no contrariedad de los pactos sucesorios con el orden público. Esta evolución se puede percibir en distintos planos, esto es, doctrinal, jurisprudencial y legal.

En el plano doctrinal se aprecia con carácter general una tendencia a no considerar los pactos sucesorios previstos por leyes extranjeras como contrarios al orden público francés. Salvo excepción aislada, la doctrina francesa es reacia a rechazar la aplicación de esas leyes por ser contrarias al orden público. Entre los que entienden que sí hay una contrariedad, destaca NIBOYET, para quien la prohibición de los pactos sucesorios se considera una cuestión de orden público basada en razones morales, de tal forma que una ley extranjera que admita los pactos sucesorios nunca podrá prevalecer sobre la prohibición de la legislación francesa $^{280}$. Sin embargo, la mayor parte de la doctrina entiende que la tradicional prohibición no es contraria al orden público, entendiéndose que tal consideración

\footnotetext{
${ }^{279}$ Trib. Civ. de la Seine, $1 \mathrm{ch}$. 18 juillet 1885 , donde de forma tajante se señala que la ley que prohíbe todo pacto sobre una sucesión futura es un principio de orden público, JDIP, 1886, p. 208.

280 J-P. NiBOYET (1947), p. 763, distinguía el tratamiento de los pactos sucesorios en función de que la ley sucesoria fuera francesa o extranjera y en este último caso, entendía que la prohibición de los pactos sucesorios recogida por el CC francés se consideraba como contraria al orden público. También entienden que los pactos sucesorios son contrarios al orden público, G.R. DELAUME/G. FlatTET (1952), comentario al asunto núm. 6845, párrafo I.
} 
es excesiva, sobre todo si se tiene en cuenta la existencia de excepciones a tal prohibición, como es el caso de la institución contractual ${ }^{281}$.

En el plano jurisprudencial, la sentencia de la Cour d’appel de Colmar de 1949 evitó pronunciarse directa y expresamente sobre la contrariedad o no con el orden público francés de un pacto sucesorio con elemento extranjero. El caso planteado ante la Cour d’appel trataba de dos cónyuges de nacionalidad alemana y residencia habitual en Alemania que otorgaron un pacto sucesorio en el que se instituían recíprocamente legatarios universales para el conjunto de los bienes del primero que falleciera, incluido un bien inmueble situado en la Alsacia, sin considerar la eventual existencia de legitimarios ${ }^{282}$. El Tribunal debía pronunciarse sobre la eficacia en Francia de un pacto sucesorio regulado conforme a la ley extranjera, que afectaba a un bien inmueble sito en Francia. El resultado fue el de la ineficacia de tal pacto sucesorio, si bien no porque el pacto sucesorio en sí resultase contrario al orden público. El tribunal dio dos argumentos para llegar a esta conclusión; uno de ellos relacionado con la aplicación de la ley francesa al pacto sucesorio en lo que concierne al bien inmueble sito en Francia y otro, más categórico, relacionado con el hecho de que las partes no habían otorgado el pacto sucesorio en observancia de los derechos de legitimarios, siendo sí esta materia una cuestión de orden público. Constatado que el pacto sucesorio era contrario a las disposiciones de la ley francesa sobre derechos de reserva, se decretó la ineficacia del mismo en lo que respecta a la transmisión del bien inmueble sito en la Alsacia. En definitiva, sin perjuicio de la mencionada ineficacia del pacto en el caso concreto, de esta sentencia se deriva una postura favorable a la no contrariedad de plano de los pactos sucesorios con el orden público francés.

\footnotetext{
${ }^{281}$ Entre los autores que hacen referencia expresa al tema del orden público y los pactos sucesorios, A. Pillet (1924), pp. 393 y ss., ponía en duda esa contrariedad y se refería críticamente a la sentencia del tribunal de Seine de 1885 que había claramente declarado la contrariedad de los pactos sucesorios con el orden público; H. BATIFFOL/P. LAGARDE (1983), p. 398, npp. núm 640, donde señalan que la declaración de los pactos sucesorios como contrarios al orden público parece excesiva, señalando que el Derecho material francés los admite a través de la institución contractual; también entre la doctrina más moderna, P. LAGARDE (2004), p. 594; M. REVILLARD (2010), p. 434 y 435.

${ }^{282}$ Cour d'appel de Colmar, 19 febrero 1949, consultada en Rev. crit. dr. int. pr., núm 1, 1950, pp. 52 y ss.
} 
Esta postura se ha confirmado en fechas más recientes con una sentencia de la Cour d'appel d'Aix en Provence en el año 2003 en la que se da efecto en Francia a un pacto sucesorio válidamente constituido bajo el Derecho alemán ${ }^{283}$. Por otro lado, es de mencionar también la existencia de práctica judicial en la que se intentan validar pactos sucesorios a través de una falsa calificación de la operación jurídica $^{284}$. Esta manipulación de la calificación es especialmente perceptible en una sentencia del tribunal civil de Mulhose califica un pacto sucesorio realizado en Suiza, siguiendo las exigencias del Derecho suizo, como un testamento conjunto ${ }^{285}$. Se trataba de un acuerdo inter vivos realizado entre el causante y sus hermanos en el que pactan sobre la sucesión futura, puesto que deciden que cada uno de los hermanos sobrevivientes heredarán a partes iguales los bienes del que fallezca, no pudiéndose revocar el acto de manera unilateral. El tribunal se apoya en aquella doctrina que califica la prohibición de los testamentos conjuntos como una cuestión de forma, lo que le lleva a la aplicación de la ley suiza y a evitar la declaración de invalidez del acto de conformidad con la ley francesa $^{286}$. El orden público francés no tuvo ninguna presencia, como suele ser habitual cuando la ley aplicable viene condicionada por una calificación formal y la consiguiente articulación de las normas de conflicto orientadas al favor validitatis.

Desde el punto de vista legal, se debe considerar la propia existencia desde siempre de excepciones a la tradicional prohibición de los pactos sucesorios en Francia, fundamentalmente la institución contractual y la donation-partage, así como las modificaciones que recientemente se han producido en el Derecho material francés con la introducción de nuevas figuras, esto es, la donationpartage transgénérationnelle y la renuncia anticipada a la acción de reducción,

\footnotetext{
${ }^{283}$ Cour d'appel d'Aix-en-Provence, 16 de octubre de 2003, consultada en Rev. crit. dr. int. pr., núm 3, 2004, pp. 589 y ss.

${ }^{284}$ M. REVILLARD (2010), p. 435.

${ }^{285}$ Sentencia del Tribunal Civil de Mulhose, de 19 de enero de 1950, consultada en JCP, 1952 , núm. 6845

${ }^{286}$ Críticos, G.R. Delaume/G. Flattet (1952), comentario al asunto núm. 6845.
} 
que permiten hablar de una erosión de la tradicional prohibición de pactos sucesorios que recoge el Código francés ${ }^{287}$.

El desarrollo de los acontecimientos en estos tres planos permiten sostener que hoy día la contrariedad con el orden público de los pactos sucesorios está superada y podemos centrarnos en el estudio de la determinación de la ley aplicable sin la losa que en de un orden público apriorístico y contaminante del proceso ordinario de aplicación de la norma de conflicto. Para ello, basándonos tanto en la jurisprudencia, como en la doctrina, ya podemos adelantar que en el ordenamiento jurídico francés se aboga por una clara calificación sucesoria de los pactos sucesorios.

La calificación sucesoria de los pactos se ha basado fundamentalmente en el hecho de que la ley sucesoria es la que determina los modos de delación de la sucesión y la que determina, por tanto, las formas en que se pueden transmitir los bienes hereditarios. Como hemos visto la Cour d'appel de Colmar en la sentencia de 1949 ya aplicó la lex rei sitae a la parte de un pacto sucesorio de institución recíproca celebrado por cónyuges de nacionalidad alemana de conformidad con el Derecho alemán que afectaba a un bien inmueble sito en Francia; la ley francesa se aplicó a título de ley aplicable a la transmisión hereditaria de inmuebles sitos en Francia, esto es, a título de norma de conflicto para las sucesiones inmobiliarias (art. $3.2 \mathrm{CC}$ francés) ${ }^{288}$. El ejemplo más claro de calificación sucesoria de los pactos se puede observar en la también citada sentencia de la Cour d'appel d'Aix-en-Provence de 16 de octubre de 2003. En esta sentencia se aplica a un pacto sucesorio extranjero la norma de conflicto de sucesiones del sistema de DIPr francés. Se trataba en este caso de un pacto sucesorio otorgado entre cónyuges alemanes y domiciliados en Alemania en el que se instituyeron recíprocamente herederos. El litigio afectaba a una serie de bienes muebles sitos en Francia y el tribunal aplicó la norma de conflicto para las

\footnotetext{
${ }^{287}$ En opinion de P. MALAURIE, (2008), p. 297. la vigencia de esta prohibición es más teórica que práctica; en este sentido también, N. BAILLON-WIRTZ (2006), pp. 8-13.

${ }^{288}$ H. BATIFFOL (1950), p. 55,donde el autor destaca el hecho de que en esta sentencia el tribunal no tuvo problema alguno en calificar el pacto sucesorio como una forma de delación de la sucesión, pese a los problemas de la calificación ex lege fori ante una institución extranjera desconocida para el ordenamiento francés.
} 
sucesiones mobiliarias lo que le llevó a considerar la validez del pacto sucesorio bajo la ley alemana como ley del último domicilio del causante. El juez francés termina por dar efecto en Francia a un pacto sucesorio válidamente constituido según la ley aplicable a la sucesión mobiliaria, por lo que, coherentemente, en la sentencia se destaca el hecho de que el efecto del pacto sucesorio sólo se extiende a la sucesión mobiliaria sita en Francia y no a la sucesión inmobiliaria ${ }^{289}$.

Por su parte, la doctrina francesa ha mantenido también desde principios del siglo XX una calificación sucesoria de los $\operatorname{pactos}^{290}$. La idea de que los pactos sucesorios suponen una derogación del orden de sucesión ab intestato ha estado presente con carácter general como fundamento para esta calificación ${ }^{291}$; la ley sucesoria es la que debe determinar cuáles son las formas permitidas de transmisión mortis causa. Pero este no es el único fundamento que se ha dado, pues también hay quien ha relacionado la oportunidad de la aplicación de la ley sucesoria con los objetivos de la prohibición de pactos sucesorios se recogen en Derecho material, que no sólo es el de evitar que se frustren las normas sobre delación de la sucesión, sino también evitar la frustración de aquellas normas que garantizan ciertos derechos de reserva sobre la herencia a determinadas personas $^{292}$.

No obstante, al lado de esta idea unánime de calificación sucesoria de los pactos sucesorios, debemos prestar una atención particular a los matices incluidos en la adelantada construcción de J.-P. NIBOYET. El punto de partida de este autor es la aplicación de la ley sucesoria para determinar si un pacto sucesorio puede modificar la sucesión intestada; esto es, es la ley sucesoria la que va a determinar si un pacto sucesorio puede y en qué medida modificar la sucesión ab intestato.

\footnotetext{
${ }^{289}$ Sobre esta diferenciación pone especial atención en su comentario P. LAGARDE (2004), p. 594.

${ }^{290}$ A. Pillet (1924), p. 395; E. BARTin (1932), p. 71; H. BATIFFOL (1967), p. 712, núm. 640; H. BatifFol/P. Lagarde (1983), p.398; P. MAYer/V. HeUzÉ, (2007), p. 602; B. Audit (2008), p. 750; M. REVILLARD (2010), p. 434, núm 781.

${ }^{291}$ Expresamente, J-P., NIBOYET (1947), p. 763, quien señala que un pacto sobre sucesión futura destinado a modificar la sucesión ab intestato, no puede ser válido si la ley que regula tal sucesión lo prohíbe; también señalan que se trata de una cuestión relacionada con la delación de la sucesión, E. BARTIN (1932), p. 71; H. BATIFFOL (1967), p. 712; H. BATIFFOL/P. LAGARDE (1983), p. 398; M. REVILLARD (2010), p. 434, núm. 781.

${ }^{292}$ A. PILLET (1924), p. 395.
} 
De esta aseveración parece derivarse una calificación sucesoria de los pactos sucesorios. No obstante, acto seguido el autor señala que además de la ley sucesoria es necesario la toma en consideración de otras leyes, a saber, la ley del foro, en su caso, y la ley aplicable al acto jurídico del pacto sucesorio; se refiere concretamente a la ley del contrato que contiene el pacto sobre sucesión futura, ya sea un contrato cualquiera o un contrato matrimonial. En definitiva, dicho autor concluye con la idea de que para determinar la validez del pacto sucesorio es necesario que concurran varias leyes: ley de la sucesión, ley de la situación efectiva de los bienes muebles, ley del contrato o del régimen matrimonial y, eventualmente, lex for ${ }^{293}$

En cualquier caso, la aplicación de la ley sucesoria a los pactos sucesorios implica que entren en juego distintas leyes en función de la naturaleza de los bienes que estén afectados por el contenido del pacto y del lugar donde se encuentren. La consideración de la norma de conflicto francesa prevista para las sucesiones supone la aplicación, por un lado, de la ley del último domicilio del causante a aquella parte del pacto que afecte a bienes muebles y, por otro, la aplicación de la lex rei sitae a la parte del pacto sucesorio que se refiera a bienes inmuebles. En definitiva, implica trasladar la concepción del fraccionamiento de las sucesiones a los pactos sucesorios. La aplicación de distintas leyes a un mismo pacto sucesorio puede generar determinados problemas, derivados fundamentalmente de la posibilidad de que el pacto sea válido de conformidad con una ley e inválido según la otra ${ }^{294}$.

\subsubsection{Los problemas particulares del fraccionamiento en los pactos sucesorios}

Ya hemos tenido ocasión de anunciar que los problemas del fraccionamiento de las sucesiones que particularmente afectan a los pactos sucesorios están directamente relacionados con el carácter generalmente reglado y

\footnotetext{
${ }^{293}$ J.-P. NiBOYET (1947), pp. 763 y 764.

${ }^{294}$ La doctrina francesa ha señalado el desequilibrio que puede suponer el aplicar más de una ley a un pacto sucesorio y la dificultad de conciliar la dualidad o multiplicidad de regímenes con la unidad del pacto; sobre esta idea, ya en la doctrina antigua, E. BARTIN (1932), p. 70; y también, P. LAGARDE (2004), p. 594.
} 
típico de estas figuras. Es habitual encontrarnos con ordenamientos jurídicos que reconocen pactos sucesorios pero de una forma limitada, señalando qué tipo de pactos en concreto y en qué circunstancias están admitidos por ese sistema ${ }^{295}$. Tales limitaciones pueden afectar a distintos aspectos de los pactos, tales como la tipología, el contenido y, particularmente, la legitimación para otorgarlos.

La admisión de la celebración de pactos sucesorios puede ser más amplia o más limitada desde el punto de vista de las personas que pueden otorgarlo. Así, hemos visto como hay pactos sucesorios que tienen un carácter matrimonial, esto es, sólo se pueden otorgar entre cónyuges, hay pactos sucesorios con un carácter familiar, que son aquellos cuya celebración está limitada a un círculo de personas más o menos amplias en cuanto al grado de parentesco, y existen los pactos sucesorios libres, respecto de los que no se establece limitación alguna en cuanto a la legitimación para otorgarlos. La variedad, en definitiva, es considerable y ya se puede intuir que diversos regímenes aplicables a un mismo pacto sucesorio pueden suponer problema en este sentido. Imaginémonos que dos hermanos otorgan un pacto sucesorio por el que uno instituye heredero a otro. El hermano otorgante instituyente tiene nacionalidad española y vecindad civil catalana y el pacto sucesorio afecta a dos bienes inmuebles, uno sito en Barcelona y el otro sito en Viena. El fraccionamiento de la sucesión implica que, al menos, dos leyes van a regular este pacto sucesorio: la ley catalana y la ley austriaca. De conformidad con la ley catalana el pacto será válido, al corresponderse con un heredamiento simple, previsto en el art. 431 19.1 CCCat. Las partes estarán legitimadas para celebrar tal pacto, puesto que son hermanos y su vínculo de parentesco entra dentro del círculo de legitimados admitidos por la legislación catalana [art. 431 2c) CCCat]. Por el contrario, este pacto es inválido conforme a la ley austriaca, puesto que según esta legislación sólo los cónyuges pueden otorgar pactos sucesorios (art. § 1249 AGBG). En definitiva, en este caso el fraccionamiento del

\footnotetext{
${ }^{295}$ Encontramos el ejemplo de esta gran variedad en los propios Derechos civiles españoles, tal y como hemos tenido ocasión de ver en el capítulo I; así por ejemplo, mientras en el Derecho civil de Galicia se admiten unos determinados pactos sucesorios, con ciertas características y exigencias en cuanto a la legitimación para otorgarlos, en Navarra o Aragón se admiten los pactos sucesorios de manera amplia. En Derecho comparado tenemos el ejemplo en Austria y Alemania; mientras que en Austria sólo se admiten los pactos sucesorios otorgados entre cónyuges, en Alemania la regulación es mucho más generosa y abierta.
} 
pacto implica también el fraccionamiento de su validez por motivos de legitimación, de tal forma que la parte del pacto que afecta al bien inmueble sito en Austria será inválido.

Los problemas del fraccionamiento también pueden venir de la mano de la tipología de pacto sucesorio de que se trate, pues una de las consecuencias del carácter reglado de los pactos es que no en todas las legislaciones se reconoce el mismo tipo de pacto en concreto. Imaginemos un pacto de renuncia a través del cual un hijo renuncia a la herencia de su padre a cambio de una determinada cuantía de dinero que en el momento de la celebración del pacto se pone a disposición del renunciante. La herencia está compuesta, entre otros bienes, por un bien inmueble sito en Zurich y otro inmueble situado en Coímbra, por lo que el pacto de renuncia se regulará al menos por la ley suiza y la ley portuguesa. En consecuencia, la renuncia será válida respecto del inmueble sito en Zurich, pues un tal pacto de renuncia está reconocido por el art. 495 CC suizo, e inválida respecto del inmueble sito en Coímbra, al no reconocerse por la legislación portuguesa los pactos de renuncia ${ }^{296}$.

La razón económica del pacto sucesorio se puede ver comprometida como consecuencia de este tipo de fraccionamiento en su validez. En el propio ejemplo anterior se puede dar la paradoja de que el que ha renunciado, y ha recibido una determinada cantidad en su día por ello, pueda ahora reclamar parte del inmueble sito en Coímbra, de conformidad con la legislación portuguesa. La razón económica del pacto se puede ver comprometida no sólo por el carácter aleatorio del pacto de renuncia ${ }^{297}$, sino también por la frustración de la ampliación de libertad de disposición del causante, quien pudo realizar el pacto de renuncia para poder disponer libremente de tales bienes inmuebles a favor de otras personas.

\footnotetext{
${ }^{296}$ El CC portugués establece una prohibición genérica de pactos sucesorios (art. 2028.2 CCport.) y recoge algunas excepciones, entre las que no se encuentra pacto de renuncia alguno, de tal forma que todos los pactos sucesorios que no sean expresamente reconocidos por la ley portuguesa se consideran nulos, vid., L.A. CARVALHO FERNANDES (2004), pp. 513 y ss. y pp. 523 y ss.

297 Con el carácter aleatorio del pacto de renuncia nos estamos refiriendo al hecho de que económicamente el pacto puede ser, aleatoriamente, más o menos beneficioso del que renuncia, en función de que el causante vaya o no a mejor fortuna.
} 
Un ejemplo más claro en el que se rompe la razón económica del pacto lo constituye aquel caso en el que el pacto sucesorio contenga disposiciones recíprocas, de tal forma que una disposición se fundamente en la existencia de la otra y viceversa. Pensemos en un pacto de institución recíproca entre dos hermanos en el que el mayor hace una atribución particular de un bien inmueble sito en Zaragoza a favor de su hermano pequeño, y éste otra atribución particular de un inmueble sito en Viena a favor de aquél. El resultado de aplicar dos leyes distintas a este pacto daría lugar al siguiente resultado: el hermano mayor nunca podría llegar a heredar contractualmente el bien sito en Viena, puesto que según la ley austriaca este pacto sería nulo, por no estar legitimados los otorgantes para otorgar tal pacto entre sí298; mientras que el hermano menor sí podría heredar por vía del pacto sucesorio el bien inmueble sito en Zaragoza (arts. 318 y 377 y ss. del Código del Derecho Foral de Aragón) pues el Derecho aragonés permite un pacto sucesorio de estas características. El carácter recíproco de las disposiciones no se produce en la práctica, rompiéndose así la razón económica del pacto como consecuencia del fraccionamiento del pacto sucesorio. Obviamente, en estos ejemplos estamos partiendo del modelo analizado (sistema de fraccionamiento de la ley aplicable, calificación sucesoria de los pactos sucesorios y ausencia de norma especial sobre los mismos) y no de la solución real que podría darse en función de la aplicación de otro modelo o de la legislación vigente (en el último caso en España, por ejemplo).

\section{Análisis de la solución de ley aplicable a los pactos sucesorios: especial referencia a los pactos sucesorios que afectan a más de una sucesión}

Los pactos sucesorios que afectan a más de una sucesión presentan una problemática particular en lo que respecta a la determinación de ley aplicable. En este apartado nos vamos a cuestionar si la solución, o en realidad no solución, del modelo de sistemas que venimos analizando es suficiente para identificar la ley aplicable y resolver convenientemente los problemas derivados de la peculiaridad de estos pactos.

\footnotetext{
${ }^{298}$ Según la ley austriaca sólo cabe la realización de pactos sucesorios entre cónyuges.
} 
Los pactos sucesorios que afectan a más de una sucesión requieren una atención especial; su particularidad viene determinada por la existencia de más de un futuro causante en el otorgamiento del pacto sucesorio, lo que implica más de una sucesión afectada y, en definitiva, más de una ley sucesoria en juego. El ejemplo típico y habitual de este tipo de pactos es aquel en el que los otorgantes, generalmente cónyuges, se instituyen recíprocamente herederos; pero nada impide que se celebre un pacto con más sucesiones implicadas $\mathrm{y}$, por tanto, más complejidad añadida. No obstante, dos sucesiones afectadas ya son suficientes para que se plantee el problema a la hora de determinar la ley aplicable al pacto sucesorio en cuestión.

De la calificación sucesoria que de los pactos sucesorios siguen los sistemas que ahora nos ocupan sólo se deriva un dato: la aplicación de la ley sucesoria. Pero no hay indicación alguna de cómo proceder cuando, como en el caso de los pactos sucesorios que afectan a más de una sucesión, hay más de una ley sucesoria a considerar. La cuestión se plantea en torno al modo en que se debe articular la concurrencia de distintas leyes sucesorias para determinar la ley aplicable al pacto. Se nos plantea, por tanto, la duda de cómo procedería, por ejemplo, un juez francés que conociera de un pacto sucesorio de institución recíproca. Pensemos en el supuesto de que dos hermanos, uno domiciliado en Francia y otro domiciliado en Alemania, realizan un pacto de institución recíproca; dicho pacto, para evitar ahora los problemas del fraccionamiento, afecta únicamente a bienes muebles. El hermano domiciliado en Francia fallece y el hermano domiciliado en Alemania solicita la ejecución del pacto sucesorio. A nuestro juicio, cabe enfrentarse de dos maneras distintas a un problema como este, en función de la atención más o menos particular que se le preste al pacto dentro de la sucesión del causante de que se trate. Dicho de otro modo, el juez debe determinar si el pacto sucesorio es válido o no y para ello puede hacerlo desde el estricto punto de vista de la sucesión del causante de que se trate, caso en el que sólo tomará en consideración la ley sucesoria de éste, o desde un punto de vista más atento con el pacto sucesorio como acto jurídico, caso en el que no sólo tendría en cuenta la ley sucesoria del causante que ya ha fallecido, sino también la existencia de otra ley sucesoria en juego. 
En realidad la última de las opciones para abordar el caso no es posible tratándose de sistemas que aplican la ley sucesoria, puesto que, al no haber fallecido aún el segundo de los causantes que otorgaron el pacto sucesorio, en el ejemplo el hermano que de momento está domiciliado en Alemania, el juez francés no puede conocer la ley sucesoria de éste, pues es incierta hasta que se abra su sucesión. Ante esta circunstancia, la solución que queda, por tanto, es la de valorar el pacto sucesorio desde el estricto punto de vista de la sucesión que ya está abierta, en el ejemplo la del hermano domiciliado en Francia ${ }^{299}$. La aplicación de la norma de conflicto de sucesiones francesa lleva en este caso a aplicar la ley francesa como ley del último domicilio del causante y a decretar la invalidez del pacto. En definitiva, el hermano sobreviviente no podrá heredar a través del pacto sucesorio. Distinta suerte tendría el hermano domiciliado en Francia en el caso de fallecer en primer lugar el hermano domiciliado en Alemania. En tal caso, el juez francés aplicaría la ley alemana, como ley del último domicilio del causante, lo que llevaría a decretar la validez del pacto y el derecho del hermano sobreviviente a heredar a través del pacto sucesorio $(\S 2278 \text { I BGB })^{300}$.

Se trata, en realidad, de una aplicación aleatoria de la ley sucesoria, en el sentido de que en función de cuál de los dos otorgantes fallezca primero el pacto será válido o inválido ${ }^{301}$. Esta solución es del todo insatisfactoria puesto que rompe la lógica material del pacto sucesorio en aquellos casos en los que las disposiciones se han otorgado recíprocamente, esto es, teniendo una disposición su razón de ser en la otra y viceversa. En definitiva, los sistemas que se corresponden con el modelo de regulación de los pactos cuyas características son la ausencia de referencia a los mismos en el sistema de DIPr y la calificación

\footnotetext{
${ }^{299}$ Esta es la opción que se siguió en el asunto conocido por la Cour d'appel d'Aix-en-Provence de 16 de octubre de 2003, en la que el tribunal conoció de un pacto sucesorio en el que las partes se instituyen recíprocamente herederos a título exclusivo e ilimitado; el tribunal declara la validez del pacto con base en la ley aplicable a las sucesiones mobiliarias, ley alemana como ley correspondiente al último domicilio del causante.

${ }^{300}$ Vid. H. BROX, H./W.D. WALKER, (2007), núms. 153 y 154.

${ }^{301}$ Ello siempre y cuando las partes mantengan su domicilio en el momento del fallecimiento, de tal forma que se aplique o bien la ley alemana o bien la ley francesa; sobre los problemas que plantea la determinación del punto de conexión de la ley aplicable a los pactos sucesorios en el momento del fallecimiento volveremos más adelante.
} 
sucesoria, no ofrecen una solución satisfactoria para la determinación de la ley aplicable a los pactos sucesorios que afectan a más de una sucesión.

\section{CALIFICACIÓN SUCESORIA: TRATAMIENTO INDIFERENCIADO DE LA CONEXIÓN Y ESPECIALIDAD EN EL MOMENTO TEMPORAL}

\section{La toma en consideración de los pactos sucesorios por el sistema de DIPr}

\subsection{La inclusión de los pactos sucesorios en la norma de conflicto de sucesiones}

El modelo de sistemas de regulación de ley aplicable a los pactos sucesorios que vamos a analizar ahora tiene como punto de partida, y a distinción de los que hemos analizado hasta ahora, una mención específica a los pactos sucesorios en sus normas de DIPr. Tal modelo corresponde a ordenamientos jurídicos que reconocen y admiten en su Derecho material la posibilidad de otorgar pactos sucesorios. Este tipo de sistemas otorgan una calificación sucesoria a los pactos sucesorios, lo que se desprende del hecho de que la solución que para los mismos se prevé se contiene en la norma de conflicto de sucesiones. El sistema español vigente es un ejemplo de este tipo de modelo de regulación de los pactos sucesorios.

La norma de conflicto para las sucesiones prevista en el sistema español de DIPr recoge en su texto referencia expresa a los pactos sucesorios. Como ya hemos visto, este interés por los pactos sucesorios no ha existido siempre, pues el precedente del actual art. 9.8 CC, esto es, el antiguo art 10.2 CC, nada decía sobre los mismos, generándose así un debate entre la doctrina española en torno a la calificación sucesoria o contractual de estas figuras, que ya hemos analizado más atrás. Omisión que no dejaba de ser sorprendente, fundamentalmente por el hecho de que los pactos sucesorios eran figuras habituales en los Derechos civiles forales o especiales. Bajo la vigencia del antiguo art. $10.2 \mathrm{CC}$ la mayor parte de la doctrina española ya se decantaba por una calificación sucesoria de los pactos sucesorios; pero fue el vigente art. 9.8 CC el que, con su referencia expresa a los pactos sucesorios dejó atrás toda duda y polémica en torno a la calificación de estas figuras. 
El art. 9.8 CC consagra el principio de unidad de la sucesión al señalar que se aplicará a la sucesión por causa de muerte la ley de la nacionalidad del causante en el momento del fallecimiento, con independencia de la naturaleza de los bienes y el lugar donde se encuentren. Acto seguido, este artículo señala que no obstante, las disposiciones hechas a través de testamento y los pactos sucesorios ordenados de conformidad con la ley nacional del testador o del disponente en el momento de su otorgamiento, conservarán su validez, aunque sea otra la Ley que rija la sucesión, si bien las legítimas se ajustarán, en su caso, a esta última. En definitiva, la solución de ley aplicable a los pactos sucesorios prevista en el sistema español de DIPr se basa en la conexión sucesoria, esto es, la ley de la nacionalidad del causante, si bien con cierta especialidad en torno a su determinación en el tiempo.

\subsection{La especialidad temporal de la conexión sucesoria: Errichtungsstatut}

La característica más reseñable de este modelo de regulación de los pactos sucesorios es la modulación que de la ley sucesoria hacen para su aplicación a los pactos sucesorios; dicha modulación consiste en una especialidad en torno al momento en el que la conexión sucesoria debe ser determinada. Ya hemos tenido oportunidad de ver, al hilo del análisis de aquellos sistemas en los que la defensa de una calificación sucesoria lleva a la aplicación pura y simple de la norma de conflicto de sucesiones a los pactos sucesorios, cómo una conexión determinada en el momento del fallecimiento del causante resulta inadecuada para los pactos sucesorios. El carácter contractual que presentan estas figuras exige el conocimiento del régimen aplicable al pacto desde el mismo momento en que éste es otorgado; sólo de esta forma se pueden proteger las legítimas expectativas de las partes y se puede garantizar la razón económica del pacto. Este carácter de los pactos sucesorios exige en el plano del DIPr una ley aplicable determinada en el momento en el que el pacto es otorgado. Así se empieza hablar del estatuto del otorgamiento (Errichtungsstatut), de la ley sucesoria hipotética o de la ley sucesoria anticipada; en concreto, se trata de aplicar al pacto sucesorio la ley sucesoria, si bien determinada en el momento del otorgamiento, esto es la ley que se aplicaría a la sucesión de fallecer el futuro causante en el momento en que el 
pacto es otorgado. Las conexiones con la que se juegan para determinar la ley aplicable a los pactos sucesorios son las conexiones de las sucesiones internacionales, con la especialidad de su determinación temporal en el momento de celebración del pacto. De esta forma, las partes podrán conocer desde el mismo momento en que el pacto despliega efectos si dicho pacto es válido y a qué régimen jurídico está sometido, con especial atención a las causas de extinción y revocabilidad unilateral del pacto sucesorio.

En el sistema español esta especialidad significa la aplicación a los pactos sucesorios de la ley de la nacionalidad que ostente el disponente en el momento en que el pacto sucesorio es otorgado. Ello se deriva del segundo inciso del art. 9.8 CC, esto es, aquel en el que se proclama la conservación de la validez de los pactos sucesorios de conformidad con la ley nacional del disponente en el momento de otorgamiento. Este párrafo del art. $9.8 \mathrm{CC}$ ha sido objeto de distintas interpretaciones en lo que respecta a su naturaleza en relación con la ley sucesoria. En primer lugar, una parte de la doctrina española señala que, puesto que los pactos sucesorios están incluidos en la norma de conflicto de sucesiones, se les aplica la ley sucesoria y sólo después se refieren al segundo inciso del artículo bien como una excepción a dicha $\operatorname{ley}^{302} \mathrm{o}$ bien como una solución para el problema específico del conflicto móvil ${ }^{303}$, de tal forma que la validez de los pactos se regirá por la ley nacional del disponente (o ley sucesoria anticipada), sin perjuicio de lo establecido por la ley sucesoria en torno a las legítimas. En segundo lugar, otra parte de la doctrina española se limita a señalar directamente la ley sucesoria anticipada como ley aplicable a los pactos sucesorios ${ }^{304}$. Una tercera postura es la que ha mantenido que el art. 9.8 CC es en realidad una norma de conflicto con una conexión alternativa, de tal forma que cabe la posibilidad de aplicar al pacto sucesorio o bien la ley de la nacionalidad del causante en el momento en que otorgó el pacto, o bien la nacionalidad de causante en el momento del fallecimiento ${ }^{305}$; incluso cabe la interpretación de que junto a la ley

\footnotetext{
${ }^{302}$ Vid., J.C. FERNÁNDEZ ROZAS/S. SÁNCHEZ LORENZO, (2009), p. 454.

${ }^{303}$ Vid. E. CASTELlanOS RUIZ, (2010), p. 377;

${ }^{304}$ Vid., A.L. Calvo CaravaCA, (1995), p. 362; C. AzCÁrraga Monzonís, (2008), p. 179.

${ }^{305}$ Vid., M. AguILAR BeníteZ DE LugO, (1978), p. 191.
} 
sucesoria anticipada, pudiera entrar en juego la ley sucesoria como norma de validación. Por último, no ha faltado quien ha defendido una interpretación amplia o extensa del segundo inciso del art. $9.8 \mathrm{CC}$, de tal forma que se limite la aplicación de la ley sucesoria al tema de las legítimas ${ }^{306}$. Es esta la postura a la que nos sumamos nosotros, tal y como ya hemos tenido ocasión de poner de relieve $^{307}$. Son varias las razones que nos llevan a mantener esta interpretación: en primer lugar, la regulación de los pactos sucesorios por la ley sucesoria anticipada del disponente o futuro causante evita la creación de situaciones absurdas como puede ser aquella según la cual dicha ley prevea la validez del pacto sucesorio, pero la ley sucesoria regule las formas de vocación de la herencia y no prevea la modalidad paccionada ${ }^{308}$. En segundo lugar, si se limita la aplicación de la ley sucesoria a la determinación de las legítimas se excluye la posibilidad de que esta ley funcione como norma de validación en los casos en los que el pacto sucesorio no fuera válido conforme a la ley sucesoria anticipada. Exclusión ésta con la que estamos de acuerdo, tal y como veremos con mayor detenimiento, en cuanto que la norma de validación genera problemas en su puesta en funcionamiento que pueden llegar a provocar la pérdida de la razón económica del pacto sucesorio. Por último, la aplicación de la ley sucesoria a la determinación de las legítimas debe limitarse únicamente a la cuantía de las mismas y no al modo en que deba hacerse efectivo el derecho. Esta limitación tiene como objetivo que la protección de los legitimarios afecte lo menos posible a la eficacia del pacto sucesorio y tal afectación es distinta en función de que se pueda pagar la legítima en metálico o que se tengan que reservar ciertos bienes hereditarios. En definitiva, con esta

\footnotetext{
${ }^{306}$ Esta interpretación fue defendida por A. FONT I SEGURA, (2000), p. 45, al hilo del análisis de la ley aplicable al testamento; la colocación sistemática de los pactos sucesorios junto a las disposiciones testamentarias arrastraría esta interpretación a las figuras que nos ocupan. Es más, el propio autor hace una propuesta de lege ferenda abogando por una modificación del art. 9.8 en el sentido de que la sucesión testada y la paccionada quedara regida por la ley personal del futuro causante en el momento de otorgamiento, incluyendo en el ámbito de aplicación de esta norma también las legítimas; y la sucesión intestada quedara regida por la ley personal del causante en el momento del fallecimiento; esto supondría la existencia de una norma de conflicto para la sucesión paccionada, otra para la testada y otra para la intestada, vid. p. 43 y 46 y ss.; de nuevo A. FonT I SEGURA, (2009), p. 13; también se muestra acorde con esta interpretación, B. AÑOVEROS TERRADAS, (2009), pp. 169-170; S. ÁlVAREZ GONZÁlEZ (2012), pp. 185 y ss.

${ }^{307}$ Con mayor profundidad, I. RoDRíGUEZ-URÍA SUÁREZ (2010), pp. 647 y ss.

${ }^{308}$ A. Font SEgURA (2009), p. 13; A. BonOMi (2008), p. 22.
} 
interpretación se consigue una mayor seguridad jurídica y una mayor preservación de los pactos sucesorios.

En todo caso, a la luz de las variadas interpretaciones que del art. 9.8 CC se han mantenido, ya podemos intuir uno de los problemas más importantes que este artículo deja abiertos y que se deriva de la posible convivencia de dos leyes distintas. Se trata de saber cuál es la relación entre la ley aplicable al pacto sucesorio (ley sucesoria anticipada) y la ley sucesoria. Ambas, de ser distintas, confluyen en un mismo fenómeno: la sucesión hereditaria del causante de que se trate; esto plantea la necesidad de determinar qué aspectos del pacto sucesorio y de la sucesión en general quedan regulados bajo una ley y otra suponiendo que ambas sean simultáneamente aplicables.

Sea como fuere, este modelo de regulación lo podemos encontrar en otros sistemas europeos en los que generalmente se reconocen los pactos sucesorios en el plano del Derecho material. Este es el caso, en primer lugar, del ordenamiento jurídico alemán. El EGBGB dedica los $\S 25$ y 26 a las sucesiones internacionales; el $\S 25$ recoge la ley aplicable a las sucesiones en general, adoptando el principio de unidad de la sucesión, bajo el imperio de la ley nacional del causante determinada en el momento del fallecimiento. Los pactos sucesorios, sin embargo, entran dentro del ámbito de aplicación del $\S 26$, que regula la ley aplicable a las disposiciones por causa de muerte; este artículo recoge en su apartado V el estatuto del otorgamiento para la determinación de la ley aplicable a la validez de las disposiciones por causa de muerte, al señalar que se aplicará la ley sucesoria anticipada o hipotética en el momento de la celebración del acto ${ }^{309}$. No obstante, el Derecho alemán presenta una peculiaridad derivada de la posibilidad que permite el $\S 25$. II de realizar una professio iuris limitada, a favor de la ley alemana en aquellos casos en los que se trate de la sucesión de inmuebles sitos en dicho país. Trasladada esta posibilidad a los pactos sucesorios significa que, por ejemplo, un francés puede realizar en Alemania un pacto sucesorio válido, a través del cual realice una atribución particular de un inmueble sito en

${ }^{309}$ Sobre la aplicación del estatuto del otorgamiento a los pactos sucesorios, H. DÖRNER (2007), p. 202, núm. 258, p. 228, núm. 360 y p. 424, núm. 60; R. BIRK (2006), p. 1617, núm. 133 y p. 1618, núm. 138. 
Berlín a favor de un tercero, siempre y cuando en el pacto se escoja la ley alemana $^{310}$.

El sistema austriaco es otro ejemplo de este modelo de regulación; la ley austriaca de DIPr dedica los $\S 28$ a 30 a las sucesiones internacionales. El $\S 28$ recoge el principio de unidad de la sucesión, bajo la aplicación del estatuto personal del causante, esto es, su nacionalidad, determinado en el momento del fallecimiento. Pero, al igual que lo que ocurre en la EGBGB, el $\S 30$ establece una norma especial para determinar la validez de las disposiciones por causa de muerte. Dicho parágrafo recoge el estatuto del otorgamiento, de tal forma que los pactos sucesorios se regirán por la ley nacional del causante en el momento de otorgamiento; pero, al lado del estatuto del otorgamiento, es posible determinar la validez de los pactos sucesorios bajo la ley sucesoria, cuando estos sean inválidos bajo la ley sucesoria anticipada. Es decir, el sistema austriaco recoge la denominada norma de validación ${ }^{311}$.

Otro ejemplo cercano lo encontramos en el sistema portugués; los pactos sucesorios están recogidos en el art. 64 c) CCPort., junto a la regulación prevista para la interpretación de las disposiciones sucesorias y los vicios de la voluntad. Según dicho artículo, los pactos sucesorios se regirán por la ley personal del causante, esto es, la ley nacional, determinada en el momento de la declaración. No obstante, el sistema portugués también presenta una particularidad derivada de la posibilidad de que los pactos sucesorios se integren dentro de pactos prematrimoniales; en este sentido, el art. 64 c) CCPort. señala una salvedad, de tal forma que la norma especial prevista para los pactos sucesorios, se entiende sin perjuicio de lo dispuesto en el art. 53 del mismo código que regula la ley aplicable a los pactos prematrimoniales. En definitiva, los pactos sucesorios que se realicen

\footnotetext{
${ }^{310}$ La doctrina no se pone de acuerdo en torno a la naturaleza que debe tener la elección de ley aplicable en un pacto sucesorio; a favor de un carácter unilateral y, por tanto, de una posible professio iuris, H. DÖRNER (2007), p. 269, núm. 508; a favor del carácter bilateral, R. BIRK (2006), p. 1500, núm. 38.

311 A. DUCHEK/F. SCHWIND (1979), p. 75, § 30; F. SCHWIND (1990), p. 172, núm. 359; M. SCHWIMANN (1993), p. 92; W. Posch, (2002), p. 68, núm. 12/6; F. HAUnSCHMIDT (2008), p. 1092, núm. 7; La ley sucesoria, determinada en el momento del fallecimiento, sólo entra en juego en el caso de que el pacto sucesorio no sea válido de conformidad con el estatuto del otorgamiento; sobre la norma de validación, nos detendremos más adelante.
} 
a través de un pacto prematrimonial no se regirán por la ley nacional del causante en el momento de la declaración, sino por la norma de conflicto prevista para los contratos prematrimoniales $^{312}$.

\section{La solución de ley aplicable a los pactos sucesorios que afectan a más de una sucesión}

\subsection{La falta de solución expresa y las propuestas de interpretación}

Tal y como hicimos con el modelo anterior, en el presente apartado analizaremos la problemática particular de la solución de ley aplicable a los pactos sucesorios que afectan a más de una sucesión a la luz del modelo de regulación que ahora nos ocupa. Para ello nos serviremos de un ejemplo en el que aplicaremos la solución del art. 9.8 CC a un pacto sucesorio con instituciones recíprocas. El supuesto podría ser el de un pacto sucesorio otorgado entre cónyuges, uno de nacionalidad española y vecindad civil catalana y otro de nacionalidad italiana, en el que se instituyen recíprocamente herederos. De acuerdo con la solución del art. 9.8 CC se aplicará a este pacto la ley nacional del causante en el momento del otorgamiento del pacto; lo que ocurre es que aquí tenemos dos potenciales causantes y, por tanto, dos leyes sucesorias anticipadas: la ley italiana, que prohíbe los pactos sucesorios y la ley catalana (puesto que la aplicación del art. 9.8 CC en caso de conflicto de leyes interno nos lleva a aplicar la ley de la vecindad civil) que recoge la posibilidad de realizar este pacto a través del denominado heredamiento mutual (art. 431.2 y art. 431.20 CCCat). El art. 9.8 CC sólo señala que los pactos sucesorios conservarán su validez de conformidad con la ley nacional del disponente en el momento del otorgamiento, pero no da solución alguna para los casos en los que haya dos o más disponentes. En el ejemplo, del art. 9.8 CC no se deriva ni la aplicación de la ley catalana ni la aplicación de la ley italiana.

\footnotetext{
${ }^{312}$ Vid., J. BAPTISTA MACHADO (2009), p. 444. El art. 53 CCPort. recoge una norma de conflicto en cascada para determinar la ley aplicable a los pactos prematrimoniales, donde se tiene en cuenta el carácter bilateral de estos pactos. Según este artículo, se aplicará, en primer lugar, la ley nacional común de los cónyuges determinada en el momento en que contraen matrimonio; en el caso de que no tengan la misma nacionalidad, se aplicará, en segundo lugar, la ley de la residencia habitual común en el momento en que contraen matrimonio y, de no tenerla, la ley correspondiente a la primera residencia habitual conyugal.
} 
Lo mismo ocurre con otros ordenamientos jurídicos que se corresponden con este modelo de regulación. En definitiva, no se da respuesta, al menos de manera expresa, a la determinación de la ley aplicable a los pactos sucesorios que afectan a más de una sucesión. La doctrina, consciente de esta ausencia, se ha preocupado por articular una solución a este problema. La cuestión reside en determinar cómo se debe conjugar el funcionamiento de las distintas leyes sucesorias anticipadas que concurren en el pacto sucesorio. Las opciones posibles se reducen a tres: la interpretación distributiva, la interpretación cumulativa y la interpretación alternativa.

La interpretación distributiva implica el tratamiento de cada disposición sobre la herencia realizada en el pacto sucesorio de manera independiente; de esta forma, se aplicará cada ley sucesoria anticipada a cada disposición sucesoria realizada en el pacto. En el ejemplo que hemos puesto supondría la aplicación, por un lado, de la ley catalana para la determinación de la validez de la disposición del cónyuge catalán a favor del cónyuge italiano; y, por otro lado, la aplicación de la ley italiana para la determinación de la validez de la disposición del cónyuge italiano a favor del cónyuge catalán. Esta solución ha sido defendida por parte de la doctrina portuguesa ${ }^{313}$. No obstante, presenta importantes inconvenientes, pues anula la reciprocidad y rompe la unidad del pacto sucesorio, pudiendo implicar la ruptura de la razón económica del mismo. Se trata de una opción que a nuestro juicio debe rechazarse por esta razón.

La segunda opción que se baraja es la interpretación cumulativa; esta solución consiste en la aplicación de todas las leyes sucesorias anticipadas en juego al pacto sucesorio; en el ejemplo, supondría la aplicación tanto de la ley catalana, como de la ley italiana al pacto sucesorio. Para determinar la validez de éste es necesario que ambas leyes así lo reconozcan; por ello, en el ejemplo, esta solución determinaría la invalidez del pacto sucesorio. La opción cumulativa de las leyes sucesorias anticipadas en juego es la interpretación que la mayor parte de la doctrina ha defendido para dar solución al problema de la falta de respuesta de este modelo de regulación para señalar la ley aplicable a los pactos sucesorios que

${ }^{313}$ Vid., J. BAPTISTA MACHADO, (2009), p. 444; L. DE LiMA PinHEIRO, (2002), p. 317. 
afectan a más de una sucesión ${ }^{314}$. Se trata de una solución conservadora, restrictiva a la validez de los pactos sucesorios; pero por otro lado, es una opción que busca una validez fuerte de estas figuras y asegura su eficacia en el espacio. Creemos, no obstante, que la propuesta de una conexión cumulativa puede ser más operativa en términos de admisibilidad (y, a nuestro juicio, esta es la idea que late tras las diversas propuestas doctrinales) que de régimen jurídico en sí mismo considerado. Someter el régimen jurídico de un pacto sucesorio admisible por dos leyes distintas a las exigencias de contenido de ambas resulta un ejercicio técnico de enorme complejidad y de potenciar frustración del pacto sucesorio.

La tercera posición que sobre este problema se puede tomar es la de una interpretación alternativa; el funcionamiento de esta opción consiste en que basta con que una de las leyes sucesorias anticipadas en juego reconozca el pacto sucesorio, para que éste sea válido y eficaz. En el ejemplo supondría la validez del pacto sucesorio con base en el ordenamiento jurídico catalán y a pesar de la invalidez del pacto al amparo de la ley italiana. Esta interpretación, claramente favorecedora a la validez de los pactos sucesorios, no ha tenido, por el momento, especial consideración por parte de la doctrina; ello se puede deber, probablemente, a su previsible frustración en la práctica, derivada de los posibles problemas de eficacia que en el ámbito internacional pueden tener los pactos sucesorios otorgados bajo estas circunstancias, máxime con el recelo que aún hoy en día existe en torno a estas figuras en muchos ordenamientos jurídicos.

\subsection{La situación del art. $9.8 \mathrm{CC}$}

El art. 9.8 CC no da solución expresa al problema de la ley aplicable a los pactos sucesorios que afectan a más de una sucesión en los casos en los que los causantes tienen distinta nacionalidad al tratar a estas figuras como meros actos unilaterales $\mathrm{y}$, por tanto, como en el resto de sistemas que adolecen de esta ausencia, se plantea cuál es la opción más adecuada para dar respuesta a este

\footnotetext{
314 Entre la doctrina alemana, H. DöRnER, (2007), p. 227, núm. 351; R. BIRK, (2006), p. 1617, núm. 134; J. KROPHOLLER, (2004), p. 440; en la doctrina austriaca, F. SCHWIND (1990), p. 172, núm. 359; K. FIRSCHING (2004), p. 109, núm. 584: de forma más tímida, L. RAAPE (1961), p. 426.
} 
problema. De las opciones interpretativas que hemos visto, sólo se han barajado dos de ellas para el art. $9.8 \mathrm{CC}$.

La solución distributiva se ha tomado en consideración por ser la interpretación que más se ajusta al sentido literal del art. 9.8 CC. No obstante, rápidamente se descarta por su inoperatividad en los pactos sucesorios al atacar directamente la lógica material del pacto sucesorio ${ }^{315}$. La solución que más ha convencido a la doctrina española ha sido la interpretación cumulativa, esto es, la aplicación de todas y cada una de las leyes sucesorias anticipadas en presencia, de tal forma que el pacto sucesorio sólo podrá ser válido cuando todas las leyes implicadas así lo reconozcan ${ }^{316}$.

La interpretación cumulativa supone una postura restrictiva respecto de los pactos sucesorios, pero también más segura para la eficacia de los mismos; es más, siendo la cuestión de la admisión o prohibición de los pactos sucesorios un tema delicado, esta opción conservadora puede parecer a priori la más adecuada. Sin embargo, no alcanzamos a ver ninguna razón categórica que impida abogar por una interpretación alternativa de las leyes sucesorias anticipadas en presencia en el marco del art. 9.8 CC. Tal interpretación implica un claro favor negotii en la regulación de los pactos sucesorios, que se puede justificar en varias razones.

En primer lugar, la interpretación alternativa toma en consideración tanto la autonomía de la voluntad de las partes, en general, como la propia libertad del causante, en particular. El pacto sucesorio no deja de ser una manifestación más de la autonomía de la voluntad de las partes, interés éste que, por tanto, se ve respetado y consagrado a través de una interpretación favorable a la celebración y validez del pacto sucesorio. En cuanto a la libertad del causante en particular, la celebración de un pacto sucesorio es también un concreto uso de la misma. Una de las tradicionales razones, y la que mayor peso ha tenido y sigue teniendo, que se manifiestan para el mantenimiento de la prohibición de los pactos sucesorios es

\footnotetext{
${ }^{315}$ A. FonT I SEGURA (2009), p. 18.

${ }^{316}$ A. FONT I SEGURA (2000), p. ; el mismo autor, (2009), p 18. ; B. AÑOVEROS TERRADAS (2009), p. 170; respecto de los testamentos mancomunados también se ha defendido una interpretación cumulativa, E. ZABALO ESCUDERO (1989), p. 6364.
} 
la de la pérdida de libertad de disposición mortis causa del causante, derivada del carácter irrevocable de las disposiciones contenidas en los pactos sucesorios. El carácter de estas disposiciones choca frontalmente con el principio de libre revocabilidad de las disposiciones por causa de muerte que el causante debe tener hasta el mismo momento de su fallecimiento ${ }^{317}$. No obstante, un sencillo cambio de punto de vista sobre la cuestión nos permite observar cómo el otorgamiento de un pacto sucesorio no se presenta como algo tan traumático para la libertad del causante. De hecho, como ya hemos dicho, la celebración de un pacto sucesorio es una manifestación de esta libertad, pues es el causante el que decide disponer de su patrimonio mortis causa a través de pacto sucesorio. Sabiendo que podría planificar su sucesión a través de testamento, el causante prefiere realizar un pacto sucesorio, consciente que de esta forma renuncia desde ese mismo momento a la posibilidad de revocar sus disposiciones por causa de muerte hasta su fallecimiento, pero obteniendo a cambio la ventaja que específicamente le reporte la celebración del pacto sucesorio de que se trate. Dicho de otro modo, nos parece a todas luces soportable que el futuro causante decida otorgar libremente un pacto sucesorio, siendo consciente de que con ello renuncia a su derecho a revocar libremente esas disposiciones por causa de muerte; no vemos ninguna razón por la que se deba al causante impedir esta posibilidad, pues de otro modo, eso significaría elevar el principio de libre revocabilidad a la categoría de indisponible e irrenunciable, lo que además de ser excesivamente proteccionista, sería incoherente, pues dicho principio sólo entraría en juego cuando el causante hubiera tomado la decisión de disponer de su patrimonio para después de su muerte, lo cual no es más que una opción. Por otro lado, piénsese que pactos sucesorios típicos, como el de renuncia anticipada a la legítima o renuncia al derecho de acrecer, lejos de reducir la libertad de disposición del causante, lo que hacen es aumentarla.

En segundo lugar, no debemos ignorar la presencia cada vez mayor de un interés social en estas figuras en cuanto mecanismo facilitador de la pacífica transmisión sucesoria de las pequeñas y medianas empresas. Como ya hemos

${ }^{317}$ M. HerRero OVIEDO (2009), p. 205. 
tenido ocasión de ver, los estudios que en el ámbito de la UE se han realizado sobre las empresas europeas han dado como resultado que alrededor de un $30 \%$ de las mismas cierran su actividad empresarial como consecuencia de problemas en su transmisión sucesoria. Esta preocupación ha llevado a la UE a mostrar una actitud positiva en torno a la admisión de los pactos sucesorios, por constituir estas figuras un buen medio para la transmisión de estas empresas ${ }^{318}$. Desde este punto de vista, una solución favorecedora de la validez de los pactos sucesorios se presenta como más satisfactoria que una solución restrictiva ${ }^{319}$.

Por último, nos parece de igual modo oportuno tomar en consideración la actual tendencia al renacimiento de los pactos sucesorios; ordenamientos jurídicos en los que tradicionalmente se han prohibido radicalmente estas figuras dan paso ahora a una nueva etapa caracterizada por la erosión de tal prohibición a través de la introducción de nuevas posibilidades que constituyen verdaderas excepciones a la misma. Recordemos que la solución de DIPr en términos de materialización no puede dejar de tener en cuenta las soluciones $\mathrm{y}$, sobre todo, las tendencias del Derecho material o, en su caso, de los Derecho materiales en presencia. En definitiva, una interpretación alternativa es más acorde con la tendencia actual a la ampliación del campo de actuación de los pactos sucesorios ${ }^{320}$.

\section{CALIFICACIÓN SUCESORIA: TRATAMIENTO INDIFERENCIADO \\ 1. La existencia de una norma de conflicto ad hoc para pactos sucesorios}

El modelo de regulación de pactos sucesorios que nos resta por analizar es aquel en el que el sistema de DIPr prevé una solución específica para estas figuras. Los pactos sucesorios gozan de un tratamiento autónomo, pero la

\footnotetext{
318 Vid., Recomendación de la Comisión de 7 de diciembre de 1994, sobre la transmisión de pequeñas y medianas empresas, DOUE L 385 de 31 de diciembre de 1994, pp. 0014-0017 y Comunicación de la Comisión sobre transmisión de las pequeñas y medianas empresas, DOUE C 93/2 de 28 de marzo de 1998.

${ }^{319}$ Lamentablemente, a las iniciales expectativas positivas que había levantado la Propuesta de Reglamento de 2009 le ha seguido un texto final que opta por la más conservadora opción cumulativa.

${ }^{320}$ En Derecho civil, vid., M. Herrero OvIEDo (2009), pp. 207 y ss. y 212 y ss.; también, M.P. GARCÍA RUBio/M. HERRERo OVIEDO (2011), pp. 1283 y ss.
} 
calificación sigue siendo sucesoria; además, junto a las eventuales soluciones particulares, en todos los casos aparecerá la presencia de una ley sucesoria general de uno u otro modo. El ejemplo paradigmático lo encontramos en el ordenamiento jurídico suizo, donde la ley de DIPr reserva su art. 95 para dar solución a los concretos problemas de ley aplicable a los pactos sucesorios. Ya podemos adelantar aquí que la regulación del mencionado artículo supone el sistema vigente más desarrollado y específico de los pactos sucesorios internacionales en una codificación nacional de DIPr.

El art. 95 de la LSDIPr se integra sistemáticamente dentro de su capítulo sexto, dedicado a las sucesiones internacionales. Por ello, antes de realizar el análisis concreto de su alcance, es conveniente contextualizarlo dentro del sistema suizo para las sucesiones internacionales. Este sistema sigue la concepción de la unidad de la sucesión, bajo la competencia de la ley correspondiente al último domicilio del causante (art. 90. 1 LSDIPr). No obstante, es posible que la competencia para regular la sucesión pase a ser de la ley de la última nacionalidad del causante como consecuencia del ejercicio de la professio iuris que el sistema suizo pone en manos de éste ${ }^{321}$.

El mencionado artículo contiene cuatro apartados, en los que se regula la ley aplicable a la validez y efectos de los pactos sucesorios, la posibilidad de realizar una professio iuris y la ley aplicable a la validez formal y a la capacidad para contratar a través de estas figuras. Pero la característica más importante es, como vamos a ver, la diferenciación que en términos conflictuales se recoge entre los pactos sucesorios que afectan a una sucesión y los pactos sucesorios que afectan a varias sucesiones.

En el primer apartado del art. 95 LSDIPr se regula la ley aplicable a los pactos sucesorios que afectan a una única sucesión, señalando que se les aplicará

\footnotetext{
${ }^{321}$ El art. 90.2 LSDIPr permite al causante extranjero domiciliado en suiza someter el conjunto de su sucesión a través de testamento o de pacto sucesorio a la ley de una de sus nacionalidades, siempre y cuando dicha nacionalidad se conserve en el momento de su fallecimiento; en cuanto al causante suizo domiciliado en el extranjero, el art. 87.2 LSDIPr prevé la posibilidad de que pueda someter el conjunto de su sucesión o la parte de ella que en Suiza se encuentre, a través de testamento o de pacto sucesorio, a la regulación de la ley suiza.
} 
la ley correspondiente al domicilio del causante en el momento de otorgamiento del pacto sucesorio. El punto de conexión, por tanto, es el mismo que el previsto para las sucesiones en general, encontrándose la especialidad en el momento en que es determinado. Esta misma solución era la prevista en el sistema suizo anterior al vigente (art. 25 LRDC $^{322}$ ), con el fundamento de que los otorgantes no podían conocer en el momento de celebración del pacto, la ley del último domicilio del causante ${ }^{323}$. No obstante, cabe que el pacto sucesorio se rija por la ley de la nacionalidad del causante si se realiza la professio iuris en este sentido y para el conjunto de la sucesión, tal y como posibilita específicamente el art. 95.2 LSDIPr.

El art. 95.1 LSDIPr señala genéricamente que el pacto sucesorio se regirá por la ley del domicilio del causante; se nos plantea la cuestión de si esta norma de conflicto señala una ley dirigida a regular la sucesión contractual al completo. A este respecto, debemos señalar, por un lado, que el apartado cuarto del mismo artículo, excluye de esta ley las cuestiones de validez formal del pacto sucesorio y de capacidad para su otorgamiento, remitiéndose a los artículos correspondientes. Por otro lado, debemos tener en cuenta lo dispuesto en el Message $\left(\mathrm{n}^{\mathrm{o}}\right.$ 264.1), donde se señala que esta ley rige el pacto sucesorio en su conjunto, determinando tanto su admisibilidad, como su fuerza obligatoria y efectos sucesorios ${ }^{324}$. Pese a esta concreción queda abierta la cuestión de la convivencia entre la ley aplicable al pacto y la ley sucesoria, fundamentalmente en lo que atañe a un aspecto tan crucial como la protección de los derechos de legitimarios. Efectivamente, se trata de un tema sobre el que no hay acuerdo entre la doctrina suiza. Algunos autores entienden que las disposiciones contenidas en los pactos sucesorios y realizadas de conformidad con la ley determinada en el momento del otorgamiento no podrán atentar contra los derechos legitimarios que la ley sucesoria prevea en el

\footnotetext{
${ }^{322}$ Loi fédérale sur les rapports de droit civil des citoyens établis ou en séjour, de 25 de junio de 1891; CH. Soldan (1884), pp. 533-584; P. DES GouTtes (1892); M. GuldenER (1951); A.F. SCHNITZER (1954), pp. 143-163; M. SCHOCH (1988), pp. 738-779.

${ }^{323}$ A. F. SCHNITZER (1958), p. 519.

${ }^{324}$ Vid., Message du Conseil Fédéral concernant une loi fédérale sur le droit international privé, du 10 novembre 1982, Fueille Fédérale, 1983, vol. 1, pp. 255-501.
} 
momento del fallecimiento del causante ${ }^{325}$, mientras que otros dan más relevancia a esta ley sucesoria anticipada que incluiría dentro de su ámbito de aplicación a las legítimas ${ }^{326}$.

\section{Diferenciación conflictual entre pactos sucesorios}

El carácter diferenciador del modelo de regulación que nos brinda el Derecho suizo se basa principalmente en la existencia en el sistema de una respuesta concreta a la problemática particular que en cuanto a la determinación de la ley aplicable encierran los pactos sucesorios que afectan a más de una sucesión. El apartado tercero del art. 95 LSDIPr establece una solución concreta para la ley aplicable a este tipo de pactos sucesorios. Esta previsión constituye una novedad en el sistema de DIPr suizo, puesto que la antigua ley de 1891 no realizaba distinción alguna entre los pactos sucesorios que afectan a una sucesión y los que afectan a varias; lo que sí preveía dicha ley era la aplicación de otra norma de conflicto para el caso de que el pacto sucesorio se insertara en un contrato matrimonial $^{327}$. Dicho apartado se refiere a las disposiciones recíprocas por causa de muerte, lo que la doctrina ha interpretado como aquellas disposiciones cuya validez está condicionada por la validez de la otra y viceversa $^{328}$.

La concreta solución que ha adoptado la LSDIPr es la de la aplicación cumulativa de las leyes en presencia, de tal forma que el pacto sucesorio se regulará por las leyes correspondientes a los domicilios de los futuros causantes en el momento del otorgamiento del pacto. En el caso de que tales leyes sean distintas, la validez de cada disposición contractual dependerá de que así lo reconozca cada una de las leyes que haya que considerar. No obstante, el propio artículo permite la posibilidad de realizar una elección de ley aplicable al pacto

\footnotetext{
${ }^{325}$ A. Von Overbeck, (1988), p. 77; A. Bucher (1992), p. 316, núm. 979; B. Dutoit (2005), p. 313.

${ }^{326}$ A. HEINI, (2004), p. 1067, núm. 11.

${ }^{327}$ En tal caso, el art. 24 de la LRDC preveía la aplicación de la ley correspondiente al primer domicilio de los cónyuges, vid., A.F. SCHNITZER (1944), p. 432.

${ }^{328}$ A. VON OVERBECK (1988), p. 77.
} 
sucesorio que, al haber más de un causante cuya sucesión está afectada, sólo podrá realizarse a favor de la ley nacional común de los otorgantes disponentes.

En definitiva, no podemos sino aplaudir el hecho de que la clasificación entre pactos sucesorios que afectan a una sucesión y pactos sucesorios que afectan a varias sucesiones tenga su reflejo en el plano del DIPr suizo, pues tal y como hemos visto esta necesaria clasificación de los pactos en función del número de sucesiones afectadas por los mismos exige su correlativa traslación en el plano de la ley aplicable.

\section{BALANCE DE LOS SISTEMAS DE REGULACIÓN DE LA LEY APLICABLE A LOS PACTOS SUCESORIOS EN TÉRMINOS DE INTERESES}

\section{Los modelos de regulación caracterizados por la ignorancia de los pactos sucesorios: la ausencia de intereses contractuales}

Los sistemas de regulación caracterizados por una ausencia de regulación de los pactos sucesorios tienen ciertas características en común. Los analizados se corresponden con ordenamientos jurídicos en los que los pactos sucesorios están prohibidos en Derecho material; la combinación de esta prohibición junto con la ausencia de referencia en el plano del DIPr ha llevado a la doctrina y jurisprudencia a plantearse su posible contrariedad con el orden público. El caso vivido en España bajo la vigencia del antiguo art. 10.2 CC es el más llamativo y sorprendente, pues el hecho de que la doctrina se planteara e incluso defendiera la contrariedad de los pactos sucesorios con el orden público español no deja de ser el resultado de la traducción al DIPr del ordenamiento jurídico representado por el CC, ignorando la existencia de otros ordenamientos españoles en los que desde siempre se han admitido en mayor o medida los pactos sucesorios. En estos sistemas se puede apreciar una evolución favorable a los pactos sucesorios, tanto en la doctrina como en la jurisprudencia, lo que tiene sus consecuencias en cuanto a la ley aplicable. Nuestro art. 9.8 CC sería paradigma, de no ser porque, a la luz de la reglamentación autonómica, no puede considerarse sino un ejercicio de mero realismo (con independencia de su pertinencia o no).

Dejando de lado la calificación contractual que de manera marginal se ha defendido de los pactos sucesorios en este modelo, una vez superada la 
problemática de la contrariedad o no contrariedad de los pactos sucesorios con el orden público, la mayor parte de la doctrina y jurisprudencia aboga por una calificación sucesoria de estas figuras. Esta calificación significa la aplicación de la ley sucesoria a los pactos sucesorios. Así por ejemplo, bajo el sistema italiano se les aplicará la ley nacional del causante en el momento del fallecimiento o bajo el sistema francés la ley del último domicilio del causante si el pacto afecta a bienes muebles y la lex rei sitae en lo que el pacto afecte a inmuebles.

La característica fundamental de este tipo de sistemas reside en el hecho de que el punto de conexión, tratándose de una conexión personal, viene determinado en el momento del fallecimiento. Con esta solución, los intereses contractuales existentes en los pactos sucesorios se ven claramente comprometidos. Respecto del interés de la autonomía de la voluntad de las partes sólo cabe señalar que juega simplemente dentro de los márgenes más o menos amplios de la libertad de disposición mortis causa que tenga el causante; sin embargo, ni la vinculación de las partes al contenido del pacto ni la seguridad jurídica son valores presentes en esta solución de DIPr.

La vinculación de las partes al pacto sucesorio es un efecto que, por definición, debe darse desde el mismo momento en que las partes otorgan el pacto y se comprometen a determinados derechos y obligaciones en el mismo. Las partes tienen que saber a qué se vinculan en el momento en que prestan sus consentimientos. Así, por ejemplo, en un pacto de institución el causante tiene que conocer desde el momento de la celebración en qué medida se va a limitar su capacidad de disponer mortis causa; o, por el contrario, en un pacto de renuncia, debe saber en qué medida tal pacto implica una ampliación de su libertad de disposición para así poder seguir planificando su herencia de la mejor manera que estime. De igual forma, el cootorgante no disponente, debe conocer, en su caso, los derechos y obligaciones que haya podido adquirir; sólo de esta forma las partes podrán ver garantizadas sus expectativas. Todo ello se resume en la necesidad de seguridad jurídica para las partes; seguridad, en este caso, que se traduce en la necesidad de conocer el régimen al que el pacto sucesorio está sometido desde el mismo momento de su otorgamiento. Pues bien, tales intereses 
no están presentes en una solución que determina la ley aplicable en el momento del fallecimiento del causante. Los otorgantes no pueden conocer con certeza si el pacto será válido o no y qué contenido puede tener, así como cuáles son, en su caso, las causas de extinción y revocación unilateral del mismo hasta un momento posterior al de su celebración; en efecto, en el momento del otorgamiento del pacto no sabrán cuál es el último domicilio o la última nacionalidad del causante y, por tanto, no se puede determinar cuál es la ley aplicable al pacto sucesorio ${ }^{329}$. Es más, se plantea la posibilidad de que el causante, una vez otorgado el pacto sucesorio, pueda dejar de tener interés en verse vinculado por las disposiciones del mismo y evitarlo frustrando las expectativas del cootorgante, con un simple cambio de la circunstancia personal que determina la ley sucesoria, sobre todo en el caso de que ésta se determine a través de su domicilio ${ }^{330}$.

En suma, desde el punto de vista de los intereses vinculados a la dimensión contractual de los pactos sucesorios, la solución de aplicar la ley sucesoria determinada en el momento del fallecimiento del causante implica que las partes nunca verán garantizadas sus expectativas y podrán conocer si realmente están vinculados o no a algo que jurídicamente exista; esta falta de seguridad jurídica conlleva, en muchas ocasiones, la pérdida de la razón económica del pacto.

\section{Los sistemas que prevén una solución específica para los pactos sucesorios: la atención a los intereses contractuales}

La agrupación de los dos tipos de modelos de regulación que prevén una solución expresa para la determinación de la ley aplicable a los pactos sucesorios se justifica en el hecho de que la característica fundamental que ahora nos interesa concurre en todos ellos, con independencia de cómo se formule y con independencia también del hecho de que haya o no solución expresa para los

\footnotetext{
${ }^{329}$ Es preciso matizar que este problema de desconocimiento de la ley aplicable no ocurre en el caso de la aplicación de la lex rei sitae a los bienes inmuebles, si bien esto depende de la norma de conflicto del foro.

${ }^{330} \mathrm{La}$ inadecuación de una conexión determinada temporalmente en el momento del fallecimiento del causante para la determinación de la ley aplicable a los pactos sucesorios ya se puso de manifiesto por la doctrina desde hace muchos años. Vid., por ejemplo, en Francia, E. BARTIN (1932), p. 71; H. BATIFFOL (1967), p. 713.
} 
pactos sucesorios que afectan a más de una sucesión. Tal característica no es otra que la concreción del punto de conexión de la ley que se va a aplicar a los pactos sucesorios en el momento en que estos son otorgados; a su vez, esta característica es la diferencia más importante que en la práctica existe entre estos sistemas y los que se corresponden con el modelo de regulación en donde nada se prevé sobre los pactos sucesorios.

La determinación de la ley aplicable al pacto sucesorio desde el momento en que éste es celebrado presenta diversas ventajas desde el punto de vista de seguridad y previsibilidad. En primer lugar, permite a las partes saber si el pacto sucesorio es válido o no y, por tanto, conocer si están o no vinculados por el mismo y en qué términos. Así, por ejemplo, pensemos en un pacto sucesorio de renuncia realizado entre un padre alemán y su hijo pequeño, a través del cual éste renuncia al derecho a la legítima en la herencia de su padre; la aplicación de la ley nacional del causante en el momento del otorgamiento, permite al causante saber que el pacto es válido $\mathrm{y}$, por tanto, le permite poder seguir planificando su sucesión de la forma que estime conveniente con garantías. De este modo, este mismo causante, confiando en la mayor libertad de disposición mortis causa como consecuencia del pacto de renuncia realizado, vuelve a otorgar otro pacto sucesorio, esta vez con su hijo mayor, a través del cual le instituye heredero en la empresa familiar. De nuevo, la aplicación de la ley nacional que el causante ostenta en ese momento permitirá a las partes saber si el pacto es válido o no. Siendo válido el pacto, el causante sabrá a qué está vinculado y será consciente de la consiguiente pérdida de libertad de disposición mortis causa; por su parte, el hijo instituido tendrá la seguridad de que la empresa familiar le pertenecerá en el futuro, lo que generalmente garantiza el compromiso del hijo con el negocio familiar, razón que suele ser la causa de la celebración de este tipo de pactos. Las partes, por otro lado, podrán conocer el régimen jurídico del pacto sucesorio; así por ejemplo, saber cuáles son las causas por las que se puede revocar unilateralmente el pacto sucesorio permite a las partes adecuar su actuación a las circunstancias o al menos saber en qué casos corren el riesgo de que el pacto sea revocado. En definitiva, la aplicación a los pactos sucesorios de una ley determinada en el momento del otorgamiento de los mismos, permite a las partes 
asegurar sus expectativas y, aspecto no menos importante, jugar en el tráfico con esas expectativas que tienen un real contenido económico también para terceros.

No obstante, no podemos dejar de señalar que la permanente presencia de la ley sucesoria general junto a la ley rectora del pacto sucesorio (la que sea) puede plantear problemas de eficacia del mismo. En realidad, el equilibrio real entre los intereses sucesorios y contractuales de los pactos sucesorios en la norma de conflicto depende precisamente de la mayor o menor presencia de la ley sucesoria o, dicho de otro modo, de los distintos aspectos que estén dentro del ámbito de aplicación de la ley aplicable al pacto sucesorio y del ámbito de aplicación de la ley sucesoria, algo que, como ya hemos dicho, es una cuestión que estos sistemas dejan abierta.

\section{La permanente presencia de la ley sucesoria y los intereses sucesorios presentes en los pactos}

Como hemos dicho con anterioridad, en los pactos sucesorios concurren al menos dos tipos de intereses sucesorios que se contraponen necesariamente; tales son el interés del causante en tener el mayor margen de libertad de disposición mortis causa sobre su patrimonio y el interés de determinados familiares próximos al causante de recibir cierta parte de la herencia de éste. La libertad de disposición del causante se traduce en pactos sucesorios como un mecanismo más en sus manos para planificar su sucesión por anticipado. En los pactos que afectan a una sucesión ninguno de los modelos de regulación añade especialidad alguna a este respecto, esto es, ni se amplían ni se aminoran las posibilidades que el causante tiene para disponer de su herencia a través de un pacto sucesorio. Dicha posibilidad dependerá directa y únicamente de lo que diga la ley sucesoria o la ley sucesoria anticipada al respecto y, por tanto, de la libertad de disposición que esta ley otorgue al causante.

Mayor enjundia puede encontrarse en el caso de los pactos sucesorios que afectan a más de una sucesión. En tales pactos concurren varias leyes sucesorias o varias leyes sucesorias anticipadas y en función de cómo se articule la concurrencia entre ellas un causante puede ver ampliada o aminorada su libertad de disposición para otorgar pactos sucesorios. La solución distributiva 
nada suma ni resta a este respecto, puesto que en realidad el pacto sucesorio que afecta a dos sucesiones se divide en dos pactos sucesorios, a cada uno de los cuales se les aplica la ley correspondiente como si se trataran de pactos que afectan a una única sucesión.

La solución cumulativa puede aminorar la libertad de disposición de aquel causante que según su ley puede otorgar pactos sucesorios; pensemos en el ejemplo de un causante nacional alemán que realiza un pacto sucesorio de institución recíproca con su mujer de nacionalidad francesa. Bajo la solución prevista en el art. 26 EGBGB las leyes a considerar son la ley alemana y la ley francesa. Una aplicación cumulativa de las leyes en presencia implicaría la invalidez del pacto sucesorio, al no admitir la ley francesa un pacto de estas características. El causante alemán, que conforme a su ley nacional podía realizar un pacto válido de estas características, se ve constreñido a planificar su sucesión por medio de un pacto sucesorio, como consecuencia de la restricción de otra ley, la ley nacional del otro otorgante.

La solución alternativa, sin embargo, puede ampliar la libertad de disposición del causante; el ejemplo podría ser el mismo que hemos visto para la solución cumulativa, pero visto desde el punto de vista de la causante de nacionalidad francesa. Ésta realiza un pacto sucesorio con su cónyuge alemán, en el que se instituyen recíprocamente herederos. La aplicación de una solución alternativa de la concurrencia en el pacto de la ley alemana y la ley francesa daría lugar a la validez del pacto sucesorio. La causante francesa, que según su ley nacional no puede otorgar un pacto sucesorio de institución recíproca, ve ampliada su libertad de disposición al poder realizar un pacto sucesorio válido de acuerdo con la ley nacional del otro causante.

En cuanto al otro de los intereses sucesorios, esto es, la protección de ciertos familiares próximos al causante, cuya intensidad depende, al menos en principio, de la mayor o menor presencia de la ley sucesoria, tradicionalmente se ha entendido que la norma de conflicto con conexiones sucesorias (fundamentalmente la nacionalidad y el domicilio, pues la aplicación de la lex rei sitae en los sistemas que siguen el fraccionamiento de la sucesión se basa en otras 
razones relacionadas con el principio de soberanía) determinadas en el momento del fallecimiento del causante, es la más competente para determinar, en su caso, qué familiares y en qué medida tienen derecho a una parte de la herencia del causante; dicho de otro modo, se considera que es la norma competente para dar cumplimiento al interés sucesorio de la protección de los familiares próximos al causante $^{331}$.

Desde este tradicional punto de vista, el interés de la protección de los familiares próximos al causante está claramente presente y salvaguardado en aquellos sistemas en los que se aplica la ley sucesoria a los pactos sucesorios sin ninguna especialidad; la conexión se determina en el momento del fallecimiento y la misma ley que dice si los pactos sucesorios son válidos, establece la protección de los familiares próximos al causante. Sin embargo, en aquellos sistemas en los que hay alguna diferencia entre la ley aplicable al pacto y la ley sucesoria la cuestión de la protección de los familiares próximos al causante puede presentar distintos matices; la cuestión depende de la idea, que ya hemos venido adelantando, de la convivencia entre esas dos leyes potencialmente distintas, la ley aplicable al pacto y la ley sucesoria. Estos sistemas no dan solución concreta a este problema; hemos visto cómo el art. 9.8 CC señala que los derechos legitimarios estarán regulados, en todo caso, por la ley sucesoria. Sin embargo, esta afirmación no es suficiente, pues nos podríamos preguntar qué legitimarios, si todos o sólo los terceros ajenos al pacto, o qué aspectos de la legítima deben estar cubiertos por la ley sucesoria, si sólo la cuantía o también el aspecto cualitativo de la misma.

Por último, cabe reflexionar sobre la propia competencia de la ley sucesoria determinada en el momento del fallecimiento como la única y exclusiva para determinar la protección de los familiares próximos al causante. Como ya hemos dicho esta es la idea que tradicionalmente se ha mantenido; no obstante, a nuestro juicio, cabría preguntarse por la bondad de la ley sucesoria anticipada para

331 H. LeWALd (1925), pp. 79 y ss.; F. Boulanger (1981), p. 119; A.L. Calvo CaravaCA (1995), p. 376; D. DAMASCELLI (2003), p. 92; B. DUTOIT (2005), p. 308 y p. 313 a propósito de la regulación de los pactos sucesorios; J. CARRASCOSA GONZÁlEZ/J.J. MARTínEZ NAVARRO (2011), p. 43 y pp. 57 y ss.; S. ÁlvAREZ GonZÁLEZ (2012), pp. 158 y ss.; B. AUdiT (2010), p. 798. 
proteger los derechos legitimarios de estas personas próximas al entorno del causante. 


\section{CAPÍTULO III. LA LEY APLICABLE A LOS PACTOS SUCESORIOS: LA AUTONOMÍA DE LA VOLUNTAD}

\section{UN MODELO REGULATIVO GLOBAL: LEY APLICABLE A LA SUCESIÓN Y LEY APLICABLE A LOS PACTOS SUCESORIOS}

\section{Interacción entre ley sucesoria y ley rectora de los pactos sucesorios}

En el examen de los modelos de regulación de la ley aplicable a los pactos sucesorios hemos conscientemente excluido el sistema que será de aplicación en un futuro cercano en los EEMM; se trata de la regulación prevista en el Reglamento de sucesiones que será de aplicación a partir del 17 de agosto de 2015, quedando desplazadas las normas internas de los EEMM para la determinación de la ley aplicable a las sucesiones internacionales ${ }^{332}$. Delimitados los términos sustantivos del objeto de estudio (Cap. I) y analizadas las distintas opciones que hasta ahora se han barajado en cuanto a la ley aplicable, en términos de modelos ofrecidos por el Derecho comparado (Cap. II, donde también hemos incluido las soluciones del Convenio de La Haya de 1989), corresponde ahora establecer cuál o cuáles son las mejores opciones regulativas en la determinación de la ley aplicable a los pactos sucesorios. En este sentido, creemos que, precisamente porque el Reglamento será la norma que se aplicará con carácter general en Europa, la opción de partir de su regulación para articular en torno a ella, sus virtudes y sus defectos es casi la única razonable. Aunque sería posible abordar nuestra tarea sin referencia normativa $\mathrm{y}$, consecuentemente, sin límites, con mayor libertad, lo cierto es que el Reglamento establece una regulación completa de las sucesiones internacionales al prever normas de competencia judicial internacional, ley aplicable, reconocimiento y ejecución de resoluciones

\footnotetext{
${ }^{332}$ El Reglamento vincula a todos los EEMM a excepción de Dinamarca, por su especial estatus, ni a Reino Unido ni Irlanda que han decidido no participar; vid. los Considerandos núms. 82 y 83.
} 
extranjeras así como ciertas normas sobre el certificado sucesorio europeo ${ }^{333}$. Y dentro de las soluciones sobre ley aplicable, la oferta que realiza es, asimismo, completa y exhaustiva, por lo que resulta una guía, un esquema, si se quiere, difícil de rechazar. Ello no nos va a impedir continuar con el tipo de discurso que más nos interesa, en el que las soluciones concretas, las reglas, son contextualizadas en términos de grandes opciones metodológicas (autonomía de la voluntad, proximidad, etc.); pero este discurso lo realizaremos en el molde que configura el Cap. III del Reglamento.

Esta opción, estudiar las soluciones, las reglas concretas, en su contexto metodológico, justifica el contenido de este Capítulo III y del siguiente (Capítulo IV). No obstante, el tratamiento analítico que efectuamos exige una contextualización sin la cual es fácil perder de vista el sistema global. Un sistema que no nos permite centrarnos exclusivamente en el art. 25 del Reglamento, que por su rúbrica parecería tener que ser el centro del análisis. Un sistema en el que se establecen peculiares relaciones entre las soluciones específicas para los pactos sucesorios y la ley rectora de la sucesión: que es potencialmente otra. Por simplificar, podríamos decir que la ley aplicable a los pactos sucesorios es una entente entre la ley sucesoria y la ley rectora de la admisibilidad del pacto y la ley rectora de su validez sustancial. Pero, además de esta necesaria visión global (conocida, por otro lado, de soluciones otorgadas por el Derecho comparado, incluso por nuestro propio art. 9.8 CC), existen otras relaciones entre las reglas de determinación de la ley sucesoria y las que establecen la ley aplicable a los pactos sucesorios. La ley sucesoria puede llegar a ser y es un dato en la economía del art. 25 Reglamento. Y más: soluciones particulares de determinación de la ley sucesoria, como la professio iuris prevista por el art. 22, están presentes, con otra dimensión, en, por ejemplo, la determinación del alcance de la autonomía de la voluntad en la concreta materia de pactos sucesorios (leyes elegibles que sujetas al

\footnotetext{
${ }^{333}$ Sobre el Reglamento en general, vid. H. DÖRNER (2012), pp. 505 y ss.; P. LAGARDE (2012), pp. 691 y ss.; K.W. LANGE (2012), pp. 160 y ss.; U. SiMON/M. BuSCHBAUM (2012), pp. 2393 y ss.; P.W. VOLLMER (2012), pp. 227 y ss.; F.M. WILKE (2012), pp. 601 y ss.; D. LEHMANN (2012), pp. 2085 y ss.; A. DUTTA (2013), pp. 4 y ss.; I. RodríGUEZ-URÍA SuÁREZ (2013); C.F. NORDMEIER (2012), pp. 513 y ss.; M. LEITZEN (2012), pp. 520 y ss.; M. BUSCHBAUM/U. SIMON (2012), pp. 525 y ss.; C.F. NORDMEIER (2013), pp. 117 y ss.; M. MARGONSKI (2013), pp. 106 y ss.
} 
mismo límite apriorístico de la professio iuris). Estas interrelaciones se aprecian a primera vista de una lectura del art. 25 del Reglamento.

El art. 25 se divide en tres apartados ${ }^{334}$ con una estructura muy determinada: el primer apartado se dedica a la determinación de la ley aplicable a los pactos sucesorios que afectan a una sucesión; en el segundo apartado se establece una solución específica para los pactos sucesorios que afectan a más de una sucesión, que como ya hemos tenido ocasión de ver presentan ciertas particularidades que hay que atender de manera concreta; el tercer apartado, por último, hace referencia a la posibilidad de elegir la ley aplicable al pacto sucesorio a través de un pacto de lege utenda realizado por los otorgantes.

Como decíamos, el art. 25 se abre con un apartado dedicado a la determinación de la ley aplicable a los pactos sucesorios que afectan a una única sucesión. Se prevé la aplicación de la ley sucesoria anticipada o ley que hubiera sido aplicable a la sucesión del causante de haber fallecido éste en el momento del otorgamiento del pacto sucesorio. Para ello se realiza una remisión a las normas generales previstas en el Reglamento para la determinación de la ley sucesoria, si bien modificando el momento relevante de la concreción del punto de conexión, pues en vez de ser en el momento del fallecimiento del causante es en el momento del otorgamiento del pacto sucesorio. Esta remisión a las normas generales para la determinación de la ley aplicable a los pactos sucesorios junto a la especialidad temporal que se prevé significa que se aplicará a los pactos sucesorios bien la ley de la nacionalidad del causante en el momento del otorgamiento, en el caso de que hubiera realizado una professio iuris, bien la ley de la residencia habitual del causante en el momento del otorgamiento u otra ley más estrechamente vinculada $^{335}$.

\footnotetext{
${ }^{334}$ Se ha suprimido el cuarto apartado que la Propuesta de Reglamento preveía en el art. 18, donde se hacía referencia a la protección de los derechos de legitimarios de terceros ajenos al pacto sucesorio.

${ }^{335}$ La solución de los vínculos más estrechos es una novedad que prevé el Reglamento respecto de la Propuesta. El art. 21 tras recoger como regla general la aplicación de la ley de la residencia habitual del causante en el momento del fallecimiento, establece una cláusula de escape, cuando de forma excepcional y del conjunto de las circunstancias del caso resulte que en el momento del fallecimiento el causante mantenía un vínculo más estrecho con un Estado distinto al de su
} 
La novedad más destacable de la regulación de la ley aplicable a los pactos sucesorios que afectan a una única sucesión en el Reglamento respecto de la regulación prevista en la Propuesta es la eliminación de la denominada norma de validación. En el art. 18.1 de la Propuesta se preveía que en el caso de que la ley sucesoria anticipada no previera la validez material del pacto sucesorio, aún se podía reconocer su validez si la ley sucesoria, determinada en el momento del fallecimiento, así lo preveía. Tal y como veremos más adelante, la supresión de la norma de validación es, a nuestro juicio, un gran acierto, por ser un mecanismo que puede plantear en su puesta en funcionamiento importantes problemas que pueden llevar a la pérdida de la razón de ser del pacto sucesorio ${ }^{336}$.

El segundo apartado del art. 25 establece una solución específica para la determinación de la ley aplicable a los pactos sucesorios que afectan a más de una sucesión. Como ya hemos tenido ocasión de ver, la especialidad de este tipo de pactos sucesorios reside en que hay más de una sucesión afectada, más de un futuro causante y más de una ley sucesoria anticipada, de tal forma que es necesario dar un paso más y establecer una solución específica para coordinar el juego de esas leyes sucesorias anticipadas a la hora de determinar la ley aplicable al pacto sucesorio.

A este respecto el Reglamento también se ha separado de lo que recogía la Propuesta; finalmente se ha desechado la solución alternativa que aquella recogía y el Reglamento ha optado por una solución cumulativa de las leyes en presencia; es decir, en cuanto a la admisibilidad del pacto sucesorio, éste será admisible siempre y cuando todas y cada una de las leyes sucesorias anticipadas en presencia así lo prevean. Cada ley sucesoria anticipada se determinará aisladamente, de tal forma que podrá ser bien la ley de la nacionalidad del futuro causante de que se trate, en el caso de que éste hubiera hecho un ejercicio de professio iuris, o la ley de la residencia habitual del causante en el momento del

residencia habitual. Como bien es sabido, la cláusula de los vínculos más estrechos sólo juega en el caso de que no se haya realizado un ejercicio de la autonomía de la voluntad conflictual.

336 También ya hemos tenido ocasión de pronunciarnos en contra de la norma de validación en otros lugares, vid. I. RodrígueZ-Uría SuÁreZ (2010), p. 650; S. Álvarez GonZÁlez/I. RodríGUEZ-URÍA SUÁREZ (2011), p. 11; I. RodRÍGUEZ-URÍA SUÁREZ (2013), p. 29. 
otorgamiento del pacto sucesorio salvo que exista otra que presente claramente unos vínculos más estrechos con el causante siempre en el momento del otorgamiento del pacto sucesorio.

En la regulación de los pactos sucesorios que afectan a más de una sucesión, el Reglamento diferencia a efectos regulativos, y con buen criterio, la admisibilidad del pacto sucesorio de la validez material y efectos vinculantes entre las partes, incluidas las condiciones para su resolución. La aplicación cumulativa de las leyes sucesorias anticipadas en presencia se limita a la determinación de la admisibilidad o inadmisibilidad del pacto sucesorio; pero una vez admitido éste es necesario, para simplificar y hacer posible una regulación del resto de los aspectos del pacto sucesorio en cuestión, señalar una única ley aplicable. Por ello, el Reglamento prevé la aplicación de entre las leyes sucesorias anticipadas, la ley que presente los vínculos más estrechos con el pacto sucesorio; tal ley regulará la validez material y los efectos vinculantes entre las partes, incluidas las condiciones para la resolución del pacto sucesorio.

La regulación prevista para los pactos sucesorios en el Reglamento se cierra con un tercer apartado en el que se prevé la posibilidad de que las partes otorgantes escojan ad hoc la ley aplicable al pacto sucesorio. Según el art. $25.3 \mathrm{del}$ Reglamento, las partes podrán elegir como ley aplicable a la admisibilidad, validez material y efectos vinculantes entre las partes, incluidas las condiciones para su resolución, la ley que la persona o una de las personas de cuya sucesión se trate hubiera podido elegir de acuerdo con las normas generales que sobre la professio iuris recoge el propio Reglamento. Dicho de otro modo, se podrá elegir la ley de la nacionalidad del futuro causante, en los pactos sucesorios que afectan a una única sucesión, o de cualquiera de los futuros causantes, en el caso de los pactos sucesorios que afectan a varias sucesiones. No se trata aquí ya de una elección unilateral del causante, sino de un verdadero pacto sobre la ley aplicable acordado entre los otorgantes. 


\section{Significado y alcance de la ley aplicable a los pactos sucesorios}

Una vez señalada la ley aplicable al pacto sucesorio, debemos hacer referencia a una cuestión de carácter estructural, cual es la determinación de qué concretos aspectos quedan regulados bajo esta ley. Para ello vamos a seguir la estructura del Reglamento, por ser, a nuestro juicio, la más adecuada a efectos analíticos y por ser además la que se aplicará en el futuro próximo. En concreto, el Reglamento habla en su art. 25 de la admisibilidad, la validez material y los efectos vinculantes entre las partes incluidas las causas que determinen la extinción del pacto sucesorio. Para simplificar, nos vamos a referir a este último aspecto como el régimen jurídico de los pactos sucesorios.

La distinción entre admisibilidad, validez material y régimen jurídico de los pactos sucesorios plantea un problema de ámbito de aplicación. En efecto, esta diferenciación exige determinar qué aspectos del pacto sucesorio están dentro de la admisibilidad, qué aspectos dentro de la validez material y qué aspectos se refieren al régimen jurídico del mismo. Discernir esta cuestión es fundamental para saber qué ley es la aplicable a cada una de las cuestiones relacionadas con el pacto sucesorio. Este problema de delimitación del ámbito de aplicación se planteó en el marco de la Propuesta de Reglamento. El art. 18.2 de la Propuesta establecía una solución de ley aplicable para los pactos sucesorios que afectan a más de una sucesión; para ello se refería en primer lugar a la validez en cuanto al fondo y en segundo lugar, para el caso de que el pacto sucesorio fuera válido en cuanto al fondo, establecía otra solución de ley aplicable para determinar qué ley regirá el pacto sucesorio. La vaguedad de esta descripción creó la duda en torno a qué aspectos de la celebración de un pacto sucesorio se encuentran en el ámbito de la validez en cuanto al fondo y qué otros aspectos son parte del régimen jurídico del mismo ${ }^{337}$. El Convenio de La Haya de 1989, claro antecedente inmediato de la Propuesta de Reglamento, había sido sin embargo más explícito en este aspecto. El art. 10 del Convenio se refiere por un lado a la validez en

\footnotetext{
337 Tal y como ya hemos tenido ocasión de poner de relieve, vid. S. ÁLVAREZ GonZÁLEZ/I. RodríGUEZ-URÍA SUÁREZ (2011), núm. 9. También críticos con este aspecto, MPI (2010), núm. 154; A. BONOMI (2010), p. 903.
} 
cuanto al fondo y, por otro lado, a los efectos del pacto sucesorio y a las circunstancias que den lugar a la extinción de los mismos. Sin embargo, tal distinción no es tan importante en el contexto del Convenio, en cuanto que la solución de ley aplicable para unos y otros aspectos de los pactos sucesorios que afectan a más de una sucesión es la misma.

Es la versión definitiva del Reglamento la que, tras hacerse eco de las críticas recibidas por el texto de la Propuesta, establece una solución mucho más clara sobre la cuestión. El Reglamento diferencia a la hora de dar solución de ley aplicable entre la admisibilidad de los pactos sucesorios que afectan a más de una sucesión y la validez material y efectos vinculantes entre las partes, incluidas las condiciones para su resolución. Pero además de esta diferenciación, se prevé en un artículo específico qué se entiende por validez material de las disposiciones mortis causa, refiriéndose tanto a los pactos sucesorios como a las disposiciones testamentarias (art. 26). Dicho precepto establece que a los efectos de los arts. 24 y 25 , esto es a los efectos de la regulación de las disposiciones testamentarias y también las disposiciones realizadas a través de pactos sucesorios, se entiende por validez material los siguientes elementos: en primer lugar, entran dentro del concepto de validez material las cuestiones relativas a la capacidad del disponente para realizar las disposiciones mortis causa, o dicho de otro modo, la capacidad para otorgar un pacto sucesorio (art. 26.1 a). En segundo lugar, se incluyen también las causas específicas que impidan al disponente disponer a favor de ciertas personas o que impidan a una persona recibir bienes de la sucesión de otra (art. 26.1 b); en este apartado se incluye la legitimación para el otorgamiento de los pactos sucesorios, aspecto ciertamente importante en cuanto que no es extraño que en Derecho material se prevea limitaciones de parentesco para el otorgamiento de estas figuras ${ }^{338}$. En tercer lugar, entran también dentro del

\footnotetext{
${ }^{338}$ A título de ejemplo podemos señalar el caso catalán, donde tradicionalmente la realización de pactos sucesorios exigía matrimonio; sin embargo, en la reforma que tuvo lugar en el año 2008, con la promulgación del Libro IV del Código Civil catalán, se eliminó tal exigencia y el otorgamiento de pactos sucesorios se abrió a otros parientes. En concreto, el art. 431.2 establece que el pacto sucesorio podrá ser otorgado con el cónyuge o futuro cónyuge, con el conviviente y con parientes por consanguinidad y por afinidad en línea directa sin limitación de grado o en línea colateral dentro del cuarto grado; también los parientes por consanguinidad en línea directa o en línea colateral, dentro del segundo grado, del otro cónyuge o conviviente. El Derecho civil de Galicia también constituye un ejemplo en el que hay limitaciones de parentesco a la hora de
} 
concepto de validez material todas aquellas cuestiones que tengan que ver con la admisión de la representación para el otorgamiento de disposiciones mortis causa (art. 26.1 c). En cuarto lugar, se incluye un aspecto de gran importancia, cual es el de la interpretación de las disposiciones mortis causa realizadas (art. $26.1 \mathrm{~d}$ ) ${ }^{339}$. Por último, forman parte del concepto de validez material todas aquellas cuestiones que tengan que ver con los vicios en la prestación del consentimiento para otorgar las disposiciones mortis causa; en concreto se incluyen el fraude, la coacción, el error o cualquier otra que se refiera a la voluntad del disponente o al consentimiento (art. $26.1 \mathrm{e}$ ).

Dicho esto, debemos destacar también que el Reglamento atiende también de forma particular a la denominada admisibilidad del pacto sucesorio, que se refiere a un aspecto anterior al de la validez material; la admisibilidad sería un aspecto primario del pacto sucesorio que se refiere a la propia legitimación jurídica del mismo. Es decir, a la cuestión de si, por ejemplo, un pacto sucesorio de institución (sin más detalles) se admite por una u otra legislación. Pongamos el ejemplo de un pacto sucesorio de institución, celebrado entre dos amigos: según el Derecho italiano, por ejemplo, este pacto sucesorio no estaría admitido, en cuanto que este sistema prohíbe los pactos sucesorios en general; sin embargo, un pacto de institución sí está admitido en el Derecho catalán. Cuestión distinta, puesto que sería dar un paso más, es si ese pacto sucesorio es válido materialmente, que en el ejemplo daría como resultado su invalidez en cuanto que dos amigos, sin vínculo de parentesco alguno, no están legitimados para celebrar un pacto sucesorio entre ellos.

Por último y en cuanto al régimen jurídico, nos estamos refiriendo al contenido del pacto sucesorio, esto es, los derechos y obligaciones de las partes, al régimen de modificación y a las causas de extinción del pacto sucesorio, entre las

otorgar pactos sucesorios; así el denominado pacto de mejora es un pacto celebrado entre ascendiente y descendiente en el que se acuerda la sucesión de bienes concretos a favor de los descendientes (vid. art. 214 de la Ley de Derecho civil de Galicia); o la apartación, que debe realizarse entre el apartante, futuro causante, y un legitimario (art. 224 de la Ley de Derecho civil de Galicia).

${ }^{339}$ Es especialmente llamativa esta cuestión que, como vamos a ver, va a quedar al albur de varias leyes sucesorias anticipadas, lo que puede complicar enormemente la tarea de interpretación. 
que ocupa un lugar especialmente relevante la determinación de las causas por las que el pacto sucesorio puede ser revocado unilateralmente.

\section{LA AUTONOMÍA CONFLICTUAL, JUSTIFICACIÓN Y EXTENSIÓN A LOS ÁMBITOS PERSONAL, FAMILIAR Y SUCESORIO}

\section{Introducción}

Aunque el Derecho comparado nos proporcione escasas y, sobre todo, muy tímidas muestras de la fuerza de la autonomía de la voluntad en su dimensión conflictual en el ámbito sucesorio, lo cierto es que doctrinalmente fue este uno de los que primeramente despertó la inquietud por abrirse a la irresistible penetración de la autonomía de la voluntad en materias en principio alejadas de aquellas donde su operatividad era esencial. La idea de una professio iuris no es fruto de la actualidad, sino que tiene unos orígenes más remotos.

En todo caso, fuese cual fuese el alcance de esa autonomía en el ámbito genérico de la sucesión por causa de muerte, parece que en el más específico de los pactos sucesorios su presencia o, al menos, la valoración de su conveniencia resulta una actividad indefectible. Como hemos señalado reiteradamente, los pactos sucesorios participan de esa doble naturaleza sucesoria y contractual, que ha hecho incluso que en algunos casos el régimen de ley aplicable a las obligaciones contractuales haya sido considerado el más adecuado para la identificación de la ley aplicable. Si analizar el alcance de la autonomía conflictual en materia sucesoria es una nota esencial de nuestro tiempo, analizar cómo se manifiesta o puede manifestarse en relación con los pactos sucesorios resulta un imperativo ineludible.

No puede obviarse en este hecho la circunstancia de que contamos con unas soluciones positivas en las que dicha autonomía tiene una presencia fundamental y compleja. Las soluciones del Reglamento imponen comenzar, precisamente, por el análisis de la autonomía de la voluntad en materia de pactos sucesorios en particular y de ley sucesoria en general. Las relaciones entre ambas dimensiones (autonomía de la voluntad y ley sucesoria y autonomía de la voluntad y pactos sucesorios) veremos que son complejas y no exentas de problemas. 
También hay que tener en cuenta que el modelo del Convenio de La Haya de 1989 ya introducía una presencia notable de la autonomía conflictual. En ambos casos, la elección por el causante de la ley aplicable a su sucesión y, en su caso, la elección por las partes de la ley rectora de la validez del pacto sucesorio es la primera solución, o la primera conexión, si se quiere. Es cierto que nunca se ha considerado como la ley genéricamente aplicable, porque en todos los casos plantea límites apriorísticos y, sobre todo, porque el ejercicio de la autonomía conflictual es siempre un alea: nadie puede ser obligado a elegir una u otra ley. Pero, de existir, la ley elegida es la ley aplicable.

En el presente capítulo nos proponemos analizar el régimen jurídico de la ley aplicable a los pactos sucesorios cuando ésta es consecuencia de una elección de ley. Dadas las posibilidades existentes en el juego entre la ley sucesoria y la ley rectora de la validez del pacto, necesariamente habremos de abordar ambas dimensiones (professio iuris y pacto de lege utenda). Antes realizaremos una sucinta introducción sobre la autonomía conflictual como punto de conexión y como punto de conexión prioritario en una de las dimensiones de los pactos sucesorios: la contractual. A continuación, sentaremos las bases de las dos manifestaciones señaladas (professio iuris y pacto de lege utenda) para abordar a continuación y de manera específica todos los entresijos de la autonomía conflictual y los pactos sucesorios.

\section{Autonomía de la voluntad material y autonomía de la voluntad conflictual}

La autonomía de la voluntad es pilar esencial en el Derecho privado, donde los sujetos tienen una gran parcela de libertad para autorregular sus relaciones jurídico-privadas. Ahora bien, la autonomía de la voluntad actúa en distintos ámbitos o planos del Derecho y cumple también distintas funciones en cada uno de ellos. En nuestra disciplina es lugar común distinguir dos tipos de autonomía de la voluntad que juegan en distintos ámbitos y que tienen distinta función; nos estamos refiriendo a la autonomía de la voluntad material y la autonomía de la voluntad conflictual, distinción que fue realizada por primera vez 
por ZITELMANN en el ámbito de las obligaciones contractuales y desarrollada por otros más tarde $\mathrm{e}^{340}$.

Por autonomía de la voluntad material se entiende la autorregulación que los sujetos realizan de sus propias relaciones jurídicas, fijando el contenido de las mismas a través de acuerdos, estipulaciones o cláusulas. Esta autonomía de la voluntad sólo puede jugar dentro del margen dispositivo que permita la ley, es decir, en todo aquello que no esté regulado por normas imperativas. Las concretas cláusulas o estipulaciones sustantivas de un pacto sucesorio son manifestación de esta autonomía.

La autonomía de la voluntad conflictual, por su parte, actúa en el sector de la determinación de la ley aplicable a una situación jurídica internacional y es la posibilidad que tienen los sujetos de una relación jurídica de elegir la ley aplicable a la misma. El ejercicio de la autonomía de la voluntad conflictual puede tener distinto alcance, esto es, la posibilidad de elegir la ley aplicable a una situación jurídica internacional puede ser absolutamente libre, caso en el que las partes pueden escoger la ley que tengan por conveniente, o puede estar limitada a un círculo de leyes más o menos amplio, tratándose de leyes que ya presentan una determinada vinculación con la relación jurídica en cuestión. Además, la ley elegida, puede ser corregida, como cualquier otra ley aplicable determinada de forma objetiva, por expedientes típicos como pueda ser el orden público o las llamadas normas de aplicación inmediata. Por el contrario, la ley aplicable en función del ejercicio de la autonomía conflictual tiene cierta resistencia a otros expedientes (reenvío, cláusulas de excepción) que pueden afectar a la ley objetivamente identificada.

\section{Origen y ámbito primario de la autonomía de la voluntad conflictual: justificaciones}

Generalmente se atribuye el origen de la autonomía de la voluntad conflictual, o posibilidad de escoger la ley aplicable para regular las relaciones jurídicas, a Dumoulin, quien se refirió en distintas ocasiones al papel de la

${ }^{340}$ Citado en M. CALEB (1927), p. 41. 
autonomía de la voluntad en los conflictos de leyes ${ }^{341}$. En concreto, DuMOULIN se ocupó de la voluntad de las partes para determinar la ley aplicable en materia $\operatorname{contractual}^{342}$, sector donde se sitúa el origen y hábitat natural de la autonomía de la voluntad conflictual ${ }^{343}$. Ahora bien, la teoría de la autonomía de la voluntad conflictual se desarrolló de forma importante a lo largo del siglo XIX y no se puso en práctica hasta la segunda mitad del siglo XIX e inicios del siglo $\mathrm{XX}^{344}$. Esta plasmación práctica tuvo lugar, por un lado, directamente a través del reconocimiento por los distintos ordenamientos jurídicos del principio de autonomía de la voluntad conflictual; a este respecto, de aquella época datan las primeras legislaciones que recogieron la posibilidad de escoger la ley aplicable ${ }^{345}$. Por otro lado, la otra dimensión que consagró la autonomía de la voluntad conflictual fue la jurisprudencial, a través de una extensión del principio de autonomía de la voluntad contractual en el ámbito del Derecho interno al ámbito de las relaciones internacionales ${ }^{346}$. El resultado de esta extensión es que las

${ }^{341}$ M. CALEB (1927), p. 135. Se destaca de Dumoulin su teoría de la elección tácita de la costumbre del lugar del domicilio conyugal por los cónyuges para regular el régimen de sus bienes, en aquellos casos en los que no hubieran acordado expresamente el régimen de tales bienes; sobre la idea de la atribución de la teoría de la autonomía de la voluntad conflictual a Dumoulin, J-P. NiBOYET, (1927), p. 9; M. CALEB (1927), p. 128, quien matiza que si bien Dumoulin es el primer jurista que formula expresamente la idea de autonomía de la voluntad, no se le puede considerar el autor de una verdadera teoría de la autonomía de la voluntad en Derecho internacional privado, p. 141 y p. 142; H. BATIFFOL (1938), p. 23; K. SIEHR (1989), p. 485; S. SÁNCHEZ LORENZO (1994), p. 572.

${ }^{342}$ M. CALEB (1927), p. 139 y 140.

343 J-P NIBOYET (1927), p. 7.

${ }^{344}$ M. CALEB (1927), pp. 163 y ss.; J-P NiBOYeT (1927), pp. 12 y ss.; M. GiUliANO (1977), p. 199;

345 A título de ejemplo, en Suiza el Código Civil del Cantón de Zurich de 1855 recoge la autonomía de la voluntad como ley aplicable a las obligaciones contractuales; sin embargo, la Ley federal suiza de 1891 no hace mención alguna a la autonomía de la voluntad en el sector contractual, si bien sí permitía en materia de testamentos la elección de la ley nacional o ley del domicilio (vid arts. 22 y 32); en Italia se recogió el principio de autonomía de la voluntad de los contratantes en las disposiciones preliminares del Código Civil de 1865; para un análisis de mayor amplitud sobre los orígenes de la autonomía de la voluntad conflictual en los contratos, M. CALEB (1927), pp. 129 y ss. y pp. 167 y ss.; M. GIULIANO, (1977), pp.199 y ss.; también J-Y. CARLIER (1992), p. 58 y ss.

${ }^{346}$ En el contexto del ordenamiento jurídico francés se suele citar una sentencia de 1910 como hito del reconocimiento de la autonomía de la voluntad conflictual en los contratos; la Corte de Casación francesa, en la sentencia de 5 de diciembre de 1910 sobre el caso American Trading Company v. Quebec Steamship Company Limited, declaró expresamente que la ley aplicable a los contratos, tanto a lo que se refiere a la formación, como a los efectos y condiciones, es la ley escogida por las partes; vid. Journal de Droit international, 1912, pp. 1156-1159; en Bélgica una sentencia de la Corte de Casación de 1938 aplicó la regla de la autonomía de la voluntad 
partes contratantes pueden escoger la ley aplicable al contrato o, dicho de otro modo, el contrato se rige, en un primer término, por la ley elegida por las partes.

Se dice que originariamente la autonomía de la voluntad conflictual en el ámbito de los contratos surgió como consecuencia de la inadecuación de las conexiones objetivas sobre las que se basaba la determinación de la ley aplicable a este tipo de negocios. En concreto, la extensión y generalización del comercio internacional supuso la superación de la conexión basada en la ley de lugar de celebración del contrato; la lex loci contractus estaba pensada para otro tipo de contexto socioeconómico preindustrial propio del Medievo en el que lo habitual era que los contratos se celebraran entre presentes ${ }^{347}$. Con el aumento del tráfico internacional la inadecuación de las conexiones objetivas como la lex loci contractus o también la lex executionis dio entrada a la autonomía de la voluntad conflictual, como solución que permitía un mayor respeto de los intereses en juego.

A lo largo del siglo XX se produjo una evolución o desarrollo de esta posibilidad de escoger la ley rectora de los contratos. Por un lado, las legislaciones nacionales fueron recogiendo en términos de Derecho positivo la autonomía de la voluntad conflictual en este ámbito; así por ejemplo, en nuestro sistema de DIPr, el art. 10.5 CC surgido de la reforma del Título Preliminar de 1974, recogió una autonomía de la voluntad conflictual limitada para los contratos internacionales $^{348}$. La elección de ley aplicable a los contratos también obtuvo reconocimiento, por otro lado, en el ámbito convencional; cabe mencionar el Convenio de La Haya de 1955 sobre ley aplicable a las ventas de carácter internacional de objetos muebles corporales, cuyo art. 2 recoge que la venta se

conflictual a un contrato, aplicándole la ley elegida por las partes, asunto Societé Antwerpia c. Ville d'Anvers de 24 de febrero de 1938, Rev. crit. dr. int. priv., 1938, pp. 661 y ss.

${ }^{347}$ O. LANDO (1985), p. 256; G. CARELla (1992), p. 20; P. DE CESARI (2001), p. 12.

${ }^{348} \mathrm{El}$ art. $10.5 \mathrm{CC}$ exige que la ley escogida por las partes tenga algún tipo de conexión con el contrato de que se trate. La doctrina ha procurado una interpretación amplia de esta limitación, de tal forma que se permita la elección de aquellos ordenamientos jurídicos estatales que estén relacionados con el contrato a través de cualquiera de los elementos personales, reales, objetivos y formales del contrato. Vid. A. REMIRO BROTONS (1978), pp. 295 y ss.; F.J. ZAMORA CABOT (1983), p. 401; M. VIRGÓS SORIANO (1991), p. 117; 
regirá por la ley interna del país designado por los contratantes ${ }^{349}$. No obstante, el reconocimiento definitivo de esta autonomía de la voluntad conflictual en materia de contratos tuvo lugar con el Convenio de Roma sobre ley aplicable a las obligaciones contractuales de 1980. La previsión en su art. 3 de una libertad de elección de ley aplicable a los contratos, sin exigencia de vinculación alguna entre el negocio y la ley elegida, ha elevado a la autonomía de la voluntad conflictual a un principio del Derecho europeo de los contratos ${ }^{350}$.

Hoy en día la posibilidad de elegir la ley aplicable en el ejercicio de la autonomía de la voluntad conflictual es una solución indiscutible e indiscutida desde hace tiempo en el ámbito de las obligaciones contractuales, con justificaciones diversas que el tiempo y la doctrina han acumulado y que resulta interesantes con vistas a, en su momento, proyectarlas, en su caso, sobre los pactos sucesorios

En el punto en el que nos encontramos es interesante conocer cuáles son esas razones que han llevado a la elección de ley aplicable a ser un principio base del Derecho aplicable a los contratos, así como conocer la función que esa autonomía de la voluntad conflictual cumple en materia de contratos. El interés en detenernos en esta justificación no sólo deviene por ser la materia en la que naturalmente se ha dado la elección de ley aplicable, erigiéndose, por tanto, como punto de comparación con la elección de ley aplicable en otros ámbitos, sino también porque no hemos de olvidar que la doble naturaleza jurídica de los pactos sucesorios encierra un aspecto contractual de necesaria atención a la hora de establecer o valorar las soluciones de ley aplicable.

La primera de las justificaciones, ya mencionada en el epígrafe anterior, se basó en una extensión al ámbito internacional del principio de autonomía de la voluntad contractual del Derecho material, reconocido por la generalidad de los ordenamientos jurídicos; las normas materiales que regulan las obligaciones contractuales son generalmente de carácter dispositivo, de tal forma que las partes

349 Convenio de 15 de junio de 1955 sobre ley aplicable a las ventas de carácter internacional de objetos muebles corporales, que España no llegó a ratificar.

${ }^{350}$ S. LEIBLE (2008), p. 61; E. JAYME (2009), p. 1. 
pueden, a salvo de algunas normas excepcionalmente imperativas, regular su relación jurídica como estimen oportuno y las normas dispositivas sólo entran en juego para el caso de que las partes nada hayan dispuesto. Dicho de otro modo, la libertad contractual o autonomía de la voluntad material permite a las partes determinar el contenido jurídico del contrato en cuestión, en todo aquello que no esté regulado por normas imperativas. Por otra parte, a través de la elección de ley, las partes enmarcan jurídicamente el contrato; la ley elegida no sólo va a determinar el régimen jurídico del contrato en todo aquello que las partes no hayan regulado particularmente, sino también determinará la extensión de la autonomía de la voluntad material, que se tiene que acomodar a los límites impuestos por las normas imperativas de la ley en cuestión. Ahora bien, en esta autonomía de la voluntad conflictual también existen límites, generalmente derivados del orden público y de las leyes de policía. La autonomía de la voluntad conflictual se trataba como una manifestación más del principio de libertad contractual $^{351}$.

La segunda justificación se fundamenta en los problemas de localización que presentaban las conexiones de la norma de conflicto aplicable a los $\operatorname{contratos}^{352}$. En ocasiones las conexiones objetivas que determinan la ley aplicable a los contratos son vagas o flexibles, de tal forma que suscitan dudas en torno a la localización de la relación jurídica en cuestión. Como paradigma de este problema se suele citar el asunto Baumann suscitado ante el Tribunal Federal suizo $^{353}$, en el que se trataba de determinar la ley aplicable a un contrato de transporte. En este asunto, ante la imposibilidad de determinar cuál era el lugar de conclusión del contrato, factor que a su vez señalaba cuál era la ley aplicable al

\footnotetext{
${ }^{351}$ Esta justificación fue considerada en un primer momento, fundamentalmente a inicios del siglo XX cuando la jurisprudencia y la doctrina empezaron a introducir la autonomía de la voluntad conflictual como solución de ley aplicable a los contratos; M. GIULIANO (1977), p. 209; P. DE CESARI (2001), p. 12.

352 M. PATOCCHI (1985), pp. 109 y ss.; G. CARELLA (1999), pp. 47 y ss.; P. DE CESARI (2001), p. 11; fue H. Batiffol quien defendió la teoría localizadora de la autonomía de la voluntad conflictual en materia contractual. Para Batiffol la autonomía de la voluntad de las partes es necesaria para determinar cuál de las leyes que concurren simultáneamente en el contrato debe ser la aplicable, de tal forma que las partes cuando eligen la ley del contrato no están más que localizándolo; vid. $\mathrm{H}$. BATIFFOL (1938), pp. 35 y ss.

${ }^{353}$ ATF 48 II 260.
} 
contrato, el Tribunal federal suizo tomó en consideración la voluntad de las partes para determinar la ley aplicable al negocio en cuestión. Hoy no es difícil imaginarse la complejidad de la "localización" de la lex contractus en las nuevas formas de contratación, por ejemplo, a través de medios y recursos electrónicos.

Esta dificultad de localización de los contratos explica en cierta medida que el legislador opte por que sean las partes, en primer lugar, las que puedan determinar la ley aplicable al contrato que han celebrado, renunciando a intervenir directamente para dar una solución. Desde este punto de vista, la solución de la autonomía de la voluntad conflictual se ha considerado como una solución de compromiso o Verlegenheitslösung, ante la idea de que señalar una conexión adecuada para los contratos es algo difícil, que produce incertidumbre ${ }^{354}$. Este argumento en sí mismo considerado lleva a la consideración de una función localizadora de la elección de ley a los contratos; es decir, los contratantes escogerían la ley aplicable al contrato con el fin de localizar la relación jurídica que les une. Sin embargo, esta perspectiva localizadora fue superada al reconocerse que las partes contratantes, al escoger la ley aplicable, tienen en cuenta además otros factores, lo que nos lleva a la siguiente de las justificaciones $^{355}$.

Al observar la función de la elección de ley a los contratos se llega a la conclusión de que las partes no escogen la ley con el sólo propósito de localizar el contrato. Como decíamos, se toman en consideración otros factores que se pueden agrupar en el interés (los heterogéneos intereses) de las partes ${ }^{356}$. La idea supone

\footnotetext{
${ }^{354}$ M. PATOCCHI (1985), pp. 108 y ss. que se refiere al argumento de la elección de ley por las partes contratantes como consecuencia de la dificultad de localización de los contratos como una justificación de carácter negativo de la autonomía de la voluntad conflictual, en contraposición a las justificaciones positivas, que son el interés de las partes, la seguridad y previsibilidad jurídica y otras como la armonía internacional de soluciones o las exigencias del comercio internacional.

${ }^{355}$ Esta función localizadora de la autonomía de la voluntad conflictual también se ha relacionado con aquellos casos en los que la elección de la ley aplicable al contrato está limitada a un círculo de leyes que tienen algún tipo de conexión con la relación jurídica en cuestión, vid., P. LAGARDE (1986), p. 62 al hilo de la posibilidad valorada en el seno de la Conferencia de La Haya de limitar la elección de la ley aplicable a los contratos en el Convenio sobre la ley aplicable a los contratos de compraventa internacional de mercaderías.

356 Terminología adoptada por Patocchi, quien señala que toda elección de ley para regular un contrato tiene un criterio de elección implícito y tal criterio puede ser un interés material variado que sintetiza en el interés de las partes, vid. M. PATOCCHI (1985), p. 115;
} 
que las partes escogen la ley que estimen más conveniente para sus intereses y que puede basarse en distintas razones; así, por ejemplo, pueden escoger una ley que conocen y con la que están familiarizados, una ley que regula particularmente la relación jurídica que les une o con la que alcanzan unos determinados efectos que les interesan, etc ${ }^{357}$. En definitiva, al elegir la ley aplicable al contrato existe un criterio, una razón material, que lleva a las partes a escoger una determinada ley y no otra; criterio que encierra el concreto interés de las partes expresado a través de su voluntad. Este argumento es el que niega la función localizadora de la autonomía de la voluntad conflictual y abre paso a la perspectiva material de esta técnica de determinación de la ley aplicable; dicho de otro modo, las partes realizan su elección de ley aplicable en función de aspectos materiales, en consideración del contenido sustantivo de la ley que eligen y con el propósito de conseguir unos determinados efectos materiales ${ }^{358}$.

Otro de los argumentos de peso que se han manejado en defensa de la autonomía de la voluntad conflictual en los contratos es la búsqueda de seguridad jurídica. Con la posibilidad de elegir la ley aplicable se pretende evitar riesgos y dificultades que produce el desconocimiento del régimen jurídico del contrato. A falta de la autonomía de la voluntad conflictual las partes no pueden con carácter general saber cuál es la ley aplicable al contrato hasta que se conoce al tribunal competente e incluso, una vez conocido el foro, hasta la concreción de la norma de conflicto aplicable a los contratos ${ }^{359}$. La posibilidad de que las partes puedan escoger la ley aplicable al contrato posibilita que ya puedan saber desde ese momento con certeza cuáles son sus derechos y obligaciones, así como las consecuencias de sus actos, de tal forma que pueden adecuar sus actuaciones a la normativa en cuestión. Obviamente, ello parte de la generalizada aceptación de la solución por los distintos sistemas de Derecho internacional privado. En suma, la

\footnotetext{
${ }^{357}$ En este sentido, O. LANDO (1985), p. 285; M. PATOCCHI (1985), p. 115;

358 Sobre la idea de que la autonomía de la voluntad de las partes no ejerce una función simplemente localizadora de la relación jurídica, sino que se trata de una técnica de materialización, M. GIULIANO (1977), p. 213; M. PATOCCHI (1985), p. 112; P. LAGARDE (1986), p. 63; J-C. POMMIER (1992), pp. 15 y ss.; P. DE CESARI (2001), pp. 27 y ss.

${ }^{359}$ M. GIULIANO (1977), p. 212; O. LANDO (1985), p. 284.
} 
autonomía de la voluntad proporciona una solución segura y previsible, valor que tiene una especial relevancia en las relaciones económicas internacionales.

Por último, y con un peso menor, también se ha apelado en ocasiones a la armonía internacional de soluciones en defensa de la autonomía de la voluntad conflictual $^{360}$. Al estar reconocida la autonomía de la voluntad conflictual en materia contractual casi sin excepción en la totalidad de ordenamientos jurídicos, es una solución que contribuye a la consecución de una regulación uniforme de las situaciones jurídicas internacionales en esta materia; no obstante, debemos reconocer que en contra de esta armonía internacional de soluciones se erigen los límites que cada ordenamiento jurídico pueda poner a la elección de la ley aplicable a los contratos.

En las líneas anteriores hemos esbozado las principales razones sobre las que la autonomía del la voluntad conflictual ha tenido su desarrollo en materia de contratos hasta llegar a ser una solución generalizada hoy en día. Superada la visión estrictamente localizadora, se puede decir que la elección de ley a los contratos cumple principalmente una función de materialización, al tener un peso destacable el hecho de que las partes escojan la ley en virtud de su contenido material o, dicho de otro modo, en la búsqueda de la consecución de unos determinados efectos jurídicos materiales.

\section{La autonomía de la voluntad conflictual en los ámbitos personal y familiar}

Tal y como acabamos de señalar, la autonomía de la voluntad conflictual ha tenido tradicionalmente su hábitat natural en el ámbito de las obligaciones contractuales, donde constituye un principio regulador desde hace tiempo. En las últimas décadas se aprecia una tendencia en el DIPr de Europa continental consistente en una progresiva ampliación del juego de la autonomía de la voluntad como mecanismo para la determinación de la ley aplicable a las relaciones jurídicas internacionales. Hoy en día, el aumento de la presencia de la autonomía

\footnotetext{
${ }^{360}$ M. PATOCCHI (1985), p. 117; J-C. POMMIER (1992), pp. 30 y ss.
} 
de la voluntad conflictual para determinar la ley aplicable a las situaciones jurídicas internacionales es un hecho incontestable.

Esta expansión de más allá del ámbito contractual se ha producido de manera paulatina o progresiva. La expansión se ha orientado hacia otras materias de carácter patrimonial, como es el caso de las obligaciones extracontractuales, como consecuencia de la crisis del criterio de la lex loci delicti, cuya rigidez provocaba en muchas ocasiones resultados absurdos como consecuencia de las dificultades de la localización de la situación fáctica. Mas también se fue introduciendo en instituciones jurídicas de carácter familiar y/o sucesorio, principalmente en aquellas con un contenido económico, tales como la regulación del régimen económico matrimonial o las sucesiones por causa de muerte, yendo más allá y proyectándose sobre aquellas otras cuyo contenido es estrictamente personal, como puedan ser los efectos del matrimonio (v. gr., art. 9.2 CC, aún con su limitado alcance) o la regulación del nombre y apellidos de las personas físicas $^{361}$.

El juego de la autonomía de la voluntad conflictual en el ámbito familiar y personal se ha articulado de distintas maneras, de tal forma que en ocasiones se prevé como una solución de ley aplicable de carácter principal, como por ejemplo el art. 52 de la ley suiza de DIPr que determina que la ley rectora del régimen económico matrimonial será la ley escogida por los cónyuges, y otras como solución de carácter subsidiario, como ocurre en el caso de nuestro art. $9.2 \mathrm{CC}$, que prevé la posibilidad de que los cónyuges escojan la ley aplicable a los efectos del matrimonio cuando no tengan nacionalidad común. Ahora bien, la principal característica de la autonomía de la voluntad conflictual en estos nuevos ámbitos es su limitación y su muy heterogénea proyección o intensidad como técnica de

\footnotetext{
${ }^{361}$ Para un análisis general de la introducción de la autonomía de la voluntad conflictual en el ámbito familiar y personal, vid., J-Y., CARLIER (1992), pp. 281 y ss.; P. GANNAGÉ (1992), pp. 425 y ss.; A.E. von OVERBECK (1993), pp. 627 y ss.; en el marco de la Conferencia de La Haya, N. WATTÉ (1991), pp. 422 y ss. En la materia de nombre últimamente citada, a las opiniones doctrinales fundadas, vid. M.A. LARA AGUADO (1998), hay que unir las exigencias de la UE que han motivado interpretaciones como las de la Instrucción DGRN de 23 de mayo de 2007, Instrucción DGRN de 20 de marzo de 2006 sobre prevención del fraude documenta en materia de estado civil y, fundamentalmente, Instrucción DGRN de 24 de febrero de 2010 sobre reconocimiento de los apellidos inscritos en los Registros Civiles de otros países miembros de la Unión Europea.
} 
identificación de la ley aplicable ${ }^{362}$. Frente a la amplia libertad reconocida en el ámbito contractual, donde las partes pueden libremente escoger la ley que estimen por conveniente para regular sus relaciones jurídicas ${ }^{363}$, en el ámbito familiar y/o personal, la característica fundamental de la autonomía de la voluntad conflictual es su carácter apriorísticamente limitado. Esto significa que en este sector las posibilidades de elegir la ley aplicable se encuentran restringidas a determinadas leyes con las que el supuesto de hecho presenta ya una determinada vinculación. En este sentido, y con carácter general, se consideran elegibles las leyes bien de la nacionalidad, de la residencia habitual o del domicilio de las partes implicadas en la relación jurídica en cuestión ${ }^{364}$. Esta circunstancia se relaciona con una de las razones que contribuyeron a la expansión de la autonomía de la voluntad. Nos referimos al juego de la autonomía de la voluntad conflictual como solución de compromiso para superar la oposición entre los sistemas que determinan la aplicación de la ley del domicilio, de los que determinan la aplicación de la ley de la nacionalidad y así superar las dificultades de localización de determinadas situaciones jurídicas internacionales ${ }^{365}$.

El cambio demográfico supuso un importante factor que ha influido en la penetración de la autonomía de la voluntad conflictual en el ámbito familiar y personal $^{366}$. Por todos son conocidos los problemas generados para el DIPr por los grandes flujos migratorios y el consiguiente aumento de la población extranjera que tuvieron lugar a lo largo del siglo pasado. El creciente número de inmigrantes generó la oposición en el ámbito familiar entre el estatuto de origen o de la

362 S. ÁlVAREZ GONZÁLEZ (2005), p. 144.

${ }^{363}$ Siempre a salvo los límites derivados del juego del orden público y de las leyes de policía.

${ }^{364}$ Hay casos en los que también se da entrada a la posibilidad de escoger la lex rei sitae

${ }^{365}$ Vamos a ver cómo este juego de la autonomía de la voluntad como solución de compromiso no ha sido ajeno a la elección de ley aplicable a las sucesiones. Sobre esta función de la autonomía de la voluntad conflictual en general, P.M. PATOCCHI (1985), p. 110; P. GANNAGÉ (1992), pp. 440 y ss; en el ámbito de las sucesiones A.E. VON OVERBECK (1965). Un ejemplo del juego de la autonomía de la voluntad conflictual como solución de compromiso entre las conexiones del domicilio y de la nacionalidad lo podemos encontrar en el art. 52 de la ley suiza de DIPr, con ocasión de la determinación de la ley aplicable al régimen económico matrimonial; dicho artículo permite a los cónyuges elegir la ley bien de su domicilio, bien de la nacionalidad de cualquiera de ellos; vid. B. DUTOIT (2005), p. 178; P.M. PATOCCHI (1985), p. 110 ya con ocasión del Proyecto de codificación suizo.

366 J-Y. CARLIER (1992), pp. 234 y ss.; P. GANNAGÉ (1992), p. 449; 
nacionalidad, fundamentado en un criterio de respeto a la identidad cultural de los inmigrantes, y el estatuto del domicilio, que favorece el fenómeno de la integración. La autonomía de la voluntad conflictual aparecía en muchas ocasiones como la solución a la insalvable oposición entre estos dos estatutos ${ }^{367}$; ejemplo paradigmático de esta problemática lo encontramos en el ámbito de las relaciones matrimoniales, sector donde es habitual que se dé a los cónyuges la posibilidad de que escojan la ley aplicable a los efectos del matrimonio o al régimen económico matrimonial, dándoles fundamentalmente la posibilidad de escoger entre la ley de la nacionalidad y la ley del domicilio o de la residencia habitual $^{368}$.

Una nueva dimensión de la autonomía de la voluntad, relacionado también con los fuertes flujos migratorios que se perciben en la actualidad es la idea de la sociedad multicultural y la consiguiente apertura a nuevos valores jurídicos de otros sistemas; en este sentido, en los últimos años ha aumentado el protagonismo de un nuevo valor, de creciente importancia en el orden jurídico internacional, cual es el respeto a la autonomía cultural de la persona ${ }^{369}$. En su contexto, el DIPr debe aportar mecanismos que den solución a ciertas situaciones encontradas, como consecuencia del choque entre el principio de integración, con importantes principios como el de igualdad y no discriminación, y el respeto a esa autonomía cultural del individuo. En este sentido, la autonomía de la voluntad se

\footnotetext{
${ }^{367}$ P. GANNAGÉ (1992), p. 428; S. SÁNCHEZ LORENZO (1994), p. 575.

${ }^{368}$ Ejemplo de ello lo encontramos en nuestro propio sistema autónomo de DIPr, donde, como ya hemos mencionado, se permite en el art. 9.2 CC la posibilidad de que los cónyuges escojan la ley de la nacionalidad o de la residencia habitual de cualquiera de ellos para regular los efectos del matrimonio; esta posibilidad se introdujo con la reforma del CC que tuvo lugar a través de la Ley 11/1990, de 15 de octubre (BOE 18 octubre de 1990), sobre reforma del Código Civil, en aplicación del principio de no discriminación por razón de sexo y fue considerada como una solución progresista entre la doctrina de la época, vid J-Y. CARLIER (1992), p. 332; P. GANNAGÉ (1992), p. 447; I. VIARENGO (1996), p. 119. En el ámbito convencional es de mencionar el Convenio de La Haya sobre ley aplicable a los regímenes matrimoniales, de 14 de marzo de 1978, del que España no es parte, prevé con carácter principal para determinar el régimen patrimonial la aplicación de la ley elegida por los cónyuges, limitando la posibilidad de elegir la ley a la ley de la nacionalidad de cualquiera de los cónyuges en el momento de la elección, la ley de la residencia habitual de cualquiera de ellos o la ley de la residencia habitual que vayan a establecer.

${ }^{369}$ E. JAYME (1993), pp. 295 y ss.
} 
ha presentado también como una técnica idónea para llegar a soluciones de compromiso entre estos valores en ocasiones encontrados ${ }^{370}$.

Por último, en este repaso somero de factores determinantes de una progresiva ampliación del ámbito material de la autonomía conflictual, no puede desconocerse, desde el punto de vista sociológico si se quiere, la influencia la extensión del individualismo; la creciente importancia del individuo como tal en la organización de la sociedad se ha venido traduciendo paralelamente en un mayor reconocimiento en los Derechos materiales internos del ámbito de actuación de la voluntad del individuo en sus relaciones jurídicas ${ }^{371}$. La extensión de esta autonomía al DIPr no es sino la consecuencia de la necesaria coherencia de esta rama del ordenamiento jurídico con las soluciones de Derecho material. El aumento del juego de la autonomía de la voluntad en Derecho material se proyecta correlativamente en una extensión de la posibilidad de elegir la ley aplicable a las situaciones privadas internacionales ${ }^{372}$.

\section{AUTONOMía de LA VOLUNTAD CONFLICTUAL EN MATERIA DE SUCESIONES: LA PROFESSIO IURIS}

\section{Autonomía de opción, pacto de lege utenda y professio iuris}

En el contexto someramente descrito en párrafos anteriores no es extraño que la materia sucesoria fuese caldo de cultivo abonado para que la autonomía conflictual tuviese una presencia importante: el carácter en cierta manera híbrido entre lo familiar y lo patrimonial lo hacía previsible. La importancia que la autonomía de la voluntad ha tenido desde tiempos inmemoriales en los supuestos de anticipación sucesoria (testamentos y pactos) pronosticaba una más pronta o tardía recepción en el marco de la ley aplicable a la sucesión internacional. El manido principio de que la voluntad del testador es la ley de la sucesión (principio fundamental en Derecho sustantivo) debía tener algún tipo de expresión en

\footnotetext{
${ }^{370}$ E. JAYME (1993), p. 303.

${ }^{371}$ J-Y. CARLIER, (1992), pp. 239 y ss.; P. GANNAGÉ (1992), p. 429; S. SÁNCHEZ LORENZO (1994), p. 573, donde el autor fundamenta la tendencia de la autonomía de la voluntad en el ámbito no patrimonial por estar estos sectores justificados en el principio de libertad individual. E. JAYME (2000), pp. 31 y ss.

${ }^{372}$ K. SIEHR (1989), p. 488; S. ÁLVAREZ GONZÁLEZ (2005), p. 143.
} 
términos de ley aplicable. Esta expresión, que hemos visto en términos positivos en el Capítulo anterior, comienza con una modesta aceptación de la professio iuris y evoluciona hacia su expansión y su convivencia con otras realidades como el pacto de lege utenda para los pactos sucesorios.

El primer dato que debemos retener en este ámbito es que, tal y como se ha concebido hasta el momento, se trata siempre de una posibilidad de carácter limitado; esto es, la elección de la ley aplicable a la sucesión tiene como punto de partida y principal característica que no es una elección libre, sino que se encuentra limitada a un mayor o menor número de leyes determinadas apriorísticamente por el legislador y que presentan una determinada vinculación con la sucesión en cuestión. Y esta limitación, hasta la fecha, preside tanto la determinación de la ley aplicable a la total sucesión, como la relevancia de la autonomía de la voluntad en la determinación de la ley aplicable a los pactos sucesorios.

En efecto, antes de adentrarnos en el análisis de la solución de ley aplicable a los pactos sucesorios basada en una elección de ley aplicable, es necesario realizar algunas precisiones conceptuales. En concreto, debemos diferenciar dos conceptos distintos que, aunque tienen importantes puntos en común, es necesario diferenciar; nos estamos refiriendo a la professio iuris y a los pactos de lege utenda operativos respecto de los pactos sucesorios.

Ambas realidades tienen, hasta la fecha, un denominador común la limitación apriorística por parte del legislador de las leyes que son susceptibles de elección. La ley señala un catálogo de leyes más o menos amplio, que presentan una vinculación objetiva con la situación fáctica y las partes pueden escoger de entre esas leyes cuál se va a aplicar a su relación jurídica ${ }^{373}$. Aunque esta

\footnotetext{
${ }^{373}$ Esta técnica de limitación de la autonomía de la voluntad conflictual se diferencia de la autonomía de la voluntad conflictual de localización relativa, que es otra forma de limitar la posibilidad de elegir la ley aplicable. En el caso de la autonomía de la voluntad conflictual de localización relativa no hay intervención apriorística alguna del legislador, sino que se exige que las partes elijan una ley que presente un cierto nexo con la relación jurídica en cuestión, lo que será valorado por el juez competente; es el caso, por ejemplo, del art. 10.5 de nuestro CC. Para un análisis amplio de estas dos técnicas de limitación de la autonomía de la voluntad conflictual, J.M. FONTANELLAS MORELL (2010), pp. $201 \mathrm{y}$ ss.
} 
característica es contingente, es decir, no tiene por qué darse de manera imperativa, lo cierto es que por razones que tratan de conciliar intereses de distinta índole, se ha generalizado con la extensión de la autonomía de la voluntad más allá del ámbito contractual (donde la limitación apriorística no es un dato). Por ello, hoy en día podemos encontrar distintos ejemplos de autonomía de opción como es el caso del art. 8 del Protocolo sobre la ley aplicable a las obligaciones alimenticias, que establece la posibilidad de que se escoja la ley de la nacionalidad o residencia habitual del deudor o del acreedor alimenticio, la ley elegida o aplicada a las relaciones patrimoniales entre las partes o la ley elegida o aplicada al divorcio o separación ${ }^{374}$; o en el art. 5 del Reglamento núm. 1259/2010, donde se permite a los cónyuges también escoger la ley aplicable al divorcio o separación judicial, siempre y cuando la ley elegida sea la ley de la residencia habitual de los cónyuges, la ley del último lugar de residencia habitual común siempre y cuando al menos uno de ellos aún permanezca allí, la ley de cualquiera de la nacionalidad de los cónyuges o la ley del foro ${ }^{375}$.

En todo caso, más interesante para nuestro análisis es destacar que cuando se hace referencia a la elección de ley aplicable a las sucesiones internacionales se habla generalmente de la professio iuris, para referirse a una elección de ley unilateral y revocable. Se han dado definiciones más o menos completas de la professio iuris sucesoria, pero como contenido mínimo destaca que se trata de la elección de la ley aplicable a la sucesión. Ahora bien, la professio iuris encierra una serie de caracteres que afectan a su extensión, alcance y elementos personales. Es ilustrativo el concepto otorgado por J.M. FONTANELLAS quien la define como la "facultad conferida al causante para que, en una disposición por causa de muerte, designe, dentro de ciertos límites, la ley que debe regir, en todo o en parte, su sucesión" ${ }^{\text {376 }}$. De las características que se derivan de esta definición, destaca la unilateralidad de la elección y la aludida

\footnotetext{
${ }^{374}$ Art. 8 Protocolo sobre la Ley aplicable a las obligaciones alimenticias, DO núm. L 331 de 16 de diciembre de 2009.

375 Art. 5 del Reglamento (CE) núm. 1259/2010 del Consejo, de 20 de diciembre de 2010, por el que se establece una cooperación reforzada en el ámbito de la ley aplicable al divorcio y a la separación judicial (DOUE L 343, de 29 de diciembre de 2010).

${ }^{376}$ J.M. FONTANELLAS MORELL (2010), p. 187.
} 
designación de la ley dentro de ciertos límites. El profesor VON OVERBECK definió la professio iuris como "la elección entre dos o más legislaciones determinadas por conexiones objetivas" ${ }^{377}$; de nuevo se destaca la limitación. En ambos casos se trata de elegir una ley de entre las prefijadas a priori por el legislador, con base en unas conexiones objetivas con la situación jurídica en cuestión ${ }^{378}$.

No obstante, como hemos adelantado, la professio iuris sucesoria tiene una característica particular que permite delimitarla con mayor claridad del resto de ejercicios de autonomía de opción ${ }^{379}$. Se trata en este caso de los elementos personales intervinientes en la elección de ley aplicable; según la definición que hemos seguido, la professio iuris es una facultad del causante $\mathrm{y}$, por tanto, es unilateral. Es el causante el que escoge, en su caso, qué ley quiere que regule su sucesión. La nota de unilateralidad de la professio iuris permite diferenciarla de otros ejercicios de autonomía de opción bilaterales, esto es aquellos que se llevan a cabo a través de los denominados pactos de lege utenda. Por pacto de lege utenda podemos entender, por tanto, aquel ejercicio de autonomía de opción o elección de ley aplicable (dentro de ciertos límites en materia sucesoria), plasmada en un pacto o acuerdo entre, al menos, dos sujetos. La elección es multilateral y su revocación o modificación exigiría la misma multilateralidad.

Debemos poner de manifiesto desde este momento que al abordar las sucesiones internacionales se suele hablar en general de la professio iuris y no de pactos de lege utenda, sin distinguir entre ambas realidades $\mathrm{y}$, en ocasiones, meramente confundiéndolas; esta generalización se debe a una visión de las sucesiones internacionales como algo unilateral, esto es, como una cuestión que concierne a un causante y a su sucesión, como de hecho es cuando se trata de una sucesión encauzada a través de un testamento unilateral o de una sucesión $a b$

\footnotetext{
377 A.E. VON OVERBECK (1965), p. 1087. De hecho, como veremos, la professio iuris se ha visto como una solución de compromiso o técnica de flexibilización para dar solución a la oposición existente entre los sistemas que aplican la ley de la nacionalidad del causante a su sucesión y los que aplican la ley del domicilio.

${ }^{378}$ Objetivas aquí por contraposición a la llamada "conexión subjetiva" que en los últimos tiempos y en materia de sucesiones se identifica con la autonomía de la voluntad. No es que la residencia habitual o la nacionalidad hayan dejado de ser conexiones personales o subjetivas. Es simplemente una convención terminológica.

${ }^{379}$ Sobre este particular, J.M. FONTANELLAS MORELL (2010), pp. 205 y ss.
} 
intestato $^{380}$. No obstante, en nuestro caso, a la hora de analizar la estructura de la elección de ley aplicable a los pactos sucesorios vamos a tener en cuenta, porque es absolutamente necesario, las dos formas de elección de ley; esto es, a través del ejercicio unilateral de la professio iuris y a través del ejercicio multilateral de un pacto de lege utenda. Como vamos a ver más adelante, existen instrumentos normativos que articulan la elección de ley aplicable a los pactos sucesorios a través de un ejercicio unilateral o bilateral de la autonomía de la voluntad conflictual. Pero al margen de esta normativa, nos tendremos que preguntar además por la relación de la autonomía de la voluntad conflictual y el carácter bilateral de los pactos sucesorios, máxime cuando se trata de pactos sucesorios que afectan a más de una sucesión.

\section{La professio iuris como solución de ley aplicable}

\subsection{La toma en consideración de la professio iuris sucesoria}

Tradicionalmente se entendió que la ley aplicable a la sucesión, determinada por la correspondiente norma de conflicto, regulaba de forma imperativa la sucesión, de tal forma que cualquier referencia que el causante hubiera podido realizar a favor de otra ley no tenía sino un mero valor de incorporación por referencia, que nunca podía contrariar las normas imperativas

\footnotetext{
${ }^{380}$ Se puede decir que en DIPr siempre se ha entendido que para determinar la ley aplicable a la sucesión los elementos que pueden constituir el punto de conexión pueden referirse bien a las circunstancias personales del causante, bien a los bienes que van a constituir el caudal hereditario; vid. H. LEWALD (1925), p. 12; también p. 18 donde es muy ilustrativo al rechazar la aplicación de la ley nacional del heredero por ser éste una persona que no se conoce hasta que se solucione el conflicto de leyes; también incide en esta idea, J.M. FONTANELLAS MORELL (2010), npp. núm. 14, p. 191 y remisiones que ahí se señalan. De igual forma se rechaza la posibilidad de que los sucesores puedan escoger la ley aplicable a la sucesión; generalmente se ha aceptado que la elección de la ley aplicable a la sucesión es una elección de carácter unilateral, en manos del causante, desechándose otras opciones como la posibilidad de que los propios futuros o hipotéticos herederos deban participar en la elección de la ley aplicable a la sucesión; no obstante, hemos de reconocer la existencia de algunas excepciones en las que para cuestiones particulares se ha permitido cierta elección de ley aplicable a la sucesión por parte de los herederos; el art. 24.2 del EGBGB de 1896 podían invocar la ley de domicilio del causante alemán domiciliado en el extranjero en lo que respecta a las obligaciones del caudal relicto; dicho artículo decía que "Si el nacional alemán posee al tiempo de su fallecimiento su domicilio en el extranjero, sus herederos pueden también invocar las leyes en vigor en el domicilio de causante en lo que respecta a las obligaciones del caudal relicto", traducción de J.D. GONZÁlEZ CAMPOS/J.C. FERNÁNDEZ ROZAS (1983), p. 462. Ejemplo de Derecho vigente lo encontramos en el sistema italiano, donde el art. 46.3 de la ley italiana de DIPr establece la posibilidad de que los herederos puedan escoger la ley correspondiente al lugar de apertura de la herencia para organizar la partición hereditaria.
} 
de la ley aplicable ${ }^{381}$. Existió, no obstante, una excepción aislada donde se permitía una cierta posibilidad de escoger la ley aplicable a la sucesión. Se trata, como veremos con mayor precisión, del antiguo sistema suizo bajo la ley federal de $1891^{382}$, que preveía una limitada elección de ley aplicable a la sucesión para los conflictos intercantonales, aunque se aplicó extensivamente a los conflictos internacionales ${ }^{383}$. Esta regulación prevista en el antiguo sistema suizo se considera por la doctrina como el precedente inmediato para la actual regulación de la professio iuris en el vigente sistema suizo y como el punto de partida para el posterior desarrollo y consolidación que sufre la elección de ley aplicable a las sucesiones $^{384}$.

Con anterioridad a su consagración genérica por el Reglamento, la posibilidad, más o menos limitada, de que el causante escoja la ley aplicable a su sucesión es una cuestión que había adquirido especial protagonismo, fundamentalmente desde la adopción del Convenio de La Haya de 1989 sobre ley aplicable a las sucesiones por causa de muerte, a propósito del cual tuvo lugar un rico debate sobre la professio iuris $^{385}$. Este protagonismo con un rico debate doctrinal se revitalizó en el marco de los trabajos preparatorios del Reglamento, donde desde el primer momento, desde la Propuesta, se preveía que la professio iuris tuviera un importante papel. No obstante esta actualidad innegable, la posibilidad de que el causante escoja la ley aplicable a su sucesión no es algo

\footnotetext{
${ }^{381}$ M. CALEB (1927), passim; A.E. VON OVERBECK (1965), p. 1088;

${ }^{382}$ Loi fédérale du 25 juin 1891 sur les rapports de droit civil des citoyens établis ao en séjour.

${ }^{383}$ A lo largo del siglo XIX ya se conocieron las primeras opciones de elegir la ley sucesoria en algunos sistemas de América latina, aunque tal posibilidad no gozó de una clara continuidad; también el art, 9.2 del CC italiano de 1865, aunque la doctrina acabó interpretando que se trataba de una mera remisión material llevada a cabo siempre dentro de los límites permitidos por la ley sucesoria y no una verdadera elección de ley aplicable, vid. P. DE CESARI (2001), pp. 66 y ss.; sobre todo ello vid. con mayor amplitud, J.M. FONTANELLAS MORELL (2010), pp. 137 y ss; también, A. BONOMI (2011), pp. 198 y ss.

${ }^{384}$ M. FERID (1969), p. 95; S. ÁlvAREZ GONZÁLEZ (2009), p. 27; J.M. FonTANELLAS MoRELL (2010), pp. 143 y ss.

${ }^{385}$ La previsión de la professio iuris en el Convenio de La Haya de 1989 se considera una de las principales características del Convenio; vid. W.M. WATERS (1990), pp. 534 y ss. Desde el punto de vista doctrinal se habla de la "consolidación doctrinal de la professio iuris", marcándose la década de los 60 como un punto de inflexión que marca un antes y un después, a partir del cual la elección de la ley aplicable a la sucesión por el causante se ve no sólo viable, sino incluso aconsejable; vid. al respecto, J.M. FONTANELLAS MORELL (2010), pp. 115 y ss.
} 
nuevo; las primeras manifestaciones de la professio iuris sucesoria, tal y como la conocemos en el mundo contemporáneo, tuvieron lugar durante la temprana Edad Media; desde entonces, esta figura ha tenido una difícil y tímida evolución tanto en la doctrina, como en la jurisprudencia y Derecho positivo $^{386}$.

Además de las ventajas descritas más atrás en torno a la generalización de la autonomía de la voluntad conflictual en DIPr, la professio iuris sucesoria presenta importantes ventajas que explican en gran medida su creciente protagonismo. Entre estas ventajas caben destacar fundamentalmente dos: por un lado, la aptitud de la professio iuris como medio para favorecer la previsibilidad del régimen aplicable a la sucesión y la seguridad jurídica. A través de la elección de la ley aplicable a la sucesión por el causante se asegura una mayor previsibilidad y seguridad jurídica en la regulación de las sucesiones internacionales. Esta previsibilidad del régimen jurídico de la sucesión facilita al causante la posibilidad de planificar y organizar su sucesión, así como el acceso a herramientas o mecanismos de anticipación sucesoria, tales como los propios pactos sucesorios ${ }^{387}$. Esta ventaja, que podría considerarse común a cualquier ejercicio de la autonomía conflictual, es especialmente importante en materia de sucesiones por una razón, si se quiere, contingente, pero importante: como hemos visto, el Derecho comparado pivota entre la ley de la última nacionalidad y la del último domicilio o residencia habitual (junto a la inmutable lex rei sitae) como alternativas posibles de ley aplicable a la sucesión por causa de muerte. El conocido y perturbador conflicto móvil ${ }^{388}$ tiene su mejor remedio a través de la seguridad de que la ley elegida es ley sucesoria.

\footnotetext{
${ }^{386}$ Para un análisis exhaustivo de los orígenes históricos de la professio iuris, así como de su desarrollo desde el punto de vista del Derecho positivo, de la jurisprudencia y de la doctrina, vid., J.M. FONTANELLAS MORELL (2010), pp. 29 y ss.

${ }^{387}$ Decimos que en mayor o menor medida porque el grado de seguridad jurídica y previsibilidad en el régimen aplicable que proporciona la elección de ley aplicable va a depender de la concreta configuración de la professio iuris que se adopte. Así, una professio iuris en la que se permita escoger la ley determinada en el momento de la elección, proporcionará una mayor seguridad jurídica y previsibilidad que una professio iuris que exige la vinculación de la ley elegida en el momento del fallecimiento del causante.

${ }^{388}$ En realidad no se trata de un conflicto móvil propio sensu, puesto que la localización de la conexión en el momento de la muerte lo evita. Lo que no evita es que se realice un acto de anticipación sucesoria sin saber cuál va a ser a la postre el último domicilio del causante o su última nacionalidad.
} 
Por otro lado, la segunda ventaja fundamental de la professio iuris es, como vamos a ver más adelante, su aptitud como mecanismo de flexibilización actuando como una solución de compromiso ${ }^{389}$. Se trata en este caso de una ventaja de negociación si nos encontramos en un foro de codificación del DIPr; y se trata de una solución que pone en manos del interesado la última palabra cuando las razones para optar por una conexión objetiva y otra están equilibradas, como lo están cuando hablamos de la ley de la última nacionalidad del causante y la ley del último domicilio (o de la última residencia habitual) del causante ${ }^{390}$. A priori ambas son igualmente válidas como conexiones para buscar la aplicación del Derecho más vinculado a una sucesión internacional. Sin embargo, no es inusual que el causante tenga su domicilio o residencia habitual en un país extranjero, pero que a la vez mantenga importantes vínculos con el país de su nacionalidad, tales como familiares o una parte más o menos importante de su patrimonio. En estas circunstancias se dificulta enormemente la determinación apriorística de la ley con mayor vinculación a la sucesión y, en este sentido, la existencia de una conexión rígida para determinar la ley aplicable a las sucesiones internacionales es algo inadecuado y puede conllevar a resultados absurdos ${ }^{391}$. En

\footnotetext{
${ }^{389}$ Además de estas ventajas se han valorado otras que, en menor medida o de forma más dudosa, contribuyen a la buena consideración de la professio iuris; así, por ejemplo, se atribuye a la professio iuris la cualidad de favorecer en ocasiones la armonía internacional de soluciones o se ve como un mecanismo para coordinar la aplicación de la misma ley a la sucesión de una persona casada y a su régimen económico matrimonial, evitándose así incoherencias y problemas de adaptación, entre dos estatutos colindantes. Vid. con mayor extensión, J.M. FONTANELLAS MORELL (2010), pp. 249 y ss.; A. BONOMI (2011), pp. 210 y ss.

${ }^{390}$ La opción entre la conexión de la nacionalidad o la conexión del domicilio (o residencia habitual) del causante para la regulación de las sucesiones internacionales es una de las tradicionales problemáticas que se han mantenido en este sector del DIPr; la opción por una u otra conexión responde a cuestiones técnicas (mayor flexibilidad de la conexión domiciliar, frente a la mayor estabilidad y seguridad de la conexión nacional) y de política legislativa (nos estamos refiriendo a la política migratoria de cada país, que ha explicado la preferencia por la conexión de la nacionalidad en aquellos países en los que predomina la emigración y la preferencia por la conexión integradora del domicilio en aquellos países en que predomina la inmigración). La literatura sobre esta cuestión es abundante; vid. con carácter principal, A.E. VON OVERBECK (1961), pp. 571 y ss.; G. KÜHNE (1973), pp. 64 y ss.; M. FERID (1974), pp. 91 y ss. F. BOULANGER (1975), pp. 46 y ss y (2004), pp. 52 y ss.

391 La aplicación de la ley de la nacionalidad del causante a su sucesión puede suponer la aplicación de una ley lejana al causante, en aquellos casos en los que éste lleva domiciliado largo tiempo en el extranjero, donde crea su propia familia y donde está situado su patrimonio, quedando únicamente un vínculo formal con la ley de su nacionalidad. De igual forma, la aplicación de la ley del domicilio del causante puede resultar inadecuada en aquellos casos en los
} 
este contexto, la professio iuris se presenta como un elemento de flexibilización que permite acercar las dos soluciones antagónicas y que proporcionaría una localización adecuada de la sucesión atendiendo además al caso concreto ${ }^{392}$. En consecuencia, desde esta perspectiva la professio iuris no es una posibilidad de elegir libremente la ley aplicable a la sucesión, sino la opción entre determinados criterios de conexión que a priori son igualmente pertinentes para determinar la ley aplicable a la sucesión ${ }^{393}$.

Pese a estos datos, desde una perspectiva material o sustantiva, tradicionalmente se ha visto la professio iuris sucesoria con gran recelo ${ }^{394}$; la traba fundamental que se ha puesto a la posibilidad de que el causante pueda escoger la ley aplicable a su sucesión es la garantía de la protección de determinados familiares próximos al causante, o dicho de otro modo, la protección de los denominados legitimarios, herederos forzosos o reservatarios. En este sentido, la professio iuris se ha visto como una herramienta en manos del causante a través de la cual se facilita la frustración o el fraude a los derechos sucesorios que la ley reserva a determinadas personas próximas al causante ${ }^{395}$; es decir, el causante, a

que el causante mantenga importantes vínculos con la ley de su nacionalidad, traducidos indicios como la situación de su patrimonio o la conservación de sus familiares más próximos.

392 A.E. VON OVERBECK (1965), p. 1105; H. DÖLle (1966), p. 219; G. KüHNE (1973), p. 68 y ss., quien señala dos posibilidades: bien la posibilidad del causante de ejercer autonomía de la voluntad conflictual, bien la posibilidad de buscar en el caso concreto la proper law of succession; J.M. FONTANELLAS MORELL (2010), pp. 251 y ss.; en contra, M. GoRÉ (1994), p. 195, quien afirma que la professio iuris participa de una solución de compromiso que no satisface a nadie.

${ }^{393}$ Visión de la professio iuris que coincide con la definición que de la misma dio A.E. VON OVERBECK.

${ }^{394}$ Y aún en los últimos tiempos también se mantienen detractores, vid. M. GoRÉ (1994), pp. 195 y ss.; la autora utiliza, en primer lugar, un argumento según el cual entiende que ofrecer al causante la posibilidad de escoger la ley aplicable a su sucesión es contradictorio y va en contra de la estructura del Derecho de sucesiones en tanto que la libertad de disponer del causante se deriva de la ley, de tal forma que, en su opinión, permitir tal elección de ley por parte del causante es tanto como negar que es la ley la que concede la libertad de disposición. Entiende además que a través de la professio iuris el causante no está disponiendo de sus propios intereses, sino de los intereses de sus sucesores. Por último, destaca también el argumento según el cual la autora ve en la professio iuris no un mecanismo de localización, sino un mecanismo materializador, que puede beneficiar a unos y a otros, y desde este punto de vista, en su opinión, la professio iuris no puede hacer abstracción de las disposiciones imperativas de la ley sucesoria.

395 P. DE CESARI (2001), p. 116; P. MAYER/V. HeUZÉ (2007), p. 603, quienes rechazan la posibilidad de introducir la professio iuris sucesoria en el marco del ordenamiento jurídico francés precisamente por este motivo; J.M. FonTANELlAS MORELl (2010), pp. 278 y ss.; A. BONOMI (2011), p. 217; en el marco del Convenio de La Haya de 1989 también se debatió sobre este temor, siendo una de las razones por las que se previó la reserva a la elección de ley prevista en el art. 
través de la elección de ley aplicable a su sucesión puede evitar que se apliquen las normas de protección que en materia de Derecho de sucesiones pudiera prever la ley que se aplicaría objetivamente, esto es, en defecto de elección. Este inconveniente es consecuencia de la visión de dos intereses de carácter material antagónicos en el Derecho de sucesiones: por un lado, el interés del causante a disponer de su patrimonio por causa de muerte con la mayor libertad posible y, por otro lado, el interés de determinados familiares próximos al causante de recibir una parte de la herencia del mismo.

Sin embargo, el inconveniente de la professio iuris basado en la posible frustración de los derechos sucesorios determinados por la ley aplicable objetivamente se ha visto relativizado considerablemente por la doctrina de los últimos tiempos ${ }^{396}$. Por un lado, de modo general la professio iuris no se ha usado con el fin de evadir los derechos sucesorios de herederos forzosos marcados por la ley, siendo su uso abusivo una excepción en la práctica ${ }^{397}$. Por otro lado, se han dado varias razones para relativizar este argumento contrario a la admisión de la professio iuris sucesoria. En primer lugar, se matiza el concepto de derecho del legitimario o heredero forzoso, en el sentido de que nadie es heredero forzoso o legitimario hasta que está abierta la sucesión y, por tanto, tampoco se pueden tener derechos antes de tal apertura, sino, en todo caso, meras expectativas. Además, la pretendida frustración de tales supuestos derechos se puede dar fácilmente por distintas vías, tales como la posibilidad de que el causante haya dispuesto de todo su patrimonio en vida, de tal forma que no quede activo alguno para después de su muerte, o el simple cambio deliberado por el causante de la conexión objetiva que determina la ley aplicable a la sucesión, como por ejemplo la nacionalidad o, con mayor facilidad, la residencia habitual. A ello hay que añadir la incertidumbre propia de las sucesiones internacionales en cuanto a la determinación de la norma aplicable y a falta de una norma uniforme al

24.1 d), vid. en este contexto W.M. Waters (1990), p. 612; C.S. BRUCH (1993), pp. 315 y ss., quien considera la posibilidad de professio iuris recogida en el Convenio una oportunidad en manos del testador para un "choice-of-law shopping".

${ }^{396}$ J.M. FONTANELLAS MORELL (2010), pp. 278 y ss.; A. BONOMI (2011), pp. 215 y ss.

${ }^{397}$ A. DAVÌ (2004), p. 475; M. DROZ (1970), p. 326. 
respecto $^{398}$. En efecto, en este ámbito es difícil prever cuál va a ser la ley aplicable a la sucesión del causante, cuestión que depende obviamente de la norma de conflicto del foro. Ya hemos hecho alusión a las diferencias que a este respecto existen en DIPr comparado, fundamentalmente con la tradicional oposición de aquellos sistemas que señalan la aplicación de la ley de la última nacionalidad del causante y los que señalan la aplicación de la ley del último domicilio del causante. Todos estos argumentos, en definitiva, vienen a fortalecer la idea de la inexistencia de verdaderos derechos de herederos forzosos o dicho de otro modo, de la situación precaria o considerablemente aleatoria de los hipotéticos herederos del causante en las sucesiones internacionales.

Otra cuestión fundamental a tener en cuenta para relativizar el argumento contrario a la professio iuris sucesoria tiene que ver con el propio fundamento de la limitación de la libertad de disposición del causante a favor de determinados familiares próximos al mismo. Tal finalidad no es otra que la protección de tales familiares para evitar la posible situación de desamparo en la que puedan quedar una vez que falta el causante. Por un lado, existe una tendencia en la doctrina de los últimos tiempos dirigida a deslegitimar o, dicho de otro modo, a poner de relieve la falta de justificación actual de los mecanismos de protección tales como las legítimas ${ }^{399}$. Por otro lado, y en este caso para relativizar el argumento contrario a la professio iuris sin desvirtuarlo, no hay que perder de vista que, de uno u otro modo, toda legislación prevé un mecanismo de protección de determinadas personas próximas al causante, de tal forma que, en realidad, las diferencias entre sistemas se refieren al modo de articular tal protección y a la extensión de la misma. Dicho esto, cabe afirmar que bien se aplique la ley elegida por el causante, bien se aplique la ley en defecto de elección, el fin de la

\footnotetext{
398 Vid. las consideraciones de A. BONOMI a este respecto, quien señala que el grado de incertidumbre en cuanto a la ley aplicable a la sucesión no sería del todo eliminado incluso en un ámbito uniformizado, puesto que siempre caben problemas en torno a la concreción de la conexión que determine la ley aplicable, tal como la nacionalidad del causante, el domicilio o la residencia habitual, (2011), p. 218.

399 En los últimos tiempos ha surgido un movimiento orientado a la reforma de los sistemas legitimarios y a la ampliación de la libertad de testar.
} 
protección de las personas próximas al causante se va a ver cumplido a través de uno u otro mecanismo ${ }^{400}$.

Desde el punto de vista conflictual, el supuesto miedo a la professio iuris como medio para defraudar los derechos sucesorios de determinados familiares próximos al causante se ve también mitigado por otro dato fundamental; nos estamos refiriendo a la propia limitación inherente a la posibilidad de elegir la ley aplicable a la sucesión. El hecho de que la autonomía de la voluntad del causante se vea limitada a un número reducido de leyes, que generalmente oscilan, como veremos, entre la ley de su residencia habitual o domicilio y la ley de su nacionalidad, con las que la situación ya tiene una conexión relevante es un factor suficiente para relativizar el miedo a la frustración de los supuestos derechos de terceros. Como bien es sabido, la dicotomía en lo que se refiere a la conexión que determina la ley aplicable a la sucesión en Derecho comparado se mueve entre la ley de la nacionalidad y la ley del domicilio o residencia habitual del causante. Ambas conexiones son a priori igualmente válidas para regular la sucesión internacional por estar lo suficientemente vinculadas con la situación y la elección por parte del legislador de una u otra como conexión objetiva se trata, como ya hemos mencionado, de una decisión meramente política, o migratoria, o de respeto a la tradición. Desde este punto de vista, y a la luz de que con carácter general la professio iuris se limita a la elección de alguna de estas dos leyes, no parece traumático permitir una tal elección ${ }^{401}$.

\footnotetext{
${ }^{400}$ Se trata de la idea de la equiparabilidad de las leyes sucesorias en cuanto a estos mecanismos de protección, J.M. FONTANELLAS MORELL (2010), pp. 283 y ss.

401 Sobre esta idea ya incidió A.E. vON OvERBECK (1965), pp. 1097 y ss.; en el marco del Convenio de La Haya de 1989, vid. W.M. WATERS (1990), p. 534, párrafo núm. 26; E.F. SCOLES (1994), pp. 113 y 117. No obstante, esta consideración no está desprovista de matices; la mayor o menor posibilidad de una fuga deliberada del causante a través de una professio iuris a un sistema que le conceda una mayor libertad de disposición dependerá directamente de la concreta articulación que de la professio iuris se establezca en la norma. Los mayores problemas vienen por la posibilidad de escoger la ley de la residencia habitual del causante, conexión cuya modificación es más fácil que la de la nacionalidad. Tratándose de la posibilidad de escoger la ley de la residencia habitual del causante determinada en el momento del fallecimiento, se ha puesto de manifiesto que ese temor a que el causante cambie su residencia habitual con el único propósito de acogerse a un sistema de mayor libertad no ocurre en la práctica. Mayor problema puede presentar la posibilidad de escoger la ley de la residencia habitual que ostente el causante en el momento de la elección. En este caso sí es más factible un cambio estratégico de residencia habitual con el mero propósito de escoger la ley aplicable a la sucesión beneficiosa para lo que el causante quiera disponer.
} 


\subsection{La professio iuris como mecanismo de flexibilización y de materialización en la selección de la ley aplicable}

Antes de finalizar con estas breves notas introductorias de la professio iuris sucesoria cabe detenernos en la función que cumple la misma como técnica de determinación de la ley aplicable a las sucesiones internacionales; a este respecto, la professio iuris presenta caracteres propios de las técnicas de flexibilización y materialización ${ }^{402}$. Tal y como hemos visto, una de las ventajas de la professio iuris sucesoria es la de su aptitud como solución de compromiso, de tal forma que esta técnica de elección de ley aplicable a las sucesiones se planteó en un principio como una elección entre dos leyes, la ley de la última nacionalidad del causante y la ley del último domicilio (o residencia habitual) del causante $^{403}$; es decir, la professio iuris se vio no como una elección de ley aplicable realizada con el fin de conseguir unos determinados resultados materiales, sino como una técnica de flexibilización de las dos conexiones rígidas que principalmente entran en juego en las sucesiones internacionales y como una técnica que busca, por tanto, la mejor localización del caso concreto. Desde este punto de vista, la professio iuris se articula como una opción entre distintas leyes que a priori son igualmente adecuadas o válidas para regular las sucesiones internacionales, con un fin puramente localizador, esto es, al margen de consideraciones de Derecho material. La elección, por tanto, se articula con independencia del contenido material que tengan las leyes elegibles.

Ahora bien, este planteamiento de la professio iuris sucesoria como mecanismo principalmente flexibilizador, no excluye cierto carácter sustantivo; en

\footnotetext{
${ }^{402}$ P. DE CESARI (2001), p. 112; S. ÁLVAREZ GonZÁLEZ (2009), p. 22 y ss.

${ }^{403}$ Esta es la perspectiva que se tomó en el seno de la Conferencia de La Haya en los debates sobre el Convenio de La Haya de 1989 sobre ley aplicable a las sucesiones internacionales, donde la professio iuris se presentaba como una solución de compromiso para acercar las posturas de los Estados contratantes que seguían el criterio del domicilio del causante y los que seguían el criterio de la nacionalidad del causante. Vid. Rapport de la Commission spéciale, Actes et documents de la Seizième session, t. II, p. 242, p. 252 y p. 254; A.E. VON OVERBECK (1989), p. 145; P. LAGARDE (1989), p. 260. También sobre esta visión de la professio iuris sucesoria en general como una solución de compromiso para una mejor localización de las sucesiones internacionales, A.E. vON OVERBECK (1965), passim; P. DE CESARI (2001), p. 33; A. DAVÌ (2005), p. 326; como ya hemos apuntado, claramente en contra de esta visión, M. GORÈ (1994), p. 195 y p. 197, donde señala la professio iuris no es tanto una designación de la ley aplicable, cuanto una solución sustancial que favorece a una u otra parte.
} 
efecto, mantendríamos una visión sesgada de la professio iuris sucesoria si no admitiéramos el hecho de que el causante, al escoger entre una de las leyes elegibles lo hace con base en razones de índole material y no con el fin de localizar de la mejor forma su sucesión ${ }^{404}$. Con carácter general, podemos presumir que el causante escogerá la ley que le ofrezca una mayor libertad para poder organizar y planificar su sucesión como estime conveniente. Es más, es esta función de la professio iuris la que alimenta el mayor de los temores que, como hemos visto, se han sostenido en su contra. Si en la professio iuris sucesoria se ve un mecanismo a través del cual el causante puede frustrar los supuestos derechos sucesorios de los hipotéticos herederos forzosos, tal resultado será la consecuencia de la elección de la ley aplicable a su sucesión por el causante basándose no en criterios estrictamente localizadores, sino en la búsqueda de una mayor libertad de disposición para organizar su patrimonio para después de su muerte. En definitiva, al causante le interesa disponer de su patrimonio y organizar su sucesión con la mayor de las libertades posibles.

\subsection{La professio iuris sucesoria en el Reglamento}

\subsubsection{Los antecedentes en Derecho positivo}

La professio iuris sucesoria ha sido rechazada durante mucho tiempo por los países de la Europa continental; no obstante, el creciente protagonismo del que venimos hablando, ha implicado la dulcificación de este rechazo y ha dado entrada a la elección de la ley sucesoria en normas convencionales (y próximamente europeas) y en legislaciones nacionales. En el presente apartado daremos unas breves pinceladas sobre la situación actual a este respecto en Derecho comparado, centrándonos en algunos ejemplos de legislaciones de los países europeos más representativos que admiten esta posibilidad. En este breve recorrido podremos percibir cómo la professio iuris no es una solución de ley aplicable en sí misma, sino que existen diversas professio iuris en función de la concreta articulación que cada legislación realice de la elección de ley aplicable a

\footnotetext{
${ }^{404}$ Entienden que la professio iuris es un mecanismo fundamentalmente materializador y no un mecanismo con finalidad localizadora, G. KÜHNE (1973), p. 71.
} 
la sucesión; dicho de otro modo, en función de la concreta extensión y el concreto alcance que la professio iuris tiene en cada legislación ${ }^{405}$.

Como ya hemos mencionado, en Europa la primera legislación que permitió la posibilidad de escoger la ley aplicable a la sucesión fue la ley federal suiza de 1891. El art. 22 de esta ley, previsto para las relaciones intercantonales, permitía la derogación del criterio general del domicilio del causante, a favor de la aplicación del Derecho cantonal de origen del causante. Pese a estar previsto para los conflictos de leyes intercantonales, tal previsión se aplicó analógicamente a las situaciones privadas internacionales. Con esta analogía, se le daba a un extranjero domiciliado en suiza la posibilidad de que su sucesión no se regulara por la ley suiza, a título de ley del domicilio del causante, sino por la ley de su nacionalidad $^{406}$. Esta posibilidad se mantiene y se introduce ya en la ley federal suiza de Derecho internacional privado de 1987, norma que además amplía los supuestos de hecho en los que se puede realizar una professio iuris sucesoria ${ }^{407}$. El otro supuesto de hecho se basa en la sucesión de un causante de nacionalidad suiza y domiciliado en el extranjero. En este caso, la professio iuris puede entrar en juego tanto por el art. 87.2, como por el art. 91.2 de la ley suiza. El art. 87.2 otorga competencia judicial internacional a las autoridades nacionales suizas cuando el causante suizo con domicilio en el extranjero somete bien el conjunto de su sucesión, bien la parte de la misma que se encuentre en Suiza, a las autoridades suizas o a la ley suiza; es decir, este artículo está permitiendo una professio iuris, para el conjunto de la sucesión o para la parte del patrimonio que se encuentre en Suiza, a favor de la ley nacional suiza del causante, caso en el que

\footnotetext{
${ }^{405}$ S. ÁlVAREZ GONZÁLEZ (2009), p. 18 y pp. 34 y ss.; sobre la misma idea, J.M. FonTANELLAS MORELL (2010), pp. 172 y ss., donde el autor señala que la introducción de la elección de ley en los sistemas de DIPr es un hecho probablemente imparable, quedando únicamente por determinar en qué términos puede producirse, esto es extensión de la elección y limitaciones, condiciones de la elección.

${ }^{406}$ Se suele citar como ejemplo de la aplicación del art. 22 a situaciones privadas internacionales la sentencia del Tribunal Federal suizo de 17 de agosto de 1976, en el conocido asunto Hirsch c. Cohen, en el que se admitió la validez de la elección de ley sucesoria a favor del Derecho inglés, ATF 102 II 136.

${ }^{407}$ En concreto, es el vigente art. 90.2 de la ley suiza el que permite al extranjero domiciliado en suiza someter su sucesión a la ley de su nacionalidad, siempre y cuando en el momento de su fallecimiento mantuviera tal nacionalidad y no hubiera adquirido la suiza; vid. B. DUTOIT (2005), pp. 293 y ss.
} 
además, por vía de tal professio iuris, las autoridades suizas pueden ser competentes para conocer de esa sucesión. Por su parte, el art. 91.2 de la ley suiza regula la ley aplicable a la sucesión del causante suizo domiciliado en el extranjero, cuando la cuestión jurídica se sustancie en el marco de un procedimiento en el que la competencia se determine en virtud del art. 87 de la misma ley; en tal caso, se aplica en principio la ley suiza, a título de ley de la nacionalidad del causante, salvo que éste la haya derogado a través de la elección de la ley de su último domicilio ${ }^{408}$.

En Alemania la professio iuris también tiene cabida en el Derecho positivo, aunque de forma más limitada. El art. 25 EGBGB prevé la posibilidad de que el causante someta a la ley alemana la sucesión que concierne a los bienes inmuebles situados en territorio alemán. La conexión general, objetiva, aplicable en defecto de elección, señala la aplicación de la ley de la última nacionalidad del causante, de tal forma que esta limitada articulación de la professio iuris puede conllevar un fraccionamiento de la sucesión.

El ordenamiento jurídico italiano constituye otro ejemplo en el que se permite una determinada professio iuris sucesoria. En este caso, la posibilidad de escoger la ley aplicable a la sucesión se introdujo en la ley de reforma del sistema italiano de DIPr que tuvo lugar en el año $1995^{409}$. En Italia la ley objetivamente aplicable a la sucesión es la ley de la última nacionalidad del causante, que se aplica al conjunto de la misma. No obstante, el art. 46 de la ley italiana permite al causante la posibilidad de escoger la ley de su residencia habitual para regular el conjunto de su sucesión, si bien, para que esta elección sea válida ${ }^{410}$, es necesario

\footnotetext{
${ }^{408}$ A esta regulación de la elección de ley aplicable a las sucesiones hay que añadir la concreta regulación que para la elección de ley aplicable a los pactos sucesorios se prevé en el art. 95 de la ley suiza, tal y como veremos más adelante.

409 Legge 31 maggio 1995, núm. 218, de Riforma del sistema italiano di Diritto internazionale privato

${ }^{410}$ Aunque no vamos a entrar en el tema, debemos señalar que la professio iuris a favor de la ley de la residencia habitual del causante puede plantear problemas de eficacia al prever la ley italiana una cláusula de salvaguarda de los derechos sucesorios de determinados legitimarios; esta ley prescribe que la aplicación de la ley elegida por el causante no puede perjudicar los derechos sucesorios que la ley italiana atribuya a los sujetos legitimarios o beneficiarios de tales derechos que residan en Italia.
} 
que se cumpla la condición de que el causante en el momento de su fallecimiento mantenga dicha residencia habitual.

En el ordenamiento jurídico belga podemos encontrar otro ejemplo en el que recientemente se ha introducido la professio iuris sucesoria. El Código de DIPr belga de 2004 recoge en su art. 79 la posibilidad de escoger la ley aplicable al conjunto de la sucesión ${ }^{411}$. Dicho artículo posibilita la elección bien de la ley de la nacionalidad, bien de la ley de la residencia habitual del causante, siempre y cuando el causante tenga la elegida nacionalidad o residencia habitual bien en el momento de la elección, bien en el momento de su fallecimiento ${ }^{412}$. Ahora bien, esta posibilidad generosa, o al menos más amplia que la que hemos visto en países del entorno, de elección de la ley aplicable a la sucesión, se encuentra con una importante cortapisa cuando el propio art. 79 del Código belga, prescribe acto seguido que tal elección no puede tener por resultado el privar a los legitimarios de los derechos sucesorios que pudiera prever la ley objetivamente aplicable, esto es, la ley aplicable a la sucesión a falta de elección ${ }^{413}$. Dicho de otro modo, el campo de actuación de la professio iuris en el marco del Código belga de DIPr es finalmente reducido en cuanto que se limita al ámbito correspondiente a la cuota disponible de conformidad con la ley sucesoria designada objetivamente ${ }^{414}$.

Con la legislación positiva belga, terminamos con estas breves referencias de Derecho comparado en cuanto a la admisión de la professio iuris. Pese al creciente protagonismo de la professio iuris sucesoria en los últimos tiempos, hoy día, la posibilidad de elección de ley aplicable a la sucesión no es algo común en el ámbito europeo ${ }^{415}$. Sin embargo, en el panorama actual se están

\footnotetext{
${ }^{411}$ Loi portant le Code de droit international privé, 16 julliet 2004, Moniteur, 27 de julio de 2004 (www.moniteur.be).

${ }^{412}$ Esta configuración de la professio iuris en el Código belga de DIPr está claramente inspirada en la regulación de la professio iuris que recoge el Convenio de La Haya de 1989, vid., F. BOUCKAERT (2004), p. 423; P. WAUTELET (2005), p. 10.

${ }^{413}$ Implicaciones respecto principio de unidad y fraccionamiento de la sucesión.

${ }^{414}$ F. BoucKaerT (2004), p. 423. P. WAUTELET (2005), p. 10 y p. 11.

${ }^{415}$ La mayor parte de los países europeos aún desconocen esta posibilidad; no obstante, hay más ejemplos de legislaciones europeas en las que se permite la professio iuris que las que hemos destacado, tales como por ejemplo, la legislación holandesa, por efecto de la incorporación a su normativa del Convenio de La Haya de 1989, ratificado el 27 de septiembre de 1996, vid. A.
} 
dando importantes cambios $\mathrm{y}$, fundamentalmente, la professio iuris tendrá un importante papel en un futuro cercano con la aplicación del régimen del Reglamento.

\subsubsection{La nueva regulación europea}

\subsubsection{La solución de la Propuesta}

La posibilidad de elegir la ley aplicable a la sucesión estuvo presente desde los inicios de los trabajos preparatorios del Reglamento. Recomendaciones favorables a la admisión de la professio iuris ya se contenían en el Informe Lagarde- Dörner ${ }^{416}$. El Libro Verde sobre sucesiones y testamentos incluía varias cuestiones sobre la professio iuris, que se referían tanto a la propia admisión o no admisión, cuanto a su alcance y extensión. Las respuestas conteniendo las opiniones de Estados y expertos sobre estas cuestiones del Libro Verde dan como resultado una mayoritaria posición favorable a la introducción de la professio iuris y una variedad de posiciones en cuanto a su concreta articulación ${ }^{417}$. Desde las propias instituciones europeas se defendió la postura de la admisión de la professio iuris en el Reglamento, como evidencian las recomendaciones del Parlamento Europeo a la Comisión, en las que se aconseja permitir al causante la

BORRÁS (1996), pp. 363 y 364; la legislación finlandesa, donde una reciente reforma que afecta a las sucesiones internacionales permite que el causante escoja la ley aplicable a su sucesión entre la ley nacional en el momento de la disposición o fallecimiento y la ley de domicilio en el momento de la elección, fallecimiento o un momento anterior; en el caso de que esté casado se permite también la posibilidad de que escoja la ley de su régimen económico matrimonial, http://www.finlex.fi/en/laki/kaannokset/1965/en19650040.pdf, p. 35; vid., K.F. KNORRE/W. MinCKE (2008), p. 592. También en Estonia, donde se permite al causante escoger la ley de su nacionalidad en el momento del fallecimiento, § 25 Ley de DIPr de 27 marzo 2002, consultada en versión inglesa, http://www.legaltext.ee/text/en/x30075.htm, (última consulta el 2 de mayo de 2012) vid. A. BONOMI (2011), p. 202; también el sistema búlgaro de DIPr, prevé en la ley de DIPr de 2005 una limitada professio iuris a favor de la ley de la nacionalidad que el testador ostenta en el momento de la realización de la disposición, vid., S. IVANOVA (2008), p. 389.

416 INFORME DÖRNER-LAGARDE (2002), pp. 69 y ss.; en tales recomendaciones se incluye una professio iuris bastante generosa, pues se hace referencia a la posibilidad de escoger la ley de la nacionalidad y de la residencia habitual del causante, así como la posibilidad de elegir la ley que regula las relaciones patrimoniales del causante, fundamentalmente en lo que se refiere al régimen económico matrimonial.

${ }^{417}$ Para un análisis de las respuestas al Libro Verde sobre las cuestiones referidas a la professio iuris, vid. S. ÁlvAREZ GONZÁLEZ (2009), pp. 33 y ss. 
posibilidad de que escoja la ley de su nacionalidad o de su residencia habitual para regular su sucesión ${ }^{418}$.

El siguiente paso a destacar tuvo lugar en junio de 2008, momento en el que apareció un primer texto articulado denominado "documento de reflexión" fruto de una reunión de expertos nacionales ${ }^{419}$. En dicho documento ya se articulaba una determinada professio iuris. El art. 3.2 del citado documento preveía la posibilidad de que el causante escogiera la ley aplicable al conjunto de su sucesión; entre las leyes elegibles se encuentra la de su nacionalidad y la de su residencia habitual, si bien con un importante matiz temporal que implica un distinto alcance para una y otra conexión. Mientras que tratándose de la conexión de la nacionalidad se le permitía escoger tanto la que pudiera tener en el momento de la designación, como en el momento del fallecimiento, en el caso de escoger la ley de la residencia habitual sólo se preveía el momento temporal de la designación, esto es, la ley de la residencia habitual del causante en el momento en que éste realiza la elección ${ }^{420}$.

Con estos precedentes se llega a la publicación de la Propuesta de Reglamento en octubre de 2009. Tras establecer el criterio general y unitario de la aplicación de la ley de la residencia habitual del causante determinada en el momento del fallecimiento del causante, por entenderse que esta conexión representa el centro de interés del causante y donde, generalmente, se encuentran la mayoría de sus bienes, la Propuesta de Reglamento preveía en su art. 17 una limitada posibilidad de elección de ley a la sucesión. Dicho artículo establecía que cualquier persona podrá designar la ley del Estado cuya nacionalidad posee para

\footnotetext{
${ }^{418}$ Informe del Parlamento Europeo que contiene recomendaciones a la Comisión sobre sucesiones y testamentos, de 16 de octubre de 2006, A6-0359/2006.

${ }^{419}$ Document de réflexion sur les successions a cause de mort, Réunion Experts nationaux, 30.06.2008.

${ }^{420}$ Esta diferencia temporal que implica un distinto alcance para la elección de la ley de la nacionalidad y para la elección de la ley de la residencia habitual del causante se deriva de la versión francesa del Documento de reflexión con la que trabajamos; no obstante, debemos llamar la atención sobre el hecho de que J. Harris se refiere al documento de reflexión de expertos del 30 de junio de 2008 en el sentido de que permite la elección de la ley de la nacionalidad o de la ley de la residencia habitual del causante, en ambos casos determinada bien en el momento de la elección, bien en el momento del fallecimiento de éste; vid. J. HARRIS (2008).
} 
que rija la totalidad de la sucesión ${ }^{421}$. Se desoyen, por tanto, otras propuestas que se habían mantenido, principalmente la de la elección de la ley de la residencia habitual, pero también otras que se mantuvieron con menos fuerza, como la elección de la lex rei sitae o la elección de la ley del régimen económico matrimonial $^{422}$. El art. 17 de la Propuesta de Reglamento dejaba una importante cuestión abierta, cual es la de la determinación del momento temporal en el que hay que fijar la nacionalidad del causante. Nada decía el precepto a este respecto y surgió la duda de si el causante tenía que tener la nacionalidad en el momento de la elección, en el momento del fallecimiento o en cualquiera de estos dos momentos ${ }^{423}$

La tramitación de la Propuesta incorporó una serie de enmiendas ${ }^{424}$, algunas de las cuales afectan al contenido del art. 17. Fundamental fue la enmienda propuesta por Diana Wallis, que incorporaba la elección de la ley de la nacionalidad del causante, determinada ésta bien en el momento de la elección, bien en el momento del fallecimiento ${ }^{425}$.

\footnotetext{
${ }^{421}$ Queda al margen la regulación que de la elección de ley aplicable se prevé en el marco de los pactos sucesorios, en el art. 18.3 de la Propuesta de Reglamento, que analizaremos en detalle más adelante.

${ }^{422}$ En la Exposición de Motivos que acompaña al texto de la Propuesta de Reglamento, concretamente en el comentario del art. 17, se señala que la posibilidad por parte del causante de escoger la ley aplicable debía encontrar un compromiso entre las ventajas que encierra esta solución (p. ej. en términos de seguridad jurídica y de mayor facilidad a la hora de preparar la sucesión) y la protección de los intereses legítimos de las personas próximas al causante, sobre todo el cónyuge y los hijos supérstites. A. BONOMI (2010), p. 896, donde pone de relieve que la limitación de la elección de la ley de la nacionalidad, evitando que se permita escoger la ley de la residencia habitual anterior, evita acciones abusivas por parte del causante.

${ }^{423}$ P. KINDLER (2010), p. 256;

${ }^{424}$ Vid. Proyecto de Informe Lechner, 2009/0157 (COD) y Acta de la reunión de la Comisión de Asuntos Jurídicos de los días 10 y 11 de octubre de 2011, JURI_PV (2011) 10-10.

${ }^{425}$ El texto de la enmienda disponía literalmente "Cualquier persona podrá designar, para que rija la totalidad de la sucesión, la ley interna del Estado (excluidas sus normas de Derecho internacional privado) cuya nacionalidad posee en el momento de elegir la ley aplicable. La elección de la ley aplicable será válida también cuando la persona, en el momento de su fallecimiento, posea la nacionalidad del Estado cuya ley haya elegido", Enmienda núm. 190 presentada por Diana Wallis, aprobada por la Comisión de Asuntos Jurídicos del Parlamento. Vid. Acta de la reunión de los días 10 y 11 de octubre de 2011, JURI_PV (2011) 10-10.
} 


\subsubsection{La solución prevista por el art. 22 del Reglamento}

Tras todo este largo proceso y tal y como era de esperar, la versión definitiva del Reglamento consagra la professio iuris en su art. 22. Dicho artículo dispone en su apartado primero que cualquier persona podrá designar la ley del Estado cuya nacionalidad posea en el momento de realizar la elección o en el momento del fallecimiento. La elección de ley se refiere al conjunto de la sucesión, en consonancia con el principio de unidad que de la sucesión sigue el Reglamento. El artículo 22 consta además de otros tres apartados en los que se hace referencia a distintos aspectos del régimen jurídico de la professio iuris. La posibilidad de elegir la ley aplicable a la sucesión es uno de los pilares fundamentales del Reglamento y supone también una de las innovaciones más importantes en a la determinación de la ley aplicable a la sucesión, en cuanto que supone una gran novedad para la mayor parte de los EEMM.

La discusión en torno a la professio iuris en el ámbito europeo no se centró tanto en si debía o no admitirse, pues tal y como hemos visto es una opción que ha estado presente desde los inicios de los trabajos, sino más bien en la extensión o configuración de la misma. Finalmente, podemos decir que el Reglamento ha optado por una posibilidad limitada de elección de ley, en cuanto que las posibilidades de elección se limitan a la ley de la nacionalidad del causante. En este sentido, el Reglamento ha seguido la línea de la Propuesta, respecto de la cual la doctrina ya tuvo la oportunidad de poner de manifiesto el carácter excesivamente restrictivo de la elección de ley, así como la pertinencia de ampliar el abanico de leyes elegibles, fundamentalmente a la ley de la residencia habitual del causante, pero también a otras, como la lex rei sitae o la ley del régimen económico matrimonial ${ }^{426}$.

\footnotetext{
${ }^{426}$ A favor de la posibilidad de elegir todas ellas se manifestó el MPI (2010), núms. 136-149; la ley que más apoyo ha recibido como ley elegible a la sucesión ha sido la correspondiente a la residencia habitual del causante; además del MPI, vid. también, H. DÖRNER/C. HERTEL/P. LAGARDE/W. RIERING (2005), p. 5; A. DUTTA (2009), p. 576; E. LEIN (2009), p. 132; A. BONOMI (2010-4), pp. 41 y ss.; P. KINDLER (2010), p. 49; A. DAVÍ (2004), pp. 480 y ss.; Sin embargo, a favor de la limitación de la elección de ley aplicable a la sucesión a la conexión de la nacionalidad del causante, C. NOURISSAT (2010), núm. 14.
} 
A diferencia de la Propuesta, y haciéndose eco de las críticas que la doctrina mostró al respecto, el Reglamento determina en qué momentos debe constatarse la nacionalidad del causante, pues tal y como hemos señalado, la elección será válida si se corresponde con la nacionalidad que ostente el causante bien en el momento de la realización de la elección, bien en el momento de su fallecimiento. Lo mismo ocurre con aquellas situaciones en las que el causante ostenta más de una nacionalidad; mientras que la Propuesta no daba solución alguna al respecto, el párrafo segundo del art. 22.1 del Reglamento establece como solución para estos casos la de posibilitar la elección de cualquiera de esas nacionalidades que concurran en la persona del causante ${ }^{427}$.

En el art. 22 se prevé además la forma en que debe llevarse a cabo la elección de ley; en primer lugar, del apartado segundo del artículo, se deriva que la elección habrá de realizarse en una disposición con forma de disposición mortis causa; en segundo lugar, se da entrada tanto a la elección expresa como, y esto es una novedad con respecto a la Propuesta, a la elección tácita. Es esta una novedad de calado. En efecto, el apartado segundo dispone que la elección deberá hacerse expresamente o que habrá de resultar de los términos de una disposición mortis causa. Tal y como hemos tenido ocasión de poner de manifiesto en otro lugar ${ }^{428}$, estamos de acuerdo en la introducción de la elección tácita de ley aplicable, en cuanto que permite un mayor respeto de la voluntad del testador. Pensemos en aquellos casos en los que pese a que no hay una mención expresa a la ley que se pretende elegir, el instrumento de planificación de la sucesión, sea un testamento, sea un pacto sucesorio, está repleto de remisiones a artículos de una determinada ley o hace referencia a instituciones propias de la misma, de tal forma que es indubitado que el causante estaba pensando en enmarcar su sucesión en dicha ley.

El apartado tercero del art. 22 se refiere expresamente a la determinación de la validez material del propio acto de elección. En este sentido, el artículo señala que tal validez se regirá por la propia ley elegida. Sobre esta cuestión

\footnotetext{
${ }^{427}$ Adoptando así el sentir mayoritario de la doctrina, A. DAvì (2004), p. 481; A. DUTTA (2009), p. 576; A. BONOMI (2010-4), pp. 38 y ss.; MPI (2010), núm. 141; P. KINDLER (2010), p. 49; J.M. FONTANELLAS MORELl (2011), p. 102; P. LAGARDE (2012), p. 18.

${ }^{428}$ I. RODRÍGUEZ-URÍA SUÁREZ (2013), núm. 16.
} 
debemos puntualizar que la elección de ley tiene su propia autonomía respecto de la disposición mortis causa donde se contiene; es decir, la validez de la elección de ley se va a regular por la propia ley elegida, tal y como establece el Reglamento, y esto puede dar lugar a situaciones en las que la elección de ley es válida, pero no así la disposición mortis causa que la contiene, sea un testamento o un pacto sucesorio ${ }^{429}$. Por otro lado, debemos recordar que la propia admisibilidad de la professio iuris es una cuestión del Reglamento y no de la ley elegida.

El artículo 22 se cierra con un apartado dedicado a la posible variación de la elección realizada. La professio iuris puede realizarse, modificarse o revocarse en cualquier momento, siempre y cuando se cumplan los requisitos formales requeridos, bien para su realización, bien para la modificación o revocación de las disposiciones mortis causa. Tal es la única exigencia que establece el apartado cuarto del art. 22. Esta posibilidad, como vamos a ver, puede plantear cierta problemática e incertidumbres en relación con los pactos sucesorios.

\subsection{La elección de la ley aplicable en los pactos sucesorios}

Lo primero que procede bajo este epígrafe es justificar por qué reservamos un tratamiento propio, autónomo y específico a la elección de ley aplicable a los pactos sucesorios. Cabría pensar que la problemática que rodea a la elección de la ley aplicable a estas figuras es la misma que la que presentan las sucesiones internacionales en general y que, por tanto, no se justifica un tratamiento particular al respecto. Sin embargo, lo cierto es que los pactos sucesorios presentan ciertas particularidades propias también en lo que se refiere a la elección de la ley aplicable, lo que justifica su tratamiento por separado.

En primer término, debemos realizar una precisión, pues de lo que aquí se trata no es de analizar la simple inclusión de una professio iuris sucesoria en un pacto sucesorio, como disposición por causa de muerte, sino el estudio de la posibilidad de regular los pactos sucesorios con elemento internacional por una ley pactada. En segundo término, debemos tener en cuenta determinados factores privativos de los pactos sucesorios a la hora de analizar esta cuestión. Por un lado,

${ }^{429}$ En este sentido, A. BONOMI (2011), p. 221, núm. 113. 
los pactos sucesorios son unos instrumentos de carácter bilateral; a diferencia del testamento, en el que sólo hay un otorgante, esto es el testador, los pactos sucesorios necesitan del concurso de al menos dos personas, una de las cuales debe ser el futuro causante. Esto plantea ya dudas en torno a la unilateralidad o bilateralidad de la elección de ley aplicable, es decir, si para elegir la ley aplicable a un pacto sucesorio basta con una professio iuris unilateral realizada por el futuro causante o si es necesario un pacto de lege utenda entre el causante y el cootorgante. Esta duda es mayor cuando se trata de pactos sucesorios que afectan a más de una sucesión, esto es, aquellos en los que hay al menos dos futuros causantes, como ocurre con el típico ejemplo del pacto de institución recíproca que realizan dos cónyuges. Por otro lado, es necesario analizar también la naturaleza de la elección de ley a través de una professio iuris y la naturaleza de la elección de ley a través de un pacto de lege utenda y sus consecuencias con respecto del pacto sucesorio. Nos estamos refiriendo en este caso al carácter revocable o irrevocable de la elección de ley aplicable a los pactos sucesorios y sus consecuencias para los mismos. En el caso de que la elección de ley se realice a través de un pacto de lege utenda el causante no puede revocarlo unilateralmente; sin embargo, cuando se trata de una professio iuris, realizada unilateralmente, parece que nada impide que esa elección sea posteriormente revocada; es más, tratándose de una professio iuris en el marco de un testamento o en el marco de una simple elección de la ley aplicable a la sucesión, nada impide que el futuro causante, dentro de los límites y en la forma permitida por la ley, revoque o, en su caso, cambie esa elección de ley en un momento posterior. Tratándose de pactos sucesorios, corresponde analizar cómo y en qué medida puede afectarles un cambio o una revocación posterior de la ley aplicable elegida. Por último, y relacionado con el motivo anterior, exige también un tratamiento particular la relación de la ley aplicable al pacto sucesorio y la ley aplicable a la sucesión, en el caso de que éstas sean distintas, en términos de autonomía de la voluntad conflictual.

Actualmente, algunos sistemas de Derecho comparado permiten, de manera más o menos limitada, la posibilidad de elegir la ley aplicable a los pactos sucesorios. En ocasiones, tal posibilidad se deriva simplemente del hecho de que 
los pactos sucesorios se incluyen en la norma de conflicto de sucesiones y que, por otro lado, se permite una determinada elección de ley a las sucesiones internacionales. En otros casos existe una regulación específica de la elección de ley aplicable a los pactos sucesorios.

El ejemplo más claro de la primera forma de introducción de la autonomía de la voluntad en la ley aplicable a los pactos sucesorios lo encontramos en el sistema alemán. Como ya hemos visto, en Alemania los pactos sucesorios tienen una calificación sucesoria, con una específica previsión y una especialidad en cuanto al momento temporal. En pocas palabras, a los pactos sucesorios se les aplica la ley de la nacionalidad del futuro causante determinada en el momento en que el pacto es otorgado. No obstante, como también vimos, el sistema alemán prevé una limitada elección de ley aplicable en el ámbito de las sucesiones, que consiste en la posibilidad de escoger la aplicación de la ley alemana a la parte de la sucesión que se refiere a bienes inmuebles situados en Alemania. Nada parece impedir que tal elección afecte a un pacto sucesorio, cuando la organización de la sucesión se ha realizado a través de esta figura; es más, según el art. 25.II EGBGB, la elección se debe realizar en forma de disposición por causa de muerte, por lo que uno de los medios a través del cual se puede canalizar la elección de ley es el pacto sucesorio.

Otro ejemplo viene de la mano del sistema italiano, aunque en este caso supeditado a la calificación sucesoria de los pactos sucesorios. Como hemos tenido ocasión de ver, el sistema italiano no hace referencia alguna a los pactos sucesorios, planteándose un problema de calificación de estas figuras; no obstante, este problema ha sido solventado prácticamente de forma unánime con la defensa de una calificación sucesoria, de tal forma que a los pactos sucesorios se les aplica la norma de conflicto de sucesiones. La ley aplicable a los pactos sucesorios es la ley de la nacionalidad del causante determinada en el momento del fallecimiento; ahora bien, se le puede dar entrada a la ley de la residencia habitual del causante a través de la professio iuris. Al amparo del ordenamiento italiano, el causante puede elegir la ley de la residencia habitual que ostente en el momento de la elección siempre y cuando mantenga tal residencia habitual en el momento de su 
muerte. Ahora bien, tal elección, dice la ley, debe realizarse a través de una declaración expresa en forma testamentaria. Con todos estos datos, y dado que los pactos sucesorios se rigen en Italia por la ley sucesoria, parece que a estas figuras se les puede aplicar la ley de la residencia habitual del causante, en vez de la ley de su nacionalidad, cuando se haya realizado una professio iuris en la debida forma. En este sentido, surge el interrogante de si, atendiendo a la estricta letra del art. 46 de la ley italiana, es necesario que la declaración expresa a favor de la aplicación de la ley de la residencia habitual se contenga en un testamento, que podría ser anterior o incluso posterior al otorgamiento del pacto sucesorio, o si se admitiría también la elección de ley a través de una declaración expresa contenida en el propio pacto sucesorio.

El ejemplo de la regulación específica de la elección de ley aplicable a los pactos sucesorios lo encontramos en el sistema suizo. El art. 95 de la ley suiza establece dos previsiones para la elección de ley aplicable a los pactos sucesorios, en función del tipo de pacto sucesorio de que se trate. Después de señalar como conexión objetiva la aplicación de la ley del domicilio del futuro causante determinada en el momento del otorgamiento del pacto, el apartado segundo establece que para los pactos sucesorios que afectan a una única sucesión, el causante puede escoger la aplicación de la ley de su nacionalidad, siempre y cuando lo haga para el conjunto de su sucesión. El apartado tercero del art. 95 de la ley suiza, se encarga de los pactos sucesorios que afectan a más de una sucesión, esto es, aquellos en los que concurren al menos dos futuros causantes. En este caso, es posible que el pacto sucesorio se regule por la ley de la nacionalidad común de los causantes, cuando éstos la hayan elegido. Es de destacar que la estructura de la elección de ley aplicable en la ley suiza de DIPr plantea una peculiaridad interesante. Del texto de la norma se deriva que en el caso de los pactos que afectan a una única sucesión, la elección de ley se hace a través de una professio iuris, en el sentido de que es el propio causante el que elige o no la ley de su nacionalidad, sin ser necesario el concurso del otro otorgante; sin embargo, en los pactos sucesorios que afectan a más de una sucesión, parece que la ley suiza está pensando en un pacto de lege utenda entre 
los causantes otorgantes del pacto sucesorio, en los que, además, debe concurrir la misma nacionalidad).

\section{ESTRUCTURA DE LA AUTONOMÍA CONFLICTUAL EN LOS PACTOS SUCESORIOS}

\section{Particularidades de los pactos sucesorios en torno a la estructura de la elección de la ley aplicable}

En las páginas que siguen vamos a analizar las diferentes vías a través de las que es posible elegir la ley aplicable a los pactos sucesorios; esto es, dicho de otro modo, el estudio de la estructura de la autonomía de la voluntad conflictual en los pactos sucesorios. En dicho análisis se van a contestar a las preguntas de quién puede elegir la ley aplicable a los pactos sucesorios y de qué forma se puede o se debe articular la elección. Haremos hincapié en algunas de las características propias de los pactos sucesorios, que van a explicar las particularidades de estas figuras en lo que concierne a la estructura del ejercicio de la autonomía de la voluntad conflictual; en concreto, tales particularidades vienen de la mano por un lado de la naturaleza jurídica de los pactos sucesorios y, por otro lado, de los elementos personales de los mismos. El análisis es genérico. Ninguna norma positiva, tampoco el Reglamento, lo condicionará. Aunque, obviamente, todas ellas formarán parte del estudio y las propuestas.

En principio, la estructura unilateral o bilateral de la elección de ley aplicable depende de la naturaleza del negocio jurídico que se pretende regular; de esta forma, la elección de la ley aplicable a un acto unilateral, tal como un testamento, se realiza igualmente de forma unilateral, esto es, la realiza el causante a través de una professio iuris, mientras que cuando la naturaleza del acto es bilateral, tal como un contrato, la elección de la ley aplicable debe hacerse también a través de un acuerdo entre las partes otorgantes de tal negocio ${ }^{430}$. En el caso de los pactos sucesorios ya hemos visto cómo uno de sus características reside en su naturaleza jurídica híbrida. En este caso, la doble naturaleza, contractual y sucesoria, de los pactos sucesorios va a influir en el modo en que debe articularse la elección de ley aplicable. De hecho esta naturaleza híbrida es la

${ }^{430}$ J.M. FONTANELLAS MORELL (2010), p. 207. 
que va a plantear dudas en torno a la estructura que debe tener la autonomía de la voluntad conflictual como determinante de la ley aplicable a los pactos sucesorios. Por un lado, la naturaleza sucesoria nos dirige a una vía de elección unilateral, la de la professio iuris, en la que el único sujeto relevante es el propio causante, quien puede escoger, unilateralmente y dentro de los límites de las leyes elegibles, la ley que regule su sucesión. Por otro lado, la naturaleza contractual nos lleva a una elección bilateral, de tal forma que la elección de ley debe contenerse en un pacto de lege utenda, siendo una cláusula más del pacto sucesorio, otorgada por todas las partes que celebran el pacto y quedando éstas vinculadas a dicha elección (o cualquier tipo de elección bilateral en las formas que pudieran admitirse)

Relacionada con el carácter contractual de los pactos sucesorios está la otra característica en la que nos vamos a detener; se trata de los elementos personales de los pactos sucesorios. Como ya hemos tenido ocasión de ver, en los pactos sucesorios debe haber al menos un disponente, el futuro causante, cuya sucesión queda afectada por el contenido del pacto sucesorio. Por otro lado, debe haber otra parte contratante cuya calidad jurídica puede ser distinta; se puede tratar de otro otorgante disponente o futuro causante, caso en el que el pacto afectará a más de una sucesión, o se puede tratar de un mero otorgante no disponente, caso en el que el pacto afectará a una única sucesión. Desde este punto de vista, la primera duda que se plantea en torno a la elección de la ley aplicable a los pactos sucesorios es si la elección puede realizarse únicamente por el causante o si es necesario el concurso también del otorgante no disponente. Sirviéndonos de un ejemplo, un causante de nacionalidad alemana y residencia habitual en suiza realiza un pacto sucesorio de institución, a través del cual instituye heredero a su hijo primogénito, transmitiéndole la empresa familiar. Pensemos en una solución de ley aplicable en la que se prevé como conexión objetiva la aplicación de la ley de la (eventualmente última) residencia habitual del causante, pero se permite también la posibilidad de que el pacto sucesorio se regule por la ley de la nacionalidad del causante. Cabría preguntarse en este caso si para elegir la ley aplicable a tal pacto sucesorio basta con que el causante disponga que se aplique la ley de su nacionalidad, en vez de la ley de su 
residencia habitual que sería la objetivamente aplicable a falta de elección, o si es necesario que para que entre en juego la conexión de la nacionalidad del causante deba recabarse también la voluntad del hijo instituido a través del pacto sucesorio. En el caso de que fuera suficiente la voluntad del causante para realizar una elección de ley, esto es, en el caso de que se tratara de una professio iuris, y no de un pacto de lege utenda, la elección de ley realizada en el pacto sucesorio consistiría en una cláusula unilateral posiblemente inserta en el pacto sucesorio y con un régimen distinto al de las cláusulas bilaterales, pues no produciría efecto vinculante alguno para el causante ${ }^{431}$. Es decir, habría que distinguir las cláusulas propias del pacto sucesorio, acordadas por ambos otorgantes y a cuyo contenido quedan estos vinculados, de las cláusulas simplemente unilaterales, esto es, aquellas otorgadas únicamente por el causante, entre las que se encontraría el ejercicio de elección de ley, cuyo contenido no vincula al causante ${ }^{432}$.

La segunda duda que se plantea se refiere a los pactos sucesorios que afectan a más de una sucesión, donde esta cuestión tiene un matiz distinto al tratarse de casos en los que el otro co-otorgante del pacto sucesorio también es disponente. El ejemplo sería el de un pacto sucesorio otorgado por dos cónyuges en el que se instituyen recíprocamente herederos. Basándose la conexión que determina la ley aplicable a los pactos sucesorios en una circunstancia personal del causante y habiendo varios causantes cuya sucesión está afectada por el pacto sucesorio, puede existir la posibilidad de que la elección recaiga en distintas leyes. Pensemos en el ejemplo en el que uno de los cónyuges tiene nacionalidad italiana y el otro cónyuge nacionalidad suiza. Se permite escoger la ley de la nacionalidad del futuro causante, por lo que habiendo dos causantes con nacionalidad distinta implica, a priori, la posibilidad de escoger bien la ley suiza, bien la ley italiana.

\footnotetext{
${ }^{431}$ Sobre el carácter unilateral de la cláusula de elección de ley inserta en el pacto sucesorio, J.M. FONTANELLAS MORELL (2010), p. 208.

${ }^{432}$ La posibilidad de que en el pacto sucesorio se otorguen también cláusulas de carácter unilateral se permite expresamente en algunos sistemas; así, por ejemplo, en el Derecho alemán, el BGB prevé concretamente en el $\S 2299$ la posibilidad de otorgar cláusulas unilaterales, las cuales tendrán el mismo régimen jurídico que en el caso de que se hubieran otorgado a través de un testamento. El profesor Lacruz Berdejo ha puesto de manifiesto que en principio no pueden ser contractuales aquellas disposiciones insertas en los pactos sucesorios y que no son estrictamente patrimoniales, poniendo como ejemplo el nombramiento de un tutor o de un albacea, vid. J.L. LACRUZ BERDEJO (1953), p. 133.
} 
Ahora bien, de nuevo, la duda se centra en si uno de los causantes puede escoger la ley de su nacionalidad de manera unilateral y que ésta se aplique al pacto sucesorio o si es necesario que ambos causantes estén de acuerdo para que se pueda escoger la ley de la nacionalidad de alguno de ellos. Obviamente, estamos planteando estas cuestiones previas haciendo abstracción de otros problemas fundamentales, como, por ejemplo, si un pacto sucesorio puede o no estar gobernado al mismo tiempo por más de una ley. Aspecto sobre el que volveremos.

La doctrina alemana se ha planteado esta cuestión estructural de la autonomía de la voluntad conflictual en los pactos sucesorios sin llegar a ningún acuerdo al respecto. Por un lado, se ha defendido que la elección de la ley aplicable a los pactos sucesorios debe tener una estructura unilateral, esto es, se trata de una elección de ley por parte del otorgante disponente, un simple ejercicio de la professio iuris, como ocurre con la determinación de la ley aplicable a cualquier tipo de sucesión. Según la postura de H. DÖRNER, el carácter unilateral de la elección de ley no varía por el hecho de que se realice en un testamento conjunto o en un pacto sucesorio bilateral. Es más, este autor entiende que no es necesario que ambos otorgantes opten conjuntamente por una ley, en concreto la alemana por ser la posibilidad de elección que prevé el art. 25 EGBGB, asumiendo que como consecuencia de ello puede ocurrir que el acto jurídico de que se trate, testamento conjunto o pacto sucesorio, pueda estar sometido a la vez a distintos estatutos sucesorios ${ }^{433}$. Por otro lado, se defiende la bilateralidad de la elección de ley aplicable en los casos en que se trate tanto de pactos sucesorios como de testamentos conjuntos. El profesor R. BIRK hace hincapié en el hecho de que cuando la elección se realiza a través de un testamento conjunto o pacto sucesorio, al lado del causante hay otro otorgante. Según su postura, tratándose de pactos sucesorios en los que hay dos causantes, para realizar el ejercicio de la elección de ley prevista por el ordenamiento alemán a favor de la ley alemana, es necesario que ambas partes escojan conjuntamente la mencionada ley; sólo así se

${ }^{433}$ H. DÖRNER (2007). núm. 508. 
pueden evitar las dificultades que entrañaría que un mismo acto jurídico se regulara por distintas leyes ${ }^{434}$.

En definitiva, siguiendo la recurrente clasificación de los pactos sucesorios en función del número de sucesiones afectadas, parece que al amparo del ordenamiento jurídico alemán la estructura de la elección de la ley aplicable a los pactos sucesorios es unilateral en aquellos casos en los que el pacto afecta a una única sucesión ${ }^{435}$. Sin embargo, cuando se trata de la elección de ley aplicable a los pactos que afectan a más de una sucesión la cuestión es más problemática y no hay una posición unánime al respecto. Mientras parte de la doctrina sigue defendiendo el carácter unilateral de la elección, otros entienden que para este tipo de pactos en los que hay más de un disponente otorgante, la elección debe articularse de forma bilateral.

En el análisis que realizamos a continuación acreditaremos que la opción por una u otra articulación de la elección de ley aplicable a los pactos sucesorios no es una cuestión baladí. Como vamos a ver, cada vía, además de tener su propia configuración en cuanto a quién debe realizar la elección y de qué modo, tiene un régimen jurídico diferente, un alcance distinto $\mathrm{y}$, en definitiva, unas consecuencias distintas para el pacto sucesorio. El análisis lo realizaremos prioritariamente siguiendo lo previsto por el Reglamento de sucesiones. Ello, sin embargo, no impedirá que hagamos puntuales referencias tanto al Convenio de La Haya de 1989, como a la legislación suiza, que como hemos visto prevé una regulación específica para la elección de la ley aplicable a los pactos sucesorios. El propósito no es otro que ofrecer una visión global y plantear una solución globalmente satisfactoria, si ello es posible.

\footnotetext{
${ }^{434}$ R. BIRK (2006) núm. 38.

${ }^{435}$ H. DÖRNER (2007) que afirma con carácter general la estructura unilateral de la elección de ley en los pactos sucesorios; R. BIRK (2006) a sensu contrario, cuando afirma que la exigencia de que ambos otorgantes deben elegir la ley aplicable, señala que tal afirmación sólo es válida para los pactos sucesorios en los que ambos otorgantes realizan disposiciones por causa de muerte, esto es, cuando el pacto sucesorio afecta a más de una sucesión.
} 


\section{Vías para la elección de la ley aplicable a los pactos sucesorios}

\subsection{La elección unilateral de la ley aplicable: professio iuris y pactos sucesorios}

\subsubsection{Características}

La primera de las vías posibles a través de las cuales se puede elegir la ley aplicable a los pactos sucesorios es la professio iuris. Como hemos visto, se trata de una elección unilateral a cargo del causante, por tanto, trasladado al contexto de los pactos sucesorios se trataría de una elección unilateral realizada por el otorgante disponente, en los pactos sucesorios de institución, o futuro causante, en los pactos sucesorios de renuncia. Aunque pueda parecer obvio, es de señalar que tal carácter unilateral excluye, por tanto, la participación de otros otorgantes del pacto sucesorio, sean también disponentes o sean meros contratantes que no disponen de su sucesión.

El carácter unilateral de esta elección de ley va a implicar un régimen distinto al de otras cláusulas del pacto sucesorio, siempre que esté inserta en el mismo pacto, lo que vamos a considerar como hipótesis de partida, aunque adelantando que no es la única posible. Con carácter general, lo acordado a través de un pacto sucesorio tiene un carácter contractual, bilateral, que vincula a las partes que suscriben dicho pacto. Como hemos venido manteniendo a lo largo del trabajo, una de las características más importantes de los pactos sucesorios es la vinculación que los otorgantes tienen al contenido del pacto. De dicha vinculación se deriva la característica más problemática de los pactos sucesorios que no es otra que la imposibilidad del causante de revocar de forma unilateral y libremente las disposiciones por causa de muerte realizadas en tal pacto. Sin embargo, el juego de la professio iuris va a tener un régimen distinto. Tal elección de ley no es producto de un acuerdo entre las partes del pacto sucesorio y, por tanto, no participa de la eficacia vinculatoria de las disposiciones que se acuerdan a través de pactos sucesorios. Es más, alejándonos de la hipótesis de partida, la cláusula de elección de ley no tiene por qué estar contenida en el pacto sucesorio. Es posible que el otorgante disponente hubiera realizado en un momento anterior un ejercicio de elección de la ley aplicable a su sucesión que luego pueda tener su eficacia en 
el pacto sucesorio como consecuencia de la dependencia que de la ley sucesoria tienen estas figuras a la hora de que se determine la ley que se les aplica. La otra opción consiste en que la elección de ley se realice en el propio pacto sucesorio, caso en el que se trataría de una cláusula unilateral inserta dentro del pacto sucesorio, en la que no existe el concurso de la voluntad de la otra parte contratante. En ambos casos, la consecuencia fundamental es que el causante no queda vinculado por la cláusula de elección y que, a diferencia del resto de cláusulas, el causante puede revocarla libremente cuando estime oportuno. No es descartable, tampoco, que la professio iuris se realice, o se modifique, tras la conclusión del pacto sucesorio.

El carácter revocable de la professio iuris evoca a priori ciertos interrogantes en relación con los pactos sucesorios en lo que concierne a la admisibilidad, validez material, al régimen jurídico aplicable e incluso a la propia eficacia de los mismos. Por ello es interesante analizar las relaciones entre la ley aplicable al pacto sucesorio y la ley sucesoria desde la perspectiva de la autonomía de la voluntad conflictual.

\subsubsection{Professio iuris en los pactos sucesorios: su articulación en el Reglamento de sucesiones}

La vía de la professio iuris para la elección de la ley aplicable a los pactos sucesorios que afectan a una única sucesión no parece plantear mayor problema entre la doctrina y la normativa positiva. La duda podría surgir por la naturaleza contractual de los pactos sucesorios y por el hecho de que en este tipo de pactos al lado del causante hay otro otorgante no disponente; cabría preguntarse, por tanto, si es necesaria la concurrencia de la voluntad de este otro participante no disponente en el pacto sucesorio para que tenga efecto la elección de ley. Como hemos visto, la doctrina alemana que se ha planteado cómo debe ser la estructura de la elección de ley aplicable en los pactos sucesorios está de acuerdo en la articulación unilateral de la elección cuando se trata de pactos sucesorios que afectan a una única sucesión. Pero no sólo en el plano doctrinal se aboga por esta estructura: el Reglamento o el Convenio de La Haya también la acogen. 
La professio iuris es una de las vías que se prevé en el Reglamento para articular la elección de la ley aplicable a los pactos sucesorios. Esta posibilidad se deriva de la combinación de dos artículos: el art. 25 apartados primero y segundo y el art. 22. El art. 25.1 del Reglamento está dedicado a la determinación de la ley aplicable a los pactos sucesorios que se refieren a la sucesión de una sola persona y dispone que tales pactos se regirán por la ley que habría sido aplicable a la sucesión de esa persona en caso de que el fallecimiento se hubiera producido en la fecha de conclusión del acuerdo. La fórmula "ley que, en virtud del presente Reglamento, fuese aplicable a su sucesión si aquella hubiera fallecido en la fecha de conclusión del pacto" nos remite a dos posibilidades y a dos artículos del Reglamento. Una de esas posibilidades nos remite al art. 21 del texto normativo, donde se recoge la regla general para la determinación de la ley aplicable a las sucesiones internacionales, aplicable en defecto de elección y con base en la conexión de la residencia habitual del causante determinada en el momento del fallecimiento, salvo que existiese una ley más estrechamente vinculada. En definitiva, esta remisión combinada con la especialidad temporal que prevé el art. 25.1 del Reglamento, implicaría la aplicación de la ley de la residencia habitual del futuro causante determinada en el momento en que se otorga el pacto sucesorio o, en su caso, otra ley con la que en ese mismo momento el causante mantuviera unos vínculos manifiestamente más estrechos.

La otra posibilidad, que es la que ahora nos interesa, nos remite al art. 22 del Reglamento. Como hemos visto, dicho artículo prevé con carácter general una professio iuris limitada a favor de la ley de la nacionalidad del causante. En definitiva, en el caso de que el causante hubiera hecho ejercicio de la posibilidad de elección de ley que le permite el art. 22 del Reglamento, la ley que hubiera sido aplicable a su sucesión de haber fallecido en el momento en el que se otorgó el pacto sucesorio sería la ley de su nacionalidad y, por tanto, ésta será la que se aplique al pacto en cuestión. La professio iuris se realiza al amparo del art. 22 del Reglamento, y es el art. 25 el que le da entrada al juego de esa elección de ley en el ámbito de los pactos sucesorios que afectan a una única sucesión. La professio iuris estará sometida al régimen jurídico del art. 22 y la elección de la ley de la 
nacionalidad se puede realizar bien antes del otorgamiento del pacto sucesorio, bien en el propio pacto sucesorio.

Lo mismo ocurre para los pactos sucesorios que afectan a más de una sucesión; el apartado segundo del art. 25 se refiere a la aplicación de "la ley que, de conformidad con el presente Reglamento, hubiera sido aplicable a la sucesión de cada una de ellas (esto es, de las personas cuya sucesión quede afectada por el contenido del pacto sucesorio) si hubieran fallecido en la fecha de conclusión del pacto". Tal ley será la de la nacionalidad del causante de que se trate, en aquellos casos en los que éste hubiera realizado la professio iuris al efecto.

El Reglamento no es pionero en el uso de esta técnica para introducir el juego de la professio iuris en los pactos sucesorios que afectan a una única sucesión, como tampoco lo fue la Propuesta de Reglamento que ya preveía este sistema. Su precedente inmediato, el Convenio de La Haya de 1989, cuya influencia en la regulación prevista tanto en la Propuesta de Reglamento, como en el propio Reglamento es innegable, ya había utilizado este mecanismo para estructurar la elección de ley a los pactos sucesorios que afectan a una única sucesión por la vía de la professio iuris. El art. 9.1 del Convenio dispone que tales pactos sucesorios se regirán por "la ley que, en virtud del artículo 3 o del apartado 1 del artículo 5" habría sido aplicable a la sucesión del otorgante disponente en el caso de que éste falleciera en el momento de la conclusión del pacto sucesorio. La remisión al apartado primero del art. 5 posibilita la elección unilateral de la ley aplicable a este tipo de pactos sucesorios, pues dicho precepto establece la regla general de la professio iuris, al permitir al causante escoger para regular el conjunto de su sucesión la ley de su residencia habitual o la ley de su nacionalidad, ambas determinadas bien en el momento de la propia elección, bien en el momento de su fallecimiento ${ }^{436}$.

Como hemos visto, la ley suiza de DIPr prevé también una regulación expresa de la ley aplicable a los pactos sucesorios y, dentro de ésta, una regulación concreta de la elección de ley aplicable a estas figuras. Esta regulación

${ }^{436}$ P. LAGARDE (1989), p. 270; 
acoge la posibilidad de escoger la ley aplicable a los pactos sucesorios que afectan a una única sucesión a través de una professio iuris del causante. En concreto, el art. 95.2 de la citada ley habla de la posibilidad de que el disponente, esto es el futuro causante, someta el conjunto de su sucesión a la ley de su nacionalidad, caso en el que el pacto en cuestión se regulará por esta ley y no por la ley correspondiente a su domicilio ${ }^{437}$.

\subsection{La elección bilateral de la ley aplicable: pactos de lege utenda y pactos sucesorios}

\subsubsection{Características}

La elección de ley aplicable a los pactos sucesorios a través de un pacto de lege utenda es una elección de carácter bilateral. El pacto de lege utenda se inserta en el pacto sucesorio y es acordado por todas y cada una de las partes contratantes como cualquier otra cláusula del mismo. Esto implica que tal elección de ley va a tener el mismo régimen que el resto de disposiciones contenidas en el pacto sucesorio; en concreto, nos interesa destacar el efecto vinculante que despliega el pacto de lege utenda sobre las partes otorgantes y, más concretamente, sobre las partes cuya sucesión queda afectada por el contenido del pacto sucesorio.

En el caso de los pactos sucesorios que afectan a una única sucesión el pacto de lege utenda se celebrará entre el disponente o futuro causante y el otorgante no disponente; en el caso de los pactos sucesorios que afectan a más de una sucesión se celebrará entre los disponentes o futuros causantes y, cuando también concurrieren, otros otorgantes cuya sucesión no quede afectada por el contenido del pacto sucesorio. Pero con independencia de las posibilidades de elección, esto es de la articulación concreta que se realice de la posibilidad de elección de ley, y con independencia de los elementos personales que reúna el pacto sucesorio en concreto, como punto en común hay que señalar que todos los pactos de lege utenda para elegir la ley aplicable a los pactos sucesorios contienen

\footnotetext{
${ }^{437}$ B. DUTOIT (2005), p. 313, donde en el comentario al art. 95.2 de la ley suiza DIPr señala expresamente que la professio iuris es también posible en los pactos sucesorios unilaterales o pactos sucesorios que afectan a una única sucesión.
} 
una elección de ley que está vinculada a las posibilidades de elección de la ley sucesoria del causante; esto es, la conexión que determina la ley a elegir va a depender siempre del causante o, más técnicamente, del otorgante o de los otorgantes del pacto sucesorio que tengan el carácter de disponentes.

Existen dos distinciones fundamentales que debemos tener en cuenta para realizar el análisis que procede a continuación entre la elección de ley a través de una professio iuris y la elección de ley a través de un pacto de lege utenda. La primera de ellas hace referencia a la extensión de la elección. A través de una professio iuris se escoge, en realidad, la ley sucesoria del disponente o futuro causante, que va a entrar en juego como ley aplicable al pacto sucesorio por la dependencia que de la ley sucesoria (anticipada, para ser más concretos) tienen los pactos sucesorios en la determinación de su ley aplicable. Sin embargo, la elección realizada a través de un pacto de lege utenda nunca es una elección de ley sucesoria, sino una elección de la ley aplicable al pacto sucesorio en concreto que se esté celebrando ${ }^{438}$. La ley elegida en ambos casos tiene un ámbito de aplicación distinto (la totalidad de la sucesión, incluyendo la validez del pacto en el primer caso y sólo la validez del pacto en el segundo). La segunda distinción fundamental entre la elección a través de una professio iuris y la elección a través de un pacto de lege utenda hace referencia al alcance de la elección efectuada. Mientras la elección de la ley sucesoria a través de la professio iuris es revocable

\footnotetext{
${ }^{438}$ Así se despende de lo dispuesto en las normas que prevén esta posibilidad ad hoc de pacto de lege utenda; el art. 11 del Convenio de La Haya de 1989 dispone que "las partes podrán convenir, por designación expresa, someter el pacto.... la ley de un Estado en el cual en el momento de concluirse el pacto tuviera su residencia habitual o del que fuera nacional la persona o cualquiera de las personas de cuya sucesión se trate". El art. 18.3 de la Propuesta de Reglamento señala que "las partes podrán convenir, por designación expresa, someter el acuerdo a la ley que la persona o una de las personas de cuya sucesión se trate hubiera podido designar con arreglo al art. 17". El art. 25.3 del Reglamento dispone que "las partes podrán elegir como ley aplicable al pacto sucesorio, por lo que respecta a su admisibilidad, validez material y efectos vinculantes entre las partes, incluidas las condiciones para su resolución, la ley que la persona o una de las personas de cuya sucesión se trate habría podido elegir de acuerdo con el artículo 22 en las condiciones que este establece". La excepción la podemos encontrar en el sistema suizo, donde la cuestión no está tan clara. Cuando se trata de una elección de ley aplicable a los pactos sucesorios que afectan a más de una sucesión se tiene que tratar de un acuerdo entre las partes, vid. Message concernant une loi fédérale sur le droit international privé, du 10 novembre 1982, Fueille Fédérale, 1983, vol I, pp. 255-501, esp. núm. 264.1, p. 380; pero el art. 95.2 de la ley suiza de DIPr sólo prevé la elección de la ley de la nacionalidad común de las partes. Esta limitación hace pensar en la búsqueda por el sistema suizo de la preservación del principio de unidad de la sucesión, de tal forma que las sucesiones de ambos otorgantes queden regidas por una única ley.
} 
en cualquier momento de forma unilateral por el causante, en el caso del pacto de lege utenda, al ser un acuerdo entre las partes otorgantes del pacto sucesorio, tiene como consecuencia la creación de un efecto vinculante para las partes, de tal forma que el causante no puede revocar libremente la elección de ley realizada. Esta vinculación suscita interesantes cuestiones en torno a la posibilidad de realizar posteriores professio iuris por el causante y el alcance de esta vinculación del causante, como veremos más adelante.

\subsubsection{Los pactos de lege utenda en los pactos sucesorios: el art. 25.3 del Reglamento de sucesiones}

La posibilidad de elegir la ley aplicable a través de un pacto de lege utenda no es una vía totalmente novedosa en los pactos sucesorios. La ley suiza de DIPr la prevé en su art. 95.3 en lo que se refiere a la ley aplicable de los pactos sucesorios que contienen disposiciones por causa de muerte recíprocas. Dicho artículo contiene la posibilidad de que se aplique al pacto sucesorio la ley nacional común de los disponentes, en el caso de que éstos, esto es, ambos, hayan elegido dicha ley nacional común ${ }^{439}$.

El Convenio de La Haya de 1989 también prevé esta vía de elección de ley aplicable a los pactos sucesorios en su art. 11. La posibilidad de realizar un pacto de lege utenda se contempla, en este caso, tanto para los pactos sucesorios que afectan a una única sucesión, como para los pactos sucesorios que afectan a varias sucesiones. El artículo habla, por un lado, de que "las partes podrán convenir", de lo que se deriva que se trata de un pacto de lege utenda y no de una professio iuris; y, por otro lado, se permite escoger la ley que en el momento del otorgamiento del pacto sucesorio correspondiera a la residencia habitual o a la nacionalidad de "la persona o cualquiera de las personas de cuya sucesión se trate", de lo que también se deriva que se permite esta vía de elección de ley aplicable para los dos tipos de pactos sucesorios ${ }^{440}$.

\footnotetext{
${ }^{439} \mathrm{Vid}$. B. DUTOIT (1995), p. 314, quien habla de una professio iuris en un pacto sucesorio bilateral a favor de un Derecho nacional común de los disponentes.

${ }^{440}$ Vid. en este sentido el Rapport explicatif a cargo de W.M. WATERS en CONFÉRENCE DE LA HAYE DE DROIT INTERNATIONAL PRIVÉ (1990), p. 582.
} 
La Propuesta de Reglamento, siguiendo como en muchas otras ocasiones la estructura que recoge el Convenio de La Haya de 1989, ya recogió la posibilidad de elegir la ley aplicable a los pactos sucesorios a través de un pacto de lege utenda. El art. 18.3 de la Propuesta así lo disponía cuando decía que "las partes podrán convenir por designación expresa someter el acuerdo a la ley que la persona o de una de las personas de cuya sucesión se trate hubiera podido designar con arreglo al artículo 17”. De esta forma se dio entrada a esta vía de elección de ley aplicable permitiéndola igualmente para los pactos que afectan a una única sucesión y para lo que afectan a varias sucesiones.

La posibilidad de realizar una elección de ley aplicable a los pactos sucesorios a través de un pacto de lege utenda se recoge, con alguna variación respecto de la redacción de la Propuesta de Reglamento, finalmente en el Reglamento en el art. 25.3, cuando dice que "las partes podrán elegir como ley aplicable al pacto sucesorio, por lo que respecta a su admisibilidad, validez material y efectos vinculantes entre las partes, incluidas las condiciones para su resolución, la ley que la persona o una de las personas de cuya sucesión se trate habría podido elegir de acuerdo con el art. 22 en las condiciones que este establece".

Tratándose de un pacto sucesorio que afecta a una única sucesión el pacto de lege utenda se celebrará entre el otorgante disponente y el otorgante o los otorgantes no disponentes. El ejemplo podría ser el de un pacto de renuncia realizado entre un padre y su hijo, en el que ambos tienen residencia habitual en España y en el que el padre tiene nacionalidad alemana y el hijo nacionalidad española. En el pacto sucesorio podrían realizar una disposición a través de la cual se escogiera la aplicación de la ley nacional del futuro causante, esto es, la ley nacional del padre, la ley alemana. Desde el punto de vista de las leyes elegibles, la vía del pacto de lege utenda en el Reglamento no ofrece mayores posibilidades a la aplicación al pacto sucesorio de potenciales leyes ${ }^{441}$; tanto en el caso de la realización de una professio iuris, como en el caso del otorgamiento de un pacto

\footnotetext{
${ }^{441}$ Tampoco lo ofrecía la Propuesta de Reglamento, tal y como ya hemos tenido ocasión de poner de relieve en S. Álvarez GonZÁlEZ/ I. RodríGUEZ-URÍA SuÁrEZ (2011), p. 8.
} 
de lege utenda, la ley elegida puede ser únicamente la ley de la nacionalidad del disponente, esto es en el ejemplo, la ley alemana. Sin embargo, el hecho de realizar esa elección a través del pacto de lege utenda, en vez de a través de una professio iuris, sí va a tener repercusión en cuanto al alcance de dicha elección, como veremos más adelante.

Tratándose de un pacto sucesorio que afecta a más de una sucesión el pacto de lege utenda se celebrará entre los otorgantes disponentes o futuros causantes y, en el caso de que también concurrieran, aquellos otros posibles otorgantes cuyas sucesiones no se vean afectadas por el pacto sucesorio. El ejemplo podría ser el de un pacto sucesorio celebrado entre cónyuges con residencia habitual en París en el que realizan disposiciones recíprocas a favor del otro; uno de los cónyuges tiene nacionalidad francesa y el otro nacionalidad austriaca. Las conexiones que llevan a la aplicación de la ley francesa contemplarían el pacto sucesorio como inválido; sin embargo, los cónyuges pueden escoger la ley austriaca, como ley de la nacionalidad de uno de ellos, caso en el que el pacto sucesorio sería válido ${ }^{442}$. Las posibilidades de elección de ley aplicable se limitan, como en los pactos sucesorios que afectan a una única sucesión, a la ley de la nacionalidad del otorgante disponente; por tanto, la posibilidad de realizar un pacto de lege utenda ad hoc para determinar la ley aplicable al pacto sucesorio no añade nada en términos de leyes potencialmente aplicables a los pactos sucesorios. Ahora bien, sí es cierto que, tratándose de pactos sucesorios que afectan a más de una sucesión, el número de leyes elegibles es mayor desde el punto de vista de un otorgante disponente, pues no sólo va a poder elegir la ley de su nacionalidad, sino que va a poder elegirse la ley de la nacionalidad de otro de los disponentes. En el ejemplo, el cónyuge de nacionalidad francesa va a poder "beneficiarse" la ley austriaca, a título de ley de la nacionalidad del otro otorgante disponente del pacto sucesorio.

No obstante, como ya apuntamos en el caso de los pactos de lege utenda para los pactos sucesorios que afectan a una única sucesión, la gran diferencia entre las vías elección de ley a los pactos sucesorios en el contexto del 25 del

${ }^{442} \S 364$ c) AGBG; vid., F. HAUNSCHMIDT (2008), p. 1107. 
Reglamento es el distinto alcance que tiene una forma u otra de elección de la ley aplicable. La vinculación del causante al pacto de lege utenda suscita interesantes cuestiones en torno su facultad para la realización de posteriores professio iuris sucesorias.

No es ocioso preguntarse si el pacto de lege utenda, esto es la elección de ley en él realizada, se refiere únicamente a la regulación de la parte de la sucesión que está afectada por el pacto sucesorio o si se trata o puede tratarse de una elección de ley aplicable para el conjunto de la sucesión. Desde una perspectiva estrictamente sistemática, las normas del reglamento prevén dos mecanismos distintos con función y alcance distinto. La respuesta debe ser no. La vía de elección de ley aplicable a través de un pacto de lege utenda se refiere únicamente a la determinación de la ley aplicable al pacto sucesorio (en concreto a los aspectos regulados en el art. 26 en el caso del Reglamento) y no al conjunto de la sucesión. Esta idea tiene diversos soportes. El primero, como hemos adelantado, lo integra la regulación positiva. El art. 25 del Reglamento habla de "elegir como ley aplicable al pacto sucesorio, por lo que respecta a su admisibilidad, validez material y efectos vinculantes entre las partes incluidas las condiciones para su resolución" a la ley elegible de conformidad con el art. 22. Ya en el Convenio de La Haya de 1989 el propio art. 11 habla concretamente de la posibilidad de "someter el pacto" a la ley de la residencia habitual o de la nacionalidad de la persona o cualquiera de las personas de cuya sucesión se trate. El pacto de lege utenda no está destinado directamente a elegir la ley sucesoria.

El segundo fundamento, parte de la esencia misma de la professio iuris como modo ordinario de terminación de la ley sucesoria: entendemos que no sería asumible el alcance del pacto de lege utenda en cuanto a la vinculación del causante al mismo. El carácter irrevocable del pacto de lege utenda sólo tendría sentido en el marco de la regulación del pacto sucesorio, pero no más allá, pues implicaría que el causante precisaría de la voluntad del resto de otorgantes del 
pacto sucesorio para cambiar la ley aplicable a su sucesión (cuestión que depende únicamente de su voluntad) ${ }^{443}$.

A pesar de estos motivos, señalábamos que no era ociosa la pregunta, porque existen intereses que quedarían salvaguardados si la respuesta fuese positiva; en concreto, la preservación de la unidad de la sucesión (la misma ley aplicable a la admisibilidad y validez del pacto y a la entera sucesión). Pero esta consecuencia ni si quiera podría cumplirse siempre puesto que en los pactos que afectan a más de una sucesión, la elección de la ley nacional de uno de los disponentes afectaría a todos en cuanto a la regulación del pacto sucesorio y a este disponente en cuanto a la regulación del conjunto de la sucesión, de tal forma que el resto de disponentes verán el régimen de su sucesión fraccionado ${ }^{444}$.

En definitiva, a nuestro juicio, otra de las diferencias entre la elección de ley a los pactos sucesorios a través de la professio iuris y a través de un pacto de lege utenda es que mientras en el primer caso la elección afecta en un principio al conjunto de la sucesión, en el segundo caso la elección se limita a la determinación de la ley aplicable al pacto sucesorio, y aunque teóricamente podría argumentarse que en los pactos que afectan a una única sucesión cabría la entrada del pacto de lege utenda del art. 25 en la economía del art. 22.2 (elección tácita), ello no cambiaría la doble dimensión de la ley elegida: en tanto que ley sucesoria, podría cambiarse unilateralmente por el causante; en tanto que pacto de lege utenda, no.

\footnotetext{
${ }^{443}$ Tal postura implicaría una especia de penalización para el disponente o futuro causante cuya ley nacional ha sido escogida en el marco del Reglamento. Mientras que el resto de otorgantes disponentes o futuros causantes podrían realizar sucesivas professio iuris para regular el resto de la sucesión que no quede afectada por el pacto sucesorio.

${ }^{444}$ Sobre la relación de los pactos de lege utenda y el mantenimiento de la unidad de la sucesión es interesante observar lo dispuesto en la ley suiza de DIPr. Dicha ley mantiene la concepción de la unidad de la sucesión; en consonancia con esta concepción, el art. 95.2, cuando prevé la posibilidad de que el otorgante disponente realice una professio iuris en los pactos sucesorios que afectan a una única sucesión, exige expresamente que dicha professio iuris sea para el conjunto de la sucesión. No es tan explícita, sin embargo, en los pactos sucesorios que contienen disposiciones recíprocas, si bien es cierto que la única ley elegible es la ley nacional común de los disponentes, exigencia ésta que puede responder también a la voluntad de mantener la unidad de la sucesión de cada uno de los causantes en dicho pacto.
} 


\section{Alcance de la elección de la ley aplicable a los pactos sucesorios}

\subsection{Consecuencias de la elección en términos de admisibilidad, validez y régimen jurídico del pacto sucesorio}

Hemos visto cómo es posible la elección de ley aplicable a los pactos sucesorios por dos vías distintas, consecuencia del doble carácter contractual y sucesorio de estas figuras. Al hablar de las características de cada una de estas vías, la professio iuris y el pacto de lege utenda, también hemos adelantado cómo la elección de ley realizada a través de una u otra implica distintos efectos o distintas consecuencias en términos de vinculación a la misma. En concreto, se contrapone el carácter esencialmente revocable de la elección realizada a través de la professio iuris, al carácter esencialmente irrevocable de la elección realizada a través de un pacto de lege utenda.

De lo que se trata en este apartado es de profundizar en la cuestión del alcance de la elección de la ley aplicable a los pactos sucesorios por una y otra vía desde el punto de vista de la regulación de la admisibilidad, validez material y el régimen jurídico de los pactos sucesorios. Para ello analizaremos cómo puede afectar a estos aspectos la existencia de posibles sucesivas elecciones de ley, tomando ejemplos que representen situaciones. Distinguimos entre admisibilidad, validez material y régimen jurídico de los pactos sucesorios por ser la estructura que ha seguido el Reglamento de sucesiones y la que venimos asumiendo en nuestros desarrollos. Estos condicionantes temporales hacen que no analicemos el "punto de partida", en el que puede haber o no concurrencia de la autonomía de la voluntad y en el que pueden darse situaciones tan peculiares como, por ejemplo, una simultánea concurrencia del professio iuris y pacto de lege utenda a favor de dos leyes distintas (imaginemos la situación de un doble nacional en el momento de realización del pacto). 


\subsubsection{Elección de ley aplicable al pacto a través de professio iuris y su modificación por una professio iuris posterior}

\subsubsection{La ulterior modificación unilateral de la ley aplicable a la sucesión no afecta a la admisibilidad y validez del pacto sucesorio.}

La primera situación que vamos a analizar es aquella que combina dos elecciones unilaterales de ley aplicable. Hemos visto cómo en el marco del Reglamento elección de la ley aplicable a los pactos sucesorios a través de una professio iuris del causante es posible tanto para los pactos que afectan a una única sucesión como para los pactos que afectan a varias sucesiones. Pues bien, de lo que se trata ahora es de ver si es posible y, en su caso, cómo afecta a tales pactos sucesorios el ejercicio de una distinta professio iuris posterior o incluso la mera revocación de la professio iuris realizada. El supuesto, en términos de planteamiento de problemas, absorbe el de la ausencia de professio iuris en el momento de realización del pacto (y correlativa ausencia de pacto de lege utenda) mientras que se produce una posterior elección de ley.

El primero de los ejemplos sobre el que vamos a trabajar trata de un pacto sucesorio que afecta a una única sucesión. Un hombre con residencia habitual en París y nacionalidad suiza realiza un pacto sucesorio a través del cual instituye heredera a su cónyuge, de nacionalidad francesa y residencia habitual también en París. En el pacto sucesorio sólo hay un otorgante disponente, el marido, cuyas circunstancias personales nos van a permitir fijar cuál es la ley que se aplica a la determinación de la admisibilidad y validez material del pacto sucesorio en cuestión. Según el art. 25.1 del Reglamento este pacto sucesorio se podrá regular bien por la ley de la residencia habitual del disponente determinada en el momento del otorgamiento del pacto sucesorio, esto es la francesa, salvo que hubiera otra más estrechamente vinculada (hipótesis que vamos a descartar ahora para hacer más sencillo el ejemplo), bien por la ley de la nacionalidad del disponente en el caso de que ésta fuera la ley sucesoria como resultado del ejercicio de una professio iuris en el marco del art. 22, caso en el que se aplicaría la ley suiza. La hipótesis que nos interesa ahora es, por tanto, aquella en la que el disponente ha realizado una professio iuris de tal forma que su ley sucesoria no es 
la de su residencia habitual, sino la de su nacionalidad. En el ejemplo, tal elección de ley implicaría que la ley aplicable a la admisibilidad y validez material del pacto sucesorio sería la suiza.

Ahora bien, el disponente o futuro causante puede libremente modificar o revocar la elección de ley realizada cuando estime conveniente y sin necesidad del concurso de la voluntad de nadie más. Tal modificación o revocación da lugar a un cambio de la ley sucesoria. El cambio puede venir de la mano de, a su vez, un cambio de la nacionalidad del causante (pensemos que en el ejemplo el causante acaba adquiriendo la nacionalidad francesa) y una correspondiente nueva elección de ley, o, simplemente, por el hecho de que el causante realice una declaración revocando la elección de ley realizada, caso en el que se aplicará la norma objetiva para la determinación de la ley sucesoria, esto es, aquella que viene determinada por la residencia habitual del causante u otra más estrechamente vinculada $^{445}$. Pues bien, contextualizada la situación, debe afirmarse que las vicisitudes derivadas de cambios respecto a la professio iuris realizada por el causante, no afectan a los pactos sucesorios en términos de admisibilidad y validez material cuando el pacto sucesorio está admitido y es válido de conformidad con la ley hipotética sucesoria en el momento del otorgamiento. La solución del Reglamento es clara en este sentido, al fijar temporalmente el momento del otorgamiento del pacto sucesorio para determinar la ley aplicable. Se elimina cualquier tipo de efecto pernicioso de un conflicto móvil. Trasladado al ejemplo, esto significa que la ley suiza, ley sucesoria hipotética o anticipada en el momento del otorgamiento del pacto sucesorio, sería la que determinaría si el pacto sucesorio está admitido y si es válido o no; la aplicación de esta ley daría como resultado la admisibilidad y validez material del pacto sucesorio, de conformidad con el art. 494.1 del CC suizo. Puesto que de la aplicación de esta ley deriva la admisibilidad y validez material del pacto sucesorio, nada tiene que decir la ley francesa sobre tales términos, ley que sería aplicable a la sucesión en un momento posterior al de la celebración del pacto sucesorio, bien por la

${ }^{445}$ El art. 22.4 del Reglamento permite la modificación o revocación por parte del causante de la elección de ley realizada, siempre y cuando cumpla los debidos requisitos formales. Tal posibilidad ya se recogía en la Propuesta de Reglamento, vid. J.M. Fontanellas Morell (2011), p. 118. 
adquisición de la nacionalidad francesa por parte del causante y consiguiente professio iuris, bien por la simple revocación de la professio iuris realizada y aplicación de la ley de la última residencia habitual.

Lo mismo ocurre para los pactos sucesorios que afectan a más de una sucesión; la revocación o modificación de una professio iuris, o la realización ex novo de la misma, en un momento posterior al de la celebración del pacto sucesorio no va a influir en la admisibilidad y validez material de éste. El art. 25.2 del Reglamento señala claramente el momento del otorgamiento del pacto sucesorio para la fijación de la ley aplicable a la admisibilidad y validez material de los pactos sucesorios que afectan a más de una sucesión; de tal forma, que como en el caso de los pactos sucesorios que afecta a una única sucesión, los posibles cambios posteriores no afectarán a estos términos del pacto sucesorio.

La cuestión era distinta en el marco de la Propuesta de Reglamento como consecuencia de la norma de validación que en el art. 18.1 se preveía para los pactos sucesorios que afectan a una sucesión. Recordemos que la norma de validación consistía en que, en aquellos casos en los que de conformidad con la ley hipotética sucesoria el pacto sucesorio fuera inválido, se le daba al pacto sucesorio otra oportunidad para ser válido materialmente si así lo preveía la ley sucesoria, determinada en el momento del fallecimiento (art. 18.1 in fine de la Propuesta). Desde este punto de vista, un cambio de elección de ley sí podía influir en la validez o invalidez material de los pactos sucesorios que afectan a una única sucesión. Pensemos en el ejemplo que hemos puesto, pero cambiando las circunstancias personales de causante. En el nuevo supuesto el causante de nacionalidad francesa tiene residencia habitual en Suiza, donde se casa con una suiza a la que instituye heredera a través de un pacto sucesorio. En el momento del otorgamiento del pacto sucesorio, el causante había realizado una professio iuris a favor de su ley nacional, de tal forma que la ley sucesoria anticipada es la ley francesa. La aplicación de esa ley conlleva la invalidez del pacto sucesorio, al no permitir el ordenamiento jurídico francés pactos sucesorios de tales características. Sin embargo, la modificación o revocación de la elección de ley realizada, pensemos en la posibilidad de que el causante acabara adquiriendo la 
nacionalidad suiza y realizara una modificación de la anterior professio iuris en beneficio de su nueva nacionalidad o, simplemente, en la posibilidad de que el causante revoque la elección de ley realizada y la ley aplicable a su sucesión pasara a determinarse por su última residencia habitual. En ambos casos, la ley sucesoria pasaría a ser la suiza, caso en el que el pacto sucesorio sería válido, en aplicación de la norma de validación que recogía el art. 18.1 de la Propuesta de Reglamento $^{446}$.

Ahora bien, a diferencia de lo que ocurría en los pactos sucesorios que afectan a una única sucesión, el juego de una professio iuris posterior a la realización del pacto sucesorio que afecta a varias sucesiones no podía implicar la validación del mismo en aquellos casos en los que el pacto sucesorio fuera inválido de conformidad con las leyes sucesorias anticipadas. La Propuesta de Reglamento, al igual que ocurre con el Convenio de La Haya de 1989, no previó la posibilidad de validar los pactos sucesorios que afectan a más de una sucesión a través de la aplicación de la ley sucesoria de alguno de los disponentes determinada en el momento del fallecimiento. Por ello, el ejercicio de professio iuris por parte de los disponentes con posterioridad a la celebración del pacto sucesorio que afecta a más de una sucesión en ningún caso afectaba bajo el régimen que preveía la Propuesta de Reglamento a la validez o invalidez de éste.

En definitiva, y volviendo a la regulación que finalmente se ha recogido en el Reglamento, en uno y otro tipo de pacto sucesorio, la admisibilidad y la validez de aquellos pactos sucesorios determinada en el momento del otorgamiento de los mismos como consecuencia del juego de la professio iuris de uno o varios de los disponentes no se ve afectada por posibles cambios de ley sucesoria motivados bien por sucesivas professio iuris del correspondiente

\footnotetext{
${ }^{446}$ En opinión de A. Bonomi, quien interpretó la doble solución del art. 18.1 de la Propuesta de Reglamento como una solución alternativa, la ventaja de una tal solución es la de evitar que un cambio de ley aplicable posterior a la celebración del pacto sucesorio pueda tener repercusiones sobre la validez y efectos del mismo; seguidamente señaló este autor que tal solución se aplica en aquellos casos en los que el cambio de ley aplicable sea el resultado bien de una elección de ley efectuada por el causante tras el otorgamiento del pacto sucesorio, bien por una revocación de la elección de ley realizada con anterioridad o bien por la eventual pérdida de la eficacia de la elección realizada como consecuencia de la pérdida de la nacionalidad correspondiente; vid. A. BONOMI (2010), p. 902. No vamos a analizar aquí la conveniencia o no conveniencia de determinar la validez de un pacto sucesorio en el momento del fallecimiento.
} 
disponente, bien por una simple revocación de la elección de ley realizada. Eso se deriva del propio artículo 25 del Reglamento y es además, a nuestro juicio, la solución adecuada, por ser la que más seguridad jurídica proporciona al conocer las partes desde el principio sus derechos y obligaciones y, en definitiva, por ser la que respeta en mayor medida los pactos sucesorios.

\subsubsection{La ulterior modificación unilateral de la ley aplicable a la sucesión no afecta a los aspectos dinámicos del pacto sucesorio: régimen jurídico}

Las cuestiones que se refieren al régimen jurídico corresponden a un aspecto dinámico del pacto sucesorio ${ }^{447}$; son aspectos continuados, efectos $\mathrm{y}$ circunstancias que se dan durante la vida del pacto sucesorio y no sólo en el momento del otorgamiento. Además, no debemos perder de vista el hecho de que la ley del pacto sucesorio siempre tiene una relación de dependencia con la ley sucesoria; por un lado, las conexiones que dan lugar a la ley del pacto sucesorio son siempre las conexiones que determinan la ley sucesoria y, por otro lado, la ley del pacto sucesorio no deja de ser el resultado de una especialidad temporal de la ley sucesoria, que en vez de determinarse en el momento del fallecimiento se determina en el momento del otorgamiento del pacto sucesorio. Por ello, en virtud de esta dependencia, cabe preguntarse si los aspectos dinámicos del pacto sucesorio se ven afectados por las modificaciones que pueda sufrir la conexión que determina la ley sucesoria.

A nuestro juicio, la seguridad jurídica, la necesaria certidumbre en lo que se refiere al régimen jurídico del pacto sucesorio y la defensa y salvaguarda de las expectativas de las partes como elemento fundamental para el respeto de la razón económica de los pactos sucesorios, nos llevan a defender que, al igual que lo que ocurre con la determinación de la validez del pacto sucesorio, el régimen jurídico de los pactos sucesorios no debe verse alterado por sucesivas modificaciones unilaterales de la conexión sucesoria. Debe ser la ley determinada en el momento

\footnotetext{
${ }^{447}$ Terminología utilizada por L. IMAZ ZUBIAUR (2006), pp. 417 y ss.; con el aspecto dinámico del pacto sucesorio se hace referencia a aquellas cuestiones de aspecto continuado, lo que podríamos denominar la vida del pacto sucesorio, frente a la creación del pacto sucesorio que correspondería a la admisibilidad y validez material y que, en la terminología de L. IMAZ ZUBIAUR, sería la perspectiva estática del pacto sucesorio.
} 
del otorgamiento del pacto sucesorio la que determine también cuál es su régimen jurídico y sucesivas modificaciones de la ley sucesoria que pueda realizar unilateralmente el disponente del pacto sucesorio no deben afectar al contenido del mismo ${ }^{448}$. Esta postura nos parece aún más clara en los casos en que los pactos sucesorios fueron otorgados al amparo de un sistema que los reconoce de forma muy reglada; la tipicidad de los pactos sucesorios no sólo afecta en la admisibilidad y validez material, sino también en el propio régimen jurídico de los pactos sucesorios y un cambio de ley aplicable puede suponer importantes diferencias de régimen jurídico que, a su vez, puedan implicar frustraciones de expectativas jurídicas $\mathrm{y}$, en definitiva, una inseguridad jurídica posiblemente insoportable para el funcionamiento y sentido de los pactos sucesorios.

Un ejemplo muy gráfico de la inseguridad jurídica que podría suponer el cambio sobrevenido de régimen jurídico por una declaración de voluntad conflictual unilateral del disponente es el de las causas de revocación. Como ya hemos visto, una de las características fundamentales de los pactos sucesorios es la de la irrevocabilidad unilateral de las disposiciones realizadas a través de los mismos, a salvo ciertas causas excepcionales. Generalmente, los pactos sucesorios se pueden revocar de forma unilateral por las causas expresamente pactadas y consignadas en el propio pacto sucesorio y por las causas que la correspondiente ley prevea. Las partes, por tanto, sabiendo cuáles son esas causas de revocación pueden prever los resultados de sus actuaciones y salvaguardar sus expectativas. Un padre de doble nacionalidad, suiza y española, y natural de Aragón, realiza un pacto sucesorio con su hijo a través del cual le instituye heredero de la empresa familiar. En el momento del otorgamiento del pacto sucesorio el disponente había realizado una professio iuris a favor de la ley suiza, una de las leyes correspondientes a una de sus nacionalidades, de tal forma que es esta ley la que determina la validez del pacto sucesorio. Tras la celebración del pacto sucesorio, la convivencia con el hijo instituido se hace difícil, no pareciendo que el hijo tenga excesivo interés por la empresa familiar. Bajo el Derecho suizo, esta

\footnotetext{
${ }^{448}$ Nos estamos refiriendo siempre a modificaciones no consentidas por cada una de las partes que otorgaron el pacto sucesorio; modificaciones que serían en cierto modo impuestas unilateralmente por el disponente del pacto sucesorio.
} 
circunstancia no sería suficiente para revocar el pacto sucesorio; sin embargo, esta misma circunstancia sí sería suficiente para que el padre pudiera revocar la institución realizada de forma unilateral bajo el Derecho aragonés. Con un simple cambio de professio iuris, a favor de su otra ley nacional, la española, el disponente podría hacer que se aplicara una causa de revocación que en principio era imprevista para el instituido. El art. 401. 1 b) del Código del Derecho Foral de Aragón dispone como una de las causas de revocación unilateral de los pactos sucesorios la conducta del instituido que impida la normal convivencia familiar. Si el ejercicio de la autonomía de la voluntad conflictual posterior a la celebración del pacto sucesorio implica una alteración del régimen jurídico de éste, el art, 401. 1 b) del Código del Derecho Foral de Aragón podría aplicarse al supuesto de hecho e fundamentar la revocación unilateral del pacto sucesorio por parte del disponente. En definitiva, una causa no prevista en el momento del otorgamiento del pacto sucesorio podría suponer la revocación del pacto sucesorio; o, dicho de otro modo, desde el punto de vista del instituido, se le aplica una causa de revocación que no conocía o preveía y, por tanto, tampoco tuvo la oportunidad de adecuar su actuación para la salvaguarda de sus legítimas expectativas.

Pero este tipo de situaciones no sólo se dan con respecto a las causas tasadas de revocación, sino también por otros factores que afectan directamente a la eficacia del pacto sucesorio. Por ello, el uso de la autonomía de la voluntad conflictual y la consiguiente modificación de la ley sucesoria puede cambiar la suerte del pacto sucesorio si tomamos la postura según la cual la nueva ley sucesoria del disponente es la que determina el régimen jurídico del mismo a partir del cambio. Pensemos en un pacto sucesorio celebrado entre una pareja de hecho en el que uno de los convivientes instituye heredero de la vivienda en la que viven al otro conviviente. En el momento del otorgamiento del pacto sucesorio el disponente tiene nacionalidad alemana y residencia habitual en Cataluña. El disponente había realizado la correspondiente professio iuris a favor de la ley de su nacionalidad, de tal forma que al pacto sucesorio se le aplica la ley alemana que implica la validez del pacto sucesorio. Ahora bien, en un momento posterior el disponente revoca la professio iuris realizada, de tal forma que su ley sucesoria pasa a estar determinada por la ley de su residencia habitual, esto es, la 
ley catalana. Tiempo después los otorgantes rompen su convivencia, dato que puede ser relevante o no para el pacto sucesorio en función de la norma que se aplique. Si se aplica el Derecho alemán, esto es, si la modificación de la autonomía de la voluntad conflictual no afecta al régimen jurídico del pacto sucesorio, la institución de heredero realizada seguirá siendo eficaz; sin embargo, si se aplica la "nueva ley sucesoria", esto es, el ordenamiento catalán, como resultado de la revocación de la professio iuris realizada, la disposición quedará sin efecto en aplicación del art. 431. 17 apartado segundo en combinación con el art. 422. 13 apartado segundo. La eficacia del pacto sucesorio dependerá de qué ley se aplica; si se sigue aplicando la ley alemana, por ser la ley hipotética sucesoria en el momento en que el pacto sucesorio se otorgó sin importar sucesivos cambios de esta ley, el pacto sucesorio será eficaz; si, por el contrario, los cambios resultados de la autonomía de la voluntad conflictual implican la aplicación de la ley catalana, la disposición realizada a favor del conviviente de hecho devendrá ineficaz por la ruptura de la convivencia. Y no sólo eso, sino que una $\mathrm{u}$ otra posibilidad queda en manos del disponente, que con una simple declaración de voluntad puede cambiar el destino del pacto sucesorio y frustrar las expectativas de la otra parte contratante.

La cuestión se hace aún más difícil de asumir en cuanto que el disponente puede modificar las veces que quiera la ley sucesoria; si tales modificaciones afectan al pacto sucesorio, significa que en cada una de esas alteraciones de la ley sucesoria el pacto sucesorio va a estar sometido a un régimen distinto (o a ningún régimen en aquellos casos en los que la ley sucesoria se corresponda con un ordenamiento jurídico que no permite los pactos sucesorios o no permite ese pacto sucesorio en concreto). A la luz de estas consecuencias y de los ejemplos analizados, no podemos sino concluir que, para un verdadero respeto de los pactos sucesorios, el régimen jurídico de estas figuras no puede ser modificado unilateralmente por el disponente; por ello, el ejercicio unilateral de la autonomía de la voluntad conflictual por parte del disponente en un momento posterior al de la celebración del pacto sucesorio no debe conllevar, ni de hecho conlleva en la disciplina del Reglamento, afectación alguna del régimen jurídico del pacto 
sucesorio. En este sentido, además, debemos aplaudir la solución que finalmente se ha acogido en el seno de la UE con el Reglamento de sucesiones.

Este estado de la cuestión es igualmente aplicable del supuesto en que haya habido una elección de ley al pacto sucesorio a través de un pacto de lege utenda, y una de las partes realice una professio iruis sucesoria con posterioridad. Sin perjuicio de que tal elección puede comprometer los efectos económicos del pacto, porque supondrá la elección de una ley sucesoria con lo que ello implica, no puede afectar a la admisibilidad, validez ni régimen jurídico del pacto, ni a la capacidad del pacto de lege utenda para decidir la ley aplicable al pacto.

Del mismo modo, hemos de advertir que el esquema se repite incluso aunque la alteración posterior de la ley sucesoria no derive directamente de la autonomía de la voluntad (derive, por ejemplo, de un cambio de residencia habitual). Introducimos aquí este análisis por la razón, no menor, de que el cambio de la ley sucesoria es más fácil a través del ejercicio de la autonomía de la voluntad conflictual del disponente, porque no es necesario que cambie ninguna circunstancia personal, basta con, por ejemplo revocar, la professio iuris efectuada, cambiarla, o hacerla ex novo.

\subsubsection{Elección de ley aplicable al pacto sucesorio a través de professio iuris o de pacto de lege utenda y realización de pacto de lege utenda posterior}

Desde el punto de vista de la admisibilidad y la validez material del pacto sucesorio, la pregunta sería, ¿pueden modificar las partes contratantes a través de su autonomía de la voluntad conflictual la admisibilidad y validez de un pacto sucesorio fijados por una ley determinada? Para contestar a esta pregunta vamos a diferenciar dos casos distintos: el primero de ellos se refiere al supuesto en el que el pacto sucesorio es admisible y nace válido y con el pacto de lege utenda posterior se pretende la inadmisibilidad y/o la invalidez del pacto sucesorio. Pensemos en el ejemplo de un pacto sucesorio de institución celebrado entre dos socios, a través del cual el disponente instituye heredero a su socio en la parte que le corresponde de la empresa; el disponente es doble nacional, alemán y español, con vecindad civil y residencia habitual en Cataluña. En el momento de 
otorgamiento del pacto sucesorio el disponente había realizado una professio iuris a favor de su ley nacional alemana, de tal forma que la ley aplicable a la admisibilidad y validez material del pacto sucesorio era la alemana, dando como resultado su admisión y su validez. La hipótesis que barajamos pasaría por que las partes decidieran en un momento posterior elegir, a través de un pacto de lege utenda, ergo estando ambas partes de acuerdo, la ley nacional española, aplicándose en concreto la ley catalana (en aplicación de la ley catalana el pacto sucesorio no sería válido, en cuanto que no se cumplen los requisitos de legitimación para otorgar pactos sucesorios, que exigen en este Derecho un determinado parentesco familiar). ¿Es posible esta elección y, en su caso, qué efecto tendría sobre la admisibilidad y validez material del pacto sucesorio?

A nuestro juicio la respuesta a la pregunta formulada se mueve entre dos polos de distinta naturaleza. Por un lado, el Reglamento es claro al fijar el momento temporal de determinación de la ley aplicable: "en la fecha de conclusión del pacto". Esta petrificación del estatuto es, además uno de los puntos clave de garantía de seguridad jurídica y estabilidad. Por otro, no ha de desconocerse que el art. 25.3 del Reglamento no está condicionado, al menos formalmente, por ese requisito temporal; además, remite al art. 22 (professio iuris) en cuanto a las "condiciones" de elección, donde, como sabemos, falta la concreción temporal.

Mas, al margen de estas consideraciones de análisis formal de la norma (la norma no prohíbe una elección de ley posterior a la celebración del pacto sucesorio ni impone que dicha elección deba ser simultánea), existen otras de corte más sustantivo. Si nos encontramos ante una decisión libre de las partes, tal decisión debe ser tratada como la propia de celebrar el pacto sucesorio. Y si parece que nadie duda de que las partes, de común acuerdo, pueden revocar bilateralmente el pacto sucesorio (es una cuestión que solo a ellas compete) no se ve por qué quien puede lo más no ha de poder lo menos. Cosa distinta es que sea difícil encontrar sentido a proceder a elegir una ley que destruye el pacto en vez de destruirlo directamente, mas no es descartable. Obviamente, el nuevo pacto de lege utenda solo afecta a la ley aplicable al pacto sucesorio: la professio iuris 
efectuada por el disponente seguirá surtiendo efectos, pero ya limitados a la determinación de su ley sucesoria.

En el segundo supuesto el pacto sucesorio es inválido y con el pacto de lege utenda se pretende validar el pacto sucesorio; para seguir con el mismo ejemplo, en este caso la professio iuris del disponente la habría hecho a favor de la ley española, Derecho catalán (que admite los pactos sucesorios de institución, pero no entre personas que no tienen parentesco alguno, por lo que el pacto sucesorio sería inválido). En un momento posterior se plantea la posibilidad de que las partes hagan un pacto de lege utenda a favor de la ley de la otra nacionalidad del disponente, la alemana y cabe preguntarse si esto es posible y qué efectos tendría en su caso.

La respuesta se habría de mover en los mismos parámetros fijados para el supuesto analizado más atrás. Ahora, si cabe, la cuestión es más clara en términos de libertad contractual: si, por hipótesis, las partes no están vinculadas por ningún pacto ¿qué les impediría realizar uno nuevo -el mismo- sometiéndolo a la ley alemana? Por pura economía contractual, ¿qué les impediría sin más someter el viejo pacto a la ley alemana? Es verdad que aquí también está el inconveniente de que realmente el viejo pacto no llegó nunca a ser válido. Pero en clave estrictamente contractual, sigue tratándose de un tema entre particulares. Por trasladar las soluciones contractuales de, por ejemplo, el Reglamento Roma I, se podría decir que las partes pueden cambiar de ley aplicable sus relaciones con algunos límites: que el contrato no se convierta en nulo por razones formales y que no se vean afectados los derechos de terceros (que en los ejemplos propuestos no existen). Es cierto, que la analogía también puede jugar en contra de esta visión: allí donde el cambio de ley aplicable por cambio de voluntad se acepta, se ha determinado expresamente (en el Reglamento Roma I), por lo que la ausencia de regla en el Reglamento de sucesiones podría interpretarse en sentido contrario, pero no creemos que deba llegar hasta ahí la analogía.

Lo mismo ocurre respecto del régimen jurídico del pacto sucesorio. En el caso de una modificación pactada, a través de un pacto de lege utenda, no debería haber impedimento alguno. En todo momento hemos defendido la necesidad de 
que desde el primer momento quede definido el régimen jurídico del pacto sucesorio en aras a la seguridad jurídica para las partes; evitar sorpresas y garantizar que cada uno de los intervinientes sepa en todo momento a qué normativa adaptar su comportamiento. Ahora bien, admitir un cambio de régimen jurídico pactado no menoscaba ninguno de estos intereses.

\subsection{Consecuencias para el pacto sucesorio del cambio de ley sucesoria por professio iuris: las relaciones entre la ley del pacto sucesorio y la ley sucesoria en términos de autonomía de la voluntad conflictual}

\subsubsection{Distinto alcance de la ley sucesoria: la tutela de todos los legitimarios versus La tutela de los legitimarios terceros al pacto}

En los epígrafes anteriores hemos tratado de analizar las posibles consecuencias que el recurso a la professio iuris o la realización de un pacto de lege utenda o la modificación de cualquiera de ellos tendrían para lo que hemos llamado ley aplicable a los pactos sucesorios: admisibilidad, validez y régimen jurídico. En el presente nos vamos a plantear las consecuencias de la posterior elección de ley aplicable a la sucesión por el causante sobre la eficacia los efectos propios de los pactos sucesorios. Se trata, como se puede apreciar, de esa relación inescindible y en ocasiones perniciosa entre ley sucesoria y ley sucesoria anticipada a la que ya nos hemos referido con anterioridad. Desde esta perspectiva, hemos de volver a significar que desde un punto de vista estructural, un análisis equivalente sería el derivado del mero cambio de ley sucesoria tras la realización del pacto, por ejemplo, por cambio en la residencia habitual del causante. A pesar de ello, el hecho de que el cambio venga dado por la unilateral voluntad de uno de los pactantes cuya sucesión está en juego llama a su tratamiento autónomo. La pregunta global que hemos de responder podría ser la siguiente: ¿qué es lo que ocurre con los pactos sucesorios desde el punto de vista de la corrección de la ley sucesoria en la determinación de los derechos legitimarios y otros análogos en el caso de que en un momento posterior a la celebración del pacto sucesorio se produzca un cambio de ley aplicable a la sucesión del o de los disponentes motivada por un ejercicio de autonomía de la voluntad conflictual? Este cambio implica la existencia potencial de dos leyes para regular una misma situación jurídica: la sucesión por causa de muerte del 
causante (cualquiera que sea ésta, paccionada, paccionada y testamentaria o paccionada e intestada). Por un lado, tendremos la ley del pacto sucesorio y, por otro lado, la ley sucesoria; se produce una tensión entre ambas leyes que suscita un problema de aplicación, cual es el de la determinación del ámbito de aplicación de cada una de ellas. Obviamente, también pudiera ocurrir que el cambio fuese en la dirección de unificar ambas leyes: la ley del pacto sucesorio (elegida) no coincidía con la ley sucesoria anticipada, y la professio iuris posterior tiende a que coincidan. Mas esta hipótesis queda fuera del presente análisis.

El punto de partida conocido es que la ley del pacto sucesorio es la que determina tanto la admisibilidad y validez material como el régimen jurídico del pacto sucesorio (contenido, régimen de modificación y extinción del pacto sucesorio). En este escenario, la ley sucesoria va a tener una presencia no sólo como solución subsidiaria para los casos en que el otorgamiento del pacto sucesorio no agote la sucesión del causante, sino también porque es común que la protección de los derechos legitimarios y otros derechos análogos de determinados parientes próximos al causante puedan tener sobre la sucesión de éste, se determinen por la ley sucesoria. Dicho de otro modo, con independencia de las dudas que plantea el ámbito de aplicación de la ley del pacto sucesorio y la ley sucesoria, lo cierto es que en todo caso la ley sucesoria va a tener una presencia para determinar los derechos legitimarios y otros análogos ${ }^{449}$. Este es un principio general asumido en Derecho comparado, es la solución de nuestro art. 9.8 CC y es la solución que recoge el Reglamento (art. 23.2 h). Traducido todo esto a los pactos sucesorios significa que la ordenación realizada a través de un pacto sucesorio siempre puede sufrir una potencial corrección por una ley sucesoria distinta en lo que se refiere a los derechos legitimarios u otros de análoga naturaleza ${ }^{450}$.

\footnotetext{
${ }^{449}$ La cuestión de los ámbitos de aplicación se complica aún más a la hora de profundizar en qué se entiende por legítimas, pues puede significar únicamente la cuantía, o también la forma de pago, el carácter de la legítima pars valoris o pars bonorum, o la desheredación u otras instituciones como la mejora...).

${ }^{450}$ Decimos que el pacto sucesorio está sometido a una corrección potencial de la ley sucesoria porque esta corrección sólo va a tener lugar en aquellos casos en los que el pacto sucesorio no respete las legítimas y demás derechos análogos que determine la ley sucesoria.
} 
Tratándose de la protección de los derechos legitimarios y otros análogos frente a las disposiciones de un pacto sucesorio se distinguen dos sistemas distintos de salvaguarda, que se diferencian en el alcance de las correcciones que realiza la ley sucesoria. Una de estas formas es la delimitación de la protección de derechos legitimarios y otros análogos a terceros ajenos al pacto sucesorio; esto es, la ley sucesoria sólo determinaría las legítimas y derechos análogos de personas que no hayan participado en el pacto sucesorio. Este es el alcance de la corrección de la ley sucesoria que se previó en el Convenio de La Haya de 1989 (en concreto, en su art. 12.2) y en la Propuesta de Reglamento (en el art. 18.4). La otra forma consiste en una remisión integral al sistema legitimario de la ley sucesoria, sin distinguir entre terceros ajenos al pacto sucesorio y los propios otorgantes del mismo; esta sería la solución del art. 9.8 CC o la que parece que finalmente ha acogido el Reglamento de sucesiones.

Determinar el alcance de esta protección exige hacer previamente dos consideraciones. En primer lugar, es de destacar que la diferencia entre uno y otro sistema de protección de los derechos legitimarios y otros análogos es relevante fundamentalmente para los pactos de renuncia. Es en este tipo de pactos donde la limitación de la salvaguarda a terceros ajenos al pacto sucesorio tiene mayor sentido y, por tanto, donde la extensión de la salvaguarda igualmente a los otorgantes es ciertamente perjudicial para el pacto sucesorio. Veamos las diferencias con un ejemplo. Un padre de nacionalidad española y residencia habitual en Lausana realiza un pacto de renuncia con su hijo, a través del cual éste renuncia a todo derecho legitimario que le pueda corresponder en la herencia de su padre, recibiendo a cambio una serie de bienes que le son adjudicados. En el momento del otorgamiento del pacto sucesorio el padre no ha ejercitado professio iuris alguna, de tal forma que su ley sucesoria anticipada viene determinada por la residencia habitual que ostenta en el momento del otorgamiento del pacto. La ley aplicable al pacto sucesorio es, por tanto, la ley suiza. En un momento posterior, el padre realiza una professio iuris a favor de su ley nacional y la ley sucesoria pasa a ser la ley española, en concreto el CC correspondiente a la ley de su vecindad civil común. La suerte del pacto sucesorio será muy distinta en función de que el sistema a aplicar limite la salvaguarda a terceros ajenos al pacto 
sucesorio o la extienda también a los otorgantes. En el primer caso, el pacto sucesorio se vería cumplido, pues al fallecimiento del causante el hijo no podría reclamar nada. Sin embargo, en el segundo caso, si la protección de los legitimarios se extiende también a los otorgantes, el renunciante podrá ampararse en lo que disponga la ley sucesoria. Según esta ley, el CC en el ejemplo, el hijo del causante es un legitimario y tiene derecho a dos tercios de la herencia de su padre (art. $808 \mathrm{CC}$ ). El resultado de la aplicación de la ley sucesoria a la determinación de las legítimas supone echar por tierra lo dispuesto en el pacto sucesorio, porque al amparo de dicha ley el renunciante seguiría siendo legitimario y podría exigir los dos tercios de la herencia de su padre, con independencia del funcionamiento de los mecanismos correspondientes de corrección para el cómputo de lo que hubiera recibido a través del pacto de renuncia $^{451}$.

En segundo lugar, respecto de los pactos de institución las posibles diferencias en cuanto a la frustración o no del pacto sucesorio entre la aplicación de uno u otro sistema de salvaguarda son, como vamos a ver, más discutibles. Pensemos ahora en el caso de un pacto sucesorio positivo a través del cual un cónyuge instituye heredero al otro cónyuge atribuyéndole una cuota hereditaria del $20 \%$. En el momento del otorgamiento el causante tiene nacionalidad austriaca y residencia habitual en París. El disponente había realizado una professio iuris a favor de su ley nacional, de tal forma que en el momento del otorgamiento del pacto sucesorio su ley hipotética sucesoria es la ley austriaca. Tiempo después del otorgamiento del pacto sucesorio el causante revoca la professio iuris realizada, pasando a regirse su sucesión por la ley de su última residencia habitual, por hipótesis, la ley francesa. Según esta ley, el cónyuge viudo tiene derecho a un cuarto de la herencia, esto es, un $5 \%$ más de lo que recibe a través del pacto sucesorio. En los casos como este, no hay estrictamente una afectación del pacto

\footnotetext{
451 A este respecto ha habido interpretaciones que salvan esta posibilidad de frustrar el pacto sucesorio por parte del renunciante al entender que éste, con independencia de lo que diga la ley sucesoria, no es legitimario en el momento de la apertura de la sucesión de causante; esto es, desde el momento que realiza el pacto sucesorio pierde la condición de legitimario y se le trata como si no existiera en el momento de la apertura de la sucesión del causante; vid. en este sentido, A. DíAZ FUENTES (1997), p. 261; M.P. GARCÍA RUBiO (2000), p. 1430.
} 
sucesorio con ocasión de la modificación de la ley sucesoria, pues lo previsto en el pacto sucesorio se va a cumplir, en cuanto que el cónyuge instituido va a recibir esa cuota del $20 \%$; la reclamación del $5 \%$ restante para el cumplimiento de la legítima de la ley sucesoria no afecta en sentido estricto al pacto sucesorio.

No obstante, existe también otra interpretación a considerar, según la cual el pacto sucesorio se ve igualmente frustrado cuando el instituido recibe más de lo previsto. Ahora bien, en un caso como este sí habría diferencia entre los sistemas que limitan la salvaguarda de los derechos legitimarios y otros análogos a los terceros ajenos al pacto sucesorio y los que extienden tal protección también a los otorgantes del pacto sucesorio. En el primero de los casos, esto es, si sólo los terceros ajenos al pacto sucesorio pueden invocar la ley sucesoria para hacer efectivos los derechos que sobre la sucesión del causante tal ley les otorgue, el pacto sucesorio no se vería afectado, puesto que el cónyuge instituido, como parte otorgante del pacto sucesorio, no estaría amparado por tal salvaguarda. En el caso, sin embargo, de que el sistema permita también a los otorgantes invocar la ley sucesoria para reclamar sus derechos legitimarios, el cónyuge instituido podría exigir ese $5 \%$ de diferencia entre lo recibido por el pacto sucesorio y lo que le corresponde en concepto de legítima. Desde este punto de vista, los sistemas que limitan la protección de los derechos legitimarios y otros análogos a terceros ajenos al pacto sucesorio son más respetuosos con la forma paccionada de organizar la sucesión, al ajustarse lo recibido por el instituido a lo dispuesto en el pacto sucesorio.

\subsubsection{Consecuencias del ejercicio de la professio iuris tras la conclusión del pacto}

\subsubsection{Planteamiento}

Visto el funcionamiento de la corrección de la ley sucesoria a los pactos sucesorios en lo que se refiere a la protección de los derechos legitimarios, de terceros ajenos al pacto sucesorio o de cualquier legitimario sin distinción, procederemos a analizar el funcionamiento de esta corrección que tiene lugar por un cambio de la ley sucesoria motivado por el ejercicio de la autonomía de la voluntad conflictual. Hemos visto que tratándose de pactos sucesorios hay dos 
vías diferentes para el ejercicio de la autonomía conflictual del futuro causante o disponente: la vía bilateral, a través de un pacto de lege utenda, y la vía unilateral, a través de una professio iuris. La hipótesis que ahora nos planteamos es únicamente la de ejercicio posterior al pacto de una professio iuris, pues de lo que se trata es de la determinación de la ley sucesoria y no de la determinación de una ley aplicable al propio pacto sucesorio. La elección de ley sucesoria se configura siempre como una facultad unilateral en manos del causante; así es como se prevé en el Reglamento (art. 22); en consecuencia, como ya hemos visto, no cabría pensar en un pacto de lege utenda para elegir la ley aplicable a la sucesión del disponente.

En esta hipótesis, podemos distinguir tres supuestos de hecho que determinan un cambio de ley sucesoria sin el menor esfuerzo por parte del causante y en el que la autonomía de la voluntad conflictual ya es en sí misma conflictiva: en el primero de los supuestos el disponente no ha realizado professio iuris alguna en el momento del otorgamiento de pacto sucesorio, de tal forma que la ley del pacto sucesorio viene determinada por la conexión objetiva, la residencia habitual del causante en la fecha de conclusión del pacto u otra ley más estrechamente vinculada. En un momento posterior el causante realiza una professio iuris y la ley sucesoria pasa a ser la ley de su nacionalidad o una de sus nacionalidades. El segundo caso es aquel en el que en el momento de la celebración del pacto sucesorio el disponente realiza una professio iuris, de tal forma que el pacto se regula por la ley de su nacionalidad; en un momento posterior, el causante realiza simplemente una revocación de la professio iuris, de tal forma que la ley sucesoria pasa a ser la ley de su última residencia habitual $u$ otra más estrechamente vinculada. El último caso es aquel en el que el disponente tiene doble nacionalidad; pudiendo elegir cualquiera de las leyes correspondientes a su nacionalidad, primero escoge la ley de una de sus nacionalidades, que va a ser la que va a regir el pacto sucesorio, y en un momento posterior hace una modificación de la professio iuris a favor de la ley correspondiente a su otra nacionalidad, de tal forma que esta segunda ley será la que rija su sucesión. 
Como se puede apreciar, en ninguno de estos tres casos es necesario un cambio de las circunstancias personales del disponente para que cambie la ley sucesoria. Esta afirmación tiene en el caso de los pactos sucesorios una interesante lectura: desde la posición del co-otorgante del pacto sucesorio el cambio de la ley sucesoria es más visible en el caso de que venga motivada por un cambio de las circunstancias personales del disponente (cambio de residencia habitual), que en el caso de que sea el resultado de una mera declaración de voluntad. Digamos que ese otro cambio manifestado a través de un cambio externo y perceptible por todos, podría alertarle de una eventual afectación del pacto. La professio iuris posterior no. Aunque a la vista de la corrección que la ley sucesoria puede hacer en términos de determinación de los derechos legitimarios y otros derechos análogos, la posición del co-otorgante es siempre una posición de incertidumbre y de, en definitiva, inseguridad jurídica, pero cuando el cambio puede venir dado por la mera voluntad unilateral del causante, más.

\subsubsection{Professio iuris sin ánimo de afectación del pacto}

El ejercicio de la professio iuris es un derecho que obedece a la tutela de legítimos intereses y que de forma legítima puede ejercitarse, incluso aunque con ello se afecte a un pacto sucesorio previo. Sin embargo el hecho de que el cambio de ley sucesoria por esta vía no sea tan notorio, podría suscitar un pequeño apunte desde el punto de vista de la publicidad y la información. Resulta evidente que a diferencia de lo que puede ocurrir con un cambio de ley sucesoria por cambio de residencia habitual, la realización de una professio iuris o una revocación o modificación de la professio iuris anteriormente realizada se dirige, exclusivamente, a la determinación de la ley sucesoria. El causante es plenamente consciente. Se trata de un acto dirigido a un fin. No cabe imaginar que el causante no sabe que está afectando directamente a su sucesión, incluyendo los testamentos que haya efectuado, en su caso, los que pueda efectuar y el pacto sucesorio que ahora nos ocupa. Quizá esta ignorancia sí se dé en el caso de un cambio de residencia habitual, pero no cuando se realiza una professio iuris

Desde este punto de vista, creemos que de lege ferenda habría que plantearse si el disponente que ha otorgado un pacto sucesorio y con posterioridad 
cambia su ley sucesoria debiera informar al otro otorgante con el que celebró el pacto sucesorio. Esto tiene que ver con un principio general de los contratos, cual es su eventual modificación ante la modificación de las circunstancias relevantes que determinaron su conclusión, cuando la base del negocio desaparece y se produce un desequilibrio importante en las prestaciones. La vieja regla rebus sic stantibus no debería descartarse. Y lo que cabe aquí preguntarse es si hay que esperar al fallecimiento del otorgante o si debería instaurarse el deber de comunicación para, en su caso, hacer valer el cambio. En términos de ley aplicable estas posibles consecuencias sobre el pacto de la professio iuris vendrían determinadas por la ley aplicable al propio pacto sucesorio.

Consecuencias concretas del cambio de ley sucesoria las describimos con ilustrativos ejemplos en el epígrafe siguiente, en el que introducimos la nota de intencionalidad en la afectación del pacto sucesorio.

\subsubsection{Professio iuris con ánimo de afectación del pacto}

\subsection{Hipótesis posibles}

Una segunda perspectiva de esta misma hipótesis es que a través del juego de la autonomía de la voluntad conflictual unilateral el resultado del pacto sucesorio quede en manos del disponente que puede decidir afectar directamente al alcance de lo pactado mediante una ulterior professio iuris. La plasmación de esta voluntad de afectación dependerá de las opciones de cambio que tenga el causante, esto es, de sus circunstancias personales y de lo que dispongan las leyes correspondientes a tales circunstancias del causante, en concreto, su residencia habitual y su o sus nacionalidades. Para analizar esta posibilidad partiremos de varias situaciones de hecho que afecten a distintas clases de pactos sucesorios, lo que nos permitirá ver en cada caso si es posible y en qué medida puede el disponente o futuro causante frustrar las expectativas creadas por el pacto sucesorio.

En primer lugar, hay que referirse a aquellos tipos de pactos en los que no es posible perjudicar al otro otorgante mediante una elección posterior de ley sucesoria. El primer supuesto de hecho va a tratar de un pacto sucesorio de 
renuncia. Aprovechamos el pacto de renuncia del que nos hemos servido para diferenciar entre los sistemas que limitan la salvaguarda de los derechos legitimarios a terceros ajenos al pacto sucesorio y aquellos otros sistemas que la extienden a cualquier legitimario. Habíamos dicho que en el momento del otorgamiento del pacto sucesorio el futuro causante tenía residencia habitual en Lausana y nacionalidad española y no había realizado professio iuris alguna, por lo que se aplica a la validez material del pacto sucesorio la ley suiza. Según la ley suiza el hijo tiene derecho a una cuota de tres cuartos de la herencia de su padre, a las que renuncia el hijo a cambio de una serie de bienes que le son adjudicados. En un momento posterior al otorgamiento del pacto de renuncia el futuro causante ejercita una professio iuris a favor de su ley nacional, pasando a ser su ley sucesoria el CC español. Pues bien, como habíamos visto, se abre la posibilidad de que, bajo aquellos sistemas en los que la protección de los derechos legitimarios se extiende también a los otorgantes del pacto sucesorio, el que ha renunciado a sus derechos sobre la herencia del futuro causante puede finalmente reclamar los derechos que sobre la sucesión de su padre la reconoce el CC; en concreto, el art. 808 CC prevé una cuota legitimaria a favor del hijo correspondiente a las dos terceras partes de la herencia del causante. Ahora bien, desde el punto de vista que estamos analizando ahora la situación, esto es, la posibilidad de que el futuro causante perjudique al renunciante con el cambio de ley sucesoria, debemos decir que en los casos de los pactos de renuncia no hay posibilidad de frustración para el renunciante, aunque sí al pacto sucesorio. El renunciante, en todo caso, con el cambio de ley sucesoria lo que podrá es verse beneficiado, pues en los casos en que recibió menos por el pacto de renuncia que lo que le correspondería de conformidad con la ley sucesoria está en su mano reclamar la legítima que se establece a su favor ${ }^{452}$. Para el caso de que la ley sucesoria prevea una cuota legitimaria que le dé derecho a menos de lo que ha recibido por el pacto sucesorio, el renunciante simplemente podrá dejar las cosas como están y no reclamar derecho legitimario alguno. Partimos, recordémoslo, de

\footnotetext{
${ }^{452}$ En este caso el pacto sucesorio se verá frustrado, puesto que lo dispuesto en el mismo quedará en papel mojado; pero no se verán dañadas expectativas algunas del renunciante.
} 
la solución del Reglamento que salva los derechos de todo tipo de legitimario, pactante o tercero.

Existe un segundo de los tipos de pactos sucesorios en los que no todas las expectativas personales se ven frustradas: los pactos sucesorios de institución a favor de tercero. En este tipo de pactos sucesorios dos personas, el disponente y un co-otorgante, acuerdan una institución de heredero o legatario a favor de una tercera persona, que no participa en el pacto sucesorio. En este tipo de pactos sucesorios el beneficiario, al no ser otorgante del pacto sucesorio, tiene una posición muy débil, incluso idéntica a la posición de aquel que es instituido a través de testamento. Por ello, no podemos hablar de la posibilidad de que el disponente frustre las expectativas de ese tercero beneficiario a través del ejercicio de la autonomía de la voluntad conflictual unilateral. No obstante, el cambio de ley sucesoria y con ello la potencial afectación de los derechos sucesorios de ese tercero sí frustra las expectativas del co-otorgante.

De forma muy clara, las situaciones de potencial frustración típica del pacto mediante el cambio de ley sucesoria afectan a los pactos de institución a favor del otro otorgante. Tratándose de pactos que afectan a una única sucesión, en los que el otro otorgante es instituido contractualmente, la cuestión no está exenta de polémica, pues la posibilidad de frustrar o no las legítimas expectativas del otorgante instituido dependerá de la posición jurídica que entendamos que tiene esta persona. Ya hemos visto cómo la doctrina no se pone de acuerdo sobre esta cuestión: hay autores que defienden que el instituido otorgante del pacto sucesorio adquiere verdaderos derechos, mientras que otros entienden que ni siquiera tiene una simple expectativa jurídica al mantener el disponente en todo caso su capacidad de disposición inter vivos. Ahora bien, por un lado, lo cierto es que una vez otorgado el pacto sucesorio se crea en el instituido otorgante una confianza en lo dispuesto por el pacto sucesorio. Por otro lado, incluso partiendo de la peor de las situaciones posibles del instituido otorgante, es decir, aquella en la que se entiende que ni si quiera tiene una mera expectativa jurídica, no se puede perder de vista que el disponente a través de ese ejercicio de la autonomía de la 
voluntad conflictual unilateral que da lugar al cambio de ley sucesoria está modificando disposiciones mortis causa.

Aquellos que defienden una posición débil del otorgante instituido se basan en el dato de que el disponente, cuando otorga un pacto sucesorio, se vincula o limita sus facultades únicamente mortis causa, pero nada le impide seguir disponiendo de sus bienes inter vivos. Desde este punto de vista, entienden estos autores que el otorgante instituido no tiene derecho a nada, ni siquiera una expectativa jurídica, puesto que es posible que el disponente realice negocios jurídicos inter vivos que dejen sin contenido lo dispuesto en el pacto sucesorio. Sin embargo, como decíamos antes, el disponente, a través de esta facultad de elección de ley sucesoria, no está realizando disposiciones inter vivos, sino que en realidad puede realizar de forma indirecta, esto es, a través de la corrección que la ley sucesoria realiza al pacto sucesorio en términos de protección de los derechos legitimarios, y en mayor o menor medida, dependiendo de lo que disponga la ley sucesoria, disposiciones mortis causa que contraríen lo dispuesto en el pacto sucesorio. Dicho esto, pongamos un ejemplo de cómo el otorgante instituido a través del pacto sucesorio puede ver sus expectativas frustradas con la modificación realizada unilateralmente por el disponente. Pensemos en un pacto sucesorio a través del cual el disponente instituye heredero a su socio. El causante tiene nacionalidad suiza y residencia habitual en Munich. El disponente no había realizado professio iuris alguna a favor de su ley nacional, por lo que el pacto sucesorio se rige por la ley de la residencia habitual del disponente en el momento del otorgamiento, esto es, la ley alemana. Siguiendo las prescripciones del ordenamiento jurídico alemán en materia de Derecho de sucesiones, el causante realizó la institución de heredero a favor de su socio por un valor correspondiente a la mitad de la herencia, cuota correspondiente a la parte de libre disposición del causante al tener éste un hijo ${ }^{453}$. No obstante, en un momento posterior, el

\footnotetext{
${ }^{453} \mathrm{El} \S 2303 \mathrm{BGB}$ no dispone directamente que a los descendientes les corresponda la mitad del caudal relicto en concepto de legítima, sino la mitad de la herencia legal; la herencia legal está determinada en los § 1924 - 1931 BGB, preceptos que vienen a determinar las combinaciones de herederos cuando concurre o no cónyuge supérstite. En el caso prescindiremos de cónyuge supérstite, de tal forma que el único legitimario será el descendiente y, por tanto, tendrá derecho a la mitad del caudal relicto de la herencia.
} 
disponente realiza una professio iuris a favor de su ley nacional, de tal forma que la ley sucesoria es la ley de su nacionalidad en el momento del fallecimiento, esto es, la ley suiza. Bajo lo que determine la ley suiza se realizarán, en su caso, las correcciones oportunas al pacto sucesorio para salvaguardar los derechos de legitimarios. Esta ley establece una cuota legitimaria de tres cuartos de la herencia a favor del hijo del causante ${ }^{454}$. En este caso, sí cabría corrección de la ley sucesoria a lo dispuesto en el pacto sucesorio. Si presuponemos que el pacto sucesorio se realizó observando las disposiciones del Derecho de sucesiones alemán, habíamos visto que al tener un hijo, la cuota de libre disposición del causante era de la mitad del caudal hereditario. Sin embargo, al aplicarse la ley sucesoria, la ley suiza, a la determinación de las legítimas, la cuota legitimaria a favor del hijo va a ser más alta, tres cuartos de la herencia, y, por tanto, lo dispuesto en el pacto sucesorio a favor del socio del disponente será corregido hasta que el hijo reciba esas tres cuartas partes del caudal hereditario. En este caso, el efecto del cambio de ley posterior a la celebración del pacto sucesorio, implica que el instituido va a recibir menos de lo previsto en dicho pacto; o dicho de otro modo, a través de este cambio queda en manos del disponente la posibilidad de modificar el resultado de la ordenación realizada a través del pacto sucesorio a favor de su socio. No necesita recordarse que esta posibilidad es mayor cuanto más altas sean las cuotas legitimarias de la ley sucesoria.

Esta posibilidad de frustrar el pacto sucesorio y defraudar la posición del otorgante instituido de forma unilateral por parte del disponente se ve aún más claramente en aquellos tipos de pactos sucesorios en los que existe una entrega de bienes de presente. En este tipo de pactos sucesorios el otorgante instituido tiene una posición jurídica más sólida que en los vistos anteriormente, pues la entrega de bienes estipulada supone el traspaso del derecho de propiedad al instituido directamente desde el momento del otorgamiento del pacto sucesorio, dejándose en su caso, los bienes que se haya podido reservar el disponente y aquellos otros residuales para su adquisición por parte del instituido en el momento del fallecimiento. Esta clase de pactos sucesorios están previstos en varios de los

\footnotetext{
${ }^{454}$ Según el art. 471 del CC suizo la reserva hereditaria correspondiente a los descendientes del causante asciende a una cuota de tres cuartos.
} 
Derechos civiles autonómicos españoles, tales como Cataluña, Aragón, Navarra o el Derecho mallorquín ${ }^{455}$. Esta posición más sólida, sin embargo, no le hace inmune a la decisión del disponente de cambiar la ley sucesoria mediante una professio iuris posterior al pacto. Un nuevo ejemplo nos ilustrará.

Dos amigos celebran un pacto de institución, a través del cual uno instituye heredero al otro en el único bien valioso que tiene, un piso en Pamplona, donde el disponente, de nacionalidad francesa, tiene su residencia habitual. En dicho pacto sucesorio se acuerda la institución de heredero universal del otro otorgante y se estipula una entrega de bienes de presente que afecta al piso, de tal forma que dicho inmueble pasa a ser propiedad del instituido desde que el pacto sucesorio es otorgado. A cambio se establece la obligación de convivencia de ambos otorgantes en el inmueble, teniendo el instituido que encargarse de los cuidados y demás atenciones del disponente hasta el momento del fallecimiento. En el momento del otorgamiento del pacto sucesorio el disponente no ha realizado professio iuris alguna, por lo que el pacto sucesorio se regulará por la ley de su residencia habitual en el momento del otorgamiento del pacto sucesorio, esto es, el Derecho navarro. El disponente tiene dos descendientes, pero la planificación realizada en el pacto sucesorio se ajusta a las exigencias del Derecho navarro que prevé una gran libertad de disposición mortis causa ${ }^{456}$. En un momento posterior al de la celebración del pacto sucesorio el disponente realiza una professio iuris a favor de su ley nacional, pasando a ser la ley rectora de su sucesión la ley francesa. A través de este cambio el disponente puede modificar el resultado del pacto sucesorio realizado frustrando, ya no expectativas del otro otorgante, sino derechos ya adquiridos. La corrección de la ley sucesoria al pacto sucesorio en términos de salvaguarda de los derechos legitimarios, permitirá a los

\footnotetext{
${ }^{455}$ Debemos señalar que sobre este tipo de pactos sucesorios que incluyen una entrega de bienes de presente se ha planteado la duda entre la doctrina civilista de si se trata de un único negocio jurídico, el pacto sucesorio que es la causa de la entrega de bienes de presente y, en su caso, de los bienes residuales una vez fallecido el instituido, o si se trata de un pacto sucesorio con una donación, caso en el que ya no cabría el planteamiento que ahora realizamos. A favor de la consideración de esta situación jurídica como un solo negocio jurídico, esto es, como un pacto sucesorio, J. EGEA FERNÁNDEZ (2009), p. 29, respecto de los heredamientos cumulativos del Derecho catalán; también, M.P. FERRER VANRELL (libro cat), p. 447, cuando habla del doble título, el de donatario y el de heredero, que se deriva de la donación universal mallorquina.

${ }^{456}$ Ley 267 de la Compilación Derecho Civil Foral de Navarra.
} 
descendientes del causante exigir la cuota legitimaria prevista a su favor en el Derecho sucesorio francés. El CC francés prevé, para el caso de que el causante deje dos descendientes, una cuota de libre disposición correspondiente a un tercio (art. 913 CC francés), de tal forma que se les reserva a ambos descendientes las tres cuartas partes de la herencia de su padre ${ }^{457}$.

En definitiva, a través de una simple declaración de voluntad unilateral el disponente puede frustrar el pacto sucesorio y los derechos adquiridos a través del mismo por el instituido, pues con la reclamación de los descendientes se tendrán que realizar los ajustes necesarios para que estos reciban las tres cuartas partes de la herencia del causante, pasando el instituido de recibir toda la herencia a recibir únicamente un cuarto de la misma. En el ejemplo que hemos puesto se ve claramente el peligro de esta vía de escape en manos del disponente, máxime cuando además el instituido había cumplido su compromiso de establecer su residencia en el inmueble objeto del pacto sucesorio y de proporcionar los cuidados pertinentes al causante hasta el momento del fallecimiento.

Otro tipo de pactos sucesorios en los que también es posible pensar en una vía de escape en manos del disponente para la modificación unilateral del pacto sucesorio al que está vinculado son los pactos sucesorios de institución recíproca. Dos cónyuges realizan un pacto sucesorio en el que se instituyen herederos recíprocamente. Uno de los cónyuges es nacional alemán y el otro nacional suizo, pero ambos tienen residencia habitual en Austria. Uno de los cónyuges, el que tiene nacionalidad suiza, tiene además un descendiente. En el momento del otorgamiento de pacto sucesorio ninguno de los cónyuges había realizado elección de ley sucesoria alguna, de tal forma que las leyes sucesorias anticipadas corresponden a la residencia habitual de los disponentes, esto es, en ambos casos, la ley austriaca. La aplicación de esta ley determina la validez del pacto sucesorio, de conformidad con el $\S 364$ c) AGBG. En un momento posterior al de la celebración del pacto sucesorio, el cónyuge suizo realiza una professio iuris a favor de su ley nacional, pasando a ser la ley suiza su ley sucesoria. Con

\footnotetext{
${ }^{457}$ Vid. arts. 917 y ss. del CC francés, sobre las reservas, la libertad de disposición y al reducción de las liberalidades.
} 
este cambio se va a producir el siguiente efecto: el pacto sucesorio es de institución recíproca, lo cual significa que las disposiciones en él realizadas por cada uno de los disponentes tienen unas su causa en las otras y viceversa. Con el cambio de ley sucesoria realizado por el cónyuge de nacionalidad suiza, la corrección que en términos de salvaguarda de legítimas realiza la ley sucesoria va a determinar que en el caso de que el cónyuge suizo fallezca antes que el cónyuge alemán, éste prácticamente no recibirá nada de lo dispuesto por el pacto sucesorio; mientras que en el caso de que el cónyuge alemán fallezca primero que el cónyuge suizo, éste recibirá todo lo ordenado en el pacto sucesorio. La reciprocidad del pacto sucesorio se rompe con esta posibilidad, y con ella su razón económica.

A estos ejemplos basados en pactos típicos y simples, podemos sumar otros donde la complejidad aparece. Habíamos dicho que tratándose de pactos sucesorios de renuncia el cambio de ley sucesoria consecuencia de un ejercicio unilateral de la autonomía de la voluntad conflictual del futuro causante no perjudica en nada al otorgante renunciante. Ahora bien, la realidad es más compleja y los pactos sucesorios pueden serlo también, entrelazándose distintas disposiciones y distintas clases de pactos sucesorios en un mismo acto y con el único fin de organizar la sucesión el causante. Pensemos en el supuesto de hecho en el que el futuro causante realiza un pacto sucesorio de renuncia con su hijo, a través del cual éste renuncia a su legítima recibiendo a cambio una serie de bienes que le son adjudicados en ese mismo momento; por otro lado, el mismo causante realiza un pacto de institución por el que instituye heredera universal del conjunto de su sucesión a su cónyuge. Ambos pactos sucesorios son otorgados con el fin de que el cónyuge del causante reciba todo el patrimonio de éste a su fallecimiento. En el momento del otorgamiento del pacto sucesorio el causante tiene residencia habitual en Alemania y nacionalidad española (con una vinculación de vecindad civil común). La ley aplicable a ambos pactos sucesorios es la alemana, a título de ley de la residencia habitual del causante en el momento del otorgamiento de los mismos, al no haber realizado el causante elección de ley alguna. Sin embargo, en un momento posterior a la celebración de los pactos sucesorios, el causante realiza una professio iuris a favor de su ley nacional, siendo la ley sucesoria el CC español. Este CC determina que el hijo es legitimario del causante y que tiene 
derecho a una cuota correspondiente a los dos tercios de la herencia de éste. En este caso, si el hijo, al amparo de la ley sucesoria, exige la cuota legitimaria prevista en el CC, se frustrarían los dos pactos sucesorios. Por un lado, el pacto de renuncia quedaría sin contenido, al ser finalmente el hijo un efectivo legitimario del causante y reclamar la parte que le corresponde según la ley sucesoria; por otro lado, porque esta reclamación que realiza el hijo va a afectar al otro pacto sucesorio, en el que se instituye heredera a la cónyuge del causante para el conjunto de la sucesión. Este último pacto sucesorio sufrirá las correcciones correspondientes hasta cubrir la legítima de los dos tercios prevista para los hijos.

\subsection{Posibles remedios}

En el análisis de estos casos hemos visto varios ejemplos en los que el destino del pacto sucesorio queda en manos del disponente, que puede modificarlo, en mayor o menor medida, con una posterior professio iuris, pudiendo frustrar no sólo el propio pacto sucesorio, sino expectativas jurídicas e incluso verdaderos derechos adquiridos por el otorgante instituido. Ante tales circunstancias procede plantearnos hasta qué punto es asumible esta vía de escape en manos del disponente $\mathrm{y}$, en su caso, proponer posibles soluciones a esta situación. Ningún sistema articulado, hasta la fecha, toma nota de estas situaciones y, más aún, la autonomía conflictual se configura como un pilar difícilmente reductible. Los remedios que se proponen son pues de lege ferenda.

En primer lugar cabría plantearse la opción de establecer determinados límites a esa libertad de elección que tiene en el causante tras el otorgamiento del pacto sucesorio. Ya con anterioridad hemos hecho alusión a una visión de las reglas del Reglamento Roma I, cuando analizamos las posibilidades de una modificación del pacto de lege utenda. Allí dejamos el tema no del todo cerrado, aunque abogando positivamente por la posibilidad de cambio, y aquí tenemos que hacer algunas matizaciones que no permitirían trasladar sin más el sistema contractual.

En primer lugar, la problemática que venimos analizando en este epígrafe no trata de una modificación de la ley aplicable al pacto, lo que sería más análogo 
a lo previsto en el art. 3.2. del Reglamento Roma I, sino de una modificación de la ley sucesoria del disponente o futuro causante que regula otros aspectos, en concreto la protección de los derechos de legitimarios y otros análogos, que puede en su caso afectar al contenido del pacto sucesorio. En definitiva, no se trata de un cambio dirigido directamente al pacto sucesorio, sino un cambio que puede indirectamente tener repercusiones sobre el pacto sucesorio.

En segundo lugar, el cambio de la ley sucesoria en un momento posterior al de la celebración del pacto sucesorio no está concertado por los otorgantes, como ocurre en las obligaciones contractuales que son las partes contratantes las que acuerdan esa modificación de la ley aplicable, sino que tal cambio se produce como consecuencia de un acto unilateral de una de las partes otorgantes, el disponente o futuro causante. La elección de ley sucesoria siempre se ha concebido como una facultad unilateral en manos del causante.

En tercer lugar, como hemos podido ver al analizar los diferentes ejemplos de pactos sucesorios, tampoco se trataría, en la mayor parte de los casos, de una protección de derechos adquiridos por terceros. Se trata en realidad de una protección del pacto sucesorio y de la confianza de la parte contratante; en especial, de aquellos que son otorgantes y que han sido instituidos en el pacto sucesorio. Es necesario además tener en cuenta aquí la polémica doctrinal en torno a la posición jurídica del otorgante instituido; lo cierto es que sólo cierta clase de pactos sucesorios, aquellos que prevén una entrega de bienes de presente, otorgan derechos al instituido desde el mismo momento de la celebración del pacto sucesorio.

En todo caso, que no exista un paralelismo o una equivalencia entre los supuestos que analizamos y los previstos por el Reglamento Roma I, no significa que otro tipo de limitación de la autonomía de la voluntad no pueda ser introducida para estos supuestos. Piénsese que, por ejemplo, el co-otorgante que se ve perjudicado por la posterior professio iuris del otro, es en realidad un tercero en esa professio (no es un tercero contratante, pero sí puede estimarse que lo es frente al negocio de la professio iuris) y que, en algunos supuestos, si puede ver frustrados sus derechos. 
Existen, al margen de este replanteamiento de la libertad de elección de ley tras la celebración de un pacto sucesorio, otras alternativas de menor entidad. Nos estamos refiriendo a la posibilidad de establecer como condición a esa modificación de la ley sucesoria un deber de información, al que también nos referimos con anterioridad. Es decir, en los casos en los que el causante ha celebrado un pacto sucesorio, debería informar al otro otorgante de sucesivos cambios de ley sucesoria, de tal forma que éste se pueda atener a las consecuencias de dicho cambio. Esta medida daría una mayor seguridad al otorgante instituido, puesto que podría conocer y adaptarse a las consecuencias del cambio de ley sucesoria, en lo que se refiere a la posible afectación del pacto sucesorio por la protección de derechos de legitimarios y análogos. Ahora bien, esta medida de menor entidad no es, a nuestro juicio, suficiente para salvaguardar los pactos sucesorios, pues la posibilidad de cambiar la ley sucesoria de forma unilateral va a poder seguir siendo una vía de escape del pacto sucesorio en manos del disponente o futuro causante, de tal forma que la seguridad que caracteriza a los pactos sucesorios desde el punto de vista del instituido, y a diferencia del instituido a través de un testamento, no se da en la práctica. El otorgante instituido siempre estará a expensas de los libres cambios de ley sucesoria realizados por el disponente o futuro causante, y de los consiguientes sistemas legitimarios que, en su caso, puedan afectar a las adquisiciones que a su favor se pudieran prever en el pacto sucesorio. Ciertamente no es lo mismo que esté al corriente del cambio que que no lo esté. Por ejemplo, siendo un pacto de institución recíproca, siempre podría (si es que se dan las circunstancias) hacer por su parte otra professio iuris que reequilibrase el pacto; o, por volver a traer una idea ya expuesta, atacar la validez del pacto por pérdida manifiesta de la base causal del mismo y a existencia de un desequilibrio evidente. Claro está, esto depende de cada situación concreta, pero la obligación de información, en todo caso, no perjudica en absoluto.

Por último, se encuentran las vías generales de fraude a la ley o, abuso de derecho. El considerando 26 del Reglamento da pie a ello, cuando señala que "Ningún elemento del presente Reglamento debe ser óbice para que un tribunal aplique mecanismos concebidos para luchar contra la elusión de la ley, tales como 
el fraude de ley en el contexto del Derecho internacional privado". Es cuestión de desarrollar ambos frente a un principio tan fuerte como el de la autonomía e la voluntad.

En conclusión, las relaciones de la ley del pacto sucesorio y de la ley sucesoria en términos de autonomía de la voluntad conflictual y en lo que se refiere a la posible corrección del pacto sucesorio por lo dispuesto en la ley sucesoria puede suponer una posibilidad en manos de una de las partes otorgantes, el disponente o futuro causante, para variar el resultado de lo dispuesto en el pacto sucesorio. Una consecuencia a nuestro juicio inaceptable, en cuanto que va en contra del principio general de los contratos, según el cual no se puede dejar el cumplimiento de lo acordado al arbitrio de una de las partes.

\section{EXTENSIÓN DE LA AUTONOMÍA DE LA VOLUNTAD CONFLICTUAL \\ 1. Los límites de la autonomía de la voluntad conflictual en el ámbito de las sucesiones internacionales}

A la visión estructural que hemos visto en los epígrafes anteriores y en la que partíamos de la esas dos manifestaciones de autonomía conflictual que eran la professio iuris y el pacto de lege utenda, con las intrincadas relaciones entre ambos, procede añadir la más concreta relativa al propio régimen de ejercicio de esa autonomía. Su regulación particular, si se quiere, que inevitablemente a estas alturas ya hemos ido adelantando en parte.

En primer lugar hay que hacer hincapié en la ya citada característica fundamental de la autonomía conflictual en materia sucesoria, cual es su concepción limitada. Al dar la definición de professio iuris, ya hemos destacado como uno de los elementos relevantes es el hecho de que la facultad de elección de ley a la sucesión del causante se circunscribe a ciertos límites. La elección de ley en las sucesiones internacionales no es, por tanto, una elección libre. Se exige una determinada vinculación entre la ley elegida y las circunstancias del caso. Este carácter estrictamente limitado se explica, entre otras razones, por la naturaleza imperativa de la mayor parte de las normas que integran el Derecho de sucesiones y por el temor que se ve en la elección de ley aplicable como 
mecanismo en manos del causante para evitar restricciones a su libertad de disposición al posibilitarle escapar a sistemas que amparan una mayor libertad para ordenar su sucesión por causa de muerte.

Hemos tenido ocasión de señalar también que la elección de ley en materia de sucesiones se consideró en un principio como una solución de compromiso para aproximar las dos conexiones antagónicas que tradicionalmente se han mantenido para determinar la ley aplicable a las sucesiones internacionales: la nacionalidad y el domicilio del causante en el momento del fallecimiento. Esta es la perspectiva desde la que se planteó el debate de la professio iuris en el seno de la Conferencia de La Haya durante la negociación del Convenio de 1989. Desde este punto de vista, la professio iuris se presenta como un mecanismo de flexibilización dirigido a amortiguar la rigidez de las conexiones de la nacionalidad o del domicilio del causante, cuya aplicación puede llevar en ocasiones a resultados absurdos. No obstante, no podemos negar la existencia también de un carácter materializador de la professio iuris, desde el momento en que el causante no elegirá la ley aplicable a su sucesión en términos localizadores, sino en términos de Derecho material.

La professio iuris no es una solución concreta de elección de ley, sino que hay múltiples profesiones iuris, en función de la concreta articulación que de la elección de ley se realice en cada norma ${ }^{458}$. Con carácter general, tres han sido las conexiones que se han tomado en consideración para delimitar las leyes elegibles a las sucesiones internacionales: la nacionalidad del causante, el domicilio del causante y, en menor medida, la lex rei sitae $e^{459}$. En cuanto a las dos primeras, al ser circunstancias personales que pueden variar a lo largo de la vida del causante, su articulación de una u otra forma como elementos de vinculación suficientes con la sucesión mortis causa influye directamente en la mayor o menor extensión de la autonomía de la voluntad conflictual. Se han barajado cuatro posibilidades: en primer lugar, la posibilidad de escoger la nacionalidad o domicilio que el causante ostente en el momento de la elección. En segundo lugar,

\footnotetext{
${ }^{458}$ S. ÁlVAREZ GoNZÁlez (2009), p. 18.

${ }^{459}$ J.M. FONTANELLAS MORELL (2011), pp. 93 y 94.
} 
la elección de la nacionalidad o domicilio que el causante tenga en el momento del fallecimiento. En tercer lugar, cabe una exigencia de vinculación cumulativa, de tal forma que es necesario que la ley elegida corresponda a la nacionalidad o domicilio que el causante ostente en el momento de la elección y del fallecimiento; ejemplo de esta exigencia cumulativa lo encontramos en el ordenamiento jurídico suizo. Por último, cabe una exigencia de vinculación alternativa, que consiste en la posibilidad de elegir la ley correspondiente a la nacionalidad o domicilio que el causante ostente bien en el momento de la elección, bien en el momento de su fallecimiento. Ejemplo de esta articulación alternativa lo encontramos en el Convenio de La Haya de 1989. El art. 5 de dicho Convenio establece la posibilidad de escoger la ley de la residencia habitual o la ley de la nacionalidad que el causante ostente bien en el momento de la realización de la elección, bien en el momento del fallecimiento.

La Propuesta de Reglamento, por su parte, donde la professio iuris ya tenía una importante cabida, aunque limitándose a la elección de la ley de la nacionalidad del causante, nada disponía sobre el momento en que debía ser considerada la conexión de la ley elegida. El art. 17 no fijaba en qué momento debía ostentar el causante la nacionalidad de la ley elegida, sino que se limitaba a determinar que cualquier persona podrá designar la ley del Estado cuya nacionalidad posee para que rija la totalidad de la sucesión. Ante tal ausencia la doctrina alertó sobre las dudas que se planteaban en torno al momento en que se debía determinar temporalmente la nacionalidad como signo de vinculación suficiente para elegir la ley aplicable a la sucesión ${ }^{460}$. El Reglamento, sin embargo, haciéndose eco de las críticas de la doctrina, concreta dos posibles momentos temporales en los que se puede determinar la nacionalidad del causante de forma alternativa; de esta forma, el art. 22.1 dispone que cualquier persona

\footnotetext{
${ }^{460}$ M. Buschbaum/ M. KoHLER (2010), p. 112. Según el MPI se trata de una posibilidad de elección de la nacionalidad presente, esto es, el causante puede elegir la ley correspondiente a la nacionalidad que ostenta en ese mismo momento. Vid. comentarios del MPI, (2010), núm. 140. También pone de relieve las dudas que el art. 17 suscita a este respecto; P. KINDLER (2010), p. 256; A. BONOMI (2010), pp. 895 y 896; G. KHAIRALLAH (2010), p. 67; H. DÖRNER (2010), p. 226; J.M. FONTANELLAS MORELL (2011), pp. 99 y ss.;
} 
podrá designar la ley del Estado cuya nacionalidad posea en el momento de realizar la elección o en el momento del fallecimiento.

\section{La autonomía de la voluntad conflictual en los pactos sucesorios: autonomía libre versus autonomía vinculada}

Tras haber visto la estructura e interrelaciones entre professio iuris y pacto de lege utenda, cabe plantearse ahora en relación al segundo, su extensión como pieza clave en la determinación de la ley aplicable a los pactos sucesorios. El consabido doble carácter contractual y sucesorio de los pactos sucesorios plantea, al menos teóricamente, la pregunta previa sobre si es posible o no una elección libre. El carácter sucesorio nos conduce a pensar en una elección de ley limitada, tal y como hemos visto que ocurre en el ámbito de las sucesiones internacionales con la professio iuris. Sin embargo, el carácter contractual nos lleva a una autonomía de la voluntad conflictual de mayor amplitud, tal y como ocurre en el ámbito de las obligaciones contractuales.

Como vimos en el Capítulo II, desde el punto de vista del Derecho positivo, en aquellos casos en los que no hay una regulación específica sobre la ley aplicable a los pactos sucesorios, la cuestión depende de la calificación por la que se opte a la hora de determinar la norma de conflicto aplicable. A salvo determinadas excepciones aisladas que abogaron de forma marginal por una calificación contractual de los pactos sucesorios, la mayor parte de los sistemas y de la doctrina apuestan por una calificación sucesoria.

En los hipotéticos casos en que se siguiese una calificación contractual de los pactos sucesorios, éstos se beneficiarán de la amplia libertad de elección de ley que se permite en el ámbito de las obligaciones contractuales, mientras que, en los casos en que se siga una calificación sucesoria, la mayoría como hemos visto, la elección de ley a los pactos sucesorios seguirá las pautas de la elección de ley a las sucesiones internacionales y, por tanto, será más o menos limitada, allí donde la autonomía se acepte, o incluso nula donde la autonomía conflictual esté ausente de la regulación. 
Ejemplos de esta professio iuris prevista para las sucesiones internacionales que se aplica a los pactos sucesorios los encontramos tanto en el ordenamiento jurídico alemán, como en el italiano. En el caso del ordenamiento jurídico alemán, la calificación sucesoria de los pactos sucesorios se recoge en la propia norma de conflicto de sucesiones. Por ello, se puede aplicar también la pequeña posibilidad de elección de ley prevista en el EGBGB para las sucesiones internacionales, a favor de la ley alemana para la regulación de la parte de la sucesión, o a la parte del pacto sucesorio, que afecte a la transmisión mortis causa de los bienes inmuebles sitos en territorio alemán. En el caso del ordenamiento jurídico italiano, donde nada se dice de los pactos sucesorios, la calificación sucesoria viene de la mano de la mayor parte de la doctrina y en tal caso a los pactos sucesorios, se les aplicará la norma de conflicto de sucesiones, incluyendo la posibilidad de elección de ley limitada que se prevé en el art. 46 de la ley italiana a favor de la ley de la residencia habitual del causante, siempre y cuando éste mantenga tal residencia habitual en el momento de su fallecimiento.

En aquellos otros casos en los que la ley aplicable a los pactos sucesorios tiene una regulación específica, incluyendo la posibilidad de determinar la ley aplicable a través de un ejercicio de la autonomía de la voluntad conflictual, tal posibilidad de elección de ley también se prevé de forma limitada. Tales son los casos del sistema suizo, del Convenio de La Haya de 1989, del sistema que se previó en la Propuesta de Reglamento y del propio Reglamento de sucesiones.

El sistema suizo prevé como conexión objetiva para las sucesiones internacionales y también para los pactos sucesorios la ley del domicilio del causante. Como hemos visto, tratándose de pactos sucesorios que afectan a una única sucesión la ley aplicable es la del domicilio del causante determinada en el momento del otorgamiento del pacto sucesorio, pero existe la posibilidad de que el causante escoja a través del pacto sucesorio la ley de su nacionalidad para regular el conjunto de su sucesión (art. 95.2 Ley suiza). Tratándose de pactos sucesorios que afectan a más de una sucesión, la ley suiza prevé la posibilidad de que se escoja la ley de la nacionalidad común a los disponentes para regular el pacto sucesorio art. 95.3 ley suiza). 
El Convenio de La Haya de 1989 permite también la elección de ley aplicable a los pactos sucesorios, que puede venir por dos vías, bien por la aplicación de la ley sucesoria anticipada cuando se ha realizado una elección de ley unilateral por el causante, bien por la realización de un pacto de lege utenda en el propio pacto sucesorio.

En definitiva, la dependencia de los pactos sucesorios de las normas sucesorias en DIPr implica, en el estado actual del desarrollo legislativo, la negación de la posibilidad de un ejercicio libre de la autonomía de la voluntad conflictual para la determinación de la ley aplicable a los mismos. El carácter sucesorio, por tanto, tiene un mayor peso en este ámbito y los pactos sucesorios van a seguir, salvo regulación específica al respecto, la suerte de las sucesiones internacionales también en lo que se refiere a la posibilidad de elegir ley aplicable.

\section{Autonomía de la voluntad y posibles leyes elegibles a los pactos sucesorios}

\subsection{Breve panorámica general}

En el presente epígrafe analizaremos las leyes que, con carácter general, se permiten elegir como aplicables a los pactos sucesorios. Hemos visto cómo no existe una única professio iuris, sino múltiples professiones iuris en función de la concreta articulación que de la elección de ley aplicable a la sucesión realiza cada normativa. Lo mismo ocurre en los pactos sucesorios, pues no hay una postura generalizada sobre la extensión de la elección de ley en materia de pactos sucesorios. No obstante, al igual que ocurre con ley sucesoria, hay una serie de conexiones que habitualmente se utilizan como vínculos para la delimitación de la ley aplicable: con carácter general las leyes elegibles a los pactos sucesorios son la ley de la nacionalidad, del domicilio o de la residencia habitual del disponente o futuro causante y, en menor medida, la lex rei sitae.

Podemos adelantar ya que la elección de la ley aplicable a los pactos sucesorios no se ha previsto con demasiada generosidad, salvo quizá en el ejemplo del Convenio de La Haya de 1989, en el que se articuló una extensión considerable de las leyes elegibles a las sucesiones internacionales en general y, 
coherentemente a los pactos sucesorios en particular. Como ya hemos visto, la determinación temporal de forma alternativa al momento de la elección de ley y al momento del fallecimiento del causante de las conexiones que determinan las leyes elegibles, la residencia habitual y la nacionalidad, posibilitan un amplio ejercicio de la autonomía conflictual. Esta extensión se ve, en cierto modo, aumentada cuando se trata de pactos sucesorios que afectan a más de una sucesión como veremos más adelante.

Sin embargo, en el ámbito europeo la elección de ley a las sucesiones internacionales $\mathrm{y}$, en consecuencia, a los pactos sucesorios, tiene un juego más limitado. Vamos a ver ahora cómo juega esta elección de ley aplicable a los pactos sucesorios. En el apartado de la estructura de la ley aplicable a los pactos sucesorios hemos visto cómo hay dos vías posibles en el Reglamento para canalizar la elección de ley aplicable a los pactos sucesorios: la professio iuris y el pacto de lege utenda. Será nuestro primer análisis, incidiendo en, las particularidades de la elección de la nacionalidad desde el punto de vista de la extensión de la elección. A continuación nos plantearemos la oportunidad de considerar la elección de otras posibles leyes. En este análisis tendrán una atención particular los pactos sucesorios que afectan a más de una sucesión.

\subsection{Las leyes elegibles en el marco del Reglamento}

Como ya hemos señalado, el Reglamento limita la elección de ley a la nacionalidad del causante y, a diferencia de lo que ocurría con la Propuesta de Reglamento, determina temporalmente en qué momento debe ostentar la nacionalidad elegida el causante para que tal elección sea válida: el momento de la elección o el momento del fallecimiento.

De conformidad con una de las líneas discursivas que presiden nuestras reflexiones, resulta especialmente interesante analizar el tema de la validez y régimen jurídico de los pactos sucesorios en el caso de que se permita escoger la ley de la nacionalidad que el causante tenga en cualquiera de los dos momentos. Siempre hemos defendido que estos aspectos se han de conocer y han de quedar fijados desde el mismo momento de su otorgamiento. Por eso, en lo que atañe a 
los pactos sucesorios no resulta en absoluto adecuado que se espere al fallecimiento del causante para ver si la elección de la ley de la nacionalidad es válida o no. Partiendo de que la ley aplicable al pacto sucesorio venga determinada por una professio iuris, en cualquiera de los dos casos, esto es, elección de la nacionalidad del causante en el momento de la propia elección y elección de la nacionalidad del causante en el momento del fallecimiento, el ejercicio de la professio iuris se ha realizado con anterioridad al otorgamiento de pacto sucesorio o al menos en el mismo momento en que éste es otorgado (si es posterior sólo determina la ley sucesoria, pero no la ley del pacto). Ahora bien, tratándose del juego de la professio iuris en los pactos sucesorios, y debido a la combinación entre lo dispuesto en el art. 22 y en el art. 25, nunca debe ser aplicable la ley de la nacionalidad del causante en el momento del fallecimiento. Pongamos dos ejemplos con las dos hipótesis para ver cómo funcionaría la elección en uno y otro caso.

En el primer ejemplo vamos a jugar con la hipótesis de la elección de la ley correspondiente a la nacionalidad que el causante ostenta en el momento de la propia elección. Pensemos en un pacto sucesorio que afecta a una única sucesión en el que una madre, de nacionalidad alemana y residencia habitual en Italia, instituye heredera universal a su única hermana. Antes de la realización del pacto sucesorio, la disponente había realizado una professio iuris, en el marco del art. 22 del Reglamento, a favor de la ley de su nacionalidad, en ese momento la alemana. En este ejemplo, la ley aplicable al pacto sucesorio sería la ley alemana, ley que corresponde a la nacionalidad de la disponente en el momento de la elección de ley, a título de ley hipotética sucesoria de la disponente en el momento del otorgamiento del pacto sucesorio. La ley se conoce desde el mismo momento en que el pacto sucesorio es otorgado y, con ella, el régimen jurídico del mismo, garantizando la necesaria seguridad jurídica que precisan estas figuras. Por ello, la elección de la ley correspondiente a la nacionalidad que el causante ostente en el momento de la propia elección es una vinculación adecuada cuando se trata de determinar la ley aplicable a los pactos sucesorios. 
No ocurre lo mismo con el caso en el que la efectividad de la ley elegida dependa de la nacionalidad que ostente el causante en el momento de su fallecimiento. Esta es la hipótesis con la que vamos a jugar en el siguiente ejemplo. Utilizaremos el mismo pacto sucesorio de institución de heredero universal realizado entre la causante y su hermana. Ahora bien, supongamos que en este caso la professio iuris realizada con anterioridad se refiere a la nacionalidad de la causante en el momento del fallecimiento, bien porque así se describe en términos abstractos, bien porque la disponente la nombra en previsión de una prevista futura adquisición. Si validez y efectividad de la elección de la ley aplicable al pacto sucesorio dependen de que el disponente o futuro causante ostente la nacionalidad correspondiente a la ley elegida en el momento de su fallecimiento, no sabremos con certeza cuál es la ley aplicable al pacto sucesorio en cuestión. Tal posibilidad implicaría aplazar el conocimiento de la ley aplicable hasta el momento del fallecimiento del causante, lo que, como hemos visto, no es soportable tratándose de pactos sucesorios.

Ahora bien, existe, a nuestro juicio, una interpretación para que la efectividad de la elección de ley aplicable se vincule al momento del otorgamiento del pacto cuando se trata de pactos sucesorios. Tal interpretación consistiría en entender que la exigencia de la vinculación (nacionalidad en el momento de la elección o nacionalidad en el momento del fallecimiento) tratándose de pactos sucesorios no sería en el momento del fallecimiento del disponente o futuro causante, sino en el momento del otorgamiento del pacto sucesorio. Para que la elección sea válida es necesario que el disponente o futuro causante ostente la nacionalidad de la ley elegida en el momento del otorgamiento del pacto sucesorio, que puede ser distinta de la nacionalidad que ostente finalmente en el momento de su fallecimiento. La interpretación se apoya también en el modo en que se prevé en el Reglamento la determinación de la ley aplicable a los pactos sucesorios (al margen de si es elegida o no): se habla de la ley sucesoria anticipada o la ley que sería aplicable a su sucesión de fallecer el causante en el momento del otorgamiento del pacto sucesorio. Este momento ha de definir también las posibilidades de elección de ley nacional. Dos razones, una 
sistemática o contextual, dentro de la propia letra del Reglamento y otra funcional avalan esta interpretación.

En primer lugar, es la más coherente con el funcionamiento de la combinación de los arts. 22 y 25 del Reglamento y, en concreto, la más respetuosa con el mandato del art. 25 cuando se refiere a la ley que, según el Reglamento, regiría la sucesión de fallecer el disponente en el momento del otorgamiento del pacto sucesorio. De fallecer en ese momento el disponente, su ley sucesoria sería le ley de su nacionalidad en ese momento, la ley de la nacionalidad en el momento de otorgamiento del pacto sucesorio, en el ejemplo, la alemana. En segundo lugar, si nos limitáramos a una interpretación literal del art. 22, esto es, la ley elegida es la ley de la nacionalidad determinada en el momento del fallecimiento, nunca podríamos conocer la ley aplicable al pacto sucesorio hasta la llegada de ese momento; no se podría conocer si el pacto es válido o no hasta que el disponente fallezca y se determine su nacionalidad en ese momento, consecuencia ésta que ya hemos visto cómo es insoportable para los pactos sucesorios, además de que va en contra del espíritu regulador de la ley aplicable a estas figuras en el marco del Reglamento, donde claramente el papel principal lo ostenta la ley sucesoria anticipada.

Antes de finalizar con el análisis concerniente a la elección de la ley de la nacionalidad del o de cualquiera de los disponentes o futuros causantes del pacto sucesorio, cabe hacer una breve mención a los casos en los que se ostente más de una nacionalidad y a los casos de causantes apátridas. Los casos de doble nacionalidad están previstos y la elección de ley se articula de forma generosa, pues tal y como recoge el art. 22.1 segundo párrafo del Reglamento, en el caso de que una persona posea varias nacionalidades podrá elegir la ley de cualquiera de los Estados cuya nacionalidad posea bien en el momento de la realización de la elección, bien en el momento del fallecimiento ${ }^{461}$.

\footnotetext{
461 Esta cuestión no estaba resuelta en la Propuesta de Reglamento, que nada decía sobre la posibilidad de que el causante tuviera varias nacionalidades. La doctrina abogó con carácter general por la posibilidad de elegir cualquiera de las nacionalidades que ostentara el causante, vid. A. DAVI, quien pone hincapié en la creación de cierta inseguridad jurídica en la opción de la elección de la ley nacional efectiva, vid. A. DAVí, (2004), p. 481; a raíz del silencio de la Propuesta de Reglamento sobre este particular, MPI (2010), núm. 141; P. KINDLER (2010), p. 49;
} 
No ocurre lo mismo en el caso de los apátridas; nada dispone el Reglamento al respecto. Se abre aquí el interrogante de si un apátrida puede elegir la ley aplicable a su sucesión. Se nos presentan aquí varias hipótesis. En primer lugar, a falta de un criterio comunitario para hacer frente a esta cuestión, cabría preguntarse sobre la posible aplicación de nuestro art. 9.10 CC, donde se prevé la aplicación de la ley de la residencia habitual a aquellas personas que carecieran de nacionalidad o la tuvieran indeterminada ${ }^{462}$; de tal forma que, por esta vía, se permitiera al causante apátrida elegir la ley de su residencia habitual. Sin embargo, esta opción no nos parece viable, en cuanto que creemos que es una cuestión que no puede quedar en manos de los EEMM y que, en consecuencia, el art. 9.10 CC sólo se aplicará a los casos internos.

En segundo lugar, se podría acudir al art. 12 de la Convención de Naciones Unidas sobre el Estatuto de los Apátridas ${ }^{463}$. El apartado primero de este artículo establece que el "estatuto personal de todo apátrida se regirá por la ley del país de su domicilio o, a falta de domicilio, por la ley del país de su residencia". Ahora bien, también parece bastante forzado el dar entrada a la elección de ley a la sucesión del causante apátrida en el marco del Reglamento a través de esta vía; y ello por dos razones. Por una parte, porque no todos los EEMM son parte del citado Convenio, ni tampoco lo es la UE. Por otra parte, vamos a ver sucintamente lo que ocurrió en los asuntos Micheletti ${ }^{464}$ y Hadadi $^{465}$. En ambos se sustanciaron cuestiones prejudiciales en casos que trataban sobre la doble nacionalidad; en ambos, ante la falta de respuesta concreta por parte del legislador comunitario para los casos de doble nacionalidad, se acude a la legislación interna para dar

G. Khairallah (2010), p. 67, npp. 29; A. BONOMI (2011), pp. 236 y ss. J.M. FonTANELlaS MORELL (2011), p. 102.

${ }^{462}$ Sobre este precepto, vid., J.C. FERNÁNDEZ ROZAS (1995), pp. 429 y ss.

463 Convención sobre el Estatuto de los Apátridas de 28 de septiembre de 1954; consultado en Aranzadi Westlaw RCL\1997\1709.

${ }^{464}$ Caso Mario Vicente Micheletti y otros contra Delegación del Gobierno en Cantabria; sentencia del TJCE de 7 de julio de 1992, asunto C-369/90, TJCE\1992\134.

465 Caso Laszlo Hadadi (Hadady) contra Csilla Marta Mesko, esposa de Hadadi (Hadady); sentencia del TJUE de 16 de julio de 2009, asunto C-168/08, TJCE\2009\234. 
solución a estas situaciones ${ }^{466}$. Y en ambos el TJUE rechaza la aplicación de la normativa interna para la determinación de cuáles de las dos nacionalidades debía ser la efectiva. En consecuencia, si traemos aquí a colación el resultado de estas sentencias, parece llevarnos a la conclusión de que no cabría acudir al art. 12 de la citada Convención para solucionar el problema de ausencia de nacionalidad del causante.

Dicho todo esto, resta sencillamente señalar la postura según la cual el causante que no ostenta nacionalidad alguna no puede elegir la ley aplicable a su sucesión en el marco del Reglamento.

\subsection{Otras alternativas de leyes elegibles a los pactos sucesorios}

\subsubsection{La residencia habitual del causante}

Pese al juego de la residencia habitual como conexión para determinar la ley aplicable a las sucesiones, se ha desechado en el Reglamento la posibilidad de que el causante elija como ley aplicable la ley de su residencia habitual. En este punto el Reglamento se ha desmarcado de su precedente inmediato, el Convenio de La Haya de 1989, donde, como ya sabemos, se prevé igualmente la posibilidad de elegir la ley de la residencia habitual y la ley de la nacionalidad del causante.

En la Propuesta de Reglamento, donde tampoco se permitía la elección de la ley de la residencia habitual, este mecanismo tenía una lógica: no era necesario prever la posibilidad de elegir la ley de la residencia habitual del causante porque esta ley se aplicaba directamente en el caso de que no haya elección de ley alguna ${ }^{467}$. Ante una sucesión en concreto el funcionamiento en el

\footnotetext{
${ }^{466}$ En el caso Micheletti, por ejemplo, se pretendía acudir al art. 9 de nuestro CC para determinar que prevalecía la nacionalidad argentina sobre la italiana, por ser ésa la correspondiente al lugar de residencia habitual anterior a la llegada a España del interesado.

${ }^{467}$ A. Daví matizó la cuestión de la elección de la ley de la residencia habitual del causante, pues a su juicio, la reglamentación europea debía permitir la elección de la ley de la residencia habitual que el causante ostentara en el momento de la elección; mientras que no veía interés alguno en permitir la elección de la ley de la residencia habitual que el causante ostentara en el momento del fallecimiento, al ser esta ley aplicable a título objetivo; vid. A. DAví, (2004), p. 481. En este mismo sentido también se pronunció el INFORME DÖRNER/LAGARDE, (2002), p. 70. Debe tenerse en cuenta, en cualquier caso, que no es lo mismo la aplicación de la ley de la residencia habitual determinada de forma objetiva que por mor de una professio iuris, por ejemplo, a efectos de la admisión de un eventual reenvío.
} 
marco de la Propuesta de Reglamento sería el siguiente: si el causante quiere que se regule su sucesión por la ley de su residencia habitual no tiene que realizar declaración ninguna sobre la ley aplicable a su sucesión; mientras que en el caso de que quiera que su sucesión se rija por la ley de su nacionalidad deberá realizar la declaración expresa correspondiente.

Sin embargo esta lógica no sirve ya en el Reglamento, en cuanto que la aplicación de la ley de la residencia habitual del causante no está garantizada para el caso de que no haya elección de ley, al existir la cláusula de los vínculos más estrechos que a priori posibilita dar entrada a cualquier otra ley siempre que se cumplan los requisitos del art. 21.2 del Reglamento. En estas circunstancias las razones para no permitir elegir la ley de la residencia habitual del causante, que a priori presenta un vínculo lo suficientemente fuerte con el causante, como para poder ser una ley elegida, disminuyen. $\mathrm{Y}$ en el caso de los pactos sucesorios debe lamentarse que la residencia habitual quede al margen del ejercicio de la autonomía de la voluntad.

En efecto, la posibilidad de elegir la ley de la residencia habitual tiene una especial virtualidad en el caso de los pactos sucesorios que afectan a más de una sucesión. En este tipo de pactos, sabemos que la solución objetivamente aplicable en el Reglamento es la cumulativa para determinar la admisibilidad del pacto sucesorio y que después se aplica, de entre las leyes que admiten el pacto sucesorio, aquella que presente los vínculos más estrechos con el pacto. Lo cierto es que la solución de los vínculos más estrechos no deja de provocar una cierta inseguridad jurídica en la determinación del régimen jurídico de los pactos sucesorios que afectan a más de una sucesión. Por ello, sería recomendable en la medida de lo posible evitar el tener que acudir a la solución de los vínculos más estrechos, siempre que hubiese una alternativa limpia y viable.

Al igual que lo que ocurre con la posibilidad de elección de la ley de la nacionalidad de alguno de los disponentes o futuros causantes, la posibilidad de elegir la ley de la residencia habitual de alguna de las personas cuya sucesión queda afectada por el pacto sucesorio evitaría acudir a la cláusula de los vínculos más estrechos. Pensemos en el pacto sucesorio de institución recíproca celebrado 
entre dos hermanos de nacionalidad francesa, uno con residencia habitual en Suiza y el otro con residencia habitual en Alemania. Ninguno de ellos ha realizado professio iuris alguna, por lo que las leyes sucesorias anticipadas corresponden a la residencia habitual de los hermanos: tanto la ley suiza, como la ley alemana reconoce la admisibilidad del pacto sucesorio celebrado entre los hermanos, de tal forma que para conocer cuál es la ley que en concreto se va a aplicar al pacto sucesorio hay que acudir a la cláusula de los vínculos más estrechos (art. 25.2). Además, en el ejemplo los hermanos no pueden hacer un pacto de lege utenda del art. 25.3 a favor de la ley de la nacionalidad, la ley francesa, porque tal elección supondría la no admisibilidad del pacto sucesorio. Por ello, nos encontramos con dos leyes potencialmente aplicables, la alemana y la suiza, al reconocer ambas la admisibilidad de un pacto sucesorio de tales características; ante un caso como este la única posibilidad de evitar el juego de la cláusula de los vínculos más estrechos sería permitiendo a las partes escoger a través de la celebración de un pacto de lege utenda la ley de la residencia habitual de alguno de ellos, quedando así fijado claramente desde ese mismo momento el régimen jurídico del pacto sucesorio $^{468}$.

Pero además, la posibilidad de elegir la ley de la residencia habitual de alguno de los disponentes o futuros causantes no sólo evitaría el, en este caso, siempre necesario funcionamiento de la cláusula de los vínculos más estrechos, sino que también abundaría en el favor de los pactos sucesorios. Hemos visto cómo uno de los beneficios de la posibilidad de elegir la ley de la nacionalidad de uno de los disponentes o futuros causantes del pacto sucesorio en virtud del art. 25.3 del Reglamento, es que (siempre que la ley elegida sea apropiada) basta para reconocer la admisibilidad del pacto sucesorio, con independencia de lo que dispongan al respecto el resto de leyes sucesorias anticipadas implicadas. Pues bien, ese mismo beneficio favorable a la admisibilidad de los pactos sucesorios se conseguiría con la posibilidad de elegir al amparo del art. 25.3 del Reglamento la ley de la residencia habitual de cualquiera de los disponentes o futuros causantes.

\footnotetext{
${ }^{468}$ Ya hemos tenido ocasión de poner de relieve la oportunidad de la previsión de la elección de la ley de la residencia habitual en lo que se refiere a los pactos sucesorios que afectan a más de una sucesión, vid. S. ÁlvAREZ GonZÁlEZ/I. RODRÍGUEZ-URÍA SUÁREZ (2011), p. 9.
} 
Entendemos, en definitiva, que la previsión de la elección de la ley de la residencia habitual del o de alguno de los disponentes o futuros causantes aporta importantes ventajas para los pactos sucesorios, al menos en lo que se refiere a los pactos que afectan a más de una sucesión. Entendemos además que la previsión de esta posibilidad de elección no excede de las opciones de ley aplicable del Reglamento en general y de los pactos sucesorios en particular: por un lado, la residencia habitual lejos de ser una conexión nueva, es la conexión que determina con carácter general (a salvo de ley más estrechamente vinculada) la ley aplicable a las sucesiones y pactos sucesorios cuando no hay elección de ley alguna; en definitiva, una ley de la que se presupone una vinculación suficiente con la sucesión en cuestión. Por otro lado, y respecto de la solución cumulativa para los pactos sucesorios que afectan a más de una sucesión, podría objetarse que a través de esa posibilidad de elegir directamente la ley de una de las residencias habituales de los futuros causantes o disponentes se abre una vía para evadir la exigencia cumulativa de que todas y cada una de las leyes sucesorias anticipadas en presencia reconozcan la admisibilidad del pacto sucesorio. Sin embargo, esta posibilidad de evadir tal exigencia cumulativa ya se permite cuando las partes pueden escoger a través de un pacto de lege utenda la ley de la nacionalidad de cualquiera de las personas de cuya sucesión se trate, por lo que no sería traumático que ocurra lo mismo cuando se trate de la elección de la residencia habitual. El temor a la mala utilización de un abanico amplio de leyes aplicables, que está detrás de la regulación de la professio iuris, se proyecta también sobre este tema.

\subsubsection{La ley del régimen económico matrimonial}

La posibilidad de permitir la elección de la ley del régimen económico matrimonial a los pactos sucesorios también podría tener su interés. El régimen económico matrimonial y las sucesiones son dos aspectos en muchas ocasiones íntimamente relacionados. El hecho de que estas dos cuestiones se regulen por diferentes leyes puede dar lugar a importantes dificultades y problemas de adaptación. De ahí que a la hora de dar una solución de ley aplicable a las sucesiones internacionales muchas veces se tenga en especial consideración al 
cónyuge supérstite, como ocurre en nuestro art. $9.8 \mathrm{CC}$. A estos datos hay que añadir el no de menor entidad de la frecuencia con la que los pactos sucesorios se dan entre cónyuges, como hemos tenido ocasión de ejemplificar en varias ocasiones.

El Reglamento excluye expresamente de su ámbito de aplicación material las cuestiones relacionadas con el régimen económico matrimonial, incluidos aquellos regímenes patrimoniales que se apliquen a relaciones con efectos comparables al matrimonio (art. $1.3 \mathrm{~d})^{469}$.

Al ser dos aspectos íntimamente ligados, la doctrina ha valorado y propuesto la posibilidad de escoger la ley del régimen económico matrimonial para regular las sucesiones internacionales ${ }^{470}$. La idea consiste en permitir la elección de la ley del régimen económico matrimonial, siendo tal elección eficaz siempre y cuando el causante, en el momento del fallecimiento, siga sometido a tal régimen económico matrimonial ${ }^{471}$. Las ventajas de la elección de la ley del régimen económico matrimonial son varias: en primer lugar, es una forma de

\footnotetext{
${ }^{469}$ En cuanto a la armonización europea de la materia concerniente al régimen económico matrimonial, a día de hoy ya hay sobre la mesa la Propuesta de Reglamento del Consejo relativo a la competencia, la ley aplicable, el reconocimiento y la ejecución de resoluciones en materia de regímenes económico matrimoniales, de 16 de marzo de 2011, COM (2011) 126 final. El art. 1.3 d) de dicha Propuesta de Reglamento excluye de su ámbito de aplicación los derechos sucesorios del cónyuge supérstite.

${ }^{470}$ El Libro Verde de Sucesiones y Testamentos ya valoró la posibilidad de permitir al cónyuge escoger la ley aplicable a su régimen económico matrimonial para regular su sucesión, vid, Document de Travail des Services de la Commission annexe au Livre Vert sur les Successions et Testaments, COM (2005), 65 final, p. 20. También en el INFORME DöRNER/LAGARDE se aboga por esta posibilidad, (2002), p. 73. El sistema finlandés de DIPr permite la posibilidad de escoger como ley sucesoria la ley del régimen económico matrimonial a aquel que esté casado.

${ }^{471}$ Tal propuesta de elección fue realizada por el MPI en su comentario a la Propuesta de Reglamento, vid. MPI, (2010), núm. 148; a favor de una professio que permita la coordinación de la regulación del régimen económico matrimonial y de la sucesión mortis causa, A. DAví, (2004), p. 479; aunque este autor quiso destacar que, por otro lado, era dudoso que en esos momentos fuera conveniente una professio iuris a favor de la ley del régimen económico matrimonial al no estar esta materia unificada en el ámbito de la UE, vid. pp. 484 y ss. También a favor, E. LEIN, (2009), p. 132; A. BONOMI (2011), p. 242. En el marco del Convenio de La Haya de 1989 se desechó la posibilidad de escoger la ley del régimen económico matrimonial; no obstante, una de las razones de peso que se valoraron a la hora de admitir la elección de la ley de la residencia habitual o de la nacionalidad del causante en el momento de la elección fue el hecho de que tal posibilidad permite al causante planificar y organizar sus disposiciones matrimoniales y sucesorias, conociendo el régimen de uno y otro aspecto o incluso permitiéndole que ambas cuestiones queden reguladas por la misma ley. Vid. Informe Final de W. Waters en CONFÉRENCE DE LA HAYE DE DROIT INTERNATIONAL PRIVÉ (1990), p. 554.
} 
evitar problemas de adaptación típicos en la materia en lo que se refiere a la liquidación del régimen económico matrimonial y la determinación de los derechos sucesorios del cónyuge supérstite; en segundo lugar, al estar ambas cuestiones coordinadas, por regularse por la misma ley, se facilitan las tareas de administración de la herencia.

En contra de la elección de la ley del régimen económico matrimonial se erige la posible inestabilidad que tal posibilidad podría suponer para la regulación de las sucesiones. Con carácter general, la determinación de la ley del régimen económico matrimonial está sometida a ciertas dificultades, en casos en los que por ejemplo es difícil determinar el primer domicilio conyugal o los cónyuges no comparten domicilio común. En este sentido, tales dificultades e incertidumbre podrían ser trasladadas a las sucesiones internacionales, donde es especialmente necesaria la existencia de criterios estables en la determinación de la ley aplicable ${ }^{472}$.

Tratándose de pactos sucesorios el interés de la elección de la ley del régimen económico matrimonial puede ser mayor. La realidad nos dice que muchos de los pactos sucesorios que se otorgan se celebran entre cónyuges que quieren organizar conjuntamente su sucesión, para sí mismos y para sus descendientes; muchos de los pactos sucesorios se otorgan a través de capitulaciones matrimoniales $^{473}$. Tanto el régimen económico matrimonial como

\footnotetext{
${ }^{472}$ Vid. INFORME DÖRNER/LAGARDE, p. 72.

${ }^{473}$ En ocasiones es la propia normativa la que establece el carácter matrimonial de los pactos sucesorios; así por ejemplo, en el ordenamiento jurídico austriaco sólo están legitimados para otorgar pactos sucesorios los cónyuges; en Cataluña, hasta la reforma que tuvo lugar en 2008, los pactos sucesorios tenían un carácter matrimonial y sólo podían celebrarse a través de capitulaciones matrimoniales. Hoy día, aunque se ha ampliado el círculo de legitimados y ya no se exige que el otorgamiento sea a través de capitulaciones matrimoniales, sino que basta con que se otorguen a través de escritura pública, no se puede olvidar la tradición matrimonial que estos pactos sucesorios tienen en el territorio catalán. En el ordenamiento jurídico portugués se admiten ciertos pactos sucesorios de institución, siempre vinculados a la institución del matrimonio, como prueba el hecho de que los pactos sucesorios tienen que estar celebrados a través de contrato matrimonial. Así, el art. 1700 del CC portugués recoge la convenção antenupcial, figura que puede contener tanto una disposición de heredero como legatario. En cuanto a los otorgantes de estos pactos sucesorios pueden realizarse por uno de los cónyuges a favor del otro, por una tercera persona a favor de cualquiera de los cónyuges o por los cónyuges a favor de una tercera persona. La regulación de tales figuras se remite además a la prevista para las doações para casamento (arts. 1753 y siguientes del CC portugués).
} 
la celebración de un pacto sucesorio entre dos cónyuges forman parte del mismo aspecto, cual es la organización del patrimonio de esas dos personas. Por ello, la posibilidad de elegir la ley del régimen económico matrimonial al pacto sucesorio tiene la ventaja de facilitar y simplificar esta organización del patrimonio al amparo del mismo ordenamiento jurídico. Además, esta elección sería en cierta manera, neutra: no se correspondería de forma necesaria con una circunstancia personal de los otorgantes.

\subsubsection{La lex rei sitae}

Junto a la ley de la residencia habitual, de la nacionalidad y del régimen económico matrimonial, ha habido propuestas que, aunque en menor medida, defienden la elección de la ley del lugar de situación de los bienes inmuebles ${ }^{474}$.

La elección de la lex rei sitae se concibe de forma limitada, pues se propone para regular únicamente la sucesión inmobiliaria ${ }^{475}$. Por ello, permitir la elección de la ley del lugar de situación del bien inmueble plantea el problema fundamental del fraccionamiento de la sucesión, en un momento en el que se ha consagrado el principio de unidad ${ }^{476}$. Aquellos que abogan por la elección de la lex rei sitae para la sucesión inmobiliaria entienden que una tal posibilidad permitiría facilitar las tareas de la administración de la herencia y otras que dependan de la ley del lugar de situación del inmueble.

\footnotetext{
${ }^{474}$ En el ámbito del Convenio de La Haya, se defendió la posibilidad de elegir la lex rei sitae, $\mathrm{P}$. LAGARDE, (1989), p. 262; J. PIRRUNG (1999), p. 1623; respecto del Reglamento europeo, MPI, (2010), núm. 149; en contra de la elección de la lex rei sitae ya se pronunció el Informe Dörner/Lagarde, (2002), p. 70;

${ }^{475}$ A. DAví propone la elección de la lex rei sitae para la sucesión inmobiliaria pero limitada a aquellos inmuebles que se encuentren en territorios de terceros Estados, pues tratándose de sucesión inmobiliaria dentro del territorio de la UE, entiende que no tendría virtualidad ninguna y supondría la ruptura del principio de unidad de sucesión sin necesidad alguna, al terminarse los problemas de coordinación entre los sistemas nacionales en cuanto a la concepción de las sucesiones internacionales por la armonización normativa de la mano de la norma comunitaria; vid. A. DAVÍ (2004), p. 482.

${ }^{476}$ Como bien es sabido, el principio de unidad de la sucesión ya se adoptó en el marco del Convenio de La Haya de 1989 y ahora se va a adoptar en el futuro Reglamento europeo; en los trabajos de la UE se puede apreciar cómo se quieren evitar los inconvenientes del fraccionamiento de la sucesión y la consiguiente creación de distintas masas sucesorias, mientras que adoptar un régimen unitario de la sucesión facilita al causante su planificación. Vid. por ejemplo el comentario al art, 16 de la Propuesta de Reglamento, COM (2009) 154 final.
} 
En lo que respecta a la elección de la lex rei sitae a los pactos sucesorios en concreto, esta posibilidad no tiene mayor particularidad alguna. Sí es cierto que en muchas ocasiones el objeto de los pactos sucesorios es un bien inmueble; pensemos en la tradicional explotación agrícola y actualmente en la transmisión de la empresa familiar. Sabiendo que en muchas ocasiones los bienes objeto de los pactos sucesorios son inmuebles, sí es cierto que la elección de la lex rei sitae podría facilitar el buen desarrollo de la sucesión paccionada, pero no como algo particular de los pactos sucesorios, sino por las ventajas que en cualquier tipo de sucesión presenta esta posibilidad de elección de ley.

No obstante, sí podríamos ver un cierto interés en la elección de la lex rei sitae como medio para facilitar la transmisión de la empresa familiar. Como hemos visto, desde hace dos décadas la UE muestra su preocupación por el número de pequeñas y medianas empresas que cierran su actividad como consecuencia de los problemas en su transmisión mortis causa. Por ello, los pactos sucesorios se ven como un medio idóneo de planificación anticipada de la sucesión, permitiendo así la transmisión exitosa de este tipo de empresas una vez fallecido su titular. Desde este punto de vista, y teniendo en cuenta también la postura que a favor de la promoción de los pactos sucesorios parece que mantiene la UE, sí cabría reconocer un cierto interés particular en la elección de la lex rei sitae a los pactos sucesorios cuyo objeto sea un bien inmueble, pues tal elección puede ampliar las posibilidades de encauzar la planificación y transmisión de la pequeña y mediana empresa a través de los pactos sucesorios, aumentándose así el número de transmisiones exitosas de estos bienes inmuebles.

\section{LA FORMA DE ELECCIÓN DE LA LEY APLICABLE A LOS PACTOS SUCESORIOS}

\section{La elección de ley como acto jurídico}

El ejercicio de la autonomía conflictual requiere siempre una determinada declaración de voluntad, que se deberá canalizar de una u otra forma en función de lo que exija la correspondiente normativa. La elección de ley es un acto jurídico, que como tal tiene un determinado régimen jurídico. En el presente epígrafe nos interesa ver cómo se elije la ley aplicable a las sucesiones en general 
y a los pactos sucesorios en particular ${ }^{477}$. Como vamos a ver, no es extraño que se establezcan determinadas exigencias formales a la elección de la ley aplicable a la sucesión por parte del causante, con el fin de garantizar que la ley elegida se corresponda con la verdadera voluntad del causante ${ }^{478}$. Grosso modo, se distinguen los sistemas que exigen que la elección de ley se canalice a través de una declaración expresa de voluntad del causante, de los que admiten también la elección de ley tácita o implícita. A su vez, dentro del primer tipo de sistemas se distinguen también aquellos que exigen la declaración expresa por escrito, de aquellos otros que la permiten también de forma oral.

Con carácter general, tratándose de la elección de ley aplicable a las sucesiones se exige una declaración de voluntad expresa por parte del causante. Entre este tipo de sistemas se encuentran el ordenamiento jurídico italiano, el ordenamiento jurídico belga, el Convenio de La Haya de 1989 y la Propuesta de Reglamento. Entre los sistemas que permiten una professio iuris tácita podemos señalar el ordenamiento jurídico suizo, el ordenamiento jurídico alemán y el propio Reglamento.

El art. 5.2 del Convenio de La Haya de 1989 establece que la designación de la ley aplicable a la sucesión debe expresarse en una declaración que cumpla los requisitos formales de las disposiciones por causa de muerte ${ }^{479}$. En el seno de los debates que dieron lugar a este Convenio se discutió sobre la posibilidad de la admisión de la designación de ley tácita o implícita, posibilidad que finalmente fue rechazada; incluso se debatió sobre si la designación de ley debía ser claramente expresada o únicamente expresada, bastando con que el operador jurídico en cuestión no tenga dificultad alguna en constatar la elección efectuada; se discutió también sobre si la designación de ley expresa debía constar por escrito o si bastaba con una mera declaración oral por parte del causante.

\footnotetext{
${ }^{477}$ Para un estudio completo de la professio iuris como negocio jurídico, con el análisis particular de las cuestiones de capacidad, forma y fondo, vid. J.M. FONTANELLAS MORELL (2010), pp. 225 y Ss.

${ }^{478}$ J.M. FONTANELLAS MORELL (2010), p. 220.

${ }^{479}$ La exigencia de formalidad de declaración expresa en la elección de ley aplicable se exige también en el art. 11 del Convenio, donde se establece la posibilidad de realizar un pacto de lege utenda por las partes otorgantes del pacto sucesorio.
} 
La Propuesta de Reglamento, siguiendo en este caso a su precedente inmediato, el Convenio de La Haya, estableció lo propio en su art. 17.2: la designación de ley se habría de expresar en una declaración que cumpliese los requisitos formales de las disposiciones por causa de muerte.

Lo cierto es que, con carácter general, la elección de ley tácita o implícita se ha visto con bastante recelo en el ámbito de las sucesiones. El miedo a contravenir la voluntad real del causante, en un momento en el que por las circunstancias tal voluntad puede ser difícil de constatar, ha llevado a que se prefiera una declaración expresa para que la professio iuris sea válida. La elección de ley implícita presenta además el inconveniente de crear una cierta incertidumbre en torno a la ley aplicable a la sucesión, siendo la seguridad jurídica una de las grandes ventajas a favor de la admisión de la professio iuris. No obstante, como hemos dicho, también hay sistemas en los que se ha dado entrada a la elección de ley implícita, como es el caso de Suiza y de forma más tímida Alemania. En el caso de Suiza la elección de ley implícita se ha abierto paso por vía jurisprudencial. La ley suiza de DIPr establece en distintas ocasiones en las que se refiere a la elección de ley aplicable a la sucesión el requisito de que tal designación se realice a través de testamento o pacto sucesorio ${ }^{480}$. En el marco de este sistema, por tanto, la elección de ley sucesoria se tiene que realizar a través de una de estas dos formas de disponer mortis causa. Ahora bien, no queda claro si la elección de ley debe ser expresa o si se admite también una posible elección tácita o implícita ${ }^{481}$. Sin embargo, existe ya una jurisprudencia consolidada desde hace años del Tribunal federal suizo en la que se admite la professio iuris tácita ${ }^{482}$.

\footnotetext{
${ }^{480}$ El art. 90.2 de la ley suiza de DIPr prevé la posibilidad de que el extranjero someta su sucesión a uno de sus Derechos nacionales, pero dispone que tal sometimiento se haga a través de testamento o pacto sucesorio. El art. 91.2 de la ley suiza de DIPr habla también de la elección a través de testamento o de pacto sucesorio cuando se refiere a la posibilidad del nacional suizo domiciliado en el extranjero de someter expresamente su sucesión a la ley de su último domicilio; en el art. 95.2 de la misma ley, cuando se trata de la determinación de la ley aplicable a los pactos sucesorios que afectan a una única sucesión, la ley suiza se refiere a la elección realizada en el pacto sucesorio.

${ }^{481}$ Sólo el art. 91.2 de la ley suiza de DIPr habla de que el difunto haya reservado expresamente la aplicación de la ley correspondiente a su último domicilio, lo que hace pensar a priori en la exigencia de una professio iuris expresa.

${ }^{482}$ La sentencia de 22 de diciembre de 1983 del Tribunal Federal establece que no es necesario que el testador se pronuncie en términos solemnes a favor de la aplicación del Derecho del Cantón al
} 
Además, no faltan voces dirigidas a apaciguar ese miedo y esa visión de la professio iuris implícita como una vía de inseguridad jurídica. A este respecto, se toman en cuenta distintos factores que ayudan a mostrar la voluntad indubitada del causante de la elección de una determinada ley para regular su sucesión, tales como la referencia a varios preceptos o instituciones propias de un determinado ordenamiento jurídico o la realización de la disposición por causa de muerte en un determinado idioma.

El Reglamento ha optado finalmente por permitir también la elección tácita. La elección deberá hacerse a través de una disposición con forma de disposición mortis causa y podrá tratarse bien de una elección expresa, bien de una elección tácita, esto es cuando se derive claramente de los términos de la disposición (art. 22.2) (83 $^{4}$. La inclusión de la posibilidad de la elección tácita en el Reglamento supone, a nuestro juicio, un acierto, en cuanto que permite al operador jurídico de turno valorar la verdadera intención del causante; así, existen casos en los que, pese a no hacer una elección expresa de la ley aplicable sí se

que pertecene; se admite, por tanto, una professio iuris tácita o implícita, bastando que el texto de la disposición contenga indicios inequívocos y pudiendo servirse el operador jurídico de elementos extrínsecos a la disposición por causa de muerte para esclarecer la voluntad a este respecto del causante (ATF 109 II 403). La sentencia de 6 de junio de 1985 del Tribunal Federal señaló que la professio iuris tiene que ser expresa o al menos clara e inequívoca (ATF 111 II 16). La sentencia de 3 de septiembre de 1998 del Tribunal Federal suizo permite una professio iuris tácita realizada a través de un testamento y declara que es suficiente que se den indicios suficientes para conocer la voluntad del causante de elegir una determinada ley para que se aplique a su sucesión; según este Tribunal, si la disposición a través de la que se elige la ley sucesoria no está clara o completa, se deberá interpretar el testamento e incluso usar elementos, pruebas y circunstancias exteriores al mismo para esclarecer tal elección (ATF 125 III 35). Por su parte, la doctrina a favor de una professio iuris implícita, A. BUCHER (1992), núm. 942; A. HEINI (1993), p. 759, donde se refiere a la jurisprudencia favorable a la elección tácita. No obstante, tratándose de la elección de ley respecto de los pactos sucesorios, en el comentario al art. 95.2 de la ley suiza de DIPr el autor apuesta por una professio iuris expresa, p. 783; B. DUTOIT (2005), p. 302. En el marco del sistema alemán, entienden que es posible una elección de ley tácita, H. DöLlE (1966), p. 236; también H. DÖRNER (2007), núm. 535, p. 277; R. BIRK (1998), art. 25, núm. 42, p. 1355.

${ }^{483}$ De esta forma se ha acogido la opinión de aquella doctrina que abogó por la inclusión de una elección tácita; vid. Informe Dörner/Lagarde se defendió que la elección debería resultar de forma clara de la declaración del causante, sin excluir en principio la posibilidad de elección tácita, vid. p. 71. El MPI en su comentario a la Propuesta de Reglamento también propone que para que la elección sea válida baste con que la designación de ley esté claramente demostrada y se infiera claramente de la disposición por causa de muerte y de las circunstancias, vid. MPI (2010), p. 72. También hubo quien se manifestó en contra de la admisión de la professio iuris tácita, vid. A. DAVÌ, para quien una tal posibilidad es inadecuada en el ámbito de las sucesiones, donde debe garantizarse el conocimiento de la verdadera voluntad del causante; vid. A. DAVÌ (2004), p. 486. 
infiere de manera indubitada por las referencias que el causante pueda realizar a normas o instituciones propias de la ley que quiere elegir ${ }^{484}$.

No pensamos, además, que sea inverosímil defender que una elección de ley aplicable al pacto sucesorio puede, en función de las circunstancias, constituir una elección tácita de ley sucesoria. Es decir, que la vía del art. 25.3 del Reglamento pudiera determinar una interpretación de elección tácita del art. 22.

\section{La forma de la elección de ley a los pactos sucesorios}

Las referencias normativas concretas sobre la forma en la que debe realizarse la elección de ley aplicable a los pactos sucesorios son muy escasas. El art. 95.2 de la ley suiza de DIPr parece exigir que el disponente, cuando elige la ley de su nacionalidad para regular el conjunto de su sucesión, tenga que elegir dicha ley a través del pacto sucesorio ${ }^{485}$. El Convenio de La Haya de 1989, al regular en su art. 11 la posibilidad de que las partes otorgantes del pacto sucesorio realicen un pacto de lege utenda establece que tal pacto deberá convenirse por designación expresa. De forma idéntica exigió la Propuesta de Reglamento en el art. 18.3 la elección a través de designación expresa. Por otro lado están aquellas legislaciones que no establecen previsión particular alguna respecto de la elección de ley aplicable a los pactos sucesorios, aplicándoseles las prescripciones que se exijan para la elección de ley aplicable a las sucesiones en general, como es el caso, por ejemplo, del ordenamiento jurídico alemán y el Reglamento, que en su art. 25.3 ha suprimido la referencia a la "designación expresa" que la Propuesta contenía.

Al no existir exigencia específica alguna para la elección de ley a través de los pactos de lege utenda, la forma de la elección de la ley aplicable a los pactos sucesorios va a ser la misma sea a través de una professio iuris, sea a través de un pacto de lege utenda. Tal circunstancia nos lleva al art. 22 del Reglamento

\footnotetext{
${ }^{484}$ Ya hemos tenido ocasión de analizar esta cuestión con mayor profundidad en, I. RoDRíGUEZURÍA SUÁREZ (2013), núm. 16.

${ }^{485}$ Dicho artículo, dedicado a regular la ley aplicable a los pactos que afectan a una única sucesión, establece que si, en el pacto, un disponente somete toda su sucesión al Derecho del Estado del que es nacional, este Derecho se aplicará en lugar de la ley de su domicilio.
} 
que permite en su apartado segundo tanto la elección expresa como tácita y que debe realizarse a través de una disposición mortis causa. En definitiva, la designación de ley podrá contenerse bien en un testamento, bien en un pacto sucesorio. Desde el punto de vista del pacto sucesorio, y en ausencia de pacto de lege utenda, para que el pacto se regule por la ley de la nacionalidad del disponente o de alguno de los disponentes o futuros causantes, en los supuestos de pactos que conciernen a más de una sucesión, no parece que sea necesario que la professio iuris se realice en el propio pacto sucesorio, sino que una professio iuris anterior, realizada válidamente, por ejemplo a través de un testamento, de conformidad con las exigencias del art. 22 del Reglamento, será suficiente para afectar al pacto sucesorio. Ahora bien, la elección de ley se podrá realizar igualmente en el propio pacto sucesorio, cumpliéndose así la exigencia de la inclusión de la elección en una disposición por causa de muerte.

En el caso de que la elección de la ley aplicable a los pactos sucesorios se realice a través de la vía propiciada por el art. 25.3 del Reglamento, esto es, mediante un pacto de lege utenda entre los otorgantes del pacto sucesorio, la elección de ley aplicable, que además en este caso es una elección de ley aplicable limitada únicamente al pacto sucesorio en cuestión y no al conjunto de la sucesión de quien se trate, al ser bilateral y tener que estar incluida en una declaración con forma de disposición por causa de muerte, debe contenerse en el propio pacto sucesorio o, según vimos con anterioridad, en un acuerdo posterior, que en todo caso, debería revestir la forma de pacto. La misma posibilidad de elección cierta, no necesariamente expresa, hay que considerar que está abierta para los pactos de lege utenda. Como hemos señalado en varias ocasiones, una de las características de los pactos sucesorios es su tipicidad, algo que facilita esta eventual elección tácita de ley cuando, por ejemplo, el o los pactos realizados se correspondan nominalmente (piénsese en el pacto de "mejora de labrar y poseer", de la ley de Derecho civil de Galicia) con una de las leyes nacionales de los otorgantes. 


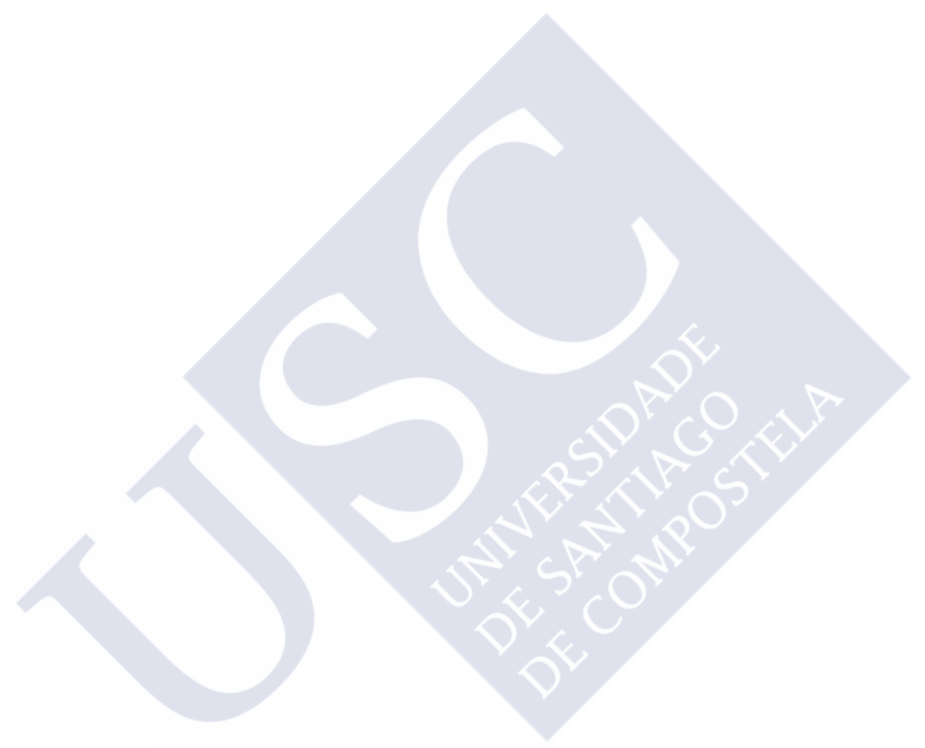




\section{CAPÍTULO IV: LA LEY APLICABLE A LOS PACTOS SUCESORIOS EN DEFECTO DE ELECCIÓN}

\section{Alternativas a la AUTONOMía CONFlictual. La CONEXiOneS SUCESORIAS}

\section{Las conexiones objetivas en el ámbito sucesorio}

Como hemos visto a lo largo de los anteriores capítulos, la ley aplicable a los pactos sucesorios ha estado ligada, con carácter general, a la ley sucesoria ${ }^{486}$. Por ello, para analizar la determinación de la ley aplicable a los pactos sucesorios en defecto de elección de ley se impone primeramente hacer referencia a las conexiones que típicamente se han utilizado para identificar la ley aplicable a las sucesiones internacionales.

Es bien sabido que estas conexiones varían de forma considerada. Tradicionalmente han existido dos formas distintas de abordar la ley aplicable a las sucesiones internacionales, distinguiéndose entre los sistemas que siguen la unidad de la sucesión y los sistemas que siguen el fraccionamiento de la sucesión. Los primeros establecen una solución basada en la aplicación de una única ley al conjunto de la sucesión. Los segundos establecen distintas soluciones de ley aplicable para la sucesión mobiliaria y para la sucesión inmobiliaria ${ }^{487}$.

Los sistemas que siguen una concepción fraccionada de la sucesión plantean soluciones distintas de ley aplicable para la sucesión mobiliaria y para la sucesión inmobiliaria. En esta concepción, por tanto, es importante tanto la naturaleza de los bienes que componen la herencia, como el lugar donde éstos se

\footnotetext{
${ }^{486}$ Tal y como hemos visto en el capítulo II lo habitual, y a salvo alguna excepción aislada y marginal, siempre ha sido la calificación sucesoria de los pactos sucesorios.

${ }^{487}$ La literatura sobre esta clásica diferenciación de las concepciones de las sucesiones internacionales es abundante; vid. principalmente, H. LEWALD (1925), pp. 12 y ss.; A.E. VON OVERBECK (1961), pp. 561 y ss.; M. FERID (1974), pp. 95 y ss.; F. BOULANGER (1981), pp. 38 y ss. Últimamente, A. BONOMI (2011), pp. 99 y ss.
} 
encuentren. Para la sucesión mobiliaria se establece una conexión basada en una circunstancia personal del causante, generalmente la ley de su último domicilio; mientras que para la sucesión inmobiliaria se establece la regla de la lex rei sitae. Esto significa que la sucesión se dividirá en distintas masas sucesorias cada una de las cuales con su propia ley aplicable. El mayor inconveniente que se predica de esta concepción es la multiplicación de leyes aplicables y el aumento de la dificultad del causante para planificar su sucesión por anticipado, en cuanto que tiene que tener en cuenta varios ordenamientos jurídicos con normas sustantivas generalmente dispares.

Por su parte, los sistemas que siguen la concepción de la unidad de la sucesión establecen una regulación unitaria de la sucesión, sin distinguir la naturaleza de los bienes que compongan la herencia y sin dar relevancia al lugar donde estén situados. Un único ordenamiento jurídico regula el conjunto de la sucesión y para determinarlo se fijan conexiones basadas en criterios personales del causante. La mayor ventaja de esta concepción es que, al aplicar una única ley al conjunto de la sucesión facilita la planificación de la sucesión, así como el propio desenvolvimiento de la misma. Estas razones, entre otras, explican que en los últimos años, la concepción de la unidad de la sucesión haya adquirido mayor peso frente a la concepción del fraccionamiento, como bien se puede ver fundamentalmente en los instrumentos multilaterales, tales como el Convenio de La Haya de 1989 o el propio Reglamento. Por ello, y con independencia del análisis que se ha realizado sobre la aplicación de la concepción fraccionada de la sucesión en los pactos sucesorios, nos ceñiremos ahora a la tendencia a la unidad de la sucesión y a las conexiones sucesorias que estos sistemas utilizan.

Precisamente, el segundo gran interrogante que siempre han suscitado las sucesiones internacionales se refiere a la elección de la conexión que va a determinar la ley sucesoria. En este sentido, es clásica también la tradicional distinción entre los sistemas que aplican la ley de la última nacionalidad del causante y los sistemas que aplican la ley del último domicilio del causante. A esta clásica dicotomía se añade en los últimos años la entrada en juego de la conexión de la última residencia habitual del causante, que ha ganado terreno, 
sobre todo en el ámbito europeo, frente a la conexión del domicilio ${ }^{488}$, de tal forma que la dialéctica se puede centrar ahora entre la conexión de la nacionalidad y la conexión de la residencia habitual.

\section{La dialéctica entre la conexión de la nacionalidad del causante y la conexión del domicilio o de la residencia habitual del causante}

\subsection{La dialéctica en el ámbito general del estatuto personal}

La dialéctica entre la aplicación de la ley de la nacionalidad o la aplicación de la ley del domicilio (o de la residencia habitual) es una de las tradicionales polémicas del DIPr que excede del ámbito de las sucesiones internacionales. En la regulación del estatuto personal se han dado diversas formas de abordar la solución de ley aplicable en función del tiempo y del espacio, de tal forma que podemos encontrar sistemas que aplican la ley de la nacionalidad, sistemas que aplican la ley del domicilio y, fundamentalmente desde mediados del siglo pasado, sistemas que aplican la ley de la residencia habitual. La opción por cada una de estas conexiones presenta, como veremos, sus propias ventajas e inconvenientes, si bien la falta de un criterio decisivo a favor de una de ellas tiene como resultado la fragmentación del Derecho comparado ${ }^{489}$. Grosso modo, se trata de primar la estabilidad en la determinación de la ley aplicable y la conservación de la una cierta identidad cultural, objetivos que encarnaría la conexión de la nacionalidad, frente a la opción de primar un criterio favorecedor de la integración y la no discriminación por razón de nacionalidad, con la conexión de la residencia habitual o del domicilio. Es un lugar común pensar que la opción por una u otra conexión responde en gran medida a razones políticas;

\footnotetext{
488 Mientras que la determinación del domicilio de una persona está más ligada a datos administrativos y registrales, se dice que la residencia habitual es un criterio que atiende a las circunstancias fácticas; vid. J.M. ESPINAR VICENTE (1994), pp. 24 y ss. Por otro lado, como vamos a ver, en el ámbito europeo el criterio de la residencia habitual es preferible al del domicilio porque éste depende de lo que diga la legislación del Estado en concreto, mientras que la residencia habitual es un concepto susceptible de una interpretación autónoma y, por tanto, uniforme, lo que es más apropiado cuando se trata de instrumentos multilaterales; vid. DE WINTER (1959), pp. 423 y ss.; A.E. Von OVERBECK (1989), p. 144; A. BonOMI (2011), pp. 177 y ss.; B. AUDIT (2010), pp. 143 y ss.; J. BASEDOW (2012), pp. 252 y ss.

${ }^{489}$ La literatura sobre esta cuestión es abundante, vid. entre otros, S. BRAGA (1953), pp. 227 y ss.; H. BATIFFOL (1956), pp. 278 y ss.; H. BATIFFOL (1959), pp. 498 y ss.; DE WinTER (1969), pp. 400 y ss.; A. BUCHER (1972), pp. 76 y ss.; P. LAGARDE (1986), pp. 67 y ss.; Y. LOUSSOUARN (1987), pp. 295 y ss.; J-Y. CARLIER (1992), pp. 216 y ss.; B. AUDIT (2010), pp. 129 y ss.;
} 
así, mientras los países con una fuerte emigración optarían generalmente por el criterio de la nacionalidad, para así conseguir la aplicación de su Derecho a sus nacionales, los países con una fuerte inmigración preferirían generalmente la conexión del domicilio, adoptando de esta forma un criterio favorecedor de la integración de los ciudadanos extranjeros. Hoy en día esto no está tan claro. El creciente peso, por ejemplo, del respeto a la identidad cultural (y dentro de esta, la jurídica) hace la nacionalidad siga contando en países de inmigración. O que los que han pasado de ser predominantemente países de emigración a países de inmigración (como España en los últimos tiempos) sigan manteniendo la conexión nacionalidad por razones, si se quiere, de tradición.

La cuestión de la dicotomía entre la ley de la nacionalidad y la ley de la residencia habitual es una discusión también tradicional en el ámbito de la UE. En los últimos años la residencia habitual ha venido ganando terreno como conexión objetiva en el ámbito comunitario, pero no obstante aún existen sectores doctrinales que no son partidarios de la utilización de esta conexión. En todo caso, esta cuestión tiene en el ámbito comunitario un cariz distinto ${ }^{490}$; la existencia de principios informadores propios del sistema de la UE modula el debate considerablemente. En este sentido, es de destacar que la aplicación de la ley nacional goza de mala fama como potencial vulneradora del principio de prohibición de discriminación por razón de la nacionalidad adelantamos que no somos de tal opinión, pero volveremos sobre el tema. A la hora de analizar la solución del Reglamento de sucesiones tendremos que tener en cuenta, por tanto, este contexto.

En este debate, la segunda mitad del siglo XX muestra una clara tendencia a favor de la utilización de la residencia habitual como criterio de conexión para la determinación de la ley aplicable a materias relacionadas con el ámbito personal y familiar, entre las que se encuentran también las sucesiones internacionales. En el ámbito convencional la residencia habitual ha cobrado protagonismo innegable y creciente como criterio de conexión en el marco de la Conferencia de La Haya; así, por ejemplo, la residencia habitual se erige como

\footnotetext{
${ }^{490}$ Vid. sobre esta dialéctica en el ámbito europeo, T. RAUSCHER (2004), pp. 130 y ss.
} 
criterio de conexión en el Convenio sobre competencia de autoridades y ley aplicable en materia de protección de menores ${ }^{491}$, el Convenio relativo a la competencia, la ley aplicable, el reconocimiento, la ejecución y la cooperación en materia de responsabilidad parental y de medidas de protección de los niños ${ }^{492} \mathrm{o}$ el Protocolo sobre la ley aplicable a las obligaciones alimenticias ${ }^{493}$, por no citar más que algunos, aunque ya podríamos remontarnos a uno de los primeros convenios post segunda guerra mundial (ley aplicable a las obligaciones alimenticias) y otros que le sucedieron.

Un proceso similar ha tenido lugar también en el seno de la UE. En este sentido, existen varios ejemplos de normas comunitarias en las que la residencia habitual se erige en la conexión principal para la determinación de la ley aplicable a las situaciones jurídicas internacionales ${ }^{494}$.

\subsection{La dialéctica en las sucesiones internacionales}

Esta clásica dicotomía también se reproduce, como hemos anunciado, en el contexto de la determinación de la ley aplicable a las sucesiones internacionales. En el ámbito de la UE la mayor parte de los EEMM siguen el criterio de la aplicación de la ley de la última nacionalidad del causante; constituyen ejemplo de este tipo de sistemas el ordenamiento jurídico alemán, el austriaco, el polaco, el húngaro, el rumano, el portugués, el italiano, el griego y el propio español. En menor medida, existen EEMM que aplican la ley del último domicilio del causante, como por ejemplo, el sistema danés, el estonio, el lituano o los sistemas que siguen la concepción del fraccionamiento de la sucesión en lo

\footnotetext{
${ }^{491}$ Convenio de 5 de octubre de 1961, arts. 1 y 2.

${ }^{492}$ Convenio de La Haya de 19 de octubre de 1996, arts. 5.1 y 15.1.

${ }^{493}$ Protocolo de 23 de noviembre de 2007, art. 3.1.

494 Reglamento (CE) núm. 4/2009, del Consejo, de 18 de diciembre de 2008, relativo a la competencia, la ley aplicable, el reconocimiento y la ejecución de las resoluciones y la cooperación en materia de obligaciones de alimentos, DOUE núm. L7, de 10 de enero de 2009, a través de la incorporación para el ámbito de la ley aplicable del Protocolo de La Haya de alimentos de 2007 (art. 15); Reglamento (UE) núm. 1259/2010 del Consejo, de 20 de diciembre de 2010, por el que se establece una cooperación reforzada en el ámbito de la ley aplicable al divorcio y a la separación judicial, DOUE núm. L343, de 29 de diciembre de 2010, donde, a falta de elección de ley, se le da preferencia al criterio de la residencia habitual frente al de la nacionalidad u otros (art. 8). Vid. sobre este proceso de incorporación paulatina del criterio de la residencia habitual en el ámbito europeo, A. RoDRíGUEZ BENOT (2010), pp. 198 y ss.
} 
que se refiere a la regulación de la sucesión mobiliaria, entre los que se encuentran el sistema francés, el luxemburgués o el inglés ${ }^{495}$. También se adhiere al criterio del último domicilio del causante en Europa el sistema suizo. Sin embargo, el criterio de la última residencia habitual del causante tiene una aplicación menor y se prevé únicamente en algunos sistemas que han sido objeto de ciertas reformas recientes, como por ejemplo el sistema búlgaro, el finlandés o el holandés.

La evolución que a favor del criterio de la residencia habitual se ha dado, con carácter general, en el ámbito del estatuto personal, también ha tenido sus manifestaciones en la regulación de las sucesiones internacionales. En este sentido, tanto el Convenio de La Haya de 1989 como el Reglamento recogen esta tendencia en sus soluciones de ley aplicable. El Convenio de La Haya de 1989 incluye la conexión de la residencia habitual del causante a la hora de establecer la solución objetiva de ley aplicable a las sucesiones internacionales, si bien no se elimina el juego de la conexión de la nacionalidad del causante. Dicho Convenio recoge una difícil solución de compromiso entre las dos conexiones antagónicas, nacionalidad y residencia habitual del causante en su art. 3. Este artículo establece en primer lugar que la sucesión se regulará por la ley de la última residencia habitual del causante, si en ese momento también fuera nacional de tal Estado (art. 3.1). Para el caso de que no coincidan residencia habitual y nacionalidad, el Convenio de La Haya establece como regla general la aplicación de la ley de la residencia habitual del causante en el momento del fallecimiento, siempre y cuando éste hubiera residido en tal Estado por un periodo no inferior a cinco años inmediatamente anterior a la fecha de su fallecimiento. Ahora bien, en cumplimiento de tal compromiso, el propio artículo prevé una excepción a esta regla, de tal forma que si en el momento del fallecimiento el causante tiene unos vínculos manifiestamente más estrechos con el Estado correspondiente a su nacionalidad, se aplicará la ley de éste (art. 3.2). Y para el caso de que el causante no cumpla el requisito mínimo de cinco años de residencia habitual, se aplica la ley de la nacionalidad, salvo que exista otra ley más estrechamente vinculada con

${ }^{495}$ DEUTSCHES NOTARINSTITUT (2002), p. 44. 
el causante (art. 3.3) ${ }^{496}$. Junto a esta solución objetiva no hay que olvidar que, como ya hemos visto, el Convenio permite también a la hora de regular la professio iuris la elección de la ley de la residencia habitual del causante, ya sea en el momento de la realización de la elección, ya sea en el momento del fallecimiento.

La conexión de la residencia habitual del causante también tiene un papel destacado en el Reglamento europeo sobre sucesiones. Es, de hecho, la primera conexión objetiva y el primer recurso en ausencia de professio iuris. Desde el inicio de los trabajos de la norma europea se valoró a la residencia habitual como la conexión sucesoria. La Propuesta de Reglamento estableció la conexión de la última residencia habitual del causante como solución de ley aplicable objetiva. El art. 16 de la Propuesta señalaba la aplicación al conjunto de la sucesión de la ley de la residencia habitual del causante en el momento del fallecimiento; es decir, a falta de elección de ley, la ley aplicable sería, sin excepción, la ley de la última residencia habitual del causante. La versión definitiva del Reglamento sigue manteniendo la conexión de la residencia habitual, si bien con un importante matiz respecto de la solución de la Propuesta. En el apartado primero de art. 21 del Reglamento se establece como regla general la aplicación de la ley de la residencia habitual del causante en el momento de fallecimiento, pero, seguidamente, en el segundo apartado, se establece una cláusula de excepción de los vínculos más estrechos. Dicho de otro modo, el juego de la residencia habitual del causante no es tan relevante, o mejor dicho definitivo, en el Reglamento como en la Propuesta, puesto que en el Reglamento la opción por la solución de la residencia habitual se ve flexibilizada con la posibilidad de excepcionar su aplicación por otra ley que de manera manifiesta está más estrechamente vinculada con el causante en el momento del fallecimiento ${ }^{497}$.

\footnotetext{
496 Sobre esta solución de compromiso, que ha sido criticada por su gran complejidad, vid. P. LAGARDE (1989), pp. 253 y ss.; A.E. VON OVERBECK (1989), pp. 144 y ss.; A. BORRÁs (1996-2), pp. 17 y ss.; J. PIRRUNG (1999), pp. 1619 y ss.

${ }^{497}$ Esta ley podrá ser cualquiera, pero seguramente la práctica nos dirá que en gran número de casos la excepción será precisamente a favor de la ley de la nacionalidad del causante.
} 
El creciente protagonismo del criterio de la residencia habitual que ha tenido lugar en el ámbito convencional y en el seno de UE, unido a la también mayor presencia de dicho criterio en los sistemas nacionales que han experimentado recientes modificaciones permite hablar del triunfo de la residencia habitual; de la residencia habitual como criterio regulativo básico o principal. No obstante esta evidencia, no han faltado voces que, como vamos a ver, han expresado su posición crítica en torno a la utilización de este criterio de conexión, frente al criterio de la nacionalidad del causante.

\section{LA DETERMINACIÓN DE LA LEY APLICABLE A LOS PACTOS SUCESORIOS QUE AFECTAN A UNA ÚNICA SUCESIÓN}

\section{Admisibilidad, validez material y régimen jurídico de los pactos sucesorios que afectan a una única sucesión: la estructura del art. 25.1 del Reglamento de sucesiones}

Antes de proceder a analizar las soluciones de ley aplicable a los pactos sucesorios que afectan a una única sucesión, creemos procedente hacer un breve recordatorio sobre los aspectos del pacto sucesorio incluidos en tales soluciones de ley aplicable. En todo negocio jurídico existen distintos aspectos que pueden ser sometidos a su vez a distintas leyes, tales como la validez material, la validez formal, los efectos... Lo mismo ocurre con los pactos sucesorios. En el análisis que realizamos, nos vamos a referir, en concreto, a la ley aplicable a la admisibilidad, validez material y régimen jurídico del pacto sucesorio. Seguimos esta clasificación (sobre todo por lo que se refiere a la diferenciación entre admisibilidad y validez material, cuestión que no es habitual en otros negocios jurídicos) por ser la que ha seguido el Reglamento de sucesiones y porque en este punto creemos que es la más adecuada de las que ofrece el panorama comparado para realizar un estudio analítico de esta cuestión.

También hemos de señalar que en el análisis de los pactos sucesorios que afectan a una única sucesión no vamos a jugar con la diferenciación de estas categorías, en cuanto que partimos del presupuesto de que la solución de ley aplicable cubre los tres aspectos de estos negocios jurídicos; es decir, la solución de la ley aplicable es la misma para la determinación de la admisibilidad, la 
validez material y el régimen jurídico de los pactos sucesorios que afectan a una única sucesión. Cosa distinta es la posible corrección que, en su caso, pueda sufrir el pacto sucesorio por parte de la ley sucesoria determinada en el momento del fallecimiento del disponente o futuro causante en lo que se refiere a la protección y determinación de los derechos de legitimarios y que además puede suponer problemas de eficacia real para lo acordado en el pacto sucesorio.

La razón fundamental por la que no se plantean especiales problemas en la determinación de la ley aplicable a la admisibilidad, validez material y régimen jurídico de los pactos sucesorios que afectan a una única sucesión es, precisamente, la existencia de una única ley sucesoria anticipada y el tradicional desdén por tener en cuenta otras posibles aproximaciones (singularmente, la contractual) en la que podrían darse entrada a dos o más centros de intereses personales (los distintos pactantes) con sus respectivos criterios de conexión. Esta clasificación o diversificación por razón del problema tiene mayor relevancia en los casos de pactos sucesorios que afectan a más de una sucesión, tal y como vamos a ver, puesto que, incluso sin salirnos de la perspectiva esencialmente sucesoria, la existencia de más de una ley sucesoria anticipada genera ciertas especialidades y puede suponer distintas soluciones de ley aplicable para cada uno de los aspectos que hemos diferenciado. Será en un momento posterior, sin embargo, cuando tratemos los pactos sucesorios que afectan a más de una sucesión analizaremos estos distintos aspectos con más detenimiento por la enjundia que respecto de este tipo de pactos se genera ${ }^{498}$.

\section{Aplicación de la ley sucesoria anticipada: neutralidad en la solución de ley aplicable}

\subsection{Aplicación de la ley de la nacionalidad del causante}

Tal y como hemos visto en el capítulo II, los sistemas que prevén una solución específica para la determinación de la ley aplicable a los pactos sucesorios se limitan a establecer una pequeña especialidad temporal respecto de

\footnotetext{
${ }^{498}$ Más adelante se analizarán los ámbitos de aplicación de estas categorías, concretándose los aspectos que forman parte de la admisibilidad, validez material y régimen jurídico de los pactos sucesorios.
} 
la conexión sucesoria, que en vez de determinarse en el momento del fallecimiento del causante se determina en el momento del otorgamiento del pacto sucesorio. Como también hemos señalado, la conexión de la nacionalidad del causante es la más habitual en los sistemas de DIPr nacionales de los Estados miembros para regular las sucesiones internacionales. Ejemplos paradigmáticos de este tipo de sistemas lo constituyen el ordenamiento jurídico alemán, que tal y como recoge el $\S 26$.V EGBGB, prevé la aplicación de la ley de la nacionalidad que el causante ostente en el momento del otorgamiento del pacto sucesorio o el propio ordenamiento jurídico español, que aplica la nacionalidad del causante en el momento del otorgamiento del pacto sucesorio ${ }^{499}$. La aplicación de la ley de la nacionalidad del causante se prevé además en el marco del Convenio de La Haya de 1989 cuando así se derive de la solución de compromiso que recoge el art. 3. Sin embargo, el Reglamento ha abandonado la conexión de la nacionalidad en el plano de las conexiones objetivas para determinar la ley aplicable a la sucesión.

Con carácter general, debemos destacar como dato fundamental que la aplicación de la ley de la nacionalidad del causante a los pactos sucesorios no implica mayor particularidad respecto de la utilización de esta misma conexión para las sucesiones internacionales en general. Por ello, en las líneas siguientes analizaremos cuestiones concernientes al uso de la conexión de la nacionalidad que serían igualmente válidas tanto para la sucesión testamentaria, intestada y para los pactos sucesorios en particular, con independencia de alguna pequeña particularidad que será destacada. En este sentido, la nacionalidad del causante, ya sea determinada en el momento del fallecimiento ya en el momento del otorgamiento del pacto sucesorio, presenta una serie de ventajas e inconvenientes que han de tomarse en consideración frente a la utilización de la conexión antagónica del domicilio o residencia habitual del causante ${ }^{500}$.

La primera de las ventajas que se predica de la conexión de la nacionalidad es que se trata de un criterio estable, que permite conocer con

\footnotetext{
${ }^{499}$ Según la interpretación que hemos seguido al analizar el artículo en el cap II.

${ }^{500}$ Vid. una buena síntesis de las ventajas e inconvenientes de la conexión de la nacionalidad en general, R. VANDER ELST (1991), pp. 403 y ss.; en el ámbito de las sucesiones internacionales, vid. A. BONOMI (2010-3), pp. 163 y ss.
} 
facilidad la ley aplicable a la sucesión ${ }^{501}$; la modificación de la nacionalidad es una cuestión compleja, sometida a ciertos requisitos estrictos, de tal forma que los cambios de nacionalidad son menos frecuentes que los cambios de domicilio o de residencia habitual. La estabilidad de la conexión de la nacionalidad se ha visto por la doctrina como una característica que en el ámbito sucesorio favorece una mayor facilidad en la planificación anticipada de la sucesión por parte del causante $^{502}$. La segunda de las grandes ventajas a predicar de la conexión de la nacionalidad es la de su fácil determinación; a diferencia de lo que ocurre con otros criterios de conexión, y fundamentalmente con la residencia habitual, es fácil conocer cuál es la nacionalidad de una persona (o incluso la ausencia de nacionalidad con la entrada de las soluciones especiales de reemplazo), lo que proporciona seguridad a la hora de conocer la ley aplicable a la sucesión ${ }^{503}$. En tercer lugar, es también habitual señalar el respeto a la identidad cultural como otra de las grandes ventajas de la conexión de la nacionalidad. En este sentido, ya vimos que el criterio de la nacionalidad permite mantener el arraigo cultural que las personas que viven en el extranjero tienen a su país de origen y, por tanto también, a su cultura jurídica, con la que pueden estar más familiarizadas ${ }^{504}$; y esto es especialmente real en el caso de las reglas sobre sucesiones. Por último, se ha legitimado también el uso de la conexión de la nacionalidad con base en una justificación democrática; la idea consiste en que desde el momento en que los nacionales son los que generalmente escogen a través del proceso electoral al parlamento de un país, tal persona está participando en la elaboración del sistema

\footnotetext{
${ }^{501}$ M.BuschBAum/M. KOHLER (2010), p. 111; A. BonOMI (2011), p. 185. Con carácter general, una de las ventajas que siempre se ha predicado de la conexión de la nacionalidad es la de su estabilidad, lo cual se ha valorado especialmente para los asuntos concernientes al estatuto personal, vid. E. JAYME (1988), p. 29.

${ }^{502}$ P. KINDLER (2010), p. 256. No obstante, como vamos a ver, en el marco del Reglamento la ley de la nacionalidad del causante va a poder ser la ley sucesoria, aunque no haya elección de ley, por el posible juego de la cláusula de los vínculos más estrechos.

${ }^{503}$ No obstante esta fácil determinación, no hay que olvidar las complicaciones que se pueden crear en los casos en los que el causante tiene más de una nacionalidad, si bien ya se establecen posibles soluciones a estas situaciones, tales como la aplicación de la nacionalidad correspondiente al foro o la búsqueda de la nacionalidad efectiva; vid. A. BONOMI (2011), p. 186: J. BASEDOW (2010), pp. 453 y ss.

${ }^{504}$ H-P. MANSEl (2010), p. 297; N. BouZA VidAL (2007), p. 15; E. JAYME (2012), pp. 24 y ss.
} 
legal de dicho país, de tal forma que lo esperable este sea el ordenamiento jurídico aplicable a esta persona ${ }^{505}$.

En contra de la conexión de la nacionalidad se suele apelar al criterio de la proximidad, en el sentido de que se entiende que generalmente el causante tiene el centro principal de su vida e intereses en el lugar donde reside en el momento de su fallecimiento, de tal forma que, en muchas ocasiones, los vínculos que se conservan con el país de la nacionalidad son meramente testimoniales. No obstante, vamos a ver cómo este argumento puede servir tanto para defender, como para ir en contra de criterio de la nacionalidad, pues en realidad va a depender de las circunstancias del caso concreto y no de la valoración genérica de la nacionalidad como punto de conexión. En efecto, si bien hay un número de casos en lo que la integración en el país de la residencia habitual es tal que el causante no guarda vínculo significativo alguno con el país de su nacionalidad, también hay casos en los que ocurre exactamente lo contrario; pensemos en el ejemplo de una persona que cambia su residencia habitual por motivos de trabajo, pero que mantiene su cónyuge e hijos, vivienda familiar y demás patrimonio hereditario relevante en el país de su nacionalidad. El tema de las segundas residencias en los países del sur de Europa por parte de jubilados procedente del norte o del Reino Unido, también es exponente de que residencia habitual y mayor proximidad no siempre van de la mano. Por otro lado, también se ha mencionado como un inconveniente a la utilización de la conexión de la nacionalidad el hecho de que la aplicación de tal criterio implica en la mayor parte de los casos la aplicación de un Derecho extranjero; generalmente las autoridades competentes para el conocimiento de la sucesión son las autoridades del país donde se abre la sucesión, normalmente el país del último domicilio del causante. Por ello, se plantean los problemas típicos de aplicación de Derecho extranjero, fundamentalmente de dificultad y de aumento de los costes, así como una mayor entrada al juego, en su caso, del orden público ${ }^{506}$.

\footnotetext{
${ }^{505}$ H-P. MANSEL (2010), p. 298.

${ }^{506}$ A. BONOMI (2010), p. 187.
} 
A estos datos, genéricos unos y más próximos al Derecho de sucesiones, otros, se uno en el ámbito de la UE la tradicional prevención contra la conexión nacionalidad. Tal y como hemos adelantado, el criterio de la nacionalidad se ha visto como difícilmente conciliable con el principio de la prohibición de discriminación por razón de nacionalidad, recogido en el art. 18 del TFUE y que se ha erigido en uno de los principios fundamentales de la integración europea. Ahora bien, el art. 18 del TFUE no llega a prohibir en ningún momento la utilización de la conexión de la nacionalidad ${ }^{507}$ y existen argumentos más que suficientes para no considerar de principio que la nacionalidad, como punto de conexión, pueda atentar contra dicha interdicción de no discriminación por razón de nacionalidad ${ }^{508}$. Además, la nacionalidad se ve con carácter general como un criterio contrario a la integración de las personas, lo que constituye un importante principio en el ámbito europeo. Según esta idea el principio de libre circulación y la creciente movilidad de los ciudadanos europeos recomiendan la integración de los ciudadanos en el país de acogida, lo que conduce al uso de criterios como el domicilio o la residencia habitual. Pero tampoco este argumento es absoluto, como bien pone de relieve la doctrina que no siempre identifica el uso de la conexión de la nacionalidad como algo necesariamente contrario a la integración ${ }^{509}$.

Como decíamos, todas estas ventajas e inconvenientes que se predican de la conexión de la nacionalidad respecto de las sucesiones internacionales son igualmente trasladables al concreto ámbito de la ley aplicable a los pactos sucesorios. Como única particularidad en lo que a estos atañe, sólo podemos significar que la nacionalidad del causante es una conexión extraña desde el punto

${ }^{507}$ U. Drobnig (1970), pp. 636 y ss.; A. RodríGUEZ BenOt (2010), p. 197; A. DUTTA (2009), p. 566; P. KINDLER (2010), p. 254; no estima que la conexión de la nacionalidad sea contraria al principio de prohibición de no discriminación, H. GAUDEMET-TALLON (2004), pp. 211 y ss.

${ }^{508}$ A. BONOMI (2010-3), pp. 163 y ss.

${ }^{509}$ En opinión de A. BONOMI la opción por la ley de la nacionalidad no tiene por qué implicar un obstáculo a la integración de las personas que viven en un país extranjero ni tampoco a la libertad de circulación en la UE; entiende, por el contrario, que el distinto tratamiento que puede derivarse para los extranjeros por la aplicación de la ley de su nacionalidad no tiene por qué verse de manera perjudicial, puesto que de hecho puede ser más beneficiosa para el causante y sus herederos y, además, la aplicación de tal Derecho es expresión del reconocimiento de la identidad cultural, como una forma más de integración basada en el respeto. Vid. las consideraciones a este respecto de A. BONOMI (2010), pp. 190 y ss. 
de vista de la naturaleza contractual de los pactos sucesorios. Los pactos sucesorios tienen una calificación sucesoria, pero ello no implica que debamos olvidar su doble naturaleza y, en concreto, su naturaleza contractual. Desde este punto de vista, debemos alertar de que la conexión de la nacionalidad no tiene relevancia sustancial en el ámbito de las obligaciones contractuales, por lo que desde esta estricta perspectiva de los pactos sucesorios tampoco debería tener relevancia en la determinación de la ley aplicable a estas figuras si pusiésemos énfasis en su dimensión contractual con preferencia a su dimensión sucesoria.

Obviamos referirnos aquí a la virtualidad de la nacionalidad a través de su utilización mediata mediante la professio iuris, pues en este caso no es tanto la conexión nacionalidad como la autonomía conflictual el elemento decisivo.

\subsection{EI Reglamento y la aplicación de la ley de la residencia habitual del causante.}

La importancia de la conexión de la residencia habitual ha ido creciendo en los últimos tiempos, tal y como ya hemos tenido ocasión de ver. En el ámbito de las sucesiones internacionales la conexión de la residencia habitual del causante no sólo se ha tomado en consideración en las últimas reformas legislativas de sistemas nacionales de DIPr, sino que el triunfo de esta conexión frente a la nacionalidad del causante ha culminado con la adopción del Reglamento. En el Reglamento la ley de la residencia habitual del causante en el momento del fallecimiento es la norma general aplicable a falta de elección de ley. Con la puesta en aplicación del Reglamento de sucesiones el 17 de agosto de 2015, ésta será la solución aplicable por nuestros tribunales, quedando desplazado el art. $9.8 \mathrm{CC}$, que previsiblemente seguirá aplicándose para las sucesiones que impliquen un conflicto interregional ${ }^{510}$.

\footnotetext{
${ }^{510}$ El Reglamento prevé en el art. 38 la habitual cláusula de inaplicación del mismo a los conflictos internos de leyes, si bien se abre la posibilidad a los EM de utilizar las soluciones previstas en el Reglamento para solucionar tales conflictos. Esto requeriría una toma de posición por parte del EM en particular. Vid. sobre la posibilidad de aplicar la solución comunitaria a los conflictos de leyes internos con un análisis concreto precisamente de las soluciones de ley aplicable a los pactos sucesorios, I.RODRÍGUEZ-URÍA SUÁREZ (2010), pp. 639-665. También, con carácter general, A. FONT I SEGURA (2007), pp. 212 y ss.
} 
Lo mismo ocurre en el caso de la determinación de la ley aplicable a los pactos sucesorios. El art. 25 del Reglamento establece una concreta solución de ley aplicable para estas figuras y, en concreto, el apartado primero se encarga de los pactos sucesorios que afectan a una única sucesión. En defecto de elección de ley aplicable a los pactos sucesorios (posibilidad prevista en el art. 25.3, a la que nos hemos referido en el Capítulo anterior), la ley aplicable a un pacto sucesorio que afecta a una única sucesión será la ley que, en virtud del Reglamento, fuese aplicable a la persona cuya sucesión queda afectada por el contenido del pacto sucesorio de haber fallecido ésta en el momento del otorgamiento. Dicho de otro modo, se aplicará la ley sucesoria anticipada, que será, con carácter general, la ley de la residencia habitual del futuro causante o disponente en el momento del otorgamiento del pacto sucesorio si no ha habido professio iuris alguna a favor de la ley de su nacionalidad, y siempre a salvo la operatividad de la cláusula de excepción a la ley más estrechamente vinculada.

También hemos visto cómo el criterio de la residencia habitual tiene una buena acogida en el ámbito de la UE al ser una conexión que promueve o favorece el desarrollo de ciertos principios estructurales europeos. En este sentido, es lugar común que la residencia habitual es una conexión que favorece la libre circulación de los ciudadanos europeos por la UE, ya que es un criterio claramente favorecedor de la integración de los ciudadanos extranjeros. Por otro lado, es un criterio de conexión que, a diferencia de lo que ocurre con la nacionalidad y el domicilio cuya determinación depende de lo que disponga al respecto la legislación de cada uno de los Estados Miembros, permite una interpretación autónoma, característica de especial relevancia cuando se trata del criterio de conexión de un Convenio o de una norma comunitaria ${ }^{511}$. Esta es una razón esencial para preferir el criterio de la residencia habitual y al criterio del domicilio; la determinación del domicilio depende de lo que diga la legislación de

\footnotetext{
${ }^{511}$ Vid. MPI (2010), núm. 132, pp. 64-65, donde se menciona la posibilidad de una interpretación autónoma de la residencia habitual como un valor determinante para decantarse por esta conexión. Especialmente significativa es la postura de A. DUTTA, que da un mayor valor al criterio de la residencia habitual frente al criterio de la nacionalidad, porque el ser un criterio susceptible de una interpretación autónoma permite una mayor unificación conflictual, frente al criterio de la nacionalidad que depende de lo que disponga la legislación de cada EM; vid. A. DUTTA (2009), pp. 566 y ss.; también, A. BONOMI (2011), pp. 177 y ss.
} 
cada Estado miembro, lo que puede dar lugar a una interpretación divergente en el contexto del Reglamento ${ }^{512}$.

Existen además otras razones específicas, privativas del fenómeno sucesorio a favor del criterio de la residencia habitual de causante. Se entiende que la residencia habitual del causante es el centro principal de su vida e intereses $^{513}$; esto es, se entiende que, con carácter general, ese es el lugar donde el causante tiene sus relaciones personales y patrimoniales más importantes. Es el lugar donde en principio estarán la mayor parte de los bienes hereditarios y también, por último, es el lugar donde seguramente residen los futuros herederos y posibles acreedores que el causante pudiera tener. Para terminar con esta batería de argumentos favorables al criterio de la residencia habitual del causante, se ha esgrimido también a favor de esta conexión el argumento del forum-ius. Dado que el criterio general de competencia judicial internacional es el de la residencia habitual del causante, con la utilización de esta conexión en el plano de la ley aplicable se consigue que los tribunales apliquen su propio Derecho, lo que es positivo porque permite acceder a unos procesos más justos y rápidos y evita a las partes los costes de la averiguación del Derecho extranjero ${ }^{514}$. Obviamente, es esta una ventaja o cualidad contingente, pues depende de que efectivamente las normas sobre competencia judicial internacional estén coordinadas a tal fin. Si pensamos en una competencia judicial internacional basada, por ejemplo, en el lugar de situación de los bienes (como ocurre con uno de los criterios de nuestro art. 23.3 LOPJ), la ecuación, y con ella, la ventaja, se rompe.

Entre los inconvenientes de la residencia habitual como criterio de conexión destacan dos fundamentalmente. El primero de ellos es el carácter inestable de la residencia habitual, que genera cierta inseguridad en el uso de esta

\footnotetext{
${ }^{512}$ Lo pone claramente de relieve, A. BONOMI (2010), p. 885; también, P. LAGARDE (2012), p. 699; G. KHAIRALLAH (2013), p. 50.

${ }^{513}$ A. DutTA (2009), p. 567; M. BuschBAuM/M. KohLER (2010), p. 112; MPI (2010), núm. 132, pp. 64 y 65; K. SCHURIG (2010), p. 345; también, A. BONOMI (2010), p. 887, quien se cuestiona qué factores pueden ser relevantes para la determinación de la residencia habitual.

${ }^{514}$ A. DUTTA (2009), p. 568; MPI (2010), núm. 132, p. 65; A. BONOMI (2011), pp. 180 y 181.
} 
conexión $^{515}$; su fácil modificación se ve como un peligro para las sucesiones internacionales, desde el punto de vista de que se puede convertir en una herramienta en manos del causante para frustrar los derechos inalienables que sobre su sucesión puedan tener determinados parientes próximos a su persona ${ }^{516}$. Ahora bien, también es cierto que en aquellos sistemas en los que se aboga por al aplicación de la ley de la residencia habitual del causante no se conocen casos en los que el causante haya buscado la frustración de los derechos de los parientes más próximos. Por otro lado, existen posturas escépticas por parte de la doctrina en torno a estos casos en los que supuestamente una persona cambia de residencia habitual con el único propósito de acogerse a una ley sucesoria que le da una mayor libertad de disposición ${ }^{517}$. Sobre este particular inconveniente debemos añadir además un matiz.

El fácil cambio de la residencia habitual del causante siempre se ha visto desde la perspectiva del peligro que supone para los derechos de legitimarios $\mathrm{u}$ otros análogos a favor de parientes próximos al causante ${ }^{518}$. Sin embargo, lo cierto es que un causante puede estar interesado en buscar en la ley sucesoria aspectos distintos al de unas cuotas legitimarias bajas; así, por ejemplo, puede buscar el uso de una concreta figura que se reconoce en un concreto Derecho, como por ejemplo la posibilidad de hacer un testamento por comisario; o puede buscar una forma distinta de disponer mortis causa que le ofrece unos resultados más adecuados para sus concretos intereses o su concreta planificación sucesoria, como por ejemplo, la sucesión contractual. Tratándose de pactos sucesorios el temor a la conexión de la residencia habitual por su fácil modificación podría ser mayor, en cuanto que cabría plantearse la posibilidad de un cambio de residencia habitual para el otorgamiento del pacto sucesorio; este cambio sería diferente al

\footnotetext{
${ }^{515}$ Vid. K. SCHURIG (2010), p. 346.

516 Vid. T. FRANTZEN (2004), pp. 188 y ss., donde el autor explica su posición contraria a la utilización en el ámbito europeo de la conexión de la residencia habitual por ser una conexión de carácter inestable y porque, en su opinión, tal criterio no expresa el vínculo más estrecho con las sucesiones internacionales.

${ }^{517}$ Vid. S. ÁlVAREZ GONZÁLEZ (2011), pp. 378 y ss.

518 Se habla de la posibilidad de cambio de residencia habitual en busca de un régimen más favorable a este respecto, vid. A. BONOMI (2010-2), p. 607; también A. BONOMI (2011), núm. 85, p. 182;
} 
cambio de residencia habitual para evadir derechos sucesorios, puesto que mientras este último sería un cambio para siempre, para no volver (ley de la residencia habitual del causante en el momento del fallecimiento), el cambio para el otorgamiento del pacto sucesorio podría ser momentáneo (ley de la residencia habitual del causante en el momento del otorgamiento del pacto sucesorio). Sin embargo, al igual que cuando se trata de la ley sucesoria, parece poco probable que una persona vaya a modificar toda su vida, aunque en este caso pueda ser temporalmente, con el único propósito de realizar un pacto sucesorio. Por otro lado, el peligro no es de la misma entidad que cuando se trata de la frustración de derechos legitimarios, aunque no hay que olvidar la postura recelosa de muchos ordenamientos jurídicos respecto de los pactos sucesorios. En todo caso, tanto tratándose de la ley sucesoria, como de la ley del pacto sucesorio, hay que tener en cuenta que en el marco del Reglamento, el causante no sólo tendrá que articular el cambio de residencia habitual, sino que además deberá poner los medios necesarios para evitar el juego de la cláusula de los vínculos más estrechos, lo que supone una mayor garantía para evitar la manipulación de la residencia habitual con tales fines.

El segundo de los inconvenientes a destacar es la difícil determinación de la residencia habitual; esta cuestión ha planteado siempre ciertas dudas, puesto que la residencia habitual, como circunstancia fáctica que es, nunca ha estado ajena a un cierto halo de incertidumbre en su determinación. Sin embargo, ha sido en el proceso de elaboración del Reglamento de sucesiones en donde las críticas se han acrecentado. Ya en la Propuesta de Reglamento se optó por no introducir noción alguna de lo que se debe considerar por residencia habitual del causante. Esta ausencia provocó que parte de la doctrina se planteara la pertinencia de la introducción de una definición o, al menos, ciertas pautas de lo que debiera entenderse por residencia habitual en el texto definitivo del Reglamento ${ }^{519}$. Sin embargo, finalmente se ha optado por mantener la ausencia de definición en el texto, quedando por tanto la determinación de cuándo el causante tiene su

${ }^{519}$ Vid. las consideraciones a este respecto de J. HARRIS (2008), quien recomendó si no introducir una definición de residencia habitual en la norma europea, si al menos establecer una especie de test autónomo que permita identificar dónde tiene la residencia habitual el causante, con el fin de asegurar así una aplicación uniforme de la norma europea. 
residencia habitual en un determinado lugar en manos de la jurisprudencia, aun a costa de no poder cerrar convenientemente el ámbito subjetivo del Reglamento, dejando fuera a importantes Estados, como el Reino Unido o Irlanda. Es conocido el desencuentro del Reino Unido con la utilización de la residencia habitual (amén de no estar de acuerdo tampoco con el sistema de claw back consagrado por el Reglamento).

Una de las cuestiones más problemáticas en la determinación de la residencia habitual de una persona es la fijación del tiempo necesario para entender que ha habido un cambio de residencia y que, por tanto, se ha adquirido por parte del causante una nueva residencia habitual. Existen casos claramente dudosos, por ejemplo en desplazamientos temporales por motivos de trabajo. Pensemos en el ejemplo de una persona que tiene su residencia habitual en España, donde además tiene la mayor parte de sus bienes y su familia; por motivos laborales tiene que ser desplazado a trabajar durante un cierto periodo de tiempo, y siempre con vistas a regresar a trabajar en España, a Italia. Si esa persona fallece en Italia, durante el periodo en que se encuentra en ese país por razones laborales, ¿cuál sería su residencia habitual? Otro supuesto habitual y problemático que se plantea en el ámbito de la UE es el caso, al que sumariamente nos referimos más atrás, de las segundas residencias o residencias temporales; generalmente se trata de pensionistas que pasan parte del año en su país de origen y otra parte en otro país, generalmente en búsqueda del buen tiempo. Un ejemplo habitual y representativo de este tipo de situaciones es el del pensionista alemán que pasa una temporada de seis meses en su país de origen y el resto del año Mallorca. Se plantea ante una situación así la difícil cuestión de determinar si esa persona tiene su residencia habitual en Alemania o en España ${ }^{520}$. Es un problema real que podría solventarse mediante el establecimiento de un plazo mínimo determinado de residencia continuada para entender que se ha adquirido una nueva residencia habitual a efectos de determinar la ley aplicable. Esta es la técnica que se incluyó en el Convenio de La Haya de 1989, donde el art. 3.2 establece que la sucesión se regulará por la ley de la residencia habitual del

\footnotetext{
${ }^{520}$ Vid. K. SCHURIG (2010), p. 346, donde se ponen además otros posibles casos problemáticos, como el de un estudiante universitario que se marcha un año al extranjero.
} 
causante en aquellos casos en los que éste hubiera residido en ese Estado durante el periodo de al menos cinco años que preceden de manera inmediata el momento del fallecimiento del causante ${ }^{521}$. En el marco del Reglamento de sucesiones, esta posibilidad fue desechada y no se exige periodo de residencia alguno para activar la aplicación de la ley de la residencia habitual del causante ${ }^{522}$.

Con carácter general son muchas las críticas que ha recibido el uso de la conexión de la residencia habitual del causante en el proceso de elaboración del Reglamento. A los problemas técnicos enumerados, generadores potenciales de una cierta inseguridad jurídica en la determinación de la ley aplicable, habría que añadir que la aplicación de esta ley va a suponer, por un lado, un cambio radical para la mayor parte de los EEMM, que como hemos señalado tradicionalmente han aplicado la ley de la última nacionalidad del causante. Ahora bien, no se debe dejar de tener en cuenta que la solución de la ley de la residencia habitual del causante convive con otras que flexibilizan en gran medida la opción por esta conexión y que amortiguan los inconvenientes de la misma. Ahí tenemos la estudiada posibilidad de elección de ley aplicable a la sucesión o a los pactos sucesorios directamente (posibilidades que ya han sido analizadas en el Capítulo III), y el posible juego de la cláusula de excepción de los vínculos más estrechos que supone una novedad de la versión definitiva del Reglamento europeo de sucesiones y que analizaremos a continuación. No negaremos en relación a esta última opción que la ley más estrechamente vinculada no plantea menores problemas de concreción que la residencia habitual, como pasamos a analizar.

\footnotetext{
${ }^{521}$ La regla se completa con una cláusula de los vínculos más estrechos a favor de la ley de la nacionalidad; ahora bien, para que se aplique la ley de la residencia habitual es necesario que se cumpla ese periodo mínimo de residencia de cinco años.

${ }^{522}$ La posibilidad de exigir un periodo mínimo de residencia, como medio para facilitar la determinación de la residencia habitual y también para evitar cambios sencillos de residencia por parte del causante con el fin de evadir las normas imperativas sobre reservas hereditarias, ha sido tomada en consideración; vid. en este sentido, las respuestas al Libro Verde de Sucesiones y Testamentos de la Cámara de Notarios Austriaca, p. 1; también del gobierno alemán, p. 2; la Federal Chambers of Notaries, p. 2; la Conferencia de Notarios de la Unión Europea, p. 3; Consejo Superior del Notariado, p. 12; la Corte de Casación francesa, p. 4; el gobierno finlandés, p. 2; GEDIP, p. 2; Ulrik Huber Institute, p. 3; gobierno de Lituania, p. 2; Nederlans Vereniging van Rechtspraak, p. 2; el gobierno holandés, p. 3; el gobierno sueco, p. 2. El MPI también tomó en consideración la posibilidad de exigir un periodo mínimo de residencia habitual, pero finalmente se rechazó esta posibilidad por ser un criterio inadecuado y del todo arbitrario; Vid. MPI (2010), núm. 113, p. 65; también, A. DUTTA (2009), p. 565.
} 


\subsection{EI Reglamento y la aplicación de la ley más estrechamente vinculada como excepción a la ley de la residencia habitual}

Con la versión definitiva del Reglamento europeo de sucesiones se añade otra posibilidad de ley aplicable a los pactos sucesorios a través de la previsión general de una cláusula de los vínculos más estrechos para la determinación de la ley sucesoria. El art. 21.2 del Reglamento dispone que cuando de forma excepcional, y cuando se desprenda claramente de las circunstancias del caso concreto, en el momento del fallecimiento del causante existan unos vínculos manifiestamente más estrechos con la ley de un Estado distinto al de su residencia habitual en el momento del fallecimiento, se aplicará la ley de ese otro Estado. Se trata de una típica (dentro de lo que de típicas pueden tener estas cláusulas) cláusula de excepción a la aplicación de la ley de la residencia habitual, sobre la base de la existencia de vínculos más estrechos a otra ley ${ }^{523}$. En el proceso de elaboración del Reglamento la previsión de esta cláusula de excepción es una novedad de la versión definitiva, pues la Propuesta no permitía exceptuar la aplicación de la ley de la residencia habitual del causante en el momento del fallecimiento, salvo por el ejercicio de una professio iuris a favor de la ley de la nacionalidad.

Aunque el juego de la cláusula de los vínculos más estrechos no es una solución habitual en las sucesiones internacionales ${ }^{524}$, no es la primera vez que se prevé tal posibilidad en este ámbito. Ya el Convenio de La Haya de 1989, dentro de la compleja solución de compromiso que recoge el art. 3, previó dos cláusulas de excepción de los vínculos más estrechos con un alcance distinto. La primera de ellas se recoge en el apartado segundo, en el que se establece la aplicación de la ley de la residencia habitual del causante, siempre y cuando se hubiera cumplido

\footnotetext{
${ }^{523}$ Vid. por todos, C.E. DuBLER (1983), passim.

${ }^{524}$ Más allá de la operatividad de cláusulas de excepción generales, como la del art. 15 LSDIP, la técnica de la cláusula de los vínculos más estrechos ha jugado tradicionalmente en el ámbito patrimonial. Algunos ejemplos los constituyen: arts. 4.5 y 6 Convenio sobre la ley aplicable a las obligaciones contractuales, hecho en Roma el 19 de junio de 1980; art. 4.3 o 8.4 del Reglamento (CE) núm. 593/2008 del Parlamento Europeo y del Consejo de 17 de junio de 2008 sobre la ley aplicable a las obligaciones contractuales (Roma I); art. 4.3 del Reglamento (CE) núm. 864/2007 del Parlamento Europeo y del Consejo de 11 de julio de 2007 relativo a la ley aplicable a las obligaciones extracontractuales (Roma II).
} 
el periodo mínimo de residencia continuada de cinco años en dicho Estado en un periodo inmediatamente anterior al del fallecimiento, a salvo que existan en ese momento unos vínculos manifiestamente más estrechos con el país de su nacionalidad, caso en el que se aplicará la ley correspondiente a este Estado. Se trata de una cláusula de excepción de los vínculos más estrechos limitada, pues sólo puede jugar a favor de la nacionalidad. La segunda cláusula de excepción que recoge este Convenio está en el apartado tercero del art. 3; en dicho apartado, aplicable cuando no se cumpla el requisito de residencia continuada del apartado segundo, se establece la aplicación de la ley de la nacionalidad del causante en el momento del fallecimiento, a salvo que el causante tenga unos vínculos manifiestamente más estrechos con otro Estado, caso en el que se aplicará la ley de éste. Esta segunda cláusula de excepción excluye la ley nacional, pero no se limita apriorísticamente a ninguna ley, con lo que podría ser incluso la de la residencia habitual del causante $\mathrm{u}$ otra ${ }^{525}$. Otro ejemplo de posible juego de la cláusula de los vínculos más estrechos en el ámbito de las sucesiones internacionales se recoge en el sistema suizo; la ley suiza de DIPr establece una cláusula general de excepción, aplicable a todas las soluciones de ley aplicable previstas por el sistema, entre ellas las sucesorias. Tal posibilidad está prevista en el art. 15 de la ley suiza DIPr y no se aplica en los casos en que haya habido elección de ley aplicable ${ }^{526}$.

En lo que se refiere al funcionamiento de la cláusula de excepción del Reglamento, debemos destacar que, como es habitual en este tipo de cláusula, no entra en juego en los casos en los que haya habido un ejercicio de autonomía de la voluntad conflictual por parte del causante ${ }^{527}$. Con la cláusula de excepción sólo se puede exceptuar la aplicación de la ley de la residencia habitual del causante. $\mathrm{Su}$ puesta en funcionamiento, es excepcional y exige un vínculo manifiestamente

\footnotetext{
${ }^{525}$ Vid. sobre estas cláusulas de excepción, P. LAGARDE (1989), pp. 255 y ss.; J. PIRRUNG (1999), pp. 1619 y ss.; A. BORRÁS (1996), pp. 17 y 18; A.E. VON OVERBECK (1989), pp. 144 y 145.

${ }^{526}$ Vid. F. VisChER (1988), pp. 15; B. DutOIT (2005), pp. 50 y ss; M. KELlER/D. GIRSBERGER (2004), pp. 185 y ss.: A. BUCHER/A. BONOMI (2004), pp. 104 y ss.

527 Así lo dispone el propio art. 21.2 del Reglamento, cuando se refiere a la ley "que fuese aplicable de conformidad con el apartado 1", esto es, cuando se trate de la ley del Estado en que el causante tuviera su residencia habitual en el momento del fallecimiento.
} 
más estrecho del causante con otra ley distinta a la de la residencia habitual ${ }^{528}$. No exige, sin embargo (como lo hace, por ejemplo el art. 15 LSDIP, que la ley de la residencia habitual tan sólo presente un muy débil vínculo con el causante). Tratándose de la determinación de la ley sucesoria ese posible vínculo manifiestamente más estrecho del causante con otra ley distinta a la de su residencia habitual se ha de valorar en el momento del fallecimiento de éste, tal y como señala el art. 21.2. Por último, debe reseñarse que los vínculos más estrechos se predican del causante y no, por ejemplo, de la sucesión. Se trata de un correlato entre la referencia personal de la ley excepcionada (residencia habitual del causante) y la que excepciona (más vinculada con el causante); correlato que también se produce en relación con el momento en el que ambas deben ser apreciadas: el momento del fallecimiento o el momento de otorgamiento de testamento o pacto.

En efecto, no perdamos de vista que el análisis que efectuamos lo hacemos porque la regla relativa a la ley aplicable a los pactos sucesorios importa la solución general convirtiéndola en ley sucesoria anticipada. La solución examinada se traslada a los pactos sucesorios, desde el momento en que el art. 25 dispone que se aplicará la ley que hubiera sido aplicable de conformidad con el propio Reglamento de haber fallecido el disponente o causante en el momento del otorgamiento del pacto sucesorio. La combinación de lo dispuesto en el art. 25.1 y el art. 21 del Reglamento da como resultado que la ley aplicable a los pactos sucesorios podrá ser, dejando siempre a un lado el posible ejercicio de la professio iuris, la ley de la residencia habitual del causante en el momento de otorgamiento u otra ley con la que en ese mismo momento el causante tuviera unos vínculos más estrechos. Dicho de otro modo, tratándose de la determinación de la ley aplicable a los pactos sucesorios, el posible vínculo más estrecho del causante con otra ley distinta a la de su residencia habitual debe valorarse en el momento del otorgamiento del pacto sucesorio. Además, debemos puntualizar que tratándose del juego de la cláusula de excepción para determinar la ley aplicable a los pactos

\footnotetext{
${ }^{528}$ Vid. con carácter general sobre la puesta en funcionamiento de las cláusulas de excepción, C.E. DUbler (1983), pp. 69 y ss.; también, W. WenGLER (1990), pp. 663 y ss.; J.D. GonZÁleZ CAMPOS (2002), pp. 253 y ss.
} 
sucesorios, los vínculos más estrechos de la ley en cuestión deben darse con el futuro causante o disponente y no con el pacto sucesorio en su conjunto. Esto es relevante en el sentido de que la ley más estrechamente vinculada con el causante no tiene por qué ser la ley más estrechamente vinculada con el pacto sucesorio, del mismo modo que, como hemos señalado, los vínculos más estrechos en la determinación de la ley sucesoria se predican del causante y no de la sucesión.

Pensemos en el ejemplo de un causante nacional alemán; éste debe trasladarse por un periodo más o menos largo a Francia por motivos laborales, pero deja en Alemania su esposa e hijos, así como su vivienda habitual y demás patrimonio. En Francia ostenta la participación de una empresa que lleva junto a su socio; el causante decide hacer un pacto sucesorio con su socio instituyéndole heredero en su parte de la empresa. La empresa es francesa, el pacto sucesorio se celebra en Francia y tanto el futuro causante como el instituido, el otro otorgante, tienen en ese momento su residencia habitual en París. En principio la ley aplicable a este pacto sucesorio sería la ley de la residencia habitual del causante en el momento del otorgamiento del pacto sucesorio, esto es, la ley francesa. Sin embargo, la conexión del causante con el territorio francés parece mucho más débil que la conexión con el territorio alemán, donde el causante mantiene su familia, vivienda familiar y la mayor parte de su patrimonio. Éste podría ser un caso en el que la cláusula de excepción de los vínculos más estrechos podría entrar en juego, dando lugar a la aplicación de la ley alemana que, por otro lado, determinaría la validez del pacto sucesorio celebrado. Esta es una importante diferencia entre el funcionamiento de la cláusula de los vínculos más estrechos en los pactos sucesorios y el funcionamiento de la misma cláusula en las obligaciones contractuales. En este último ámbito los vínculos más estrechos se valoran respecto de la relación contractual en general, tomando en cuenta todas las circunstancias del contrato (esto es, circunstancias personales de los contratantes, objeto del contrato, lugar de celebración, etc.); dicho de otro modo, los vínculos más estrechos se predican respecto del contrato ${ }^{529}$. Sin embargo, tratándose de los pactos sucesorios, y pese a su carácter contractual, los vínculos

${ }^{529}$ C.E. DUBler (1983), pp. 54 y ss.; M. VIRGÓs SORIANO (1996), p. 5295; C. PARRA RODRÍGUEZ (2001), pp. 323 y ss.; J.C. FERNÁNDEZ ROZAS/S. SÁNCHEZ LORENZO (2011), pp. 521 y ss. 
más estrechos se predican respecto del disponente o futuro causante, en cuanto que, en realidad, lo que se está determinando es su ley sucesoria anticipada. Obvia señalar, que el ejemplo podría darse la vuelta y el resultado ser el contrario: que la ley más estrechamente vinculada no admitiese el pacto o no lo considerase válido en el caso concreto.

La ley más estrechamente vinculada podrá ser en principio la ley de la nacionalidad del causante o podrá ser alguna otra ley distinta a la de su nacionalidad o residencia habitual, puesto que la cláusula de excepción no establece límite alguno en este sentido ${ }^{530}$. Tras el análisis de las conexiones antagónicas de la nacionalidad y la residencia habitual y la observación de casos muy variados que hacen difícil a priori determinar cuál de las dos conexiones es más adecuada por ser más próxima al causante, cabe pensar que en el caso de que haya una ley más estrechamente vinculada con el causante distinta a la de su residencia habitual, esta sea la ley de su nacionalidad ${ }^{531}$. Pero nada impide que pueda ser otra, como por ejemplo la ley del lugar donde el causante tenga la mayor parte de su patrimonio. Como bien es sabido, la razón de ser de la cláusula de los vínculos más estrechos es evitar que la aplicación de la clásica norma de conflicto rígida lleve a resultados inadecuados o absurdos en el caso concreto ${ }^{532}$..

Con carácter general, la cláusula de los vínculos más estrechos dota de flexibilidad a la solución de ley aplicable con el fin de conseguir una mejor localización en el caso concreto ${ }^{533}$; ahora bien, esta flexibilidad lleva aparejada en

\footnotetext{
${ }^{530}$ Como hemos visto, una de las cláusulas de excepción previstas en el Convenio de La Haya de 1989 sólo permite la excepción de la ley de la residencia habitual del causante a favor de la ley de su nacionalidad; vid. art. 3.2.

531 C.E. Dubler (1983), p. 100, donde señala que en el ámbito de las sucesiones cabría excepcionar la aplicación de la ley del último domicilio del causante a favor de la aplicación de la ley de la nacionalidad de éste, en aquellos casos en los que la mayor parte de los bienes se encuentren en este último país y con el fin de asegurar la eficacia de las decisiones en el espacio.

${ }^{532}$ Las cláusulas de excepción son la respuesta más directa de la doctrina europea a las críticas de la doctrina americana sobre el tradicional método conflictual de Savigny; vid. C.E. DUBLER (1983), p. 23.

${ }^{533}$ A la hora de poner en funcionamiento la cláusula de los vínculos más estrechos no se busca un resultado material concreto, sino únicamente una mejor localización de la relación jurídica en cuestión; por ello, esta cláusula se fundamenta en el principio de proximidad, vid. J.D. GoNZÁLEZ CAMPOS (2002), pp. 255; P. LAGARDE (1986), pp. 97 y ss.; D. KOKKINI-IATRIDOU (1994), p. 3; R. MEYER (1994), p. 311.
} 
cierta medida cierta imprevisibilidad a la hora de hallar la solución última de ley aplicable. En este sentido, hay quien entiende que la cláusula de los vínculos más estrechos es contraria a la seguridad jurídica ${ }^{534}$. En nuestra opinión, esta cláusula podrá ser un elemento garante de esa seguridad jurídica en el marco del Reglamento, con la ventaja fundamental de evitar esos absurdos a los que lleva en ocasiones la aplicación pura y simple de la ley de la residencia habitual del causante. Ahora bien, no hay que confundir estos casos con aquellos en los que no está clara cuál es la residencia habitual del causante; es decir, la cláusula de los vínculos más estrechos no podrá funcionar directamente como solución para determinar cuál es la ley aplicable en aquellos casos en los que la residencia habitual del causante es difícil de determinar ${ }^{535}$, sino que jugará como solución subsidiaria cuando, una vez determinada cuál es la residencia habitual del causante, se derive del caso concreto que hay otra ley manifiestamente más vinculada con el causante.

\section{El juego de la ley sucesoria como regla de validación: solución materialmente orientada}

\subsection{La regla de validación y su funcionamiento}

Hasta ahora hemos visto las soluciones de ley aplicable a los pactos sucesorios que afectan a una única sucesión y que tienen un carácter neutro o no materialmente orientado. Pero este tipo de pactos sucesorios pueden ser objeto también de soluciones de ley aplicable materialmente orientadas. Dejando al margen la materialización que conlleva la posibilidad de elegir la ley aplicable ${ }^{536}$, los pactos sucesorios que afectan a una única sucesión también han sido objeto de soluciones materialmente orientadas en soluciones y propuestas de soluciones. Ejemplo paradigmático lo constituye la llamada regla de validación ${ }^{537}$, expediente

\footnotetext{
${ }^{534}$ A. DAVÌ (2005), p. 319, quien señala que no es recomendable el uso de la cláusula de excepción de los vínculos más estrechos en materia sucesoria, dado el gran valor de seguridad jurídica en esta materia sobre todo para la planificación de la sucesión

${ }^{535}$ Vid. Considerando núm. 25 del Reglamento de sucesiones.

${ }^{536}$ Pues dicha elección se realizará, sin duda, en función del contenido material de la ley elegida. Vid. S. ÁlvAREZ GonZÁleZ (2005), p. 140; también en (2009), 23 y ss.

${ }^{537}$ El término "regla de validación" se debe a A.A. EHRENZWEIG (1974), p. 45 (con referencia a anteriores escritos a los que no hemos tenido acceso). El término se tomó prestado para los pactos
} 
que contemplaba la Propuesta de Reglamento, pero que decayó en el texto definitivo. Se trata de uno de estos tipos de materialización en los que la norma de conflicto busca una ley aplicable determinada o condicionada por la consecución de un determinado resultado material ${ }^{538}$. En el caso de la materialización operada a través de la regla de validación, tal resultado material no es otro que el de la propia validez de los pactos sucesorios que afectan a una única sucesión.

Aunque resulte obvio, debe partirse de que la regla de validación tiene cabida en aquellos sistemas en los que se establece una solución específica de ley aplicable para los pactos sucesorios, basada en la especialización temporal de la ley sucesoria; esto es, en aquellos sistemas en los que, en principio, la ley aplicable al pacto sucesorio que afecta a una única sucesión, es la ley sucesoria anticipada, esto es, la ley que hubiera sido aplicable a la sucesión del futuro causante de haber fallecido éste en el momento del otorgamiento del pacto sucesorio. En estos sistemas, por tanto, la ley sucesoria anticipada es la que determina en principio si el pacto sucesorio es válido o no (incluimos un concepto genérico de validez que incluye también la admisibilidad, por ejemplo).

La materialización que ahora analizamos consiste en dar entrada también (junto a la ley rectora del pacto sucesorio) a la ley sucesoria en términos de validez/invalidez del pacto sucesorio. Puede ocurrir que la ley sucesoria anticipada determine la invalidez del pacto sucesorio. Pensemos por ejemplo en un pacto sucesorio celebrado entre un padre que tiene residencia habitual en Italia en el momento del otorgamiento del pacto sucesorio y su hijo, a través del cual aquel instituye heredero a éste. En el marco, por ejemplo, de la Propuesta de Reglamento, este pacto sucesorio sería inválido de conformidad con la ley italiana, ley sucesoria anticipada, que prohíbe estas figuras con carácter general ${ }^{539}$. En estos casos de invalidez del pacto sucesorio de conformidad con la ley

sucesorios en el seno de la Conferencia de La Haya. Vid. Conférence de La Haye de droit international privé (1990), p. 436. El profesor Ehrenzweig mantuvo la hipótesis de la existencia de una "rule of validation" para los contratos internacionales una vez analizada la jurisprudencia al respecto en los tribunales de los EEUU, como veremos más adelante.

${ }^{538}$ Vid. con carácter general, H. BATIFFOL (1973), pp. 132 y ss.; A.E. VON OVERBECK (1983), pp. 73 y ss.; J.D. GONZÁLEZ CAMPOS (2002), pp. 355 y ss.

${ }^{539}$ Art. 458 CCit. 
sucesoria anticipada, la regla de validación constituye una posibilidad más de darle validez al pacto sucesorio, cuando así lo prevea la ley sucesoria, determinada en el momento del fallecimiento del causante. Esto es, pensemos que, en el ejemplo, el padre y disponente del pacto sucesorio modifica tiempo después su residencia habitual, que pasa a estar en Alemania, donde fallece. La ley sucesoria sería la ley alemana, ley que reconoce validez al pacto sucesorio celebrado entre el causante y su hijo ${ }^{540}$. La regla de validación, en definitiva, supone la posibilidad de reconocer validez al pacto sucesorio de conformidad con la ley sucesoria, determinada en el momento del fallecimiento, cuando ésta reconozca tal validez y a pesar de que de conformidad con la ley sucesoria anticipada el pacto sucesorio es inválido. En el caso de que sea la ley sucesoria la que reconozca la validez del pacto sucesorio será además ésta la que se aplique al mismo (esto es, a la validez y a su régimen jurídico).

La relación entre la ley sucesoria anticipada y la ley sucesoria en este contexto no es de alternatividad; no se aplica indistintamente una u otra ley. La ley aplicable a los pactos sucesorios que afectan a una única sucesión es la ley sucesoria anticipada y sólo para el caso de que ésta no prevea la validez del pacto sucesorio se entra a valorar la aplicación de la ley sucesoria como regla de validación. Es decir, se trata de una aplicación de forma sucesiva, que funciona únicamente en el caso de que la ley sucesoria anticipada declare inválido el pacto sucesorio. En un pacto sucesorio celebrado entre un padre y su hijo, a través del cual el padre instituye heredero a su hijo, el padre tiene residencia habitual en Suiza en el momento del otorgamiento del pacto sucesorio y residencia habitual en Alemania en el momento del fallecimiento. En un sistema en el que la residencia habitual fuera la conexión que determina tanto la ley sucesoria, como la ley sucesoria anticipada ocurriría que ambas leyes, la alemana y la suiza, prevén la validez del pacto sucesorio; pero sólo sería aplicable la ley suiza, a título de ley sucesoria anticipada; al reconocer ésta ley la validez del pacto sucesorio en

${ }^{540} \S 2278 . I$ BGB; BROX/WALKER (2007), núms. 153 y 154. 
cuestión $^{541}$, ni siquiera se entraría a valorar lo que diga la ley sucesoria, la alemana, al respecto.

Esta relación es importante, ya no tanto desde el punto de vista de la determinación de la validez de los pactos sucesorios, sino fundamentalmente respecto de la determinación del régimen jurídico de los mismos, que puede variar significativamente. Tratándose de pactos sucesorios que afectan a una única sucesión no hay distinción entre ley aplicable a la validez del pacto sucesorio y ley aplicable al régimen jurídico del mismo, esto es, contenido del pacto sucesorio, modificación y causas de extinción del mismo. Debe recordarse que el carácter generalmente reglado o incluso típico de los pactos sucesorios implica que no sea lo mismo aplicar una ley u otra. Puede ocurrir que exista una causa de revocación en la ley sucesoria, que sin embargo no exista en la ley sucesoria anticipada. Pensemos por ejemplo en un pacto sucesorio a través del cual un cónyuge instituye heredero al otro; tanto la ley sucesoria anticipada como la ley sucesoria reconocen la validez del pacto sucesorio, pero la ley sucesoria anticipada prevé una causa de revocación automática para el caso de separación o divorcio de los cónyuges, mientras que la ley sucesoria nada dice al respecto. En el momento del fallecimiento del causante los cónyuges estaban divorciados; de aplicarse la ley sucesoria anticipada el pacto sucesorio se entenderá recovado y el instituido no heredará nada a su través. Sin embargo, de aplicarse la ley sucesoria no habrá revocación alguna y el instituido sí heredará. La aplicación de una u otra ley, por tanto puede tener consecuencias muy distintas. De ahí que tenga tanta relevancia la relación entre ambas leyes; en el ejemplo, esta relación sucesiva implicaría la aplicación de la ley sucesoria anticipada, al reconocer ésta la validez del pacto sucesorio, tanto a la validez como al régimen jurídico del pacto sucesorio, sin importar lo que diga al respecto la ley sucesoria.

Como resulta evidente, con la regla de validación se aumentan las posibilidades de celebrar válidamente pactos sucesorios que afectan a una única sucesión, en cuanto que abre la posibilidad de que se aplique a los mismos otra ley distinta a la ley sucesoria anticipada; por ello, la previsión de una regla de

${ }^{541}$ Arts. 494 y ss. del CC suizo. 
validación es una forma de materialización donde el objetivo material a conseguir es el de la validez de los pactos sucesorios que afectan a una única sucesión.

La idea de la validación no es originaria de los pactos sucesorios; han existido y existen otros ejemplos de validación en otras materias, especialmente en contratos internacionales. De hecho, debe recordarse a este respecto la teoría de EHRENZWEIG sobre la regla de validación de los contratos internacionales que derivó del análisis de la jurisprudencia de los tribunales de EEUU. Según esta hipótesis, los tribunales podrían aplicar (y de hecho aplicaban) la ley del foro $\mathrm{u}$ otra ley que tuviera suficientes contactos con el contrato en cuestión, de tal forma que la aplicación de tal ley supusiera la validación del contrato por cumplir éste con las exigencias formales de la misma ${ }^{542}$. Este es el supuesto más parecido a la regla de validación de los pactos sucesorios. Existen otros ejemplos que recogen la idea de validación, si bien el mecanismo es técnicamente distinto. No idéntico, también en el ámbito contractual, es el art. 3112 del CC de Québec, que impide la aplicación de la ley elegida cuando ésta determine la invalidez del contrato; para tales casos, el CC de Québec establece la aplicación de la ley que presente los vínculos más estrechos con el acto en cuestión ${ }^{543}$. La idea de validación también derivó en lo que ahora conocemos como soluciones de ley aplicable con conexiones alternativas, como ocurrió por ejemplo con la ley aplicable a la forma de los contratos ${ }^{544}$. Esta es una técnica cercana a la de la regla de validación, pero con un funcionamiento distinto. Como hemos visto, tratándose de la regla de validación de los pactos sucesorios la relación entre la ley sucesoria anticipada y la ley sucesoria se construye en términos sucesivos; es decir, sólo cuando la primera ley no prevé la validez del pacto sucesorio entra en juego la segunda. Sin embargo, tratándose de conexiones alternativas, la relación entre las leyes es de igualdad y de simultaneidad en el tiempo; es decir, no hay una preferencia en el tiempo para la aplicación de una de las leyes, sino que cualquiera de ellas puede

\footnotetext{
${ }^{542}$ Vid. una síntesis de esta teoría, A.A. EhrenZweIG (1959), pp. 874-881. También, crítico con esta teoría, B. CURRIE (1965), pp. 243-339. Con carácter más general, M. ABEND (1994), passim.

${ }^{543} \mathrm{El}$ art. 3112 del CC de Québec dice, "si la loi désignée rend l'acte juridique invalide, les tribunaux appliquent la loi de $\mathrm{l}^{\prime}$ Etat qui, compte tenu de la nature de l'acte et des circonstances qui l'entourent, présente les liens plus étroits avec cet acte".

${ }^{544}$ M. ABEND (1994).
} 
ser la aplicable indistintamente ${ }^{545}$. En definitiva, existen distintas técnicas que recogen la idea de validación de un acto jurídico, pero la que más se acerca a la técnica prevista para los pactos sucesorios que afectan a una única sucesión es la teoría construida por el profesor Ehrenzweig sobre la "rule of validation" empleada por los tribunales de EEUU para los contratos internacionales.

\subsection{Contexto sustantivo de la regla de validación: pactos sucesorios que afectan a una única sucesión}

\subsubsection{Instrumentos normativos que prevén la regla de validación}

Existen varios instrumentos normativos en los que se recoge (o se ha recogido) una regla de validación aplicable a los pactos sucesorios. Hemos estado hablando de la regla de validación como solución materializadora aplicable a los pactos sucesorios que afectan a una única sucesión. En este epígrafe, por tanto, deberíamos hablar únicamente de casos en los que se prevé una regla de validación para este tipo de pactos sucesorios. Sin embargo, existen supuestos en los que la regla de validación está prevista para cualquier tipo de pacto sucesorio, aunque ello sea posiblemente consecuencia de la inconsciencia o falta de visión del legislador a la hora de tratar el tema, pues resulta altamente inadecuado aplicar una solución tal a los pactos sucesorios que afectan a más de una sucesión, como veremos en el epígrafe siguiente. Algunos de los sistemas que prevén la regla de validación lo regulan de forma específica, como es el caso del Convenio de La Haya de 1989 o como fue el caso de la Propuesta de Reglamento. Otros la prevén de forma genérica, como es el caso del sistema austriaco o el caso del propio art. 9.8 CC según cómo se interprete. Es precisamente en este segundo tipo de sistemas que recogen la posibilidad de validación con carácter general donde la fórmula implica la posibilidad de aplicar la validación también a los pactos sucesorios que afectan a más de una sucesión.

El instrumento normativo más notable en que se ha recogido el posible juego de la ley sucesoria como regla de validación para los pactos sucesorios que

${ }^{545}$ M. REQUEJO ISIDRO (1998), pp. 102 y ss. 
afectan a una única sucesión es el Convenio de La Haya de $1989^{546}$. Uno de los debates más intensos que tuvo lugar en el seno de la Conferencia fue precisamente el de la inclusión o no de la regla de validación, dada su polémica desde el propio punto de vista de los intereses conflictuales de los pactos sucesorios. El art. 9 del Convenio, después de establecer la aplicación de la ley sucesoria anticipada en el primer párrafo, establece en el segundo apartado que aún en el caso de que conforme a dicha ley el pacto sucesorio no sea válido, se admitirá su validez cuando dicho pacto lo sea según la ley aplicable a la sucesión en el momento del fallecimiento. El apartado concluye con la referencia a la aplicación de esta misma ley a los efectos del pacto y a las circunstancias que den lugar a la extinción de tales efectos; es decir, en el caso de que sea la ley sucesoria la que valide el pacto sucesorio, se aplicará ésta también a su régimen jurídico.

Su inclusión no fue pacífica, tal y como se desprende de los debates en el seno de la Conferencia. El mayor inconveniente que se presentaba era precisamente el mismo que había aconsejado establecer un punto de conexión en el momento del otorgamiento del pacto sucesorio y no en el momento del fallecimiento del causante: la seguridad jurídica. Finalmente, el deseo de facilitar el reconocimiento de la validez de este tipo de pactos sucesorios hizo que la regla de validación se mantuviera ${ }^{547}$, aunque la votación a través de la cual finalmente se aprobó fue muy ajustada; de hecho, hubo empate ${ }^{548}$.

\footnotetext{
${ }^{546}$ Como sabemos, el Convenio de La Haya de 1989 nunca llegó a entrar en vigor puesto que sólo fue ratificado por Países Bajos, si bien sus soluciones son aplicables en este país por la incorporación que se realizó del Convenio a través de la ley de 4 de septiembre de 1996 en la que se regulaban los conflictos de leyes en materia de sucesiones y cuyo primer artículo disponía la remisión a las normas del citado Convenio para la determinación de la ley aplicable a las sucesiones internacionales. Esta ley se puede consultar en Rev. crit. dr. int. pr., 1997, anotada por D. VAN ITERSON (1997), pp. 135-138 Vid. también la nota informativa a la ley de A. BORRÁS RODRÍGUEZ (1996), pp. 363-364.

${ }^{547}$ W.M. WATERS (1990), p. 580.

${ }^{548}$ La votación tuvo un resultado de: 9 votos a favor de la supresión de la regla de validación (Argentina, Australia, Bélgica, Finlandia, Francia, Grecia, Japón, Luxemburgo y Suiza), 9 votos en contra de la supresión, es decir, a favor del mantenimiento de la regla de validación (Canadá, Chile, Dinamarca, España, EEUU, Hungría Irlanda, Italia y Países Bajos) y 11 abstenciones (República Federal de Alemania, Austria, China, Israel, México, Polonia, Portugal, Reino Unido, Suecia, la antigua Checoslovaquia y Venezuela); finalmente se mantuvo de conformidad con la regla de la ballotage. Vid. Conférence de La Haye de droit international privé (1990), p. 437.
} 
La regla de validación para los pactos sucesorios que afectan a una única sucesión también se recogió en la Propuesta de Reglamento. El texto era considerablemente más favorable a la validez de los pactos sucesorios que la versión definitiva del Reglamento y una de esas manifestaciones del favor validitatis era a través de esa regla de validación. Siguiendo, como muchas otras veces, la estructura del Convenio de La Haya de 1989, la Propuesta de Reglamento establecía en su art. 18.1 in fine la posibilidad de validar el pacto sucesorio que afecta a una única sucesión cuando la ley sucesoria previera su validez y pese a que la ley sucesoria anticipada lo entendiera inválido. Se señalaba igualmente que en tal caso sería esa misma ley la que se aplicaría al régimen jurídico del pacto sucesorio validado. La regla de validación para los pactos sucesorios que afectan a una única sucesión ha desaparecido en el texto definitivo del Reglamento europeo de sucesiones, bien porque la UE haya tomado conciencia de los inconvenientes que en muchas ocasiones crea esta opción, bien por ese giro político drástico que supone el abandono de la clara tendencia favorecedora a la validez de los pactos sucesorios que recogía la Propuesta de Reglamento y que no afecta solamente a la técnica que ahora analizamos.

Como hemos adelantado, tanto el Convenio de La Haya de 1989 como el texto de la Propuesta de Reglamento limitaban la aplicación de la regla de validación a los pactos sucesorios que afectan a una única sucesión. Esta limitación sólo se recoge en estos casos, donde hay una regulación específica de los pactos sucesorios y una debida clasificación de los mismos a efectos conflictuales realizada en función del número de sucesiones afectadas. Sin embargo, como hemos señalado, hay otros sistemas que recogen una posibilidad de validación genérica y que, por tanto, se aplica indistintamente a pactos sucesorios que afectan a una única sucesión y a pactos sucesorios que afectan a varias sucesiones.

Forma parte de este segundo tipo de sistemas el art. 9.8 CC de conformidad con una de las posibles interpretaciones que admite este artículo. Según esta interpretación el segundo inciso del art. 9.8 CC, cuando dice que "los pactos sucesorios ordenados conforme a la ley nacional del testador o del 
disponente en el momento de su otorgamiento conservarán su validez, aunque sea otra la ley que rija la sucesión" en realidad está estableciendo una norma específica para la ley aplicable a los pactos sucesorios basada en la ley sucesoria anticipada; ahora bien, dado que la regla general del art. 9.8 CC es la aplicación de la ley de la nacionalidad del causante en el momento del fallecimiento, nada parece impedir la validez del pacto sucesorio si así lo es conforme a esta última ley y aunque no lo sea de conformidad con la ley de la nacionalidad de disponente en el momento del otorgamiento del mismo ${ }^{549}$.

Junto con el art. 9.8 CC según la interpretación mostrada, existe también una posibilidad de validación recogida de forma genérica en el sistema austriaco. Tal y como hemos visto en el capítulo II, la ley austriaca de DIPr dedica los $\S 28$ a 30 a las sucesiones internacionales. En cuanto a los pactos sucesorios recoge el estatuto del otorgamiento, de tal forma que se les aplica la ley de la nacionalidad del futuro causante determinada en el momento del otorgamiento del pacto sucesorio. Pero al lado de esta solución, se permite la aplicación de la ley sucesoria, la ley de la nacionalidad del causante en el momento del fallecimiento, cuando ésta prevea la validez del pacto sucesorio y el estatuto del otorgamiento hubiera determinado su invalidez.

Ni el sistema español ni el sistema austriaco realizan la pertinente diferenciación de los pactos sucesorios en función del número de sucesiones afectadas a efectos de dar las soluciones de ley aplicable. Es ésta la razón por la que en estos sistemas la regla de validación se aplicaría igualmente a los pactos sucesorios que afectan a una única sucesión y a los pactos sucesorios que afectan a varias sucesiones. Sin embargo, debemos destacar que la regla de validación,

\footnotetext{
${ }^{549}$ Somos conscientes de que esta es una de las interpretaciones posibles del art. $9.8 \mathrm{CC}$ y que es igualmente posible defender una posible validación en sentido inverso al que venimos analizando; es decir, podría entenderse que en primer lugar se aplica la ley de la nacionalidad del disponente en el momento del fallecimiento y que sólo para el caso de que ésta entienda que el pacto sucesorio es válido se consulta la ley de la nacionalidad en el momento del otorgamiento. No obstante, tal y como hemos visto en el capítulo II esta interpretación es inadecuada por ser contraria a los intereses de los pactos sucesorios; por ello entendemos que la mejor de las interpretaciones del art. 9.8 desde el punto de vista de los pactos sucesorios es la que pasa por aplicar a los mismos la ley sucesoria anticipada o ley de la nacionalidad del causante en el momento del otorgamiento. Sobre las posibles interpretaciones vid. S. ÁlvarEZ GONZÁLEZ (2012), pp. 158 y ss.
} 
con independencia de sus ventajas e inconvenientes que serán analizadas a continuación, es un mecanismo adecuado únicamente para los pactos sucesorios que afectan a una sola sucesión. Esta razón, unida a que la validación aplicable a los pactos sucesorios que afectan a varias sucesiones en los sistemas que la prevén de forma genérica es posiblemente más bien fruto de la inconsciencia del legislador a la hora de tratar el tema que un resultado intencionado (en el caso español, sin duda estaba pensando en la validación de testamentos ${ }^{550}$ ), explica que estemos analizando la regla de validación en el epígrafe dedicado a la solución de ley aplicable a los pactos sucesorios que afectan a una única sucesión.

\subsubsection{Problemas de inadecuación de la regla de validación en los pactos sucesorios que afectan a más de una sucesión}

Tal y como hemos sostenido hasta el momento la regla de validación es un mecanismo adecuado para los pactos sucesorios que afectan a una única sucesión. Pese a la existencia de sistemas como el austriaco o como el art. 9.8 CC que pueden posibilitar la aplicación de la regla de validación a los pactos sucesorios que afectan a varias sucesiones, nosotros sostendremos que éste es un mecanismo de materialización para los pactos sucesorios que afectan a una sucesión. El objeto del presente epígrafe es poner de manifiesto los porqués de la inadecuación de una tal solución a los pactos sucesorios que afectan a más de una sucesión.

La clave está precisamente en el hecho de que haya más de una sucesión afectada por el contenido del pacto sucesorio. Ello nos lleva a que hay varias leyes sucesorias anticipadas, tantas como número de sucesiones afectadas tenga el pacto sucesorio. De igual forma, habrá tantas leyes sucesorias (esto es, leyes que podrían prever la validación de pacto sucesorio) como sucesiones estén afectadas por el contenido del pacto sucesorio. El problema está precisamente en articular el funcionamiento de la regla de validación cuando hay más de una ley sucesoria en juego. Pensemos en un ejemplo que podría darse al amparo de las soluciones previstas en nuestro art. 9.8 CC: dos cónyuges con nacionalidad francesa realizan un pacto sucesorio por el que se instituyen recíprocamente herederos. En el

${ }^{550}$ Vid. A. FONT I SEGURA (2000), pp. 42 y 43. 
momento del fallecimiento uno de los cónyuges sigue siendo francés y el otro tiene nacionalidad alemana. Tanto la ley sucesoria anticipada como la ley sucesoria vienen determinadas por la conexión de la nacionalidad de los disponentes; de conformidad con la ley sucesoria anticipada, la francesa en los dos casos, el pacto sucesorio es inválido. De conformidad con la ley sucesoria de uno de ellos, el que tiene nacionalidad francesa, el pacto sucesorio es inválido, por lo que no cabe validación alguna, mientras que de conformidad con la ley sucesoria del otro cónyuge, el que tiene nacionalidad alemana en el momento del fallecimiento, el pacto sucesorio es válido y sí cabría la validación.

Los problemas de articulación empezarían aquí, pues ante una situación tal cabría hacerse varias preguntas. En primer lugar, cabría preguntarse si es necesario que ambas leyes sucesorias prevean la validación del pacto sucesorio para que ésta sea efectiva. En caso contrario, habría que preguntarse, en qué momento se valoraría la posibilidad de validación: en el momento del fallecimiento del primero de los cónyuges, cualquiera que sea y con independencia de lo que diga su ley sucesoria al respecto; en el momento del fallecimiento de ambos cónyuges; en el momento del fallecimiento del segundo cónyuge... Lo cierto es que cualquiera de las opciones presenta algún inconveniente no menor, tal y como vamos a ver a continuación.

La primera de las opciones que vamos a barajar como hipótesis es la que pasa por exigir que ambas leyes sucesorias prevean la validez del pacto sucesorio en cuestión para que el pacto sucesorio sea válido. Esta opción es sencillamente imposible de mantener porque para saber si el pacto sucesorio es válido o no habría que esperar al fallecimiento del segundo cónyuge, momento en el que ya perdería todo sentido la validación del pacto sucesorio. En el caso de un pacto sucesorio de institución recíproca, el pacto sucesorio perdería su razón de ser porque la validación tendría lugar una vez fallecidos los posibles beneficiarios del propio pacto. Pero incluso aunque hubiera un tercero beneficiario, pensemos en el pacto sucesorio celebrado por esos dos mismos cónyuges en el que cada uno de ellos instituye heredero al hijo de uno de ellos, esta opción de validación tampoco sería operativa. Lo que ocurriría es que al fallecimiento del primero de los 
cónyuges no se sabría si el pacto sucesorio es válido o no, porque habría que esperar a ver qué dice la ley sucesoria del cónyuge supérstite, aún desconocida; con lo cual, se abriría la sucesión del causante sin saber si el tercero instituido debe heredar a través del pacto sucesorio o si se abre la sucesión intestada u otra sucesión alternativa que el causante hubiera podido prever.

La segunda de las opciones pasa por que al menos una de las leyes sucesorias en juego prevea la validez del pacto sucesorio, pero faltaría por determinar cuál de ellas. ¿La ley sucesoria del primero que fallezca? ¿La ley sucesoria del segundo? Esta última posibilidad tiene el inconveniente de que retardaría considerablemente la regulación de la sucesión (al igual que ocurre con la primera opción que hemos visto), por ello, restaría por analizar la consideración de la ley de la sucesión del primero que fallezca. Esta opción supone someter al pacto sucesorio a un grado de aleatoriedad insoportable porque las personas cuya sucesión está afectada por el contenido del pacto sucesorio fallecerán generalmente en fechas distintas; así, en el ejemplo que hemos puesto del pacto sucesorio de institución recíproca celebrado entre dos cónyuges, la suerte del pacto sucesorio será muy distinta en función del cónyuge que primero fallezca. En concreto, en el caso de que fallezca el cónyuge cuya nacionalidad en el momento del fallecimiento era la francesa, el pacto sucesorio no será validado. Mientras que si fallece en primer lugar el cónyuge que en el momento del fallecimiento tiene nacionalidad en Alemania, el pacto sucesorio podría ser validado ${ }^{551}$.

La falta de un criterio racional para articular el funcionamiento de una posible regla de validación a los pactos sucesorios que afectan a más de una sucesión es la causa fundamental por la que aquellos sistemas que, como el Convenio de La Haya de 1989, diferencian a efectos conflictuales entre los pactos sucesorios que afectan a una y los pactos sucesorios que afectan a varias sucesiones y limitan el funcionamiento de la regla de validación a los pactos

\footnotetext{
${ }^{551}$ La insoportable aleatoriedad de esta opción fue puesta de manifiesto por el profesor LAGARDE en los debates al Convenio de La Haya de 1989, quien se refirió a esta solución como una especie de ruleta rusa. Vid. Conférence de La Haye de droit international privé (1990), p. 433.
} 
sucesorios que afectan a una única sucesión ${ }^{552}$. No obstante, tal y como veremos a continuación, la regla de validación presenta en sí misma importantes inconvenientes que a nuestro juicio deben llevar a su reconsideración también en lo que concierne a los pactos sucesorios que afectan a una única sucesión.

\subsection{Análisis valorativo de la regla de validación}

\subsubsection{Naturaleza de la regla de validación}

La regla de validación es una solución materialmente orientada, en la que el valor material intrínseco es el del favorecimiento de la validez de los pactos sucesorios. Se ampara, por tanto, en el favor negotii o favor validitatis. El fundamento del mecanismo de validación es potencial, en el sentido de que es necesario que la ley sucesoria anticipada y la ley sucesoria sean distintas, lo cual no siempre va a suceder ${ }^{553}$. La regla de validación puede ponerse en funcionamiento, en primer lugar, cuando hay un "conflicto móvil",554, esto es, cuando hay un cambio de la circunstancia que determina el punto de conexión entre el momento del otorgamiento del pacto sucesorio y el momento del fallecimiento del causante, como por ejemplo un cambio de la residencia habitual o de la nacionalidad del causante. Así, por ejemplo, pensemos en una hipótesis en el marco de la regulación que se previó en la Propuesta de Reglamento; en concreto, pensemos en el pacto sucesorio celebrado entre un padre y su hijo, a través del cual el padre instituye heredero a su hijo. En el momento del

\footnotetext{
${ }^{552}$ De hecho en el seno de los debates del Convenio de La Haya una de las críticas que se realizaron a la regla de validación es que suponía una ventaja injustificada a favor de los pactos sucesorios que afectan a una sucesión frente a los pactos sucesorios que afectan a varias sucesiones. Esta discriminación en el tratamiento de uno y otro tipo de pactos sucesorios añadido a que tampoco se imponía la política de favorecer la validez de los pactos sucesorios explicó que algunos delegados rechazaran de pleno la regla de validación Especialmente ilustrativo es el debate sobre esta cuestión en el seno de la Conferencia de La Haya; vid. Conférence de La Haye de droit international privé(1990), pp. 432 y ss.

${ }^{553}$ No vamos a estudiar aquí la posibilidad de que la ley sucesoria anticipada y la ley sucesoria sean la misma pero que el Derecho material de la ley aplicable cambie entre el momento del otorgamiento del pacto sucesorio y el momento del fallecimiento del causante, de tal forma que mientras que en el primer momento el pacto sucesorio era inválido, tras la modificación es válido. Este es un problema distinto, en un nivel diferente y cuya solución compete a las normas de Derecho transitorio de la ley en cuestión.

${ }^{554}$ No se trata de un conflicto móvil en sentido estricto, puesto que la concreción temporal del punto de conexión está llamada precisamente a evitar este problema; vid. S. ÁLVAREZ GonZÁLEZ (2011), p. 377.
} 
otorgamiento el padre reside en París, con lo que la ley sucesoria anticipada, la ley francesa a título de ley de la residencia habitual en el momento del otorgamiento del pacto sucesorio (art. 18.1 Propuesta de Reglamento), determina la invalidez del pacto sucesorio. Sin embargo, en el momento del fallecimiento del causante éste residía en Berlín, de tal forma que su ley sucesoria, la alemana, determina la validez del pacto sucesorio. En segundo lugar, la regla de validación puede ponerse en funcionamiento cuando haya un cambio en el criterio de conexión que identifica la ley sucesoria; por ejemplo, es posible que la ley sucesoria anticipada se determine por la ley de la residencia habitual del causante en el momento del otorgamiento del pacto sucesorio y que la ley sucesoria, como consecuencia del ejercicio posterior de una professio iuris, se determine por la ley de la nacionalidad del causante. Pensemos en el ejemplo del pacto sucesorio celebrado entre su padre y su hijo, siendo el padre nacional alemán y teniendo su residencia habitual en París. La ley sucesoria anticipada es la ley francesa, a título de ley de la residencia habitual del causante en el momento del otorgamiento del pacto sucesorio, lo que determina la invalidez del pacto sucesorio. Tras el otorgamiento del pacto, el causante realiza una professio iuris a favor de la ley de su nacionalidad, de tal forma que su ley sucesoria es la ley alemana, según la cual es pacto sucesorio podría ser validado. En definitiva, la regla de validación puede operar tanto en el caso de cambio de criterio de conexión, como en el caso de cambio de la circunstancia que determina la misma conexión, pero el presupuesto de partida es la necesidad de que ley sucesoria anticipada y ley sucesoria sean distintas.

Como sabemos, las normas de conflicto materialmente orientadas pueden revestir distintas técnicas para orientarse sustantiva o materialmente, pero todas ellas tienen en común la existencia de diversas conexiones ${ }^{555}$. Las distintas técnicas de la materialización vienen de la mano de la relación entre esas distintas conexiones de la norma de conflicto: en este sentido, se han distinguido, en primer lugar y con carácter general, las conexiones alternativas, en las que las distintas conexiones están en un plano de igualdad y se puede aplicar indistintamente

${ }^{555}$ J.D. GONZÁLEZ CAMPOS (2002), p. 356. 
cualquiera de ellas; en este tipo de normas de conflicto la intensidad del grado de materialización es mayor. En segundo lugar, las normas de conflicto subsidiarias con inclusión de un factor material; la relación entre ellas es de jerarquía, de tal forma que la primera conexión subsidiaria con conexiones sucesivas, en las que hay una conexión principal y otra u otras sólo se toma en consideración cuando de la aplicación de la ley a la que lleva la conexión principal no se derive la consecución del resultado material buscado. En este tipo de norma de conflicto la intensidad de la materialización es menor y la localización sigue teniendo un importante papel $^{556}$.

La regla de validación no se enmarca estrictamente en ninguna de estas dos vías de materialización. La diferencia fundamental reside en que la regla de validación, tal y como hemos visto, es una norma de conflicto multilateral que no cuenta con numerosas conexiones en sentido estricto. Bien es cierto que en los casos en los que se ha previsto la regla de validación de forma específica, en el Convenio de La Haya de 1989 y en el texto de la Propuesta de Reglamento, puede haber un cambio de conexión como consecuencia de un ejercicio de la professio iuris en ambos casos, o como consecuencia de la solución de compromiso del Convenio de La Haya para determinar la ley aplicable a las sucesiones internacionales ${ }^{557}$. No ocurre, sin embargo, en el caso de las normas de validación previstas en el sistema español y en el austriaco, donde únicamente se juega con la conexión de la nacionalidad del causante. En definitiva, el posible juego de conexiones distintas en la regla de validación no es una característica propia de la misma, sino que depende de las soluciones que el sistema prevea con carácter

\footnotetext{
${ }^{556}$ Vid. con carácter general sobre estas técnicas de materialización, A. BUCHER (1979), pp. 39 y ss.; P.M. PATOCCHI (1985), pp. 343 y ss.; J.D. GONZÁLEZ CAMPOS (2002), pp. 360 y ss.; A. BUCHER (2011), pp. 104 y ss. y 173 y ss.;

${ }^{557}$ En el caso del Convenio de La Haya, a falta de elección de ley la ley sucesoria anticipada y la ley sucesoria podrían ser, en virtud de la solución de compromiso que recoge el Convenio, bien la ley de la residencia habitual del causante, bien la ley de la nacionalidad del causante; y en el marco del mismo es posible realizar una professio iuris a favor de cualquiera de esas dos leyes. De ahí que puedan entrar en juego distintas conexiones, aunque no necesariamente. En el caso de la Propuesta de Reglamento ocurría algo parecido; a falta de elección de ley la ley aplicable, bien al pacto sucesorio bien a la sucesión, era la ley de la residencia habitual del causante; pero el art. 17 de la Propuesta permitía la posibilidad de escoger la ley de la nacionalidad de causante.
} 
general para la determinación de la ley aplicable a las sucesiones ${ }^{558}$. No obstante, la regla de validación se acerca más a la categoría de las normas de conflicto con conexiones sucesivas subsidiarias. En este sentido, la conexión principal sería la determinada por la ley sucesoria anticipada y la conexión subsidiaria la determinada por la ley sucesoria. La relación entre ambas leyes es de jerarquía, pues la ley sucesoria sólo entra en juego cuando el objetivo material a observar, esto es, la validez del pacto sucesorio, no se realice con la aplicación de la ley sucesoria anticipada.

Esta técnica mantiene un gran valor localizador, como en el caso de las normas de conflicto con conexiones sucesivas; no es lo mismo, como vamos a ver, aplicar al pacto sucesorio la ley sucesoria anticipada que aplicar la ley determinada en el momento del fallecimiento del causante, pues, en éste último caso, pese a la posible validación del pacto sucesorio, se pierde en el valor de la localización creándose en muchas ocasiones problemas contrarios a los intereses sustantivos que están detrás de los pactos sucesorios.

Por último, debemos realizar un breve comentario sobre la incidencia del tiempo en la técnica de materialización de la regla de validación. Como hemos dicho, se trata de una orientación material de un posible pseudo conflicto móvil. La validación del pacto sucesorio se realiza con efectos retroactivos; es decir, se realiza en el momento del fallecimiento del causante con la determinación de la ley sucesoria, pero con efectos desde la propia celebración del pacto sucesorio. Como hemos ya mencionado reiteradamente, los pactos sucesorios producen efectos desde el mismo momento de su otorgamiento, principalmente el de la vinculación de las partes y la consiguiente restricción de la libertad de disposición mortis causa del causante. Esta validación con efectos retroactivos puede plantear en ocasiones importantes inconvenientes por su difícil articulación, tal y como vamos a ver a continuación.

\footnotetext{
${ }^{558}$ Razón además por la que el juego de la regla de validación es potencial, sólo cuando ley sucesoria anticipada y ley sucesoria no coincidan.
} 


\subsubsection{La regla de validación desde el punto de vista de los otorgantes}

Como hemos visto, los pactos sucesorios producen efectos desde el mismo momento de su otorgamiento. Al menos, se produce el efecto de la vinculación de las partes, con la consiguiente pérdida de libertad de disposición mortis causa del causante (como siempre, en el caso de los pactos de institución), pero también se pueden producir otros, como la entrega de bienes de presente o la existencia de la obligación del contratante beneficiario de cumplir con determinadas cargas en vida del causante. Por ello, tal y como también hemos visto, los pactos sucesorios exigen conocer su régimen aplicable desde el mismo momento de su otorgamiento, razón por la cual, los sistemas que prevén una regulación específica de estas figuras establecen la aplicación de la ley sucesoria anticipada o ley que hubiera sido aplicable a la sucesión del causante de haber fallecido éste en el momento del otorgamiento del pacto sucesorio. La regla de validación, sin embargo, supone la aplicación al pacto sucesorio de la ley sucesoria, determinada en el momento del fallecimiento del causante. Con estos datos, ya podemos intuir que la regla de validación puede plantear algún que otro problema en relación con el pacto sucesorio validado. En los siguientes epígrafes vamos a analizar la regla de validación desde distintos puntos de vista: por un lado, analizaremos esta técnica desde el punto de vista de los otorgantes del pacto sucesorio y, por otro lado, la analizaremos desde el punto de vista de los terceros. En el presente epígrafe vamos a analizar cómo puede afectar el uso de la regla de validación a las partes otorgantes del pacto sucesorio.

Para comenzar es necesario recordar aquí que la realización de disposiciones mortis causa a través de pactos sucesorios tiene un valor distinto que la realización de las mismas disposiciones a través de testamento. Se puede decir que, con carácter general, el otorgamiento del pacto sucesorio y la organización de la sucesión del causante por anticipado a través de pacto sucesorio generan más seguridad para las partes. Pensemos en el típico ejemplo de pacto sucesorio de institución para la transmisión de una empresa familiar. Ya hemos visto cómo los pactos sucesorios tienen un gran valor como mecanismos para organizar la transmisión generacional exitosa de las pequeñas y medianas 
empresas. A través de la realización de un pacto sucesorio el causante y propietario de la empresa puede organizar el futuro de ésta con mayores garantías. En este sentido, celebra un pacto sucesorio con la persona que quiere que dirija la empresa a su fallecimiento, por ejemplo, uno de sus cuatro hijos. El causante celebra el pacto sucesorio con ese hijo a través de cual le instituye heredero en la empresa familiar. El hijo instituido, que ha dedicado toda su vida a la empresa familiar, tiene de esta forma la seguridad de que al fallecimiento del causante heredará la empresa familiar ${ }^{559}$, con lo cual pierde el miedo a centrar su vida en la empresa y luego no recibir nada por ello (mientras que, por ejemplo sus hermanos, han dirigido su vida a otra formación). El causante, por su parte, se asegura que el hijo instituido tenga interés por la empresa y se involucre en ella, lo que reporta beneficio directo para el negocio familiar.

Del mismo modo tienen un importante valor los pactos de renuncia. Como sabemos, a través de este tipo de pactos sucesorios el causante adquiere mayor margen de maniobra, respecto de la existencia de legitimarios, para organizar su sucesión por anticipado (así, por ejemplo, el causante que quiere transmitir por entero la empresa familiar a uno de sus hijos es posible que tenga que realizar con los otros pactos de renuncia), mientras que el renunciante adquiere generalmente algo a cambio de la renuncia realizada, ya sea una cuantía de dinero o un bien. El adquirir estos valores de presente (y no la legítima al fallecimiento del causante) tiene un determinado valor y además el pacto de renuncia encierra cierta aleatoriedad, por la posible diferencia entre lo que sería la legítima del renunciante y lo que recibió a cambio de la renuncia. Pero la seguridad de realización es total.

Sentados estas premisas (si nos fijamos, todas girando en torno a la seguridad y previsibilidad jurídicas), podemos analizar cómo afecta o cómo puede afectar la regla de validación a los intereses de las partes otorgantes de los pactos

\footnotetext{
${ }^{559}$ Siempre a salvo las causas de revocación que se pudiera negociar en el propio pacto sucesorio y las que prevea de manera excepcional la ley; no obstante, pese a esta posibilidad de revocación, su posición es claramente más sólida que la de un instituido a través de testamento, puesto que en este caso el causante puede cambiar de opinión cuantas veces quiera y revocar libremente la institución hasta el mismo momento de su fallecimiento.
} 
sucesorios. Para ello partiremos del ejemplo típico que venimos usando del pacto sucesorio de institución en la empresa familiar, y variaremos los datos con el fin de abarcar distintas situaciones que se puedan dar en la realidad. El punto de partida, por tanto, es un pacto sucesorio de institución, realizado entre un padre y su hijo, a través del cual el padre instituye heredero a su hijo en la empresa familiar. La ley sucesoria anticipada del causante determina la invalidez del pacto sucesorio, mientras que la ley sucesoria prevé la validez del mismo, con lo cual, el pacto sucesorio es validado en el momento del fallecimiento del causante, por la aplicación al mismo de la ley sucesoria. En los casos de validación ya hemos señalado que es la ley que valida la que se va a aplicar al pacto sucesorio, esto es, no sólo a su validez, sino también a su régimen jurídico.

La aplicación de la ley sucesoria al pacto sucesorio significa que hay un lapso de tiempo, que va desde el otorgamiento del pacto sucesorio hasta el fallecimiento del causante, en el que no se conoce si el pacto sucesorio va a ser o no finalmente válido. Las partes no saben si están vinculadas o no al pacto sucesorio y no pueden saberlo con absoluta certeza hasta el fallecimiento del causante y la averiguación de la ley sucesoria. Ante estas circunstancias la regla de validación puede ser el remedio oportuno que da cobertura legal a una situación fáctica o puede ser una solución que cree más inconvenientes que beneficios, lo cual va a depender, fundamentalmente, del desarrollo de los hechos respecto del pacto sucesorio en cuestión.

Vamos a jugar, en primer lugar, con una hipótesis en la que la regla de validación da más soluciones que inconvenientes. El pacto sucesorio de institución en la empresa familiar es inválido, de conformidad con la ley sucesoria anticipada. Las partes, sin embargo, confían en que el pacto sucesorio es válido y de facto cumplen con sus obligaciones y adecuan su comportamiento como si el pacto sucesorio fuese válido. En concreto, el causante planifica el resto de su sucesión contando con la disposición realizada a través del pacto sucesorio de institución y con la restricción que para su libertad de disposición mortis causa dicho pacto supone. Por su parte, el hijo instituido, se sigue involucrando en la empresa familiar con la confianza de que en el futuro será de su propiedad y 
cumple con las cargas que, en su caso, se hayan podido acordar en el pacto sucesorio (como por ejemplo, la exclusividad de su trabajo en la empresa familiar o el cuidado del causante hasta el momento del fallecimiento). En un caso como éste la regla de validación sería claramente ventajosa, en cuanto que supondría la cobertura legal de una situación fáctica; pero además, y más importante, la validación del pacto sucesorio en este caso supondría el respeto de la voluntad del causante, que confió en la validez de la ordenación realizada y que, por tanto, no realizó nuevas disposiciones para ordenar su sucesión. En un caso como éste, la no validación del pacto sucesorio supondría la frustración de las expectativas de las partes y, fundamentalmente, de la voluntad del causante, pues, en el caso de que no hubiera sucesión alguna a través del pacto sucesorio lo que ocurriría es que se abriría la sucesión intestada, dando como resultado una sucesión completamente distinta a la planteada por el causante (que, generalmente, supondría la división de la empresa familiar a partes iguales entre todos los hijos del causante).

La segunda hipótesis que vamos a manejar nos conduce al resultado contrario. Partimos del mismo pacto sucesorio, inválido de conformidad con la ley sucesoria anticipada, pero con reacciones distintas de los otorgantes en relación al mismo. En este caso las partes otorgantes toman conciencia de la invalidez del pacto sucesorio que han otorgado y actúan como si no existiera. En concreto, el causante no se siente vinculado al contenido del pacto sucesorio y, por tanto, organiza su sucesión conforme a su nueva voluntad, bien a través de otros pactos sucesorios, bien a través de un testamento. El hijo no tiene la confianza de que la empresa familiar vaya a ser suya y no dirige exclusivamente su actividad profesional a la empresa ni cumple con las cargas a las que se había comprometido en el pacto sucesorio. En el momento del fallecimiento de causante resulta que de la aplicación de la ley sucesoria se deriva la validación del pacto sucesorio, de tal forma que, en principio, el instituido va a heredar la empresa familiar y que las disposiciones mortis causa realizadas por el causante que contraríen el pacto sucesorio serán inválidas. La ley que valida el pacto sucesorio es la que tiene que decidir también qué ocurre cuando el instituido no ha cumplido con las cargas que se le impusieron en el pacto sucesorio y si afecta o no a su 
derecho a heredar. En suma, la validación, por un lado, puede suponer, en casos como el de esta hipótesis, la transgresión de la voluntad del causante; por otro lado, en ocasiones se van a plantear problemas en cuanto a la determinación de las consecuencias que sobre el pacto sucesorio tenga el incumplimiento de posibles cargas puestas al instituido. Pero no sólo eso: lo más importante es que las partes, creyendo en la invalidez del pacto sucesorio, no han adecuado sus comportamientos al mismo; así, por ejemplo, pensemos en la posibilidad de que las relaciones entre el causante y el instituido se hayan deteriorado hasta el punto de suponer una posible causa de revocación del pacto sucesorio prevista en el mismo y acordada por las partes; o, por ejemplo, la posible relajación de las funciones del instituido en la empresa familiar, también como posible causa de revocación. Ante esta realidad el causante pudo no realizar declaración de revocación alguna por pensar que era innecesario al no existir el pacto sucesorio; y, sin embargo, de haber conocido su validación sí hubiera hecho uso de alguna de las causas de revocación.

\subsubsection{La regla de validación desde el punto de vista de terceros}

Para dar cumplimiento al objeto de la rúbrica que ahora nos ocupa debemos determinar quiénes son esos terceros con posible relevancia para el pacto sucesorio. El primero de los terceros relevantes a los que nos vamos a referir es el tercero instituido a través de pacto sucesorio; esto es, el beneficiario del pacto sucesorio de institución que no es parte otorgante del mismo. En segundo lugar, debemos tomar en consideración también aquellos posibles beneficiarios de la sucesión en caso de invalidez del pacto sucesorio, esto es, los instituidos a través de un testamento o los beneficiarios de la sucesión intestada.

La primera de la hipótesis con la que vamos a trabajar es el caso de un pacto de institución celebrado entre dos cónyuges a través del cual uno de ellos instituye heredero al hijo del otro cónyuge; es decir, se trata de un pacto de institución a favor del hijo del cónyuge del causante o disponente en el pacto sucesorio. El presupuesto como siempre es que el pacto sucesorio es inválido de conformidad con la ley sucesoria anticipada y que sin embargo, la ley sucesoria prevé su validez y, por tanto, el pacto sucesorio es validado en el momento del 
fallecimiento del causante. El instituido es un mero beneficiario, que no tiene cargas ni obligaciones derivadas del pacto sucesorio; su posición es parecida al instituido a través de testamento, en cuanto que el hecho de que herede no depende de su voluntad, sino de la voluntad y comportamiento de las partes otorgantes del pacto sucesorio. Para él no existe vinculación al pacto sucesorio ni derechos y obligaciones derivados del mismo al no ser parte contratante. El tercero beneficiario tiene una mera expectativa a heredar a través del pacto sucesorio. Por todo ello, la regla de validación siempre es beneficiosa para el tercero instituido a través del pacto sucesorio, en cuanto cumplimiento de su mera expectativa a heredar.

La segunda hipótesis trata de la posición de aquellos posibles terceros beneficiarios de la sucesión del causante en caso de invalidez del pacto sucesorio. Estos terceros pueden ser bien los llamados por la ley en caso de apertura de la sucesión intestada, los instituidos en un posible testamento que el causante haya realizado con posterioridad al pacto sucesorio que cree inválido o los instituidos en otro posible pacto sucesorio (sean otorgantes o no del mismo) que el causante haya podido celebrar por la misma razón. Tomemos como ejemplo el caso en que hay un pacto sucesorio entre un padre y su hijo, a través del cual el padre instituye heredero a su hijo. El pacto sucesorio es inválido de conformidad con la ley sucesoria anticipada y tal invalidez es conocida por las partes. Por ello, el causante, confiando en la invalidez del pacto sucesorio y, por tanto, en la ausencia de limitación a su libertad de disposición mortis causa, realiza, por ejemplo, un segundo pacto sucesorio en el que instituye heredero a su hermano. En este caso el hermano es el tercero respecto del primer pacto sucesorio realizado, esto es, aquel por el que el causante instituye heredero a su hijo. El segundo pacto sucesorio, el realizado entre el causante y su hermano, sí es válido de conformidad con la ley sucesoria anticipada. Ahora bien, ¿qué es lo que ocurre con el segundo pacto sucesorio y con las legítimas expectativas del hermano del causante como otorgante y beneficiario del pacto de institución realizado en caso de validación del primer pacto sucesorio por la ley sucesoria? Si al momento del fallecimiento del causante la ley sucesoria determina la validez del primer pacto sucesorio y éste es finalmente validado se plantea un importante problema respecto de las 
instituciones posteriores realizadas por el causante y, también, respecto del propio respeto a la voluntad del causante. La validación ocurre con efectos retroactivos, de tal forma que el pacto sucesorio que era inválido pasa a ser válido desde el mismo momento de su otorgamiento. Esto, en términos formales, significa que el causante tiene su libertad de disposición mortis causa limitada y que toda disposición de este carácter que se haya realizado con posterioridad al pacto sucesorio y que contraríe el contenido de éste será nula. En el ejemplo esto significa que el pacto sucesorio celebrado entre el causante y su hermano será nulo por contrariar el primer pacto sucesorio celebrado por el causante y por carecer éste de la libertad de disposición mortis causa. Nos encontramos con el problema de que una disposición mortis causa, en concreto en el ejemplo el pacto sucesorio celebrado entre el causante y su hermano, nace en el momento de su otorgamiento como un acto jurídico válido, pero sobreviene inválido con posterioridad como consecuencia de uno de los efectos que se derivan de la validación de otro acto jurídico anterior. Desde el punto de vista del tercero beneficiario del segundo pacto sucesorio la regla de validación es claramente perjudicial en cuanto que implica la frustración sobrevenida de sus legítimas expectativas $^{560}$. No obstante, no debemos dejar de plantearnos si esto es soportable o si hay razones basadas en la seguridad jurídica e incluso el respeto a los derechos adquiridos (pensemos en un pacto sucesorio de institución con entrega de bienes de presente) que pudieran proteger a ese tercero cuya situación jurídica fue regular desde un principio.

\subsubsection{Balance}

Analizadas las ventajas e inconvenientes de la regla de validación nuestra postura pasa por su supresión o su no admisión, según los casos, por las razones que a continuación sintetizamos. Visto el análisis de la regla de validación desde los distintos puntos de vista podemos concluir que, pese a que esta técnica encierra un favor negotii o favor validitatis, la validación del pacto sucesorio no

\footnotetext{
${ }^{560}$ La cuestión es especialmente llamativa cuando el tercero al que nos referimos es un otorgante y beneficiario de un pacto sucesorio de institución, dada la posición jurídica cualificada que tienen respecto de otros instituidos. No obstante, este problema se daría también con el instituido en testamento y con los beneficiarios de la línea de sucesión intestada.
} 
siempre es la solución más adecuada o la solución más justa. Debemos reconocer que en ocasiones puede suponer la cobertura jurídica a una situación que de hecho se está dando en la realidad; pero en muchas otras genera una gran dosis de inseguridad jurídica que pueden conducir a situaciones injustas o a la pérdida de la razón de ser del propio pacto sucesorio.

El carácter retroactivo de la validación unido a la existencia de efectos desde el mismo momento del otorgamiento del pacto sucesorio genera en muchos casos problemas en cuanto a la buena ejecución o al buen cumplimiento del pacto sucesorio. La validación del pacto sucesorio aparecerá compleja por la difícil adaptación de la situación; así, puede ser injusto que una persona herede a través del pacto sucesorio validado por la ley sucesoria cuando no cumplió alguna de las obligaciones que se previó en el pacto sucesorio por creer que éste era inválido. Ciertamente, esta situación habrá de encontrar previsiblemente algún tipo de respuesta en la "ley validante" pero, ni es seguro, ni en todo caso se librará de delicados problemas de adaptación.

Otro de los puntos con posible problemática de la regla de validación que queremos destacar ahora tiene que ver con la relación entre la autonomía de la voluntad conflictual del causante y la propia regla de validación. Como bien es sabido, en los sistemas como el Convenio de La Haya o el Reglamento se introdujo la posibilidad de professio iuris a favor del causante para determinar la ley aplicable a su sucesión. La combinación de la regla de validación con la professio iuris da como resultado que, dependiendo del caso, la validación o no del pacto sucesorio puede quedar en manos del causante. La ley sucesoria es la ley que va a posibilitar la validación del pacto sucesorio y, a su vez, ésta puede depender de la voluntad conflictual del causante; por ello, éste puede determinar la ley sucesoria con una simple declaración de voluntad y manejar la validación o no del pacto sucesorio según le convenga. Pensemos en un pacto sucesorio en el marco del Reglamento, realizado entre un padre y su hijo, a través del cual el padre instituye heredero a su hijo en la totalidad de la herencia. En el momento del otorgamiento del pacto sucesorio el padre, de nacionalidad inglesa, tiene residencia habitual en Madrid, por lo que la ley sucesoria anticipada es el CC 
español al no haber ejercicio alguno de professio iuris a favor de la ley nacional. El CC español prohíbe los pactos sucesorios, por lo que el pacto sucesorio es inválido. Años después el causante se muda a Suiza donde empieza una relación con una nueva mujer. En el momento del fallecimiento el causante tenía residencia habitual en Zurich; de ser la ley sucesoria la ley de la residencia habitual del causante en el momento del fallecimiento, el pacto sucesorio sería validado, al permitirse un pacto de estas características por el $\mathrm{CC}$ suizo. El causante, sin embargo, quiere dejar su herencia a su nueva pareja, por lo que realiza un testamento en el que además escoge la ley de su nacionalidad, la ley inglesa, para regir su sucesión; de esta forma evita la aplicación del Derecho civil suizo y la validación del pacto sucesorio.

En definitiva, la bondad de la solución de la regla de validación depende de un factor psicológico, cual es verdadero sentimiento de vinculación de las partes al pacto sucesorio. Sólo si las partes no conocían la invalidez del pacto sucesorio, sólo si confiaban en su validez, de tal forma que han adaptado sus comportamientos a lo dispuesto en el pacto sucesorio, la regla de validación es una solución realmente sanadora. En otro caso, es una solución que crea incertidumbres e inseguridades que pueden llevar a resultados injustos o es una solución que llega demasiado tarde, cuando la razón del pacto sucesorio ya ha desaparecido.

Por último, aunque sea un fundamento de menor peso, debe denunciarse el distinto trato a los pactos sucesorios que afectan a una única sucesión y a los pactos sucesorios que afectan a más de una sucesión. Desde el punto de vista de la regla de validación los primeros gozan de un trato más favorable que los segundos, sin justificación sustantiva alguna, pues la única razón de la diferencia de trato es la inexistencia de una articulación técnica adecuada de la regla de validación para los pactos sucesorios que afectan a más de una sucesión ${ }^{561}$.

\footnotetext{
${ }^{561}$ No obstante, hay quien entendió que esta diferencia de trato entre los pactos sucesorios que afectan a una única sucesión y los pactos sucesorios que afectan a varias sucesiones no plantea problema alguno. Vid. la contribución de P. PICONE en Conférence de La Haye de droit international privé(1990), p. 436.
} 


\section{LA DETERMINACIÓN DE LA LEY APLICABLE A LOS PACTOS SUCESORIOS QUE AFECTAN A MÁS DE UNA SUCESIÓN}

\section{Especialidades de los pactos sucesorios que afectan a más de una sucesión: la estructura del Reglamento de sucesiones}

Los pactos sucesorios que afectan a varias sucesiones presentan ciertas especialidades en cuanto a la determinación de la ley aplicable que exigen un tratamiento diferente al de los pactos sucesorios que afectan a una única sucesión. Los pactos sucesorios que afectan a varias sucesiones deben ser, como hemos tenido oportunidad de comprobar en el capítulo II, objeto de una atención específica por parte del legislador. Las especialidades de los pactos sucesorios que afectan a varias sucesiones implican que no es suficiente para ellos soluciones técnicamente suficientes (con independencia de su bondad) previstas para los que afectan a una única sucesión.

El punto de partida de estas especialidades es que existe una especie de axioma según el cual la ley aplicable a los pactos sucesorios, cuando tienen una normativa conflictual específica, se determina por la ley sucesoria anticipada del disponente o futuro causante. Este es el punto de partida que guía las presentes consideraciones. Podría haber otras perspectivas $-\mathrm{y}$ más adelante haremos referencia a ellas- pero lo cierto es que allí donde existe la solución específica, la ley sucesoria anticipada es la regla. El Convenio de La Haya de 1989 y ahora el Reglamento asumen este hecho. Pues bien, cuando hay más de un disponente o futuro causante hay tantas leyes potencialmente aplicables como sucesiones estén afectadas por el contenido del pacto sucesorio. Mientras que en los pactos sucesorios que afectan a una única sucesión sólo hay una ley sucesoria anticipada, en los pactos sucesorios que afectan a varias sucesiones concurren potenciales leyes distintas y, por tanto, es necesario buscar un mecanismo para articular la combinación entre ellas. En un pacto sucesorio de institución recíproca celebrado entre dos hermanos, uno con residencia habitual en Francia y otro con residencia habitual en Alemania, en el momento del otorgamiento del pacto, tenemos dos leyes sucesorias anticipadas: la francesa y la alemana; y es necesario fijar una solución en la combinación de estas leyes. Bien es cierto, repetimos, que no tiene 
por qué seguirse este punto de partida para este tipo de pactos sucesorios; es decir, cabrían otras soluciones que no exigen la combinación de varias leyes, tales como la solución de la ley más estrechamente vinculada o la ley del lugar de celebración del pacto sucesorio. Pero en aquellos sistemas en los que se ha previsto una solución específica para este tipo de pactos sucesorios sólo se han barajado opciones que combinan las leyes sucesorias anticipadas de una u otra forma.

Como adelantamos más atrás, en este tipo de pactos como consecuencia de la existencia de distintas leyes sucesorias anticipadas, es necesario distinguir entre la determinación de la ley aplicable a la admisibilidad del pacto sucesorio, a la validez material del pacto sucesorio y al régimen jurídico del pacto sucesorio. Mientras que para la determinación de la admisibilidad y validez material del pacto sucesorio van a entrar en juego, de una $u$ otra forma, distintas leyes sucesorias anticipadas, en lo que respecta a la regulación del régimen jurídico no necesariamente se tratará de una combinación de las leyes sucesorias en presencia. En ocasiones, se establece una solución para determinar la aplicación de una de las leyes anticipadas (como es el caso del Reglamento, que apela a la ley más estrechamente vinculada con el pacto sucesorio); y en otras, se establece igualmente una solución que combina las leyes sucesorias anticipadas (como es el caso del Convenio de La Haya de 1989), aunque ya podemos adelantar aquí, que en este último caso se complica enormemente la regulación de los pactos sucesorios debido al fuerte carácter reglado de estas figuras en Derecho material. Sea como fuere, una regulación completa de los pactos sucesorios que afectan a más de una sucesión es aquella que prevé una solución no sólo para la determinación de la validez de tales pactos, sino también para su régimen jurídico.

En definitiva, en lo que respecta a la pertinente distinción entre admisibilidad, validez material y resto del régimen jurídico de los pactos sucesorios que afectan a más de una sucesión debemos aplaudir la regulación prevista por el Reglamento, por ser considerablemente más completa y adecuada que la prevista en instrumentos anteriores tales como el Convenio de La Haya de 1989 y la propia Propuesta de Reglamento. Esta regulación más evolucionada no sólo es consecuencia de la existencia de soluciones de ley aplicable para todos 
estos aspectos del pacto sucesorio, tal y como vamos a ver más adelante, sino también por el necesario esclarecimiento del ámbito de aplicación que en su texto se recoge.

\section{La ley aplicable a la admisibilidad de los pactos sucesorios que afectan a varias sucesiones: el art. 25.2 párrafo primero del Reglamento de sucesiones}

Tal y como ya hemos apuntado, la admisibilidad se refiere a un aspecto muy primario de los pactos sucesorios; se trata de saber si un pacto sucesorio es admitido genéricamente por un determinado sistema jurídico. Es decir, en este estadio no se entran a valorar otras cuestiones tales como la legitimación de las partes otorgantes, la capacidad para otorgar el pacto sucesorio, etc. El ejemplo podría ser el de preguntarse si el Derecho catalán permite un pacto sucesorio en el que se instituye heredero a alguien o si el Derecho alemán permite un pacto sucesorio de renuncia a la herencia.

La admisibilidad de los pactos sucesorios no siempre se ha tratado de forma autónoma; es más, en la mayor parte de los casos se entiende que es un elemento incluido en el concepto de validez material de los pactos sucesorios. Tal es el caso, por ejemplo, del Convenio de La Haya de 1989, donde sólo se distingue entre validez en cuanto al fondo, efectos y circunstancias que den lugar a la extinción de tales efectos; también fue el caso de la Propuesta de Reglamento, donde se hablaba con imprecisión de validez en cuanto al fondo y de regir el pacto sucesorio. Lo mismo ocurre en aquellos sistemas en los que se establece una solución específica para los pactos sucesorios basada en la aplicación de la ley sucesoria anticipada pero no se diferencia entre los pactos sucesorios que afectan a una única sucesión y los que afectan a varias sucesiones ${ }^{562}$.

Sin embargo, es en la versión definitiva del Reglamento donde se realiza un tratamiento autónomo y diferenciado de la admisibilidad de los pactos sucesorios. En efecto, como vamos a ver, en el Reglamento se diferencian

\footnotetext{
${ }^{562}$ Es el caso, por ejemplo, del sistema alemán, donde la doctrina se refiere a la admisibilidad del pacto sucesorio como uno de los aspectos que deben regirse por el Errichtungsstatut; vid. H. DöRNER (2007), núm. 351; R. BIRK (2010), núm. 134.
} 
perfectamente la admisibilidad y la validez material de los pactos sucesorios y se prevé una solución específica para cada una de estas cuestiones.

En el presente apartado, por tanto, analizaremos las posibilidades de ley aplicable a la admisibilidad, tanto la prevista específicamente por el Reglamento, como otras opciones igualmente posibles, que aunque no se hayan traducido de manera concreta en las distintas legislaciones, sí se derivan de la solución prevista para la validez material de los pactos sucesorios cuando la admisibilidad forma parte de tal categoría.

\subsection{Solución neutral de ley aplicable: la aplicación aleatoria de la ley sucesoria anticipada}

La primera de las soluciones a analizar la podemos denominar solución aleatoria o distributiva. La aplicación de esta solución a la admisibilidad de los pactos sucesorios es posible por la correspondiente aplicación de esta misma solución a la validez material de los pactos sucesorios y la inclusión de la admisibilidad dentro del ámbito de aplicación de ésta ${ }^{563}$. Esta opción consiste en aplicar de manera independiente cada una de las leyes sucesorias anticipadas en juego, de tal forma que se predica la admisibilidad o inadmisibilidad del pacto en el marco de la sucesión de cada uno de los disponentes o futuros causantes del pacto sucesorio. El ejemplo sería el de un pacto sucesorio de institución recíproca celebrado entre dos socios, a través del cual se instituyen uno al otro heredero por el conjunto de la sucesión. Supongamos que se aplica la solución prevista en el art. 9.8 CC y que uno de los otorgantes tiene nacionalidad alemana y el otro nacionalidad italiana. En el caso de que fallezca en primer lugar el socio de nacionalidad alemana se aplicará esta ley y se tendrá como admitido el pacto sucesorio; sin embargo, en el caso de fallecer en primer lugar el socio de nacionalidad italiana, el pacto sucesorio no será admitido, por no permitir estas figuras el Derecho italiano.

\footnotetext{
563 Tal y como vamos a ver, esta posibilidad se da en casos en los que no hay una solución específica para los pactos sucesorios que afectan a más de una sucesión y además la doctrina interpreta que deben aplicarse de forma distributiva las leyes sucesorias anticipadas (o leyes sucesorias) en juego.
} 
Tal y como veremos con mayor detenimiento cuando analicemos la solución distributiva en el marco de la validez material de los pactos sucesorios, se trata de una solución neutra, en cuanto que por sí misma no añade nada a favor ni en contra de la admisibilidad o inadmisibilidad de los pactos sucesorios que afectan a más de una sucesión. Por otro lado, como solución de ley aplicable es ciertamente inadecuada, por no respetar los intereses de los pactos sucesorios que afectan a más de una sucesión. Las consecuencias del ejemplo descrito son más que elocuentes.

\subsection{Soluciones materialmente orientadas en la determinación de la admisibilidad de los pactos sucesorios que afectan a más de una sucesión}

También son posibles soluciones con cierta orientación material a la hora de determinar la admisibilidad de los pactos sucesorios. Se trata de la solución alternativa y la solución cumulativa. La primera de ellas era recogida por la Propuesta de Reglamento, donde al no haber un tratamiento diferenciado de la admisibilidad se entendía que ésta formaba parte de la validez en cuanto al fondo del pacto sucesorio. La segunda de ellas, la cumulativa, es la específicamente prevista por el Reglamento; también es posible en el marco de la aplicación de la solución cumulativa a la validez material en aquellos casos en los que no hay tratamiento diferenciado para la admisibilidad de los pactos sucesorios ${ }^{564}$. Vamos a analizar brevemente, y con independencia del mayor desarrollo que se hará en el apartado de validez material, cada una de ellas.

La solución alternativa consiste en combinar de manera alternativa las leyes sucesorias anticipadas, de tal forma que basta con que al menos una de ellas prevea la admisibilidad del pacto sucesorio para que éste sea admitido. Es una solución que incorpora un valor material favorecedor de la admisibilidad de los pactos sucesorios. En el ejemplo de un pacto sucesorio de institución recíproca celebrado entre dos socios, uno con residencia habitual en Francia en el momento del otorgamiento del pacto sucesorio y el otro con residencia habitual en

\footnotetext{
${ }^{564}$ Vid. B. DutolT (2005), pp. 313 y ss. núms. 1 y 4. Por la doctrina alemana, H. DöRNER (2007), núm. 351; R. BIRK (2010), núm. 134.
} 
Alemania, el pacto sucesorio estaría admitido, por estar previsto en la legislación alemana y pese a que según la otra ley sucesoria anticipada, la francesa, no fuera admisible. La ley alemana, por tanto, determinaría la admisibilidad del pacto sucesorio. En el caso de que todas las leyes sucesorias anticipadas en presencia admitieran el pacto sucesorio (pensemos que en vez de tener residencia habitual en Francia ese socio tiene residencia habitual en Suiza) no existiría problema alguno relacionado con el carácter generalmente reglado de los pactos sucesorios, por tratarse la admisibilidad de un aspecto superficial o previo en el régimen jurídico.

La solución cumulativa se sitúa en el polo opuesto. Es una solución claramente restrictiva de la admisibilidad de los pactos sucesorios. Según esta solución, todas y cada una de las leyes sucesorias en presencia deben prever la admisibilidad del pacto sucesorio para que éste se considere efectivamente admitido. En el caso del ejemplo de los socios con residencia habitual en Francia y en Alemania en el momento del otorgamiento del pacto sucesorio, la solución cumulativa daría como resultado el de la inadmisibilidad del pacto sucesorio en cuestión, por no admitirlo una de las leyes sucesorias anticipadas en presencia, la francesa. Sí estaría admitido, sin embargo, en el caso de que el socio tuviera residencia habitual en Suiza, en vez de en Francia, puesto que ambas leyes sucesorias anticipadas, la suiza y la alemana, permiten los pactos sucesorios de institución. Tratándose de un aspecto tan primario como el de determinar genéricamente si un pacto sucesorio está admitido o no, no es necesario establecer qué concreta ley, de entre las leyes sucesorias anticipadas, es la que determina la admisibilidad del pacto sucesorio. Es decir, la solución cumulativa, en cuanto que conlleva la aplicación de distintas leyes a la vez, no implica aquí problemática alguna de adaptación de las distintas regulaciones, pues sólo se trata de decir sí o no a la admisibilidad genérica de un tipo de pacto sucesorio. Como hemos adelantado, esta será la solución cuando se empiece a aplicar el Reglamento de sucesiones; el art. 25.2 dispone que un pacto sucesorio relativo a la sucesión de varias personas únicamente será admisible en el caso de que lo sea conforme a la ley que, de conformidad con el Reglamento, hubiera sido aplicable a la sucesión de cada una de las personas de cuya sucesión se trate de haber fallecido en la 
fecha de conclusión del pacto sucesorio. Esta solución, que supuso un giro completo de la regulación de estas figuras respecto de lo previsto en la Propuesta donde la solución alternativa implicaba una tendencia claramente favorecedora a la celebración de pactos sucesorios, supondrá finalmente una tendencia restrictiva a la celebración de los pactos sucesorios en Europa.

\section{Ley aplicable a la validez material de los pactos sucesorios que afectan a más de una sucesión}

\subsection{Soluciones neutrales de ley aplicable a la validez material}

\subsubsection{Aplicación distributiva o aleatoria de las leyes en presencia}

La solución distributiva o aleatoria consiste en aplicar de manera independiente cada una de las leyes sucesorias anticipadas en juego; la validez material del pacto sucesorio se valora de manera independiente para cada sucesión afectada por el contenido del pacto. Tomando un ejemplo del pacto de institución recíproca celebrado entre los socios con nacionalidad alemana e italiana, respectivamente, la aplicación de la solución distributiva o aleatoria sería del siguiente modo: la ley alemana determinaría si las disposiciones realizadas por el otorgante con nacionalidad alemana son válidas y la ley italiana, haría lo propio respecto de las disposiciones realizadas por el otorgante italiano. El juicio de validez se hace de manera independiente para cada sucesión afectada. El resultado, en el ejemplo, sería que las disposiciones realizadas por el otorgante nacional alemán son válidas, mientras que las disposiciones realizadas por el otorgante nacional italiano son inválidas.

La solución distributiva o aleatoria tiene, frente a otras combinaciones de las leyes sucesorias anticipadas en juego, un carácter neutral. Esta solución de ley aplicable no encierra ningún tipo de valor material respecto de la validez o invalidez de los pactos sucesorios; es decir, la solución distributiva ni favorece ni restringe la validez de los pactos sucesorios que afectan a más de una sucesión. Por el contrario, tal cuestión depende, precisamente de forma aleatoria, de lo que digan las leyes sucesorias anticipadas al respecto, pero la solución de ley aplicable en sí, nada suma a este respecto. Sería, no obstante, altamente desaconsejable. 
Esta solución no se ha previsto de manera específica en regulación alguna. Surge, entonces, de posibles interpretaciones doctrinales o de la aplicación en los tribunales de soluciones de ley aplicable incompletas para los pactos sucesorios que afectan a más de una sucesión. Dicho de otro modo, la solución distributiva o aleatoria sólo tiene lugar en aquellos casos en los que la norma no presta una especial atención a los pactos sucesorios que afectan a más de una sucesión. En estos casos, lo que ocurre es que la solución de ley aplicable a los pactos sucesorios es apta únicamente para los pactos sucesorios que afectan a una única sucesión, como es el caso, por ejemplo, de nuestro art. $9.8 \mathrm{CC}$, y que, por tanto, la doctrina y la jurisprudencia tienen que realizar una interpretación de tal solución para hacerla apta para los pactos sucesorios que afectan a más de una sucesión. En el caso de nuestro art. 9.8 CC, se dispone que los pactos sucesorios ordenados conforme a la ley nacional del disponente en el momento del otorgamiento conservarán su validez aunque sea otra la ley que rija la sucesión; nada se dice, por tanto, para los pactos sucesorios que afectan a varias sucesiones $\mathrm{y}$, al ser el texto del art. 9.8 CC insuficiente, la doctrina y la jurisprudencia tienen que realizar el pertinente esfuerzo interpretativo. Lo mismo ocurre con otras soluciones en Derecho comparado ${ }^{565}$; por supuesto en aquellas en las que ni siquiera hay una mención especial a los pactos sucesorios en la norma de conflicto de sucesiones, como es el caso del sistema francés o del sistema italiano; pero también en otras en las que sí hay mención específica, como es el caso del sistema alemán o del sistema portugués. En lo que se refiere a nuestro sistema, tal y como ya se ha puesto de manifiesto por la doctrina, la interpretación distributiva sería a priori la más adecuada por ser la que respeta en mayor medida la coherencia interna del art. $9.8 \mathrm{CC}^{566}$; sin embargo, tal y como vamos a ver, esta solución debe desecharse por los inconvenientes que plantea al ser completamente contraria a los intereses de los pactos sucesorios que afectan a varias sucesiones.

\footnotetext{
${ }^{565}$ En Portugal, por ejemplo, donde la solución de ley aplicable a los pactos sucesorios se limita a los que afectan a una única sucesión, la doctrina ha defendido la interpretación distributiva, J. BATISTA MACHADO (2009), p. 444; L. DE LIMA PINHEIRO (2002), p. 317.

${ }^{566}$ Vid. A. FONT (2009), p. 18.
} 
La denominación de solución aleatoria hace referencia precisamente a la aleatoriedad de la ley aplicable a la validez material del pacto sucesorio y, por tanto, al destino del mismo, por depender de quién sea el primero que fallezca. Así, en el ejemplo, en el caso de que fallezca en primer lugar el socio con nacionalidad alemana, el pacto sucesorio será válido y se llevará a cabo la sucesión contractual. Pero no ocurre lo mismo a la inversa, es decir, si fallece el socio de nacionalidad italiana en primer lugar, el pacto sucesorio es inválido y la sucesión contractual no tendrá lugar. La denominación de solución distributiva, por su parte, hace más incidencia al hecho de que el pacto sucesorio no se toma como un todo, como un mismo acto jurídico, sino que de la aplicación distributiva de las leyes sucesorias anticipadas en presencia, se deriva en realidad la división del pacto sucesorio en tantos pactos sucesorios como sucesiones estén afectadas por el contenido del mismo. En el ejemplo que estamos manejando, el pacto sucesorio se divide en dos: el pacto sucesorio a través del cual el socio alemán instituye heredero a su socio italiano por el conjunto de la sucesión; y el pacto sucesorio a través del cual el socio italiano instituye heredero al socio alemán también por el conjunto de su sucesión. Lo mismo ocurre en pactos sucesorios que afecten a más de una sucesión pero sin disposiciones recíprocas a favor de los propios otorgantes; nos estamos refiriendo, por ejemplo, al pacto sucesorio celebrado entre dos cónyuges a través del cual ambos instituyen heredero al hijo de uno de ellos. En este pacto lo que ocurriría sería la división del mismo en dos: un pacto sucesorio a través del cual uno de los cónyuges instituye heredero a su hijo y un pacto sucesorio a través del cual el otro cónyuge instituye heredero al hijo de su cónyuge; cada uno de los cuales se regirá por su propia ley sucesoria anticipada que determinará si es válido o no.

Lo dicho hasta el momento ya es suficiente para intuir los problemas que esta solución de ley aplicable genera para los pactos sucesorios que afectan a más de una sucesión. Vamos a ver a través de distintos ejemplos cómo esta solución hace inoperativo el pacto sucesorio. En primer lugar, vamos a detenernos en cómo la solución aleatoria o distributiva implica la negación del pacto sucesorio como un todo y cómo por consecuencia de esta negación pierde su razón de ser. En el ejemplo del pacto sucesorio celebrado entre los socios de nacionalidad alemana y 
nacionalidad italiana la aplicación de la solución distributiva supone directamente la pérdida de la razón económica del pacto. Además de lo injusto de la solución (porque en el caso de que fallezca primero el socio alemán hay sucesión contractual, y no en el caso de que fallezca primero el socio italiano), la pretendida reciprocidad se pierde y la causa por la cual cada uno de los socios decide realizar disposiciones sobre su sucesión desaparece. Cada uno de los otorgantes realiza disposiciones de su sucesión en un determinado sentido, en cuanto que el otro otorgante hace lo propio; las disposiciones de ambos disponentes son interdependientes. Sin embargo, en la práctica la reciprocidad no existe más que en una dirección, esto es, en la sucesión del causante con nacionalidad alemana.

Lo mismo ocurre, en segundo lugar, con el ejemplo del pacto sucesorio celebrado entre dos cónyuges en el que no hay disposiciones a favor de los otorgantes, sino a favor de un tercero, el hijo de uno de ellos. Puede ocurrir que según la ley sucesoria anticipada de uno de los otorgantes el pacto sucesorio sea válido y tenga cabida sucesión contractual a favor del beneficiario; y que sin embargo, según la ley sucesoria anticipada del otro otorgante el pacto sucesorio sea inválido y, por tanto, no haya sucesión contractual. El resultado es del todo incoherente y el pacto sucesorio no cumple su función, puesto que en realidad no existen los efectos que se esperan de realizar disposiciones por causa de muerte de manera conjunta en un mismo pacto sucesorio en vez de en testamentos o incluso en pactos sucesorios separados que afecten a una única sucesión.

La solución aleatoria o distributiva es inadecuada e ineficaz, en definitiva, por negar la propia existencia del pacto sucesorio que afecta a más de una sucesión como un todo jurídico. Todos estos inconvenientes y la inseguridad jurídica que genera nos llevan a descartar esta opción que es a todas luces contraria a los intereses de los pactos sucesorios que afectan a más de una sucesión $^{567}$.

\footnotetext{
${ }^{567}$ En este sentido, A. FONT (2009), p. 18; también nosotros hemos tenido ocasión de ponerlo de manifiesto en, I. RODRÍGUEZ-URÍA SUÁREZ (2010), p. 656.
} 


\subsubsection{Aplicación de la ley más estrechamente vinculada: el art. 25.2 segundo párrafo del Reglamento}

La otra solución neutral que se ha previsto para determinar la validez material de los pactos sucesorios que afectan a más de una sucesión es la aplicación de la ley más estrechamente vinculada. No obstante, vamos a ver cómo tal neutralidad viene acompañada de ciertos matices.

El Reglamento prevé la aplicación de la ley más estrechamente vinculada a la determinación de la validez material de los pactos sucesorios que afectan a más de una sucesión. En concreto, el art. 25.2 en su segundo párrafo, y después de establecer la solución cumulativa para la determinación de la admisibilidad de los pactos sucesorios, establece que un pacto sucesorio que sea admisible en virtud del párrafo primero se regirá en cuanto a su validez material por aquella de las leyes referidas en dicho párrafo con la que presente los vínculos más estrechos. Debemos diferenciar esta solución de la prevista con carácter general para la determinación de la ley sucesoria en el art. 21.2 del Reglamento; en ese caso, se establece la excepción a la aplicación de la ley de la última residencia habitual del causante, cuando haya otra ley manifiestamente más vinculada. En el caso del art. 21.2 los vínculos más estrechos se determinan respecto de la persona del causante; sin embargo, en el caso de la solución que ahora analizamos, la ley más estrechamente vinculada se predica respecto del pacto sucesorio y no respecto de los futuros causantes o disponentes del mismo.

La solución de la ley más estrechamente vinculada para determinar la ley aplicable a la validez material de los pactos sucesorios que afectan a más de una sucesión no es una solución que se pueda considerar de manera aislada; por el contrario, es una solución que viene precedida de otra en la que se determina la admisibilidad de tal pacto sucesorio. La aplicación de la ley más estrechamente vinculada, por tanto, sólo entra en juego cuando de la aplicación cumulativa de las leyes sucesorias anticipadas en presencia se deriva la admisibilidad del pacto sucesorio. De ahí que adelantáramos que la neutralidad de la solución de la ley más estrechamente vinculada tenga matices, pues tal ley siempre va a ser una de las que ha entrado en juego para determinar la admisibilidad del pacto sucesorio. 
La regla es un complemento necesario de la solución cumulativa para la admisibilidad de los pactos sucesorios. Su neutralidad viene matizada por el hecho de que la valoración de la ley más estrechamente vinculada se circunscribe a ciertas leyes que ya han entrado en juego en un paso anterior, el de la determinación de la admisibilidad del pacto sucesorio. Por ello, no se garantiza que la ley que se vaya a aplicar, que siempre va a ser una de las leyes sucesorias anticipadas que ha determinado la admisibilidad del pacto sucesorio, vaya a ser necesariamente la ley más estrechamente vinculada, en términos absolutos, al pacto sucesorio.

Ahora bien, dentro de las leyes sucesorias anticipadas que determinan la admisibilidad del pacto sucesorio no concurre razón material alguna que haga decantarse por una u otra. Dentro de este círculo la solución de la ley más estrechamente vinculada juega en su plenitud buscando la mejor localización de la situación, sin consideración material alguna. La diferencia entre aplicar una u otra ley puede ser muy grande, pudiendo determinar la validez o invalidez del pacto sucesorio, al comprenderse dentro del ámbito de aplicación de la validez material aspectos tan importantes y que difieren enormemente de una legislación a otra como el de la legitimación para su otorgamiento. Pensemos en un pacto sucesorio de institución recíproca, regulado en el marco del Reglamento, celebrado entre dos socios, que se instituyen recíprocamente herederos en la empresa que tienen a medias. En el momento de otorgamiento del pacto sucesorio uno de los socios tiene residencia habitual en Frankfurt y el otro socio residencia habitual en Barcelona (y vecindad civil catalana ${ }^{568}$ ). Vamos a dar por hecho que las leyes sucesorias anticipadas son la alemana y el Derecho catalán; ambas admiten un pacto sucesorio de institución recíproca, si bien sólo una de ellas va a determinar si el pacto sucesorio es válido o no. Se aplicará la ley que de entre las dos esté más estrechamente vinculada con el pacto sucesorio; vamos a jugar con las dos hipótesis para ver el funcionamiento de esta solución y los posibles resultados fijándonos en uno de los aspectos que entran dentro del concepto de validez

\footnotetext{
${ }^{568}$ Art. 36.1 Reglamento, que recoge una solución mediata para la determinación de la concreta ley aplicable en los Estados plurilegislativos. Los arts. 16.1 y 9.8 CC nos llevarían a la aplicación del Derecho catalán, por ser el correspondiente al de la vecindad civil del disponente.
} 
material y que varían considerablemente de una legislación a otra, cual es el de la legitimación de los otorgantes. En primer lugar, vamos a jugar con la hipótesis según la cual, el pacto sucesorio es celebrado en Alemania y además la empresa sobre la que versa tiene su sede y actividad completa en dicho país. La única conexión con el Derecho catalán es la de la vecindad civil de uno de los socios, mientras que el resto de conexiones se vinculan al país germano. En este caso, la ley más estrechamente vinculada con el pacto sucesorio sería la ley alemana y el pacto sucesorio sería válido, por permitir el ordenamiento jurídico alemán la celebración de un pacto sucesorio entre dos socios que no tienen vínculo de parentesco alguno. En segundo lugar, jugaremos con la hipótesis contraria; es decir, el pacto sucesorio se celebra en Barcelona, donde además la empresa tiene su sede y desarrolla su actividad. En este caso, la única conexión con Alemania se deriva de la residencia habitual de uno de los socios, situándose el resto de vínculos de la situación con el Derecho catalán. En esta hipótesis la ley más estrechamente vinculada sería el Derecho catalán y el resultado sería el de la invalidez del pacto sucesorio, puesto que este Derecho exige cierto grado de parentesco entre los otorgantes del pacto sucesorio, que no se da en el caso ${ }^{569}$. La solución de los vínculos más estrechos, en definitiva, es completamente neutral, en cuanto que no establece criterio material alguno para determinar qué ley de entre las que admiten el pacto sucesorio es la que debe aplicarse a la validez material del mismo.

La determinación de cuál es la ley más estrechamente vinculada con el pacto sucesorio no siempre es una tarea fácil, dependiendo de las circunstancias del caso. Como hemos dicho, la vinculación más estrecha se predica respecto del pacto sucesorio en conjunto y no respecto de los disponentes o futuros causantes; por ello, los factores a tener en cuenta no sólo se limitan a las circunstancias personales de los disponentes o futuros causantes, sino también a otras tales como la situación de los bienes a los que se refiere el pacto sucesorio, el lugar de celebración del pacto sucesorio, las circunstancias personales de posibles otorgantes no disponentes del pacto sucesorio... En las dos hipótesis que hemos

${ }^{569}$ Vid. art. 431.2 Libro IV CCCat. 
manejado las circunstancias llevaban claramente a la aplicación de una u otra ley, pero no siempre es una cuestión clara. Pensemos en una tercera hipótesis en la que el pacto sucesorio celebrado entre los dos socios versa sobre una empresa que tiene sede en Frankfurt y Barcelona y que comparte su actividad de manera equitativa en estos dos lugares. Por ello, esta solución genera en ocasiones cierta inseguridad jurídica a la hora de determinar la ley aplicable a los pactos sucesorios que afectan a más de una sucesión ${ }^{570}$. No obstante, los operadores jurídicos tendrán que adaptarse a esta solución, cuyo juego además es sustancialmente distinto como solución de ley aplicable directa que como cláusula de excepción.

\subsection{Soluciones materialmente orientadas para la validez material de los pactos sucesorios que afectan a más de una sucesión}

\subsubsection{Solución alternativa: la solución de la Propuesta de Reglamento}

En las páginas que siguen vamos a ver las soluciones que se han barajado para la determinación de la ley aplicable a la validez de los pactos sucesorios que afectan a más de una sucesión, cuando estas soluciones están presididas por una orientación material o sustantiva tendente a favorecer o restringir esa validez. Tales soluciones son la utilización de conexiones en forma cumulativa, por un lado, y su utilización de manera alternativa, por el otro. Ambas tienen en común que son el resultado de la combinación de las leyes sucesorias anticipadas en juego 571 .

La solución o articulación alternativa de las leyes en presencia consiste en que para determinar la validez material de un pacto sucesorio que afecta a más de una sucesión, basta con que al menos una de las leyes sucesorias anticipadas (o de las leyes sucesorias en aquellos casos en los que no haya normativa específica para pactos sucesorios) así lo prevea, con independencia de lo que digan las otras

\footnotetext{
570 Vid. sobre la inseguridad jurídica que crea la cláusula de los vínculos más estrechos en el ámbito de las sucesiones, O. REMIEN (2010), p. 63.

571 Nos referimos a las leyes sucesorias anticipadas en juego por ser la normativa más especializada; pero nada impediría que en un sistema como el italiano o el francés, donde se aplica la ley sucesoria determinada en el momento del fallecimiento, se predicara una solución cumulativa o alternativa respecto de tales leyes.
} 
leyes en presencia. El ejemplo podría ser el de un pacto sucesorio celebrado entre dos amigos, uno con residencia habitual en Alemania en el momento del otorgamiento del pacto sucesorio y el otro con residencia habitual en Luxemburgo. Las leyes sucesorias anticipadas son la alemana y la luxemburguesa. Con la solución alternativa el pacto sucesorio sería válido en aplicación de la ley alemana y pese a que el derecho luxemburgués prohíbe los pactos sucesorios.

Esta solución alternativa se corresponde con una de las clásicas técnicas de materialización suficientemente conocida y extendida en determinados ámbitos. Nos referimos a las normas de conflicto materialmente orientadas con conexiones alternativas. Esta técnica de materialización en la búsqueda de la ley aplicable encierra el valor material del favor negotii o favor validitatis; en concreto, en el caso de los pactos sucesorios es una solución dirigida al favorecimiento de la validez de estas figuras. La tradicional técnica de las normas materialmente orientadas con conexiones alternativas consiste en la coexistencia en una misma norma de conflicto de distintas conexiones, que en un plano de igualdad se aplican a la situación jurídica con el fin de conseguir un determinado resultado material ${ }^{572}$. Las normas de conflicto con conexiones alternativas son habituales en el ámbito de la determinación de la ley aplicable a la validez formal, ya que existe un consenso general en torno a evitar la declaración de invalidez de los negocios jurídicos por cuestiones de forma ${ }^{573}$. Un ejemplo claro de solución de ley aplicable con conexiones alternativas lo encontramos en la determinación de la ley aplicable a la forma de los testamentos y el Convenio de La Haya de 1961; su artículo primero establece distintas conexiones que en plano de igualdad se pueden aplicar para determinar la validez formal de las disposiciones testamentarias; así, tales disposiciones serán válidas en cuanto a la forma si ésta se ajusta a la ley interna del lugar donde se hizo la disposición, de la nacionalidad del testador sea en el momento en que realizó disposición sea en el momento del fallecimiento, de la residencia habitual o del domicilio del testador en esos dos mismos momentos; por último, también a la ley del lugar de situación cuando se

\footnotetext{
572 Vid. con carácter general, J.D. GONZÁLEZ CAMPOS (2002), pp. 360 y ss.; A. BUCHER (1979), pp. 39 y ss.; M.P. PATOCCHI (1985), p. 252.

${ }^{573}$ Vid. M. REQUEJO ISIDRO (1998), pp. 102 y ss.
} 
trate de disposiciones testamentarias que afecten a bienes inmuebles. Este precepto retiene, por tanto cinco puntos de conexión distintos (a los que además hay que añadir las mayores posibilidades que da la doble determinación temporal, en el momento de la realización de la disposición y en el momento del fallecimiento del causante, de tres de esas conexiones). Todos estos puntos de conexión se contemplan en pie de igualdad, es decir, no hay preferencia alguna para aplicar prioritariamente una ley respecto de las otras. Se busca evitar que los testamentos sean declarados inválidos como consecuencia de razones formales, con lo que el convenio está inspirado en un claro favor validitatis ${ }^{574}$.

En el caso de la solución alternativa que analizamos ahora ocurre lo mismo. La alternatividad viene dada por la aplicación indistinta de las leyes sucesorias anticipadas en juego. Además tales leyes están en pie de igualdad, como ocurre, con carácter general, con las conexiones alternativas en una norma de conflicto materialmente orientada ${ }^{575}$. Cada una de las leyes sucesorias anticipadas se corresponde con cada sucesión afectada por el contenido del pacto sucesorio y todas las sucesiones afectadas tienen el mismo peso a la hora de establecer la solución de ley aplicable al pacto sucesorio; esto es, con independencia de que una sucesión esté más afectada que otra por el contenido del pacto sucesorio, como consecuencia por ejemplo de que en un caso se disponga de la mitad de la herencia y en otro de la totalidad de la misma.

\footnotetext{
${ }^{574}$ Efectivamente, el Convenio de La Haya de 1961 se inspira claramente en el principio de favor negotii o favor validitatis en lo que respecta a las cuestiones de validez formal de las disposiciones testamentarias, si bien dentro de ciertos límites, puesto que no se trata de desconocer las prescripciones en torno a la forma en este caso de las disposiciones testamentarias, ni de obviar el papel que en general reviste la forma de los negocios jurídicos; si así fuera, tal y como ha puesto de relieve la doctrina, hubiera bastado con una norma material que condujera a la validez formal de los testamentos en cualquier caso; vid. a este respecto, H. BATIFFOL (1979), p. 437; M. REQUEJO ISIDRO (1998), p. 356.

${ }^{575}$ La norma general es que en las normas de conflicto con conexiones alternativas todas ellas estén en pie de igualdad, sin prioridad por la aplicación de ninguna de ellas. Vid. en estos términos, M.P PATOCCHI (1985), p. 252, núm. 512. No obstante, también hay ocasiones en las que puede haber matices en esa alternatividad, vid. por ejemplo, respecto del art. $11 \mathrm{CC}$, donde la literalidad del precepto parecía dar mayor importancia a la ley de lugar de celebración del acto, frente a la ley personal, la ley aplicable al fondo y la ley del lugar de situación de los inmuebles. No obstante, hoy día se mantiene la irrelevancia del orden de las distintas conexiones. Vid. M. REQUEJO ISIDRO (1998), p. 130.
} 
Hoy en día, podemos decir que solución alternativa se puede considerar residual en el ámbito de los pactos sucesorios. En realidad, de manera articulada, se previó únicamente en la Propuesta de Reglamento, en cumplimiento de uno de los objetivos confesados del legislador, que se refería a la promoción del otorgamiento de este tipo de figuras para planificar la sucesión del causante. En el seno del Convenio de La Haya se tomó en consideración e incluso se llegó a aprobarse en una primera votación ${ }^{576}$; sin embargo, rápidamente se volvió a debatir sobre la solución para los pactos sucesorios que afectan a más de una sucesión y se realizó una nueva votación en la que se prefirió definitivamente la solución cumulativa ${ }^{577}$. Posiblemente razones políticas explican este cambio, puesto que la mayor parte de los Estados contratantes en dicho Convenio no reconocían o ni siquiera conocían las figuras de los pactos sucesorios y se entendía que una solución excesivamente favorable a la validez de esas figuras podía provocar que muchos de tales Estados realizaran sistemáticamente una reserva al capítulo III del Convenio dedicado a la sucesión contractual. Esta circunstancia no se da en el marco europeo, donde al tratarse de un espacio de integración, hubiera sido una buena oportunidad para mantener la solución alternativa y promover así la celebración válida de este tipo de figuras. Sin embargo, ya hemos visto cómo el Reglamento de sucesiones ha optado finalmente por una solución cumulativa para la admisibilidad de los pactos sucesorios, cambiando el rumbo u optando por una política más restrictiva en lo que atañe a la validez de estas figuras.

Pese a que finalmente se ha desechado la solución alternativa, es una posibilidad que ha existido y se ha articulado en un texto normativo, lo que nos permite, siquiera teóricamente, analizar ahora el alcance de la alternatividad tal cual fue prevista en el art. 18.2 de la Propuesta de Reglamento. En un primer nivel la alternatividad se limita a la aplicación de cualquiera de las leyes sucesorias

\footnotetext{
576 Conférence de La Haye de droit international privé (1990), p. 417 donde se documenta que el día 10 de octubre 1988 se aprueba la propuesta de Dinamarca de una solución alternativa por diecinueve votos a favor, cero en contra y diez abstenciones.

${ }^{577}$ Conférence de La Haye de droit international privé (1990), p. 438, donde se documenta que dos días más tarde de la aprobación de la solución alternativa, el 12 de octubre de 1988, se aprueba la propuesta alemana a favor de una solución cumulativa.
} 
anticipadas en presencia; existirá entonces una mayor alternatividad cuantas más leyes sucesorias anticipadas en presencia existan ${ }^{578}$, es decir, cuantas más sucesiones estén afectadas por el contenido del pacto sucesorio. Sin embargo, el alcance de esta solución alternativa no se limita a la existencia de diversas leyes sucesorias anticipadas en juego; si observamos un segundo nivel, la ley sucesoria anticipada puede venir determinada por distintas conexiones. Desde este punto de vista, cuantas más posibilidades haya para determinar la ley sucesoria anticipada, mayor alcance tendrá la alternatividad. En este aspecto tiene un papel fundamental, como vamos a ver, la posibilidad de determinar la ley sucesoria anticipada a través de la autonomía de la voluntad.

Entrado en concreto en la previsión de la Propuesta de Reglamento, se impone un primer y breve comentario sobre la letra de su art. 18.2 y el distinto alcance del llamamiento a la ley sucesoria anticipada se realizaba, literalmente, entre los pactos sucesorios que afectaban a una única sucesión y los pactos sucesorios que afectaban a varias sucesiones. Mientras que el apartado primero del art. 18 se remitía a la ley que "habría sido aplicable a su sucesión en caso de que el fallecimiento se hubiera producido en la fecha de conclusión de acuerdo", el apartado segundo se refería a la ley que "en aplicación del artículo 16, habría sido aplicable a la sucesión de una de dichas personas en caso de que esta hubiera fallecido en la fecha de conclusión del acuerdo". Esta diferente redacción implicaba que, desde un punto de vista estrictamente literal, en el caso de los pactos sucesorios que afectan a una única sucesión la ley sucesoria anticipada podría venir determinada bien por la ley de la residencia habitual del causante en el momento del otorgamiento (como conexión objetiva: recordemos que la Propuesta no contemplaba la actual cláusula de excepción), bien por la ley de la nacionalidad del causante en el momento del otorgamiento del pacto sucesorio (como consecuencia del correspondiente ejercicio de professio iuris por parte del causante).

\footnotetext{
${ }^{578}$ Y también, claro está, cuando tales leyes sucesorias anticipadas se traduzcan en la aplicación de distintos sistemas jurídicos.
} 
Sin embargo, el llamamiento de la ley sucesoria anticipada en los pactos sucesorios que afectan a más de una sucesión se limitaría a la ley de la residencia habitual, como consecuencia de la remisión al art. 16. Esta cuestión resultaba de cierta importancia para poder determinar cuál es el alcance potencial de aquella solución alternativa. En el caso de que nos limitemos a una interpretación estrictamente literal, las posibilidades de determinar la ley sucesoria anticipada se restringirían a una sola ley, la de la residencia habitual del causante en el momento del otorgamiento del pacto sucesorio y, por tanto, no suma nada a la alternatividad que hemos visto en un primer nivel, esto es, a la referente únicamente a las leyes sucesorias anticipadas en juego. Sin embargo, si entendemos que esta diferencia de redacción fue un mero descuido inintencionado por parte del legislador y que el llamamiento a la ley sucesoria anticipada tiene el mismo alcance que en los pactos sucesorios que afectan a una única sucesión, la cuestión es cualitativamente distinta. En este caso ya entrarían potencialmente en juego dos conexiones distintas por cada ley sucesoria anticipada, la de la residencia habitual del correspondiente causante y la de su nacionalidad en aquellos casos en los que realice un ejercicio de professio iuris. Por tanto, la solución alternativa tendría un mayor alcance en términos sustanciales, puesto que aumentan las posibilidades de aplicar una ley que prevea la validez de los pactos sucesorios al haber crecido el abanico potencial de leyes aplicables.

Es más, el hecho de que una de las posibilidades de la determinación de la ley sucesoria anticipada venga de la mano de la autonomía de la voluntad conflictual aumenta aún más el carácter sustancial de esta solución, en cuanto que la elección de ley ya supone en sí misma una materialización ${ }^{579}$. En efecto, la combinación de la autonomía de la voluntad y la solución alternativa aumenta las posibilidades de celebración válida de un pacto sucesorio en cuanto que abre la posibilidad de la aplicación de una ley elegida, pudiendo ser las razones de la elección precisamente la búsqueda de la validez del pacto sucesorio en cuestión. Pensemos en el ejemplo de un pacto sucesorio celebrado entre dos cónyuges que

\footnotetext{
579 Tal y como hemos visto en el capítulo III, la elección de ley es un mecanismo de materialización en cuanto que tal elección se realiza por razones materiales, esto es, en atención al contenido de la ley elegida.
} 
residen habitualmente en París, uno de ellos tiene nacionalidad francesa y el otro nacionalidad alemana. En el caso de que no haya professio iuris alguna, las leyes sucesorias anticipadas coinciden, por coincidir la residencia habitual de los disponentes en el momento del otorgamiento del pacto sucesorio, y supone la aplicación de la ley francesa y la invalidez del pacto sucesorio. Sin embargo, la nacionalidad alemana de uno de los cónyuges abre una posibilidad a la validez del pacto sucesorio: es posible que el cónyuge alemán realice una professio iuris de tal forma que su ley sucesoria anticipada sea la ley alemana, en vez de la francesa, caso en el que el pacto sucesorio será válido como consecuencia del juego de la autonomía de la voluntad y de la solución alternativa que proponía el art. 18.2 de la Propuesta de Reglamento.

Por último, resulta obligado analizar las posibles consecuencias prácticas de la aplicación de la solución alternativa. Esta solución no presenta problema alguno para la determinación de la validez material del pacto sucesorio en aquellos casos en los que sólo una de las leyes sucesorias anticipadas así lo reconoce; sin embargo, para el caso de que haya más de una ley sucesoria anticipada que contemple la validez material del pacto sucesorio habrá que arbitrar una solución para concretar cuál de esas leyes es la que va a regular la validez material, puesto que puede haber diferencias regulativas entre unas y otras. Cuestión técnica menor que podría resolverse sin mayores problemas.

Lo que sí es cierto es que la solución alternativa puede plantear un problema de reconocimiento de la validez material del pacto sucesorio, fundamentalmente por la existencia de ordenamientos jurídicos plenamente contrarios a estas figuras. Dicho de otro modo, el carácter favorable a la validez de los pactos sucesorios de la solución alternativa se traduce en el ámbito internacional en una validez débil de este tipo de figuras. Se trata también de un efecto natural de este tipo de normas materialmente orientadas, cuando no cuentan con un soporte de Derecho comparado apropiado. Ahora bien, este problema pierde intensidad en el marco de un instrumento multilateral, fundamentalmente en el ámbito europeo de integración entre los Estados miembros, razón por la cual en su día mantuvimos la defensa de una solución alternativa en el marco del 
Reglamento de sucesiones ${ }^{580}$. Cosa distinta es su proyección sobre terceros Estados.

\subsubsection{Solución cumulativa: la solución del Reglamento}

La solución cumulativa parte de que se exige la aplicación de todas y cada una de las leyes sucesorias anticipadas en juego para determinar validez material del pacto sucesorio en cuestión. En concreto, para que el pacto sucesorio sea válido es necesario que todas las leyes sucesorias anticipadas así lo prevean. Basta con que al menos una de ellas no prevea la validez del concreto pacto sucesorio, para que éste sea inválido. Un pacto sucesorio de institución recíproca, por ejemplo, celebrado entre dos hermanos, uno con residencia habitual en Munich y otro con residencia habitual en París, visto al amparo del Reglamento de sucesiones sería inválido. Las leyes sucesorias anticipadas, la alemana y la francesa, se tienen que aplicar cumulativamente, lo que da como resultado la invalidez del pacto sucesorio por no permitirse una figura tal en el Derecho francés. Sin embargo, este mismo pacto sucesorio sí sería válido si los otorgantes tienen uno residencia habitual en Munich y el otro en Lausana, puesto que las dos leyes sucesorias anticipadas, la alemana y la suiza, sí permiten un pacto sucesorio de estas características. Dicho de otro modo, de la aplicación cumulativa de las leyes sucesorias anticipadas en juego se deriva la validez del pacto sucesorio.

La solución cumulativa es la más habitual en Derecho comparado y también por la que optó el Convenio de La Haya de 1989 tanto para la admisibilidad como para la validez material de los pactos sucesorios, y la que finalmente será aplicable en el Reglamento de sucesiones en lo que respecta a la admisibilidad de los pactos sucesorios. De igual forma, en aquellos casos en los que no hay una solución específica para los pactos sucesorios que afectan a más

${ }^{580}$ Vid. I. RodríGUeZ-URÍA SuÁrez (2010), p. 661 y ss.; M. BuschBAUM/M. KohLer (2010), p. 113. En el marco del Convenio de La Haya de 1989 la solución alternativa fue propuesta y defendida por la delegación danesa; vid. por ejemplo su propuesta y fundamentos en CONFERÉNCE DE LA HAYE DE DROIT INTERNATIONAL PRIVÉ (1190), p. 286. 
de una sucesión, la regla general en la doctrina es la de interpretar que deben aplicarse cumulativamente las leyes sucesorias anticipadas en juego ${ }^{581}$.

La aplicación de la solución cumulativa de las leyes sucesorias anticipadas en presencia a la admisibilidad del pacto sucesorio no constituye problema alguno. Como hemos dicho, la admisibilidad se limita a un aspecto muy primario, que se refiere a la admisión de un pacto sucesorio como el celebrado con carácter general, sin el análisis de más elementos. La cuestión, por tanto, se limita a determinar si un pacto sucesorio de institución recíproca o un pacto sucesorio de renuncia a la herencia son admitidos por los ordenamientos jurídicos pertinentes. Sin embargo, no se puede predicar lo mismo respecto de la validez material de los pactos sucesorios. En este caso, el carácter fuertemente reglado de los pactos sucesorios complica sobremanera la aplicación de una solución cumulativa. Es el ejemplo del Convenio de La Haya de 1989 que, como hemos visto, establece que los pactos que se refieren a la sucesión de más de una persona son válidos en cuanto al fondo cuando todas y cada una de las leyes sucesorias anticipadas así lo prevean. Pongamos el ejemplo de un pacto sucesorio de institución recíproca realizado entre dos socios, sin parentesco alguno, visto al amparo de la normativa prevista en el Convenio de La Haya. En el momento del otorgamiento del pacto sucesorio uno de los socios tiene residencia habitual en Berlín y el otro tiene residencia habitual en Barcelona (y vecindad civil catalana). Las leyes sucesorias anticipadas son la alemana y el Derecho civil catalán (este último como consecuencia de la aplicación del art. 36 que remite a las normas del Estado plurilegislativo para identificar qué ley de qué concreta unidad territorial debe ser aplicada al caso). En este caso, la aplicación cumulativa de las leyes sucesorias anticipadas en presencia da como resultado el de la invalidez del pacto sucesorio por no cumplirse en todas ellas los requisitos de legitimación para celebrar el pacto sucesorio. En concreto, el pacto sucesorio es válido para el

\footnotetext{
${ }^{581}$ H. DÖRNER (2007), p. 227, núm. 351; R. BIRK (2006), p. 1617, núm. 134; J. KROPHOLLER (2004), p. 440; K. FIRSCHING (2004), p. 109, núm. 584. También en la propia doctrina española se ha optado por una aplicación cumulativa de las leyes en presencia, A. FONT SEGURA (2009), p. 18; B. AÑOVEROS TERRADAS (2009), p. 170. También se ha defendido la solución cumulativa con ocasión del análisis de la ley aplicable a los testamentos mancomunados, E. ZABALO ESCUDERO (1989), p. 6364.
} 
sistema alemán, donde no se conoce limitación alguna para los otorgantes, pero es inválido para el sistema catalán, donde como ya hemos visto más atrás se exige cierto grado de parentesco entre los otorgantes de un pacto sucesorio. Lo mismo ocurriría en el caso de que el otorgante en vez de tener residencia habitual en Barcelona la tuviera, por ejemplo, en Viena. El sistema austriaco permite un pacto sucesorio de estas características pero sólo entre cónyuges. Y lo mismo ocurre con el resto de aspectos que se comprendan dentro del concepto de validez material del pacto sucesorio y cuya regulación puede tener numerosos matices y diferencias entre una legislación y otra.

Por todo ello, consideramos un acierto la regulación prevista en la versión definitiva del Reglamento donde, tal y como hemos visto, la solución cumulativa se limita a la determinación de la admisibilidad de los pactos sucesorios que afectan a más de una sucesión; mientras que para la validez material se prevé una solución distinta en la que ya se concreta la aplicación de una única ley, evitándose así todos los posibles problemas de coordinación de legislaciones. A nuestro juicio, por tanto, la solución cumulativa debe limitarse a la determinación de si el pacto sucesorio es admisible o no, mientras que para el resto de aspectos del pacto sucesorio, validez material y resto de régimen jurídico, se debería arbitrar una solución de la que se desprendiera una única ley aplicable (la que sea, con o sin orientación material), evitándose así problemas de coordinación y adaptación de la aplicación de simultánea de varias legislaciones.

La solución cumulativa supone también una solución materialmente orientada; en este caso, como en todo caso en el que existe una aplicación cumulativa de conexiones $^{582}$, la materialización va en la dirección de restringir la válida celebración de los pactos sucesorios. De forma paralela a como hemos visto a la hora de analizar la solución alternativa, la solución cumulativa se corresponde con el tradicional mecanismo de las normas de conflicto materialmente orientadas con conexiones de aplicación cumulativa; la

\footnotetext{
${ }^{582}$ Vid. las afirmaciones al hilo de las conexiones cumulativas en materia de validez formal, $\mathrm{H}$. BATIFFOL (1979), p. 434.
} 
acumulación no viene determinada por conexiones distintas, sino por las distintas leyes sucesorias anticipadas.

\section{La ley aplicable al régimen jurídico de los pactos sucesorios que afectan a más de una sucesión}

\subsection{Consideraciones previas en torno al concepto de régimen jurídico del pacto sucesorio}

Los últimos aspectos concernientes al negocio jurídico del pacto sucesorio que nos restan por analizar los vamos a agrupar bajo la denominación de régimen jurídico. Antes de empezar a analizar las soluciones de ley aplicable sobre este aspecto es necesario aclarar a qué concretos elementos nos referimos cuando hablamos de régimen jurídico de los pactos sucesorios. Las normas que han tratado el tema de manera específica utilizan términos ambiguos. El Convenio de La Haya habla de los efectos del pacto sucesorio y las circunstancias que den lugar a la extinción de tales efectos; el Reglamento, por su parte, se refiere a los efectos vinculantes entre las partes, incluidas las condiciones para la resolución del pacto sucesorio. Para analizar esta cuestión vamos a dividir convencionalmente el término régimen jurídico en efectos del pacto sucesorio y circunstancias que determinen la extinción del pacto sucesorio. Sobre esta última cuestión ocupará un lugar fundamental las causas de revocación del pacto sucesorio $^{583}$; esto es, aquellas causas que recoge la ley y que de manera excepcional permiten que el futuro causante o disponente pueda revocar de manera unilateral las disposiciones realizadas a través del pacto sucesorio (a las que está vinculado). A estas causas se les sumaría también aquellas otras que hubieran podido acordar las partes otorgantes. Ahora bien, la mención a las causas de extinción de los efectos de los pactos sucesorios en vez de a la revocación es un concepto más amplio que abarca otros posibles aspectos que puedan dar lugar

\footnotetext{
${ }^{583}$ De hecho en el seno de la Conferencia de La Haya se habló durante mucho tiempo directamente de efectos y revocación del pacto sucesorio, en vez de extinción; no obstante, El Comité de redacción modificó el texto de revocación por el de "circunstancias que den lugar a la extinción de tales efectos", por ser este último más acertado, cambio que fue acogido sin problema por las delegaciones de los Estados contratantes. Vid. las consideraciones al respecto del ponente en CONFÉRENCE DE LA HAYE DE DROIT INTERNATIONAL PRIVÉ (1990), p. 441.
} 
a la extinción del pacto sucesorio y que no necesariamente tienen que ser a través de una revocación del mismo ${ }^{584}$.

En cuanto al concepto de efectos de los pactos sucesorios debemos señalar que tampoco es una categoría pacífica. Como en muchas otras ocasiones, buena muestra de ello fueron los muy ilustrativos debates seguidos en el proceso de elaboración del Convenio de La Haya de 1989, donde tuvo lugar una interesante discusión respecto de los efectos de los pactos sucesorios y la ley que se les debería aplicar. Los problemas más importantes son el determinar cuáles son los efectos de los pactos sucesorios y cómo clasificarlos. Así, se han mantenido criterios en los que se distingue los efectos contractuales del pacto sucesorio de los efectos propiamente sucesorios; o aquellos otros en los que se distingue entre los efectos del pacto sucesorio entre las partes y los efectos para terceros. Tal y como hemos venido defendiendo a lo largo de este trabajo, el efecto más importante y más característico de los pactos sucesorios es el de la vinculación de las partes al contenido del pacto. Esta vinculación tiene como consecuencia fundamental el de la correlativa pérdida de libertad de disposición mortis causa por parte del disponente o futuro causante (como también sabemos, es cierto que este efecto se produce únicamente en los pactos sucesorios de institución, si bien debemos destacarlo por ser el más polémico y la causa fundamental de la postura contraria a los pactos sucesorios por parte de muchos ordenamientos jurídicos). Pero también hay otros efectos derivados del pacto sucesorio que deben ser considerados. Destacan, sin duda los efectos sobre la sucesión del causante, ya sea la herencia en un pacto de institución, ya sea la renuncia a la legítima o a la herencia en un pacto sucesorio negativo. Junto a estos, deben mencionarse otros efectos del pacto sucesorio que se pueden dar en vida del futuro causante o disponente, tales como la posibilidad de recibir en vida efectos de la sucesión o las obligaciones adquiridas por algún otorgante a través de compromisos acordados a cambio de la institución de heredero (por ejemplo, el cuidado de la empresa familiar con la diligencia debida o la obligación de prestar

\footnotetext{
${ }^{584}$ Es el ejemplo de la posible pérdida de eficacia de las disposiciones realizadas a favor de un cónyuge en caso de crisis matrimonial; vid. art. 431-17 Libro IV CCCat; o art. 404 Código del Derecho Foral de Aragón.
} 
los cuidados necesarios al causante hasta el momento de su fallecimiento) o la concurrencia de una causa de revocación. Otros efectos, sin embargo, tienen lugar una vez fallecido el causante, generalmente el recibimiento de la herencia estipulada.

A la hora de determinar la ley aplicable a todas estas consecuencias, se entendió por algunos autores que se debía separar el efecto fundamental de la vinculación al pacto sucesorio por las partes otorgantes del resto (aquellos que son susceptibles de producirse también en un testamento) que se pudieran derivar del mismo. Y sobre la base de esta diferenciación hubo quien defendió la aplicación de la ley sucesoria anticipada para el efecto principal de la vinculación, dejando el resto de los efectos al albur de la ley sucesoria ${ }^{585}$. No podemos estar de acuerdo con esta postura, dado que, como siempre hemos mantenido, todo el régimen jurídico del pacto sucesorio, y por tanto también sus efectos, deben conocerse desde el mismo momento del otorgamiento. Sólo de esta forma pueden las partes conocer sus derechos y obligaciones y adecuar su comportamiento al mismo y sólo así pueden conocer realmente a qué están vinculados. Es más, como ya hemos mencionado, existen otros muchos posibles efectos, además de la vinculación al pacto, que se dan en vida del causante, a los que la aplicación de una ley determinada en el momento del fallecimiento de aquél es, sencillamente, ilógica. La diferenciación entre el efecto de la vinculación y los efectos sucesorios supone una simplificación irreal de los pactos sucesorios. Cosa distinta es que siempre se mantenga la clásica solución de la determinación de los derechos de legitimarios a través de la ley sucesoria concretada en el momento del fallecimiento del causante y que tal competencia pueda afectar al pacto sucesorio. En efecto, es posible una limitación de los efectos del pacto sucesorio determinada por otra ley, la sucesoria. En los casos en los que el contenido del pacto sucesorio afecte a los derechos de legitimarios tendrá lugar una corrección por parte de la ley sucesoria, que afectará a la eficacia del pacto sucesorio hasta ajustar su contenido y garantizar tales derechos. Ahora bien, el planteamiento es

\footnotetext{
${ }^{585}$ Esta postura se ve bien en el debate sobre el Convenio de La Haya de 1989; vid. especialmente la contribución de PIRRUNG, en CONFÉRENCE DE LA HAYE DE DroIT INTERNATIONAL PRIVÉ (1990), p. 434.
} 
distinto, pues esta es una corrección que puede, en su caso, sufrir el pacto sucesorio, y no una solución de ley aplicable a los efectos de un pacto sucesorio.

\subsection{Soluciones neutrales de ley aplicable}

\subsubsection{Solución aleatoria o distributiva}

Al igual que ocurre en el caso de la admisibilidad y la validez material de los pactos sucesorios, la solución distributiva o aleatoria es susceptible de ser aplicada en el régimen jurídico de los pactos sucesorios que afectan a más de una sucesión como consecuencia de una interpretación doctrinal ante la falta de una solución específica para este tipo de pactos sucesorios ${ }^{586}$.

La aplicación de la solución distributiva o aleatoria al régimen jurídico del pacto sucesorio presenta importantes problemas que tienen el mismo fundamento del que hemos hablado a la hora de analizar la aplicación de esta solución a la validez material. Aplicar distintas leyes de forma independiente a cada parte del pacto sucesorio, esto es a cada una de las sucesiones afectadas por el pacto, supone, por un lado, la negación del pacto sucesorio como un todo y que, por otro lado, exista un régimen jurídico distinto del pacto sucesorio según de la sucesión de que se trate.

Para ver cómo esta solución puede crear una situación indeseable en la regulación de los pactos sucesorios vamos a tomar, de nuevo, un ejemplo centrándonos en una causa de extinción de los pactos sucesorios. Pensemos en un pacto sucesorio celebrado entre dos cónyuges que se instituyen recíprocamente herederos; vamos a valorar la ley aplicable al pacto sucesorio con un sistema que juegue con la conexión de la nacionalidad, como nuestro art. 9.8 CC, y con la interpretación distributiva a falta de una solución específica para los pactos sucesorios que afectan a más de una sucesión. Uno de los cónyuges es nacional

\footnotetext{
${ }^{586}$ En las negociaciones del Convenio de La Haya de 1989, la solución distributiva fue propuesta por la delegación italiana, si bien sin ningún tipo de repercusión. Vid. el Documento de trabajo núm. 91 en CONFÉRENCE DE LA HAYE DE DROIT INTERNATIONAL PRIVÉ (1990), p. 334, así como las consideraciones al respecto de PICONE en CONFÉRENCE DE LA HAYE DE DROIT INTERNATIONAL PRIVÉ (1990), p. 444. No obstante, esta propuesta no tuvo casi consideración por el resto de delegados y rápidamente fue rechazada; vid. las votaciones en CONFÉRENCE DE LA HAYE DE DROIT INTERNATIONAL PRIVÉ (1990), p. 444.
} 
alemán y el otro es nacional español y tiene vecindad civil en Cataluña. El pacto sucesorio está admitido y es válido según la ley alemana y el Derecho catalán. Ahora bien, el régimen jurídico es distinto. El supuesto de divorcio de los cónyuges nos sirve de piedra de toque. Para la parte del pacto sucesorio regulado por la ley alemana, la ruptura matrimonial no afecta al pacto sucesorio, de tal forma que en el caso de que fallezca en primer lugar el causante con nacionalidad alemana, el pacto sucesorio mantendrá su vigencia y el excónyuge heredará según lo dispuesto en el pacto sucesorio. Sin embargo, para la parte del pacto sucesorio regulada por el Derecho catalán, el pacto sucesorio se verá afectado por la crisis matrimonial, en cuanto que el art. 431. 17 del Libro IV CCCat dispone que los heredamientos y atribuciones particulares realizadas a favor del cónyuge devienen ineficaces en ciertos casos (remitiéndose al art. 422-13. 1 y 2), entre los que se encuentra el de divorcio. Por tanto, en el caso de que fallezca en primer lugar el cónyuge español y vecindad civil catalana, las disposiciones a favor de su excónyuge serán ineficaces $y$, por tanto éste no heredará a través del pacto sucesorio. Tal y como se puede ver en este sencillo ejemplo, la aplicación de la solución distributiva o aleatoria al régimen jurídico de los pactos sucesorios va completamente en contra de los intereses de estas figuras, negando su razón de ser y haciendo que el pacto sucesorio pierda su razón económica.

\subsubsection{La aplicación de la ley más estrechamente vinculada: de nuevo sobre el art. 25.2 párrafo segundo del Reglamento de sucesiones}

La otra solución neutral que se ha dado para la determinación del régimen jurídico de los pactos sucesorios que afectan a más de una sucesión es la de la aplicación de la ley que presente los vínculos más estrechos con el pacto sucesorio. Al igual que ocurría con la solución de ley aplicable a la validez material, la aplicación de la ley más estrechamente vinculada tiene matices, en cuanto que dicha ley está limitada a aquellas que han participado en la determinación de la admisibilidad del pacto sucesorio. Esta solución se recoge en el Reglamento de sucesiones, en el art. 25.2 párrafo segundo, en cuanto que dispone que un pacto sucesorio que fuera admisible, de conformidad con la solución cumulativa establecida en el párrafo primero del mismo artículo, se regirá en cuanto a sus efectos vinculantes entre las partes, incluidas las 
condiciones para su resolución, por aquella de las leyes referidas en ese primer párrafo con la que presente una vinculación más estrecha.

Dado que la solución es la misma que la que hemos visto para la determinación de la validez material de los pactos sucesorios que afectan a más de una sucesión, nada nuevo hay que añadir aquí. La solución es neutra puesto que la elección de la ley aplicable, de entre las leyes que han admitido el pacto sucesorio, no se realiza en consideración de contenido material alguno del régimen jurídico del pacto sucesorio; es decir, no se establece preferencia alguna por algún tipo de régimen jurídico, como podría ser por ejemplo, por aquél que supusiera una mayor probabilidad de conservación del pacto sucesorio por no prever causa de revocación alguna o al contrario. La solución busca únicamente la mejor localización, eso sí, siempre dentro de los límites de las leyes sucesorias anticipadas en juego, del pacto sucesorio en cuestión.

Para ver el funcionamiento de esta solución neutra en la determinación de la ley aplicable al régimen jurídico de los pactos sucesorios que afectan a más de una sucesión vamos a continuar con el ejemplo que hemos usado en el apartado dedicado a la solución aleatoria o distributiva. Se trataba de un pacto sucesorio de institución recíproca realizado entre dos cónyuges. En este caso aplicamos el Reglamento y para hacer más sencillo el ejemplo, partiremos de que las leyes sucesorias anticipadas son las correspondientes a la nacionalidad de cada uno de los otorgantes como consecuencia de sendos ejercicios de professio iuris a favor de tales leyes. Las leyes sucesorias anticipadas son, por tanto, la alemana, correspondiente a la nacionalidad de uno de los cónyuges, y el Derecho catalán, correspondiente a la nacionalidad española del otro cónyuge y a su vecindad civil catalana. Como habíamos dicho, ambas leyes prevén la admisibilidad del pacto sucesorio; ambas prevén también su validez material. Queda por determinar cuál es la ley que va a regir su régimen jurídico. Tal y como también vimos en el apartado anterior, los cónyuges se divorcian, por lo que se trata de ver cómo esta circunstancia puede afectar al pacto sucesorio. En la primera hipótesis con la que vamos a jugar el pacto sucesorio se celebra en Barcelona, donde residen habitualmente los cónyuges y donde tienen su patrimonio. La ley más 
estrechamente vinculada es sin duda el Derecho catalán. El pacto sucesorio deviene ineficaz, como consecuencia de la ruptura matrimonial, en virtud de lo dispuesto en el art. 431. 17 del Libro IV del CCCat. En la segunda hipótesis, sin embargo, los cónyuges residen habitualmente en Berlín, donde celebran el pacto sucesorio y donde tienen su patrimonio. En este caso, la ley más estrechamente vinculada será la alemana y la ruptura matrimonial no afectará en sí misma al pacto sucesorio. El resultado material es, pues, aleatorio, en el sentido de que la solución de ley aplicable no lo toma en consideración.

La ley aplicable al régimen jurídico de los pactos sucesorios que afectan a más de una sucesión en el marco del Reglamento será la misma que la ley aplicable a la validez material, pues ambas se determinan por la ley más estrechamente vinculada con el pacto sucesorio de entre aquellas que hayan determinado su admisibilidad. Los problemas que pueda presentar la solución de los vínculos más estrechos son, por tanto, los mismos que hemos señalado en el apartado de la validez material y a los que nos remitimos. Ahora bien, debemos destacar lo positivo de esta solución, porque permite concretar como aplicable una única ley de entre las leyes sucesorias anticipadas en juego, lo que permite a las partes otorgantes conocer con mayor seguridad jurídica y previsibilidad el régimen jurídico del pacto sucesorio. Se evitan además los problemas que puede producir la aplicación de varias leyes sucesorias anticipadas, tal y como vamos a ver continuación.

\subsection{Soluciones materialmente orientadas}

\subsubsection{Aplicación alternativa de las leyes en presencia}

La aplicación de la solución alternativa al régimen jurídico de los pactos sucesorios que afectan a más de una sucesión supone la aplicación de cualquiera de las leyes en presencia a los efectos y a las circunstancias que entrañan la extinción del pacto sucesorio. Esta aplicación se puede plantear de dos formas distintas: bien como una aplicación en bloque, es decir, una de las leyes se aplica a todo el régimen jurídico, o bien como una aplicación a cada uno de los distintos aspectos del régimen jurídico del pacto sucesorio; es decir, en este último caso bastaría con que el concreto efecto estuviera previsto o permitido por alguna de 
las leyes sucesorias anticipadas en presencia para que fuera reconocido y esta valoración se repite con cada uno de los efectos y con cada una de las causas que determinan la extinción del pacto sucesorio. La solución alternativa fue valorada en el seno del debate del Convenio de La Haya de 1989, si bien es cierto que en aquel momento aún concretaban el tema a la determinación de la ley aplicable a la revocación del pacto sucesorio ${ }^{587}$.

La aplicación de esta solución puede antojarse problemática y también implica un cierto grado de inseguridad en el régimen jurídico del pacto sucesorio, ante la dificultad de delimitar el concreto régimen jurídico del pacto sucesorio, que podrá ser cualquiera que se pueda derivar de las múltiples combinaciones de la aplicación alternativa de las leyes sucesorias anticipadas en presencia. En consecuencia, cuantas más leyes sucesorias anticipadas distintas existan, mayores combinaciones posibles de régimen jurídico del pacto sucesorio habrá. Pero el mayor problema de esta solución es su inoperatividad en su aplicación para el régimen jurídico del pacto sucesorio; tal inoperatividad viene de la mano de la falta de un criterio para optar por una ley u otra. Sólo en el caso de las causas de revocación podríamos tener un criterio, que en el caso de una aplicación alternativa sería el de permitir con la mayor facilidad posible la revocación del pacto sucesorio $\mathrm{y}$, por tanto, se traduciría en una postura contraria a la conservación de estas figuras. La solución alternativa implica la posibilidad de aplicar cualquiera de las causas de revocación previstas por las leyes sucesorias anticipadas en juego; basta con que alguna de esas leyes prevea la causa de revocación pretendida, para que ésta pueda tener lugar en el pacto sucesorio. Desde este punto de vista, esta solución implica una tendencia contraria a la conservación de los pactos sucesorios; en efecto, la solución alternativa implica una mayor concurrencia de causas de revocación $\mathrm{y}$, por tanto, una mayor posibilidad de revocar el pacto sucesorio. Hay que concluir, no obstante, que por

\footnotetext{
${ }^{587}$ La solución alternativa, enfocada para la revocación de los pactos sucesorios, fue propuesta y defendida por la delegación alemana, vid. CONFÉRENCE DE LA HAYE DE DROIT INTERNATIONAL PRIVÉ (1990), pp. 285, 324.
} 
paradójico que parezca, es una solución coherente y consistente con la solución cumulativa aplicada a la validez sustancial del pacto ${ }^{588}$.

Ahora bien, en el resto de aspectos del régimen jurídico no existe criterio material alguno que nos permita optar por la aplicación de una ley y desechar la otra o las otras. La inoperatividad de esta solución se puede ver en el ejemplo repetido de la posible ineficacia del pacto sucesorio como consecuencia de una crisis matrimonial; no se trata de una causa de revocación, sino de otra posible vía de extinción del pacto sucesorio. Sigamos, pues, trabajando con el ejemplo del pacto sucesorio celebrado entre los dos cónyuges, uno con nacionalidad alemana y el otro con nacionalidad española y vecindad civil catalana; y sigamos también con la hipótesis de la ruptura del matrimonio y cómo puede afectar esta circunstancia al pacto sucesorio. Las leyes sucesorias anticipadas en juego son la alemana y el Derecho catalán. El cónyuge con nacionalidad alemana quiere mantener la vigencia del pacto sucesorio, mientras que al cónyuge con vecindad civil catalana le interesa que el divorcio afecte al pacto sucesorio deviniendo ineficaces las disposiciones a favor de su excónyuge. Si aplicamos la ley alemana, el pacto sucesorio seguirá en vigor por no preverse disposición alguna por la cual se entienda extinguido el pacto sucesorio en caso de ruptura matrimonial; sin embargo, si aplicamos el Derecho catalán, el pacto sucesorio deviene ineficaz y se entiende extinguido. Según la solución alternativa cualquiera de las leyes en juego puede aplicarse a esta cuestión, pero no hay criterio alguno que nos haga decantarnos por una solución material u otra, de ahí la inoperatividad de esta solución. En estas circunstancias, la solución alternativa necesitaría de otro criterio adicional para concretar la aplicación de una de las leyes sucesorias en presencia, como podría ser el caso de la ley más estrechamente vinculada (como, por ejemplo, se previó en la Propuesta de Reglamento).

\subsubsection{Aplicación cumulativa de las leyes en presencia}

La otra de las soluciones de ley aplicable al régimen jurídico de los pactos sucesorios que afectan a más de una sucesión con cierto carácter

\footnotetext{
588 Vid. la contribución del profesor Lagarde, en CONFÉRENCE DE LA HAYE DE DROIT
} INTERNATIONAL PRIVÉ (1990), p. 444. 
materializador es la solución cumulativa. Según esta solución para que se dé un concreto efecto del pacto sucesorio es necesario que todas y cada una de las leyes sucesorias anticipadas en juego así lo prevean. Esta es la solución que finalmente se previó el Convenio de La Haya, en su art. 10.2, donde después de haber determinado la solución cumulativa para la validez en cuanto al fondo de los pactos sucesorios que afectan a más de una sucesión, establece que los efectos del pacto y las circunstancias que den lugar a la extinción de los mismos serán los reconocidos por el conjunto de las leyes sucesorias anticipadas.

Como ya hemos señalado en otros análisis de la aplicación cumulativa de las leyes sucesorias anticipadas en juego a otros aspectos de los pactos sucesorios, el problema fundamental de esta solución es el de su puesta en aplicación en relación con el carácter reglado de los pactos sucesorios. Esta cuestión es especialmente importante en lo que respecta a las causas de revocación unilateral previstas por la ley de manera excepcional, dado que generalmente es el aspecto más reglado del régimen jurídico de los pactos sucesorios precisamente por esa excepcionalidad. Según la solución cumulativa, para que pueda operar una causa de revocación unilateral es preciso que todas y cada una de las leyes en juego la reconozcan. Esto puede plantear problemas de interpretación o adaptación, de los distintos términos que las distintas legislaciones puedan utilizar. Así, por ejemplo, puede ser problemático determinar qué se entiende o qué casos entran dentro de la indignidad o la desheredación, que habitualmente suponen causas de revocación de los pactos sucesorios.

Cuando se trata de la revocación de los pactos sucesorios se puede ver el carácter materializador de la solución cumulativa. La exigencia de que todas las leyes tengan que prever la causa de revocación que se pretende para que ésta se pueda poner en funcionamiento supone que la revocación es más difícil y que, por tanto, en este caso, la solución cumulativa está dirigida a la conservación de los pactos sucesorios. Tal cual concluíamos uno de los párrafos del epígrafe anterior, esta solución sería coherente con una solución alternativa en la determinación de la ley aplicable a la validez. 


\section{Alternativas neutrales de ley aplicable a los pactos sucesorios que afectan a más de una sucesión}

Tal y como hemos visto hasta ahora, se barajan con carácter general tres soluciones de ley aplicable a los pactos sucesorios que afectan a más de una sucesión: la solución distributiva o aleatoria, la solución cumulativa y la solución alternativa. También entra en juego la solución de los vínculos más estrechos, pero siempre en un segundo momento, esto es, cuando ya han entrado en juego o la solución cumulativa o la alternativa. En definitiva, tenemos una solución neutral y dos soluciones materialmente orientadas. Respecto de la solución neutral distributiva o aleatoria hemos visto, sin embargo, cómo se trata de una solución de ley aplicable contraria a los intereses de los pactos sucesorios, ya estemos contemplando su aplicación a la admisibilidad, a la validez material o al régimen jurídico de los pactos sucesorios. La total inadecuación de esta solución nos lleva a rechazarla de plano. La soluciones cumulativa y alternativa, por su parte, son con carácter general aptas para la regulación de este tipo de pactos sucesorios ( $\sin$ perjuicio de que en ocasiones deban completarse con una criterio adicional, que generalmente es la de la aplicación de la ley más estrechamente vinculada) pero presentan una orientación material, en un caso favorable y en el otro caso restrictiva a la celebración de los pactos sucesorios.

Estas tres soluciones tienen en común que se trata en todas ellas de una combinación de las leyes sucesorias anticipadas (o leyes sucesorias en aquellos casos en los que no hay regulación específica para los pactos sucesorios) en presencia. Es decir, la solución de ley aplicable a los pactos sucesorios que afectan a más de una sucesión parte, como en el caso de los pactos sucesorios que afectan a una única sucesión, de la ley sucesoria anticipada. Desechada la solución neutral, el debate se centró entre la solución cumulativa o alternativa; ambas con orientaciones materiales contrarias. La cuestión nunca estuvo clara tal y como se puede ver tanto en el desarrollo de los debates previso a la celebración del Convenio de La Haya, como en el proceso de elaboración del Reglamento europeo. En el primer caso, se llegó a votar la solución alternativa para la determinación de la validez material de los pactos sucesorios que afectan a más de una sucesión, pero finalmente se optó por la solución más conservadora de la 
aplicación cumulativa de las leyes sucesorias anticipadas en presencia. En el segundo caso ocurrió prácticamente lo mismo: mientras que la Propuesta de Reglamento optó por una solución alternativa, finalmente, el texto definitivo del Reglamento recoge la solución cumulativa. En estas circunstancias, vemos que la orientación material de los pactos sucesorios no es un tema que esté claro; por ello, cabe preguntarse ahora por la posibilidad de otro tipo de solución de ley aplicable a estos pactos sucesorios que afectan a más de una sucesión, de carácter neutral y que, a diferencia de la solución distributiva o aleatoria, no sea contraria a los intereses de los pactos sucesorios.

La tarea no es fácil, pues tal y como hemos visto podemos decir ya que la tradición en lo que respecta a la determinación de la ley aplicable a los pactos sucesorios es la de partir de la ley sucesoria anticipada (o la ley sucesoria). Las soluciones que se han dado son combinaciones de las leyes sucesorias anticipadas en juego y aunque existen otras posibles combinaciones, como vamos a ver, no son suficientes para dar una solución a todos los casos.

Para construir esta alternativa es necesario tener presente que partimos de un negocio jurídico bilateral; en concreto, en los pactos sucesorios que afectan a más de una sucesión hay al menos dos personas cuya sucesión está afectada por el contenido del pacto sucesorio. Por otro lado, tratándose de un tema que afecta al Derecho de sucesiones, lo habitual es la utilización de conexiones personales. Estos dos factores nos conducen a una posible alternativa qu podría pasar por una solución de ley aplicable con conexiones colectivas (nacionalidad común, residencia habitual común de los pactantes...) con eventuales soluciones de cierre.

Creemos en este marco de reflexión que lo más adecuado es que cualquier alternativa de ley aplicable a las analizadas con anterioridad siga pasando por la utilización de las leyes sucesorias anticipadas en presencia. Como hemos dicho, esta es la solución que tradicionalmente se ha seguido en la determinación de la ley aplicable a los pactos sucesorios; además, la ley sucesoria anticipada es la solución que se predica respecto de los pactos sucesorios que afectan a una única sucesión, por lo que una diferencia en la conexión entre una clase y otra de pactos sucesorios no es fácil de justificar. Como bien sabemos, 
tratándose de pactos sucesorios que afectan a más de una sucesión hay más de una ley sucesoria anticipada, con lo que debemos establecer una combinación (distinta de las que ya se han barajado y hemos analizado) de estas leyes. En definitiva, la primera conexión posible para construir esta alternativa a la determinación de la ley aplicable a los pactos sucesorios que afectan a más de una sucesión es la aplicación de la ley sucesoria anticipada común a los futuros causantes o disponentes.

En el marco del Reglamento de sucesiones la solución de la aplicación de la ley sucesoria anticipada común de las personas cuyas sucesiones estén afectadas por el contenido del pacto sucesorio implicaría dar entrada indirectamente tanto a la ley de la residencia habitual en el momento del otorgamiento, como a la ley de la nacionalidad, en aquellos casos en los que se hubiera ejercitado una professio iuris. El ejemplo podría ser el de un pacto sucesorio de institución recíproca celebrado entre un alemán con residencia habitual en Francia y su socio que reside habitualmente en Alemania. El otorgante con residencia habitual en Francia realizó una professio iuris a favor de su nacionalidad: la ley sucesoria anticipada es la alemana para las dos sucesiones afectadas, en un caso a título de ley de la residencia habitual del disponente en el momento del otorgamiento y en el otro caso a título de ley de la nacionalidad elegida del otro disponente. La ley aplicable, por tanto, sería la alemana y el pacto sucesorio sería válido.

Ahora bien, esta solución por sí sola no es suficiente. Por un lado, la simplificación de la hipótesis no aporta nada al régimen analizado; por otro no da respuesta a todos los posibles supuestos de hecho que se pueden presentar. En concreto, no es apta para todos aquellos supuestos en los que los futuros causantes o disponentes no tengan una ley sucesoria anticipada común. En el caso de que las leyes sucesorias anticipadas no coincidan, la solución de ley aplicable podría pasar por la aplicación de la ley de la residencia habitual común de los futuros causantes o disponentes en el momento del otorgamiento del pacto sucesorio. Esta solución nos parece adecuada ahora por tres razones: en primer lugar, porque sigue atendiendo a circunstancias personales de los futuros causantes o 
disponentes. En segundo lugar, porque en el marco del Reglamento, la residencia habitual es la conexión objetiva y, por tanto, esta solución no se desvincularía de la línea general del Reglamento (esta es la razón por la que creemos que no sería adecuada una conexión basada en la nacionalidad común de los futuros causantes o disponentes). Por último, esta solución abarca otros posibles supuestos, distintos de los de la aplicación de la ley sucesoria anticipada. Así, en el caso, por ejemplo, de que uno de los otorgantes haya realizado una professio iuris a favor de la ley de su nacionalidad, de tal forma que la ley sucesoria sea la correspondiente a su nacionalidad, es posible que comparta, sin embargo, residencia habitual con el otro disponente. Pensemos en el caso de un pacto sucesorio de institución recíproca en el que ambos otorgantes residen habitualmente en Suiza, pero uno tiene nacionalidad alemana, y su ley sucesoria anticipada es la alemana como consecuencia de una professio iuris que hubiera realizado anteriormente. En este caso, no se puede aplicar la solución de la ley sucesoria anticipada común, pero sí la solución de la ley de la residencia habitual común, en el ejemplo la suiza. En definitiva, la solución de la aplicación de la ley de la residencia habitual común de los futuros causantes o disponentes, es el paso natural tras la falta de ley sucesoria anticipada común y cubre supuestos distintos a los previstos en el primer paso de esta solución alternativa.

No obstante, al igual que ocurre con la solución de la ley sucesoria anticipada común, la aplicación de la ley de la residencia habitual común tampoco es una solución suficiente. Llegado a este punto se podría intentar otra solución de ley aplicable con conexiones comunes; en concreto, se podría valorar la propuesta de la aplicación de la ley de la nacionalidad común de los disponentes o futuros causantes. Se trata del uso de otra conexión personal, la nacionalidad, común en el Derecho de sucesiones y además abarcaría supuestos distintos a los de la aplicación de la ley sucesoria anticipada común y la ley de la residencia habitual común. Sin embargo, situados en el contexto del Reglamento, por ser la norma que se aplicará en el futuro en los, no parecería coherente el uso de la conexión de la nacionalidad como conexión objetiva. La nacionalidad en el Reglamento entra en juego como ley elegida, pero no como ley objetivamente aplicable (a salvo que resulte de la aplicación de la excepción de los vínculos más estrechos la ley de la 
nacionalidad del causante, pero no a título de ley de la nacionalidad del causante, sino a título de ley más estrechamente vinculada). Por ello, sería del todo chocante que no habiendo cabida para la nacionalidad del causante como conexión objetiva en la norma general, se incluyera en una norma específica para cierto tipo de sucesiones. Además, esta solución tendría el mismo problema que las anteriores, en cuanto que tampoco sería suficiente para cubrir todos los supuestos de hecho.

Es preciso pues, una cláusula de cierre a esta solución alternativa que ahora nos planteamos. Desechadas otro tipo de conexiones referidas a circunstancias objetivas de la celebración del pacto sucesorio, del tipo ley del lugar de celebración del pacto sucesorio, podría plantearse la aplicación de la ley más estrechamente vinculada como conexión de cierre. Es decir, en todos aquellos casos en los que no haya ni ley sucesoria anticipada común ni ley de la residencia habitual común, se podría aplicar la ley más estrechamente vinculada con el pacto sucesorio.

La solución de los vínculos más estrechos no es una novedad, ni en el ámbito general de las sucesiones, ni en el ámbito específico de los pactos sucesorios. Como hemos visto, en el Reglamento se prevé la posibilidad de aplicar excepcionalmente la ley más estrechamente vinculada con el causante en el momento del fallecimiento en vez de la ley de la última residencia habitual (art. 21.2). También en el Convenio de La Haya de 1989 se previeron dos cláusulas de excepción de los vínculos más estrechos en la regla general objetiva para la determinación de la ley sucesoria (art. 3 apartados segundo y tercero). Por su parte, en la regulación específica de los pactos sucesorios la solución de los vínculos más estrechos aparece en el Reglamento a la hora de concretar cuál de entre las leyes sucesorias anticipadas en presencia que ha determinado la admisibilidad del pacto sucesorio que afecta a más de una sucesión, es la que se va a aplicar a la validez material y efectos vinculantes entre las partes, incluidas las condiciones para su resolución.

Ahora bien, la solución de los vínculos más estrechos no ha funcionado en este contexto como solución directa de ley aplicable. En el caso de la 
determinación de la ley sucesoria, se trata de una cláusula de escape o cláusula de excepción; mientras que en el contexto de la solución a la ley aplicable a los pactos sucesorios que afectan a más de una sucesión, los vínculos más estrechos sólo entran en juego en un segundo momento, para completar la solución cumulativa donde entran todas las leyes sucesorias anticipadas en juego. En el modelo que ahora valoramos, la introducción de la solución de los vínculos más estrechos como cláusula de cierre supondría una importante novedad regulativa en el contexto de las sucesiones internacionales.

En suma, a nuestro juicio, la mejor alternativa posible a la determinación de la ley aplicable a los pactos sucesorios que afectan a más de una sucesión, sin implicar ningún resultado material alguno, pasaría por aplicar en primer lugar, la ley sucesoria anticipada común de los otorgantes cuya sucesión esté afectada por el contenido del pacto sucesorio. En segundo lugar, y a falta de ley sucesoria anticipada común, se aplicaría la ley de la residencia habitual común de los otorgantes cuya sucesión esté afectada por el contenido del pacto sucesorio. Y por último, como cláusula de cierre y para el caso de que no haya ni ley sucesoria anticipada común ni ley de la residencia habitual común, se aplicaría la ley de los vínculos más estrechos.

Reténgase esta alternativa no como propuesta regulativa global, sino como posible modelo en función del discurso analítico que hemos realizado en este Capítulo. Las soluciones, pueden ser otras (y de hecho lo son) y pueden ser globalmente satisfactorias, siendo materialmente orientadas o no; incluyendo mayor o menor presencia de la autonomía de la voluntad. La propuesta ahora manejada sólo es un modelo que se ciñe a la idea de solución objetiva no materializada. 


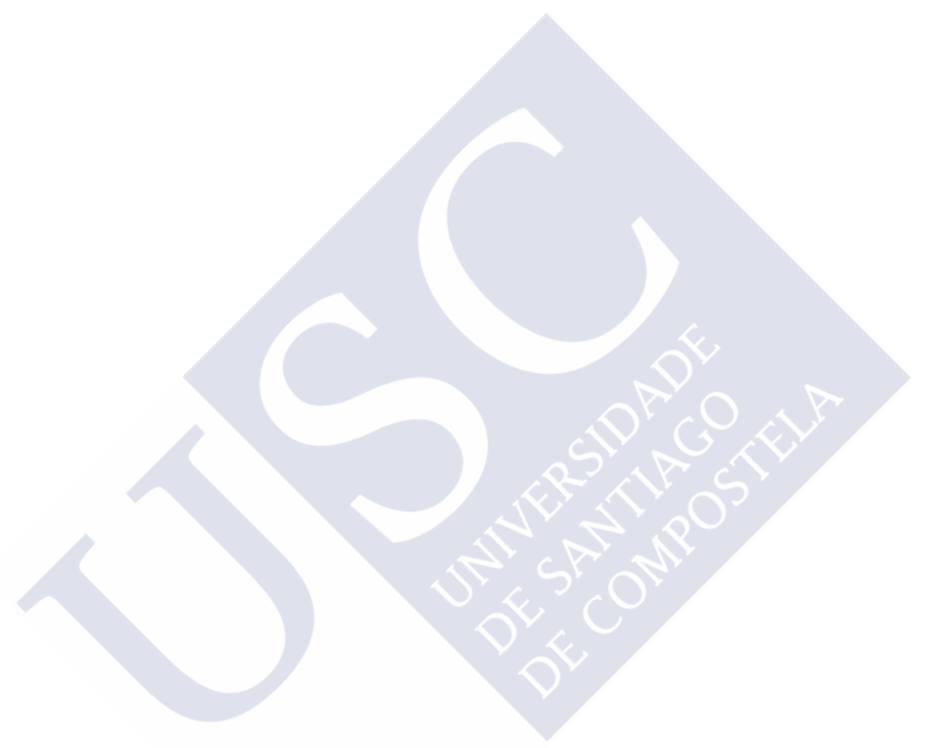




\section{CONCLUSIONES}

1. Los pactos sucesorios son una forma de ordenación del patrimonio mortis causa de carácter voluntario, que consiste en unos acuerdos entre dos o más personas que tienen una trascendencia directa sobre la sucesión de una persona viva. A través de un pacto sucesorio el disponente o futuro causante vincula su voluntad a la del otro u otros contratantes, de tal forma que, con carácter general, no puede revocar unilateralmente las disposiciones realizadas en tales acuerdos. Existen, por un lado, pactos de institución, a través de los cuales se constituye un derecho sucesorio en la herencia del otorgante disponente a favor de una persona, otorgante o no, que se denomina beneficiario o instituido. Por otro lado, los pactos de renuncia son aquellos en los que uno de los otorgantes renuncia de manera anticipada a parte o todo derecho sucesorio que sobre la herencia del otro otorgante pudiera tener. La característica más importante de esta forma de disponer mortis causa es la vinculación que desde el momento del otorgamiento se crea para las partes otorgantes sobre el contenido del pacto sucesorio. En el caso de los pactos sucesorios de institución esta vinculación implica, además, la correspondiente pérdida de libertad de disposición mortis causa del futuro causante Preservar esta libertad es lo que ha supuesto la razón fundamental de aquellos sistemas que mantienen una postura negativa respecto de los pactos sucesorios.

2. Existe una muy evidente heterogeneidad a nivel de Derecho material comparado en torno a los pactos sucesorios. Esta diversidad, unida al carácter generalmente reglado y en muchas ocasiones típico que los pactos sucesorios presentan, constituye el punto de partida de la enorme complejidad que manifiestan los problemas de determinación de la ley aplicable a estas figuras. En concreto, podemos distinguir tres tipos de sistemas: aquellos sistemas que se muestran completamente contrarios a los pactos sucesorios, como 
tradicionalmente han sido el francés o el italiano; los sistemas que los admiten de manera limitada, como el portugués o el austriaco; y los sistemas que los admiten de manera amplia, como el alemán o el suizo. No obstante, en los últimos años se ha creado un movimiento a favor de los pactos sucesorios, que podemos denominar el renacer o la revitalización de los pactos sucesorios: por un lado, sistemas que, como el francés o el italiano, eran tradicionalmente reacios a los pactos sucesorios, han realizado reformas legislativas que de manera más o menos tímida suponen una apertura hacia la admisión de estas figuras o al menos una flexibilización de la clásica prohibición de los pactos. Por otro lado, desde la década de los noventa, se ha llevado a cabo un proceso en el seno de la UE de promoción de los pactos sucesorios, fundamentalmente como figuras idóneas para la planificación por anticipado de la transmisión mortis causa de las pequeñas y medianas empresas.

3. A la diversidad existente a nivel de Derecho material sobre los pactos sucesorios, se une la diversidad que a nivel de DIPr existe a la hora de dar soluciones de ley aplicable a estas figuras. Se pueden distinguir distintos modelos en la regulación de la ley aplicable a los pactos sucesorios en función de su nivel de especialización.

El modelo menos especializado se corresponde con aquellos sistemas de DIPr que no hacen referencia alguna a los pactos sucesorios, como es el caso del sistema francés, del italiano o de nuestro anterior sistema regido por el antiguo 10.2 CC. Ante esta ausencia se plantea una duda fundamental en torno a la calificación sucesoria o contractual de los pactos sucesorios. Salvo alguna interpretación doctrinal aislada a favor de la calificación contractual de los pactos sucesorios, la generalidad de la doctrina y la jurisprudencia de estos sistemas ha abogado por una calificación sucesoria. Tal calificación implica la aplicación de la ley sucesoria, determinada en el momento del fallecimiento del causante. Además, se traslada a los pactos sucesorios la concepción que de la sucesión siga el correspondiente sistema: unidad de la sucesión, del que constituye un ejemplo el sistema italiano; o fraccionamiento de la sucesión, del que constituye un ejemplo el sistema francés. El problema fundamental de los sistemas que siguen este 
modelo es que no atienden al carácter contractual de los pactos sucesorios. La determinación de la ley aplicable a los pactos sucesorios en el momento del fallecimiento, a través de la ley sucesoria, es totalmente inadecuada, en cuanto que retarda el conocimiento de la validez y régimen jurídico del pacto sucesorio al momento del fallecimiento del causante, mientras que el carácter contractual de estas figuras implica que generan efectos desde el mismo momento de su otorgamiento, en especial el de la vinculación de las partes otorgantes al contenido del pacto sucesorio, y que es necesario que desde ese mismo momento se conozca tanto su validez como su régimen jurídico para que estas figuras no pierdan su razón de ser.

El siguiente modelo en la escala de especialización corresponde a aquellos ordenamientos jurídicos que prestan especial atención a los pactos sucesorios en su sistema de DIPr, pero sin realizar la necesaria diferenciación entre los pactos sucesorios que afectan a una única sucesión y los pactos sucesorios que afectan a varias sucesiones. Estos sistemas se caracterizan por mantener una calificación sucesoria de los pactos sucesorios, si bien con una importante especialidad temporal: la ley aplicable a los pactos sucesorios será la ley sucesoria determinada en el momento del otorgamiento del pacto, o también denominada, ley sucesoria anticipada. Ejemplo de este tipo de sistemas lo constituyen el ordenamiento jurídico alemán o nuestro propio art. 9.8 CC según la interpretación que del mismo mantenemos. Este modelo atiende a las particularidades contractuales de los pactos sucesorios, pues con esa pequeña especialidad temporal se permite que las partes otorgantes puedan saber con seguridad desde el momento del otorgamiento del pacto sucesorio si éste es válido y qué régimen jurídico se le aplica. Sin embargo, la solución de la ley sucesoria anticipada no es suficiente para los casos en los que el pacto sucesorio afecta a más de una sucesión. En estos casos hay más de una ley sucesoria anticipada y se hace preciso establecer las relaciones entre ambas.

El modelo que contiene una regulación más especializada en Derecho comparado lo constituye el ordenamiento jurídico suizo. En este caso no sólo se atiende a los pactos sucesorios de manera particular, a través de la determinación 
de la aplicación de la ley sucesoria anticipada, sino que también se da respuesta específica a la determinación de la ley aplicable a los pactos sucesorios que afectan a más de una sucesión. En concreto, el sistema suizo prevé la aplicación cumulativa de las leyes sucesorias anticipadas en presencia; es decir, para que el pacto sucesorio sea válido, es necesario que todas y cada una de las leyes sucesorias anticipadas así lo prevean.

4. El panorama actual, marcado por esta diversidad en cuanto a la determinación de la ley aplicable a los pactos sucesorios, va a sufrir importantes cambios en Europa como consecuencia de la adopción del Reglamento de sucesiones el pasado 4 de julio de 2012. Su puesta en aplicación, prevista a partir del 17 de agosto de 2015, implicará la unificación de los criterios para la determinación de la ley aplicable a los pactos sucesorios entre los EEMM, a excepción de Reino Unido, Irlanda y Dinamarca. El Reglamento prevé una regulación completa de los pactos sucesorios en su art. 25, donde no sólo distingue convenientemente entre los pactos sucesorios que afectan a una sucesión y los pactos sucesorios que afectan a varias sucesiones, sino que se da una importante entrada a la autonomía de la voluntad conflictual.

El Reglamento parte de la aplicación de la ley sucesoria anticipada, sea ésta la derivada de las conexiones objetivas del Reglamento, esto es, residencia habitual del causante en el momento del otorgamiento del pacto sucesorio $\mathrm{u}$ otra ley más estrechamente vinculada, sea ésta el resultado del ejercicio de una elección a favor de la ley de la nacionalidad del disponente o futuro causante. La ley del pacto sucesorio se aplicará a la admisibilidad, validez material y efectos vinculantes entre las partes, incluidas las condiciones de extinción del pacto (lo que hemos denominado régimen jurídico). En el caso de los pactos sucesorios que afectan a más de una sucesión, apartándose de la solución prevista en la Propuesta de Reglamento que favorecía la validez de los pactos sucesorios, el Reglamento prevé una solución cumulativa para determinar la admisibilidad de este tipo de pactos. Es decir, es necesario que todas y cada una de las leyes sucesorias anticipadas prevean el pacto sucesorio para que ésta sea admisible. En el caso de que así lo sea, el Reglamento establece una solución para concretar una única ley 
aplicable a la validez material y régimen jurídico del pacto sucesorio, que será aquella de entre las leyes sucesorias anticipadas en presencia que presente los vínculos más estrechos con éste. Esta solución es aceptable. Además, se permite a las partes otorgantes hacer una elección bilateral ad hoc a favor de la ley de la nacionalidad o de cualquiera de los disponentes o futuros causantes. Esta solución es igualmente aceptable en sí misma. No obstante, la relación entre la ley aplicable a los pactos sucesorios y la ley sucesoria no está convenientemente resuelta, ni en lo que atañe a su recíproca influencia (ámbitos de aplicación) ni en lo que se refiere a las relaciones entre las distintas formas de determinación de la ley aplicable a una y otros. Esto es especialmente visible en las diversas manifestaciones de la elección de ley.

5. La elección de ley aplicable a los pactos sucesorios puede tener cabida a través de dos vías, consecuencia de la doble naturaleza contractual y sucesoria que presentan. La primera vía es unilateral y se corresponde con el carácter sucesorio de los pactos sucesorios; se trata de la vía de la professio iuris y funciona en cierta manera como una conexión accesoria a la ley sucesoria: la ley elegida mediante el ejercicio de la professio iuris es al mismo tiempo la ley sucesoria y la ley rectora del régimen jurídico del pacto. La segunda vía posible es bilateral (o multilateral) y se corresponde con el carácter contractual de los pactos sucesorios; se trata de los pactos de lege utenda. Cada una de estas posibles vías de elección de ley aplicable a los pactos sucesorios tiene su propio régimen jurídico.

6. El juego de la professio iuris como una de las posibles vías en la elección de ley aplicable a los pactos sucesorios se articula a través de la elección de la ley sucesoria; es decir, la conexión de la ley aplicable al pacto sucesorio viene determinada por las conexiones sucesorias y éstas pueden ser fruto de una elección de ley unilateral a través de una professio iuris. En el caso de que haya habido una elección de ley sucesoria por parte del disponente o futuro causante, la ley sucesoria anticipada vendrá determinada por el ejercicio de una professio iuris. El art. $25.1^{\circ}$ y $2^{\circ}$ del Reglamento fijan la ley aplicable al pacto sucesorio por referencia a la ley sucesoria determinada en el momento del otorgamiento del 
pacto sucesorio. Si esta viene determinada por una professio iuris, habrá sido la voluntad del causante la determinante de la ley aplicable al pacto. En los pactos que afectan a una sola sucesión esta regla no tiene matices. En los que afectan a dos sucesiones, la voluntad unilateral de cada causante, de existir, es determinante en el tema de la admisibilidad y un mero dato a la hora de fijar la única ley rectora del régimen jurídico.

7. La vía bilateral de elección a los pactos sucesorios viene de la mano de los pactos de lege utenda, es decir, la posibilidad de que las partes otorgantes del pacto sucesorio, todas ellas, con independencia de que su sucesión esté afectada o no por el contenido del pacto sucesorio, acuerden la elección de la ley aplicable al pacto sucesorio en cuestión. Esta posibilidad está prevista en el art. $25.3^{\circ}$ del Reglamento, donde se permite a las partes escoger la ley correspondiente a la nacionalidad de cualquiera de los disponentes o futuros causantes en el pacto sucesorio en los términos en que pudieran haberla escogido como su ley sucesoria (professio iuris), es decir: cualquiera de sus leyes nacionales si tienen más de una y en cualquier momento: el de la elección o el del fallecimiento. No obstante, en materia de pactos sucesorios esta remisión a las reglas de la professio iuris debería limitarse a las leyes nacionales actuales (en el momento del otorgamiento del pacto). En caso contrario se produce uno de los vicios típicos de algunos sistemas: no conocer el régimen jurídico del pacto hasta el fallecimiento del causante.

8. El régimen jurídico y el alcance de las dos vías de elección posibles en los pactos sucesorios son distintos. En primer lugar, la professio iuris no es una elección de ley aplicable al pacto sucesorio, sino que se trata de una elección general de la ley sucesoria. El pacto de lege utenda, sin embargo, es una elección que se circunscribe al pacto sucesorio y no al conjunto de la sucesión del disponente o futuro causante. En segundo lugar, la professio iuris es una elección unilateral y como tal puede ser revocada o modificada libremente por el causante en cualquier momento, antes o después del pacto sucesorio. Incluso en el caso de que la professio iuris se realice en el propio pacto sucesorio, va a tener un régimen distinto y particular, en cuanto que no va a tener el carácter contractual y 
vinculante para el disponente o futuro causante, como lo tienen el resto de cláusulas del pacto sucesorio. El pacto de lege utenda, por su parte, tiene un carácter bilateral, contractual y vinculante y no podrá ser modificado unilateralmente por el disponente o futuro causante, sino que será necesaria la concurrencia de todas las voluntades que otorgaron el pacto sucesorio. En tercer lugar, el cambio unilateral de elección de ley, es decir, la posible revocación o modificación de la professio iuris realizada, en un momento posterior al de la celebración del pacto sucesorio, por parte del disponente o futuro causante no afecta a la admisibilidad, validez y régimen jurídico del pacto sucesorio. No tiene por qué ocurrir lo mismo si se trata de la modificación o revocación de un pacto de lege utenda; si las partes han realizado un pacto de lege utenda y en un momento posterior todas están de acuerdo en su modificación o revocación no debe haber impedimento alguno, salvo que se pudieran perjudicar derechos adquiridos de terceros ajenos al pacto sucesorio, que no es el caso, en cuanto que el tercero beneficiario del pacto sucesorio sólo tiene una mera expectativa.

9. Especial importancia tienen las relaciones entre la ley del pacto sucesorio y la ley sucesoria en términos de autonomía de la voluntad conflictual. El pacto sucesorio siempre tiene que convivir con la ley sucesoria, que puede ser potencialmente distinta. Ley del pacto sucesorio y ley sucesoria tienen su propio ámbito de aplicación; ahora bien, es prácticamente indiscutido, y esta es también la solución del Reglamento, que la ley sucesoria tenga la competencia para determinar la libertad de disposición del causante y los derechos de legitimarios u otros de naturaleza análoga, de tal forma que lo que disponga a este respecto la ley sucesoria puede afectar a la eficacia del pacto sucesorio. Las relaciones entre la ley sucesoria y la ley del pacto sucesorio responden a un problema estructural que excede de la problemática relacionada con la elección de ley; ahora bien, cuando la ley sucesoria es consecuencia de una professio iuris esta relación presenta importantes matices que deberían ser tomados en consideración.

Las relaciones entre la ley del pacto sucesorio y la ley sucesoria en términos de autonomía de la voluntad conflictual pueden dejar en manos del causante la frustración del contenido del pacto sucesorio a través de la potencial 
corrección que la ley sucesoria realiza al pacto sucesorio para la protección de los derechos de legitimarios u otros análogos. El disponente o futuro causante puede modificar la ley sucesoria a través de una simple declaración de voluntad y frustrar el contenido del pacto sucesorio.

A falta, a nuestro juicio, de una razón lo suficientemente fuerte para arbitrar un mecanismo que suponga la limitación de la facultad del causante para elegir su ley aplicable a la sucesión, como medio de protección del contenido del pacto sucesorio, sólo queda proponer otras alternativas de menor alcance. En primer lugar, se podría exigir al disponente o futuro causante un deber de información de la modificación de la ley sucesoria como consecuencia su ejercicio unilateral de la autonomía de la voluntad conflictual. De esta manera, el otorgante podrá al menos conocer el estado real de la cuestión y adaptar, en su caso, su comportamiento a las circunstancias; pensemos sobre todo en el otorgante instituido heredero en la empresa familiar, que ha dedicado y dirigido toda su vida a dicha empresa, en confianza de que en un futuro ésta sería suya. En segundo lugar, en aquellos casos en los que se pudiera probar que el cambio de ley sucesoria se ha realizado con el ánimo de frustrar el contenido del pacto sucesorio, podría acudirse a mecanismos como el abuso de derecho o el fraude a la ley.

10. En todo caso, y más allá de la contextualización de esta cuestión en el marco de la autonomía de la voluntad conflictual, el hecho de que la ley sucesoria pueda ser una cortapisa que deje sin efecto lo estipulado en el pacto sucesorio, nos lleva a proponer lo siguiente: la ley sucesoria debería determinar únicamente la cuota legitimaria, y no otras cuestiones como por el ejemplo el carácter cualitativo de la legítima, esto es, si tiene que ser pars bonorum o pars valoris. Además, se debería limitar la protección de los legitimarios a terceros ajenos al pacto sucesorio, tal y como previó la Propuesta de Reglamento en su art. 18.4. El Reglamento ha suprimido esta limitación, pero sin embargo, creemos que es posible una interpretación que permite la limitación de los derechos legitimarios a terceros ajenos al pacto sucesorio: el art. 25 habla siempre de que la ley del pacto sucesorio regirá los efectos vinculantes entre las partes otorgantes del pacto sucesorio, vía a través de la cual se podría mantener la limitación de los 
derechos legitimarios a terceros ajenos al pacto sucesorio. Todo ello se propone con el propósito de preservar en la mayor medida posible lo estipulado y planificado en el pacto sucesorio.

11. Con la puesta en aplicación del Reglamento la única posibilidad de elegir ley aplicable a la sucesión y, correspondientemente, a los pactos sucesorios es la elección de la ley de la nacionalidad del causante. Se han desechado, por tanto, otras posibles leyes que también pueden tener una vinculación suficiente con el causante; fundamentalmente se desecha la elección de la ley correspondiente a la residencia habitual del causante. No podemos sino lamentar esta ausencia en el Reglamento, en cuanto que entendemos que la posibilidad de elegir la ley de la residencia habitual es, en primer lugar, aceptable en términos de proximidad y vinculación con el causante; en segundo lugar, tendría una gran virtualidad en relación con la determinación de la ley aplicable a los pactos sucesorios que afectan a más de una sucesión, no sólo porque podría evitarse el escollo de la solución cumulativa para el reconocimiento de la admisibilidad de este tipo de pactos, sino que además permitiría evitar el tener que acudir a la cláusula de los vínculos más estrechos, que genera cierta inseguridad jurídica, para concretar la ley aplicable a la validez material y régimen jurídico de estos pactos.

12. La forma de la elección de ley aplicable a los pactos sucesorios no tiene un régimen particular en el Reglamento. Tanto si la elección se realiza a través de una professio iuris, como si se trata de un pacto de lege utenda el régimen es el general previsto para la elección de ley en el art. 22 del Reglamento. Se ha suprimido para los pactos de lege utenda, la referencia que contenía la Propuesta a "designación expresa", remitiéndose integralmente al art. 22 del Reglamento para el régimen jurídico de la elección. Esto supone, por un lado, que la elección de ley debe tener forma de disposición mortis causa; y, por otro lado, con esta remisión se da entrada no sólo a la designación expresa, sino también a la tácita, opción ésta que aplaudimos. Como consecuencia, cabe la posibilidad de entender que a través de un pacto de lege utenda pueda existir además una 
elección tácita de ley sucesoria por parte del causante, en función de las circunstancias.

13. Para el caso de que no haya elección de ley aplicable, hay que acudir a las conexiones objetivas, que, tratándose de los pactos sucesorios tienen una característica fundamental: su dependencia de la ley sucesoria. La calificación sucesoria de los pactos sucesorios implica que las conexiones que van a determinar su ley aplicable son las conexiones de la sucesión mortis causa, si bien determinadas no en el momento del fallecimiento del causante, sino en el momento del otorgamiento del pacto sucesorio. En el análisis de las soluciones objetivas de ley aplicable a los pactos sucesorios es fundamental la clasificación de los pactos sucesorios en función del número de sucesiones afectadas. Así, se da solución, por un lado, a los pactos sucesorios que afectan a una única sucesión y, por otro lado, a los pactos sucesorios que afectan a varias sucesiones, en cuanto que estos últimos exigen un paso más por parte del legislador para determinar su ley aplicable. El análisis de estas soluciones está marcado además por el posible carácter neutral o materializador de las mismas.

14. La solución aplicable a los pactos sucesorios que afectan a una única sucesión es más simple: se aplicará la ley sucesoria anticipada, cualquiera que sea ésta, a la admisibilidad, validez material y régimen jurídico del pacto sucesorio. La ley sucesoria anticipada se determina en función de la conexión objetiva sucesoria, ya sea la nacionalidad, el domicilio o la residencia habitual. Se traslada aquí, por tanto, la clásica dicotomía entre la ley de la nacionalidad del causante y la ley del domicilio o de la residencia habitual del causante. En el marco del Reglamento la ley sucesoria anticipada estará determinada por la ley de la residencia habitual del causante a salvo que existiera otra ley más estrechamente vinculada, siempre en el momento del otorgamiento del pacto sucesorio. Esta solución es neutral, en cuanto que no suma ni deja de sumar para la válida celebración de los pactos sucesorios. Es una solución que busca la proximidad de la ley aplicable con el supuesto de hecho, máxime con el gran elemento de flexibilización que se ha introducido en el Reglamento con la cláusula de los vínculos más estrechos. 
15. Sin embargo, sí se ha conocido un mecanismo materializador en la determinación de la ley aplicable a los pactos sucesorios que afectan a una única sucesión. Se trata de la denominada norma de validación que se previó en el Convenio de La Haya de 1989 y en la propia Propuesta de Reglamento, pero que finalmente se ha suprimido, con buen criterio, en la versión definitiva del Reglamento. La norma de validación consiste en la posibilidad de dar entrada a la ley sucesoria, determinada en el momento del fallecimiento del causante, para validar el pacto sucesorio si ésta así lo prevé, en el caso de que el pacto fuera inválido de conformidad con la ley sucesoria anticipada. Se le da una oportunidad más al pacto sucesorio para ser válido, con lo cual es una solución materialmente orientada en cuanto que busca favorecer la validez de estas figuras.

Si bien la norma de validación puede suponer un beneficio en cuanto que puede dar cobertura legal a una situación fáctica (cuando las partes otorgantes creen en la validez del pacto sucesorio y actúan conforme a ella), lo cierto es que es una solución que provoca una elevada incertidumbre en torno al régimen jurídico del pacto sucesorio. La existencia de un lapso de tiempo que va desde el momento del otorgamiento del pacto sucesorio hasta el fallecimiento del causante, en el que no se sabe si el pacto sucesorio existe y es válido, provoca, en muchas ocasiones, situaciones en las que pese a que el pacto sucesorio sea validado éste ya ha perdido su razón de ser. Por ello, estimamos que la regla de validación no es una solución aceptable en materia de ley aplicable a los pactos sucesorios. Su supresión en el Reglamento respecto de su previsión por la propuesta es correcta.

16. La solución de ley aplicable sí es más compleja en el caso de los pactos sucesorios que afectan a más de una sucesión. En este caso hay más de una ley sucesoria anticipada y lo que se ha realizado hasta ahora, tanto en Derecho comparado, como en el Convenio de La Haya e instrumentos comunitarios es la búsqueda de la solución de ley aplicable en la combinación de las distintas leyes sucesorias anticipadas. En este análisis es necesario además diferenciar entre admisibilidad y validez material y régimen jurídico. El Reglamento sigue esta estructura que es, a nuestro juicio, correcta.. 
La primera de las combinaciones posibles es la denominada solución distributiva o aleatoria; esta solución es neutral, en cuanto que no suma nada a favor o en contra de la celebración de pactos sucesorios. La solución distributiva implica la división del pacto sucesorio en tantas partes como sucesiones están afectadas por el contenido del mismo, de tal forma que se aplica a cada parte su correspondiente ley. Esto puede dar como resultado que un pacto sucesorio sea válido en parte e inválido por otra parte, o que puedan tener un régimen jurídico distinto en función de quien fallezca primero. En definitiva, supone la negación del pacto sucesorio como un todo y es una solución inadecuada porque rompe la razón económica del pacto sucesorio.

Las otras dos combinaciones de las leyes sucesorias anticipadas tienen un carácter materializador: se trata de la solución cumulativa y de la solución alternativa. La solución alternativa implica que para que un pacto sucesorio sea admitido y válido basta con que al menos una de las leyes sucesorias en presencia así lo prevea. Se trata de una solución materialmente orientada a favor de la celebración de los pactos sucesorios y tuvo su virtualidad en la Propuesta de Reglamento. En el otro extremo está la solución cumulativa, que implica una postura restrictiva respecto de la admisibilidad de los pactos sucesorios, en cuanto que es necesario que todas y cada una de las leyes sucesorias en presencia prevean el pacto sucesorio para que éste se considere admitido. Es la solución que finalmente se ha adoptado en el Reglamento de sucesiones. Ninguna de ellas basta por sí sola para dar una solución completa a la determinación de la ley aplicable a los pactos sucesorios que afectan a más de una sucesión. En el caso de la solución cumulativa es necesario, en todo caso, una solución complementaria para concretar cuál de entre las leyes sucesorias anticipadas es la que va a determinar la validez material del pacto sucesorio y su régimen jurídico: la opción vale para la admisibilidad. Desechamos la posibilidad de que se apliquen varias leyes a estos aspectos del pacto sucesorio porque supondría una gran complejidad dado el carácter reglado que generalmente presentan los pactos sucesorios. En el caso de la solución aleatoria, basta con que al menos dos de las leyes sucesorias anticipadas en juego reconozcan el pacto sucesorio en cuestión para que se precise 
también un paso más para concretar cuál de ellas será finalmente la aplicable a su régimen jurídico.

17. El Reglamento ha sido consciente de esta cuestión y además de prever una solución cumulativa para la determinación de la ley aplicable a la admisibilidad de los pactos sucesorios que afectan a más de una sucesión, establece que se aplicará la ley más estrechamente vinculada a la validez y régimen jurídico del pacto en cuestión. La solución de los vínculos más estrechos es una solución en sí misma neutra.

18. Desechada la solución distributiva, por ser completamente contraria a los intereses de los pactos sucesorios, y dado que no parece haber un criterio material claro para justificar una postura favorable o reacia a la celebración de los pactos sucesorios, nos preguntamos sobre la posibilidad de establecer una solución de ley aplicable a los pactos sucesorios que afectan a más de una sucesión alejada de las combinaciones de las leyes sucesorias en presencia y neutral. Conscientes de que no es una tarea fácil y de que la propuesta es asimismo arriesgada, hemos valorado la posibilidad de que se opte por una solución basada en conexiones comunes y subsidiarias: en concreto, se aplicaría en primer lugar la ley sucesoria anticipada común de los disponentes o futuros causantes; en el caso de que ésta no existiera, la ley de la residencia habitual común y, en su defecto, la ley más estrechamente vinculada. Esta es, obviamente, una alternativa que no tiene presencia en ni en el Derecho comparado ni en el Reglamento.

Para cerrar estas conclusiones estimamos pertinente hacer una síntesis valorativa sobre la regulación prevista en el Reglamento. Con carácter general, podemos decir que se trata de una regulación completa y con un gran nivel de especialización. Como puntos positivos cabe destacar, en primer lugar, la diferenciación entre los pactos sucesorios que afectan a una única sucesión y los pactos sucesorios que afectan a varias sucesiones. En segundo lugar, destaca también la concreción de las cuestiones que quedan bajo el ámbito de aplicación del pacto sucesorio; en particular, es de valorar positivamente el art. 26 que determina qué se entiende por validez material. En tercer lugar, también es un 
acierto la regulación que se hace de los pactos sucesorios que afectan a más de una sucesión distinguiendo entre admisibilidad, donde entran en juego todas las leyes sucesorias anticipadas de forma cumulativa, y validez material y efectos vinculantes entre las partes, para los que se prevé la aplicación de una única ley, la más estrechamente vinculada. Por último, y en relación con la Propuesta de Reglamento, es todo un acierto la supresión de la norma de validación para los pactos sucesorios que afectan a una única sucesión.

Como puntos negativos, destaca, por un lado, la falta de claridad en torno a la relación entre la ley aplicable al pacto sucesorio y la incidencia que en la eficacia de éste pueden tener sucesivas professio iuris que el causante, de forma unilateral pudiera realizar. Por otro lado, pensamos que ha sido un paso atrás la supresión del apartado que preveía la Propuesta en el que se limitaba la protección de los derechos de legitimarios a terceros ajenos al pacto sucesorio. No obstante, tal y como hemos defendido, pensamos que aún es posible una interpretación del vocablo "efectos vinculantes entre las partes", que permita mantener la limitación de los derechos de legitimarios a terceros ajenos al pacto sucesorio y no extenderla indiscriminadamente a los otorgantes. 


\section{BIBLIOGRAFÍA CITADA}

- ABEND, M., (1994), Die lex validitatis im internationalen Vertragsrecht, Heidelberg, Universitätsverlag C. Winter.

- ACHILle, D., (2012), Il divieto dei patti successori. Contributo allo studio dell'autonomia private nella successione futura, Napoles, Jovene Editore.

- ADAM, H., (2011), "Freedom of testation/freedom of contract", Minnesota Law Review, vol. 95, núm. 6, pp. 2180-2253.

AGUILAR BENÍTEZ DE LUGO, M., (1978), “Art. 9.8”, en M. Albaladejo (dir.), Comentarios al Código Civil y Compilaciones Forales, tomo I, Madrid, Edersa, pp. 189-194.

- AgUILAR NAVARRO, M./ ET ALT. (1970), Textos y materiales de Derecho internacional privado, vol. I, Madrid, Facultad de Derecho-Sección de Publicaciones.

- ALBIEZ DOHRMANN, K.J., (2005), "Disposiciones patrimoniales en vida para después de la muerte", en M. Garrido Melero/J.M. Fugardo Estivoll/A. Serrano de Nicolás/D. Vázquez Albert (coords.), El patrimonio familiar, profesional y empresarial. Sus protocolos. Tomo II. Patrimonios personales, familiares, sucesorios y profesionales, Barcelona, Bosch, pp. 581-637.

— Álvarez GONZÁleZ, S., (1995), “Art. 12”, en M. Albaladejo/S. Díaz Alabart (dirs.), Comentarios al Código Civil y Compilaciones Forales, tomo I, vol. 2, Madrid, Edersa, pp. 842-880.

- Álvarez GONZÁleZ, S., (2005), "Breves notas sobre la autonomía de la voluntad en Derecho internacional privado", en A.J. Rodríguez Carrión/E. Pérez Vera (coords.), Soberanía del Estado y Derecho internacional. Homenaje al profesor Juan Antonio Carrillo Salcedo, tomo I, Sevilla, Servicio de Publicaciones de las Universidades de Córdoba, Sevilla y Málaga, pp. 137-153.

- Állarez GONZÁlez, S., (2009), "La professio iuris y la sucesión internacional en una futura reglamentación comunitaria", en M.P. García Rubio (coord.), Estudios Jurídicos en memoria del profesor José Manuel Lete del Río, Navarra, Civitas Thomson Reuters, pp. 17-49.

- ÁlvareZ GONZÁleZ, S., (2011), "Las legítimas en el Reglamento sobre sucesiones y testamentos”, AEDIPr, t. XI, pp. 369-406.

- ÁlVAREZ GONZALEZ, S., (2012), “Legítimas y Derecho interregional”, en T.F. Torres García (coord.), Tratado de legítimas, Barcelona, Atelier, pp. 153202. 
- ÁlVAREZ GONZÁLEZ, S./RODRÍGUEZ-URÍA SUÁREZ, I., (2011), “La ley aplicable a los pactos sucesorios en la Propuesta de Reglamento sobre sucesiones", Diario La Ley, n ${ }^{\circ}$ 7726, Sección Doctrina, 31 octubre 2011, Año XXXII, La Ley 15801/2011.

- ANCEL B./LEQUETTE, Y., (1987) Grands arrêts de la jurisprudence française de droit international privé, París, Sirey.

- ANDERSON, M., (2006), "Una aproximación al derecho sucesorio inglés", $A D C$, vol. 59, núm. 3, pp. 1243-1282.

- AngOITIA GOROStiagA, V., (1999), El usufructo poderoso del Fuero de Ayala, Vitoria, Imprenta de la Diputación Foral de Álava.

- ANNIBALE S., (1997) Riforma del sistema italiano di diritto internazionale privato, Padua, Cedam.

- $\quad$ ANTONINI, I., (1996), "Il divieto di patti successori”, Studium Iuris, núm. 1, pp. 601-608.

- AÑOVEROS TERRADAS, B., (2009), "Tratamiento conflictual de los pactos sucesorios en DIPr español”, en R. Viñas/G. Garriga (coords.), Perspectivas del Derecho sucesorio en Europa, Madrid, Marcial Pons, pp. 157-174.

- ATKINSON, T.E., (1953), Handbook of the Law of Wills and other principles of succession including intestacy and administration of decedent's estates, $2^{\mathrm{a}}$ ed., St. Paul, West Publishing.

- $\quad$ AUDIT, B., (2010), Droit international privé, 6ª ed., París, Economica.

- AZCÁRRAGA MONZONÍS, C., (2008), Sucesiones internacionales. Determinación de la norma aplicable, Valencia, Tirant lo Blanch.

- BAILLON-WIRTZ, N., (2006), "Que reste-t-il de la prohibition des pactes sur succession future?”, Droit de la famille, vol. 11, noviembre 2006, pp. 8-13.

- BALlADORE PALliERI, G., (1974), Diritto internazionale privato italiano, Milán, Giufrè.

- BAllarinO, T. (1996), Diritto internazionale privato, 2a ed., Padua Cedam.

- BAllarinO, T., (1999), Diritto internazionale privato, $3^{\mathrm{a}}$ ed., Padua, Cedam.

- BAPTISTA MACHADO, J., (1997), Lições de direito internacional privado, $3^{\mathrm{a}}$ ed., Coímbra, Almedina.

- BAREL, B./ARMELLINI, S., (2008), Manuale breve Diritto internazionale privato, Milán, Percorsi.

- BARRÁN DE, ARNICHES, P., (1999), "La definición y el finiquito de legítima en el Derecho civil de Baleares", La notaría, núm. 5, mayo, consultado en VLEX232981, p. 1-29. 
- BARTIN, E., (1932), Principes de Droit international privé selon la loi et la jurisprudence françaises, tomo II, París, Domat-Montchrestien.

- BASEDOW, J., (2010) "Le rattachement à la nationalité et les conflits de nationalité en droit de 1'Union européenne", Rev. crit. dr. int. pr., núm. 3, pp. 427456.

BASEDOW, J., (2012), "The law of open societies-private ordering and public regulation of international relations", $R d C$, t. 360, pp. 9-515.

- BATIFFOL, H., (1938), Les conflits de lois en matière de contrats: étude de droit international privé comparé, París, Sirey.

- BATIFFOL, H., (1956), Aspects philosophiques du droit international privé, en la edición de Y. Lequette, Dalloz, 2002.

- BATIFFOL, H., (1959), "Principes du droit international privé”, RdC, t. 97, núm. II, pp. 431-573.

- BATIFFOL, H., (1967), Droit international privé, $4^{\mathrm{a}}$ ed., París, L.G.D.J.,

- BATIFFOL, H., (1973), "Le pluralisme des méthodes en Droit international privé", $R d C$, t. 139 , pp. 75-147.

- $\quad$ BATIFFOL, H., (1979), "Une succession de méthodes. La forme des testaments en droit international privé", en O. Sandrock (ed.), Festschrigt für Günther Beitzke sum 70. Geburtstag, Berlín- Nueva York, Walter de Gruyter, pp. 429-441.

- BATIFFOL, H./LAGARDE, P., (1983), Droit international privé, tomo II, $7^{\mathrm{a}}$ ed., París, L.G.D.J.

- BAYOD LÓPEZ, C., (2003), "Las novedades en materia de pactos sucesorios en la ley aragonesa de sucesiones por causa de muerte (Ley 1/1999 de 24 de febrero)", en A. Cabanillas Sánchez (coord.), Estudios en homenaje al profesor Luis Díez-Picazo, t. IV, Madrid, Thomson-Civitas, pp. 5123-5140.

- BETTI, E. (1959), Teoría general del negocio jurídico, $2^{\mathrm{a}}$ ed., traducción a cargo de A, Martín Pérez, Editorial Revista de Derecho Privado, Madrid.

- BILLARANT, S., (2004), Le caractère substantiel de la réglementation française des successions internationales, París, Dalloz.

- BIRK, R., (2006), “Art. 26”, en Münchener Kommentar BGB, Internationales Privatrecht, vol. 10, $4^{\mathrm{a}}$ ed., Munich, C.H. Beck.

- BIONDI, B. (1943), Successione testamentaria. Donazioni, Trattato di Diritto Romano, Milán, Dott. A. Giuffrè.

- BIONDI, B., (1954), Diritto ereditario romano. Parte generale, Milán, Dott. Antonino Giuffrè.

- BONFANTE, P., (1930), Corso di Diritto Romano, vol. VI, Le successioni. Parte generale, Roma, Società Editrice del Foro Italiano. 
BONOMI, A. (2008), "Les pactes successoraux en droit international privé Remarques comparatives à la lumière des droits français, italien, espagnol et suisse", en A. BONOMI/M. STEINER, Les pactes successoraux en droit comparé et en droit international privé, Ginebra, Droz, pp. 11-25.

- BONOMI, A., (2010), "Prime considerazioni sulla Proposta di Regolamento sulle successioni”, Riv. dir. int. priv. proc., núm. 4, pp. 875-914.

BONOMI, A., (2010-2), "Testamentary freedom or torced heirship? Balancing party autonomy and the protection of family members", NiPR, núm. 4, pp. 605610.

- BONOMI, A., (2010-3), "Choice of laws aspects of the future EC Regulation in matters of succession. A first glance at the Comission's Proposal", en K. BoeleWoelki/T.Einhorn/D. Girsberger/S. Symeonides (eds.), Convergence and Divergence in Private International Law. Liber Amicorum Kurt Siehr, La Haya, Schulthess, pp. 157-171.

- BONOMI, A., (2011), "Successions internationals: conflits de lois et de juridictions", $R d C$, t. 350 .

- BORKOWSKI, A., (2002), Textbook on Succession, $2^{\mathrm{a}}$ ed., Oxford, University Press.

- BORRÁS RODRÍGUEZ, A., (1996), "La ratificación por Holanda del Convenio de La Haya de 1 de agosto de 1989 sobre la ley aplicable a la sucesión por causa de muerte", REDI, vol. XLVIII, núm. 2, pp. 363-364.

- BORRÁS RODRÍGUEZ, A. (1996-2), "La Convention de La Haye de 1989 sur la loi applicable aux successions à cause de mort et $\mathrm{l}^{\prime}$ Espagne", en A. Borrás/A. Bucher/T. Atruycken/M. Verwilghen (eds./coords), Liber Amicorum Georges A. L. Droz sur l'unification progressive du droit international privé, Martinus Nijhoff Publishers, Boston/Londres, pp. 7-23.

- BOSCHIERO, N., (1996), Appunti sulla Riforma del sistema italiano di Diritto internazionale privato, Turín, Giappichelli.

- BOUCKAERT, F., (2004), "Professio iuris dans le Code de Droit international Privé belge", en DNotI (ed.), Les successions Internationales dans l'UE. Perspectives pour une Harmonisation, Würzburg, pp. 417-430.

- BOUlANGER, F., (1975), Les successions internationals. Problèmes contemporains, París, Economica.

- BOUlANGER, F., (2004), Droit international des successions. Nouvelles approches comparatives et jurisprudentielles, París, Economica.

BOUZA VIDAL, N., (2007), "Los problemas que plantea el Derecho de familia y sucesiones en el Derecho internacional privado", La notaría, núm. 42, vol. I, pp. 11-40. 
- BRAGA, S., (1953), "Staatsangehörigkeitsprinzip oder Wohnsitzprinzip", RabelsZ, pp. 227-246.

- $\quad$ BRANCÓS NÚÑEZ, E., (2009), "Els pactes successoris en el Llibre IV del Codi Civil de Catalunya”, Revista Jurídica de Catalunya, núm. 4, pp. 953-982.

- BRANDI, T., (1996), Das Haager Abkommen von 1989 über das auf die Erbfolge anzuwendende Recht, Berlín, Duncker \& Humblot.

- BROX H./WALKER, W.D., (2007), Erbrecht, 22ª ed., Colonia, Carl Heymanss.

- BRUCH, C.S., (1993), "The Hague Convention on the law applicable to succession to the estates of deceased persons: do quasi-community property and mandatory survivorship laws need protection?", Law and Contemporary problems, pp. 309-328.

- BUCHER, A., (1992), Droit internacional privé suisse, tome II, Personnes, Famille, Successions, Helbing \& Lichtenhahn, Basilea.

- BUCHER, A., (1972), "Staatsangehörigkeits und Wohnsitzprinzip. Eine rechtsvergleichende Übersicht", Annuaire Suisse de Droit International, pp. 76170.

- BUCHER, A., (1979), "Sur les règles de rattachement a caracteres substantiel", en Liber amicorum Adolf F. Schnitzer, Ginebra, pp. 37-55.

- BUCHER, A., (2011), La dimension sociale du droit international privé, Adi Poche.

- BUCHER, A./BONOMI, A. (2004), Droit international privé, 2a ed., BasileaGinebra-Munich, Helbing\&Lichtenhahn.

- BUSCHBAUM, M./KHOLER, M., (2010), "Vereinheitlichung des Erbkollisionsrechts in Europa. Eine kritische Würdigung des Kommissionsvorschlags zur Erbrechtsverordnung”, GPR, núm. 3, pp. 106-113.

- BUSCHBAUM, M./SIMON, U., (2012), "EuErbVO: Das Europäische Nachlasszeugnis", ZEV, pp. 525-530.

- BUSTO LAGO, J.M., (2008), "Los pactos sucesorios en la Ley 2/2006, de 14 de junio, de Derecho Civil de Galicia", Revista Crítica de Derecho Inmobiliario, núm. 706, marzo-abril, pp. 517-578.

- CACCAVAlE, C. (1994), "Il divieto dei patti successori”, en Successioni e donazioni a cura di Pietro Rescigno, vol. I, Cedam, Padua, pp. 25-52.

- CAlATAYUd SIERRA, A., (1995), "Consideraciones acerca de la libertad de testar”, Anales de la Academia Sevillana del Notariado, t. IX, pp. 241-264.

- CALEB, M., (1927), Essai sur le principe de l'autonomie de la volonté en droit international privé, París, Siroy.

- CALÓ, E., (2007), Le successioni nel diritto internazionale privato, Italia, Ipsoa. 
- CALVO CARAVACA, A.L., (1991), "Sucesión hereditaria”, en J. GONZÁLEZ CAMPOS y otros, Derecho internacional privado, Parte especial, $4^{\mathrm{a}}$ ed., Madrid, Centro de estudios superiores sociales y jurídicos Ramón Carande, pp. 539-579.

- CAlvo CARAVACA, A.L., (1995), “art. 9.8”, en M. Albaladejo/S. Díaz Alabart (dir.), Comentarios al Código Civil y Compilaciones forales, tomo I, vol. II, Madrid, Edersa, pp. 350-391.

- CAlVO CARAVACA, A.L., (1995-2), “Capítulo IX. Sucesión hereditaria”, en VV.AA., Derecho internacional privado. Parte especial, 6a ed., Madrid, Eurolex, pp. 393-422.

- CANO MARTÍNEZ DE VELASCO, J.I., (2002), La prohibición de los pactos sucesorios, Barcelona, Bosch.

- CARElla, G., (1999), Autonomia della volontà e scelta di legge nel Diritto internazionale privato, Bari, Cacucci Editore.

- CARLIER, J-Y, (1992), Autonomie de la volonté et statut personnel, Bruselas, Bruylant.

- CAROTA, L. (2008), Il contratto con causa successoria. Contributo allo Studio del patto di famiglia, Padua, Cedam.

- CARVAlHO FERNANDES, L.A., (2004), Lições de Direito das Sucessões, $2^{\mathrm{a}}$ ed., Lisboa, Quid Juris.

- CASTÁN TOBEÑAS, J., (1944), Derecho de familia (relaciones paternofiliales y tutelares). Derecho de sucesiones, $6^{\mathrm{a}}$ ed. rev., Madrid, Instituto Editorial Reus.

- CASTÁN VÁZQUEZ, J.M., (1964), "Notas sobre la sucesión contractual en el Derecho español”, $A D C$, t. XVII, fasc. II, (abril junio), pp. 367-381.

- CAStellanos RUIZ, E., (2001), Unidad vs. Pluralidad legal de la sucesión internacional, Granada, Comares.

- CASTEllanOS RUIZ, E., (2010), "Sucesión hereditaria", en A.L. Calvo Caravaca/J. Carrascosa González (dir.), Derecho internacional privado, vol. II, $11^{\mathrm{a}}$ ed., Granada, Comares, pp. 351-401.

- CElAYA IBARRA, A., (1965), Vizcaya y su Fuero Civil, Pamplona, Aranzadi.

- CELAYA IBARRA, A., (1997), “Art. 134”, en M. Albaladejo/S. Díaz Alabart (dirs.), Comentarios al Código Civil y Compilaciones Forales. Ley sobre el Derecho Civil Foral del País Vasco, tomo XXVI, Madrid, Edersa, pp. 568-573.

- CleriCI, R./MOSCONI, F./POCAR, F., (2009), Legge di Riforma del Diritto internazionale privato e testi collegati, $6^{\mathrm{a}}$ ed., Milán, Giuffrè.

- COMITATO REGIONALE NOTARILE LOMBARDO, (1996) La reforma del Diritto internazionale privato, Milán, Giufrè. 
- CONETTI, G./TONOLO, S./VISMARA, F., (2000), Commento alla Riforma del Diritto internazionale privato italiano, Turín, Giappichelli.

- CONFÉRENCE DE LA HAYE DE DROIT INTERNATIONAL PRIVÉ, (1928) Actes et documents de la sixième sesión, VI, La Haya.

- CONFÉRENCE DE LA HAYE DE DROIT INTERNATIONAL PRIVÉ (1990), Actes et documents de la Seizième session, t. II, La Haya.

- CURRIE, B., (1965), "Ehrenzweig and the Statute of Frauds: an inquiry into the rule of validation”, Oklahoma Law Review, 18, pp. 234-339.

- DAMASCELLI, D., (2003), "La legge applicabile alla successione per causa di norte secondo el Diritto internazionale privato italiano", Riv. dir. int. priv. pro., núm. 1, pp. 85- 108.

- DAMASCELLI, D., (2008), "Le pacte de famille en droit international privé italien”, EN A. BONOMI/M. STEINER, Les pactes successoraux en droit comparé et en droit international privé, Ginebra, Droz, pp. 85-96.

- DAVI, A., (2004), "L'autonomie de la volonté en Droit International privé des successions dans la perspective d'une future Réglementation européenne", Riv. dir. int. priv. pro., núm. 2, pp. 473-498.

- DAVI, A., (2005), "Riflessioni sul futuro Diritto internazionale privato europeo delle successioni”, Rivista di Diritto internazionale, vol. 88, núm. 1, pp. 297-341.

- DE ANGUlO, M., (1977), “Art. 9.8”, en VV.AA., Comentarios a las reformas del Código Civil, vol. I, Madrid, Tecnos, pp. 481-489.

- DE CESARI, P., (2001), Autonomia della volontà e legge regolatrice delle successioni, Milán, Cedam.

- DE LASALA LLANAS, (1933), Sistema español de Derecho civil internacional e interregional, Madrid, Revista de Derecho Privado.

- DE LIMA PINHEIRO, L., (2002) Direito internacional privado, $2^{\mathrm{a}}$ ed., vol. II, Lisboa, Almedina.

- DE WINTER, L.I. (1969), "Nationality or Domicile. The present state of affairs", $R d C$, t. 128, núm. III, pp. 349-503.

- DELAUME, G.R./FLATTET, G., (1952), nota a la sentencia del Trib. Civ. Mulhose, $2^{\text {a }}$ Ch., de 19 de enero de 1950, JCP, núm. 6845.

- DELGADO ECHEVERRÍA, J., (2011), "El fundamento constitucional de la facultad de disponer para después de la muerte", Diario La Ley, núm. 7675.

- DEUTSCHES NOTARINSTITUT, (2002), "Étude de droit comparé sur les règles de conflits de juridictions et de conflits de lois relatives aux testaments et successions dans les Etats membres de 1'Union Européenne", disponible en www.successions.org 
- DÍAZ FUENTES, A., (1977), Dereito Civil de Galicia. Comentarios á lei 4/1995, A Coruña, Publicacións do Seminario de Estudos Galegos.

- DÍEZ PICAZO, L./GULlÓN, A., (1989), Sistema de Derecho civil, vol. IV, $5^{\text {a }}$ ed., Madrid, Tecnos.

- DÍEZ PICAZO, L./GUllón, A., (2006), Sistema de Derecho Civil. Vol. IV. Derecho de Familia. Derecho de Sucesiones, $10^{\mathrm{a}}$ ed., Madrid, Tecnos.

- DÖLLE, H., (1966), "Die Rechtswahl im internationalen Erbrecht", RabelsZ, núm. 30, pp. 205-240.

— DOMÍNGUEZ LUELMO, A., (2010a), “Arts. 826”

— DOMÍNGUEZ LUELMO, A., (2010.b) “Art. 1056”,

— DÖRNER, H., (1984), “Großbritannien”, M. Ferid/F. Firsching, Internationales Erbrecht, vol. III, Beck, Munich.

- DÖRNER, H., (2007), “Art. 25”, en Staudinger BGB Kommentar, EGBGB/IPR, Arts. 25-26, Internationales Erbrecht, Berlin, Sellier de Gruyter.

- DÖRNER, H., (2010), "Der Entwurf einer europäischen Verordnung zum internationalen Erb- und Erbverfahrensrecht- Überblick und ausgewählte Probleme", Zeitschrift für Erbrecht und Vermögensnachfolge, pp. 221-228.

- DÖRNER, H., (2012), "EuErbVO: Die Verordnung zum Internationalen Erb- und Erbverfahrensrecht ist in Kraft!”, ZEV, pp. 505-513.

- DROBNIG, U., (1970), "Verstösst das Staatsangehörigkeitsprinzip gegen das Diskriminierungsverbot des EWG-Vestrages?", RabelsZ, pp. 636-662.

- DROZ, M., (1970), "La codification du Droit international privé des successions. Perspectives nouvelles”, Trav. Comité fr. dr. int. pr., 1966-1966, pp.319-339.

- DUCHEK, A./SCHWIND, F., (1979), Internationales Privatrecht, Viena, Manz.

- DUBLER, C.E., (1983), Les clauses d'exception en droit international privé, Ginebra, Gerog \& Cie S.A.

- DUTOIT, B., (2005), Droit international privé Suisse. Commentaire de la loi fédérale du 18 décembre 1987, $5^{\text {a }}$ ed., Basilea, Helbing \& Lichtenhahn.

- DUTTA, A., (2009), "Succession and Wills in the Conflict of Laws on the Eve of Europeanisation”, RabelsZ, t. 73, pp. 547-606.

- DUTTA, A., (2013), "Das neue internationale Erbrecht der Europäischen Union. Eine erste Lektüre der Erbrechtsverordnung”, FamRZ, pp. 4-15.

- EGEA, J., (2009), "El nou règim jurídic de la successió contractual”, Revista Jurídica de Cataluña, núm. 1, pp. 9-58. 
- EHRENZWEIG, A.A., (1959), "The statute of frauds in the conflict of laws: the basic rule of validation”, Columbia Law Review, núm. 59, pp. 874-881.

- EHRENZWEIG, A.A., (1974), Private International Law. A Comparative Treatise on American International Conficts Law, Including the Law of Admiralty, General Part, Leyden.

- $\quad$ ESPEJO LERDO DE TEJADA, M., (1999), La sucesión contractual en el Código Civil, Granada, Servicio de Publicaciones de la Universidad de Sevilla.

- ESPINAR VICENTE, J.M., (1994), La nacionalidad y la extranjería en el sistema jurídico español, Madrid, Civitas.

- FERID, M., (1969), "Die gewillkürte Erbfolge im internationalen Privatrecht", en W. Lauterbach, Vorschläge und Gutachten zur Reform des deutschen internationalen Erbrechts, Berlin-Tübingen, J.C.B. Mohr.

- FADDA, C., (1900), Concetti fondamentali del Diritto ereditario romano. Parte prima, Nápoles, Liugi Pierro Tip.

- FERID, M., (1974), "Le rattachament autonome de la transmission successorale en Droit international privé", $R d C$, vol. 142, II, pp. 71-202.

- FERNÁNDEZ ROZAS, J.C./SÁNCHEZ LORENZO, S., (2009), Derecho internacional privado, $5^{\mathrm{a}}$ ed., Cizur Menor, Civitas-Thomson.

- FERNÁNDEZ ROZAS, J.C./SÁNCHEZ LORENZO, S. (2011), Derecho internacional privado, $6^{\mathrm{a}}$ ed., Cizur Menor, Civitas, Thomson.

- FERRER PONS, J., (1980), “Art. 50”, en M. Albaladejo (dir.), Comentarios al código Civil y Compilaciones Forales, t. XXXI, vol. I, Arts. 1 a 65 de la Compilación de Baleares, Madrid, Edersa.

- FERRER VANRELL, M.P., (2009), "Los protocolos familiares y la ley balear 22/2006, de 19 de diciembre, como factores determinantes del resurgir de los pactos sucesorios", La Ley. Actualidad Civil, Sección a fondo, núm. 12, tomo 1, La Ley 12143/2009.

- FIRSCHING, K., (2004), "Deutschland”, en M. Ferid/K. Firsching, Internationales Erbrecht, vol II, Beck, Munich.

- FONT I SEGURA, A., (2000), "La sucesión hereditaria en Derecho interregional”, Anuario de Derecho Civil, vol. 53, núm. 1, pp. 23-81.

- $\quad$ FONT I SEGURA, A., (2007), Actualización y desarrollo del sistema de Derecho interregional, Santiago de Compostela, Servicio de Publicaciones de la Universidad de Santiago de Compostela.

FONT I SEGURA, A., (2009), "La ley aplicable a los pactos sucesorios”, InDret, mayo. 
- FONTANELLAS MORELL, J.M., (2010), La professio iuris sucesoria, Madrid, Barcelona, Buenos Aires, Marcial Pons.

- FONTANELLAS MORELL, J.M., (2011), "La professio iuris sucesoria a las puertas de una reglamentación comunitaria”, Dereito, vol. 20, núm. 2, pp. 83-129.

- FRANTZEN, T., (2004), "Europäisches internationales Erbrecht”, en Festchrift für Erik Jayme, t. I, Sellier, Munich, pp. 187-196.

- GANNAGÉ, P., (1992), "La pénétration de l'autonomie de la volonté dans le droit international privé de la famille", Rev. cr. dr. int. pr., tomo 81, 1992-3.

- GARCÍA DEL CORRAL, I.L./KRIEGEL, A./KRIEGEL, M./HERMAAN E./OSENBRÜGGEN E. (1889), Cuerpo del Derecho Civil Romano. Primera Parte. Instituta. Digesto, tomo I, Barcelona, Jaime Molinas Editor.

- GARCÍA DEL CORRAL, I.L./KRIEGEL, A./KRIEGEL, M./HERMAAN E./OSENBRÜGGEN E. (1892), Cuerpo del Derecho Civil Romano. Primera Parte. Digesto, tomo II, Barcelona, Jaime Molinas Editor.

- GARCÍA DEL CORRAL, I.L./KRIEGEL, A./KRIEGEL, M./HERMAAN E./OSENBRÜGGEN E. (1897), Cuerpo del Derecho Civil Romano. Primera Parte. Digesto, tomo III, Barcelona.

- GARCÍA DEL CORRAL, I.L./KRIEGEL, A./KRIEGEL, M./HERMAAN E./OSENBRÜGGEN E. (1892), Cuerpo del Derecho Civil Romano. Segunda Parte. Código, tomo I, (texto latino revisado por E. Hermann), Barcelona, Jaime Molinas Editor.

- GARCÍA RUBIO, M.P., (2000), "El apartamiento sucesorio en el Derecho civil gallego", $A D C$, t. LIII, octubre-diciembre, pp. 1397-1481.

- GARCÍA RUBIO M.P./HERRERO OVIEDO, M. (2009), "Las disposiciones generales, sobre pactos sucesorios en el Libro IV del Código Civil de Cataluña. Apertura, innovación y alguna perplejidad", en El nou dret successori del codi civil de Catalunya: materials de les Quinzenes Jornades de Dret Català a Tossa, pp. 465-484.

- GARCÍA RUBIO, M.P./HERRERO OVIEDO, M., (2011), "Pactos sucesorios en el Código Civil en la ley de Derecho de Galicia", en M.C. Gete-Alonso y Calera (dir.), Tratado de Derecho de sucesiones, tomo I, Navarra, Civitas Thomson Reuters, pp. 1259-1315.

- GARCÍA GOYENA, F., (1852), Concordancias, motivos y comentarios al Código Civil español, tomo 3, Madrid.

- GARETH, M., (2000), International aspects of succession, Aldershot, Ashgate/Dartmouth.

- GAS, F.J., (1953), "Pactos sucesorios", Revista jurídica de Cataluña, núm. 4, julio-agosto, pp. 314-323. 
- GAUDEMET-TALLON, H., (2004), "Nationalité, statut personnel et droits de l'homme", en H.P. Mansel/T. Pfeiffer/H. Kronke/C- Kohler/ R. Hausmann (eds.), Festschrift für Erik Jayme, t. I, Munich, Sellier, pp. 205-221.

- GENSOLÍN, R.R. (1962), Las donaciones "mortis causa”, Barcelona, Colección Nereo.

- GIAMPICCOLO, G., (1954), Il contenuto atipico del testamento, Milán, Giuffrè.

- GINÉS CASTELLET, N., (2011), "Los pactos sucesorios en Cataluña: entre la tradición y la innovación”, Actualidad Civil, núm. 5, marzo, pp. 508-557.

- GIULIANO, M., (1977), "La loi applicable aux contrats: problémes choisis", $R d C$, vol. 158, V, pp. 183-270.

- GOLDSCHMIDT, W., (1954), Sistema y filosofía del Derecho internacional privado, tomo II, $2^{a}$ ed., Buenos Aires, Ediciones Jurídicas Europa-América.

- GONZÁlEZ CAMPOS, J.D./FERNÁNDEZ ROZAS, J.C., (1983), Derecho internacional privado. Materiales de prácticas, Madrid, Tecnos.

- GORÉ, M., (1994), “«De la mode...» dans les successions internationales: contre les prétentions de la «professio iuris»", en L'internationalisation du Droit. Mélanges en l’honneur de Yvon Loussouarn, París, Dalloz.

- GOUTTES, P. DES, (1892), Les rapports de droit civil des Suisses établis ou en séjour en Suisse. Essai d'interpretation et de critique de la loi fédérale du 25 juin 1891, tesis Ginebra.

- GULDENER, M., (1951), Das internationale und interlokale Zivilprozessrecht der Schweiz, Zurich, Schulthess.

- HARRIS, J., (2008), "The proposed EU regulation on succession and wills: prospects and challenges", Trust Law International, 2008, pp. 181-235.

- HAUNSCHMIDT, F., (2008), "Erbrecht in Österreich", en R. Sü $\beta$, Erbrecht in Europa, 2a ed., Basilea, Zerb, pp. 1089-1143.

- HEINI, A., (2004), “Art. 95”, en VVAA., Zürcher Kommentar zum IPRG, 2a ed., Zürich, Schulthess.

- HEPP, E.M., (1991), Der amerikanische Testiervertrag -contract to make a willaus Sicht des deutschen Rechts, Munich, VVF.

- HEREDIA CERVANTES, I., (2011), "Lex successionis y lex rei sitae en el Reglamento de sucesiones”, AEDIPr, t. XI, pp. 415-445.

- HERERRO OVIEDO, M., (2009-1) "El renacer de los pactos sucesorios", en S. Álvarez González (ed.), Estudios de Derecho de familia y de sucesiones, Imprenta universitaria, Santiago de Compostela, pp. 199-217. 
ERRERO OVIEDO, M., (2009-2), "Los pactos sucesorios en el Código Civil francés”, en M.P. GARCíA RUBIO (coord.), Estudios jurídicos en memoria del profesor José Manuel Lete del Río, Navarra, Thomson-Aranzadi, pp. 443-475.

- HÉRON, J., (1986), Le morcellement des successions internationales, París, Economica.

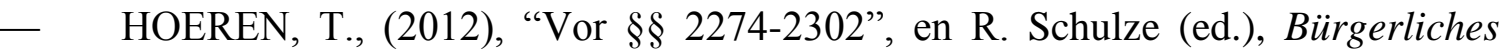
Gesetzbuch. Handkommentar, $7^{\text {a }}$ ed., Baden-Baden, Nomos, pp. 2332-2367.

- IMAZ ZUBIAUR, L., (2006), La sucesión paccionada en el Derecho civil vasco, Madrid, Barcelona, Marcial Pons.

- INZITARI B./DAGNA, P./FERRARI, M./PICCININI V., (2006), Il patto di famiglia. Negoziabilità del diritto successorio con la legge 14 febbraio 2006, $n$. 55, Turín, Giappichelli.

- IVANOVA, S., (2008), "Erbrecht in Bulgarien”, en R. Süß (ed.), Erbrecht in

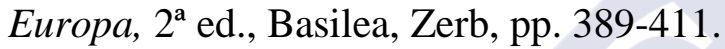

- JAYME, E., (1988), Pasqueale Stanislao Mancini. Il diritto internazionale private tra Risorgimento e attività forense, Padua, Cedam.

- JAYME, E., (1993), "Diritto di famiglia: società multiculturale e nuovi sviluppi del Diritto internazionale privato", Riv. dir. int. priv. proc., núm. 2, pp. 295-304.

- JAYME, E., (2000), "Le Droit international privé du Nouveau millénaire: la protection de la personne humaine face à la globalisation", $R d C$, t. 282, pp. 11-40.

- JAYME, E., (2009), "Party autonomy in international family and succession law: new tendencies", Yearbook of Private International Law, vol. I, pp. 1-10.

- JAYME, E., (2011), "Zur Reichweite des Erbstatuts", en G. Reichelt/W.H. Rechberger (eds.), Europäisches Erbrecht. Zum Verordnungsvorschlag der Europäischen Kommission zum Erb- und Testamentsrecht, Viena, Jan Sramek Verlag, pp. 27-40.

- JAYME, E. (2012), Zugehörigkeit und kulturelle Identität. Die Sicht des Internationalen Privatrechts, Göttigen, Wallstein.

- JOSLYN, R.B., "Surviving spouse's rights to share in deceased spouse's estate", The American college of Trusts and Estate Counsel, Study 10, 2004.

- JUBAUlT, C., (2010), Droit civil. Les successions, les libéralités, $2^{\mathrm{a}}$ ed., París, Montchrestien.

- KHAIRALlaH, G., (2010), "La loi applicable à la succession", en G. Khairallah/M. Revillard (dirs.), Perspectives $d u$ Droit des successions européennes et internationales. Étude de la Proposition de Règlement du 14 octobre 2009, París, Defrénois, pp. 61-79. 
- KHAIRALlAH, G., (2013), "La détermination de la loi applicable à la succession", en G. Khairallah/M. Revillard (dirs.), Droit européen des successions internationales. Le Règlement du 4 juillet 2012, París, Defrénois, pp. 47-65.

- KANZLEITER, R., (2006), "Erbvertrag", en StAudinger, Kommentar, vol. V, Berlin, Sellier de Gruyter.

- KEGEL, G., (1953), "Begriffs- und Interessenjurisprudenz im internationalen Privatrecht", en M. Gerwig/A.Simonius/K. Spiro/T. Süss/E. Wolff (eds.), Festschrift Hans Lewald, Basilea, Helbing\&Lichtenhahn, pp. 259-288.

- KELLER, M./GIRSBERGER, D. (2004), “Art. 15”, en D. Girsberger/A. Heini/M. Keller/ J. Kren Kostkiewicz/K. Siehr/F. Vischer/P. Volken (eds.), Zürcher Kommentar zum IPRG, 2a ed., Zurich, Basilea, Ginebra, Schulthess, pp. 182-213.

- KERRIDGE, R., (2011), "Freedom of testation in England and Wales", en M. Anderson/E. Arroyo (ed.), The law of Succession: Testamentary freedom. European perspectives, European Law Publishing, Groninga-Amsterdam, pp. 131-153.

- KINDLER, P., (2010), "From nationality to habitual residence: some brief remarks on the future EU Regulation on International Successions and Wills", en K. Boele-Woelki/T.Einhorn/D. Girsberger/S. Symeonides (eds.), Convergence and Divergence in Private International Law. Liber Amicorum Kurt Siehr, La Haya, Schulthess, pp. 251-258.

- $\quad$ KIPP. T., (1976), Derecho de sucesiones, vol. I, $2^{\mathrm{a}}$ ed., Barcelona, Bosch.

- KNORRE, K.F./MINCKE, W., (2008), "Erbrecht in Finnland", en R. Süß, Erbrecht in Europa, Basilea, Zerb, pp. 585-610.

- KOKKINI-IATRIDOU, D., (1994), "Les clauses d'exception en matière de conflits de loit et de conflits de jusrisdictions", en D. Kokkini-Iatridou (ed.), Les clauses d'exception en matière de conflits de lois et de conflits de jurisdictions ou le principe de proximité, Dordrecht-Boston-Londres, Martinus Nijhoss Publishers, pp. 3-41.

- KROPHOLlER, J., (2004), Internationales Privatrecht, $5^{\mathrm{a}}$ ed., Tübingen, Mohr Siebeck.

- $\quad$ KÜHNE, G., (1973), Die Parteiautonomie im internationalen Erbrecht, Bielefeld, Verlag Ernst und Werner Gieseking.

- LACRUZ BERDEJO, J.L., (1953), Traducción y notas a Derecho de sucesiones de Julius Binder, Barcelona, Ed. Labor.

- LACRUZ BERDEJO, J.L., (2005), Elementos de Derecho civil. Tomo I, vol. III, Madrid, Dykinson.

- LACRUZ BERDEJO, J.L./SANCHO REBULLIDA, F., (1976), Derecho de sucesiones I. Parte general. Sucesión voluntaria, $2^{\mathrm{a}}$ ed., Barcelona, Bosch. 
- LACRUZ BERDEJO, J.L./SANCHO REBULLIDA, F., (1981), Elementos de Derecho civil. Derecho de sucesiones, tomo V, Barcelona, Bosch.

- LAGARDE, P., (1986), "Le principe de proximité dans le droit international privé contemporain: cours général de droit international privé”, $R d C$, t. 196, 1986-I, pp. 9-238.

- LAGARDE, P., (1989), "La nouvelle Convention de La Haye sur la loi applicable aux successions", Rev. crit. dr. int. pr., pp. 249-275.

- LAGARDE, P., (2004), nota a la sentencia de la Cour d'appel d'Aix-en-Provence, 16 de octubre de 2003, Rev. crit. dr. int. pr., núm 3, pp. 593-595.

- LAGARDE, P., (2005), "Vers un Règlement communautaire du Droit international privé des régimes matrimoniaux et des successions", en Obra homenaje al Profesor Julio D. González Campos, tomo II, Madrid, Eurolex, pp. 1687-1708.

- LAGARDE, P. (2012), "Les principes de base du nouveau règlement européen sur les successions”, Rev. crit. dr. int. pr., núm. 4, pp. 691-732.

- LANDO, O., (1985), "The conflict of laws of contracts. General principles", $R d C$, vol. 189, pp. 229-445.

- LANGE, K.W., (2012), "Das Erbkollisionsrecht im neuen Entwurf einer EUErbVO”, Zerb, pp. 160-165.

- LAUTERBAH, W., (1969), Vorschläge und Gutachten zur Reform des deutschen internationalen Erbrechts, Berlín-Tübingen, Walter de Gruyter-J.C.B. Mohr.

- LEE, W.E., (1971), "Contracts to make wills", The Law Quarterly Review, vol. 87, pp. 358-366.

- LEHMANN, D., (2012), "Die EU- Erbrechtsverordnung zur Abwicklung grenzüberschreitender Nachlässe”, DStR, PP. 2085-2089.

- LEIBLE, S., (2008), "Choice of the applicable law", en E. Cashin Ritaine/A. Bonomi, Le nouveau règlement européen "Rome I" relative à la loi applicable aux obligations contractuelles”, Ginebra-Zurich-Basilea, Schulthess, pp. 61-75.

- LEITZEN, M., (2012), "EuErbVO: Praxisfragen an der Schnittstelle zwischen Erb- und Gesellschaftsrechr", ZEV, pp. 520-524.

— $\quad$ LEROYER, A.M., (2009), Droit des successions, París, Dalloz.

- LEVENEUR, L./LEVENEUR, S., (1999), Leçons de Droit Civil, Mazeaud/Chabas, t. IV, $5^{\text {a }}$ ed., París.

- LEWALD, H., (1925), "Questions de Droit international des successions", $R d C$, vol. 9, pp. 5-123.

- LI, H., (1990), "Some recent developments in the conflict of laws of succession", $R d C$, vol. 224, 1990-V, pp. 9-122. 
- LOUSSOUARN, Y., (1987), "La dualité des principes de nationalité et de domicile en droit international privé", Institut de Droit International. Annuaire, vol. 62 , t. I, pp. 295-349.

- MARÍN LÓPEZ, A., (1957), Las sucesiones en Derecho internacional privado: con especial referencia al Derecho español, Granada, Universidad de Granada.

- MARÍN PADILLA, M.L., (1992), Historia de la sucesión contractual, Zaragoza, Cometa.

— MALAURIE, P., (2008), Les successions, les liberalités, $3^{\mathrm{a}}$ ed., París, Defrénois.

- MANSEL, H-P., (2010), "The impact of the European Union's prohibition of discrimination and the right of free movement of persons on the Private International Law rules of Member States - With comment son the SaynWittgenstein case befote the European Court of Justice", en K. Boele-Woelki/T. Einhorn/D. Girsberfer/S. Symeonides, Convergence and Divergence in Private International Law. Liber Amicorum Kurt Siehr, Zurich, Schulthess, pp. 291-309.

- MARCHAL ESCALONA, N., (1996), "La Ley de reforma de Derecho internacional privado italiano de mayo de 1995”, REDI, vol. XLVIII, núm. 1, pp. 474-500.

- MARGONSKI, M., (2013), "Ausländische Vindikationslegate nach der EU Erbrechtsverordnung”, GPR, núm. 2, pp. 106-111.

- MARTÍNEZ VÁZQUEZ DE CASTRO, L., (1982), "El pacto sucesorio en el nuevo Estatuto de la Explotación Familiar Agraria", Diario La Ley, 1982, p. 1074, t. 4, La Ley 15352/2001.

- MAYER, P./ HEUZÉ, V., (2007), Droit international privé, 9a ed., París, Montchrestien.

- McCABE P./JOHNSON, S.J., (2010), "United States - California", en L. Garb/J. Wood (eds.), International succession, 3 ed., Oxford, University Press, pp. 743757.

- MENGOZZI, P., (2002), La reforma del Diritto internazionale privato italiano, $3^{\mathrm{a}}$ ed., Nápoles, Editoriale Scientifica.

- MEYER, R., (1994), "Les clauses d'exception en matière de conflits de lois et de conflits de jurisdictions. Suisse”, en D. Kokkini-Iatridou (ed.), Les clauses d'exception en matière de conflits de lois et de conflits de jurisdictions - ou le principe de proximité, Dordrecht-Boston-Londres, Martinus Nijhoss Publishers, pp. 299-332.

- MEZQUITA DEL CACHO, J.L., (2002), "De los pactos o contratos sucesorios", en E. Rubio Torrano (dir.), Comentarios al Fuero Nuevo, Navarra, ThomsonAranzadi, pp. 522-553.

- MIAJA DE LA MUELA, A., (1955), Derecho internacional privado II Parte especial, Madrid. 
- MIAJA DE LA MUELA, A., (1967), Derecho internacional privado II Parte especial, $4^{\mathrm{a}}$ ed., Madrid.

- MIAJA DE LA MUELA, A., (1975), "El legislador interno, en funciones de legislador internacional ante los conflictos de leyes", en VV.AA, Curso Monográfico sobre la Ley de Bases para la Modificación del Título Preliminar del Código Civil, Valencia, pp. 169-205.

- MIAJA DE LA MUELA, A., (1977), Derecho internacional privado II Parte especial, $7^{\mathrm{a}}$ ed., Madrid, Atlas.

- MIQUEL SALA, R., (2007), "El Libro Verde sobre sucesiones y testamentos. Primeros pasos hacia el Reglamento de Bruselas IV", AEDIPr, núm. 7, pp. 695718.

- MONASTERIO ASPIRI, I., (1994), Los pactos sucesorios en el Derecho vizcaíno, Bilbao, Diputación Foral de Bizkaia-Universidad de Deusto.

- MUSIELAK, H-J. (1997), "Vierter Abschnitt. Erbvertrag", en G. Schlichting (red.), Münchener Kommentar zum Bürgerlichen Gesetzbuch, tomo 9, $3^{\mathrm{a}}$ ed., Munich, Beck, pp. 1673-1799.

- NAVAS NAVARRO, S., (2009), "El pacto sucesorio de atribución particular en el Código Civil de Catalunya", InDret, mayo, pp. 1-35.

- NAVAS NAVARRO, S. (2011), "Libertad de testar versus libertad de celebrar pactos sucesorios y costes de transacción”, ADC, t. LXIV, núm. 1, pp. 41-74.

- NIBOYET, J-P., (1927), "La théorie de l'autonomie de la volonté", $R d C$, vol. 16, 1927-I, pp. 1-116.

- NIBOYET, J-P., (1947), Traité de Droit international privé français, tomo IV, París, Recueil Sirey.

- NORDMEIER, C.F., (2012), "EuErbVO: Neues kollissionsrecht für gemeinschaftliche Testamente", ZEV, pp. 513-519.

- NORDMEIER, C.F., (2013), "Erbverträge und nachlassbezogene Rechtsgeschäfte in der EuErbVO - eine Begriffsklärung”, ZEV, pp. 117- 124.

- ODERSKY, F., (2008), "Erbrecht in Großbritannien: England und Wales", en R. Süß, Erbrecht in Europa, 2a ed., Basilea, Zerb, pp. 719-785.

- ORDÓÑEZ ARMÁN, F.M./PEÓN RAMA, V.J./VIDAL PEREIRO, V.M. (2007), "De los pactos sucesorios", en Derecho de sucesiones y régimen económico familiar de Galicia. Comentarios a los Títulos IX y X y a la Disposición Adicional Tercera de la Ley 2/2006 de 14 de junio y a la Ley 10/2007, de 28 de junio, vol. I, Consejo General del Notariado, pp. 333 y ss.

- PARRA LUCÁN, M.A., (2009), "Legítimas, libertad de testar y transmisión de un patrimonio", Foro galego: revista xurídica, núm. 199, pp. 7-123. 
- PARRA RODRÍGUEZ, C., (2001), El nuevo Derecho internacional de los contratos, Barcelona, Bosch.

- PATOCCHI, P. M., (1985), Règles de rattachement localisatrices et règles de rattachement à caractère substantiel, Ginebra, Georg \& Cie S.A.

- PELAYO HORE, S., (1967), "Los pactos sucesorios en la Compilación de Aragón”, Anuario de Derecho Civil, Tomo XX, oct-dic., pp. 819-865.

- PEÑA BERNALDO DE QUIRÓS, M., (2006), El Anteproyecto del Código Civil español (1882-1888). Con un estudio preliminar, notas y concordancias, $2^{\mathrm{a}}$ ed., Madrid, Colegios Notariales de España.

- PEREÑA VICENTE, M., (2008), "Nuevo marco legal de los pactos sucesorios en el Derecho francés", Revista crítica de Derecho Inmobiliario, núm. 170, pp. 24852502.

- PÉREZ VERA, E., (1973), Intereses del tráfico jurídico externo y Derecho internacional, Granada, Universidad de Granada.

- PÉREZ VERA, E., (1980), Derecho internacional privado. Parte especial, Madrid, Tecnos.

- PERONI, G., (2007), "Patti successori, patto di famiglia e ámbito di aplicazione delle norme di Diritto internazionale privato", Diritto del comercio internazionale, núm. 21, pp. 611-640.

- PERREAU-SAUSSINE, L., (2011), "La professio iuris et l'unité de la succession", en H. Bosse-Platière/N. Damas/Y. Dereu (dirs.), L'avenir euripéen $d u$ Droit des successions internationales, París, Lexis Nexis, pp. 33-44.

- PICONE, P., (1998), La reforma italiana del Diritto internazionale privato, Padua, Cedam.

- PILLET, A., (1924), Traité de Droit international privé, tomo 2, París.

- PIRRUNG, J, (1999), "Die Haager Konferenz für IPR und ihr Übereinkommen vom 1. August 1989 über das auf die Rechtsnachfolge von Todes wegen anzuwendende Recht“, en Mélanges Fritz Sturm, vol. II, Editions Juridiques de 1 'Université de Liège, pp. 1607-1627.

- POCAR, F., (2002) Il nuovo diritto internazionale privato italiano, $2^{\mathrm{a}}$ ed., Milán, Giuffrè.

- POMMIER, J.C., (1992), Principe d'autonomie et loi du contrat en Droit international privé conventionnel, París, Economica.

- POSCH, W., Internationales Privatrecht, $3^{\mathrm{a}}$ ed., Viena-N. York, Springer, 2002.

- PRATDESABA RICART, R. (2009) "La successió contractual en el nou Llibre IV del Codi Civil de Catalunya", en El nou dret successori del codi civil de 
Catalunya: materials de les Quinzenes Jornades de Dret Català a Tossa, pp. 151180.

- PUIG FERRIOL, LL. (1990), en M. Albaladejo (dir.), Comentarios al Código Civil y Compilaciones Forales, t. XXVII, vol. 2, Madrid, Edersa.

- PUIG FERRIOL, L./ROCA TRÍAS, E. (2009), Institucions del Dret civil de Catalunya. Dret de successions, vol. 3, $7^{\text {a }}$ ed., Valencia, Tirant lo Blanch.

- PUIG PEÑA, F., (1976), Compendio de Derecho civil español. Sucesiones, tomo VI, $3^{\text {a }}$ ed., Madrid, Pirámide.

- $\quad$ RAAPE, L., (1961), Internationales Privatrecht, 5 ${ }^{\text {a }}$ ed., Franz Vahlen, BerlinFrankfurt.

- RAMS ALBESA, J. (1993), "Del objeto de los contratos", en M. Albaladejo/S. Díaz Alabart (dir.), Comentarios al Código Civil y Compilaciones Forales, Arts. 1261-1280 del Código Civil, tomo XVII, Vol. $1^{\circ}$ B, Madrid, Edersa, pp. 441-469.

- RAUSCHER, T., (2004), "Heimatlos in Europa? Gedanken gegen eine Aufgabe des Staatsangehörigkeitsprinzip im IPR", en H.P. Mansel/T. Pfeiffer/H. Kronke/C- Kohler/ R. Hausmann (eds.), Festschrift für Erik Jayme, t. I, Munich, Sellier, pp. 719-745.

- REBOlledO VARELA, A.L., (2008), "De los pactos sucesorios", en A.L. Rebolledo Varela (coord.), Comentarios a la Ley de Derecho Civil de Galicia: Ley 2-2006, de 14 de junio", Navarra, Thomson-Aranzadi, pp. 905-984.

- REMIEN, O., (2010), "La validité et les effets des actes à cause de mort", en A. Bonomi/C. Schmid (eds.), Successions internationales. Réflexions autour du future règlement européen et de son impact pour la Suisse, Zurich-Basilea, Schulthess, pp. 57-68.

- REMIRO BROTONS, A., (1978), “Art. 10.5”, en M. Albaladejo (dir.), Comentarios al Código Civil y Compilaciones Forales, tomo I, Arts. 1 a $41 \mathrm{CC}$, Madrid, Edersa, pp. 289-321.

- REQUEIXO SOUTO, X.M., (2012), "Pactos de atribución particular post mortem. Ámbito del artículo 1271, ap. $2^{\circ}$ del Código Civil”, $A D C$, tomo LXV, fasc. IV, pp. 1745-1781.

- REQUEJO ISIDRO, M. (1998), Ley local y forma de los actos en el Derecho internacional privado español, Madrid, Eurolex.

- REVILlaRD, M., (2010), Droit international privé et communautaire. Pratique notariale, $7^{\mathrm{a}}$ ed., París, Defrénois.

- RHEINSTEIN, M., (1955), “Critique: contracts to make a will”, N.Y.U.L.Rev, pp. 1224-1237. 
ROCA SASTRE, R.M., (1948), "La sucesión contractual en Derecho común y en las legislaciones forales", en Estudios de Derecho privado. Sucesiones II, Madrid, ed. Revista de Derecho privado.

- RODRÍGUEZ BENOT, A., (2008), "La superación de las divergencias en los principios de solución del Derecho conflictual sucesorio", en M. di Filippo/B. Campuzano Díaz/A. Rodríguez Benot/M.A. Rodríguez Vázquez (coords.), Hacia un Derecho conflictual europeo: realizaciones y perspectivas, Sevilla, Universidad de SevillaSecretariado de Publicaciones, pp. 121-150.

- $\quad$ RODRÍGUEZ BENOT, A., (2010), "El criterio de conexión para determinar la ley personal: un renovado debate en Derecho internacional privado", Cuadernos de Derecho Transnacional, vol. 2, núm. 1, pp. 186-202.

- RODRÍGUEZ-URÍA SUÁREZ, I. (2010), “La Propuesta de Reglamento sobre sucesiones y testamentos y su posible aplicación al Derecho interregional: especial consideración de los pactos sucesorios", AEDIPr, t. X, pp. 639-665.

- RODRÍGUEZ-URÍA SUÁREZ, I. (2013), "La ley aplicable a las sucesiones mortis causa en el Reglamento (UE) 650/2012”, InDret, núm. 2, pp. 1-58.

- ROGUIN, E., (1912), Traité de droit civil comparé. Les successions, vol. IV, París.

- ROMERO CANDAU, P.A., (1998), "Pactos sobre la herencia de un tercero", Anales de la Academia Matritense del Notariado, t. XXXVIII, pp. 181-203.

- ROYO MARTINEZ, M., (1951), Derecho sucesorio “mortis causa”,Sevilla, Edelce.

- SANCHEZ ARISTI, R., (2003), Dos alternativas a la sucesión testamentaria: pactos sucesorios y contratos post-mortem, Granada, Comares.

- SÁNCHEZ ARISTI, R., (2006), "Propuesta para una reforma del Código Civil en materia de pactos sucesorios", en Derecho de Sucesiones. Presente y futuro. XI Jornadas de la Asociación de profesores de Derecho civil, Servicio Publicaciones Universidad de Murcia, pp. 477-541.

- SÁNCHEZ-CALERO ARRIBAS, B., (2010), “Art. 1341”, en A. Domínguez Luelmo (dir.), Comentarios al Código Civil, Valladolid, Lex Nova, pp. 14761477.

- SÁNCHEZ LORENZO, S., (1994), "Postmodernismo y Derecho internacional privado", REDI, vol. XLVI, núm. 2, pp. 557-585.

- SAPENA TOMÁS, J. (1954), “El pacto sucesorio en el Alto Aragón”, RDP, vol. 38, pp. 734-783.

- SCOLES, E.F./HAY, P./ BORCHERS, P.J./SYMEONIDES, S.C., (2004), Conflict of laws, $4^{\mathrm{a}}$ ed., St. Paul, Thomson West. 
- SCOLES, E.F., (1994), "The Hague Convention on Succession”, The American Journal of Comparative Law, vol. 42, pp. 85-123.

- $\quad$ SCHNITZER, A.F., (1944), Handbuch des Internationalen Privatrechts, vl. II, $1^{\mathrm{a}}$ ed., Basilea.

- SCHNITZER, A.F., (1954), "Le droit international privé suisse", Rev. Hell. $d r$. int., pp. 143-163.

- $\quad$ SCHNITZER, A.F., (1958), Handbuch des internationalen Privatrechts, vol. II, $4^{\mathrm{a}}$ ed., Basilea.

- SCHOCH, M. (1942), "Conflicts of Law in a Federal State: the Experience of Switzeerland”, Harvard L. Rev., VOL. 55, PP. 738-779.

- SCHÖMMER, H.P./BÜRGI, U., (2006), Internationales Erbrecht, Schweiz, 2a ed., Munich, C.H. Beck.

- SCHURIG, K., (2010), "Das internationale Erbrecht wird europäischBemerkungen zur kommenden Europäischen Verordnung", Festschrift für Ulrich Spellenberg zum 70. Geburtstag, Munich, Sellier, pp. 343-353.

- $\quad$ SCHWIMANN, M., (1993), Internationales Privatrecht, Viena, Manzsche.

- SCHWIND, F., (1990), Internationales Privatrecht, Viena, Manzsche.

- SCYBOZ, G./SCYBOZ, P./GUILLIÉRON, P.R./BRACONI, A., (2008), Code civil Suisse et Code des obligations annotés, $8^{\mathrm{a}}$ ed., Basilea, Helbing Lichtenhahn.

- SIEHR, K., (1989), "Die Parteiautonomie im Internationalen Privatrecht", en P. Forstmoser/H.Giger/A.Heini/W.R. Schluep, Festschrift für Max Keller zum 65. Geburtstag, Zurichm Schulthess Polygraphisher Verlag, 1989, pp. 485-510.

- SIMON, U./BUSCHBAUM, M., (2012), "Die neue EU-Erbrechtsverordnung", NJW, pp. 2393-2398.

- SIRVENT GARCÍA, J., (2003), Las donaciones por razón de matrimonio en el Código Civil, Valencia, Tirant lo Blanch.

- SOHM, R., (1951), Instituciones de Derecho Privado Romano, (traducción a cargo de W. Roces), $2^{a}$ ed., Mexico, Grafica Panamericana.

- SOLDAN, CH., (1884), "La loi fédéral sur les rapports de droit civil des Suisses établis ou en séjour”, $R D S$, pp. 533-584.

- SPARKS, B.M., (1956), Contracts to make wills, Nueva York, New York University Press.

- SPECKERT, T., (1951), Unterschied zwischen Testament und Erbvertrag, Zurich, Juris Verlag.

- TAMBURINI, A., (2008), "Divieto dei patti successori", en L.Balestra/M. di Marzio, Successioni e Donazioni, Padua, Cedam, pp. 31 y ss. 
TASSINARI, F., (2006), "Il patto di famiglia per l'impresa e la tutela dei legittimari”, Giurisprudenza Commerciale, t. 33, núm. I, pp. 808-833. italien et perspectives de réforme", en A. BONOMI/M. STEINER, Les pactes successoraux en droit comparé et en droit international privé, Ginebra, Droz, pp. 65-83.

\section{TOMÁS ORTIZ DE LA TORRE, J.A., (1973), “}

TOMÁS ORTIZ DE LA TORRE, J.A. (1975), "Las sucesiones en el Derecho civil internacional", en M. Aguilar Navarro (dir.), Derecho civil internacional, vol. II, $4^{\text {a }}$ ed., Madrid.

- TONOLO, S., «Legge applicabile ai patti successori », Studium Iuris, núm. 2, 2002, pp. 1238-1240.

- TORRES GARCÍA, T.F., (2006), "Legítima, legitimarios y libertad de testar (síntesis de un sistema) ", en Derecho de sucesiones. Presente y futuro. XI Jornadas de la Asociación de Profesores de Derecho Civil, Murcía, Servicio de Publicaciones de la Universidad de Murcia, pp. 173-227.

- VALLADARES RASCÓN, E., (2004), "Por una reforma del sistema sucesorio del Código Civil", en J.M. González Porras/F.P. Méndez González (coords.), Libro homenaje al profesor Manuel Albaladejo García, tomo II, Murcia, Servicio de Publicaciones de la Universidad de Murcia, pp. 4893-4902.

- VAllet DE GOYTiSOLO, J.B., (1993), “Art. 826 CC”, en C. Paz-Arez Rodríguez/L. Díes-Picazo Ponce de León/R. Bercovitz/P. Salvador Coderch (dirs.), Comentario del Código Civil, tomo I, Madrid, Ministerio de JusticiaCentro de Publicaciones, pp. 2047-2049.

- VALLET DE GOYTISOLO, J.B./FRAGUAS MASSIP, R./MARTÍNEZ GIL, J.L./SIMÓ SANTOJA, V.L. (1967), Conflicto de leyes en materia de sucesión por causa de muerte: cuestiones preliminares e incidentales, orden público, capacidad, transmisión y adquisición, IX Congreso Internacional del Notariado Latino, Madrid, Junta de Decanos.

- VALTIER FUENZALIDA, C., (1983), "Los perfiles esenciales de un nuevo Derecho de sucesiones. Estudio de un proyecto de ley sobre la explotación agrícola familiar", Revista Crítica de Derecho Inmobiliario, núm. 557, julioagosto, pp. 871-935.

- VAN ITERSON, D., (1997), "Pays-Bas; Successions; Convenion de La Haye du 1er août 1989; Mise en application”, Rev. crit. dr. int. pr., pp. 135-138.

- VANDER ELST, R., (1991), "La loi nationale dans les Conventions de La Haye", Revue belge de Droit international, núm. 1, pp. 398-407.

- VAQUER ALOY, A., (2007), "Algunas reflexiones sobre una eventual reforma de la legítima", InDret, julio. 
- VERPLAETSE, J.G., (1954), Derecho internacional privado, Madrid, Artes Gráficas.

- VIARENGO, I., (1996), Autonomia della volontà e rapporti patrimoniali tra coniugi nel diritto internazionale privato, Padua, Cedam.

- VIRGÓS SORIANO, M., (1991), “Art. 10.5”, en Comentarios del Código Civil, t. I, Madrid, Ministerio de Justicia, Secretaría General Técnica, pp. 116-121.

- VIRGÓS SORIANO, M. (1995), "Capítulo V. Las cosas y los derechos reales", en VV.AA., Derecho internacional privado. Parte especial, $6^{\mathrm{a}}$ ed., Madrid, Eurolex, pp. 241-285.

- VIRGÓS SORIANO, M., (1996), "La ley aplicable a los contratos internacionales: la regla de los vínculos más estrechos y la presunción basada en la prestación característica del contrato", en J.L. Iglesias Prada (coord.), Estudios jurídicos en homenaje al profesor Aurelio Menéndez. IV, Derecho civil y Derecho público, Madrid, Civitas, pp. 5289-5309.

- VISCHER, F., (1988), "Loi fédérale de droit international privé. Introduction générale", en F. Dessemontet (ed.), Le Nouveau Droit international privé suisse. Travaux des Journées d'étude organices par le Centre du droit de l'entreprise les 9 et 10 octobre 1987, à l'Université de Laussane, Lausana, Cedidac, pp. 11-26.

- VISMARA, G., (1986), Storia dei patti successori, Milán. Dott. A. Giufrè,

- VITTA, E., (1975), Diritto internazionale privado, vol. III, Turín, Utet.

- VITTA, E., (1992), Corso di Diritto internazionale privato e processuale, $4^{\mathrm{a}}$ ed., editado por F. Mosconi, Turín, Utet.

- VOCI, P., (1960), Diritto ereditario romano, vol. 1. Introduzione. Parte Generale, Milán, Dott. A. Gieuffrè.

- VOLLMER, P.W., (2012), "Die neue europäische Erbrechtsverordnung - ein Überblick", ZErb, pp. 227-234.

- VON OVERBECK, A. E., (1961), «Divers aspects de l'unification du Droit international privé, spécialement en matière de successions », $R d C$, vol. 104, 1961-III, pp. 529-633.

- VON OVERBECK, A. E., (1965), «La professio iuris comme moyen de rapprocher les principes du domicile et de la nationalité en droit international privé », J. LIMPENS (ed.), Liber Amicorum Baron Louis Fredericq, Gante, pp. 1085-1112.

- VON OVERBECK, A.E., (1983), "Les questions générales du Droit international privé à la lumière des Codifications et projets récents”, $R d C$, t. 176, pp. 9-258.

- VON OVERBECK, A. E., (1988), "Les régimes matrimoniaux et les successions dans le nouveau droit international privé suisse", en F. DESSEMONTET (dir.), Le nouveau droit international privé suisse, Lausana, Cedidac, pp. 59-78. 
- VON OVERBECK, A. E., (1989), «La Convention du premier Août 1989 sur la loi applicable aux successions pour cause de mort », Annuaire suisse de droit international, pp. 138-152.

- VON OVERBECK, A. E., «L'irrésistible extension de l'autonomie en Droit international privé », en Nouveaux itinéraires en droit. Hommage à François Rigaux, Bruselas, Bruylant, 1993, pp. 619-636.

- VON SAVIGNY, F.K., System des heutigen römischen Rechts, vol. 8, Darmstadt, 1849.

- WALSH, K.J., (1981), "The Statute of Fraud's Lifetime and Testamentary Provisions: Safeguarding Decedent's Estates", Fordham Law Review, vol. 50, núm. 2, pp. 239-270.

- WARD, P., (2010), Family Law in Ireland, Reino Unido, Wolters Kluwer.

- WATTÉ, N., "L'autonomie de la volonté dans les Conventios de La Haye", Revue belge de Droit international, núm. 1, 1991, pp. 413-437.

- WAUTELET, P., "Le nouveau régime des successions internationales", Revue Génerale de Droit Civil, 2005, pp. 375-388; consultado en internet http://www.ajn.be/textes/dipe/wautelet1.pdf

- WENGLER, W., (1952), "Les principes généraux du droit international privé et leurs conflits", Rev. crit. dr. int. pr., pp. 595-622.

- WENGLER, W., (1953), "Les principes généraux du droit international privé et leurs conflits (suite et fin)", Rev. crit. dr. int. pr., pp. 37-60.

- WENGLER, W., (1990), “L 'évolution moderne du droit international privé et prévisibilité du droit applicable", Rev. crit. dr. int. pr., pp. 657-674.

- WILKE, F.M, (2012), "Das internationale Erbrecht nach der neuen EU Erbrechtsverordnung”, RIW, núm. 9, pp. 601-609

- WILLIAMS, W.J, The law relating to wills with precedents of particular clauses and complete wills, $3^{\mathrm{a}}$ ed., Londres, Butterworths, 1967.

- WOOD, J., (2010), "England and Wales", en L. Garb/J. Wood (eds.), International succession, $3^{\mathrm{a}}$ ed., Oxford, University Press, pp. 229-245.

- ZABALO ESCUDERO, E., "El testamento conjunto en DIPr. Especial referencia al testamento mancomunado aragonés", Revista General de Derecho, 1989, pp. 6351-6370.

- ZAMORA CABOT, F.J., (1983), “Derecho De las obligaciones. Teoría General”, en M. Aguilar Navarro (dir.), Lecciones de Derecho civil internacional español, $2^{\mathrm{a}}$ ed. revisada, Madrid, Servicio de Publicaciones de la Universidad Complutense, pp. 383-407. 
ZWEIGERT, K., (1973), "Zur Armut des internationalen Privatrechts an sozialen Werten”, RabelsZ, núm. 37, pp. 435-452. 


\section{PRÁCTICA JUDICIAL CITADA}

\section{Práctica judicial española}

- $\quad$ STS de 4 de mayo de 1910 (Jurisprudencia civil mayo de 1910)

- $\quad$ STS de 8 de octubre de 1915 (Jurisprudencia civil octubre 1915)

- $\quad$ STS de 6 de mayo de 1940 (RJ $1940 \backslash 416$ bis)

- $\quad$ STS de 4 de octubre de 1982, RJ 198215537

- $\quad$ STS de 22 de julio de 1997, núm. 718/1997, RJ/1997/5807

- SAP de León de 8 de noviembre de 1995, núm. 428/1995, AC 1995/2254

- SAP Zaragoza de 5 de diciembre de 2002, núm. 713/2002, AC 2003/222

- SAP Cuenca de 30 de octubre de 2009, núm. 250/2009, JUR 2009/497002

\section{Práctica judicial de EEUU}

- District Court Massachusetts, Emery v. Burbank, North Eastern Reporter, vol. 39, 1895, pp. 1026 y ss.

- Court of Appeals of New York, Rubin v. Irving Trust Co., North Eastern Reporter, 2d Series, vol. 113, 1953, pp. 424 y ss.

- District Court of Appeal of California, Bernkrant v. Fowler, West's California Reporter, vol. 8, 1961, pp. 326 y ss

- Supreme Court California, Bernkrant v. Fowler, West's California Reporter, vol. 12, 1961, pp. 266 y ss.

- Surrogate's Court, New York County, In re Bulova's Will, New York Supplement, 2d Series, vol. 216, 1961

- Supreme Court New Yoek, Apellate Division, In re Bulova's Will, New York Supplement, 2d Series, vol. 220, 1962, pp. 540 y ss.

- Court of Civil Appeals of Texas, Frey v. Estate of Sargent, South Western Reporter, 2d Series, vol. 533, pp. 142 y ss.

- Missouri Court of Appeals, L.G. v. F.G.H., South Western Reporter, 2d Series, núm. 729, 1987, pp. 634 y ss.

- District Court of Appeal of Florida, Johnson v. Girtman, Southern Reporter, 2d Series, núm. 542, 1989, pp. 1032 y ss. 


\section{Otra práctia judicial}

- Cour de Cassation de France, sentencia de 14 marzo 1837, consultada en B. Ancel/Y. Lequette (1987), pp. 10 y ss.

- Hammersley v. De Biel, XII CLARK \& Finnelly, 44, 1845, pp. 312 y ss.

- $\quad$ Tribunal Civil de la Seine, 1 ch. 18 juillet 1885, JDIP, 1886, p. 208

- Queen’s Bench Division, Synge v. Synge [1894] 1. Q.B. 466

- Corte di Cassazione di Firenze, 12 diciembre de 1895, consultada en Foro italiano, 1896, vol. I, pp. 142 y ss.

- Cour de Cassation de France, sentencia de 5 de diciembre de 1910 sobre el caso American Trading Company v. Quebec Steamship Company Limited, Journal de Droit international, 1912, pp. 1156-1159.

- Cour de Cassation de Belgique, Societé Antwerpia c. Ville d'Anvers de 24 de febrero de 1938, Rev. crit. dr. int. priv., 1938, pp. 661 y ss.

- Cour d'appel de Colmar, 19 febrero 1949, consultada en Rev. crit. dr. int. pr., núm 1, 1950, pp. 52 y ss.

- Tribunal Civil de Mulhouse, de 19 de enero de 1950, consultada en JCP, 1952, núm. 6845.

- Zamet v. Hyman, [1961] 3 All. E.R. 933.

- Tribunal de Bolzano, sentencia de 8 de marzo de 1968, Repertorio Generale Annuale del Foro Italiano, vol. XCII, 1969, p. 2703, núm. 34.

- Tribunal Féderal de Suisse, sentencia de 17 de agosto de 1976, Hirsch c. Cohen, ATF 102 II 136, http://www.bger.ch

- Tribunal Féderal de Suisse, sentencia de 22 de diciembre de 1983 (ATF 109 II 403), http://www.bger.ch

- Tribunal Féderal de Suisse, sentencia de 6 de junio de 1985 (ATF 111 II 16), http://www.bger.ch

- TJCE, Caso Mario Vicente Micheletti y otros contra Delegación del Gobierno en Cantabria; sentencia del TJCE de 7 de julio de 1992, asunto C-369/90, TJCE\1992\134

- Corte di Cassazione, sentencia de 18 de diciembre de 1995, núm. 12906, Il Foro Italiano. Razzolta generale di Giurisprudenza, 1997, vol. CXX, pp. 558-562, esp. p. 562.

- Tribunal Fédéral de Suisse, sentencia de 3 de septiembre de 1998 (ATF 125 III 35), http://www.bger.ch

- Cour d'appel d'Aix-en-Provence, 16 de octubre de 2003, consultada en Rev. crit. dr. int. pr., núm 3, 2004, pp. 589 y ss.

- TJUE, Caso Laszlo Hadadi (Hadady) contra Csilla Marta Mesko, esposa de Hadadi (Hadady); sentencia del TJUE de 16 de julio de 2009, asunto C168/08, TJCEL2009\234. 
